\title{
II. Außenminister unter Bundeskanzler Konrad Adenauer 1961-1963
}

\section{Die Berufung zum Außenminister}

Bis zum August 1961 prophezeiten alle Meinungsumfragen CDU und CSU einen überzeugenden Sieg bei den Bundestagswahlen im Herbst 1961. Daß die Union die absolute Mehrheit wiedererlangen würde, stand für die Demoskopen außer Frage; es wurde sogar ein noch größerer Stimmenanteil als bei der schon legendären Wahl 1957 für möglich gehalten'1. Doch mit dem Bau der Berliner Mauer am 13. August 1961 setzte ein Stimmungsumschwung ein. Die Teilung der Stadt und die Tatenlosigkeit der Westmächte deprimierten nicht nur die Berliner, sondern die gesamte bundesdeutsche Bevölkerung. Die Ereignisse des 13. August schienen ein Symbol für das Scheitern der Deutschland-Politik Konrad Adenauers zu sein². Das ungeschickte Verhalten des Bundeskanzlers in den Tagen nach der Abriegelung von Berlin (West) durch die Behörden der DDR kostete ihn weitere Sympathien in der Bevölkerung. Erst neun Tage nach dem Mauerbau fuhr Adenauer an die Spree. Zu spät, um der Bevölkerung die erwartete psychologische Rückendekkung zu geben, indem er sich persönlich am Brennpunkt des Geschehens zeigte ${ }^{3}$. Er setzte statt dessen den Wahlkampf fort und ließ sich in seinen Reden zu diffamierenden Angriffen gegen seinen Konkurrenten, den Regierenden Bürgermeister von Berlin, Willy Brandt, hinreißen ${ }^{4}$. Während die Nation aufgewühlt nach Berlin blickte, erweckte Adenauer den Eindruck, als denke er nur an die kommenden Wahlen, die zu gewinnen ihm fast jedes Mittel recht sei. Zudem versicherte er nur drei Tage nach dem Mauerbau dem sowjetischen Botschafter in Bonn, Andrej Andrejewitsch Smirnow, „daß die Bundesregierung keine Schritte unternimmt, welche die Beziehungen zwischen der Bundesrepublik und der UdSSR erschweren und die internationale Lage verschlechtern" 5 . Dabei hatte nicht Bonn, sondern Moskau soeben eine neue weltpolitische Krise ausgelöst! Buchheim bemerkt zu

1 Vgl. Osterheld, „Ich gehe nicht leichten Herzens ...“, S. 67; SCHWARZ, Epochenwechsel, S. 152. Bei der Bundestagswahl 1957 erhielt die Union 50,2\% der abgegebenen Stimmen und damit 270 von insgesamt 497 Mandaten. Vgl. WOYKE, Stichwort: Wahlen, S. 48 und S. 52.

2 Vgl. unter anderem BARING, Sehr verehrter Herr Bundeskanzler!, S. 341.

3 Vgl. OSTERHELD, „Ich gehe nicht leichten Herzens ...“, S. 55-66. Der Hauptgrund für Adenauers Zögern war die Angst, daß sein Erscheinen an der Mauer eine Revolte der Ostberliner auslösen könnte, die nach Lage der Dinge nur zu sinnlosem Blutvergießen führen würde. Vgl. dazu den Diskussionsbeitrag des Persönlichen Referenten des Kanzlers, Franz-Josef Bach, in SCHWARZ (Hrsg.), Berlinkrise und Mauerbau, S. $49 \mathrm{f}$.

4 So sprach Adenauer am 14. 8. 1961 auf einer Wahlveranstaltung in Regensburg unter anderem von "Herr[n] Brandt, alias Frahm" und spielte damit auf dessen uneheliche Geburt sowie Brandts Emigration während der NS-Zeit an. Vgl. ADENAUER, Reden, S. 417.

5 Vgl. das Kommuniqué über die Besprechung am 16. 8. 1961, in: DzD IV/7, S. 48. 
Recht, daß Adenauer wohl die psychologische Wirkung seiner Handlungen auf die verunsicherte Bevölkerung unterschätzt hatte ${ }^{6}$. Dieser sah es aber als seine oberste Pflicht in dieser bedrohlichen Situation an, die Krise nicht noch weiter anzuheizen ${ }^{7}$.

Die Zustimmungswerte für den Kanzler und seine Partei fielen bei den Meinungsumfragen rapide in den Keller. Es war „der stärkste Klimasturz in der Demoskopie“, wie Elisabeth Noelle-Neumann vom Allensbacher Institut später konstatierte ${ }^{8}$. Zu Beginn des Monats September tendierte die politische Stimmung eindeutig zur SPD. Nur durch stärkstes Engagement gelang es Adenauer in den verbliebenen zwei Wochen bis zum Wahltag am 17. September, das Ruder wieder zugunsten von CDU und CSU herumzureißen ${ }^{9}$. Der triumphale Wahlsieg von 1957 konnte jedoch nicht mehr wiederholt werden. Zwar verteidigte die Union ihre Position und stellte weiterhin die stärkste Fraktion im Bundestag, doch mußte sie einen empfindlichen Rückgang von 4,9\% der Wählerstimmen beklagen. Mit einem Stimmenanteil von $45,3 \%$ verfügte sie über 242 Sitze. Zur absoluten Mehrheit fehlten aber acht Mandate. Die SPD steigerte sich hingegen um 4,4\% auf $36,2 \%$ der Stimmen. Die eigentlichen Wahlsieger waren aber die Freien Demokraten, die mit der Parole ,Mit der CDU/CSU, ohne Adenauer' das bis zum heutigen Tag beste Ergebnis ihrer Parteigeschichte einfuhren und nach einem Zugewinn von $5,1 \%$ jetzt $12,8 \%$ der abgegebenen Stimmen auf sich vereinigen konnten ${ }^{10}$. Die FDP strebte eine parlamentarische Zusammenarbeit mit der Union an. Sie machte jedoch ihre Koalitionsbereitschaft davon abhängig, daß CDU und CSU „den alten Staatsmann durch einen anderen, jüngeren Mann ersetzen" würden"11. Der Vorsitzende der FDP, Erich Mende, nannte sogleich den Wunschkandidaten der Liberalen für die Nachfolge: „Professor Erhard hat unser volles Vertrauen."12 Auch in der Union war der Widerstand gegen eine Wiederwahl des,Alten' gewachsen. Führende Kreise aus CDU und CSU hatten den Liberalen schon vor dem Wahltag eine Ablösung Adenauers signalisiert. Hinter verschlossenen Türen hatte der Vorsitzende der CSU, Franz Josef Strauß, seine Parteifreunde ebenfalls schon auf Erhard eingestimmt ${ }^{13}$. So mancher in der Union, der an der Befähigung

6 Vgl. BuCHHEIM, Deutschlandpolitik, S. $111 \mathrm{f}$.

7 Vgl. SCHWARZ, Adenauer II, S. $660 \mathrm{f}$.

8 Zitiert nach OSTERHELD, „Ich gehe nicht leichten Herzens ...“, S. 67. Vgl. auch ebenda, S. 281, Anm. 32.

9 Vgl. ebenda, S. 67-69; SCHWARZ, Adenauer II, S. 670.

10 Vgl. WOYKE, Stichwort: Wahlen, S. 49 und S. 52. Zum Wahlkampf der FDP vgl. MENDE, Die schwierige Regierungsbildung 1961, S. 305. In der Literatur wird die Zahl der Mandate, die CDU und CSU zur absoluten Mehrheit fehlten, alternierend mit sieben bzw. acht angegeben. Dieser Unterschied ist auf eine Nachwahl im Wahlkreis Cochem zurückzuführen, die erst am 1. 10. 1961 stattfand: Am Wahltag selbst fehlten der Union also sieben, im Endergebnis schließlich acht Mandate. Vgl. ebenda, S. 312.

11 Vgl. Protokoll der FDP-Bundesvorstandssitzung am 19. 9. 1961, in: FDP-BUNDESVORSTAND, S. 91.

12 Ebenda.

13 Vgl. dazu DeXHeImer, Koalitionsverhandlungen, S. 41 f.; KOERFer, Kampf ums Kanzleramt, S. 559; KRONE, Tagebücher, Eintrag vom 1.10. 1961, S. 535; SCHWARZ, Epochenwechsel, S. 228. 
des Wirtschaftsministers zum Kanzleramt zweifelte, sah in diesem Schachzug den Versuch des CSU-Vorsitzenden, nach einem Übergangskanzler Erhard sich selbst auf den Kanzlerthron zu setzen ${ }^{14}$.

Doch es gab noch andere potentielle Kandidaten für die Nachfolge Adenauers. Der Fraktionsgeschäftsführer der CDU/CSU, Will Rasner, brachte Schröder ins Spiel. Er berichtete dem Staatssekretär im Bundeskanzleramt, Hans Globke, ein Teil des Fraktionsvorstands könne sich sehr wohl auch den bisherigen Innenminister als neuen Kanzler vorstellen ${ }^{15}$. Auch der Fraktionsvorsitzende, Heinrich Krone, ließ durchblicken, daß er im Zweifelsfall lieber seinen Kontrahenten Schröder im Palais Schaumburg sähe, wenn anders Strauß' Griff nach der Macht nicht $\mathrm{zu}$ verhindern sei $^{16}$. Krone hatte selbst Chancen auf die Kanzlerschaft, genauso wie Bundestagspräsident Eugen Gerstenmaier, der als aussichtsreichster Kandidat für eine Allparteienregierung galt, die Bundespräsident Lübke favorisierte. Gerstenmaier zögerte aber vor dem entscheidenden Schritt, da er nicht, wie er erklärte, als "Kanzler-Killer" in die Geschichte eingehen wollte ${ }^{17}$. Im Grunde war aber kein wirklich aussichtsreicher Konkurrent Erhards im Kampf um die Nachfolge Adenauers auf der politischen Bühne auszumachen, denn die große Mehrheit der Partei sah in ihm immer noch den natürlichen Erben Adenauers ${ }^{18}$.

Die prekäre Lage in Berlin ließ jedoch keine Zeit für interne Personalquerelen. Außerdem war es CDU und CSU sowieso nicht möglich, diese Frage allein zu entscheiden, da sie, um eine handlungsfähige Regierung mit parlamentarischer Mehrheit zu bilden, auf einen Koalitionspartner angewiesen war. Adenauer machte zudem deutlich, daß er nicht bereit war, kampflos sein Amt aufzugeben ${ }^{19}$. Er konnte sich immer noch auf eine große Anhängerschaft stützen, vor allem an der Parteibasis. Erhard mangelte es zwar auch nicht an Rückhalt, doch die Zahl seiner Gegner war nicht gering. Innerhalb der Union schreckte man auch davor zurück, den erfahrenen und in der Bevölkerung - trotz mancher Schwächen in jüngster Zeit - hoch angesehenen, Alten' handstreichartig davonzujagen ${ }^{20}$. Dennoch wäre Erhard im Herbst 1961 der Sprung ins Kanzleramt wohl geglückt, hätte er nur entschlossen genug seinen Anspruch angemeldet. Unter dem Druck seiner Anhängerschaft, der sogenannten Brigade Erhard ${ }^{21}$, zeigte sich der Wirtschaftsminister auch zunächst ungewohnt kämpferisch, doch als Adenauer seinen ungebrochenen Machtwillen zu erkennen gab, machte er relativ schnell einen

14 Vgl. Baring, Sehr verehrter Herr Bundeskanzler!, S. 343; SCHWARZ, Adenauer II, S. 677. $15 \mathrm{Vgl}$. SCHWARZ, Adenauer II, S. 678.

16 Vgl. KRONE, Tagebücher, Eintrag vom 30. 9. 1961, S. 535.

17 Zitiert nach MENDE, Die neue Freiheit, S. 482.

$18 \mathrm{Vgl}$. SCHWARZ, Adenauer II, S. 678.

19 Vgl. dazu z.B. die Äußerungen Adenauers gegenüber dem Bonner Korrespondenten der Times, Charles Hargrove, am 20. 9. 1961, in: ADENAUER, Teegespräche 1961-1963, S. 12 14.

${ }^{20} \mathrm{Zu}$ den internen Diskussionen in der Union vgl. KOERFER, Kampf ums Kanzleramt, S. 559-580; SCHWARZ, Adenauer II, S. 678.

21 Dies war eine Anspielung auf das Freikorps des Korvettenkapitäns Ehrhardt, das im sogenannten Kapp-Putsch 1920 eine entscheidende Rolle spielte. Vgl. dazu HüRTEN, Bürgerkriege in der Republik, S. $88 \mathrm{f}$. 
Rückzieher ${ }^{22}$. Den entscheidenden Ausschlag für die Verlängerung der Ära Adenauer war die Zusage des Kanzlers am 19. September gegenüber dem Bundesvorstand der CDU, er beabsichtige nicht, bis zum Ende der Legislaturperiode, also bis 1965, im Amt zu bleiben, sondern er werde „etwa in der Mitte dieser vier Jahre" zurücktreten ${ }^{23}$. Adenauer versprach, diese Aussage nach seiner Wahl zum Kanzler in einem Schreiben an den Fraktionsvorsitzenden schriftlich zu fixieren $^{24}$. Die Ankündigung einer befristeten Kanzlerschaft bewog auch die Zweifler in der Partei, sich noch einmal hinter Adenauer zu stellen ${ }^{25}$.

Doch wie sollte der Wunschpartner der Union, die FDP, dazu gebracht werden, entgegen ihrer Ankündigung doch unter einem Kanzler Adenauer in eine Koalition einzutreten? Der mittlerweile 86-jährige erwies sich bei seiner inzwischen vierten Regierungsbildung erneut als gewiefter Taktiker: Mit dem Vorschlag, zunächst nur Sachfragen zu erörtern und sich den strittigen Personalfragen erst danach zuzuwenden, brachte er die Liberalen an den Verhandlungstisch ${ }^{26}$. Außerdem führte er am 25. September demonstrativ Gespräche mit der sozialdemokratischen Parteispitze, um der FDP zu signalisieren, die Union sei nicht auf Gedeih und Verderb auf die Freien Demokraten angewiesen ${ }^{27}$. Zwar wurden bei dieser Unterredung nur Freundlichkeiten ausgetauscht ${ }^{28}$, die Wirkung nach außen war dennoch enorm ${ }^{29}$. Ob Adenauer tatsächlich auch eine Koalition mit den Sozialdemokraten in Erwägung zog, sei dahingestellt ${ }^{30}$. Die Warnung wurde in der FDPParteizentrale jedenfalls verstanden. Mende wußte seit einer Unterredung mit Brandt, daß die SPD zu einem Eintritt in die Regierung bereit war und Adenauer über die gesamte Legislaturperiode als Kanzler mittragen würde. Im Hinblick auf Bestrebungen in den beiden großen Parteien, das Wahlrecht zu Ungunsten der FDP zu ändern, sagte er zu seinen Parteifreunden: „Freunde, wenn wir jetzt nicht umfallen, werden wir ausfallen. " Den Liberalen blieb nichts anderes übrig, als eine erneute Kanzlerschaft Adenauers hinzunehmen, da alle Unions-Diadochen entge-

22 Vgl. Koerfer, Kampf ums Kanzleramt, S. 571 und S. 577-580.

23 Protokoll der CDU-Bundesvorstandssitzung am 19. 9. 1961, ACDP VII-001-010/6, bzw. in: PROTOKOLLE DES CDU-BUNDESVORSTANDS, S. 7.

24 Vgl. Protokoll der CDU-Bundesvorstandssitzung am 19. 9. 1961, ACDP VII-001-010/6, bzw. in: PROTOKOLLE DES CDU-BUNDESVORSTANDS, S. 43. Tatsächlich richtete Adenauer am 8. 11. 1961 an Krone ein derartiges Schreiben. Von einer Begrenzung der Kanzlerschaft auf zwei Jahre war aber dort nicht mehr die Rede. Der Kanzler erklärte lediglich: „Den Wahlkampf 1965 beabsichtige ich nicht für meine Partei zu führen. Ich werde daher mein Amt als Bundeskanzler so rechtzeitig niederlegen, daß mein Nachfolger in diesem Amt eingearbeitet ist, dies zu tun." Vgl. ACDP, Nachlaß Krone I-028-008/1. Vgl. ferner BARING, Sehr verehrter Herr Bundeskanzler!, S. 349. Ein gleichlautendes Schreiben erhielt der FDP-Vorsitzende Mende. Vgl. den Artikel „Kanzler schrieb an Mende und Krone. Kein Rücktrittstermin genannt.“, in: GENERAL-ANZEIGER vom 9. 11. 1961, S. 1.

$25 \mathrm{Vgl}$. SCHWARZ, Adenauer II, S. 678.

26 Vgl. MENDE, Die schwierige Regierungsbildung 1961, S. 313.

27 Vgl. Koerfer, Kampf ums Kanzleramt, S. 567 f. und S. 574 f.; SCHWARZ, Epochenwechsel, S. $233 \mathrm{f}$.

28 Vgl. BRANDT, Begegnungen, S. 45.

29 Vgl. KÖHLER, Adenauer, S. 1120.

$30 \mathrm{Zu}$ den Überlegungen Adenauers vgl. SCHWARZ, Adenauer II, S. $675 \mathrm{f}$. 
gen früherer Zusagen nicht gegen den ,Alten' votieren wollten ${ }^{31}$. Zudem fand in der Union inzwischen ein Stimmungsumschwung statt: Trotz einiger Unzufriedenheit mit Adenauer wollte man sich von den Liberalen nicht den Kanzler vorschreiben lassen ${ }^{32}$.

So wurden am 2. Oktober 1961 zwischen CDU, CSU und der FDP Koalitionsgespräche aufgenommen. Für die Union saßen Konrad Adenauer und Franz Josef Strauß am Verhandlungstisch, die Freien Demokraten waren durch Erich Mende und Willi Weyer, den Vorsitzenden des größten liberalen Landesverbandes, Nordrhein-Westfalen, vertreten. Adenauer konnte erfreut feststellen, daß seine liberalen Gesprächspartner sich nach zähen Verhandlungen weitgehend mit dem Inhalt des von der Union als Verhandlungsgrundlage vorgelegten Papiers einverstanden erklärten. Vor allem die uns hier interessierenden Punkte zur Deutschland- und Sicherheitspolitik stellten den Kanzler zufrieden ${ }^{33}$ : Oberstes Ziel der Bundesregierung blieb die Wiedererlangung der staatlichen Einheit. Sowohl die Neutralisierung eines vereinten Deutschlands wie ein Verzicht auf die Westbindung der Bundesrepublik wurden jedoch strikt ausgeschlossen. Grundlage für die Hoffnung auf Wiedervereinigung blieb Artikel 7 des Deutschland-Vertrags in der Fassung vom 23. Oktober 1954, in dem sich die drei Westmächte, Frankreich, Großbritannien und die USA, verpflichtet hatten, „ein wiedervereinigtes Deutschland, das eine freiheitlich-demokratische Verfassung, ähnlich wie die Bundesrepublik, besitzt und das in die europäische Gemeinschaft integriert ist", anzustreben und auf eine „frei vereinbarte friedensvertragliche Regelung für ganz Deutschland“ hinzuwirken, wobei „die endgültige Festlegung der Grenzen

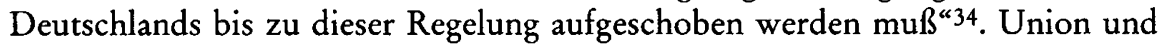
FDP betonten, sie würden am Alleinvertretungsanspruch der Bundesrepublik festhalten und lehnten infolgedessen jegliche Aufweichung der Nichtanerkennungspolitik gegenüber der DDR ab. Im Hinblick auf die amerikanisch-sowjetischen Berlin-Verhandlungen wurde die Aufrechterhaltung der bestehenden Bindungen zwischen Berlin (West) und der Bundesrepublik gefordert und die Gültigkeit der nach dem Zweiten Weltkrieg entstandenen Rechtslage betont. Das Koalitionsabkommen gab ferner der neuen Bundesregierung den Auftrag, die Initiative in der Deutschland-Politik zurückzugewinnen und Friedensverhandlungen für

31 FlisZAR, Mit der FDP regieren, S. 142f. Zur Diskussion in der FDP vgl. auch KOERFER, Kampf ums Kanzleramt, S. 576-593; MENDE, Die schwierige Regierungsbildung 1961, S. 307-312; ders., Die neue Freiheit, S. 482-485; ders., Straußen vor der Tür. Die Alternative einer sozialliberalen Koalition stellte sich nicht, da die programmatischen Differenzen zwischen SPD und FDP noch zu groß waren. Vgl. dazu ders., Die schwierige Regierungsbildung 1961, S. 311.

32 Vgl. KOERFER, Kampf ums Kanzleramt, S. 577. Vgl. dazu auch entsprechende Äußerungen des Bundestagsabgeordneten und Landesvorsitzenden der CDU Hamburg, Erik Blumenfeld; Protokoll der CDU-Bundesvorstandssitzung am 19. 9. 1961, ACDP VII-001010/6, bzw. in: Protokolle DEs CDU-Bundesvorstands, S. 43.

$33 \mathrm{Vgl}$. SCHWARZ, Adenauer II, S. 681.

34 Für den Wortlaut von Artikel 7 des Vertrags vom 26. 5. 1952 über die Beziehungen zwischen der Bundesrepublik Deutschland und den Drei Mächten in der Fassung vom 23. 10. 1954 (General- bzw. Deutschland-Vertrag) vgl. DOKUMENTE DES GETEILTEN DEUTSCHLAND, Bd. 1, S. 232. 
Gesamtdeutschland anzustreben. Bezüglich der Sicherheitspolitik einigten sich die beiden Parteien, auf eine Verstärkung der Konsultation und Integration in NATO und WEU hinzuarbeiten. Durch die Verlängerung der Wehrpflicht auf 18 Monate kam man der Forderung Washingtons nach, die konventionellen Streitkräfte zu verstärken. Des weiteren stimmte die FDP dem Ziel zu, eine multilaterale Atomstreitmacht der NATO ins Leben zu rufen. Adenauer mußte dafür hinnehmen, daß die neue Bundesregierung auch über die von ihm abgelehnten Zonen mit militärischem Sonderstatus verhandeln würde, sofern diese Frage im Falle von Verhandlungen über die deutsche Frage zur Sprache kommen sollte ${ }^{35}$. Obwohl der Kanzler jeglichen militärischen Sonderstatus für ein wiedervereinigtes Deutschland bislang mit dem Argument abgelehnt hatte, eine Diskriminierung müsse verhindert werden, stellte er jetzt seine Einwände zurück, da Verhandlungen über eine Wiedervereinigung der beiden Teile Deutschlands im Augenblick sowieso nicht realistisch waren. Angesichts der schwelenden Berlin-Krise hatte in seinen Augen die Einigung auf eine tragfähige Grundlage in der Deutschland- und Sicherheitspolitik für die kommende Legislaturperiode Priorität ${ }^{36}$.

Ende Oktober 1961 stand der Koalitionsvertrag. Nun rückten die personellen Fragen in den Vordergrund. Nachdem die Freien Demokraten einer zeitlich begrenzten Verlängerung der Kanzlerschaft Adenauers zugestimmt hatten, konzentrierten sich die personellen Querelen jetzt auf die Leitung des Auswärtigen Amts. Zunächst hatte Mende daran gedacht, die Schaffung eines dritten Staatssekretärpostens an der Koblenzer Straße zu fordern, der der FDP überlassen werden sollte ${ }^{37}$. Außerdem beabsichtigte er, den Vorsitz im Auswärtigen Ausschuß des Bundestages für sich zu beanspruchen ${ }^{38}$. Plötzlich erklärte er jedoch, der bisherige Außenminister, Heinrich von Brentano, sei krank und deshalb seinen Aufgaben nicht mehr gewachsen. Die CDU solle personelle Vorschläge für die Leitung des Außenministeriums machen ${ }^{39}$. Brentano sah sich - nicht zu Unrecht - in der Rolle eines Bauernopfers, welches die FDP nun der Öffentlichkeit präsentieren wollte, nachdem sich ihr Wahlversprechen, eine erneute Kanzlerschaft Adenauers zu verhindern, nicht realisieren ließ: „Man schlägt den Sack und meint den Esel“, kommentierte er die Forderung nach seinem Rücktritt, den er zunächst kategorisch ablehnte. Er war aber bereit, einen Liberalen als dritten Staatssekretär zu akzeptieren ${ }^{40}$. Die FDP bestand aber auf seiner Demission ${ }^{41}$. Die Regierungs-

${ }^{35}$ Für den Wortlaut des Koalitionsabkommens vgl. MENDE, Die schwierige Regierungsbildung 1961, S. 314-318.

$36 \mathrm{Vgl}$. SCHWARZ, Adenauer II, S. 683.

37 Vgl. Protokoll der CDU/CSU-Fraktionsvorstandssitzung am 27. 10. 1961, ACDP VIII001-1503/4.

38 Vgl. SCHWARZ, Adenauer II, S. 689.

39 Vgl. Protokoll der CDU/CSU-Fraktionsvorstandssitzung am 27. 10. 1961, ACDP VIII001-1503/4.

40 Ebenda.

41 Mende behauptete im Rückblick: „Die FDP hatte zu keiner Zeit den Rücktritt des Bundesaußenministers gefordert." Vgl. MENDE, Die neue Freiheit, S. 486. Dies entspricht aber nicht den Tatsachen. So erklärte z. B. Willi Weyer vor dem Bundeshauptausschuß der FDP am 21. 10. 1961: „Wir haben [die] Forderung in die CDU hineintragen müssen, nämlich daß Herr von Brentano für die Freie Demokratische Partei nicht akzeptabel sei. In 
bildung drohte nun an einer einzigen Streitfrage zu scheitern. Adenauer stand vor der Wahl, entweder den Verhandlungspoker wieder am Nullpunkt zu beginnen oder sich dem Ultimatum zu beugen. Der Kanzler schlug daraufhin eine zweigleisige Taktik ein: Seinen Parteifreunden versicherte er, er werde dem Erpressungsversuch der Freien Demokraten nicht nachgeben; am Verhandlungstisch hingegen machte er gegenüber Mende Andeutungen, er sei durchaus gesprächsbereit ${ }^{42}$.

Die Liberalen hatten dem Kanzler inzwischen eine Liste der für die Nachfolge Brentanos in Frage kommenden Personen vorgelegt. Neben den Namen Krone, Schröder und Gerstenmaier stand auf ihr auch der des Vorstandssprechers der Deutschen Bank, Hermann Josef Abs, sowie der des Ministerpräsidenten von Baden-Württemberg, Kurt Georg Kiesinger ${ }^{43}$. Letzterer erhielt auch sogleich Unterstützung von Strauß ${ }^{44}$. Doch Adenauer wollte weder Kiesinger noch Gerstenmaier am Kabinettstisch haben ${ }^{45}$. Die übrigen Kandidaten waren aber innerhalb der Union umstritten. Eine Entscheidung für einen von ihnen mußte zwangsläufig zu heftigen internen Auseinandersetzungen führen. Eine Zerreißprobe, so glaubte man, sei nur zu vermeiden, wenn die FDP selbst das Amt besetzte. Offensichtlich bewog diese Erkenntnis den Kanzler dazu, Mende das überraschende Angebot zu machen, selbst das Auswärtige Amt zu übernehmen. Doch der Parteivorsitzende der Liberalen lehnte die Übernahme eines Ministerpostens mit der Begründung ab, er könne nicht in ein Kabinett Adenauer eintreten, nachdem er sich im Wahlkampf so deutlich gegen den Kanzler ausgesprochen habe ${ }^{46}$. Ein Kompromißvorschlag der FDP sah den Verzicht auf den Rücktritt von Brentanos vor, sofern im Außenministerium der Posten eines im Kabinett stimmberechtigten Staatsministers geschaffen und von einem Liberalen besetzt würde. Außerdem forderten die Freien Demokraten die Einrichtung eines Europaministeriums, dessen Leitung Walter Scheel übernehmen sollte. Diesen Plan lehnte aber Brentano entschieden $a b^{47}$. Auch Bundeswirtschaftsminister Erhard sprach sich gegen die Errichtung eines eigenständigen Ministeriums für Europa-Politik aus, das die Kompetenzen seines Hauses eingeschränkt hätte ${ }^{48}$. Gleichzeitig sorgte ein neuerlicher Streit um das Koalitionsabkommen wieder für Aufregung. Schließlich wurden am 26. Oktober die Verhandlungen zwischen Union und FDP ergebnislos abgebrochen ${ }^{49}$. Die Bildung eines vierten Kabinetts Adenauer schien gescheitert.

diesem Triumvirat Adenauer-Strauß-Brentano müsse auf jeden Fall der Außenminister weichen. Denn alle Aussagen zur Außenpolitik, die wir vereinbart haben, seien nur glaubwürdig, wenn in der Leitung des Auswärtigen Amtes ein Wechsel vorgenommen würde." Zitiert nach KOERFER, Kampf ums Kanzleramt, S. 590.

42 Vgl. SCHWARZ, Adenauer II, S. 689-693.

43 Vgl. Protokoll der CDU/CSU-Fraktionsvorstandssitzung am 27. 10. 1961, ACDP VIII001-1503/4.

44 Vgl. KRONE, Tagebücher, Eintrag vom 21. 10. 1961, S. 546.

45 Vgl. SCHWARZ, Adenauer II, S. 692; ders., Epochenwechsel, S. 236.

46 Vgl. Koerfer, Kampf ums Kanzleramt, S. 590 f. und S. 597; MENDE, Die neue Freiheit, S. 484.

$47 \mathrm{Vgl}$. BARING, Sehr verehrter Herr Bundeskanzler!, S. 356-365; KOSTHORST, Brentano und die deutsche Einheit, S. 398.

48 Vgl. KOERFER, Kampf ums Kanzleramt, S. 595.

49 Vgl. ebenda, S. 595 f. 
Der nach Adenauers eigenem Bekunden „völlig überraschend[e]“50 Beschluß Brentanos, sein Amt niederzulegen, bot unerwartet einen Ausweg aus der Sackgasse. Der Außenminister hatte zunehmend physisch wie psychisch unter der immer hektischer gewordenen Diskussion um seine Person gelitten ${ }^{51}$. Am 28. Oktober erklärte er deshalb dem Kanzler in einem Schreiben, er beabsichtige aus dem Kabinett auszuscheiden und begründete dies zum einen mit seiner Enttäuschung über das Verhalten Adenauers, der ihm seiner Ansicht nach zu wenig den Rücken gestärkt hatte, zum andern wollte er der Parteiräson Genüge tun, da seine Person zum größten Hindernis für die Regierungsbildung geworden war ${ }^{52}$. Hinter der Forderung nach seiner Demission, warnte er Adenauer, stehe aber in Wahrheit die Absicht, einen politischen Kurswechsel durchzuführen ${ }^{53}$. Dieser versuchte zwar seinen langjährigen politischen Weggefährten noch einmal umzustimmen, doch erkannte er auch, daß sich nun die Chance bot, die Regierungsbildung endlich abzuschließen ${ }^{54}$. Adenauers Verhalten in dieser Angelegenheit war in der Tat etwas dubios: Brentano war überzeugt, daß der Kanzler nicht wirklich interessiert war, ihn im Amt zu halten, während jener beteuerte, er sei entschlossen gewesen, dessen Verbleib an der Koblenzer Straße durchzusetzen ${ }^{55}$.

Doch wer sollte der Nachfolger Brentanos werden? Wie bereits erwähnt, lehnte Adenauer Gerstenmaier und Kiesinger als Außenminister ab; auf den Vorschlag, Abs zu berufen, ging er nicht ein ${ }^{56}$, und Krone verzichtete von sich aus ${ }^{57}$. Damit blieb nur noch Schröder als Wunschkandidat der Freien Demokraten übrig. Obwohl er sich bisher gegenüber dem Kanzler stets loyal verhalten hatte und dafür als „Adenauers Musterschüler und Adenauers Treuester" 58 oder als „Adenauers Musterknabe "59 verspottet wurde, hatte der Kanzler dennoch Zweifel an der Zuverlässigkeit seines Innenministers. Schröders gute Beziehungen zur FDP, insbesondere zu Weyer, Mende und Scheel, weckten Adenauers Mißtrauen. Zudem war dem Kanzler bewußt, daß einem neuen Außenminister in Anbetracht der gespannten Situation in Berlin keine Schonfrist gewährt werden würde ${ }^{60}$. Schröder

50 Protokoll der CDU-Bundesvorstandssitzung am 11.12. 1961, ACDP VII-001-010/6, bzw. in: PROTOKOLLE DES CDU-BUNDESVORSTANDS, S. 66.

51 Vgl. BARING, Bundeskanzler, S. 347 und S. $368 \mathrm{f}$.

52 Vgl. das Schreiben Brentanos an Adenauer vom 28.10. 1961 sowie die offizielle Rücktrittserklärung Brentanos vom 30. 10. 1961, in: BARING, Sehr verehrter Herr Bundeskanzler!, S. 363-366 bzw. S. $372 \mathrm{f}$.

53 Vgl. das Schreiben Brentanos an Adenauer vom 28. 10. 1961, in: ebenda, S. 363-366. Brentano wurde von seinen Mitarbeitern gedrängt, diese Formulierung in das Schreiben aufzunehmen. Damit sollte er seine Unabhängigkeit von Adenauer unterstreichen und so seine Chancen auf die Kanzlernachfolge erhöhen. Vgl. dazu OSTERHELD, „Ich gehe nicht leichten Herzens ...", S. 79.

54 Vgl. Baring, Sehr verehrter Herr Bundeskanzler!, S. 371-374; KÖHLER, Adenauer, S. $1125 \mathrm{f}$.

55 Vgl. SCHWARZ, Adenauer II, S. 689-692; BARING, Sehr verehrter Herr Bundeskanzler!, S. $368-370$.

56 Vgl. KÖHLER, Adenauer, S. 1124.

57 Vgl. KRONE, Tagebücher, Eintrag vom 21. 10. 1961, S. 547.

58 HENKELS, 111 Bonner Köpfe, S. 293.

59 Vgl. den Artikel „An der Mende-Marke“, in: Der SPIEGEL vom 4. 10. 1961, S. 25.

60 Vgl. SCHWARZ, Adenauer II, S. 693. 
verfügte aber über keine vorzeigbaren Erfahrungen in der auswärtigen Politik. Die Zweifel an seiner Eignung - vielleicht durch die Warnung Brentanos verstärkt, die Liberalen strebten eine außenpolitische Richtungsänderung an - brachten Adenauer dazu, einen neuen Kandidaten ins Spiel zu bringen, nämlich Walter Hallstein. Der Präsident der EWG-Kommission konnte nicht nur auf eine langjährige Tätigkeit auf dem internationalen Parkett zurückblicken, er war als früherer Staatssekretär im Auswärtigen Amt auch mit dem Apparat des Ministeriums vertraut. Außerdem konnte Adenauer von Hallstein erwarten, daß dieser den Kurs seiner Außenpolitik ohne Veränderungen fortsetzen würde - war sein Name doch untrennbar mit der Nichtanerkennungspolitik gegenüber der DDR verbunden. So empfing er Hallstein am 1 . November zu einem längeren Gespräch in seinem Rhöndorfer Haus ${ }^{61}$. Erwartungsgemäß stieß Adenauers Alternativvorschlag bei der FDP auf Ablehnung. Für sie war Hallstein der Repräsentant einer nicht mehr zeitgemäßen, doktrinären Deutschland-Politik ${ }^{62}$. Wohl oder übel mußte der Kanzler nun auf Schröder zurückgreifen. Den Liberalen konnte aber zumindest der Verzicht auf die Schaffung eines Staatsministerpostens im Auswärtigen Amt abgerungen werden. Als Ausgleich wurde ein Entwicklungshilfeministerium eingerichtet, das Walter Scheel anvertraut wurde63. 19 Besprechungen zwischen CDU, CSU und FDP von insgesamt 60 Stunden Dauer waren notwendig gewesen, um zu diesem Kompromiß zu gelangen. Die langwierigen Verhandlungen, die hier nur komprimiert dargestellt werden konnten ${ }^{64}$, hatten an den Nerven aller Beteiligten gezerrt. Noch ein Jahr später, als nach der Spiegel-Krise wiederum ein neues Kabinett gebildet werden mußte, erinnerte sich Mende mit Schaudern an die Auseinandersetzungen dieser Regierungsbildung65.

Nachdem mit der Nominierung Schröders die Kabinettsliste komplettiert war, stand einer Vereidigung der neuen Regierung im Grunde nichts mehr im Weg. Doch der Kanzler sah sich nun mit Opposition aus den eigenen Reihen gegen den designierten Außenminister konfrontiert. Das Zentrum des Widerstandes bildete die Berliner CDU. Das Verhältnis zwischen diesem Landesverband und Schröder war schon seit einiger Zeit erheblich belastet, denn 1959 hätte der Innenminister Schröder beinahe die Beteiligung der Berliner Abgeordneten an der Wahl des Bundespräsidenten verhindert, weil sie seiner Meinung nach nicht stimmberechtigt waren ${ }^{66}$. Jetzt schien für seine Gegner die Stunde der Revanche gekommen. Als Schröder am 2. November dem CDU/CSU-Fraktionsvorstand als künftiger Chef des Auswärtigen Amts vorgestellt wurde, protestierten die Vertreter Berlins

$61 \mathrm{Vgl}$. ebenda.

62 Vgl. MENDE, Die neue Freiheit, S. $487 \mathrm{f}$.

63 Vgl. Protokoll der CDU/CSU-Fraktionsvorstandssitzung am 2.11. 1961, ACDP VIII001-1503/4.

${ }^{64}$ Zur Regierungsbildung 1961 vgl. DEXHEIMER, Koalitionsverhandlungen, S. 28-73; KOERFER, Kampf ums Kanzleramt, S. 555-609; KOERFER, Schwierige Geburten; MENDE, Die schwierige Regierungsbildung 1961; SCHOLLWER, FDP im Wandel, S. 15-29; SCHWARZ, Epochenwechsel, S. 228-239; STRAUSS, Erinnerungen, S. 397-410.

65 Vgl. KÖHLER, Adenauer, S. 1128.

66 Vgl. den Artikel „Der Mitschreiber“, in: DeR SPIEGEL vom 22. 7. 1959, S. 18, sowie das Schreiben Gradls an Adenauer vom 6. 11. 1961, ACDP, Nachlaß Krone I-028-011/5. 
auf das heftigste. Man hielt ihm sein damaliges Verhalten in der Bundesversammlung vor und beschuldigte ihn, er verhindere eine Eingliederung Berlins in den Bund, weil er den Vier-Mächte-Status der Stadt überbetone. Außerdem wurde bezweifelt, daß Schröder sich mit den Aussagen des Koalitionsabkommens zur künftigen Berlin-Politik identifiziere. Dieser bestritt die Vorwürfe, unterstrich aber seine Ansicht über die herausragende Bedeutung des Vier-Mächte-Status der Stadt. Er sei „der beste Schutz Berlins"67.

Auf der anschließenden Fraktionssitzung trat Johann Baptist Gradl als Wortführer der Kritiker Schröders auf. Der einflußreiche CDU-Abgeordnete beklagte dessen Mangel an persönlichen Beziehungen zu den maßgeblichen Persönlichkeiten des Auslands. Es fehle ihm auch an Kenntnissen der internationalen Politik, monierte Gradl und meinte, diese Wissenslücken wären nicht zu schließen, weil Schröder wegen der Lage in Berlin keine Zeit zur Einarbeitung bleibe. Der Haupteinwand gegen die Berufung Schröders zum Außenminister war jedoch seine angeblich zu kompromißbereite Haltung in der Berlin-Frage. Gradl behauptete, Schröder fehle hier ,jenes äußerste $\mathrm{Maß}$ an Festigkeit“, das angesichts der Bedeutung der Sache unverzichtbar sei68. Der Abgeordnete wiederholte damit die Kritik des Vorsitzenden des Arbeitskreises für Außenpolitik der CDU/CSUFraktion, Ernst Majonica, die dieser bereits zwei Tage zuvor im ParlamentarischPolitischen Pressedienst der SPD geäußert hatte. Majonica, einer der maßgeblichen Köpfe der Union in außenpolitischen Fragen, hatte die Ansicht vertreten, Schröder sei für die Aufgabe des Außenministers "nicht hart genug “69.

Um ihr negatives Urteil zu untermauern, verwiesen die Kritiker auf ein Hintergrundgespräch Schröders, das er zusammen mit Verteidigungsminister Strauß am 20. September 1961 mit dem Bonner Korrespondenten der International Herald Tribune, Gaston Coblentz, dem deutschen Journalisten Wolfgang Wagner sowie Fred Luchsinger von der Neuen Zürcher Zeitung geführt hatte ${ }^{70}$. Schröder hatte dabei die Meinung vertreten, es sei ein Fehler der Vereinigten Staaten gewesen, daß sie die nach Kriegsende in ihrer Hand befindlichen Gebiete Sachsens und Thüringens im Ausgleich für eine Beteiligung an der Kontrolle Berlins im Juni 1945 der Sowjetunion übergeben hatten. Eine um diese bevölkerungsreichen und wirtschaftlich hoch entwickelten Regionen reduzierte sowjetische Besatzungszone hätte nämlich die Entwicklungschancen der DDR wesentlich verschlechtert, auch wenn sie im Gegenzug über das gesamte Berliner Gebiet hätte verfügen können. In diesem Fall würde der Bundesrepublik heute eine um vieles schwächere Ostzone gegenüberstehen ${ }^{71}$. Natürlich waren die Berliner nicht begeistert, als sie von diesen Gedankenspielereien hörten. Ihren Zorn weckte aber vor allem Schröders Einschätzung der Berlin-Krise. Er zweifelte nämlich, ob der Westen sich in

67 Protokoll der CDU/CSU-Fraktionsvorstandssitzung am 2.11. 1961, ACDP VIII-0011503/4.

68 Protokoll der CDU/CSU-Fraktionssitzung am 2. 11. 1961, ACDP VIII-001-1009/1.

69 Parlamentarisch-Politischer Pressedienst vom 30. 10. 1961, zitiert nach BARING, Sehr verehrter Herr Bundeskanzler!, S. 468, Anm. 103.

70 Vgl. KoERFER, Kampf ums Kanzleramt, S. 842, Anm. 167.

71 Vgl. HeRwarTH, Von Adenauer zu Brandt, S. 259. 
Berlin auf Dauer behaupten könne, da seiner Ansicht nach der sowjetische Druck auf lange Sicht zu stark sein würde. Schröder empfahl deshalb, rechtzeitig eine "Frontbegradigung" vorzunehmen ${ }^{72}$, weil es im Grunde nur die Wahl zwischen „Krieg oder Räumung Berlins“ gebe ${ }^{73}$. Angeblich soll er sogar allen Ernstes den Umzug der Bevölkerung und einen Wiederaufbau der Stadt in der Lüneburger Heide vorgeschlagen haben ${ }^{74}$. Ob Schröder sich wirklich derart radikal geäußert hatte oder ob es sich hierbei um Übertreibungen oder Entstellungen handelte, läßt sich nicht mehr klären. Allerdings hatte der designierte Außenminister - ebenso wie auch Strauß - bereits mehrmals darauf hingewiesen, es dürfe bezüglich Berlin keine Politik betrieben werden, die zu einem dritten Weltkrieg führen könne ${ }^{75}$. Dennoch läßt sich die Erregung innerhalb der CDU nachvollziehen, als die Abgeordneten mit Schröders ketzerischen Aussagen konfrontiert wurden. Gradl erklärte ultimativ: „Ein Mann, der Berlin abgeschrieben hat, kann nicht Außenminister werden." ${ }^{76}$ Adenauer wies aber alle Vorwürfe pauschal als „unbegründet" zurück ${ }^{77}$. Lediglich auf den Einwand, Schröder verfüge nur über mangelhafte Kenntnisse der auswärtigen Politik, ging der Kanzler konkret ein. Er erinnerte daran, daß die beiden im Auswärtigen Amt tätigen Staatssekretäre, Karl Carstens und Rolf Lahr, über langjährige Erfahrungen verfügten und die Unerfahrenheit des neuen Mannes ausgleichen könnten ${ }^{78}$.

Adenauers Verteidigungsrede brachte die Kritik aber nicht zum Verstummen. Nun schaltete sich auch die Presse in die Diskussion ein. Unter der Überschrift „Schröder - ausgerechnet Schröder!“ machte die Bild-Zeitung am 6. November 1961 auf der Titelseite gegen ihn Front: „Er ist forsch. Er ist schneidig. Er ist ,schön'. Aber ist Gerhard Schröder auch der richtige Außenminister für die Bundesrepublik? Wir meinen: Er ist es nicht." 79 Am selben Tag faßte Gradl in einem Schreiben an den Kanzler alle Bedenken noch einmal zusammen: Das Argument Adenauers, der neue Außenminister sei in der Berlin-Politik an die Kabinettsbeschlüsse, die Vorgaben des Koalitionsabkommens sowie an die mit den Westmächten getroffenen Entscheidungen gebunden, ließ er nicht gelten. Schröders Auffassung, daß „Berlin nicht zu halten sei und daß ein Arrangement mit der Sowjetunion auf der Basis der Zonengrenze gefunden werden müsse“, zeige, daß er die Stadt nicht mit der erforderlichen Härte verteidigen werde. Sein Mangel an Risikobereitschaft könnte aber „zu schrecklichen Fehlkalkulationen“ im Kreml führen, warnte der CDU-Abgeordnete. Die Sowjetunion werde die Berufung

72 Zitiert nach SCHWARZ, Epochenwechsel, S. 241.

73 So Schröder laut den Notizen des stellvertretenden Bürgermeisters von Berlin, Franz Amrehn. Vgl. KRONE, Tagebücher, S. 503, Anm. 142.

$74 \mathrm{Vgl}$. KOERFER, Kampf ums Kanzleramt, S. 598. Koerfers Darstellung des Hintergrundgesprächs basiert weitgehend auf dem Gesprächsvermerk von Wolfgang Wagner, der Schröder aber nicht wohlgesonnen war, wie sein 1962 in der Zeitschrift Die politische Meinung erschienenes Porträt des Außenministers zeigt: WAGNER, Der neue Mann im Außenamt.

75 Vgl. Krone, Tagebücher, Einträge vom 18. 8. und 12. 10. 1961, S. 525 bzw. S. 543.

76 Zitiert nach dem Artikel "Flaschen blieben stehen“, in: DER SPIEGEL vom 8.11. 1961, S. 24.

77 Protokoll der CDU/CSU-Fraktionssitzung am 2. 11. 1961, ACDP VIII-001-1009/1.

78 Vgl. ebenda. Carstens war seit 1954 im Auswärtigen Amt, Lahr seit 1953.

79 BILD-ZEITUNG vom 6. 11. 1961, S. 1. 
Schröders nämlich als „Signal der Nachgiebigkeit“" werten und glauben, die Bundesregierung habe ihre bislang unnachgiebige Haltung in der Berlin-Politik aufgegeben und sei zu Kompromissen bereit. Schröder könne deshalb nicht zum Außenminister berufen werden ${ }^{80}$. Wie ernst es der Berliner CDU mit ihrem Widerstand gegen Schröder war, zeigt ein ebenfalls auf den 6. November 1961 datiertes Schreiben ihres stellvertretenden Vorsitzenden, Peter Lorenz, an Heinrich Krone. Lorenz drohte, daß die Mehrheit der Berliner Abgeordneten bei der Kanzlerwahl im Bundestag Adenauer ihre Stimme verweigern würde, sollte dieser seinen Entschluß nicht revidieren. Zudem würde sein Landesverband eine Presseerklärung veröffentlichen, in der Schröder das Mißtrauen ausgesprochen werde ${ }^{81}$. Eine derartige beispiellose Mißfallensbekundung gegenüber einem designierten Minister aus der eigenen Partei hätte sicherlich die Ernennung Schröders verhindert. Waren die Berliner aber wirklich bereit, sich öffentlich gegen den Kanzler zu stellen? Ein Scheitern bei der Kanzlerwahl hätte unweigerlich das politische Aus für Adenauer bedeutet. Die Kanzlerfrage wäre erneut gestellt worden, und die Regierungsbildung hätte zwei Monate nach der Bundestagswahl wieder am Nullpunkt begonnen.

Ganz soweit kam es schließlich nicht, wenn auch der Ausgang der Abstimmung im Bundestag am 7. November nicht als berauschender Vertrauensbeweis für Adenauer gewertet werden konnte. Er erhielt 258 Stimmen und damit nur acht mehr als für die absolute Mehrheit notwendig war. 48 Abgeordnete der Koalition hatten ihm die Gefolgschaft verweigert ${ }^{82}$. Sicherlich stammte ein großer Teil der Abweichler aus den Reihen der FDP-Abgeordneten, die gegen ihre eigene Überzeugung für Adenauer votieren sollten, sowie aus den Kreisen der Brigade Erhard, aber auch einige CDU-Parlamentarier aus Berlin werden ihre Drohung wahrgemacht haben, nicht für Adenauer zu stimmen. Welche Motive auch immer hinter dem Stimmverhalten dieser vier Dutzend Parlamentarier steckten, das miserable Resultat zeigte der Öffentlichkeit, wie brüchig die Koalition bereits war, noch bevor sie ihre Arbeit überhaupt aufgenommen hatte. Man hätte erwarten können, daß Adenauer, um wenigstens den parteiinternen Streit zu beenden und sich die Unterstützung der Unionsabgeordneten zu sichern, im Fall Schröder mehr Kompromißbereitschaft zeigte. Dieser hielt jedoch unverdrossen an seiner Entscheidung fest. Da der Kanzler, wie geschildert, durchaus Bedenken hatte, ob sein bisheriger Innenminister tatsächlich der geeignete Mann für das Auswärtige Amt war, ist man geneigt, dieses Verhalten mit seinem Charakterzug zu erklären, an einem einmal getroffenen Entschluß gegen alle Widerstände festzuhalten. Vermutlich dachte Adenauer aber auch daran, daß alle personellen Kontroversen von neuem aufgebrochen wären, wenn er die mühsam ausgehandelte und austarierte Kabinettsliste jetzt wieder umgeworfen hätte.

Freilich, auch Schröders Gegner waren noch nicht willens, ihre Opposition aufzugeben. Einen potentiellen Verbündeten sahen sie in Bundespräsident Lübke,

80 Vgl. das Schreiben Gradls an Adenauer vom 6. 11. 1961, ACDP, Nachlaß Krone I-028$011 / 5$.

81 Vgl. das Schreiben Lorenz an Krone vom 2. 11. 1961, ACDP, Nachlaß Krone I-028-026/7.

82 Vgl. dazu KöHLER, Adenauer, S. 1129. 
der in der Berlin-Frage jegliche Kompromisse gegenüber der Sowjetunion ablehnte ${ }^{83}$. Gradl, Lorenz sowie der Berliner Bürgermeister Franz Amrehn sprachen deshalb bei ihm mit der Bitte vor, die Ernennung Schröders abzulehnen. Ganz wie sie erwartet hatten, reagierte der Bundespräsident entsetzt, als sie ihn über die angebliche Einstellung Schröders zur Berlin-Frage informierten. Lübke versicherte spontan, die Ernennungsurkunde nicht zu unterschreiben ${ }^{84}$. Seine Abneigung gegen Schröder hatte aber auch religiöse Gründe. Dem streng katholischen Lübke, so beobachtete Mende, „war der kühle Jurist zu protestantisch “85. Die Ablehnung Schröders begründete der Bundespräsident mit seinem Amtseid. Er habe geschworen, Schaden vom deutschen Volk abzuwenden, und könne deshalb nicht jemanden zum Minister ernennen, der hinsichtlich Berlins "nicht felsenfest“ sei86. Dies teilte er auch dem Kanzleramt mit. Lübke empfahl Adenauer, auf Kiesinger oder Abs zurückzugreifen ${ }^{87}$. Kiesinger war aber aus verschiedenen Gründen bei Adenauer in Ungnade gefallen ${ }^{88}$, und eine Berufung von Abs, zu dem der Kanzler ein enges Verhältnis pflegte, lehnte er mit der jeder Grundlage entbehrenden $\mathrm{Be}-$ hauptung ab, dieser sei im Dritten Reich Mitglied des Freundeskreises Heinrich Himmler gewesen - einer Vereinigung von Industriellen, welche die Germanenforschung der SS finanziert hatte ${ }^{89}$.

Der Bundespräsident zog daraufhin diesen Vorschlag zurück, war aber immer noch nicht bereit, Schröder zu akzeptieren ${ }^{90}$. Er ließ im Bundespräsidialamt ein Gutachten erstellen, wonach er das Recht habe, einen designierten Minister, den er nicht für geeignet halte, abzulehnen. Gleichzeitig arbeitete das Bundeskanzleramt ein Gegengutachten aus, das den Standpunkt vertrat, das Staatsoberhaupt sei verpflichtet, jedem personellen Vorschlag des Bundeskanzlers zu entsprechen ${ }^{91}$. Der Zwist drohte in einem Verfassungsstreit zu eskalieren. $\mathrm{Daß}$ es sich die Bundesrepublik angesichts der gespannten Lage in Berlin nicht leisten konnte, Kompetenzstreitigkeiten zwischen zwei obersten Bundesorganen auszutragen und diese in einem langwierigen Verfahren vor dem Bundesverfassungsgericht klären zu lassen, war man sich jedoch auch in der engsten Umgebung des Bundespräsidenten bewußt. Der Staatssekretär im Bundespräsidialamt, Hans Herwarth von Bittenfeld, versuchte daher, Lübke zum Einlenken zu bewegen. Er vertrat den Standpunkt, der Artikel 64 des Grundgesetzes dürfe nicht dahingehend ausgelegt werden, daß der Bundespräsident das Recht habe, nur ihm genehme Minister zu ernennen. Es müsse schon der Verdacht einer Straftat oder etwas Ähnliches vorliegen, um die

83 Zum Eintreten Lübkes für Berlin vgl. HeRWARTH, Von Adenauer zu Brandt, S. 260-262.

84 Vgl. ebenda, S. 259; KRONE, Tagebücher, Eintrag vom 12. 11. 1961, S. 549; BARING, Sehr verehrter Herr Bundeskanzler!, S. 376.

85 MENDE, Die neue Freiheit, S. 488.

86 HeRWARTH, Von Adenauer zu Brandt, S. 259.

$87 \mathrm{Vgl}$. KRONE, Tagebücher, Eintrag vom 12. 11. 1961, S. 549.

88 Vgl. SCHWARZ, Adenauer II, S. 690 f. und S. 694; ders., Epochenwechsel, S. 242.

89 Vgl. KÖHLER, Adenauer, S. 1127.

90 Später unternahm Lübke sogar noch einen zweiten Vorstoß, Adenauer die Ernennung von Abs nahezulegen. Dieses Vorhaben gab er erst auf, als der Bankier in einem Schreiben vom 12. 11. 1961 seine Bereitschaft erklärte, im Falle einer nationalen Notlage das Außenministerium zu übernehmen. Vgl. ebenda.

91 Vgl. ebenda. 
Unterschrift unter der Ernennungsurkunde verweigern zu können ${ }^{92}$. Lübke beharrte jedoch auf seinem Standpunkt. Am 9. November legte er Adenauer erneut nachdrücklich nahe, sich einen anderen Außenminister zu suchen ${ }^{93}$. Daraufhin rief Herwarth den Präsidenten des Bundesverfassungsgerichts, Gebhard Müller, an, den er seit dessen Zeit als Ministerpräsident von Baden-Württemberg persönlich kannte, um die verfassungsrechtliche Lage auszuloten. Dieser versicherte dem Staatssekretär, er teile dessen Interpretation des Grundgesetzes: Der Bundespräsident könne sich in diesem Fall der Unterschrift unter der Ernennungsurkunde nicht entziehen ${ }^{94}$. Unabhängig von Herwarth versuchten auch Thomas Dehler, Heinrich Krone und Karl Carstens, auf Lübke einzuwirken ${ }^{95}$. Carstens gab dem Bundespräsidenten zu bedenken, eine schwere Staatskrise sei die Folge, wenn er auf seiner Position beharre, und versicherte ihm, der designierte Außenminister würde die deutschen Interessen „mit aller Energie“ verfolgen. Alle gegenteiligen Befürchtungen seien haltlos ${ }^{96}$.

Von seiten des Kanzlers war in diesem Punkt kein Einlenken zu erwarten. Dieser war sogar entschlossen, die Entscheidung des Bundespräsidenten nicht abzuwarten. Er teilte Lübke mit, Schröder werde ihn auf der für Ende November vorgesehenen Reise in die USA begleiten, ob er nun bis dahin ernannt sei oder nicht ${ }^{97}$. Einerseits wollte Adenauer nicht auf Schröder verzichten und ließ das auch dessen Gegner wissen, andererseits bemühte er sich aber, die Bedenken des Bundespräsidenten sowie der Berliner CDU-Abgeordneten auszuräumen. Ein Ausweg aus der Krise bot sich, als Krone, einer der schärfsten innerparteilichen Rivalen Schröders, seine Bereitschaft erklärte, den Vorsitz der CDU/CSU-Bundestagsfraktion niederzulegen und als Bundesminister für besondere Aufgaben ins Kabinett einzutreten. Dort sollte er als „Aufpasser" des Außenministers fungieren ${ }^{98}$. Krone bekam den Auftrag, sich speziell um alle mit Berlin zusammenhängenden Fragen zu kümmern. Schröder mußte zudem dem Bundespräsidenten versprechen, er werde seinen Kabinettskollegen über jede Entwicklung in der Berlin-Frage informieren und ihn bei allen diesbezüglichen Entscheidungen konsultieren ${ }^{99}$. Diese Regelung bot zudem den Vorteil, daß Brentano auf den frei werdenden Posten des Fraktionsvorsitzenden rücken und dadurch einigermaßen besänftigt werden konnte. Der bisherige Außenminister sah seine neue Aufgabe ebenfalls als ein "Wächteramt" an und versicherte, er werde seine Aufmerksamkeit der Kontrolle der Außenpolitik der Bundesrepublik widmen ${ }^{100}$. Des weiteren wurde der Minister für gesamtdeutsche Fragen, Ernst Lemmer, mit der Vertretung der Interessen

\footnotetext{
92 Vgl. Herwarth, Von Adenauer zu Brandt, S. 259.

93 Vgl. MORSEY, Heinrich Lübke, S. 348.

94 Vgl. HeRwarth, Von Adenauer zu Brandt, S. $259 \mathrm{f}$.

95 Vgl. dazu CarSTENS, Erinnerungen, S. 234; KrONE, Tagebücher, Eintrag vom 12.11. 1961, S. 549; MENDE, Die neue Freiheit, S. 488.

96 CARSTENS, Erinnerungen, S. 234.

97 Vgl. die Notiz „Bundespräsident“, in: DeR SPIEGEL vom 6. 12. 1961, S. 25.

98 Vgl. SCHWARZ, Adenauer II, S. 697; BARING, Sehr verehrter Herr Bundeskanzler!, S. 381.

99 Vgl. BARING, Sehr verehrter Herr Bundeskanzler!, S. 471, Anm. 121.

100 Ebenda, S. 382.
} 
Berlins beauftragt ${ }^{101}$. Schröder waren damit drei gewichtige Unionspolitiker zur Seite gestellt, die ihn sozusagen einrahmen sollten. Damit gaben sich seine Gegner zufrieden. Am 14. November 1961 konnte schließlich das Bundeskabinett ernannt und vereidigt werden. Eine der „dramatischsten und langwierigsten Regierungsbildungen in der Geschichte der Bundesrepublik" fand ihr Ende ${ }^{102}$.

Als Schröder seine Amtsgeschäfte aufnahm, wußte er noch nicht, daß er der bis zum heutigen Tage letzte Außenminister der CDU sein würde. Der Nachfolger Adenauers und Brentanos im Auswärtigen Amt galt als „eigentlicher Gewinner" der Regierungsbildung, denn es war ihm trotz erheblichen Widerstands geglückt, sich durchzusetzen. Der einflußreiche und öffentlichkeitswirksame Posten als Außenminister bot ihm die Möglichkeit, sich zu profilieren und seine Aussichten zu erhöhen, bei der spätestens in zwei Jahren wieder aktuell werdenden Kanzlerfrage das Erbe Adenauers anzutreten ${ }^{103}$. Schröder, der bislang „zu den ergebenen Gefolgsleuten Adenauers“ zählte ${ }^{104}$, wollte diese Chance nutzen und deswegen ab sofort seine eigene Politik betreiben ${ }^{105}$. Bald mußte Adenauer erfahren, daß die Loyalität dieses „klügsten seiner Schüler“ begrenzt war und Schröder ihm gefährlich werden konnte, da dieser nach acht Jahren am Kabinettstisch Adenauers wußte, welche Eigenschaften nötig waren, um sich zu behaupten ${ }^{106}$. Die Feststellung Eugen Gerstenmaiers, die beiden seien miteinander nicht glücklich geworden ${ }^{107}$, beschönigt das Verhältnis zwischen dem Kanzler und seinem Außenminister. Tatsächlich war das gegenseitige Verhältnis sehr schnell durch tiefgreifende Meinungsverschiedenheiten über den außenpolitischen Kurs getrübt.

101 Vgl. Protokoll der CDU/CSU-Fraktionssitzung am 14.11. 1961, ACDP VIII-001$1009 / 1$.

102 DedRIng, Die CDU als Regierungspartei, S. 167.

103 KOERFER, Kampf ums Kanzleramt, S. 605.

104 Gerstenmaier, Streit, S. 453.

105 Vgl. SCHWARZ, Adenauer II, S. 697.

106 So die Einschätzung von Schwarz. Vgl. ebenda.

107 Vgl. GerstenMaieR, Streit, S. 453. 


\section{Schröders außenpolitische Konzeption}

Für ein tieferes Verständnis von Schröders außenpolitischem Handeln ist es unerläßlich, zunächst einen Einblick in seine Vorstellungen über die auswärtige Politik zu gewinnen. Nun hat der Außenminister keine dem Kissinger Diktat Bismarcks vergleichbare Schrift hinterlassen, das die Grundkonstanten seines außenpolitischen Weltbildes enthält. Er war ein pragmatischer Mensch, der es für falsch hielt, an ein Problem der internationalen Politik mit einer vorgefertigten Meinung heranzugehen ${ }^{1}$. Schröder nahm für sich in Anspruch, ein Realpolitiker zu sein, der eine Entscheidung ausschließlich unter Berücksichtigung der tatsächlichen Gegebenheiten trifft. Nachdrücklich wies er die Ansicht zurück, eine derartige Politik, sei „richtungslos, prinzipienlos und opportunistisch“2. Sein Pragmatismus orientierte sich also durchaus an Grundsätzen, die aber objektiven Kriterien standhalten und nicht ideologisch gefärbt sein sollten. Seine außenpolitischen Grundüberzeugungen legte er in mehreren programmatischen Reden dar, die er zumeist vor dem Evangelischen Arbeitskreis der CDU oder auf deren Bundesparteitagen hielt. Besondere Bedeutung kommt dabei seiner Rede auf dem 11. Bundesparteitag der CDU in Dortmund am 4. Juni $1962^{3} \mathrm{zu}$, die - so bereits das zeitgenössische Urteil - „gewissermaßen die außenpolitische ,Theorie“ des Ministers“ enthält ${ }^{4}$. Die in diesem Kapitel analysierten Reden machen die Konstanten in Schröders Denken sichtbar, sofern dabei berücksichtigt wird, daß sie nicht im politikfreien Raum gehalten wurden, sondern natürlich auch eine Reaktion auf das jeweilige tagespolitische Geschehen waren. Es wäre deshalb falsch, ihre konkreten programmatischen Aussagen überzubewerten. Bedeutsamer sind die von Schröder angeführten Argumente, warum er eine bestimmte politische Handlungsweise für notwendig hielt. Der potentielle Einwand, der Stellenwert dieser Reden sei gering, weil sie vordringlich zu propagandistischen Zwecken gehalten worden seien, läßt sich mit dem Argument zurückweisen, daß Schröder nur dann andere Menschen von seinen Ansichten überzeugen konnte, wenn er selbst seine Argumentation als zutreffend empfand.

Eine Analyse des außenpolitischen Denkens Gerhard Schröders muß zunächst danach fragen, welcher Bedeutung er der auswärtigen Politik innerhalb des $\mathrm{Be}-$ reichs des politischen Handelns beimaß. Es fällt auf, daß Schröder den Gedanken eines Primats der Außenpolitik strikt zurückwies. Für ihn waren Innen- und Außenpolitik nicht nur untrennbar miteinander verknüpft, sondern die inneren Verhältnisse eines Staates bildeten nach seiner Einschätzung die Grundlage für außenpolitisches Handeln. Er war der Überzeugung, daß die Außenpolitik eines Staates nur glaubwürdig sein konnte, wenn sie von einer großen Mehrheit der Be-

1 Vgl. dazu die Rede Schröders auf der 10. Bundestagung des Evangelischen Arbeitskreises vom 4. bis 6. 10. 1962 in Wiesbaden, in: BullETIN 1962, S. 1579.

2 Rede Schröders auf dem 11. Bundesparteitag der CDU am 4.6. 1962 in Dortmund, in: BULLETIN 1962, S. 897.

3 Für den Wortlaut der Rede Schröders auf dem 11. Bundesparteitag der CDU am 4. 6. 1962 in Dortmund vgl. BuLLETIN 1962, S. 897-902.

4 Dietrich MENDE, „Politik in und für Deutschland“, S. 695. 
völkerung unterstützt wurde. Würde sie lediglich die politische Ansicht der Regierung oder die persönliche Meinung des Außenministers widerspiegeln, könne sie nicht erfolgreich sein ${ }^{5}$. Das Fundament der Außenpolitik Bonns lag nach seiner Auffassung in der wirtschaftlichen Stabilität der Bundesrepublik. Zwar wollte er die Außenpolitik nicht auf eine bloße „Funktion der Wirtschaft“ reduziert sehen, doch war seines Erachtens die wichtige weltwirtschaftliche Rolle der Bundesrepublik der Ausgangspunkt für eine erfolgreiche Tätigkeit der Bonner Diplomatie 6 .

Während das erste Argument, auswärtige Politik müsse mit und nicht gegen den Willen des Volkes betrieben werden, sofort einleuchtet, erstaunt der politische Stellenwert, den Schröder dem ökonomischen Potential eines Staates einräumt. Dies läßt nämlich den Schluß zu, daß für ihn der politische Einfluß der Bundesrepublik in erster Linie von ihrer Wirtschaftskraft abhängig war. Gemeint war aber damit, daß die weltwirtschaftliche Bedeutung der Bundesrepublik ihrer auswärtigen Politik große Durchsetzungschancen auf dem internationalen Parkett eröffnete. Diese Erkenntnis hatte ihre Wurzeln in den historischen Erfahrungen seit 1945. Schröder führte es auf das Wirtschaftswunder der fünfziger Jahre zurück, daß die Deutschen die politische Isolierung der Nachkriegszeit so schnell überwunden hatten und wieder in die Völkergemeinschaft aufgenommen worden waren: Durch die ökonomischen Erfolge habe man „die Achtung und den Respekt der Welt“ zurückgewonnen und sei zu einem „attraktiven Partner“ geworden. Schließlich komme dem wirtschaftlichen Aufschwung auch das Verdienst zu, daß die Forderung nach der Wiederherstellung der staatlichen Einheit Deutschlands in der freien Welt Unterstützung gefunden habe ${ }^{7}$. Er war sich aber bewußt, daß weder die weltweite Nachfrage nach Waren aus der Bundesrepublik, noch die Unterstützung ihrer politischen Anliegen durch die Verbündeten einen Erfolg auf internationaler Ebene garantieren konnte. Beide Faktoren gewährleisteten lediglich, $\mathrm{da} ß$ die Stimme Bonns auch gehört wurde. Entscheidend blieb in seinen Augen letztlich eine vernünftige Konzeption der auswärtigen Politik, für die die Bundesregierung aber selbst verantwortlich war.

Es stellt sich deshalb die Frage, wie nach seiner Auffassung die Außenpolitik gestaltet werden mußte, um ihre Erfolgschancen zu erhöhen. Zunächst einmal stand für Schröder fest, daß im Bereich der auswärtigen Politik Gefühle, Wünsche oder vorgefertigte Denkmuster fehl am Platz waren ${ }^{8}$. Ideologie konnte seines Erachtens niemals die Grundlage für politisches Handeln sein, da es im Bereich der Politik keine „Zauberformel“ gäbe9. Auch Dogmatismus hielt er nicht für ange-

5 Vgl. dazu die Rede Schröders auf der 10. Bundestagung des Evangelischen Arbeitskreises vom 4. bis 6. 10.62 in Wiesbaden, in: Bulletrr 1962, S. 1579.

6 Ebenda.

7 Ebenda.

8 Vgl. dazu die Rede Schröders auf dem 11. Bundesparteitag der CDU am 4.6. 1962 in Dortmund, in: BULLETIN 1962, S. 897.

9 Rede Schröders auf der 10. Bundestagung des Evangelischen Arbeitskreises vom 4. bis 6. 10. 1962 in Wiesbaden, in: BulletiN 1962, S. 1579. 
bracht, da dadurch der Blick für den Handlungsspielraum getrübt werde ${ }^{10}$. Die Politik der kommunistischen Staaten war für ihn der Beweis, daß Dogmatismus keinen Beitrag zur Lösung von Problemen leisten könne, da diese Länder immer dann die "schwersten Rückschläge" hinnehmen müßten, sobald sie nach den Richtlinien ihrer Doktrin handelten ${ }^{11}$. Daraus zog er den Schluß: „Eine Außenpolitik ist nur dann durchführbar und kann nur dann erfolgreich sein, wenn sie alle ausschlaggebenden Faktoren erkennt, analysiert und berücksichtigt." Der ideale Außenpolitiker sollte deshalb ein Verantwortungsethiker im Sinne Max Webers sein. Er sollte ein Gespür für die „gute Sache“ besitzen und sich „mit Augenmaß" bemühen, „die Realitäten in ihrer Gesamtheit und Verflechtung zu erkennen, sie zu wägen und sich zu entscheiden“12. Der „Schlüssel für eine erfolgreiche Außenpolitik" lag also für ihn darin, Realpolitik im Sinne der von Ludwig August von Rochaus 1853 geprägten Definition ${ }^{13}$ zu betreiben. Schröder wollte nach dem Grundsatz handeln, die eigenen Grenzen nicht zu überschreiten, jedoch die Möglichkeiten, über die man verfüge, voll auszuschöpfen. Von dieser „Politik des Möglichen“ grenzte er eine „Politik des Wunschdenkens oder dogmatischer Gebote“ ab, die nicht zum Erfolg führen könne ${ }^{14}$.

Welche Ziele sollte nun die Außenpolitik der Bundesrepublik verfolgen, und an welche Prinzipien sollte sie sich dabei orientieren? Schröder gab als Maßstab vor, stets drei wesentliche Punkte im Auge zu behalten, nämlich „Frieden, Freiheit und gerechte Ordnung "15. Niemals dürfe die Politik der Bundesregierung in Gegensatz zu einem dieser drei Ziele geraten, da sie "untrennbar“ zusammengehörten: Frieden sei die Voraussetzung für Ordnung; Freiheit wiederum brauche Ordnung, da sie sonst zur Anarchie führe; Ordnung und Frieden würden schließlich ohne Freiheit zur Diktatur führen ${ }^{16}$. Um diese drei Ziele zu erreichen, hatte die auswärtige Politik der Bundesrepublik fünf Aufgaben zu erfüllen:

"- jeden Angriff auf uns und unsere Freiheit zu verhindern;

- das Recht der Selbstbestimmung für unsere Landsleute in der Sowjetzone durchzusetzen;

- ein wirtschaftlich geeintes, zu gemeinsamem politischen Handeln fähiges, freies Europa zu schaffen;

10 Vgl. die Rede Schröders auf dem 11. Bundesparteitag der CDU am 4.6. 1962 in Dortmund, in: BuLLETIN 1962, S. 897.

11 Rede Schröders auf der 10. Bundestagung des Evangelischen Arbeitskreises vom 4. bis 6. 10. 1962 in Wiesbaden, in: BULLETIN 1962, S. 1579.

12 Rede Schröders vor der Wirtschaftsvereinigung Eisen- und Stahlindustrie am 28. 6. 1963 in Düsseldorf, in: BuLlETIN 1963, S. 1003.

$13 \mathrm{Vgl}$. RochaU, Grundsätze der Realpolitik.

14 Rede Schröders auf dem 11. Bundesparteitag der CDU am 4.6. 1962 in Dortmund, in: BULLETIN 1962, S. 897.

15 Rede Schröders vor der Wirtschaftsvereinigung Eisen- und Stahlindustrie am 28. 6. 1963 in Düsseldorf, in: BulletiN 1963, S. 1003. In seiner Rede auf der 10. Bundestagung des Evangelischen Arbeitskreises der CDU/CSU vom 4. bis 6.10.1962 in Wiesbaden sprach Schröder in seiner Trias nur von „Ordnung“ (vgl. BULLETIN 1962, S. 1580). Wohl um eine autoritäre Interpretation des Begriffs zu vermeiden, ergänzte er ihn später um das Adjektiv, gerecht'.

16 Vgl. ebenda. 
- die engste Verbindung zu den Vereinigten Staaten von Amerika zu halten und zu festigen;

- für ein nachbarschaftliches Verhältnis zu den osteuropäischen Staaten einzutreten." 17

Die Reihenfolge zeigt deutlich, daß Schröder der Bewahrung der Freiheit der Bundesrepublik Vorrang vor der Wiederherstellung der staatlichen Einheit einräumte ${ }^{18}$. Zwar war für ihn die gesamte Außenpolitik Bonns letztlich „im Grunde genommen Wiedervereinigungspolitik "19, doch im Zweifelsfall mußte der Schutz der freiheitlich-demokratischen Grundordnung über dem Streben nach Einheit stehen. Daß sein Eintreten für die Wiedervereinigung einer inneren patriotischen Überzeugung entsprang, steht außer jedem Zweifel. Für ihn war selbstverständlich, daß „Deutschland nicht an der Mauer zu Ende ist“20. Die Überwindung der Teilung bezeichnete er dementsprechend als „unser vordringlichstes und unser größtes Anliegen“21. Für die Einheit Deutschlands durfte aber die Westbindung nicht aufgegeben werden, da es zur Westverankerung der Bundesrepublik, wie sie von Adenauer seit 1949 kontinuierlich betrieben worden war, keine Alternative gab. In diesem Punkt war nach Auffassung Schröders ein Tauschgeschäft mit Moskau undenkbar. Im übrigen hatte es seiner Ansicht nach bislang keine einzige realistische Gelegenheit gegeben, durch Verhandlungen mit der Sowjetunion die Einheit zu erreichen und dabei gleichzeitig die Freiheit zu bewahren. Damit stellte er sich gegen die These, es habe in der Vergangenheit durchaus ernst zu nehmende Gesprächsangebote Moskaus gegeben, so zum Beispiel die sogenannten StalinNoten des Jahres 195222. In solchen Behauptungen sah Schröder den Versuch einer gefährlichen Legendenbildung23. Die Bewahrung der Freiheit der Bundesrepublik stand also im Mittelpunkt seiner Politik. Er war überzeugt, daß die

17 Rede Schröders vor der Wirtschaftsvereinigung Eisen- und Stahlindustrie am 28. 6. 1963 in Düsseldorf, in: BULLETIN 1963, S. 1003.

18 Zur Diskussion, ob die Freiheitssicherung der Bundesrepublik Priorität vor der Wiederherstellung der staatlichen Einheit Deutschlands haben sollte, vgl. u. a. SCHWARZ, Das außenpolitische Konzept Konrad Adenauers, S. 85f. und S. 99-102; ders., Adenauer I, S. 518-527 und S. 834-850; ZITELMANN, Adenauers Gegner.

19 Rede des Bundesministers Schröder auf dem 13. Bundesparteitag der CDU am 30. 3. 1965 in Düsseldorf, in: DzD IV/11, S. 343.

20 Rede des Bundesministers Schröder am 2. 10. 1962 in Berlin, ACDP Pressearchiv, Sammlung „Gerhard Schröder“.

21 So Schröder in einer Rundfunkansprache am 8. 12. 1961, in: BulletiN 1961, S. 2179.

22 Für den Wortlaut der sowjetischen Note vom 10. 3. 1952 sowie des darauf folgenden Notenwechsels zwischen den drei Westmächten und der UdSSR vgl. DOKUMENTE ZUR DEUTSCHLANDFRAGE, Bd. 1, S. 138-166. Zur Bewertung der sowjetischen Initiative vgl. u. a. GRAML, Die Legende von der verpaßten Gelegenheit; GrEWE, Die deutsche Frage in der Ost-West-Spannung, S. 143-155; SCHWARZ (Hrsg.), Die Legende von der verpaßten Gelegenheit; STEININGER, Eine Chance zur Wiedervereinigung?; sowie den Diskussionsbeitrag von Fritz Schenk, in: WETTIG (Hrsg.), Die sowjetische Deutschlandpolitik in der Ära Adenauer, S. 161-166. Für einen Überblick über die wissenschaftliche Diskussion vgl. MORSEY, Die Bundesrepublik Deutschland, S. 164-167.

23 Vgl. BT StENOGRAPHISCHE BERICHTE, Bd. 52, S. $2634 \mathrm{f}$. 
UdSSR auf Expansion ausgerichtet war ${ }^{24}$. Selbst wenn die sowjetische Regierung zuweilen den Eindruck einer Verständigungsbereitschaft erwecke, sei sie in Wahrheit nicht an einem Ausgleich mit dem Westen interessiert, sondern strebe danach, "die kommunistische Herrschaft in der sowjetischen Zone und Ost-Berlin aufrechtzuerhalten und - wenn möglich - auch auf das freie West-Berlin und noch weiter auszudehnen“ 25 .

Angesichts der Bedrohung durch den Warschauer Pakt hielt Schröder die NATO und den nuklearen Schutz durch die USA für unverzichtbar, da nur sie die Sicherheit der Bundesrepublik garantieren konnten ${ }^{26}$. Eine weitere Maxime seiner Außenpolitik lautete folglich, daß die Bundesrepublik, auf sich alleine gestellt, weder ihre Freiheit verteidigen, noch die Einheit Deutschlands erreichen könne, da sie zwar eine bedeutende Wirtschaftsmacht, aber keine politische Großmacht sei. Bonn war auf die Unterstützung anderer Staaten angewiesen. Zu einer Politik der Zusammenarbeit mit den westlichen Partnern, wie sie sich seit 1949 bewährt hatte, sah Schröder keine Alternative. Dies bedeutete für ihn aber nicht, daß die Bundesrepublik keine eigenständige auswärtige Politik betreiben könne ${ }^{27}$. Aus der Erkenntnis, daß Bonn auf Kooperation nicht verzichten konnte, zog er den Schluß, daß die Bundesrepublik stets eine ausgleichende Position einnehmen müsse, um „die Einigkeit unter den Verbündeten zu erhalten und zu festigen"28.

Wie realistisch schätzte Schröder aber das Ziel ein, eines Tages die Wiedervereinigung Deutschlands herbeizuführen? Wie er auf der 12. Bundestagung des Evangelischen Arbeitskreises am 28. Mai 1965 ausführte, setzte er auf eine „Politik des langen Atems"29. Keinesfalls, so der Außenminister, dürfe die Bundesrepublik in der Phase der Teilung den Eindruck erwecken, als halte sie den Status quo für endgültig. Außerdem sei das Zusammengehörigkeitsgefühl zwischen West- und Ostdeutschen zu bewahren ${ }^{30}$. Ungeduld war für Schröder fehl am Platz, da immer klar gewesen sei, „daß dieses Ziel nicht von heute auf morgen erreicht werden könnte" 31 . Trotz der nicht gerade ermutigenden internationalen Lage rief er dazu auf, die Hoffnung nicht aufzugeben, daß es irgendwann zur Wiederherstellung der staatlichen Einheit Deutschlands komme. Schröder wies darauf hin, daß in der Weltpolitik weitreichende Veränderungen innerhalb kürzester Zeit möglich seien. So könnten sich Chancen eher eröffnen, als man damit rechne ${ }^{32}$. Als Beispiel

24 Vgl. dazu die Rede Schröders auf dem 11. Bundesparteitag der CDU am 4.6. 1962 in Dortmund, in: BulLETIN 1962, S. 900.

25 Rede Schröders auf der 10. Bundestagung des Evangelischen Arbeitskreises vom 4. bis 6. 10. 1962 in Wiesbaden, in: BulLETIN 1962, S. 1583.

26 Vgl. die Rede Schröders auf dem 11. Bundesparteitag der CDU am 4.6. 1962 in Dortmund, in: BulLETIN 1962, S. 900.

27 Vgl. ebenda, S. 897.

28 Rede Schröders vor der Wirtschaftsvereinigung Eisen- und Stahlindustrie am 28. 6. 1963 in Düsseldorf, in: BULLETIN 1963, S. 1003.

29 SCHRÖDER, Deutsche Politik heute und morgen, S. 15.

$30 \mathrm{Vgl}$. ebenda, S. 18.

31 Rede Schröders auf dem 11. Bundesparteitag der CDU am 4. 6. 1962 in Dortmund, in: BULLETIN 1962, S. 901.

32 BT STENOGRAPHISCHE BERICHTE, Bd. 51, S. 1771. Schröder hat eine rasche Veränderung der politischen Nachkriegsordnung in Europa stets für möglich gehalten. Noch am 16. 6. 
führte er zuweilen die Lösung der Saar-Frage an. Schröder erinnerte daran, daß zu Beginn der fünfziger Jahre eine Verständigung über das Saargebiet zwischen Frankreich und der Bundesrepublik unerreichbar schien. Dann habe man jedoch relativ rasch dieses Problem bereinigen können und es sei in Vergessenheit geraten, welche Schwierigkeiten jahrelang mit dieser Frage verbunden gewesen seien $^{33}$. Daher gelte es, unbeirrt an der Forderung nach dem Selbstbestimmungsrecht für alle Deutschen festzuhalten: „Nur wenn man der Welt klarmache, daß hier ein Verstoß gegen dieses Recht stattfindet [...], dann kämen Veränderungen nicht morgen oder übermorgen, aber diese Kraft müsse man aufbringen und dabei aushalten." 34

Er sah zwei Wege, die eines Tages zur Wiedervereinigung führen konnten: Zum einen spekulierte er damit, daß die UdSSR, bei der der Schlüssel zur Einheit lag35, das Interesse an der Aufrechterhaltung der Teilung Deutschlands verlieren könnte. Sie werde möglicherweise zu der Einschätzung gelangen, „daß auch in ihrem Interesse ein freies wiedervereinigtes Deutschland, das ihr, der Sowjetunion, freundlich gegenübersteht, besser ist, als ein geteiltes Deutschland mit ungewisser Zukunft und mit offensichtlich starken Spannungen “36. Freilich bezweifelte er, ob die Aussicht auf eine enge ökonomische Zusammenarbeit mit einem wiedervereinigten Deutschland so verlockend sein würde, daß der Kreml eine radikale Kehrtwende seiner Deutschland-Politik vornehmen und die DDR aufgeben würde ${ }^{37}$. Wie Adenauer hielt er es aber für denkbar, Moskau könnte im Falle einer $\mathrm{Zu}$ nahme des sowjetisch-chinesischen Gegensatzes an einem Ausgleich mit dem Westen interessiert sein, um sich den Rücken gegenüber Peking freizuhalten ${ }^{38}$. Die zweite Möglichkeit sah er in einer tiefgreifenden Umwälzung der bestehenden Machtverteilung in Europa. Diese Alternative deutete er am 2. Oktober 1962 in einer Rede im Berliner Sportpalast an. Dort sprach er von der Möglichkeit, daß „neue Kräftefelder“ zu „politische[n] Veränderungen“ führen könnten. Aus dem Zusammenhang wird deutlich, daß er dabei an die Politik der europäischen Eini-

1984, also zu einem Zeitpunkt, da der Status quo auf unabsehbare Zeit festgeschrieben schien, erklärte er in einer Rede zum 17. Juni 1953 im Bundestag: „Von dem Ziel, der deutschen Einheit, werden wir uns nicht abbringen lassen, da der Weg dorthin mühsam sein wird. Die Geschichte lehrt, daß sich größere Veränderungen nur allmählich, in langen Zeiträumen vollziehen. Wir sollten aber nicht übersehen, daß unsere Zeit auch den raschen Wandel kennt, und so die Hoffnung wachhalten, daß sich unser Wunsch nach Wiedervereinigung in einem vereinten Europa schneller verwirklicht, als dies im Augenblick möglich zu sein scheint.“ Vgl. BT STENOGRAPHISCHE BERICHTE, Bd. 128, S. 5513 (Hervorhebung im Original).

33 Vgl. dazu FRUS 1961-1963, XIV, Dok. 218, S. 609.

34 Protokoll der CDU/CSU-Fraktionssitzung am 2. 10. 1962, ACDP VIII-001-1009/1.

35 Vgl. die Rede Schröders auf der 10. Bundestagung des Evangelischen Arbeitskreises vom 4. bis 6. 10. 1962 in Wiesbaden, in: BULLETIN 1962, S. 1583.

36 Pressekonferenz Schröders am 27. 11. 1962 in Neu-Delhi, in: DzD IV/8, S. 1436.

37 Vgl. dazu das Gespräch des Bundesministers Schröder mit Abgeordneten des Bundestages am 12. 7. 1963, in: AAPD 1963, Dok. 225, S. 748.

38 Vgl. dazu das Gespräch des Bundesministers Schröder mit Präsident Kennedy am 24. 9. 1963, in: AAPD 1963, Dok. 361, S. 1216. 
gung dachte. Explizit bezeichnete er sie als eine „Politik für alle Deutschen“ 39 . Schröder hielt es für möglich, daß sich das politische Klima zwischen einem vereinigten Europa und der Sowjetunion grundlegend ändern könnte, weil für Moskau die Zusammenarbeit mit einem wirtschaftlich derart starken Gebilde attraktiv sein könnte. Eventuell wäre die sowjetische Regierung dann sogar bereit, „sich mit Deutschland auf der Basis des Selbstbestimmungsrechts zu verständigen“, anstatt den Kalten Krieg, der auch sie finanziell stark belaste, fortzuführen ${ }^{40}$. Mit Blick auf diese Überlegungen beteuerte er daher wiederholt, daß das wirtschaftliche und politische Zusammenwachsen Europas sich nicht gegen die Sowjetunion richte, und bekräftigte das in der Note der Bundesrepublik vom 21. Februar 1962 enthaltene Angebot an die UdSSR zu einer Zusammenarbeit zwischen der EWG und den Ostblock-Staaten nach einer „Lösung der noch anstehenden politischen Fragen". Außerdem wies er bei vielen Gelegenheiten darauf hin, die deutschsowjetischen Beziehungen würden um so besser werden, je mehr Freiheit den Menschen in der DDR gewährt werden würde ${ }^{41}$. Auch hier folgte er der Linie Adenauers, für den die Verbesserung der Lebensbedingungen der Ostdeutschen Priorität vor der Einheit Deutschlands hatte.

Da dem Kreml bei der Wiederherstellung der staatlichen Einheit Deutschlands die Schlüsselrolle zukam, hatte sich die Ostpolitik der Bundesrepublik bis zu Schröders Amtsantritt weitgehend auf die Beziehungen zur UdSSR konzentriert. Schröder trat nun für eine Erweiterung der Ostpolitik ein und sprach sich für eine Verbesserung des Verhältnisses zu den bislang von Bonn vernachlässigten Staaten Ostmittel- und Südosteuropas aus. Er wollte den Staaten, die sich zwar in unmittelbarer Nachbarschaft der Bundesrepublik befanden, aber zum Blocksystem der Sowjetunion gehörten, in direktem Kontakt die Positionen Bonns darlegen und das "Bild von den militaristischen, revanchelüsternen Deutschen“, welches die kommunistische Propaganda dort über Jahre hinweg ungehindert zeichnen konnte, als "Schreckgespenst“ entlarven. Mittels einer Entspannung der Atmosphäre und einer Verbesserung der Beziehungen sollte das „Verständnis für die gegenseitigen Probleme" gefördert werden ${ }^{42}$. Den Osteuropäern gelte es zu vermitteln, daß die Bundesrepublik nur ein Ziel habe, nämlich „mit ihnen in Frieden und guter Nachbarschaft zu leben"43. Auf diese Weise wollte er ihre Angst vor einem wiedervereinigten Deutschland abbauen.

39 Rede des Bundesministers Schröder am 2. 10. 1962 in Berlin (West), ACDP Pressearchiv, Sammlung "Gerhard Schröder“.

40 Vgl. das Gespräch des Bundesministers Schröder mit Vertretern der französischen Presse am 20. 10. 1962, PA/AA, Ministerbüro, Bd. 242.

41 Rede Schröders auf dem 11. Bundesparteitag der CDU am 4.6. 1962 in Dortmund, in: Bulletin 1962, S. 898. Vgl. auch ebenda, S. 901, sowie die Rede Schröders auf der 10. Bundestagung des Evangelischen Arbeitskreises vom 4. bis 6.10. 1962 in Wiesbaden, in: BUlleTiN 1962, S. 1580-1583. Vgl. ferner sein Gespräch mit dem sowjetischen Botschafter Smirnow am 26. 10. 1962, PA/AA, Ministerbüro, Bd. 242.

42 Rede Schröders vor der Wirtschaftsvereinigung Eisen- und Stahlindustrie am 28. 6. 1963 in Düsseldorf, in: Bulletin 1963, S. 1007.

43 Rede Schröders auf der 10. Bundestagung des Evangelischen Arbeitskreises vom 4. bis 6. 10.1962 in Wiesbaden, in: BULLETIN 1962, S. 1584. 
Aufgrund der Vier-Mächte-Verantwortung für Gesamtdeutschland besaßen neben der UdSSR auch Frankreich, Großbritannien und die USA ein deutschlandpolitisches Mitspracherecht. Alle drei Westmächte standen hinter der Forderung Bonns nach staatlicher Einheit, wobei Schröder der amerikanischen Unterstützung die größte Bedeutung zumaß. Wie er rückblickend berichtete, hatte er während seiner Amtszeit niemals Zweifel, daß die Vereinigten Staaten in Erwägung zogen, vom gemeinsamen Ziel, die Spaltung Deutschlands zu überwinden, abzurücken. Niemals, so Schröder, hätten die Amerikaner die vertraglich vereinbarte Deutschland-Politik in Frage gestellt ${ }^{44}$. Der stärkste Anhaltspunkt für die unveränderte amerikanische Haltung war für ihn das Engagement der USA in Berlin. Die Amerikaner seien dort auch "der deutschen Frage wegen" präsent, erklärte er 1962 in einem Interview mit dem WDR 45 . Schröder warnte allerdings davor, die Hilfe Washingtons für selbstverständlich zu halten. Eine „der wesentlichsten Aufgaben deutscher Politik“ sah er darin, „das kostbare Gut der deutschamerikanischen Freundschaft zu wahren, zu entwickeln, nicht zu gefährden, sondern es mit allen Mitteln zu kräftigen " 46 . Die Bundesregierung habe darauf zu achten, „diese größte Macht der Welt unbedingt interessiert zu halten für diese, unsere Probleme, sie nicht auf den Gedanken kommen zu lassen, daß es vielleicht doch nur ein Randproblem der freien westlichen Welt ist". Nur wenn es gelinge, $\mathrm{daß}$ sich die USA weiterhin mit den Anliegen der Bundesrepublik identifizierten, könne die Teilung Deutschlands überwunden werden ${ }^{47}$.

Das Mittel, um die Vereinigten Staaten eng an die Bundesrepublik zu binden, sah Schröder in der konsequenten Fortführung des europäischen Einigungsprozesses. Nach seinen Vorstellungen sollte einem politisch vereinigten Europa aber nicht nur die sechs Unterzeichnerstaaten der Römischen Verträge von $1957^{48}$ - die Bundesrepublik, Frankreich, Italien und die Benelux-Staaten - angehören, sondern alle freien, demokratischen Staaten Europas, inklusive der neutralen Länder. Explizit nannte er Schweden und Österreich. Besonderen Wert legte er auf die Einbeziehung Großbritanniens, das seiner Ansicht nach nicht vom Kontinent isoliert werden durfte. Das vereinigte Europa sollte auf dem Prinzip der Gleichberechtigung beruhen; eine Vormachtstellung einer oder zweier Nationen lehnte er strikt $\mathrm{b}^{49}$. Nachdrücklich wehrte er sich dagegen, daß die Schaffung eines politisch und wirtschaftlich vereinigten Europas gegen die USA gerichtet sei, und verwies darauf, daß Washington diese Einigung wünsche ${ }^{50}$. Die amerikanische

44 Vgl. dazu SCHRÖDER, Im Gespräch mit Meinhold Krauss, S. 48.

45 Interview Schröders mit dem WDR am 24. 6. 1962, in: BULLETIN 1962, S. 982.

46 Protokoll der CDU/CSU-Fraktionssitzung am 2. 10. 1962, ACDP VIII-001-1009/2.

47 Rede des Bundesministers Schröder am 2. 10. 1962 in Berlin, ACDP Pressearchiv, Sammlung „Gerhard Schröder“.

48 Für den Wortlaut der Römischen Verträge vom 25. 3. 1957 vgl. BUNDESGESETZBLATT 1957, Teil II, S. 753-1223.

49 Vgl. die Rede Schröders auf der 10. Bundestagung des Evangelischen Arbeitskreises vom 4. bis 6. 10.1962 in Wiesbaden, in: BulLETIN 1962, S. 1582, sowie die Rede Schröders vor der Wirtschaftsvereinigung Eisen- und Stahlindustrie am 28.6. 1963 in Düsseldorf, in: Bulletin 1963, S. 1004.

50 Vgl. ebenda, S. 1005. 
Regierung, so Schröder, zöge es vor, mit einem Partner zusammenzuarbeiten, der mit einer Stimme spreche, als mit einer Vielzahl von europäischen Ländern, die untereinander uneins seien ${ }^{51}$. Außerdem könne ein vereinigtes Europa bei der Bewältigung der globalen Probleme den USA, „die bisher die Hauptlast trugen, allmählich einen Teil ihrer Bürde abnehmen" 52 .

Die drei letzten Punkte seiner oben zitierten Aufgabenliste - die Europa-Politik, die Bindung an die USA und die Annäherung an Osteuropa - ergaben sich für Schröder zwangsläufig aus den ersten beiden Aufgaben, die Sicherheit der Bundesrepublik zu bewahren und die Wiedervereinigung anzustreben. Sie waren zwingende Konsequenzen einer Politik, die die Freiheit der Bundesrepublik sichern und zur Einheit Deutschlands führen sollte. Daß für ihn die Vereinigten Staaten der wichtigste Verbündete der Bundesrepublik waren, wird schon dadurch deutlich, daß er der von ihm verlangten, engen Zusammenarbeit Bonns mit Washington einen eigenständigen und den anderen vier Aufgaben gleichrangigen Wert zumaß.

Um Schröders Europa-Politik besser nachvollziehen zu können, muß auf die fundamentalen Unterschiede zwischen seinen europapolitischen Vorstellungen und denen des französischen Staatspräsidenten, Charles de Gaulle, eingegangen werden. Im Gegensatz zu de Gaulle wollte der Außenminister kein Europa, das lediglich ein lockeres Bündnis mit den USA schließen, ansonsten aber auf der politischen Bühne eine weitgehend unabhängige Rolle neben den beiden Supermächten spielen sollte. Er identifizierte sich mit Kennedys Konzept des Grand Design, welches eine dauerhafte Verbindung und Zusammenarbeit zwischen einem vereinigten Europa und den USA in Form einer ,atlantischen Partnerschaft" vorsah $^{53}$. Seine Absicht war es deshalb, um den „engeren Ring“, der die europäischen Staaten umfassen sollte, einen weiteren zu legen, der die Europäer „fest mit den USA verbindet“ 54 . Europa sollte „einen kräftigen Pfeiler“ der zu errichtenden „Brücke über den Atlantik“ bilden ${ }^{55}$. Dagegen lehnte de Gaulle den Gedanken einer engen Bindung Europas an die Vereinigten Staaten entschieden ab. Für den General stand fest, daß dadurch Europa in seinen Entscheidungen von Washington abhängig werde und den Status eines Vasallen der Vereinigten Staaten erhalte. Der französische Staatspräsident wurde zudem von der Sorge umgetrieben, angesichts des atomaren Patts könnten die USA sich über die Köpfe der Europäer hin-

51 Vgl. die Rede Schröders auf dem 11. Bundesparteitag der CDU am 4.6. 1962 in Dortmund, in: BulleTIN 1962, S. 900.

52 Rede Schröders auf der 10. Bundestagung des Evangelischen Arbeitskreises vom 4. bis 6. 10. 1962 in Wiesbaden, in: BuLLETIN 1962, S. 1582.

53 In einer Rede am 4.7. 1962 in Philadelphia nannte Kennedy als Ziel seiner Politik die Schaffung einer "Atlantischen Partnerschaft" mit einem vereinten Europa. Die beiden Partner sollten in der Außen-, Verteidigungs-, Handels-, Wirtschafts- und Entwicklungspolitik "eine koordinierte Politik“ betreiben. Für den Wortlaut der Rede vgl. PUBLIC PAPERS, KenNEDY 1962, S. 537-539. Nach dem Titel des Buches von Joseph KRAFT, The Grand Design, From Common Market to Atlantic Partnership, New York 1962, erhielt das Konzept des Präsidenten die Bezeichnung "Grand Design“.

54 Rede Schröders auf dem 11. Bundesparteitag der CDU am 4.6. 1962 in Dortmund, in: BULLETIN 1962, S. 900.

55 BT STENOGRAPHISCHE BERICHTE, Bd. 51, S. 1771. 
weg mit der Sowjetunion verständigen. Die NATO war für ihn daher nicht mehr der Garant der europäischen Sicherheit, sondern sie war in seinen Augen zu einem Instrument geworden, durch das die Vereinigten Staaten die Hegemonie in Westeuropa ausübten. Doch auch de Gaulle wußte, daß ein auf sich allein gestelltes Europa eine leichte Beute Moskaus war, selbst wenn Frankreich ein eigenes atomares Abschreckungssystem aufbaute. Er beabsichtigte daher nicht, den Bündnispakt mit den USA zu kündigen, strebte allerdings danach, das integrative System der NATO zu Fall zu bringen, um den Mitgliedstaaten ihre militärische Souveränität zurückzugeben. Auf lange Sicht sollte das vereinigte Europa aber eine eigenständige Entwicklung ansteuern, um schließlich zu einer Dritten Kraft neben UdSSR und USA zu werden ${ }^{56}$.

Derartigen Vorstellungen, die bei Politikern und der politischen Öffentlichkeit der Bundesrepublik zum Teil auf Zustimmung stießen, widersprach Schröder vehement. Seiner Ansicht nach brauchten die Europäer keine Angst zu haben, ein Satellit Amerikas zu werden. Das Verhalten der USA in der Nachkriegszeit zeigte ihm zufolge, daß die Amerikaner nicht beabsichtigten, Europa in ein Abhängigkeitsverhältnis zu bringen. Dazu, so erläuterte er in einer Rede im Jahr 1963, müßten sie eine vollkommen andere Politik betreiben, wie dies am Verhalten der UdSSR gegenüber den osteuropäischen Völkern zu beobachten sei. Der Marshallplan, die amerikanische Unterstützung für die geplante Europäische Verteidigungsgemeinschaft zu Beginn der fünfziger Jahre, die Förderung des europäischen Einigungswerks durch die USA, die Stationierung von 400000 amerikanischen Soldaten auf europäischem Boden sowie das kollegiale Verhalten Washingtons in der NATO seien ausreichende Beweise, daß sie die Europäer als Partner betrachteten. Die USA hätten niemals ihre Machtstellung ausgenützt: „Sie sind hier, um zu schützen, nicht um zu herrschen. "Es war für ihn unverständlich, daß mancher Politiker den Einfluß der USA auf die europäische Politik für zu groß hielt, nachdem noch wenige Jahre zuvor Washington aufgefordert worden war, mehr Führungsstärke zu zeigen ${ }^{57}$.

Aus diesen positiven Äußerungen über die amerikanische Europa-Politik sollte aber nicht der Schluß gezogen werden, Schröder habe die vorhandenen Defizite in den amerikanisch-europäischen Beziehungen nicht erkannt. Tatsächlich war ihm sehr wohl bewußt, daß noch einiges im argen lag. Es war aber fest davon überzeugt, daß die Zusammenarbeit nur gemeinsam mit Washington verbessert werden konnte und nicht mit einer gegen Amerika gerichteten Politik. Von einer Realisierung seiner europapolitischen Vision versprach sich Schröder einen neuen partnerschaftlichen Umgang zwischen den USA und ihren europäischen Verbündeten: $\mathrm{Da}$ ein vereinigtes Europa ein größeres politisches Gewicht besäße, würden die Anliegen der Europäer in Washington mehr Beachtung finden und von den Amerikanern bei der Formulierung ihrer Politik verstärkt berücksichtigt werden. Die Führungsrolle der USA, die aus der politischen Zersplitterung Europas resul-

$56 \mathrm{Zu}$ den europa- und sicherheitspolitischen Vorstellungen de Gaulles vgl. DE GAULLE, Mémoires d'espoir, S. 177-288.

57 Rede Schröders vor der Wirtschaftsvereinigung Eisen- und Stahlindustrie am 28. 6. 1963 in Düsseldorf, in: BULLETIN 1963, S. 1005. 
tierte, könnte so allmählich durch eine wirklich gleichberechtigte Zusammenarbeit abgelöst werden ${ }^{58}$.

Während de Gaulle eine zu enge Bindung Europas an die USA für gefährlich hielt, da die Möglichkeit bestand, daß die Amerikaner in den Isolationismus zurückfielen und sich aus Europa zurückzogen, rechnete Schröder nicht mit einer derartigen Entwicklung, weil sie den amerikanischen Interessen zuwiderlief. Die amerikanische Regierung, so der Außenminister, sei sich nämlich bewußt, daß dann Westeuropa, „das zweitmächtigste Industrie- und Wirtschaftspotential der Welt", in die Hände der Sowjetunion fiele. Ein derartiger Machtzuwachs der UdSSR sei aber für die USA nicht hinzunehmen, da sie ansonsten zu einer „Insel in einer kommunistisch beherrschten Welt" würden. Außerdem riskierten die Amerikaner, bei einer kampflosen Aufgabe Europas sowohl ihr Prestige wie ihren Rang als Weltmacht zu verlieren. Schröder schränkte aber ein, daß die Gefahr eines Rückfalls der USA in die Monroe-Doktrin durchaus bestand, sollten die Europäer das Interesse an der Anwesenheit der amerikanischen Truppen auf ihrem Boden verlieren. Die Vereinigten Staaten, betonte der Außenminister, würden ihren Bündnispartner nicht aufgeben, „solange Europa für sie unentbehrlich ist, solange es sich nicht selbst aufgibt, solange es das Bündnis und die militärische Anwesenheit der Vereinigten Staaten auf dieser Seite des Atlantiks wünscht" 59 .

Schröder befürchtete, die Politik de Gaulles, die darauf abzielte, die Verbindungen zwischen Europa und den USA zu lockern, könnte zu einem endgültigen Bruch führen. Daher bemühte er sich, der Öffentlichkeit immer wieder vor Augen zu führen, daß es zu einer engen Zusammenarbeit mit den Vereinigten Staaten keine Alternative gebe. So sei nicht nur im Bereich der Verteidigung eine intensive Kooperation erforderlich, da ohne amerikanische Hilfe selbst ein vereinigtes Europa zu schwach sei, um sich erfolgreich gegen einen Angriff zu wehren, sondern auch auf anderen Gebieten. Denn auf sich alleine gestellt, könnten die Europäer weder wirksame Hilfe für die Entwicklungsländer leisten, noch andere Probleme des 20. Jahrhunderts, wie zum Beispiel das Bevölkerungswachstum, in den Griff bekommen. Eine enge Zusammenarbeit der gesamten freien Welt hielt er deshalb für unerläßlich ${ }^{60}$. Zudem wies er darauf hin, daß es sich vor allem die Bundesrepublik aufgrund ihrer exponierten geographischen Lage gegenüber dem Ostblock nicht erlauben könne, eine Entwicklung zu fördern, die die Abkoppelung der europäischen Staaten von den USA verlange. Da besonders die Bundesrepublik auf die Vereinigten Staaten angewiesen sei, dürfe man der Politik der europäischen Einigung keine antiamerikanische Spitze geben: „Wir müssen daher alles tun, um Europa zu einem unentbehrlichen Partner, nicht aber zu einem Rivalen der Verei-

58 Vgl. die Rede Schröders auf dem 11. Bundesparteitag der CDU am 4.6. 1962 in Dortmund, in: BulletiN 1962, S. 900, sowie die Rede Schröders auf der 10. Bundestagung des Evangelischen Arbeitskreises vom 4. bis 6.10. 1962 in Wiesbaden, in: BULLETIN 1962, S. 1582.

59 Rede Schröders vor der Wirtschaftsvereinigung Eisen- und Stahlindustrie am 28.6. 1963 in Düsseldorf, in: BulleTIN 1963, S. 1006 (Hervorhebungen im Original).

$60 \mathrm{Vgl}$. die Rede Schröders auf der 10. Bundestagung des Evangelischen Arbeitskreises vom 4. bis 6. 10. 1962 in Wiesbaden, in: BULLETIN 1962, S. 1582. 
nigten Staaten zu machen. “61 Bonn habe dafür Sorge zu tragen, „daß sich unsere lebenswichtigen Interessen mit denen der USA decken". Lediglich rhetorisch die Freundschaft zu den Vereinigten Staaten zu unterstreichen, genüge nicht; es müßten vielmehr Fakten geschaffen werden, die die transatlantische Interessengemeinschaft „unauflösbar" machen ${ }^{62}$. Dieses Postulat Schröders galt insbesondere für die NATO. Sie war für ihn das wichtigste transatlantische Bindeglied, weil sie nicht nur die Sicherheit der Bundesrepublik garantierte, sondern auch der Bonner Deutschland-Politik den notwendigen Rückhalt gab. Eines seiner wesentlichen Ziele war deshalb, „die Atlantische Allianz politisch und militärisch zu stärken und auszubauen"63. Auf diese Weise wollte er die USA, der Schutzschild der Bundesrepublik vor einem militärischen Angriff des Warschauer Paktes und wichtigste Verbündete auf dem Weg zur Wiedervereinigung, fest an Europa binden.

Schröders unbedingtes Streben nach engen und ungetrübten Beziehungen zu den Vereinigten Staaten kann mit Recht als das „Fundament seiner Außenpolitik“ bezeichnet werden ${ }^{64}$. Vehement bekämpfte er alle Bestrebungen, die Bundesrepublik von den USA zu lösen und ein europäisches Europa, wie es de Gaulle vorschwebte, zu etablieren. Er verlangte statt dessen, die transatlantischen Beziehungen noch enger zu gestalten. Dies sollte durch eine Stärkung der NATO erreicht werden; vor allem aber durch die Schaffung eines vereinigten Europas, das in „ein echtes und ausgeglichenes Partnerschaftsverhältnis“ mit Amerika treten sollte ${ }^{65}$. Im Gegensatz zu de Gaulle hatte seine Europa-Politik das Ziel, die Bindungen zu den USA zu verstärken und die atlantische Partnerschaft unauflöslich zu machen.

Aufgrund seiner an Amerika orientierten außenpolitischen Einstellung wurde Schröder - wie später noch ausführlicher dargestellt wird - als ein Hauptvertreter der sogenannten Atlantiker angesehen. Er selbst hat diese Einteilung der Bonner Politiker in Gaullisten, die eine enge Zusammenarbeit mit Frankreich favorisierten, und in eine zweite Gruppe, die als Atlantiker bezeichnet wurden, weil sie die USA als den wichtigsten Partner der Bundesrepublik und Europas betrachteten, abgelehnt ${ }^{66}$. Beide außenpolitischen Konzeptionen waren aus seiner Sicht keine gleichwertigen Optionen, zwischen denen sich die Bundesrepublik entscheiden mußte. Schröders Abneigung gegen dogmatische Positionen tritt in diesem Punkt besonders deutlich zum Vorschein. Er unterschied nicht zwischen verschiedenen außenpolitischen Denkschulen, sondern nur zwischen einer richtigen und einer falschen Außenpolitik. Richtig war in seinen Augen diejenige Politik, welche die

61 Rede Schröders auf dem 11. Bundesparteitag der CDU am 4.6. 1962 in Dortmund, in: BULLETIN 1962, S. 900.

62 Rede Schröders vor der Wirtschaftsvereinigung Eisen- und Stahlindustrie am 28.6. 1963 in Düsseldorf, in: BulletiN 1963, S. 1006.

63 Rede Schröders auf der 10. Bundestagung des Evangelischen Arbeitskreises vom 4. bis 6. 10. 1962 in Wiesbaden, in: BulletIN 1962, S. 1582.

$64 \mathrm{Vgl}$. den Artikel "Europa-Gespräch zwischen Adenauer und Ball“, in: FRANKFURTER AlLGEMEINE ZeITUNG vom 24. 5. 1962, S. 3.

65 Rede Schröders vor der Wirtschaftsvereinigung Eisen- und Stahlindustrie am 28.6. 1963 in Düsseldorf, in: BULLETIN 1963, S. 1005.

66 Vgl. SCHRÖDER, Im Gespräch mit Meinhold Krauss, S. 44-46. 
Interessen der Bundesrepublik am besten vertrat. Nach seiner Einschätzung war dies die von Adenauer eingeschlagene Linie der Westbindung, die die Grundlage seines außenpolitischen Weltbildes darstellte. Schröder legte daher später besonderen Wert auf die Feststellung, daß seine außenpolitische Konzeption mit der von Adenauer bei der Gründung der Bundesrepublik vorgegebenen Linie stets übereingestimmt hatte. Im Rückblick bestritt er kategorisch, daß während seiner Amtszeit als Außenminister die Grundkonstanten der auswärtigen Politik Bonns geändert worden seien. Mit einem inhaltlichen Vergleich der Regierungserklärungen Adenauers und Erhards suchte er diese These zu belegen ${ }^{67}$. Schröder sah in sich selbst den eigentlichen Sachverwalter der Außenpolitik Adenauers. Folglich konnte ihn die im Laufe der Zeit immer stärker werdende Kritik des Kanzlers an seiner Amtsführung nicht beunruhigen. Nicht er selbst war vom Kurs abgewichen, beabsichtigte Schröder mit seiner Analyse nachzuweisen, sondern Adenauer hielt sich nicht mehr an seine eigenen außenpolitischen Grundsätze.

$67 \mathrm{Vgl}$. SCHRÖDER, Außenpolitik im Übergang Adenauer-Erhard. 


\section{Die Differenzen mit den USA in der Berlin-Frage}

\section{Überblick über die Entwicklung der Zweiten Berlin-Krise bis zum Bau der Berliner Mauer}

Das Berlin-Ultimatum des sowjetischen Ministerpräsidenten Nikita Sergejewitsch Chruschtschow vom November 1958 beendete eine für die Bundesrepublik dreijährige außenpolitisch ruhige Periode, die mit der Erlangung der Souveränität am 5. Mai 1955 begonnen hatte und von Grewe nachträglich als „die besten Jahre der Bundesrepublik" bezeichnet wurde' ${ }^{1}$. Die Rede des sowjetischen Parteiund Regierungschefs am 10. November 1958 im Moskauer Sportpalast läutete eine neue Runde im Kalten Krieg zwischen Ost und West ein. Ultimativ forderte Chruschtschow die Beseitigung des Vier-Mächte-Status in Berlin und kündigte an, die sowjetischen Kontrollrechte über den Zugang zur Stadt auf die DDR zu übertragen ${ }^{2}$. Jedem Beobachter war klar, daß die UdSSR nun gewillt war, Bewegung in die festgefahrene deutsche Frage zu bringen und eine Entscheidung zu ihren Gunsten herbeizuführen. Den Hebel setzte die sowjetische Führung konsequenterweise am exponiertesten Ort der westlichen Hemisphäre, in Berlin, der „Achillesferse des Westens“3, an. Chruschtschow präzisierte seine Forderungen in mehreren Memoranden, die er am 27. November den drei Westmächten, der Bundesrepublik und der DDR übermittelte ${ }^{4}$. In diesen Noten erklärte die sowjetische Regierung, daß sie die Übereinkunft der EAC vom 12. September 1944 (das sogenannte Londoner Protokoll5) und die daran anknüpfenden Abkommen, die die Einteilung Berlins in Besatzungszonen sowie die Verwaltung und den Zugang zur früheren Reichshauptstadt regelten, „als ungültig betrachte“ 6 . Die „richtigste und natürlichste Lösung" des Berlin-Problems war der sowjetischen Führung zufolge der Anschluß von Berlin (West) an die DDR. Sie verkündete jedoch, sie würde auch die Alternative akzeptieren, daß „die Frage Westberlin gegenwärtig durch Umwandlung Westberlins in eine selbständige politische Einheit - eine Freistadt - gelöst werde"7. Zur Durchführung dieser Maßnahme, die praktisch die Zustimmung zu einer Dreiteilung Deutschlands in Bundesrepublik, DDR und ein

1 GREWE, Rückblenden, S. 219.

2 Für den Wortlaut der Rede Chruschtschows am 10.11. 1958 in Moskau vgl. DzD IV/1, S. 3-24. Chruschtschow bezog sich in seiner Rede irrtümlich auf das Kommuniqué vom 2. 8. 1945 über die Konferenz von Potsdam (Potsdamer Abkommen), das jedoch keinerlei Angaben über den Status Berlins enthält. Für den Wortlaut vgl. DzD II/1, S. 2101-2148. Erst in ihren Noten vom 27. 11. 1958 an die Bundesrepublik, die DDR, Frankreich, Großbritannien und die Vereinigten Staaten verwies die sowjetische Regierung dann auf die richtigen Rechtsquellen. Vgl. DzD IV/1, S. 151-201.

3 KLessmanN, Zwei Staaten, S. 88.

4 Für den Wortlaut der sowjetischen Noten vom 27.11. 1958 an die Bundesrepublik, die DDR, Frankreich, Großbritannien und die Vereinigten Staaten vgl. DzD IV/1, S. 151-201.

5 Für den Wortlaut der Vereinbarung vom 12. 9. 1944 zwischen Großbritannien, den USA und der UdSSR betreffend die Besatzungszonen in Deutschland und die Verwaltung von Groß-Berlin (Londoner Protokoll), der Frankreich am 26.7. 1945 beitrat, vgl. DOKUMENTE DES GETEILTEN DEUTSCHLAND, Bd. 1, S. 25-27.

6 DzD IV/1, S. 172.

7 Ebenda, S. 174. 
eigenständiges Völkerrechtssubjekt Berlin (West) bedeutet hätte, wurde dem Westen eine Frist von sechs Monaten gesetzt. Sollte nach Ablauf dieses Zeitraums noch keine Übereinkunft getroffen sein, beabsichtigte die Sowjetunion, „durch Übereinkommen mit der DDR die geplanten Maßnahmen durch[zu]führen"8. Ost-Berlin würde dann auch die Kontrolle über die Zugangswege nach Berlin (West) übertragen werden. Abgesehen von der auf keiner völkerrechtlichen Grundlage stehenden Ausweitung der sowjetischen Zwei- zu einer Drei-StaatenThese ${ }^{9}$, bedeutete dieses Ultimatum, daß nach einer einseitigen Kündigung des Vier-Mächte-Status durch Moskau die Westmächte gezwungen gewesen wären, über den Zugang nach Berlin (West) direkt mit der DDR zu verhandeln. Obwohl der amerikanische Außenminister John Foster Dulles die sogenannte AgentenThese entwickelte, derzufolge die Beamten der DDR, die die Zugangskontrolle ausüben würden, nicht als souverän, sondern nur als Beauftragte (agents) der Sowjetunion zu betrachten seien ${ }^{10}$, wäre zumindest eine De-facto-Anerkennung der DDR nicht zu vermeiden gewesen. Damit hätte Moskau aber einen wichtigen Teilsieg errungen, denn die völkerrechtliche Anerkennung der DDR und die damit verbundene Bestätigung des Status quo in Europa war, wie der Historiker Hans Buchheim unterstreicht, „das eigentliche Ziel“ des sowjetischen Ultimatums ${ }^{11}$.

Zwar wiesen die Westmächte in ihren Noten vom 31. Dezember $1958^{12}$ das Ultimatum zurück, signalisierten aber dennoch die Bereitschaft, „die Frage Berlins in dem weiteren Rahmen von Verhandlungen zur Lösung des deutschen Problems wie auch des Problems der europäischen Sicherheit zu erörtern"13. Chruschtschow reagierte, indem er am 10. Januar 1959 einen Entwurf für eine friedensvertragliche Regelung mit Deutschland vorlegte. Nach seinen Vorstellungen sollte dieser Vertrag von beiden deutschen Staaten separat unterschrieben werden. Danach könnten sich Bundesrepublik und DDR untereinander über die Modalitäten einer eventuellen Wiedervereinigung einigen. Neben der Festschreibung der Oder-Neiße-Linie als endgültige deutsche Ostgrenze verfolgte die UdSSR ferner die Absicht, sowohl die Bundesrepublik wie die DDR zu neutralisieren. Außerdem sollte bis zur Herstellung der Einheit Deutschlands eine Freie Stadt Berlin (West) gebildet werden. Sollten diese Forderungen abgelehnt werden, drohte Chruschtschow mit dem Abschluß eines Separatfriedensvertrages mit dem Ulbricht-Regime, in dem die in seinem Memorandum vom 27. November 1958 angekündigten Maßnahmen verwirklicht würden ${ }^{14}$. Dieser letzte sowjetische

8 Ebenda, S. 176.

9 Vgl. HaCKer, Die Rechtslage Berlins, S. $32 \mathrm{f}$.

10 Vgl. dazu die Pressekonferenz des amerikanischen Außenminister Dulles am 16. 11. 1958 in Washington, in: DzD IV/1, S. 144-150.

11 Vgl. BUCHHEIM, Deutschlandpolitik, S. 88 und S. 91. Zum Stand der Forschung über die Motive der sowjetischen Deutschland-Politik zwischen 1958 und 1962 vgl. WETTIG, Die sowjetische Politik während der Berlinkrise 1958 bis 1962.

12 Für den Wortlaut der Noten Frankreichs, Großbritanniens und der USA vom 31. 12. 1958 an die UdSSR vgl. DzD IV/1, S. 422-443.

13 Ebenda, S. 443.

14 Für den Wortlaut der sowjetischen Noten vom 10.1.1959 an Frankreich, Großbritannien 
Entwurf eines Friedensvertrags, in dem für die Wiedervereinigung nun praktisch kein vertraglich festgelegtes Verfahren mehr vorgesehen war, kann als Versuch gedeutet werden, die mehrfache Teilung Deutschlands nicht nur zu fixieren, sondern sogar zu legalisieren ${ }^{15}$.

Kurz vor Ablauf des sowjetischen Ultimatums vom November 1958 einigten sich die Vier Mächte auf die Durchführung einer Außenministerkonferenz in Genf, die in zwei Etappen, vom 11. Mai bis 20. Juni und vom 13. Juli bis 5. August 1959, stattfand und an der die beiden deutschen Staaten - an Katzentischen plaziert - mit Beraterstatus teilnahmen ${ }^{16}$. Auch wenn die Delegation der Bundesrepublik, anders als die der DDR, nicht vom Außenminister angeführt wurde, sondern von dem Diplomaten und Völkerrechtler Wilhelm Grewe, so war durch die Gleichstellung der beiden Gesandtschaften Ost-Berlin deutlich aufgewertet worden ${ }^{17}$. Drei Tage nach Beginn der Konferenz, am 14. Mai 1959, präsentierten die drei Westmächte den sogenannten Herter-Plan als Kern ihres Verhandlungsvorschlags. Der Plan trug offiziell den aussagekräftigen Titel „Grundzüge eines Stufenplanes für die deutsche Wiedervereinigung, die europäische Sicherheit und eine deutsche Friedensregelung "18. Dieser Entwurf, nach dem neuen, erst seit dem 15. April 1959 amtierenden amerikanischen Außenminister Christian Herter benannt, war in einer Arbeitsgruppe der Drei Mächte und der Bundesrepublik seit dem 25. Februar 1959 entwickelt worden ${ }^{19}$.

Der Plan verband in vier eng miteinander verflochtenen Phasen die Lösung der deutschen Frage mit Maßnahmen zur europäischen Sicherheit: Die erste Stufe sah die Wiedervereinigung Berlins vor, das bis zur Herstellung der Einheit Deutschlands von einem unter Kontrolle der Vier Mächte frei gewählten Berliner Rat verwaltet werden sollte. Gleichzeitig sollten Beratungen über weltweite Abrüstungsmaßnahmen aufgenommen werden. Als zweite Stufe wurde die Bildung eines Gemischten Deutschen Ausschusses vorgeschlagen, dem 25 Mitglieder aus der Bundesrepublik und zehn aus der DDR angehören sollten. Der Ausschuß sollte ein Wahlgesetz für Gesamtdeutschland ausarbeiten. Falls sich die Kommissionsmitglieder nicht auf einen gemeinsamen Entwurf einigen konnten, beabsichtigte man, eine Volksabstimmung über die beiden konkurrierenden Modelle durchzuführen. Der Vorschlag, der die meisten Stimmen erhielt, sollte dann als gesetzliche Grundlage für gesamtdeutsche Wahlen dienen. Zudem war in dieser zweiten Stufe vorgesehen, die Truppenstärke der Streitkräfte der Vier Mächte auf bestimmte Obergrenzen festzulegen. Im Anschluß daran hatten Wahlen zu einer Gesamtdeutschen Versammlung stattzufinden, die eine Verfassung für das wiederverei-

und die USA sowie des sowjetischen Entwurfs vom 10.1.1959 für einen Friedensvertrag mit Deutschland vgl. DzD IV/1, S. 537-566.

15 Vgl. HACKER, Irrtümer, S. 122.

16 Vgl. GREWE, Deutsche Außenpolitik der Nachkriegszeit, S. 282-297. An den runden

Tisch, an dem die Delegationen der Vier Mächte saßen, wurden nach langem Streit über die Sitzordnung zwei eckige Tische geschoben, die für die beiden deutschen Beobachter bestimmt waren.

17 Vgl. NOACK, Die Außenpolitik der Bundesrepublik Deutschland, S. 75.

18 Für den Wortlaut vgl. DzD IV/2, S. 74-82.

19 Vgl. Grewe, Rückblenden, S. 388-402; SCHWARZ, Epochenwechsel, S. $91 \mathrm{f}$. 
nigte Deutschland ausarbeiten sollte. Danach stand die Bildung einer Regierung für Gesamtdeutschland auf dem Programm. Als sicherheitspolitisches Element wurde in dieser dritten Stufe angestrebt, eine Einigung über bestimmte rüstungsmäßig verdünnte Zonen in Europa zu erzielen. Damit wurde dem vom Osten in Form des Rapacki-Plans ${ }^{20}$ wiederholt vorgebrachten Gedanken Rechnung getragen, eine regional begrenzte Abrüstung in Europa durchzuführen. Die vierte und letzte Stufe war schließlich dem Abschluß eines Friedensvertrages mit der neuen gesamtdeutschen Regierung vorbehalten.

Im Grunde wiederholte also der Herter-Plan das alte Junktim des Westens zwischen der Wiedervereinigung Deutschlands und Abmachungen zur europäischen Sicherheit ${ }^{21}$. Unverändert waren die Westmächte der Ansicht, Beschlüsse über die Sicherheit in Europa setzten die Lösung der deutschen Frage voraus, da die Teilung Deutschlands die Ursache für die Spannungen in Europa sei. Neu war indessen, daß auf die Forderung verzichtet wurde, der Prozeß zur Überwindung der deutschen Teilung müßte mit freien Wahlen in Gesamtdeutschland beginnen. Außerdem sollte jetzt die Vereinigung Berlins der Vereinigung Deutschlands vorausgehen. Bemerkenswert sind des weiteren die komplizierten Regelungen, durch die die Herstellung der staatlichen Einheit Deutschlands und allgemeine Abrüstungsvereinbarungen der Vier Mächte Schritt für Schritt miteinander verzahnt wurden.

Der sowjetische Außenminister Andrej Andrejewitsch Gromyko lehnte jedoch bereits einen Tag nach der Präsentation den westlichen Vorschlag kategorisch ab und erklärte, seine Verhandlungsbereitschaft beschränke sich ausschließlich auf den sowjetischen Friedensplan vom Januar 195922. Daß Moskau in Wirklichkeit kein Interesse an einer wirklichen Einigung hatte, zeigt auch die Aussage Chruschtschows gegenüber dem amerikanischen Diplomaten Averell Harriman am 23. Juni 1962: „Seien Sie überzeugt, daß ich der Wiedervereinigung Deutschlands nicht zustimmen werde, falls nicht ein sozialistisches System für Deutschland vorgesehen wird. " 23 So ist es nicht erstaunlich, daß auch weiterreichende $\mathrm{Zu}$ geständnisse, die die drei Westmächte auf einer nichtöffentlichen Sitzung der Genfer Konferenz am 28. Juli 1959 machten und die der UdSSR erhebliche Einflußmöglichkeiten auf die inneren Verhältnisse in den drei westlichen Sektoren Berlins gegeben hätten - wie die Einrichtung einer Vier-Mächte-Schiedskommission für Berlin (West) betreffende Fragen und das die Meinungsfreiheit außer acht lassende Angebot, von den Westsektoren der Stadt ausgehende, gegen die DDR gerichtete Propaganda zu unterbinden - vom sowjetischen Außenminister zurückgewiesen

20 Am 2. 10. 1957 unterbreitete der polnische Außenminister Rapacki der UN-Vollversammlung den Vorschlag, eine aus der ČSSR, Polen und den beiden Teilen Deutschlands bestehende kernwaffenfreie Zone zu schaffen. Rapacki präzisierte seine Vorstellung in einem Memorandum vom 14.2.1958 sowie in einer Rede am 4. 11. 1958 in Warschau, wobei er nun auch eine Verminderung der konventionellen Streitkräfte vorschlug. Vgl. DzD III/ 3, S. 1681-1686, sowie DzD III/4, S. 529-533 bzw. S. 1859f. Vgl. ferner WANDYCZ, Adam Rapacki and the Search for European Security.

21 Vgl. HACKER, Irrtümer, S. 122.

22 Vgl. VOGELSANG, Das geteilte Deutschland, S. 222.

23 Zitiert nach ebenda, S. 225. 
wurden $^{24}$. Nach der Einladung des sowjetischen Ministerpräsidenten zu einem Besuch in die USA durch den amerikanischen Präsidenten Dwight D. Eisenhower am 11. Juli zeigte sich die Sowjetunion nicht länger verhandlungsbereit. Sie setzte jetzt ganz auf ein künftiges Gipfeltreffen der vier Staats- und Regierungschefs ${ }^{25}$. So endete die für mehr als 30 Jahre letzte Außenministerkonferenz der Vier Mächte zwangsläufig mit einem „völligen Fehlschlag“26.

Am 26./27. September 1959 trafen sich Eisenhower und Chruschtschow auf dem Landsitz des amerikanischen Präsidenten in Camp David. Sie vereinbarten, eine Gipfelkonferenz der Vier Mächte abzuhalten, in deren Mittelpunkt die Berlin-Frage stehen sollte. Stillschweigend hob Chruschtschow dabei sein BerlinUltimatum auf, so daß ab sofort Verhandlungen ohne Zeitlimit möglich waren27. Zwar war der Geist von Camp David, dessen Wirken die Journalisten in der Vereinbarung erkennen wollten, nur sehr kurzlebig, doch sorgte er zumindest dafür, $\mathrm{da} ß$ sich die Lage vorläufig entspannte. Dennoch wurden die Sorgen der Bundesregierung nicht geringer, denn seit dem Rücktritt des krebskranken amerikanischen Außenministers Dulles im April 1959 beobachtete man in Bonn mit Beunruhigung, daß Eisenhower zunehmend die Bereitschaft erkennen ließ, sich notfalls auch auf Kosten Bonns mit dem Kreml zu einigen ${ }^{28}$. Spätestens seit der Moskau-Reise des britischen Premierministers im März 1959 wurde Harold Macmillan von Adenauer ebenfalls zu den Appeasern gerechnet, die nach dem Urteil des Kanzlers danach trachteten, der Sowjetunion fast um jeden Preis entgegenzukommen ${ }^{29}$. Nach Ansicht Adenauers konnte sich die Bundesrepublik nur auf de Gaulle verlassen, der sich strikt weigerte, unter sowjetischem Druck in Verhandlungen einzutreten ${ }^{30}$. Im Hinblick auf die nachgiebige Haltung der Angloamerikaner, die ganz offensichtlich zu Zugeständnissen bereit waren, sah es der Kanzler als Glücksfall für das weitere Schicksal der Bundesrepublik an, daß Chruschtschow nach dem Abschuß eines amerikanischen U 2-Spionageflugzeugs über sowjetischem Territorium die für den 16. Mai 1960 in Paris anberaumte Gipfelkonferenz platzen ließ31. $\mathrm{Da}$ der sowjetische Ministerpräsident sich ab diesem Zeitpunkt weigerte, mit Eisenhower erneut Verhandlungen aufzunehmen, war bis zum Einzug eines neuen amerikanischen Präsidenten im Januar 1961 ins Weiße Haus erneut ein Aufschub gewonnen ${ }^{32}$. Die weltpolitische Lage blieb aber auch in der Folgezeit gespannt. Internationale Krisen im Kongo und in Laos sowie die

24 Vgl. dazu GREwE, Rückblenden, S. 404 f. und S. 763-765; BUCHHEIM, Deutschlandpolitik, S. $96 \mathrm{f}$.

$25 \mathrm{Vgl}$. ebenda, S. 96.

26 SCHWARZ, Epochenwechsel, S. 94.

27 Vgl. ebenda, S. 104.

28 Vgl. GREWE, Rückblenden, S. $428 \mathrm{f}$.

29 Vgl. SCHWARZ, Adenauer II, S. 489.

30 Vgl. ebenda, S. 557.

31 Vgl. die Erklärungen Chruschtschows und Eisenhowers vom 16. 1. 1960 in Paris; DzD IV/4, S. 1037-1043. Als Adenauer die Nachricht von der Absage der Gipfelkonferenz erhielt, sagte er zu seinem Pressesprecher von Eckardt: „Entschuldigen Sie, Herr v. Eckardt, wenn ich jetzt kölnischen Dialekt spreche. Wir haben nochmals fies Jlück jehabt." Vgl. ECKARDT, Ein unordentliches Leben, S. 614.

32 Vgl. dazu Grewe, Rückblenden, S. 426; SCHWARZ, Adenauer II, S. 561. 
kubanische Revolution zeigten, daß sich die UdSSR weiterhin auf expansivem Kurs befand ${ }^{33}$. Auch der Zugangsverkehr nach Berlin wurde immer wieder Behinderungen ausgesetzt ${ }^{34}$.

Mit dem Amtsantritt John F. Kennedys am 20. Januar 1961 begann eine neue Phase der amerikanischen Deutschland-Politik. Augenfällig wurde diese weitreichende Kursänderung zunächst nur an einer Sprachregelung: So verwendete die neue Regierung in ihren Erklärungen nur noch den Begriff West-Berlin anstelle von Berlin. Auch der Ausdruck Wiedervereinigung war jetzt offensichtlich tabu. Man sprach ab sofort bevorzugt von der Lösung der deutschen Frage oder der Selbstbestimmung des deutschen Volkes ${ }^{35}$. Die USA hielten sich aber vorläufig noch bedeckt, welche Konsequenzen diese rhetorischen Änderungen letztendlich für ihre Deutschland-Politik hatten. Der „eigentliche Wendepunkt“ für die amerikanische Berlin-Politik war erst das Gipfeltreffen am 3. und 4. Juni 1961 in Wien zwischen dem sowjetischen Ministerpräsidenten und dem neuen Präsidenten ${ }^{36}$. Chruschtschow, der keinerlei Kompromißbereitschaft zeigte, schockierte Kennedy durch sein aggressives Auftreten ${ }^{37}$. Schließlich überreichte er ihm ein Aidemémoire ${ }^{38}$, in dem er die amerikanische Regierung aufforderte, „die nach dem Krieg in Europa entstandene Lage zu fixieren“ und deshalb „die Unantastbarkeit der bestehenden deutschen Grenzen juristisch zu formulieren und zu festigen "39. Das Memorandum enthielt zudem ein neues Ultimatum: Sollte es zu keiner Einigung kommen, würde die UdSSR noch vor Jahresende einen Separatfriedensvertrag mit der DDR vereinbaren und dieser die Kontrolle über die Zugänge nach Berlin übertragen. Chruschtschow ließ gegenüber seinem Gesprächspartner keinen Zweifel daran, daß eine derartige Maßnahme eine erneute Blockade der Stadt zur Folge haben würde ${ }^{40}$.

Erst nach dem Wiener Treffen legten die USA ihre Berlin-Politik endgültig fest ${ }^{41}$. In ihrer Antwortnote vom 17. Juli 1961 auf das sowjetische Aide-mémoire betonten sie ihr Recht auf Anwesenheit in Berlin sowie den freien Zugang dort$\operatorname{hin}^{42}$. Am 25. Juli kündigte Kennedy in einer Fernsehansprache zudem eine Stärkung der konventionellen Streitkräfte sowie die Erhöhung der Rüstungsausgaben um 3,2 Mrd. US-Dollar an. Schließlich wiederholte er - „unmißverständlicher als zuvor" 43 - die sogenannten drei essentials, die nicht verhandlungsfähig seien und von der UdSSR nicht verletzt werden dürften: Es handelte sich dabei um das An-

33 Vgl. ebenda, S. 108.

$34 \mathrm{Vgl}$. Riklin, Das Berlinproblem, S. $198 \mathrm{f}$.

35 Vgl. BuCHHEIM, Deutschlandpolitik, S. $105 \mathrm{f}$.

36 Vgl. PROWE, „Ich bin ein Berliner“, S. 153.

37 Vgl. Macmillan, Memoirs V, S. 357; Stützle, Kennedy und Adenauer in der BerlinKrise, S. $102 \mathrm{f}$.

38 Für den Wortlaut des sowjetischen Aide-mémoires vom 4.6. 1961 an die USA vgl. DzD IV/6, S. 817-823.

39 Ebenda, S. 820.

40 Vgl. SCHWARZ, Epochenwechsel, S. 134.

41 Vgl. STÜTZLE, Kennedy und Adenauer in der Berlin-Krise, S. 105.

42 Für den Wortlaut der Note der USA vom 17.7. 1961 an die UdSSR vgl. DzD IV/6, S. $1253-1260$.

43 STÜTZLE, Kennedy und Adenauer in der Berlin-Krise, S. 106. 
wesenheitsrecht der Westmächte in Berlin, den freien Zugang nach Berlin sowie die Freiheit der West-Berliner ${ }^{44}$. Auf Drängen Bonns wurde der letzte Punkt um die Forderung erweitert, daß auch die Lebensfähigkeit der Stadt gewahrt werden müßte. Die Bundesregierung verstand darunter den Weiterbestand der politischen, wirtschaftlichen und kulturellen Bindungen von Berlin (West) an die Bundesrepublik ${ }^{45}$. Mit der Verkündung der drei essentials hatte die amerikanische Regierung nun eine Minimalposition eingenommen, bei deren Verletzung sie auch eine militärische Konfrontation in Kauf nehmen würde. Die Aufrechterhaltung des freien Verkehrs zwischen den beiden Teilen der Stadt war jedoch nicht Bestandteil der amerikanischen Garantien. Dementsprechend bedeutete die Abriegelung der westlichen Sektoren Berlins durch den Bau der Berliner Mauer am 13. August 1961 auch keine Mißachtung der essentials ${ }^{46}$. Der Osten hatte zudem signalisiert, daß der Verkehr zwischen der Bundesrepublik und Berlin (West) nicht behindert werde ${ }^{47}$. Washington reagierte deshalb auf den Mauerbau sogar relativ erleichtert, da diese Aktion angesichts von Chruschtschows Ankündigungen vom Juni als „Rücknahme der Wiener Drohungen“ gewertet werden konnte ${ }^{48}$. Berlin (West), „die letzte noch offene Flanke der DDR “49 und Tor in die Freiheit, durch das noch im Juli circa 30000 und im August mehr als 36000 Menschen geflüchtet waren ${ }^{50}$, blieb nun für über 28 Jahre geschlossen.

Die Maßnahmen kamen für die Amerikaner, ebenso wie für den gesamten Westen, völlig überraschend ${ }^{51}$. Noch am 15. Juni 1961 hatte der Staatsratsvorsitzende der DDR, Walter Ulbricht, auf einer Pressekonferenz in Ost-Berlin unmißverständlich erklärt: „Niemand hat die Absicht, eine Mauer zu errichten.“52 Auf einer Konferenz des Warschauer Pakts vom 3. bis 5. August in Moskau ließ sich der erste Mann der DDR jedoch Rückendeckung für sein Vorhaben geben ${ }^{53}$. Die Tatenlosigkeit, mit der die Westmächte auf die Ereignisse in Berlin reagierten, war für die Deutschen ein Schock. Empört beklagte die BILD-Zeitung am 16. August in großen Lettern: „Der Westen tut NICHTS!“54 Doch seit der Verkündung der essentials war das Terrain für ein amerikanisches Eingreifen deutlich sichtbar ab-

\footnotetext{
44 Für den Wortlaut der Rede Kennedys vom 25. 7. 1961 vgl. DzD IV/6, S. 1348-1356. Die essentials gingen von der sogenannten Berliner Garantie vom 14.12. 1958 aus, in der die Westmächte erklärten, „ihre Position und ihre Rechte in bezug auf Berlin und das Recht auf freien Zugang dorthin zu wahren“. Vgl. das Kommuniqué vom 14.12. 1958 über die Besprechungen der Außenminister der Bundesrepublik Deutschland, Frankreichs, Großbritanniens und der Vereinigten Staaten in Paris, in: DzD IV/1, S. $373 \mathrm{f}$.

45 Vgl. BuchHeIM, Deutschlandpolitik, S. 108.

46 Vgl. dazu Prowe, „Ich bin ein Berliner“, S. 159; Vogelsang, Das geteilte Deutschland, S. 240.

47 So jedenfalls konnte die Erklärung der Warschauer-Pakt-Staaten vom 12. 8. 1961 gedeutet werden. Für den Wortlaut vgl. DzD IV/7, S. 3-6.

48 PROWE, "Ich bin ein Berliner“, S. 153.

49 BESSON, Die Außenpolitik der Bundesrepublik, S. 263.

50 Vgl. DrogmanN, Chronik, S. 171.

51 Vgl. dazu SCHWARZ (Hrsg.), Berlinkrise und Mauerbau.

52 DzD IV/6, S. 934.

53 Vgl. HACKER, Irrtümer, S. 124; BONWETSCH/FILITOw, Chruschtschow und der Mauerbau, S. 155-198.

54 BILD-Zeitung vom 16. 8. 1961, S. 1.
} 
gesteckt. Die amerikanische Botschaft habe man, so Diethelm Prowe, „nur am Rhein und vor allem an der Spree nicht hören wollen"55. Selbst Politiker wie Willy Brandt, denen sehr wohl bewußt war, daß die USA nicht leichtfertig eine militärische Konfrontation mit der UdSSR riskieren konnten, waren vom Zaudern der westlichen Schutzmächte überrascht. „Zwanzig Stunden vergingen, bis die erbetenen Militärstreifen an der innerstädtischen Grenze erschienen. Vierzig Stunden verstrichen, bis eine Rechtsverwahrung beim sowjetischen Kommandanten auf den Weg gebracht worden war. Zweiundsiebzig Stunden dauerte es, bis - in Wendungen, die kaum über die Routine hinausreichten - in Moskau protestiert wurde", so beschrieb der damalige Regierende Bürgermeister Berlins die Reaktion der Drei Mächte ${ }^{56}$. Da die Mauer aber nur auf gewaltsamen Weg hätte entfernt werden können, war der Westen zwangsläufig „zum Ausharren verdammt “57. Die Tatsache, daß die westlichen Partner aber nicht einmal den Anschein erweckten, irgend etwas gegen die offenkundige Zementierung der Teilung Deutschlands zu unternehmen, führte zu einer tiefen Vertrauenskrise. Wie Hans Buchheim treffend schreibt, wurden die Deutschen „aus der Illusion gerissen, daß die Verbündeten noch in der Lage seien, eine Wiedervereinigung Deutschlands in Freiheit zu fördern" 58 .

Der Bau der Berliner Mauer mag zwar im Rückblick als der Höhepunkt der zweiten Berlin-Krise erscheinen ${ }^{59}$; die Zeitgenossen glaubten indessen, dies sei erst der Auftakt für weitere Aktionen Moskaus. Allenthalben rechnete man mit einem "zweiten Schlag des Ostens" in naher Zukunft ${ }^{60}$. Auch Adenauer schrieb drei Tage nach dem Mauerbau an den Verleger Axel Springer: „Was jetzt in Berlin geschehen ist, ist der allererste Anfang einer Reihe weiterer Maßnahmen gegen uns bis zur unmittelbaren Kriegsdrohung. "61 Die Prognose des Kanzlers bewahrheitete sich zum Glück nicht. Adenauer selbst hatte jedoch im Zuge der Ereignisse des 13. August nach der Einschätzung eines seiner engsten Mitarbeiters im Kanzleramt, Horst Osterheld, die "Peripetie“ seiner politischen Karriere erreicht ${ }^{62}$ : Der Bau der Mauer war „der Anfang vom Ende seiner Kanzlerschaft"63. Auch Grewe spricht von einem rapiden Autoritätsverlust Adenauers ab diesem Zeitpunkt ${ }^{64}$. Hans-Peter Schwarz sieht den Kanzler nun „am ersten großen Katarakt“ seiner Laufbahn angelangt: Die kommenden Jahre sollten den Niedergang „in

55 Prowe, „Ich bin ein Berliner“, S. 156.

56 BRANDT, Begegnungen, S. 13 Zur Enttäuschung Brandts über das Verhalten der Westmächte vgl. auch BAHR, Zu meiner Zeit, S. 131-133; STRAuss, Erinnerungen, S. $401 \mathrm{f}$.

57 ARENTH, Die Bewährungsprobe der Special Relationship, S. 158.

58 BuCHHEIM, Deutschlandpolitik, S. 111.

59 So z.B. die Interpretation von HACKE, Weltmacht, S. 92. Dietrich Mahncke meint sogar, mit dem Bau der Mauer "war die zweite Berlin-Krise im Grunde abgeschlossen“; MAHNCKe, Das Berlin-Problem - die Berlin-Krise 1958-1961/62, S. 1807.

60 Vogelsang, Das geteilte Deutschland, S. 241. Vgl. auch STRAUSS, Erinnerungen, S. 399.

61 Schreiben Adenauers an Springer vom 16. 8. 1961, in: ADENAUER, Teegespräche 19611963, S. 546.

62 So der Titel des Kapitels über den Mauerbau in Osterhelds Erinnerungen. Vgl. OsTERHELD, „Ich gehe nicht leichten Herzens ...", S. 49-80.

63 Ebenda, S. 65.

64 Vgl. GrEwe, Rückblenden, S. 490. 
mehreren aufeinanderfolgenden Abstürzen" bringen ${ }^{65}$. Doch, um es noch einmal zu betonen, die Schicksalswende der Kanzlerschaft Adenauers war nicht der Mauerbau selbst. Dieses Ereignis hätte der Kanzler, selbst wenn er davon rechtzeitig Kenntnis gehabt hätte, nicht verhindern können. Es waren die in den Tagen nach dem 13. August begangenen Fehler, die seinen bislang mehr oder weniger unangefochtenen Nimbus in der deutschen Bevölkerung nachhaltig erschütterten ${ }^{66}$.

Kennedy hingegen konnte die Geschehnisse in Berlin als Bestätigung seiner Vermutung ansehen, daß sich die Interessensphären der beiden Supermächte für längere Zeit stabilisiert hätten ${ }^{67}$. Der Präsident war der Ansicht, daß sich seit Ende der fünfziger Jahre die Auseinandersetzung zwischen West und Ost allmählich aus dem bisherigen Zentrum Europa in die Peripherie, also nach Asien, Afrika und Südamerika, verlagert habe ${ }^{68}$. Schon auf dem Wiener Treffen hatte er deshalb Chruschtschow zu überzeugen versucht, daß es in ihrem beiderseitigen Interesse sei, keine Veränderung der nach dem Zweiten Weltkrieg in Europa entstandenen Lage anzustreben und ihm versichert, die USA würden alle Entscheidungen respektieren, die die UdSSR in ihrem Einflußbereich träfen ${ }^{69}$. Mit der von den Vereinigten Staaten angestrebten Abgrenzung der gegenseitigen Machtbereiche war aber eine weitere nachdrückliche Unterstützung der Wiedervereinigungspolitik der Bundesrepublik keinesfalls zu vereinbaren. Angesichts des in Ost und West angehäuften Nuklearpotentials wäre die Verfolgung einer Strategie des roll back im Sinne Dulles' nicht mehr realistisch, sondern geradezu selbstmörderisch gewe$\operatorname{sen}^{70}$. Während Kennedy die friedliche Koexistenz zwischen den beiden Supermächten auf der Grundlage des Status quo anstrebte, beharrte Adenauer noch darauf, man müsse gegenüber dem sowjetischen Druck hart bleiben und eine Gegenoffensive vorbereiten ${ }^{71}$. Doch im Grunde war die Errichtung der Mauer als ein Signal zu werten, daß die Sowjetunion ihren expansiven Kurs in Berlin nicht weiter fortsetzen würde. Im wahrsten Sinne des Wortes waren die gegenseitigen Einflußsphären nun abgesteckt. Kennedy interpretierte die Aktion folgerichtig als die von ihm erwartete „Konsolidierung des Status quo"72. Die Grenzen in Mitteleuropa, die die Bundesrepublik im Rahmen ihrer Deutschland-Politik zwangsläufig nicht akzeptieren konnte, waren damit - zumindest auf absehbare Zeit - festgeschrieben. Auf ein Schreiben Brandts, in dem dieser die amerikanische Reaktion auf den Bau der Mauer kritisierte und die USA zu entschlossenerem Handeln in

65 SCHWARZ, Adenauer II, S. 640.

66 Vgl. OSTERHELD, „Ich gehe nicht leichten Herzens ...“, S. 64-66.

67 Vgl. BuCHHEIM, Deutschlandpolitik, S. 104.

68 Vgl. GREWE, Rückblenden, S. 458.

69 Vgl. Catudal, Kennedy in der Mauer-Krise, S. 126.

70 Diese Strategie der Befreiung wird dem amerikanischen Außenminister Dulles zugeschrieben. Ihr Ziel war nicht nur die Eindämmung („,containment"), sondern auch die Zurückdrängung des Kommunismus („roll back“). Wie Ernst-Otto Czempiel und CarlChristoph Schweitzer betonen, war dieses Konzept aber nie ein offizieller Bestandteil der amerikanischen Außenpolitik. Vgl. CZEMPIEL/SCHWEITZER, Weltpolitik, S. 79-86. Zu Kennedys Einschätzung der Möglichkeiten der amerikanischen Außenpolitik im Zeitalter des nuklearen Patts vgl. STÜTZLE, Kennedy und Adenauer in der Berlin-Krise, S. 19-52.

71 Vgl. Besson, Die Außenpolitik der Bundesrepublik, S. 258.

72 Ebenda, S. 263. 
Berlin aufrief, riet Kennedy dem Regierenden Bürgermeister in seinem Antwortschreiben vom 18. August 1961, die neue Situation hinzunehmen, unhaltbare Positionen zu räumen und pragmatisch nach Initiativen für Verbesserungen zu suchen $^{73}$. Für die Amerikaner galt das Junktim, Maßnahmen zur europäischen Sicherheit würden Fortschritte bei der Überwindung der Teilung Deutschlands bedingen, nicht mehr. Ein Trost für Bonn war immerhin, daß die USA dennoch nicht bereit waren, den Status quo, wenn sie ihn auch im Moment stillschweigend tolerierten, zusätzlich völkerrechtlich zu sanktionieren. Kennedy stellte die amerikanische Position am 17. Oktober 1961 in einer wohl in erster Linie für Moskauer Ohren bestimmten Äußerung gegenüber dem finnischen Präsidenten Urho Kekkonen unmißverständlich klar: „Die Sowjetunion soll doch Deutschland auf der gegenwärtigen Basis geteilt lassen und sich nicht bemühen, uns legal mit der Teilung zu identifizieren. ${ }^{\circ 7}$

\section{Der eingeschränkte außenpolitische Handlungsspielraum der Bundesrepublik seit dem 13. August 1961}

Im Verhalten der Kennedy-Administration gegenüber der Bundesrepublik zeigte sich, daß die Vereinigten Staaten von der im Deutschland-Vertrag niedergelegten alliierten Verpflichtung, auf ein wiedervereinigtes, demokratisches Deutschland hinzuwirken ${ }^{75}$, zwar nicht offiziell abrückten, sie aber nicht länger als Richtschnur für ihre Außenpolitik auffaßten. Inzwischen nahm das Ziel der Friedenswahrung auf der amerikanischen Prioritätenliste den ersten Rang ein ${ }^{76}$. Wolfram Hanrieder stellt zu Recht fest: „Die Supermächte entdeckten ihr gemeinsames Interesse an der Stabilisierung des europäischen Staatensystems, das durch die Erkenntnis ihrer beiderseitigen nuklearen Verwundbarkeit [...] ergänzt und unterstrichen wurde."77 In Washington setzte sich die Überzeugung durch, Fortschritte in der deutschen Frage könnten erst nach einer generellen Entspannung des Verhältnisses zwischen West und Ost erreicht werden ${ }^{78}$. Dementsprechend wurde die Suche nach einer Lösung des Deutschland-Problems in Washington mit immer geringerem Eifer betrieben. Die amerikanische Regierung stellte auch ihre Bemühungen ein, das Problem der Teilung Deutschlands in den Dialog mit dem Kreml einzubringen.

73 Vgl. Prowe, Der Brief Kennedys an Brandt vom 18. August 1961, S. 373-383, besonders S. 379. Vgl. auch FRUS 1961-1963, XIV, Dok. 117, S. 435 f., und Dok. 120, S. 352 f. Vgl. ferner BAHR, Zu meiner Zeit, S. 135f. Dieser Brief gab Brandt nach der Einschätzung Jens Hackers den wesentlichen Anstoß zur Entwicklung seiner Ostpolitik. Vgl. HACKER, Irrtümer, S. 125.

74 Zitiert nach SCHLESINGER, Die tausend Tage Kennedys, S. 382.

75 Vgl. dazu Artikel 7 vom 26. 5. 1952 des Vertrags über die Beziehungen zwischen der Bundesrepublik Deutschland und den Drei Mächten in der Fassung vom 23. 10. 1954 (General- bzw. Deutschland-Vertrag), in: Dokumente DES GETEILTEN Deutschland, Bd. 1, S. 232.

76 Vgl. Hillgruber, Deutsche Geschichte, S. 76.

77 HANRIEDER, Deutschland, S. 177.

$78 \mathrm{Vgl}$. GrabBE, Unionsparteien, S. $296 \mathrm{f}$. 
Diese Entwicklung blieb auch der Bundesrepublik auf Dauer nicht verborgen. Die Bundesregierung mußte sich nun der Frage stellen, welche Auswirkungen die amerikanische Entspannungspolitik auf die eigene Deutschland-Politik hatte. Eine objektive Analyse des neuen amerikanischen Kurses konnte im Grunde nur zu der Schlußfolgerung führen, daß die Frage der staatlichen Einheit Deutschlands im Augenblick nicht mehr auf der Tagesordnung der Weltpolitik stand. Damit wollte man sich in Bonn aber nicht abfinden. Wie noch zu zeigen sein wird, verlangte die Bundesregierung von ihren Verbündeten umso nachdrücklicher konkrete deutschlandpolitische Schritte, je weniger diese ihren Verpflich+urs in aus dem Deutschland-Vertrag nachkamen. Nach dem Willen Bonns soi... die Wiederherstellung der staatlichen Einheit Deutschlands im Mittelpunkt jedes West-Ost-Gesprächs stehen. Angesichts der auf Ausgleich mit der UdSSR gerichteten Politik der USA führte diese Forderung, wie Helga Haftendorn treffend analysiert, unweigerlich zu Interessenkonflikten mit dem wichtigsten Verbündeten der Bundesrepublik ${ }^{79}$. Bonn, so Haftendorn, mußte die schmerzhafte Erfahrung machen, daß sich der Handlungsspielraum der Außenpolitik der Bundesrepublik nach dem Mauerbau schlagartig verringert hatte: Die USA suchten die Verständigung mit der Sowjetunion auf der Basis des Status quo und waren willens, dafür ihre bisherige Deutschland-Politik zu suspendieren. Die Folge war, daß die Bundesregierung für ihre gegen den Status quo gerichtete Wiedervereinigungspolitik in Washington keinen Rückhalt mehr fand. Der Bundesrepublik verblieb nur noch die Rolle einer "Veto-Macht“, die gegebenenfalls durch energische Proteste in Washington verhindern konnte, daß zu viele deutsche Interessen auf dem Altar der amerikanischen Verständigungspolitik geopfert würden. Durch die divergierende Interessenlage sah sich Bonn zudem einem ständigen Anpassungsdruck an die Position der USA ausgesetzt, da die Freundschaft mit den Vereinigten Staaten nicht aufs Spiel gesetzt werden durfte. Denn zum einen war die amerikanische Sicherheitsgarantie für die Bundesrepublik geradezu überlebensnotwendig, zum anderen wußte man am Rhein, daß ohne die amerikanische Unterstützung die Wiedervereinigung nicht erreicht werden konnte ${ }^{80}$. Die Bundesregierung stand also vor der schmerzhaften Aufgabe, ihre bisherigen Positionen einer Überprüfung zu unterziehen, um nicht Gefahr zu laufen, in die Isolierung zu geraten.

Schon die zurückhaltende Reaktion der USA auf den Bau der Berliner Mauer hatte den Politikern in der Bundesrepublik vor Augen geführt, daß sich das Klima für eine offensive Deutschland-Politik deutlich verschlechtert hatte. Die innenpolitische Lage ließ es jedoch im Sommer und Herbst 1961 nicht zu, neue außenpolitische Strategien zu entwickeln: Der Bundestagswahlkampf beherrschte die Republik bis zum 17. September; danach vergingen weitere acht Wochen bis die Regierungsbildung abgeschlossen war und das vierte Kabinett Adenauer am 14. November 1961 schließlich vereidigt werden konnte. Es ist nicht übertrieben, für diesen Zeitraum eine außenpolitische Handlungsunfähigkeit Bonns zu konstatieren $^{81}$. In einer wichtigen Phase des Entscheidungsfindungsprozesses versäumte

79 Vgl. HAFTENDORN, Sicherheit, S. $179 \mathrm{f}$.

80 Vgl. ebenda, S. 141.

81 Vgl. WAGNER, Das geteilte Deutschland, S. 169 und S. 175. 
es die Bundesregierung, ihren Einfluß in Washington geltend zu machen ${ }^{82}$. Die Turbulenzen der Regierungsbildung sind aber keine ausreichende Erklärung für die mangelnde Koordination der Bonner Diplomaten, vor allem des Botschafters in Washington, Grewe, auf dessen Schultern in der Zeit des Interregnums hauptsächlich die Vertretung der Bonner Interessen gegenüber der amerikanischen Regierung ruhte. Adenauer mußte sich den Vorwurf gefallen lassen, daß er zur allgemeinen Verwirrung wesentlich beitrug, da er selbst noch kein Konzept für die Verhandlungen der USA mit der UdSSR entwickelt hatte. Der Kanzler schwankte, ob er überhaupt derartigen Gesprächen zustimmen sollte, und wenn ja, welches Verhandlungsmandat der amerikanischen Regierung einzuräumen sei. Sollte nur über den Status Berlins gesprochen oder auch das Deutschland-Problem und die Frage der europäischen Sicherheit in die Erörterungen einbezogen werden 83 ?

Durch seine Tätigkeit als Vertreter der Bundesrepublik im Washingtoner Botschafterlenkungsausschuß, in dem die Deutschland-Politik der Drei Mächte und der Bundesrepublik koordiniert wurde, hatte Grewe ständigen Einblick in die aktuellen deutschlandpolitischen Überlegungen der amerikanischen Regierung. Während Adenauer noch das Für und Wider von Gesprächen mit der Sowjetunion abwog, mußte der Botschafter konstatieren, daß diese Frage von den Amerikanern längst beantwortet war. Die Kennedy-Regierung favorisierte direkte Verhandlungen mit der UdSSR, denn für sie stand eindeutig das Ziel der Status-quo-Sicherung an erster Stelle ihrer außenpolitischen Bemühungen ${ }^{84}$. So gut es ohne Rückendeckung aus Bonn und mangels klarer Direktiven möglich war, versuchte Grewe, die Interessen der Bundesrepublik zu wahren. Wiederholt machte er seine amerikanischen Gesprächspartner auf frühere Erklärungen und Verträge aufmerksam, die die USA unterzeichnet hatten und deren Aussagen wie die des bereits erwähnten Deutschland-Vertrags - mit den momentanen Plänen nur schwer in Einklang zu bringen waren. Unverblümt machte er seine $\mathrm{Ge}-$ sprächspartner darauf aufmerksam, daß die Bundesrepublik der NATO beigetreten sei, weil ihr eine Verbesserung des Status quo in Aussicht gestellt worden war. Von einer Fixierung der politischen Situation in Mitteleuropa sei dagegen nicht die Rede gewesen ${ }^{85}$. Seine Erläuterungen, die formal nicht zu widerlegen waren, empfanden die Verantwortlichen in Washington als störend. Den Amerikanern war klar, daß Verhandlungen mit der Sowjetunion nur dann erfolgreich sein konnten, wenn Fragen, über die im Moment keine Einigung erzielt werden konnte - wie das Problem der Teilung Deutschlands - nicht einbezogen wurden. Die amerikanische Regierung reagierte infolgedessen auf die Vorhaltungen verärgert und wies sie mit dem Argument zurück, der Botschafter vertrete eine zu legalistische Position ${ }^{86}$. Ohne sich von der Kritik einschüchtern zu lassen, warnte Grewe im Ge-

82 Vgl. KÖHLER, Adenauer, S. 1134.

83 Vgl. dazu Grewe, Rückblenden, S. 491-498; SCHWARZ, Adenauer II, S. 683-703.

84 Vgl. GREWE, Rückblenden, S. 491.

85 Vgl. ebenda, S. 491-505.

86 Vgl. ebenda, S. 493 f.; SCHLEsinger, Die tausend Tage Kennedys, S. 386. Selbst Wolfram Hanrieder, der Verständnis für die Verärgerung der amerikanischen Regierung über die 
genzug davor, „auf maximale Forderungen der östlichen Seite mit maximalen Konzessionen der westlichen Seite zu antworten" 87.

Auf der Konferenz der Außenminister der drei Westmächte und der Bundesrepublik vom 14. bis 16. September 1961 in Washington blieb Bonn jedoch nichts anderes übrig, als dem Vorhaben der amerikanischen Regierung zuzustimmen, den Gesprächsfaden mit Moskau aufzugreifen. Dieser erste Kontakt sollte zunächst allein dazu dienen, in Erkenntnis zu bringen, ob überhaupt die Aussicht auf eine Einigung bestand. Nur wenn dies der Fall wäre, waren offizielle Verhandlungen vorgesehen ${ }^{88}$. Im Grunde war aber kaum zu erwarten, daß Washington und Moskau nur darüber sprechen würden, $o b$ der Wille zu Verhandlungen auf beiden Seiten vorhanden war. Natürlich würden die Beteiligten auch über die Sache selbst diskutieren und ganz zwangsläufig das Gesprächsmandat ausweiten, wenn sie erst einmal an einem Tisch säßen, da sich andernfalls das Ziel der Kontaktaufnahme, die Chancen einer Übereinkunft auszuloten, nicht erreichen ließ. Mit der beschönigenden Titulierung dieser Gespräche als Sondierungen wollte man die bei den westlichen Partnern aufgetretenen Meinungsverschiedenheiten vertuschen. Während die USA und Großbritannien sich für Verhandlungen aussprachen, hatte sich die Bundesrepublik, wie bereits erwähnt, noch nicht endgültig festgelegt; Frankreich hingegen lehnte Gespräche mit der UdSSR strikt ab ${ }^{89}$. Des weiteren stimmte Bonn auf der Konferenz dem Plan zu, der Sowjetunion die Konstituierung von drei technischen Kommissionen vorzuschlagen, die paritätisch mit Beamten der Bundesrepublik und der DDR besetzt sein sollten. Einer dieser Ausschüsse sollte für den innerdeutschen Wirtschaftsverkehr zuständig sein, der zweite sich der Wiederherstellung der Freizügigkeit in Deutschland annehmen, der dritte der Ausarbeitung eines gesamtdeutschen Wahlgesetzes. Die Bundesregierung bestand aber darauf, daß die Kommissionen einen eindeutigen Auftrag der Vier Mächte erhielten, um deren Verantwortlichkeit für Gesamtdeutschland zu betonen. Zudem bekräftigte die Bundesrepublik ihren Alleinvertretungsanspruch. Die Bundesregierung machte deutlich, daß sie nicht gewillt war, eine Anerkennung der DDR, sei es de jure oder de facto, auch nur in Erwägung zu ziehen 90 .

Mit dem Beschluß Sondierungsgespräche aufzunehmen, war der Weg für einen offiziellen Dialog zwischen Washington und Moskau geebnet. Die USA drängten auch sogleich auf eine rasche Aufnahme der Gespräche, denn noch stand die sowjetische Ankündigung im Raum, bis Jahresfrist einen Separatfriedensvertrag mit der DDR zu schließen. Angesichts der damit verbundenen Drohung, die west-

starre Haltung ihres Verbündeten zeigt, gibt immerhin zu: „Die von Bonn und seinen westlichen Verbündeten festgelegten politischen Vereinbarungen zur Behandlung der deutschen Frage stellten einen wichtigen Schutz deutscher Interessen dar, auf dessen Erhaltung Bonn bestehen mußte." Vgl. HANRIEDER, Deutschland, S. 180.

87 GREWE, Rückblenden, S. 500.

88 Im Kommuniqué erklärten die Außenminister, sie seien „einig, daß festgestellt werden soll, ob eine vernünftige Grundlage für ernsthafte Verhandlungen mit der Sowjetunion besteht“. Vgl. DzD IV/7, S. 454.

89 Zur französischen Haltung vgl. z. B. WAGNER, Das geteilte Deutschland, S. 177.

90 Vgl. dazu SCHWARZ, Adenauer II, S. 695. 
lichen Sektoren Berlins einer erneuten Blockade zu unterwerfen und dadurch die Gefahr eines dritten Weltkrieges heraufzubeschwören, waren die Vereinigten Staaten bereit, notfalls auch Grundsatzpositionen aufzugeben ${ }^{91}$. Doch selbst die amerikanische Regierung war überrascht, welche exorbitante Forderungen die sowjetische Seite schließlich stellte. Als sich Ende September der amerikanische Außenminister, Dean Rusk, mit seinem sowjetischen Amtskollegen im Rahmen der UN-Vollversammlung in New York zu insgesamt drei Unterredungen traf ${ }^{92}$, trug jener nach dem Urteil Grewes den wohl „umfassendste[n] Forderungskata-

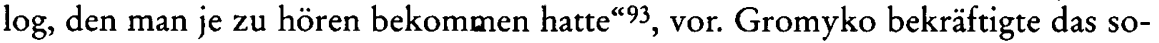
wjetische Ansinnen nach der Umwandlung Berlins (West) in eine Freie Stadt; diesmal aber um den Zusatz ergänzt, es müßten dort neben neutralen auch sowjetische Truppen stationiert werden. Neben altbekannten Forderungen, wie der Festschreibung der deutschen Teilung durch die Unterzeichnung von Friedensverträgen mit beiden deutschen Staaten, der Anerkennung der Oder-Neiße-Linie und der Schaffung atomwaffenfreier und entmilitarisierter Zonen in Europa, verlangte er eine Truppenreduzierung der Bundeswehr, die Aufgabe von amerikanischen Militärstützpunkten außerhalb des Staatsgebietes der USA - also mehr oder weniger den Rückzug der Amerikaner aus Europa - sowie den Abschluß eines amerikanisch-sowjetischen Vertrages über die Nichtweitergabe von Nuklearwaffen und den Austausch von Nichtangriffsvereinbarungen zwischen NATO und Warschauer Pakt ${ }^{94}$.

Zum Entsetzen Adenauers signalisierte Kennedy nichtsdestotrotz, er sei bereit, über alles zu sprechen ${ }^{95}$. Hätte der Kanzler von dem Briefwechsel zwischen dem amerikanischen Präsidenten und Chruschtschow Kenntnis gehabt, in dem beide Seiten ihre Bereitschaft zu einer Lösung des Berlin-Problems zu erkennen gaben $^{96}$, dann wäre seine Reaktion wohl noch heftiger ausgefallen. Doch allein das, was Bonn über die amerikanisch-sowjetischen Kontakte in Erfahrung brachte, ließ die Vermutung keimen, es sei neben der Fixierung einer Dreiteilung Deutschlands sowohl eine gravierende Verschlechterung des Status von Berlin (West), als auch eine bedeutsame Minderung der sicherheitspolitischen Stellung der Bundesrepublik zu erwarten ${ }^{97}$. Dem Kanzler war zwar bewußt, daß „die Wiedervereinigung Deutschlands in einer jetzt zu schätzenden Zeit nicht kommen werde", wie er gegenüber dem amerikanischen Botschafter in Bonn, Walter Dowling, am 6. Oktober 1961 ausführte, doch unterstrich er im gleichen Atemzug: „Man dürfe

91 Vgl. ebenda, S. 683.

$92 \mathrm{Zu}$ den Gesprächen am 21., 27. und 30. 9. 1969 vgl. FRUS 1961-1963, XIV, Dok. 156, S. 431-433, Dok. 160, S. 439-441, und Dok. 164, S. 456-460.

93 GREWE, Rückblenden, S. 504.

$94 \mathrm{Vgl}$. ebenda; OSTERHELD, „Ich gehe nicht leichten Herzens ...“, S. 73.

95 Vgl. SCHWARZ, Adenauer II, S. 684. „Aber da geben wir doch alles einfach weg!“, kommentierte der Kanzler die amerikanischen Pläne. Vgl. OSTERHELD, „Ich gehe nicht leichten Herzens ...", S. 73.

96 Vgl. das Schreiben Chruschtschows an Kennedy vom 29.9. 1961 sowie das Schreiben Kennedys an Chruschtschow vom 16. 10. 1961, in: FRUS 1961-1963, VI, Dok. 21, S. 2538, bzw. Dok. 22, S. 38-44.

97 Vgl. SCHWARZ, Adenauer II, S. 684. 
aber den Menschen die Hoffnung nicht nehmen." Mit Blick auf die Aussagen der Pariser Verträge vom 23. Oktober 1954 zur deutschen Frage forderte er unmißverständlich, „daß die drei Westmächte nicht als wort- und vertragsbrüchig erscheinen dürften "98. In den folgenden Wochen bemühte er sich, seine Bedenken ins Bewußtsein Kennedys zu bringen. In einem Schreiben, das er am 4. Oktober 1961 an den Präsidenten richtete, wies er eindringlich auf die Gefahren hin, die mit der Schaffung entmilitarisierter Zonen in Europa verbunden waren ${ }^{99}$. Sein Insistieren trug schließlich Früchte, denn in seiner Antwort vom 13. Oktober versichterte Kennedy, daß er eine Verschlechterung des militärischen Status der Bundesrepublik nicht dulden und im Falle von Verhandlungen mit der UdSSR jeglichen Disengagementplänen entschieden entgegentreten würde ${ }^{100}$.

Andererseits war aber auch Adenauer bewußt, daß die Bundesrepublik nicht ständig auf ihrer unnachgiebigen Position beharren konnte, ohne die Beziehungen zu den USA schwer zu belasten. Allmählich machte er sich daher mit dem Gedanken vertraut, daß notfalls auch Konzessionen in Kauf genommen werden mußten, um sich nicht dem Vorwurf auszusetzen, Bonn wolle ein Arrangement der Supermächte blockieren ${ }^{101}$. Der Kanzler gab jetzt die Parole aus, „es muß auf allen Seiten ein Fuß zurückgesteckt werden" ${ }^{102}$. Es lag auf der Hand, daß die Gespräche mit dem Osten keinen erfolgreichen Verlauf nehmen konnten, falls die Amerikaner nicht ein substantielles Angebot auf den Verhandlungstisch legten. Immerhin hatte Chruschtschow inzwischen einen sichtbaren Beitrag für eine Entspannung des Konflikts geleistet und auf dem XXII. Parteitag der KPdSU das zeitliche Limit seines Wiener Ultimatums offiziell fallen gelassen ${ }^{103}$. Die Unsicherheit Adenauers, welche Taktik bei den anstehenden Verhandlungen am günstigsten sei, führte zu den bereits erwähnten Irritationen in der auswärtigen Politik der Bundesrepublik, der für einige Wochen eine klare Richtlinie fehlte, welche Politik sie gegenüber den Verbündeten zu vertreten hatte. Schließlich erinnerte sich der Kanzler an die Strategie, die man in den ersten Jahren der Berlin-Krise 1958/59 eingeschlagen hatte, und kam auf den Gedanken, daß einer Beschränkung der amerikanisch-sowjetischen Gespräche auf Berlin erneut der Vorzug zu geben sei. Würden die Sondierungen auf dieses Problem eingeengt, wären die von der Bundesrepublik geforderten Zugeständnisse wohl noch am geringsten. Sie könnten zudem höchstens zu einer Verschlechterung des Status von Berlin (West) führen, jedoch nicht die Sicherheit der Bundesrepublik gefährden. Folglich konzentrierte

98 Zitiert nach SCHWARZ, Adenauer II, S. 685. Für den Wortlaut der Pariser Verträge vom 23. 10. 1954, zu denen u. a. auch der Deutschland-Vertrag gehörte, vgl. BUNDESGESETZBLATT 1955, Teil II, S. 213-576.

99 Vgl. SCHWARZ, Adenauer II, S. 684 f.; OSTERHELD, „Ich gehe nicht leichten Herzens ...“, S. 73.

100 Vgl. FRUS 1961-1963, XIV, Dok. 176, S. 493-497. Vgl. auch GrEWE, Rückblenden, S. $506 \mathrm{f}$.

$101 \mathrm{Zu}$ dieser Meinungsänderung Adenauers vgl. SCHWARZ, Epochenwechsel, S. 241; SIEBEN MORGEN, Gezeitenwechsel, S. 334 f.

102 So äußerte sich Adenauer in einem Hintergrundgespräch mit dem amerikanischen Kolumnisten Joseph Alsop am 8. 11. 1961. Vgl. ADENAUER, Teegespräche 1961-1963, S. 26.

$103 \mathrm{Vgl}$. dazu den Auszug aus der Rede Chruschtschows am 10.11.1958 in Moskau, in: DzD IV/1, S. 3-24. 
sich Adenauer nun darauf, Washington davon zu überzeugen, gegenüber der UdSSR darauf zu bestehen, ausschließlich über die Berlin-Frage zu verhandeln ${ }^{104}$.

Eine objektive Analyse der Situation, in der sich die Bundesrepublik im November 1961 befand, kann nur zu der Feststellung führen, daß sich die Lage seit den Sommermonaten eigentlich verbessert hatte, da nach der Rücknahme des sowjetischen Ultimatums zumindest keine unmittelbare Kriegsgefahr mehr bestand. Langfristig drohte jedoch die Preisgabe entscheidender sicherheits- und deutschlandpolitischer Positionen, wenn die Amerikaner ihre nach der Auffassung Bonns zu konzessionsbereite Linie weiter verfolgten und mit der Absicht, unbedingt einen Ausgleich zu erzielen, Verhandlungen mit der UdSSR aufnahmen. Folglich mußte sich die Bundesregierung bemühen, die bröckelnde deutschlandpolitische Front in Washington wieder zu festigen. Dabei war jedoch der Eindruck zu vermeiden, Bonn beabsichtige, die Verständigung der Supermächte zu stören. Angesichts der beinahe unlösbaren außenpolitischen Aufgaben, mit denen die Bundesrepublik im Augenblick konfrontiert wurde, war es wirklich „ein undankbarer Auftrag" 105 , den Gerhard Schröder übernahm, als er am 14. November 1961, nach Konrad Adenauer und Heinrich von Brentano, zum dritten Außenminister der Bundesrepublik Deutschland ernannt wurde. Wie sollte angesichts der divergierenden Positionen in der Berlin-Politik die Einheit zwischen den Drei Mächten und der Bundesrepublik wiederhergestellt werden? Während die französische Regierung es ablehnte, unter Druck mit dem Kreml zu verhandeln, bereiteten die Amerikaner ein Gesprächspaket vor, in dem sie der sowjetischen Regierung signalisierten, sie würden dem Osten in der Frage der Anerkennung der DDR entgegenkommen. Der Bundesregierung waren zwar nur Teile des amerikanischen Plans bekannt geworden, doch genügten diese schon, um die Schlußfolgerung zu ziehen, daß in Washington praktisch eine De-facto-Anerkennung der DDR diskutiert wurde. Dies hätte aber der Deutschland-Politik der Bundesregierung den Boden entzogen. Die amerikanischen Überlegungen wurden aber noch von den britischen übertroffen. In London war man der Meinung, es sei in Anbetracht der internationalen Lage an der Zeit, daß die Bundesregierung eine Totalrevision ihrer Deutschland-Politik vornahm und sie an die veränderten weltpolitischen Gegebenheiten anpaßte. Macmillan forderte Kennedy am 9. November 1961 unverblümt auf, „soviel Druck auf Adenauer aus[zu]üben, wie Sie können“. Nach der Einschätzung des Premierministers mußte dem Kanzler endlich vor Augen geführt werden, „daß er aber natürlich auch zu geben und nicht nur zu nehmen hat" ${ }^{106}$. Welche Konzessionen die Bundesrepublik im einzelnen zu machen habe, zählte Macmillan anschließend im Detail auf: „[...] erstens die Oder-Neiße-Linie, worüber allgemeine Einigkeit herrscht; zweitens irgendeine Formel, die auf ein

104 Vgl. ebenda, S. 703. Adenauer erläuterte seine Motive für die Entscheidung, isolierte Berlin-Gespräche zu bevorzugen, ausführlich in einem Hintergrundgespräch am 14.12. 1961. Vgl. dazu ADENAUER, Teegespräche 1961-1963, S. $50 \mathrm{f}$.

105 Vgl. den Kommentar von Jürgen Tern: „Der neue Außenminister“, in: FrankfurTer Allgemeine ZeITUNG vom 15. 11. 1961, S. 1.

106 Vgl. Macmillan, Memoirs V, S. 408. Zitiert nach der deutschen Übersetzung: MaCMILLAN, Erinnerungen, S. 410. 
beträchtliches $\mathrm{Maß}$ an De-facto-Anerkennung der DDR hinausläuft; [ ...] drittens, meine ich, muß Adenauer anerkennen, daß politische Bindungen zwischen West-Berlin und der Bundesrepublik aufgegeben werden müßten, daß aber die wirtschaftlichen und finanziellen Bindungen sogar noch verstärkt und erweitert werden könnten; und viertens bin ich für eine Erklärung der deutschen Bundesregierung, daß sie weder die Absicht noch den Wunsch hat, Kernwaffen herzustellen" 107.

Die für Ende November geplante Reise Adenauers und Schröders nach Washington drohte folglich ein Gang nach Canossa zu werden. Sollte schon zu Beginn von Schröders Amtszeit an der Koblenzer Straße ein Mißerfolg stehen? Angesichts der für die Bundesrepublik ungünstigen außenpolitischen Gesamtsituation konnte nicht mit raschen Erfolgen gerechnet werden. Schröder befand sich in einem Dilemma: Hielt er zu sehr an den bisherigen Positionen fest, so würde dies zu einer Krise in den deutsch-amerikanischen Beziehungen führen und gleichzeitig der sowjetischen Propaganda die Gelegenheit geben, Bonn international als Störenfried der Verständigungsbemühungen der Supermächte zu diffamieren. Eindringlich warnte er davor, auch nur in den „Schein eines Verdachts“ zu geraten, den Dialog zwischen Moskau und Washington stören zu wollen ${ }^{108}$. Im Hinblick auf die lebenswichtige amerikanische Sicherheitsgarantie könne man nicht gegen die amerikanischen Gesprächsbemühungen opponieren ${ }^{109}$. Die momentanen Gefahren waren nach seiner Einschätzung nur im Schulterschluß mit den USA zu bewältigen ${ }^{110}$. Falls sich der Außenminister aber andererseits zu stark an die amerikanischen Vorstellungen anpaßte, riskierte er, innenpolitisch in das Kreuzfeuer der deutschlandpolitischen Hardliner zu geraten, die den Vorteil hatten, alles ablehnen zu können, weil sie die Konsequenzen, die sich aus einer Verweigerungshaltung der Bundesrepublik ergaben, nicht tragen mußten. Schon bald sollte Schröder, der sich um Einklang mit der amerikanischen Politik bemühte, auf den Widerstand dieser Gruppe stoßen, deren Vertreter vor allem in seiner eigenen Fraktion zu finden waren. Doch die problematische außenpolitische Situation mußte eigentlich nach seinem Geschmack sein, denn sie bot ihm die Möglichkeit, sich zu profilieren. Die nicht unumstrittene Ernennung zum Außenminister hatte zudem das Interesse der Öffentlichkeit an ihm gesteigert, so daß jeder seiner Schritte im Augenblick besonders aufmerksam beobachtet wurde. Daß er ein außenpolitischer Neuling war, dem obendrein keine Eingewöhnungszeit gewährt wurde, und das politische Parkett, auf das er sich begab, sich durch besondere Glätte auszeichnete, kümmerte ihn nicht. Er hielt sich für den richtigen Mann für eine derart schwierige Aufgabe. Hatte er nicht schon vor einiger Zeit den Kanzler darauf aufmerksam gemacht, daß die Lage einen "tatkräftigeren Außenminister“

107 Ebd., S. 410 f.

108 Zitiert nach dem Artikel „Ein illusionsloses Gespräch über Berlin“, in: FRANKFURTER Allgemeine ZeITUNG vom 21. 4. 1962, S. 3.

109 Vgl. dazu die am 25. 4. 1962 publizierten Ausführungen Schröders auf einer Pressekonferenz in Paris, in: BulletiN 1962, S. 653.

110 Vgl. dazu das am 21. 11. 1961 veröffentlichte undatierte Schreiben Schröders an Rusk, in: BULLETIN 1961, S. 2037. 
erfordere? Obwohl seine Befähigung für dieses Ministeramt von vielen, auch von Parteifreunden, in Frage gestellt wurde, war sein Selbstbewußtsein ungebrochen: Er empfand die Berufung an die Spitze des Auswärtigen Amts als „selbstverständlich"111.

Das Vertrauen in die eigenen Fähigkeiten trübte ihm aber nicht den Blick für die Dinge, die jetzt von ihm erwartet wurden. Er wußte, daß er sich zunächst einmal von dem Makel der Nachgiebigkeit in der Berlin-Frage befreien mußte, mit dem ihm seine Gegner gebrandmarkt hatten. Was passieren konnte, wenn man es im Auge der Öffentlichkeit an Präsenz in der geteilten Stadt fehlen ließ, hatte er im August erlebt, als es Adenauer versäumte, den Berlinern während des Mauerbaus beizustehen. „Er hätte nach Berlin gemußt!“, war Schröders Lehre aus diesem Vorfall112. Noch bevor in der Presse die Aufforderung publiziert wurde, der neue Außenminister sollte in der geteilten Stadt Position beziehen ${ }^{113}$, hatte er sich bereits entschieden, Berlin einen Kurzbesuch abzustatten, um der Bevölkerung seine Verbundenheit zu zeigen und die außenpolitische Vertretung der Stadt durch die Bundesrepublik hervorzuheben ${ }^{114}$. Im Hinblick auf die bevorstehenden Gespräche mit der amerikanischen Regierung wollte er zudem die Haltung der Bundesregierung mit den politisch Verantwortlichen in Berlin abstimmen, um in Washington über die Situation vor Ort berichten zu können ${ }^{15}$. Schröder kam es vermutlich auch darauf an, damit gegenüber der Berliner CDU, die so sehr gegen seine Ernennung opponiert hatte, ein Friedenszeichen zu setzen. Den Vorwurf, er sei in der Berlin-Frage zu weich, bemühte er sich, in seinen öffentlichen Stellungnahmen nachdrücklich zu widerlegen. In einem Interview mit Marion Gräfin Dönhoff für Die Zeit unterstrich er nachdrücklich seine Entschlossenheit, den Status quo in Berlin zu verteidigen ${ }^{116}$. Auf einer Pressekonferenz am 18. November in Berlin erläuterte Schröder dann den Standpunkt der Bundesregierung in aller Ausführlichkeit: Bonn, so der Außenminister, akzeptiere Verhandlungen, sofern die Gespräche in einer Atmosphäre frei von sowjetischen Repressionen stattfinden würden. Nicht verhandlungsfähig seien aber die bestehenden Bindungen zwischen der Bundesrepublik und Berlin (West). Auch am Vier-Mächte-Status der Stadt dürfe nicht gerüttelt werden. Außerdem lehnte er den Gedanken ab, die Bundesregierung sollte in Einvernehmen mit den Drei Mächten bereits jetzt Grundsätze für einen Friedensvertrag mit Deutschland formulieren. Dies sei nicht

111 SCHRÖDER, „Je weiter östlich, desto besser“.

112 SCHRÖDER, Eine Schlacht um Otto John.

113 Vgl. z.B. den Kommentar von Jürgen Tern: „Der neue Außenminister“, in: FrankfuRTER AllgemeINe ZeITUNG vom 15. 11. 1961, S. 1.

114 Vgl. die Artikel „Schröder: Berlin und Bonn einig“, in: DiE WeLT vom 20. 11. 1961, S. 2, und „Berlin begrüßt den Besuch Schröders“, in: FRANKFURTER AlLGEMEINE ZEITUNG vom 18. 11. 1961, S. 4. Schröder besuchte Berlin am 17./18. 11. 1961. Er traf u.a. mit General Lucius D. Clay, den Sonderbeauftragten des amerikanischen Präsidenten für Berlin, zusammen. Ein Gespräch mit dem Regierenden Bürgermeister kam jedoch wegen einer Erkrankung Brandts nicht zustande.

115 Vgl. den Artikel „Schröder: Berlin und Bonn einig“, in: DiE WeLT vom 20. 11. 1961, S. 2, und das Interview Schröders mit dem WDR am 19. 11. 1961, in: BulleTIN 1961, S. 2038.

116 Vgl. den Artikel von Marion Gräfin Dönhoff: „Außenminister Gerhard Schröder. Eine Unterhaltung mit dem neuen Chef des AA“, in: DIE ZEIT vom 17. 11. 1961, S. 3. 
möglich, solange zwischen West und Ost noch keine Annäherung stattgefunden habe ${ }^{117}$. Schröders Aussagen waren ein eindeutiges Signal an die USA, daß die Bundesregierung nicht daran dachte, schon im voraus bestimmte Positionen zu räumen, wie zum Beispiel ihren Standpunkt zur Oder-Neiße-Grenze. Nach geltender Auffassung konnte die deutsche Ostgrenze erst von einer gesamtdeutschen Regierung in einem Friedensvertrag abschließend festgelegt werden ${ }^{118}$. Der AuBenminister war aber skeptisch, ob eine Friedenskonferenz mehr als 15 Jahre nach Kriegsende überhaupt noch sinnvoll sei. Für die Bundesrepublik, die inzwischen den Status eines gleichberechtigten Partners erreicht hatte, würde dies nämlich den Rückfall in die Rolle des besiegten Kriegsgegners bedeuten ${ }^{119}$. Mit der Formulierung dieser Vorbehalte beabsichtigte er aber nicht, einen Konfrontationskurs gegenüber Washington einzuschlagen. Ihm kam es darauf an, unmißverständlich deutlich zu machen, daß eine Einigung mit der UdSSR über die BerlinFrage nicht durch Konzessionen in der deutschen Frage erkauft werden durfte ${ }^{120}$. Um keine Mißstimmung in Washington aufkommen zu lassen, versicherte er Rusk schriftlich, daß die USA der wichtigste Partner Bonns sei und auch bleibe. Die anstehenden Probleme sollten nach seiner Überzeugung in partnerschaftlicher Zusammenarbeit und gegenseitigem Vertrauen gelöst werden ${ }^{121}$. Dies war ein deutlicher Hinweis, daß sich Schröder sehr wohl einen Kompromiß vorstellen konnte. Dahingehend ist wohl auch seine Ankündigung zu verstehen, das Ziel der Bundesregierung für die anstehenden Besprechungen mit der amerikanischen Regierung sei es, sich auf eine gemeinsame Haltung zu einigen ${ }^{122}$. Auch eine andere Aussage zeigt, daß er vor dem wichtigen Amerikabesuch Ende November bestrebt war, die Dissonanzen mit der Regierung Kennedy in Grenzen zu halten. Er betonte, daß die Beseitigung der Mauer keine Vorbedingung der Bundesrepublik für Ost-West-Gespräche sei, und rückte so eine gegenüber amerikanischen Journalisten am 16. November gemachte Äußerung Adenauers zurecht ${ }^{123}$. Dieser Interpretation schloß sich schließlich auch der Kanzler an ${ }^{124}$.

117 Vgl. die Artikel „Bonns Standpunkt in der Berlinfrage“, in: NeuE ZürCHER ZeITUNG, Fernausgabe vom 20.11. 1961, Blatt 2; sowie „Schröder: Berlin und Bonn einig“; DiE WELT vom 20.11. 1961, S. 2.

118 Dies bekräftigte die Bundesregierung nochmals in der Regierungserklärung am 29.11. 1961. Vgl. BT STENOGRAPHISCHE BERICHTE, Bd. 50, S. 31.

119 Vgl. den Artikel von Marion Gräfin Dönhoff: „Außenminister Gerhard Schröder. Eine Unterhaltung mit dem neuen Chef des AA ${ }^{a}$, in: DIE ZEIT vom 17. 11. 1961, S. 3.

120 Vgl. Protokoll der CDU/CSU-Fraktionssitzung am 24. 11. 1961, ACDP VIII-001-1009/ 1.

$121 \mathrm{Vgl}$. das am 21.11. 1961 veröffentlichte undatierte Schreiben Schröders an Rusk sowie das Interview Schröders mit dem WDR am 19.11. 1961, in: BULLETIN 1961, S. $2037 \mathrm{f}$.

122 Vgl. den Artikel „Schröder: Berlin und Bonn einig“, in: DIE WELT vom 20. 11. 1961, S. 2.

123 Vgl. den Artikel „Bonns Standpunkt in der Berlinfrage“, in: NeUE ZÜRCHER ZEITUNG, Fernausgabe vom 20. 11. 1961, Blatt 2; sowie den Artikel von Sidney Gruson: „Adenauer wants US to Eliminate NATO Atom Curb“, in: NEW YORK TIMES vom 17. 11. 1961, S. 1 und S. 3, bzw. DzD IV/7, S. 944 f. Vgl. auch ADENAUER, Teegespräche 1961-1963, S. 29 35.

124 Vgl. GREWE, Rückblenden, S. 518. 
Die ersten Stellungnahmen des Außenministers waren jedoch vor allem hinsichtlich seiner Haltung zur sogenannten Hallstein-Doktrin aufschlußreich. Die Hallstein- oder Hallstein-Grewe-Doktrin war 1955 im Anschluß an die Aufnahme diplomatischer Beziehungen mit der Sowjetunion als ein Instrument der bundesdeutschen Nichtanerkennungspolitik gegenüber der DDR von Wilhelm Grewe, damals Leiter der Politischen Abteilung im Auswärtigen Amt, entwickelt worden. Ihr zufolge betrachtete es die Bundesrepublik als einen „unfreundlichen

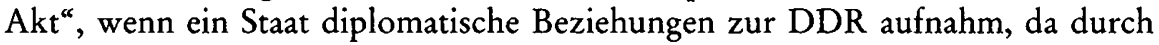
eine derartige Aufwertung Ost-Berlins der Weg zur Wiedervereinigung erschwert würde. Im Falle einer völkerrechtlichen Anerkennung der DDR sah das, fälschlicherweise als Doktrin bezeichnete und nach den Worten seines Schöpfers „am meisten und intensivsten umstrittene Stück der Deutschlandpolitik zwischen 1955 und 1969“125, einen abgestuften Katalog von Maßnahmen vor, der bis zum Abbruch der gegenseitigen Beziehungen reichen konnte, wie er 1957 gegenüber Jugoslawien durchgeführt wurde ${ }^{126}$. Anläßlich seines Besuchs in Berlin deutete Schröder nun an, daß er sich "gewisse Auflockerungen“ bei der Anwendung der Doktrin vorstellen könne, sofern sich die Lage in Berlin normalisiere ${ }^{127}$. Gegenüber Marion Gräfin Dönhoff wurde er noch präziser: Ihr sagte er, es wäre in der derzeitigen Situation ,ein Wahnsinn“, die Doktrin aufzugeben; sollte aber eines Tages eine tragbare Vereinbarung mit der Sowjetunion über Berlin geschlossen werden, könnte man diese Frage neu diskutieren. Seiner Ansicht nach schränkte die Doktrin den außenpolitischen Handlungsspielraum der Bundesrepublik ein und stand, neben dem Problem der Oder-Neiße-Linie, einer Verbesserung des Verhältnisses zu Polen im Wege ${ }^{128}$. Erstaunlicherweise fanden diese Bekenntnisse in der Öffentlichkeit keine große Aufmerksamkeit, obwohl Schröder damit seine Absicht unterstrichen hatte, in seinem neuen Amt nicht nur Besitzstandswahrung zu betreiben, sondern auch nach neuen Wegen, vor allem in der Ostpolitik, zu suchen.

Am 19. November, einen Tag nach seinem Kurzbesuch in Berlin, machte sich der Außenminister zusammen mit dem Kanzler sowie Verteidigungsminister Strauß auf den Weg nach Washington. Für Schröder war diese Reise erst sein zweiter Aufenthalt in den USA. Im Frühjahr 1953 hatte er auf Einladung des amerikanischen Senats zusammen mit fünf Abgeordneten aus verschiedenen Bundestagsfraktionen eine mehrwöchige Besichtigungstour durch die Vereinigten Staaten unternommen ${ }^{129}$. Diesmal kam er jedoch nicht mehr als einfacher Bundestagsabgeordneter, sondern als zweiter Mann der Regierungsdelegation. Die Reise stand zunächst unter keinem guten Stern. Bereits bei der Anreise zeigte der Kanzler deutliche Anzeichen einer Grippeinfektion. Er hatte hohe Temperatur, und

125 Ebenda, S. 255.

126 Zur Hallstein-Doktrin vgl. als Einführung den hervorragenden und übersichtlichen Artikel von Grewe im 2. Ergänzungsband zum 10. Band des Staatslexikons; GREWE, „Hallstein-Doktrin“. Vgl. ferner ders., Rückblenden, S. 251-262.

127 Vgl. den Artikel „Schröder: Berlin und Bonn einig“, in: DiE WELT vom 20. 11. 1961, S. 2.

128 Vgl. den Artikel von Marion Gräfin Dönhoff: „Außenminister Gerhard Schröder. Eine Unterhaltung mit dem neuen Chef des AA“, in: DIE ZEIT vom 17. 11. 1961, S. 3.

129 Vgl. dazu SCHRÖDER, Das Flugzeug hieß „Westward Ho“. 
Schröder machte sich schon mit dem Gedanken vertraut, die Gespräche allein zu führen ${ }^{130}$. Doch mit eisernem Willen stand Adenauer die Besprechungen durch $^{131}$. Nur den Termin vor dem National Press Club nahm Schröder in Vertretung des Kanzlers wahr ${ }^{132}$, und nicht nur hier, sondern während des ganzen Aufenthalts hinterließ er bei seinen amerikanischen Gesprächspartnern „einen guten Eindruck"133. Ihm gelang es sogar, einen persönlichen Draht zu seinem amerikanischen Amtskollegen zu finden ${ }^{134}$. Die Beziehungen zu dem, nach dem Urteil Grewes, "spröden Rusk" 135 vertieften sich in der Folgezeit noch. Offenbar waren sich die beiden Männer in ihrem Charakter ähnlich. Rusk wurde schließlich „ein enger Freund "136, und Schröder durfte als erster Außenminister der Bundesrepublik seinen amerikanischen Kollegen in Briefen mit dem Vornamen anreden ${ }^{137}$.

Trotz der freundschaftlichen Atmosphäre, um die sich beide Seiten nach den Spannungen in den vergangenen Monaten bemühten, vertrat Schröder in der Sache unbeirrt seinen Standpunkt ${ }^{138}$. Krone, der befürchtete, Adenauer könnte zu entgegenkommend sein, hatte den Außenminister noch kurz vor dem Abflug beschworen, eventuellen amerikanischen Forderungen nicht nachzugeben ${ }^{139}$. Inwieweit dies Schröder ermutigte, seine Position in der Berlin-Frage resolut vorzutragen, mag dahingestellt sein. Auf alle Fälle wehrte er sich entschieden gegen eine mögliche Verschlechterung des Status quo in Berlin. Er hielt es für das beste, wenn der bisherige Rechtsstatus beibehalten werden könnte. Nachdrücklich betonte er, dem sowjetischen Ansinnen, die Westmächte müßten ihre Besatzungsrechte aufgeben, fehle jegliche rechtliche Grundlage. Sollte es daher zu Verhandlungen mit der UdSSR kommen, müßte die westliche Minimalposition von diesen Rechten ausgehen. Zudem dürften weder eine gesamteuropäische Sicherheitsregelung noch das Problem der deutschen Ostgrenze Gegenstand von Ost-West-Verhandlungen sein. Schröder argumentierte, daß eine Ausweitung der Gespräche die Stellung des Westens insgesamt verschlechtern werde. Sollte Chruschtschow nämlich feststellen, daß man gewillt sei, über alles zu diskutieren, werde er den Druck erhöhen, um dem Westen noch mehr Konzessionen abzupressen. Auch werde das Interesse des Ostens an einem Friedensvertrag mit einem vereinigten Deutschland sinken, wenn alle Punkte, an denen der Kreml interessiert sei, bereits in einem Abkommen über Berlin (West) geregelt würden. Die von Rusk erwogene Beteiligung der UNO an der Kontrolle Berlins lehnte er ebenfalls ab, da es dadurch zu unmittelbaren Kontakten zwischen Bonn und Ost-Berlin käme, die nicht durch ein

$130 \mathrm{Vgl}$. SCHRÖDER, „Je weiter östlich, desto besser“.

131 Vgl. Poppinga, „Das Wichtigste ist der Mut“, S. 351-356.

132 Vgl. SCHRÖDER, „Je weiter östlich, desto besser“.

133 Vgl. OSTERHELD, „Ich gehe nicht leichten Herzens ...“, S. 87.

134 Vgl. Grewe, Rückblenden, S. 520.

135 Ebenda.

136 Adelbert SCHRÖDER, Mein Bruder Gerhard Schröder, S. 124.

137 Vgl. KÖHLER, Das Übergangsjahr 1963.

138 Vgl. den Artikel von Thilo Koch: „Treffen auf halbem Wege. Dennoch blieben nach den Adenauer-Kennedy-Gesprächen viele Fragen offen “, in: DIE ZEIT vom 1. 12. 1961, S. 1; sowie GREWE, Rückblenden, S. 520.

139 Vgl. KRONE, Aufzeichnungen, Eintrag vom 19. 11. 1961, S. 164. 
Vier-Mächte-Mandat gedeckt wären. Eine solche Lösung mußte nach Schröders Auffassung weitaus mehr als die bislang in Erwägung gezogenen, gesamtdeutschen technischen Kommissionen wie eine De-facto-Anerkennung der DDR wir$\mathrm{ken}^{140}$. Ungeachtet des prinzipiellen Interesses der USA an Verhandlungen mit der UdSSR, konnte der Außenminister zu seiner Zufriedenheit feststellen, daß Kennedy die Ansicht Bonns teilte, Chruschtschow könnte darauf aus sein, Fragen, die eigentlich erst auf einer Friedenskonferenz mit einem vereinigten Deutschland besprochen werden sollten, wie Rüstungsbeschränkungen oder die Festlegung der deutschen Ostgrenze, schon jetzt ins Spiel zu bringen und zu versuchen, sie im Sinne der Sowjetunion zu regeln ${ }^{141}$. Gleichwohl suchte die amerikanische Regierung eine Vereinbarung mit Moskau über die Verbesserung der $\mathrm{Zu}$ gangswege nach Berlin zu treffen, um auf diese Weise die Sicherheit Berlins zu erhöhen. Der Präsident hielt den Status quo für unbefriedigend, weil stets neue Aktionen des Ostens befürchtet werden mußten. Kennedy versicherte aber, die Vereinigten Staaten würden unter keinen Umständen ihre Rechte in Berlin aufgeben. Das angestrebte Abkommen sollte die Besatzungsrechte nicht aufheben, sondern lediglich überlagern. Zudem versprachen die Amerikaner, daß es weder zu einer Anerkennung der DDR noch der Oder-Neiße-Linie kommen werde. Dies bedeute allerdings nicht, daß man Bonn darin unterstützen werde, die ehemaligen deutschen Ostgebiete jenseits von Oder und Neiße zurückzubekommen, stellte Außenminister Rusk klar ${ }^{142}$. Adenauer entgegnete darauf, es sei ihm bewußt, daß nach einem Friedensvertrag die Ostgrenze Deutschlands mehr oder weniger dem jetzigen Grenzverlauf entsprechen würde ${ }^{143}$. Auch was die Wiedervereinigung betraf, machte der Kanzler eine bemerkenswerte Äußerung. Er erklärte, er würde sogar auf die Einheit Deutschlands verzichten, wenn die Menschen in der DDR ihr Leben selbst bestimmen und in Frieden führen könnten ${ }^{144}$. Kein Wunder, daß Kennedy nach Abschluß der deutsch-amerikanischen Regierungsbesprechungen am 22. November an Macmillan schrieb, er habe den Eindruck gewonnen, die Bundesregierung sei um einiges flexibler geworden ${ }^{145}$.

Dennoch bestanden weiterhin Meinungsverschiedenheiten in Einzelfragen. Schröder wollte diese Unterschiede aber nicht explizit hervorheben, sondern setzte ganz auf Verständigung. Dementsprechend war er entrüstet, als Strauß während einer Besprechung über Verteidigungsfragen im größeren Kreis die Ausführungen der amerikanischen Gesprächspartner in beinahe provozierender

140 Vgl. dazu FRUS 1961-1963, XIV, Dok. 217-221, S. 596-632.

141 Vgl. ebenda, Dok. 221, S. 624. Vgl. auch den Bericht Schröders über die Regierungsbesprechungen vor der CDU/CSU-Bundestagsfraktion; Protokoll der CDU/CSU-Fraktionssitzung am 24. 11.1961, ACDP VIII-001-1009/1.

142 Vgl. dazu FRUS 1961-1963, XIV, Dok. 217-221, S. 596-632.

143 "The Chancellor then made the statement that it was very clear to him that in an eventual peace settlement the eastern frontier of Germany would look very much like the present line and would be much like what the Poles wanted." Vgl. ebenda, Dok. 221, S. 624.

$144, \mathrm{He}$ [= Adenauer] would like to say that if he were sure that he could return the people of East Germany to freedom and a life in which they could again determine their own destiny, he would be prepared for any sacrifice, even if this should mean giving up the idea of reunification." Vgl. ebenda, Dok. 221, S. 630.

145 Vgl. ebenda, Dok. 222, S. 633. 
Weise ständig korrigierte ${ }^{146}$. Zwar lag die Federführung der Gespräche auf deutscher Seite zweifellos beim Kanzler, doch ist es sicherlich auch das Verdienst Schröders, der durch sein entschlossenes Auftreten und seine durchdachte Argumentation die Amerikaner beeindruckte ${ }^{147}$, daß es gelang, die Position der Bundesregierung den Amerikanern plausibel zu machen und Kennedy zu überzeugen, die Sondierungsgespräche auf Berlin einzugrenzen ${ }^{148}$. Im Gegenzug versprach der Kanzler, de Gaulle dafür zu gewinnen, sich der Aufnahme von Verhandlungen zwischen West und Ost nicht länger zu widersetzen. Man verabredete, auf der turnusmäßigen, halbjährigen Tagung des NATO-Ministerrats im Dezember eine gemeinsame Verhandlungsposition des Westens zu erarbeiten. Anfang 1962 sollte dann eine Konferenz der Außenminister der Vier Mächte über Berlin mit dem Ziel stattfinden, den Zugang in die Stadt zu verbessern ${ }^{149}$. Zuletzt bestätigten beide Regierungen im Kommuniqué, ihr „Endziel“ bleibe, „die Wiedervereinigung Deutschlands auf der Grundlage der Selbstbestimmung mit friedlichen Mitteln herbeizuführen" 150 . Schröder hob außerdem das Versprechen Kennedys hervor, bei Verhandlungen mit der UdSSR würden die originären Rechte der Drei Mächte in Berlin den Ausgangspunkt bilden. Der Außenminister interpretierte dies dahingehend, daß die USA nicht daran dächten, auf diese Rechte zu verzichten ${ }^{151}$. Andererseits hatte aber der amerikanische Präsident mit dieser Formulierung nicht ausgeschlossen, daß auch eine neue Vereinbarung über den Status Berlins möglich sei. Schröder gab sich allerdings überzeugt, die Amerikaner wollten die Quintessenz ihrer Rechte wahren, weil ihm in Washington glaubhaft versichert wurde, man nehme auch das Risiko eines Krieges in Kauf, um die amerikanischen Interessen in Berlin zu verteidigen ${ }^{152}$.

Nach allem, was Bonn in den vergangenen Monaten aus Washington vernommen hatte, war nicht zu erwarten gewesen, daß diese Reise des Kanzlers in die USA, die Besson als „die schwierigste seiner ganzen Amtszeit" bezeichnete ${ }^{153}$, mit einem Erfolg zu Ende ging. Angesichts des Verlaufs der Gespräche konnte die Bonner Delegation eigentlich überaus zufrieden die Rückreise antreten. Nicht

$146 \mathrm{Vgl}$. STRaUSS, Erinnerungen, S. 357.

147 Kennedy schrieb am 22. 11. 1961 an Macmillan, die Begleiter des Kanzlers hinterließen „a favorable impression“. Vgl. FRUS 1961-1963, XIV, Dok. 222, S. 633.

$148 \mathrm{Vgl}$. SCHWARZ, Adenauer II, S. 703.

149 Vgl. dazu FRUS 1961-1963, XIV, Dok. 216, S. 593-595, und Dok. 222, S. 632 f.

150 Kommuniqué vom 22. 11. 1961 über die Besprechungen zwischen Bundeskanzler Adenauer und Präsident Kennedy in Washington, in: DzD IV/7, S. 957.

151 Vgl. den Bericht Schröders über die Regierungsbesprechungen vor der CDU/CSU-Bundestagsfraktion; Protokoll der CDU/CSU-Fraktionssitzung am 24.11. 1961, ACDP VIII-001-1009/1.

$152 \mathrm{Vgl}$. ebenda. In der Tat war Kennedy nicht bereit, Berlin kampflos aufzugeben. Der Präsident ließ einen Plan ausarbeiten, der im Falle einer sowjetischen Aggression eine abgestufte Reaktion vorsah, die dem Kreml vor Augen führen sollte, daß die USA nicht zurückstecken würden. Vgl. dazu SCHILD, Die Kennedy-Administration und die BerlinKrise von 1961, S. 703-711, besonders S. 710f. Er wollte damit verhindern, im Falle einer Blockade Berlins „sehr bald mit der Alternative suicide or surrender, d. h. Selbstmord in einem Atomkrieg oder Aufgabe West-Berlins, konfrontiert zu werden“. Vgl. ebenda, S. 704.

153 BESSON, Die Außenpolitik der Bundesrepublik, S. 298. 
nur, daß man sich nach den Differenzen der vergangenen Monate nun auf eine verbindliche Linie für die Gespräche mit der UdSSR geeinigt hatte, Adenauer hatte zudem erreicht, daß seine Vorstellungen von den Amerikanern mehr oder weniger übernommen wurden. Die Beziehungen zu den USA, die wichtigste Determinante der Diplomatie der Bundesrepublik, schienen wieder so gefestigt wie in der Ära Eisenhower/Dulles. Obwohl der Kanzler keine Abstriche an seinen deutschlandpolitischen Positionen vornahm und praktisch nur einer Fortsetzung der Sondierungen zustimmte, zog auch Kennedy ein äußerst positives Fazit. Gegenüber Schröder äußerte er sogar, das Gespräch mit dem Kanzler sei das beste gewesen, das er seit seinem Amtsantritt mit einem Ausländer geführt habe ${ }^{154}$.

Die Euphorie des Präsidenten entsprang jedoch dem Glauben, die Bundesregierung würde Konzessionen schon noch zustimmen, falls die Gespräche mit Moskau im gewünschten Sinne verliefen und der Zugang nach Berlin tatsächlich verbessert werden konnte ${ }^{155}$. Zumindest die amerikanische Seite hatte also bei den Besprechungen nicht ganz mit offenen Karten gespielt. Mit dem vermeintlichen Einvernehmen zwischen beiden Regierungen war es in Wahrheit nicht weit her. Allenfalls im Bereich der Berlin-Politik bestand eine gewisse Übereinstimmung. In der Deutschland-Politik bestanden weiterhin große Diskrepanzen, vor allem hinsichtlich der Aktualität der deutschen Frage, auch wenn dies bei den Besprechungen vielleicht nicht deutlich zum Vorschein gekommen war. Nur wenige Tage nach der Abreise Adenauers wurde der Bundesregierung aber dafür um so eindrucksvoller vor Augen geführt, daß die USA die Überwindung der Teilung Deutschlands inzwischen weder für dringlich noch für besonders realistisch hielten. In einem Interview für die sowjetische Tageszeitung Iswestija am 25. November wies Kennedy gegenüber dem Chefredakteur und Schwiegersohn Chruschtschows, Alexej Adschubej, auf die gemeinsamen Sicherheitsinteressen der Vereinigten Staaten und der Sowjetunion hin und bekannte freimütig, die NATO habe unter anderem auch die Aufgabe, die Bundesrepublik zu kontrollieren. Der Präsident bekräftigte, daß aufgrund der deutschen Vergangenheit keine atomaren Waffen in deutsche Hände gelangen durften. Das Problem der Teilung Deutschlands sprach er zwar an, machte allerdings deutlich, daß er sehr viel mehr Wert auf eine Einigung mit der UdSSR in der Berlin-Frage legte, um so den Frieden in Europa auf Dauer zu sichern ${ }^{156}$. Nicht die Lösung der deutschen Frage, sondern die Verständigung mit dem Kreml hatte für Kennedy Priorität. Sein Denken kreiste vorrangig um die Bewahrung des Status quo in Europa und eine Modus-vivendiLösung für Berlin. Erneute Spannungen mit Bonn schienen folglich vorprogrammiert, da die Interessenlage der Bundesrepublik völlig anders geartet war ${ }^{157}$. Für Bonn kam auch ein temporärer Verzicht auf die Wiedervereinigung nicht in Frage.

154 Vgl. SCHRÖDER, "Je weiter östlich, desto besser“; sowie FRUS 1961-1963, XIV, Dok. 221, S. $631 \mathrm{f}$.

155 Kennedy führte am 22.11. 1961 gegenüber Macmillan aus: „The Germans will be quite forthcoming on other points, I am sure, if we can get something worth having on full and free access." Vgl. FRUS 1961-1963, XIV, Dok. 222, S. 633.

156 Vgl. DzD IV/7, S. 985-998. Vgl. auch ADSHUBEJ, Gestürzte Hoffnung, S. 289-295. Zur Wirkung des Interviews vgl. GREWE, Rückblenden, S. 521.

157 Vgl. SCHWARZ, Adenauer II, S. 707. 
Im Gegenteil, wie in der Regierungserklärung vom 29. November 1961, die Vizekanzler Erhard in Vertretung des erkrankten Adenauer im Bundestag vortrug, erneut eindeutig zum Ausdruck kam, war die Wiederherstellung der staatlichen Einheit Deutschlands nach wie vor das primäre Ziel der Bundesregierung ${ }^{158}$. Anders als die USA setzte sie weiterhin auf eine Überwindung des Status quo. In der Berlin-Frage plädierte Bonn für einen unnachgiebigen Kurs. Die Bundesregierung warf der UdSSR vor, sie sei in Wirklichkeit nicht an einer für beide Seiten akzeptablen Regelung interessiert, sondern verfolge das Ziel, Berlin (West) zu unterwandern, die Bundesrepublik international $\mathrm{zu}$ isolieren und ihren expansiven Kurs fortzusetzen. Im Falle von amerikanisch-sowjetischen Verhandlungen über Berlin müßten deshalb nicht nur die essentials Kennedys gewahrt, sondern auch drei weitere, vitale Grundsätze beachtet werden: Erstens dürfe die Sicherheit der Bundesrepublik nicht gemindert werden; zweitens müßten die bestehenden politischen, rechtlichen und wirtschaftlichen Bindungen zwischen dem Bund und Berlin (West) unberührt bleiben und drittens sei die bisherige Deutschland-Politik des Westens fortzusetzen. Darunter verstand die Regierung Adenauer, Frankreich, Großbritannien und die USA sollten aktiv die Wiedervereinigung fördern, die DDR nicht anerkennen und die Haltung Bonns unterstützen, daß die endgültige Festlegung der deutschen Grenzen erst in einem Friedensvertrag mit einer gesamtdeutschen Regierung erfolgen könne ${ }^{159}$. Wohl ganz bewußt waren diese Bedingungen der Bundesregierung in Form und Wortwahl an die essentials Kennedys vom Juli des gleichen Jahres angelehnt. Es ist somit nicht erstaunlich, daß sie unter der Bezeichnung Bonner essentials Eingang in die Zeitgeschichte fanden ${ }^{160}$.

Die Position der Bundesregierung wurde dabei weitgehend von der parlamentarischen Opposition geteilt. Während Erhard die erste Regierungserklärung der neuen Bundesregierung vortrug, registrierte Schröder zufrieden, daß deren auBenpolitischer Teil insgesamt zwanzig Mal vom Beifall der Abgeordneten unterbrochen wurde: Siebenmal hätten alle Fraktionen geklatscht, einmal sogar die SPD allein, notierte er ${ }^{161}$. Der überparteiliche Konsens in der Deutschland-Politik schien also nicht gefährdet, obwohl die Sozialdemokraten über die in Washington erzielten Ergebnisse nicht recht glücklich waren. Als Schröder nämlich am Vorabend der Bundestagsdebatte Brandt über den Verlauf der Besprechungen mit der amerikanischen Regierung informiert hatte, mißbilligte dieser die Absprache, die Gespräche mit der Sowjetunion auf Berlin zu beschränken. Der Regierende Bürgermeister befürchtete, daß dadurch unter dem Strich ein schlechterer Status für die geteilte Stadt herausspringen könnte, weil die Unterhändler nur wenig Ver-

158 Die Bundesregierung erklärte u.a.: „Die Wiederherstellung der Einheit Deutschlands in Frieden und Freiheit bleibt das unverrückbare Ziel der deutschen Politik, auch wenn wir heute noch keinen Zeitpunkt für seine Verwirklichung angeben können."Vgl. BT STENOGRAPHISCHE BERICHTE, Bd. 50, S. 31.

159 Vgl. ebenda, S. $30 \mathrm{f}$.

160 Vgl. dazu z. B. Vogelsang, Das geteilte Deutschland, S. 244.

161 Vgl. die Notiz „Zitate“, in: Der SPIEGEL vom 6. 12. 1961, S. 25. 
handlungsspielraum hätten. Er hätte es daher vorgezogen, wenn die Sondierungen nicht thematisch eingeengt worden wären ${ }^{162}$.

Dem Bestreben, eine gemeinsame Berlin-Politik der Drei Mächte und der Bundesrepublik festzulegen, stand vor allem die französische Regierung im Wege. Am 5. Dezember 1961 lehnte der französische Außenminister, Maurice Couve de Murville, nochmals Ost-West-Gespräche zum jetzigen Zeitpunkt ab ${ }^{163}$. Es war folglich keine leichte Aufgabe für Adenauer, sein gegenüber Kennedy gemachtes Versprechen einzulösen und sich zu bemühen, Frankreich in das gemeinsame Konzept einzubinden. Zwar riet de Gaulle dem Kanzler am 9. Dezember in Paris, „das deutsche Volk solle nicht zu sehr an Berlin hängen "164, doch betonte er, daß er nicht an einer Übereignung Berlins an die UdSSR beteiligt sein wolle ${ }^{165}$. Adenauer beschwerte sich bei ihm massiv über die zu konzessionsbereite Haltung der USA und speziell über die Ansicht Rusks, es bestünden im Prinzip zwischen den Vereinigten Staaten und der Sowjetunion keine Meinungsverschiedenheiten; vielmehr gäbe es Differenzen im eigentlichen Sinn nur zwischen der UdSSR und der Bundesrepublik, bzw. der UdSSR und Taiwan. Trotz aller Kritik an der amerikanischen Außenpolitik forderte er dennoch de Gaulle auf, die Kontaktsuche Washingtons nicht länger zu boykottieren. Frankreich könne ruhig alles ablehnen, was Großbritannien und die USA vorschlagen würden, meinte Adenauer, es müsse aber an den Beratungen teilnehmen, um die Einigkeit des Westens zu demonstrieren ${ }^{166}$. Der Kanzler wünschte die französische Partizipation an den Beratungen, um mit dem Hebel de Gaulle Briten und Amerikaner zu bremsen ${ }^{167}$. Jener beharrte zunächst auf seinem Standpunkt, er wolle für die Preisgabe Berlins keine Mitverantwortung tragen, sagte aber nach heftigem Insistieren des Kanzlers eine Beteiligung Frankreichs an den Verhandlungen unter der Bedingung zu, daß die Sondierungen mit der Sowjetunion positiv verliefen ${ }^{168}$. Adenauer flog befriedigt nach Bonn zurück und verkündete, die Unterredung habe seine Erwartungen übertroffen ${ }^{169}$. Er interpretierte die Äußerung de Gaulles als eine Kursänderung der französischen Politik ${ }^{170}$. Unverzüglich teilte er Kennedy mit, der General hätte seine Bedenken gegen Verhandlungen fallen gelassen und werde an einer Vierer-Konferenz teilnehmen, falls Aussichten auf einen Erfolg bestünden ${ }^{171}$.

162 Vgl. den Artikel „Schröder unterrichtet Brandt über die Berlin-Politik“, in: FRANKFURTER ALLGEMEINE ZEITUNG vom 29.11. 1961, S. 1.

$163 \mathrm{Vgl}$. die Erklärung Couve de Murvilles vor dem französischen Senat, in: DzD IV/7, S. 1060-1065, besonders S. 1063.

164 KRONE, Aufzeichnungen, Eintrag vom 15. 12. 1961, S. 165. Adenauer erwähnt in seinem Bericht über dieses Gespräch eine derartige Äußerung de Gaulles nicht. Vgl. ADENAUER, Erinnerungen IV, S. 119-133.

165 Vgl. ebenda.

166 Vgl. ebenda.

167 Vgl. KUSTERER, Der Kanzler und der General, S. 192.

168 Vgl. ADENAUER, Erinnerungen IV, S. 120-127.

169 Vgl. Protokoll der CDU-Bundesvorstandssitzung am 11. 12. 1961, ACDP VII-001-010/ 6, bzw. Protokolle des CDU-Bundesvorstands, S. 72.

$170 \mathrm{Vgl}$. AdENAUER, Erinnerungen IV, S. 132.

171 Vgl. das Schreiben Adenauers an Kennedy vom 11. 12. 1961, in: FRUS 1961-1963, XIV, Dok. 235, S. 659 f. 
Dies war jedoch ein Trugschluß, denn der französische Staatspräsident hatte seine Meinung nicht geändert, wie sich am 11./12. Dezember beim Treffen der Außenminister der Drei Mächte und der Bundesrepublik am Rande der NATOMinisterratstagung in Paris zeigte. Erneut sprach sich Couve de Murville entschieden gegen Verhandlungen aus. Es ginge der sowjetischen Regierung nicht um eine akzeptable Lösung in Berlin, sondern sie betrachte die Stadt nur als einen Ansatzpunkt, um die kommunistische Expansion voranzutreiben, erklärte er. Die Aufnahme von Gesprächen wäre somit ein Zeichen der Nachgiebigkeit. Außerdem, so führte der französische Außenminister weiter aus, müsse man sich darüber im klaren sein, daß sich durch Verhandlungen der Status quo weiter zu Ungunsten des Westens verschieben werde, da eine Vereinbarung nur auf der Basis eines Kompromisses vorstellbar sei. Der Westen wäre also gezwungen, einige seiner Positionen aufzugeben. Couve de Murville appellierte deshalb an die Verbündeten, der sowjetischen Erpressung nicht nachzugeben ${ }^{172}$. Rusk und sein britischer Kollege Lord Home drängten dagegen auf Verhandlungen, um eine kriegerische Auseinandersetzung wegen der Berlin-Frage zu verhindern. Lord Home erklärte offen, er sei bereit, über alle von Chruschtschow gewünschten Themen zu diskutieren. Auch eine De-facto-Anerkennung der DDR könne er akzeptieren ${ }^{173}$.

Schröder wiederum versuchte, zwischen der französischen und der angloamerikanischen Position zu vermitteln, um die Beziehungen zu keinem der drei Partner der Bundesrepublik zu belasten ${ }^{174}$. Indem er beiden Parteien ins Gedächtnis rief, daß man sich eigentlich über die Ziele der westlichen Berlin-Politik einig sei und es lediglich über die Methode Meinungsverschiedenheiten gebe, versuchte er, die Differenzen herunterzuspielen. Dem französischen Außenminister legte er dar, er halte prinzipiell den Standpunkt Frankreichs für richtig, sich nicht an den Verhandlungstisch zu setzen, solange Chruschtschow seine Drohungen nicht einstelle. Angesichts des großen Risikos müsse man allerdings auch im Hinblick auf die Öffentlichkeit, die dies erwarte, zumindest den Versuch unternehmen, die sowjetischen Absichten zu eruieren und sich um eine friedliche Schlichtung bemühen. Eindringlich erläuterte er, daß der Westen Verhandlungen nur verweigern könne, wenn er sich sowohl militärisch wie strategisch in einer besseren Lage befände. Das letztere wäre aber gerade in Berlin nicht der Fall! Die mit Verhandlungen verbundenen Gefahren ließen sich aber einschränken, wenn die Gespräche strikt auf Berlin begrenzt blieben. Sollte der Kreml allerdings bemerken, daß sich der Westen über sein Vorgehen nicht einig sei, dann werde er alles unternehmen, um von den Streitigkeiten zu profitieren. Nachdrücklich rief Schröder dazu auf,

172 Vgl. ebenda, Dok. 234, S. 651 f. und S. 658. Auch in der Folgezeit beteiligte sich Frankreich nicht an den gemeinsamen Beratungen. Am 5.7.1962 mußte Adenauer de Gaulle erneut bitten, die Teilnahme des französischen Botschafters an den Besprechungen der Botschaftergruppe in Washington zu veranlassen. Vgl. dazu ADENAUER, Erinnerungen IV, S. 172.

173 Vgl. FRUS 1961-1963, XIV, Dok. 234, S. 653-662.

174 Vgl. den Artikel „Schröder wünscht klassische Diplomatie“, in: DIE Welt vom 18. 12. 1961, S. 4; GREWE, Rückblenden, S. 523. 
eine gemeinsame Haltung einzunehmen, da Chruschtschow nur durch Geschlossenheit zu beeindrucken sei ${ }^{175}$.

Der Außenminister machte also die äußeren Umstände dafür verantwortlich, daß er für Verhandlungen plädierte. Zuweilen zweifelte aber auch er, ob diese für die Bundesrepublik wirklich von Vorteil wären. Einerseits hoffte er, der Kreml könnte zu der Einsicht gelangen, „daß beide Seiten ihr Gesicht wahren müssen“, und schließlich einer akzeptablen Lösung zustimmen ${ }^{176}$, andererseits rechnete er damit, daß Chruschtschow die Chance nicht verstreichen lassen würde, über eine Ausweitung der Gespräche auf den Komplex der europäischen Sicherheit sein Ziel zu erreichen, durch vertragliche Abmachungen die Bundesrepublik zu diskriminieren „und ihr die Waffen aus der Hand zu schlagen“177. Er argwöhnte, die Berlin-Frage könnte von der UdSSR als Hebel für die Schaffung von Zonen mit einem sicherheitspolitischem Sonderstatus benutzt werden, die den militärischen Status der Bundesrepublik verringern und ihre Sicherheit gefährden würden. Dennoch war er der Ansicht, die Kontakte mit dem Kreml müßten fortgesetzt werden, da die westliche Öffentlichkeit erst dann militärische Schritte befürworten würde, wenn sie von deren Notwendigkeit überzeugt sei ${ }^{178}$.

Die französische Regierung beharrte aber auf ihrem Standpunkt. Erst nach einem Telefongespräch zwischen Kennedy und de Gaulle, stimmte jener zumindest der Fortsetzung der Sondierungsgespräche $\mathrm{zu}^{179}$. Diese sollten vom amerikanischen Botschafter in Moskau, Llewellyn Thompson, sowie seinem britischen Kollegen, Frank Roberts, geführt werden ${ }^{180}$. Couve de Murville erklärte aber ausdrücklich, Frankreich werde sich nicht beteiligen ${ }^{181}$. In das Kommuniqué der NATO-Ministerratstagung wurde schließlich eine Kompromißformel aufgenommen, derzufolge die Außenminister "der am unmittelbarsten betroffenen Staaten“" den Auftrag erhielten, den Gesprächsfaden mit Moskau aufzugreifen, um festzustellen, ob „eine Verhandlungsgrundlage gefunden werden könnte" 182 . Diese Formulierung entsprach exakt der gegenüber Adenauer gemachten Zusage de Gaulles, Frankreich werde erst dann an Verhandlungen teilnehmen, wenn die Sondierungen ergeben hätten, daß „etwas Ehrbares“ erreicht werden könne ${ }^{183}$.

175 Vgl. FRUS 1961-1963, XIV, Dok. 234, S. 654, und Dok. 238, S. 676-678.

176 Zitiert nach dem Artikel von Marion Gräfin Dönhoff: „Außenminister Gerhard Schröder. Eine Unterhaltung mit dem neuen Chef des AA“, in: DIE ZEIT vom 17. 11. 1961, S. 3. Vgl. auch den Artikel "Thompson unterrichtet die Botschafter über Gromykos Ansichten“, in: FrankfuRTer Allgemeine ZeITUNG vom 4. 1. 1962, S. 1.

177 Zitiert nach dem Artikel „Schröder wünscht klassische Diplomatie“, in: DIE WELT vom 18. 12. 1961, S. 4.

178 Vgl. FRUS 1961-1963, XIV, Dok. 238, S. 677.

179 Vgl. ebenda, Dok. 239, S. 679-681.

180 Anläßlich eines Treffens am 21./22. 12. 1961 auf den Bermudas vereinbarten Kennedy und Macmillan schließlich, die Sondierungen nur von Botschafter Thompson durchführen zu lassen. Vgl. BuLlETiN 1961, S. 2260.

181 Vgl. FRUS 1961-1963, XIV, Dok. 238, S. 673.

182 Vgl. das Kommuniqué über die Tagung des NATO-Ministerrats vom 15. 12. 1961, in: DzD IV/7, S. 1171. Als „unmittelbar betroffene Staaten“ galten lediglich Großbritannien und die USA. Vgl. GREWE, Rückblenden, S. 525.

183 So de Gaulle am 9. 12. 1961 zu Adenauer. Vgl. AdENAUER, Erinnerungen IV, S. 126. 
Doch welchen Verlauf hatten die Sondierungen zu nehmen, damit sie als erfolgreich bezeichnet werden konnten? Darüber war zwischen den Westmächten und der Bundesrepublik noch kein Gedankenaustausch erfolgt. Zudem teilte de Gaulle Kennedy unverblümt mit, daß er trotz der Akzeptierung des Kommuniqués bei seiner Meinung bleibe, nicht mit Chruschtschow zu verhandeln ${ }^{184}$. Mehr als dieses schwammige Kommuniqué war angesichts der französischen $\mathrm{Hal}-$ tung nicht zu erreichen. Schröder scheute sich nicht, das Ergebnis der Konferenz offen als „einen Kompromiß zwischen einander widersprechenden Auffassungen über die westliche Taktik" zu bezeichnen ${ }^{185}$. Adenauer war dagegen über den Verlauf der NATO-Tagung äußerst ungehalten: „, [...] dafür kreißen die Berge, und geboren wird eine lächerliche Maus" 186 . Er sperrte sich gegen die Einsicht, daß er die Äußerungen de Gaulles in dem Vieraugengespräch am 9. Dezember in Paris fehlinterpretiert hatte und gab statt dessen den vier Außenministern die Schuld an dem dürftigen Ergebnis ${ }^{187}$.

Die Tatsache, daß noch nicht festgelegt worden war, wie eine Berlin-Regelung mit der UdSSR inhaltlich ausgestaltet sein sollte, ließ der amerikanischen Regierung für die Gespräche weitgehend freie Hand. Schröder war deshalb bestrebt, den Verhandlungsspielraum einzuschränken und erinnerte die USA an die Bonner essentials. Ausdrücklich hob er die Bedeutung der politischen Bindungen zwischen Berlin und der Bundesrepublik hervor, weil sie die „psychologische Grundlage“ der Lebensfähigkeit der Stadt bildeten ${ }^{188}$. Auf ihre Aufrechterhaltung legte er deswegen soviel Wert, weil dadurch allen Plänen, Berlin (West) in ein selbständiges Völkerrechtssubjekt zu transformieren, ein Riegel vorgeschoben wurde ${ }^{189}$. Ferner schloß er aus, die Bundesrepublik könnte im Zuge der Verhandlungen ihre Nichtanerkennungspolitik gegenüber der DDR aufgeben. Eine Anerkennung Ost-Berlins kam für ihn nicht in Frage, weil die Sowjetunion dies als Aufforderung begreifen würde, ihren aggressiven außenpolitischen Kurs fortzusetzen. Der Außenminister unterstrich zudem, daß für die Bundesregierung eine Vereinbarung mit dem Kreml über Berlin nur akzeptabel sei, wenn sie die Möglichkeit der Wiedervereinigung nicht ausschloß190. Im übrigen verhehlte er nicht, daß nach

184 Vgl. FRUS 1961-1963 XIV, Dok. 239, S. 681.

185 Vgl. den Artikel von Gerhard Schröder: „Auf die Bewahrung des Friedens gerichtet. Unsere Außenpolitik baut weiter auf Fundamenten, die sich bereits als tragfähig erwiesen haben", in: BULLETIN 1962, S. 21.

186 So Adenauer in einem Hintergrundgespräch am 14. 12.1961. Vgl. AdENAUER, Teegespräche 1961-1963, S. 54.

187 Vgl. ebenda, S. 61.

188 Zitiert nach dem Artikel „Keine Lockerung Berlin-Bonn“, in: DIE WELT vom 14.12. 1961, S. 2.

189 Schröder hielt nichts von der sowjetischen Idee, West-Berlin in eine Freie Stadt umzuwandeln. Er verwies auf die schlechten Erfahrungen, die man mit Danzig gemacht hätte, wobei diese Stadt noch dazu „dem Würgegriff nie so ausgesetzt [war,] wie das von der DDR umgebene Berlin“. Vgl. den Artikel von Marion Gräfin Dönhoff: „Außenminister Gerhard Schröder. Eine Unterhaltung mit dem neuen Chef des AA“, in: DIE ZEIT vom 17. 11. 1961, S. 3.

190 Vgl. den Artikel „Keine Lockerung Berlin-Bonn“, in: DiE WeLT vom 14. 12. 1961, S. 2. 
seiner Überzeugung die Wiederherstellung der Einheit Deutschlands die einzig wirklich dauerhafte Lösung für das Berlin-Problem darstellte ${ }^{191}$.

Trotz der Vorbehalte der Bundesregierung hing es aber im wesentlichen von der amerikanischen Verhandlungsführung $\mathrm{ab}$, ob und falls ja, welche Zugeständnisse des Westens die Sowjetunion erreichen konnte. Die von Kennedy formulierten essentials waren die einzigen Punkte, die die amerikanische Regierung für nicht verhandlungsfähig erklärt hatte, ansonsten war sie an kein Verhandlungsmandat gebunden. Sollte sich also die Chance auf eine Einigung mit der Sowjetunion am Horizont abzeichnen, war damit zu rechnen, daß die Weltöffentlichkeit verlangen würde, diese zu ergreifen, selbst wenn dabei irgendwelche Vorbehalte der Bundesregierung unberücksichtigt blieben. Am Rhein stellte man sich die bange Frage, ob die USA, um den Frieden zu erhalten, im Zweifelsfall dem sowjetischen Druck nachgeben und eine Vereinbarung auf Kosten der Bonner Interessen treffen würden. Welche Möglichkeiten besaß die Bundesregierung, um eine solche Entwicklung zu verhindern? Wie groß war ihr Einfluß auf den Entscheidungsprozeß innerhalb der amerikanischen Regierung? Konnte sie in Washington eine Berücksichtigung ihrer Positionen durchsetzen? Die Bonner Diplomatie war jetzt gefordert, eine Strategie zu entwickeln, die die Berücksichtigung der Interessen der Bundesrepublik bei den Berlin-Gesprächen gewährleistete.

Der Bundesregierung standen aber im Grunde nur zwei Handlungsoptionen zur Verfügung, die beide auf den ersten Blick gleichviel Risiko in sich zu bergen schienen: Die erste Möglichkeit bestand darin, jedes amerikanische Verhandlungsangebot an die UdSSR, das irgendwelche nachteilige Elemente enthielt, kategorisch abzulehnen. Wie die vergangenen Monate deutlich gezeigt hatten, war für die Bundesregierung keine Regelung akzeptabel, die die bisherige DeutschlandPolitik in Frage stellte oder zu einer Veränderung des Status quo in Berlin führte. $\mathrm{Da}$ aber die USA nicht umhin kamen, ein substantielles Angebot vorzulegen, mußte jede amerikanische Offerte zwangsläufig mit deutschen Interessen kollidieren. Folglich mußte Bonn etwaige Bedenken äußern, bevor die USA ihre Vorschläge dem Kreml präsentierten, und darauf hoffen, daß die Amerikaner angesichts des Widerstands ihres Verbündeten ihre Pläne aufgeben oder zumindest den Vorstellungen der Bundesregierung anpassen würden. Eine solche Verweigerungshaltung konnte aber nur eine Belastung der deutsch-amerikanischen Beziehungen zur Folge haben. Es war durchaus damit zu rechnen, daß die amerikanische Regierung die Einwände aus Bonn ignorierte. Ein Abkommen mit der UdSSR, das den Frieden in Mitteleuropa dauerhaft garantierte, mußte für sie von größerem Interesse sein als die Vermeidung von Dissonanzen mit der Bundesrepublik. Zudem war zu befürchten, daß die sowjetische Regierung die Haltung der Bundesregierung propagandistisch ausschlachtete und ihr die Sabotage von Friedensbemühungen vorwarf. Sollte sich Bonn also zu einer solchen Taktik der Verweigerung entschließen, mußte diese durch den Versuch flankiert sein, selbst mit Moskau ins Gespräch zu kommen, um vielleicht durch bilaterale Verhandlungen eine Lösung zu erzielen, die für die Bundesrepublik und Berlin günstiger ausfiel

191 Vgl. ADG 1961, S. 9548; sowie den Artikel „Keine Lockerung Berlin-Bonn“, in: DiE WELT vom 14. 12. 1961, S. 2. 
als eine amerikanisch-sowjetische Vereinbarung. Aber war wirklich zu erwarten, daß Chruschtschow die Regierung Adenauer als Verhandlungspartner vorzog, wenn eine Einigung mit Washington im Bereich des Möglichen lag? Die amerikanische Regierung konnte der Sowjetunion doch weitaus mehr bieten als die Bundesrepublik! Für Moskau mußte eine Globallösung mit den USA auf der Basis des Status quo immer attraktiver sein als die wenigen Konzessionen, die die Bundesrepublik machen konnte und wollte. Eine Kontaktaufnahme Bonns mit dem Kreml würde zudem die amerikanische Regierung nicht begrüßen, sondern als Versuch auffassen, ihren eigenen Verständigungsbemühungen in den Rücken zu fallen.

Als zweite Möglichkeit bot sich an, jegliche Aktivitäten, die von den Amerikanern als Störung der Ost-West-Kontakte empfunden werden konnten, zu vermeiden. Dies erforderte aber, daß Bonn nicht sofort öffentlich widersprach, sobald die USA für die Bundesrepublik mißliebige Punkte mit Moskau erörterten. Im Gegenteil, es schien sogar ratsamer, sich hinter die amerikanischen Verhandlungsangebote zu stellen, und auf diese Weise West wie Ost zu zeigen, daß die Bundesrepublik eine Einigung der beiden Supermächte wünschte. Um den Eindruck der Kooperation zu erwecken, brauchte man nicht unbedingt auf Kritik zu verzichten. Die Bundesregierung durfte aber damit nicht an die Öffentlichkeit treten, sondern mußte ihre Einwände vertraulich vorbringen. Es schien dabei ratsam, die Vorbehalte in Form von Verbesserungsvorschlägen vorzubringen, um auf diese Weise einen harten Ton zu vermeiden und $\mathrm{zu}$ versuchen, die amerikanische Regierung durch die Bereitschaft zur Mitarbeit zu einer Modifikation ihrer Pläne zu bewegen. Aber auch bei dieser Taktik mußte in Erwägung gezogen werden, daß die USA trotzdem an ihrem Konzept festhalten würden; eventuell sogar, weil die Bundesregierung ihre Kritik nicht offen und deutlich genug geäußert hatte.

Es gab also kein Patentrezept, um eine Preisgabe der Interessen der Bundesrepublik zu verhindern. Die zuletzt geschilderte Option bot aber im Vergleich zum Weg des Konfrontationskurses zwei Vorteile: Zum einen gab sie der Sowjetunion nicht die Möglichkeit, die Bundesrepublik als Kriegstreiber anzugreifen und dadurch ihre nach dem Zweiten Weltkrieg mühsam erarbeitete internationale Anerkennung zu unterminieren. Zum anderen vermied man mit dem Weg der Zusammenarbeit eine erhebliche Belastung der Beziehungen zum amerikanischen Verbündeten, auf dessen Schutz man angewiesen und dessen Unterstützung für eine erfolgreiche Deutschland-Politik unerläßlich war. Es zeigte sich bald, daß innerhalb der Bundesregierung große Differenzen bestanden, welcher der beiden Wege verfolgt werden sollte. Der Bundeskanzler und der Außenminister befürworteten jeweils eine der beiden Optionen und bemühten sich, diese als politische Leitlinie durchzusetzen. Die Folge war, daß die Bundesregierung durch widersprüchliche Äußerungen den Anschein erweckte, als handle sie ohne ein klares politisches Konzept. 


\section{Deutsch-amerikanische Meinungsverschiedenheiten über die Gestaltung der Berlin-Politik}

In einem Gespräch mit der Frankfurter Allgemeinen Zeitung nannte Schröder kurz nach seiner Berufung an die Spitze des Auswärtigen Amts als vorrangige Ziele der Bonner Außenpolitik, die staatliche Einheit Deutschlands wiederherzustellen und eine allgemeine, kontrollierte Abrüstung einzuleiten ${ }^{192}$. Beide Aufgaben waren für ihn zwei Aspekte des gleichen Problems. Dies unterstrich auch die Regierungserklärung vom 29. November 1961. In ihr hieß es, die „Probleme der europäischen Sicherheit können nur in Verbindung mit der Wiederherstellung der deutschen Einheit erörtert werden" 193 . Wie seine Vorgänger erhob Schröder die Forderung, die UdSSR müßte den Menschen in der DDR das Selbstbestimmungsrecht gewähren ${ }^{194}$. Das Streben der Bundesrepublik nach der staatlichen Einheit Deutschlands hielt er für „politisch realistisch“, auch wenn der Zeitpunkt der Wiedervereinigung noch ungewiß sei ${ }^{195}$. Zugleich wies er darauf hin, daß die Einheit nur erreicht werden könne, wenn zwischen der Bundesrepublik und den drei Westmächten in der Deutschland-Politik Übereinstimmung bestünde ${ }^{196}$. Dabei kam den USA eine Schlüsselrolle zu. Zum einen trugen sie die „Hauptlast“ im Konflikt mit der Sowjetunion, zum anderen war die amerikanische Sicherheitsgarantie für die Bundesrepublik „lebenswichtig“197. Die Überwindung der Teilung Deutschlands war für ihn ohne die tatkräftige Hilfe der Vereinigten Staaten unvorstellbar. Bonn konnte nach seiner Überzeugung nur dann seine deutschlandpolitischen Positionen bis zum Tag der Wiedervereinigung wahren, wenn es gelänge, „die stärkste Macht der Welt“ auch künftig für dieses nationale Anliegen der Deutschen zu interessieren. Zudem hinge das Schicksal Berlins davon ab, ob sich die USA weiterhin mit aller Kraft für die Freiheit der Stadt einsetzten ${ }^{198}$. Die Bundesregierung müsse deshalb eine Politik verfolgen, die der „unbedingte[n] Notwendigkeit engster deutsch-amerikanischer Zusammenarbeit" Priorität einräume ${ }^{199}$. Schröders Taktik lautete, einerseits gegenüber dem sowjetischen Druck

192 Vgl. den Artikel „Das Ziel ist Abrüstung und Wiedervereinigung“, in: FRANKFURTER ALLGEMEINE ZEITUNG vom 19. 12. 1961, S. 3.

193 BT STENOGRAPHISCHE BERICHTE, Bd. 50, S. 32.

194 Vgl. den Artikel „Das Ziel ist Abrüstung und Wiedervereinigung“, in: FrankFurTER ALLGEMEINE ZEITUNG vom 19. 12. 1961, S. 3.

195 Ebenda. Ähnlich äußerte sich Adenauer am 16. 12. 1962 gegenüber James Reston von der New York Times: „Die Franzosen haben 1871 Elsaß-Lothringen verloren und haben es 1918 wiederbekommen; das sind also fast 50 Jahre! Deswegen geben wir Deutsche die Wiedervereinigung auch nicht auf, auch wenn man sagt, jetzt darüber zu verhandeln, ist sicher ergebnislos. [...] In zehn Jahren sieht die Welt vielleicht anders aus. Ich habe immer gesagt, auch öffentlich, daß eine Wiedervereinigung nach meiner Meinung nicht kommen wird, ehe eine kontrollierte Abrüstung wirklich, effektiv begonnen hat, eine solche Entspannung; früher kommt sie nicht.“ Vgl. ADENAUER, Teegespräche 1961-1963, S. $69 \mathrm{f}$.

196 Vgl. das Interview Schröders mit dem WDR am 19. 11. 1961, in: BuLleTIN 1961, S. 2038. 197 Vgl. die am 25. 4. 1962 publizierten Ausführungen Schröders auf einer Pressekonferenz in Paris, in: BulletiN 1962, S. 653.

198 Protokoll der CDU/CSU-Fraktionssitzung am 2. 10. 1962, ACDP VIII-001-1009/2.

199 Zitiert nach dem Artikel „Ein illusionsloses Gespräch über Berlin“, in: FRANKFURTER 
fest zu bleiben, aber andererseits jede Chance für eine Verständigung zu nutzen, um eine Eskalation der Berlin-Krise zu vermeiden ${ }^{200}$. Der Außenminister wußte, daß die Weltöffentlichkeit einen Dialog mit der Sowjetunion erwartete. Sollte die Bundesrepublik Verhandlungen ablehnen, dann würde der fatale Eindruck entstehen, „daß die Deutschen auch wirklich zu gar nichts bereit sind“201. Es dürfe nicht der Meinung Vorschub geleistet werden, Bonn versuche die Kontakte zwischen den Vereinigten Staaten und der UdSSR zu sabotieren, da ansonsten der Bundesregierung bei einem Scheitern der Gespräche „der Schwarze Peter" zugeschoben werde ${ }^{202}$. An der französischen Haltung, Verhandlungen strikt abzulehnen, kritisierte er, daß Paris nicht bereit war, die mit einer solch restriktiven Position verbundenen Risiken mitzutragen, nämlich im Falle einer Blockade Berlins oder eines sowjetischen Angriffs die Bündnissolidarität zu wahren ${ }^{203}$. Den Spielraum der Bundesrepublik schätzte er als gering ein. Ihm zufolge konnte die Bundesregierung Ost-West-Gespräche nicht verhindern, selbst wenn sie es wünschte ${ }^{204}$. Auch für direkte Gespräche mit Moskau sah er keine Verhandlungsbasis ${ }^{205}$. Letztendlich blieb in Schröders Augen keine andere Möglichkeit, als die in Washington getroffene Entscheidung, den Verhandlungsweg einzuschlagen, mitzutragen. Er befürchtete aber nicht, daß eine Berlin-Regelung zu Lasten der Bundesrepublik ging, sondern war fest davon überzeugt, daß die USA nie Interessen ihres Verbündeten für eine Verständigung mit der UdSSR opfern würden ${ }^{206}$. Sein Vertrauen gründete auf den sehr guten bilateralen Beziehungen zwischen Bonn und Washington sowie der weitgehenden Interessenidentität der beiden Staaten ${ }^{207}$. Dennoch war er nicht willens, Washington völlig freie Hand zu lassen. Er verlangte, daß die Amerikaner die von ihm formulierten Positionen wahrten ${ }^{208}$. Im direkten Gespräch mit der amerikanischen Regierung vermied er es aber, seinen Einwän-

Allgemeine Zeitung vom 21. 4. 1962, S. 3. Vgl. auch das Protokoll der CDU/CSUFraktionssitzung am 8. 5. 1962, ACDP VIII-001-1009/1.

200 Vgl. den Artikel von Gerhard Schröder: „Auf die Bewahrung des Friedens gerichtet. Unsere Außenpolitik baut weiter auf Fundamenten, die sich bereits als tragfähig erwiesen haben“, in: BULLETIN 1962, S. 21. Vgl. auch den Artikel „Schröder wünscht klassische Diplomatie“, in: DIE WELT vom 18. 12. 1961, S. 4.

201 Protokoll der CDU/CSU-Fraktionssitzung am 8. 5. 1962, ACDP VIII-001-1009/1.

202 Protokoll der CDU/CSU-Fraktionsvorstandssitzung am 7.5. 1962, ACDP VIII-0011503/4.

203 Schröder berichtete dem Auswärtigen Ausschuß, er hätte de Gaulle gefragt, ob Frankreich bei einem Angriff in vorderster Front stehen würde, doch dieser sei einer Antwort ausgewichen. Vgl. dazu den Vermerk über die Sitzung des Auswärtigen Ausschusses am 19. 4. 1962, ACDP, Nachlaß Krone I-028-031/1.

204 Vgl. die am 25. 4. 1962 publizierten Ausführungen Schröders auf einer Pressekonferenz in Paris, in: Bulletin 1962, S. 653.

205 Vgl. den Artikel „Debatte über Sowjetmemorandum“, in: DIE WELT vom 26. 1. 1962, S. 2.

206 Vgl. den Vermerk über die Sitzung des Auswärtigen Ausschusses am 19. 4. 1962, ACDP, Nachlaß Krone I-028-031/1.

207 Vgl. das Interview Schröders mit der Kölnischen Rundschau am 30. 4. 1962, in: BULLETIN 1962, S. 685.

208 So z. B. auf der Sitzung des Auswärtigen Ausschusses am 19. 4. 1962. Vgl. den Vermerk über die Sitzung des Auswärtigen Ausschusses am 19.4. 1962, ACDP, Nachlaß Krone I-028-031/1. 
den einen ultimativen Charakter zu geben. Es wird noch dargelegt werden, daß Schröder seine Vorstellungen, wenn nötig, flexibel an die amerikanische Position anpaßte, um eine Belastung der Beziehungen zu vermeiden.

Eine völlig andere Vorstellung, wie die Berlin-Politik der Bundesregierung zu gestalten sei, hatte Adenauer. Wie noch ausgeführt wird, zog er im Gegensatz zu seinem Außenminister eigene Verhandlungen mit der UdSSR durchaus in Erwägung. Auf diese Weise glaubte er, Briten und Amerikaner mobilisieren zu können, eine härtere Gangart gegenüber den Sowjets einzuschlagen. $\mathrm{Da}$ sie nämlich befürchten mußten, daß durch eine direkte Verständigung zwischen Bonn und Moskau ihre Einflußmöglichkeiten auf die Bonner Politik sinken würden, setzte der Kanzler darauf, daß in diesem Fall ihre Neigung zunehme, die Wünsche der Bundesrepublik stärker zu berücksichtigen. Zudem war Adenauer der Ansicht, es sei besser, etwaige Konzessionen selbst auszuhandeln, anstatt dies den USA zu überlassen ${ }^{209}$. Zwar rechnete er damit, daß die Dinge einen für die Bundesrepublik negativen Verlauf nehmen könnten, doch hoffte er immer noch, es würden sich im Laufe der Zeit Möglichkeiten ergeben, einer amerikanisch-sowjetischen Einigung entgegenzuwirken und damit eine Verschlechterung des Status Berlins bzw. der Bundesrepublik zu verhindern. „Wenn Opfer unvermeidlich werden sollen, dann nur über meine Leiche“, äußerte er entschlossen gegenüber seinen Mitarbeitern ${ }^{210}$. Kennedy, so Adenauer, habe dem Kreml viel zu weitreichende Offerten gemacht ${ }^{211}$. Der Präsident verlangte nach der Einschätzung des Kanzlers von Bonn Zugeständnisse, die die Zukunft Deutschlands „ins Unberechenbare rükken" und den Deutschen "den Lebensatem beengen" würden. Er wolle aber nicht zulassen, daß alles vernichtet werde, was er seit 1949 aufgebaut habe, stellte Adenauer klar212. Infolgedessen setzte er sich dafür ein, den Status quo in Berlin aufrechtzuerhalten ${ }^{213}$. Die Taktik der Amerikaner, dem sowjetischen Druck durch die Aufnahme von Verhandlungen zu begegnen, hielt er für den falschen Weg: „Dadurch kriegt man den Russen wirklich nicht zur Vernunft, daß man hinter ihm herläuft." 214 Der Kanzler war davon überzeugt, daß die UdSSR beabsichtigte, den Vereinigten Staaten „in Berlin eine Schlappe“ zuzufügen und sie so „in den Augen der ganzen Welt [...] zu erniedrigen “215. Deshalb, so Adenauer, säße man einem Trugschluß auf, wenn man glaube, Chruschtschow könnte eine für den Westen akzeptable Lösung abgerungen werden. Wiederholt plädierte er nachdrück-

209 Vgl. SCHWARZ, Adenauer II, S. 730 . Andererseits sagte Adenauer am 20. 2. $1962 \mathrm{zu}$ dem amerikanischen Journalisten-Ehepaar Sidney und Flora Lewis Gruson: „Ich denke nicht an direkte Gespräche mit Rußland, denn bisher hat keiner [ ...] mir sagen können, warum Chruschtschow uns mehr geben sollte als den Amerikanern." Vgl. ADENAUER, Teegespräche 1961-1963, S. 102.

210 OSTERHELD, „Ich gehe nicht leichten Herzens ...“, S. 112.

211 So Adenauer in einem Hintergrundgespräch am 8. 2. 1962. Vgl. ADENAUER, Teegespräche 1961-1963, S. 95.

212 OSTERHELD, „Ich gehe nicht leichten Herzens ...“, S. 112.

213 Vgl. dazu Äußerungen Adenauers gegenüber dem Bonner Korrespondenten des US News and World Report, Kurt Lachmann, am 2.3. 1962, in: ADENAUER, Teegespräche 1961-1963, S. 137.

214 Ebenda, S. 93.

215 Ebenda, S. 97. 
lich an die Verbündeten, eine Politik der Stärke zu verfolgen. So schlug er unter anderem vor, Vorbereitungen für eine Seeblockade des Ostblocks durch die NATO zu treffen ${ }^{216}$.

Ohne Zweifel hätte es der Kanzler lieber gesehen, wenn die USA und Großbritannien dem Beispiel Frankreichs gefolgt wären und einen harten Kurs gegenüber der Sowjetunion eingeschlagen hätten. Er war daher nicht damit einverstanden, daß sein Außenminister die auf Verständigung ausgerichtete Politik der KennedyRegierung unterstützte und den USA ständig sein Vertrauen aussprach. Nach der Auffassung des Kanzlers war ein derart entgegenkommendes Verhalten der Sache der Bundesrepublik nicht dienlich, da es Washington nur darin bestärkte, Konzessionen zu machen ${ }^{217}$. Seiner Meinung nach irrte sich Schröder, wenn er glaubte, die Bundesrepublik könnte durch eine ausdrückliche Bejahung der amerikanischen Politik Einfluß auf die Verhandlungsführung der Vereinigten Staaten gewinnen. „Trauen Sie den Amerikanern nicht; sie bringen es fertig, sich auf unserem Rücken mit den Russen zu verständigen“, warnte er zum Beispiel den Botschafter der Bundesrepublik in Moskau, Hans Kroll218. Adenauer sprach sich deshalb für ein härteres Auftreten aus. Er wollte die US-Regierung offen mit Kritik konfrontieren, auch wenn er im Grunde bezweifelte, daß die Bedenken Bonns in Washington Gehör finden würden. Gegenüber seinen Mitarbeitern äußerte der Kanzler, es spiele keine Rolle, wie sich die Bundesregierung gegenüber den Vereinigten Staaten verhalte, da die USA sowieso ihre Politik nicht änderten. Aus diesem Grund dachte er daran, die außenpolitischen Prioritäten der Bundesrepublik zu verschieben und notfalls auch in Kauf zu nehmen, "mit den Amerikanern einige Jahre in Spannung zu leben“. Als Alternative schlug er vor, "mehr auf das deutsch-französische und das europäische Pferd [zu] setzen" 219 .

Die Auffassungen des Bundeskanzlers und seines Außenministers, wie die Bundesrepublik in der Berlin-Krise agieren sollte, waren also völlig konträr. Klaus Gotto bringt den entscheidenden Unterschied treffend auf den Punkt: „Schröder schätzte die Belastbarkeit des deutsch-amerikanischen Bündnisses geringer und die direkte sowjetische Gefahr stärker ein als Adenauer; er war folglich um der Sicherheit der Bundesrepublik willen gegenüber den USA konzessionsbereiter als Adenauer." 220 Doch dies erklärt noch nicht, warum gerade Schröder, dem der Ruf vorausging, ein äußerst loyaler Mitarbeiter Adenauers zu sein, plötzlich so entschieden dem Kanzler widersprach. Von verschiedenen Seiten wurde dem Außenminister vorgeworfen, es sei ihm in erster Linie darum gegangen, sich von seinem bisherigen Image des treuen Gefolgsmannes zu befreien, um mit Blick auf die in absehbarer Zeit anstehende Frage der Kanzlernachfolge als eigenständige Persönlichkeit aufzutreten und auf diese Weise seine Aussichten zu verbessern ${ }^{221}$. Schrö-

\footnotetext{
$216 \mathrm{Vgl}$. ebenda, S. $70 \mathrm{f}$. und S. $98 \mathrm{f}$.

217 Vgl. dazu OSTERHELD, „Ich gehe nicht leichten Herzens ...“, S. 111. Vgl. ferner die Aufzeichnung Adenauers vom 24. 4. 1962, in: KOERFER, Kampf ums Kanzleramt, S. 640 f.

218 KRONE, Aufzeichnungen, Eintrag vom 10. 2. 1962, S. 168.

219 Vgl. OSTERHELD, „Ich gehe nicht leichten Herzens ... “, S. 111.

220 GOTTO, Adenauers Deutschland- und Ostpolitik, S. 66 f. So auch beinahe wortwörtlich: NOACK, Die Außenpolitik der Bundesrepublik Deutschland, S. 95.

221 So z. B. SCHWARZ, Adenauer II, S. 747.
} 
der hingegen betonte im Rückblick, der Maßstab seines damaligen Handelns sei gewesen, ob Kennedy „deutschen Boden gegenüber der Sowjetunion preisgegeben, vernachlässigt oder beeinträchtigt" habe. Dies sei jedoch nie der Fall gewe$\operatorname{sen}^{222}$. Anders als er es später sehen wollte, waren seine Meinungsverschiedenheiten mit Adenauer aber keineswegs allein auf die unterschiedliche Bewertung der amerikanischen Berlin-Politik zurückzuführen. In jedem Fall wäre es wohl zu einer Konfrontation gekommen, denn das Verhalten des Außenministers zeigte, daß er um politische Distanz zum Kanzler bemüht war. Diesen Eindruck bestätigen mehrere Zeitzeugen. So beobachtete der Botschafter der Bundesrepublik in Frankreich und frühere enge Vertraute Adenauers, Herbert Blankenhorn, daß Schröder nach seinem Wechsel ins Auswärtige Amt nicht zögerte, seine eigenen Vorstellungen in den außenpolitischen Entscheidungsprozeß einzubringen. Er habe augenscheinlich das Ziel verfolgt, sich vom Kanzler zu emanzipieren ${ }^{223}$. Bundestagspräsident Eugen Gerstenmaier war von Schröders Wandlung überaus überrascht, da sich dieser nach seinem Eindruck in den vergangenen Jahren bei auBenpolitischen Streitfragen stets zurückgehalten hatte 224 . Karl Carstens, als Staatssekretär im Auswärtigen Amt einer der engsten Mitarbeiter Schröders, kommt in seinen Memoiren zu dem Urteil, daß sich der neue Außenminister mittels einer vom Bundeskanzleramt eigenständigen Leitung des Ministeriums profilieren wollte ${ }^{225}$. Auch manche Äußerung Schröders untermauert diesen Eindruck. Beispielsweise thematisierte er im Frühjahr 1962 gegenüber der Bonner Landesgruppe der CSU die Richtlinienkompetenz des Bundeskanzlers. Schröder vertraute den Parlamentariern an, er sei dabei, „zu klären und die Grenzen festzustellen, wo die Richtlinien aufhören und die Details beginnen“. Für ihn gab es keinen Zweifel, daß die Bundesminister nach dem Grundgesetz das Recht hatten, „ihre Ressorts unter eigener Verantwortung zu leiten“226. Der einflußreiche CSU-Bundestagsabgeordnete Freiherr von und zu Guttenberg deutete diese Bemerkung in Anbetracht von Schröders selbstbewußtem Auftreten seit seinem Amtsantritt als Ankündigung, „daß er nicht die Absicht habe, sich vom Herrn Bundeskanzler in seiner Politik stören zu lassen“227.

Diese Entwicklung blieb Adenauer nicht verborgen. Er mußte sich jetzt fragen, ob er sich hinsichtlich der Loyalität seines langjährigen Innenministers nicht getäuscht hatte. Schließlich hatte sich der Kanzler für Schröders Wechsel ins Auswärtige Amt ausgesprochen, weil er von ihm erwartete, er mache dort eine bessere Figur als von Brentano, da er gewandter und eventuell auch härter auftreten

222 SCHRÖDER, Im Gespräch mit Meinhold Krauss, S. 48.

223 Vgl. BLANKENHORN, Verständnis, S. 426.

224 Vgl. Gerstenmaier, Streit, S. 453.

225 Vgl. CARSTENS, Erinnerungen, S. 234.

226 Vgl. das Schreiben des Freiherrn von und zu Guttenberg an Krone vom 18. 5. 1962,

ACDP, Nachlaß Krone I-028-031/1. Für einen Auszug vgl. WIRZ, Karl Theodor von und zu Guttenberg und das Zustandekommen der Großen Koalition, S. 173 f. Zur Richtlinienkompetenz des Bundeskanzlers und zum Ressortprinzip vgl. MAUNZ/DÜRIG, Grundgesetz, Artikel 65.

227 Vgl. das Schreiben des Freiherrn von und zu Guttenberg an Krone vom 18.5. 1962, ACDP, Nachlaß Krone I-028-031/1. 
würde 228. Er hatte aber nicht damit gerechnet, daß Schröder seiner Kontrolle entglitt. Zwar hatte er auch mit von Brentano manchen Strauß ausgefochten ${ }^{229}$, doch meistens hatte Adenauer am Ende seine Meinung durchgesetzt, indem er sich auf seine Richtlinienkompetenz als Bundeskanzler berief und diese, wenn er es für notwendig hielt, extensiv auslegte ${ }^{230}$. Auf diese Weise versuchte Adenauer, die Zügel der auswärtigen Politik auch in den Jahren nach 1955, als er schweren Herzens das Amt des Außenministers abgeben mußte, weiterhin in der Hand zu behalten. Dem gleichen Ziel diente auch das Verfahren, das Auswärtige Amt nur soweit er es für angebracht hielt, über den Inhalt seiner Unterredungen mit ausländischen Staats- und Regierungschefs zu informieren. Dieses Verhalten führte sehr rasch zu einer ersten Machtprobe zwischen Adenauer und Schröder. Letzterer wollte es nicht hinnehmen, daß seinem Ministerium wichtige Informationen vorenthalten wurden. Als Adenauer nach einem Besuch Macmillans zu Beginn des Jahres 1962 das Dolmetscherprotokoll seines Vieraugengesprächs mit dem Premierminister nicht freigab, verlangte das Auswärtige Amt Akteneinsicht. Der Kanzler lehnte dies ab und konterte, Schröder hätte besser nach Beendigung der Beratungen seinen britischen Amtskollegen, Lord Home, nach Berlin begleitet, anstatt sich in Bonn persönlich in die Diskussion über die Formulierung des gemeinsamen Kommuniqués einzuschalten, womit bereits vier Staatssekretäre beauftragt worden waren 231 . Ein derartiger Vorfall mag zu den üblichen Machtgeplänkeln gehören, die sich zuweilen an einem Kabinettstisch ereignen, er zeigt aber exemplarisch, daß sich Schröder nicht länger widerstandslos unterordnete.

Abgesehen davon, daß er seine Amtsgeschäfte zu selbständig führte, störte Adenauer vor allem, daß der Außenminister nach seinem Empfinden die falschen politischen Prioritäten setzte ${ }^{232}$. Innerhalb weniger Monate verschlechterte sich das Verhältnis der beiden Politiker rapide. Daß die Meinungsverschiedenheiten hauptsächlich die Bewertung der amerikanischen Deutschland- und Berlin-Politik betrafen, kann nach der Darlegung ihrer diesbezüglichen Einschätzungen nicht überraschen. Zur ersten konkreten Auseinandersetzung in dieser Frage soll es bereits Mitte Januar 1962 im Rahmen einer Kabinettssitzung gekommen sein. Wie Erich Mende, der kraft seines Amtes als Parteivorsitzender der FDP an der Sitzung teilnahm, berichtet, polemisierte der Kanzler dabei über die amerikanische Politik. Adenauer erklärte, die USA betrieben „Außenpolitik wie ein Cowboy aus dem Sattel“", und unterstellte Kennedy, er wolle sich auf Kosten der Deutschen mit Chruschtschow arrangieren. Schröder bemühte sich, die Bedenken des Kanzlers zu zerstreuen, doch sein Widerspruch reizte Adenauer um so mehr ${ }^{233}$. Zwar eskalierte der Konflikt an diesem Tag noch nicht, doch die Diffe-

\footnotetext{
228 Vgl. Gerstenmaier, Streit, S. 453.

229 Zum Verhältnis zwischen Adenauer und von Brentano vgl. die einschlägigen Studien von Daniel Kosthorst und Arnulf Baring: KOSTHORST, Brentano und die deutsche Einheit; BARING, Sehr verehrter Herr Bundeskanzler! Heinrich von Brentano im Briefwechsel mit Konrad Adenauer 1949-1969.

$230 \mathrm{Vgl}$. z.B. das Schreiben Adenauers an von Brentano vom 17. 1. 1956, StBKAH III/24.

231 Vgl. OSTERHELD, „Ich gehe nicht leichten Herzens ...“, S. 95.

$232 \mathrm{Vgl}$. SCHWARZ, Adenauer II, S. 722.
}

233 Vgl. MENDE, Von Wende zu Wende, S. 17. Dem FDP-Vorsitzenden zufolge soll sich die- 
renzen waren erstmals offen zu Tage getreten. Der Kanzler versuchte nun, den Außenminister zu disziplinieren und erteilte die Weisung, mit ihm Rücksprache $\mathrm{zu}$ halten, bevor er Entscheidungen über das weitere Vorgehen hinsichtlich der amerikanischen Sondierungsgespräche treffe ${ }^{234}$. Dieser wich einem Gespräch aus und entzog sich dem Zugriff Adenauers durch einen mehrwöchigen Urlaub in der Schweiz ${ }^{235}$. Nach seiner Rückkehr rechtfertigte er sich mit Terminschwierigkeiten, die ein Treffen mit dem Kanzler verhindert hätten ${ }^{236}$. Ein derartiges Verhalten ihm gegenüber war Adenauer nicht gewohnt, und er reagierte dementsprechend hilflos: Er konfrontierte Schröder mit dem schon ans Groteske grenzenden Vorwurf, er wäre ihm gegenüber verpflichtet gewesen, vor seiner Abreise einen Urlaubsantrag zu stellen ${ }^{237}$. Der ließ sich nicht einschüchtern, sondern wies den Kanzler im Gegenzug darauf hin, er halte es für sehr wichtig, „daß das Vertrauen, das durch Ihren November-Besuch in Washington geschaffen worden ist, weiter gekräftigt wird“238. Dies mußte Adenauer als Aufforderung verstehen, seine damals gegebene Zusage einzuhalten, Sondierungen mit der Sowjetunion zu unterstützen und den amerikanischen Verständigungsbemühungen nicht in den Rücken zu fallen. Obwohl Schröder wußte, daß er dabei war, Adenauers Sympathien restlos zu verspielen, setzte er unbeirrt seine Politik fort. Dem Widerspruch des Kanzlers ging er zunächst aus dem Weg, indem er Zusammenkünfte unter vier Augen vermied. Schließlich wandte er selbst die Praktiken Adenauers an und informierte ihn seinerseits nicht mehr über wichtige Punkte seiner Beprechungen. So verschwieg er dem Bundeskanzleramt wesentliche Teile eines Gespräches von zentraler Bedeutung, das er am 11. März 1962 in Lausanne mit Dean Rusk führte ${ }^{239}$. Zum besseren Verständnis dieses Vorfalls ist es aber erforderlich, die Entwicklung der Berlin-Politik der USA seit Jahresbeginn kurz zu umreißen:

Der amerikanische Außenminister hielt sich anläßlich der für den 14. März geplanten Eröffnung der Konferenz der 18-Mächte-Abrüstungskommission der UNO in der Schweiz auf ${ }^{20}$. Schon am 10. März traf er am Tagungsort in Genf ein, um in Gesprächen mit dem sowjetischen Außenminister Bewegung in die festge-

ser Vorfall am 15.1. 1962 ereignet haben. Vom 11. bis 20.1. 1962 befand sich Schröder aber mit Bundespräsident Lübke auf einer Afrika-Reise.

$234 \mathrm{Vgl}$. das Schreiben Adenauers an Schröder vom 9. 2. 1962, StBKAH C 42.

235 Vgl. das Schreiben Adenauers an Schröder vom 21. 2. 1962, StBKAH C 42.

236 Vgl. das Schreiben Schröders an Adenauer vom 26. 2. 1962, StBKAH C 42.

237 Vgl. das Schreiben Adenauers an Schröder vom 21. 2. 1962, StBKAH C 42. Schröder bestritt dies in seiner Antwort. Vgl. das Schreiben Schröders an Adenauer vom 26. 2. 1962, STBKAH C 42.

238 Vgl. das Schreiben Schröders an Adenauer vom 26. 2. 1962, StBKAH C 42.

239 Vgl. OSTERHELD, „Ich gehe nicht leichten Herzens ...", S. 105. Osterheld datiert das Gespräch irrtümlich auf den 13. März. Zu dem Vorfall vgl. auch die Ausführungen Adenauers gegenüber Joseph Alsop am 11. 5. 1962, in: ADENAUER, Teegespräche 1961-1963, S. $180 \mathrm{f}$.

240 An dieser Konferenz über die Möglichkeiten einer internationalen Abrüstung sollten acht blockfreie Staaten sowie jeweils fünf Staaten der NATO und des Warschauer Pakts teilnehmen. Da Frankreich verzichtete, waren schließlich nur 17 Delegationen in Genf vertreten. Vgl. ADG 1962, S. 9741. 
fahrenen Berlin-Verhandlungen zu bringen ${ }^{241}$. Die Sondierungen zwischen dem amerikanischen Botschafter Thompson und Gromyko in Moskau waren nämlich nach mehreren Treffen (am 2. und 12. Januar sowie am 1. und 9. Februar) am 6. März ohne greifbaren Erfolg zu Ende gegangen. Während der dritten Begegnung am 1. Februar hatte Thompson der Sowjetunion den Plan einer internationalen Zugangsbehörde (International Access Authority) unterbreitet ${ }^{242}$. Diese Idee hatte Kennedy bereits als Senator 1959 in ihren Grundzügen entwickelt und Ende November 1961 in seinem Interview mit der Iswestija wieder aufgegriffen $^{243}$. Der Plan sah die Errichtung eines internationalen Gremiums durch ein Abkommen der Vier Mächte vor, das die Aufgabe hatte, den Verkehr über die Autobahn Helmstedt-Berlin sowie den Flugverkehr über die drei bestehenden Luftkorridore nach Berlin (West) zu regeln. Nach den Vorstellungen des Präsidenten würde die Zugangsbehörde aus 13 Mitgliedern bestehen, die Entscheidungen mit einfacher Mehrheit trafen. Der Westen sollte durch die Bundesrepublik, Berlin (West), Frankreich, Großbritannien und die USA vertreten sein. Für die östliche Seite waren ebenfalls fünf Plätze vorgesehen, darunter je einer für die UdSSR, Ost-Berlin und die DDR. Österreich, die Schweiz und Schweden würden als neutrale Vertreter der Behörde angehören ${ }^{244}$. Obwohl das Konzept von den Amerikanern bewußt nicht näher präzisiert wurde, um den Verhandlungsspielraum nicht einzuschränken, lehnte Gromyko den Vorschlag zunächst in toto ab245. Am 10. März teilte Chruschtschow dem Präsidenten jedoch mit, er könne sich durchaus ein solches Gremium vorstellen. Zuvor müßte aber ein Friedensvertrag mit Deutschland auf der Basis des Status quo geschlossen und Berlin (West) der Status einer Freien Stadt gegeben werden ${ }^{246}$. Kennedy bewertete die Stellungnahme des sowjetischen Ministerpräsidenten als Fortschritt und erteilte seinem Außenminister die Weisung, in Genf mit Gromyko den Plan erneut zu diskutieren ${ }^{247}$. Ansonsten sollte sich Rusk für seine Gespräche an einem Verhandlungspapier des State

$241 \mathrm{Vgl.} \mathrm{STÜTZle,} \mathrm{Kennedy} \mathrm{und} \mathrm{Adenauer} \mathrm{in} \mathrm{der} \mathrm{Berlin-Krise,} \mathrm{S.} 204$.

242 Vgl. FRUS 1961-1963, XIV, Dok. 278, S. 784-788.

243 Vgl. STÜTZLE, Kennedy und Adenauer in der Berlin-Krise, S. 25-27 und S. 179-181. Ursprünglich sollte die Zugangsbehörde nur für den Landverkehr nach Berlin zuständig sein, d.h. lediglich die Autobahn nach Berlin sollte unter internationale Verwaltung gestellt werden. Vgl. dazu das Interview des Präsidenten Kennedy mit dem Chefredakteur der Zeitschrift Iswestija, Adschubej, in: DzD IV/7, S. 995; sowie FRUS 1961-1963, XIV, Dok. 218, S. 607. Das Angebot wurde schließlich auf den Luftverkehr ausgeweitet, um es für die UdSSR attraktiver zu machen. Vgl. AuSLAND, Kennedy, Krushchev and the Berlin-Cuba Crisis, S. $44 \mathrm{f}$.

244 Vgl. STÜTZLE, Kennedy und Adenauer in der Berlin-Krise, S. 194-198.

245 Vgl. FRUS 1961-1963, XIV, Dok. 278, S. 784 f.

246 Vgl. das Schreiben Chruschtschows an Kennedy vom 10.3. 1962, in: FRUS 1961-1963, XV, Dok. 3, S. 7-15. Nach den Vorstellungen des sowjetischen Ministerpräsidenten sollte die Zugangsbehörde nur als Schiedsrichter (arbiter) fungieren, d.h. sie konnte weder Regelungen über den Transitverkehr treffen, noch auf eigene Initiative in den Verkehr eingreifen. Dies bliebe der DDR vorbehalten.

247 Vgl. das Schreiben Kennedys an Rusk vom 11. 3. 1962, in: ebenda, Dok. 4, S. 15 f. Zu den Vorstellungen Kennedys, wie ein solcher Modus vivendi aussehen könnte, vgl. das Schreiben Kennedys an Rusk vom 9. 3. 1962, in: ebenda, Dok. 1, S. 1-3. 
Department orientieren, dem der Präsident seine Zustimmung erteilt hatte ${ }^{248}$. Die geheime Aufzeichnung mit dem Titel Draft Modus Vivendi verband eine Regelung über Berlin mit dem Angebot an die UdSSR, den schon seit langem von ihr geforderten Nichtangriffspakt zwischen NATO und Warschauer Pakt zu schließen. Außerdem war ein Abkommen vorgesehen, in dem sich die Atommächte verpflichten sollten, keine nukleare Waffen an dritte Staaten weiterzugeben ${ }^{249}$.

Über diese amerikanischen Pläne informierte Rusk in groben Zügen seinen deutschen Kollegen, als er ihn am Nachmittag des 11. März im Hotel Beau Rivage in Lausanne aufsuchte ${ }^{250}$. Da Schröder befürchtete, wegen der gleichzeitig stattfindenden Abrüstungskonferenz könnten die USA in Versuchung kommen, die Berlin-Gespräche mit der Erörterung der Frage der europäischen Sicherheit zu verknüpfen, beabsichtigte er, dem amerikanischen Außenminister die Zusage abzuringen, seine Regierung würde sich an die auf der NATO-Ministerratstagung im Dezember 1961 getroffene Vereinbarung halten, die Sondierungen auf Berlin zu beschränken. Nach wie vor suchte er eine Ausweitung der Gespräche zu vermeiden, weil er immer noch damit rechnete, die Bundesrepublik könnte bezüglich ihres militärischen Status diskriminiert werden 251. Was Rusk ihm nun mitteilte, ließ aber keinen $\mathrm{Zweifel} \mathrm{daran,} \mathrm{daß} \mathrm{man} \mathrm{sich} \mathrm{in} \mathrm{Washington} \mathrm{entschlossen} \mathrm{hatte,} \mathrm{die}$ vereinbarte Linie zu verlassen. Nichtsdestotrotz entgegnete Schröder, er habe keine Zweifel an der amerikanischen Berlin-Politik ${ }^{252}$. Obwohl er sich bislang strikt gegen einen Nichtangriffspakt ausgesprochen hatte, meinte er nun, er könne sich notfalls für eine derartige Vereinbarung erwärmen, sofern es dadurch nicht zu einer ungewollten Anerkennung der DDR komme. Allerdings bat er Rusk eindringlich, dieses Thema nicht von sich aus gegenüber der UdSSR anzusprechen $^{253}$. Der amerikanische Außenminister legte Schröder zudem die Idee dar, eine internationale Zugangsbehörde für Berlin ins Leben zu rufen. Dieser lehnte das Vorhaben nicht explizit ab, erhob aber Einspruch gegen eine Aufnahme der DDR als gleichberechtigtes Mitglied der Behörde und eine Beteiligung von Berlin (West) als eigenständige Einheit in der Kontrollkommission. Ferner unterstrich er, daß er die Bildung gemischter deutsch-deutscher Ausschüsse nur dann gutheißen

248 Vgl. ebenda, Dok. 1, S. 1.

249 Die Entwürfe für diese Abkommen sind einer Aufzeichnung des Leiters der Europa-Abteilung im State Department, Foy Kohler, für Rusk vom 10.3.1962 beigefügt. Vgl. ebenda, Dok. 2, S. 5 f.

250 Vgl. MAYER, Adenauer und Amerika, S. 211. Schröder hatte bewußt nicht in Genf Quartier bezogen, um den Eindruck einer Einflußnahme der Bundesrepublik auf die Abrüstungsgespräche zu vermeiden. Vgl. den Artikel „Schröder und Rusk nennen ihr Treffen erfolgreich“, in: DIE WELT vom 12.3. 1962, S. 1 und S. 4.

251 Vgl. den Artikel „Rusk und Schröder sprechen über Berlin und die Abrüstungsfrage“, in:

FRANKFURTER AllgemeINE ZEITUNG vom 12.3. 1962, S. 1. Daß Schröder auf auffällige Weise Thompson für dessen Verhandlungsführung in Moskau dankte, wurde als versteckte Kritik an den neuen amerikanischen Überlegungen gedeutet, da sich der amerikanische Diplomat im Gegensatz zu seiner Regierung an die Vorgabe gehalten hatte, nur über Berlin mit Gromyko zu sprechen. Vgl. dazu die Berichterstattung der Stuttgarter Zeitung vom 12. 3. 1962, in: DzD IV/8, S. 231, Anm. 2.

252 Vgl. FRUS 1961-1963, XV, S. 17, Anm. 1.

253 Vgl. MAYER, Adenauer and Kennedy, S. 70; ders., Adenauer und Amerika, S. 209. 
könne, wenn festgelegt würde, daß sie auch das Ziel hätten, die staatliche Vereinigung Deutschlands vorzubereiten ${ }^{254}$.

Nach dieser Unterredung mußte Schröder klar sein, daß sich Washington nicht mehr an das im November gemeinsam vereinbarte Verhandlungsmandat hielt. Dennoch unterließ er eine ausführliche Unterrichtung des Kanzlers über die amerikanischen Intentionen. Das Bundeskanzleramt erfuhr lediglich, daß die USA eine internationale Kontrolle für Berlin in Betracht zögen und Schröder dagegen Bedenken geäußert habe ${ }^{255}$. Da die amerikanisch-sowjetischen Gespräche in Genf erfolglos blieben, weil die Sowjetunion lediglich ihr Interesse an einer Fortführung des Dialogs bekundete, ansonsten jedoch ihre hinreichend bekannten Positionen wiederholte ${ }^{256}$, und die USA den Plan einer Zugangsbehörde gegenüber Bonn in den folgenden Wochen nicht mehr erwähnten, nahm Adenauer offenbar an, Kennedy habe dieses Konzept wieder fallengelassen ${ }^{257}$. Um so größer war die Überraschung in Bonn, als die amerikanische Regierung am 9. bzw. 10. April 1962 ein weitreichendes Verhandlungsangebot für die nächsten Gespräche mit der Sowjetunion übermittelte und die Bundesregierung aufforderte, binnen 48 Stunden dazu Stellung zu nehmen, da das Papier am 16. April dem sowjetischen Botschafter in Washington, Anatolij Dobrynin, übergeben werden sollte 258 . Das Vorschlagspaket bestand aus zwei Teilen: Die erste Aufzeichnung enthielt das Konzept einer internationalen Zugangsbehörde, die zweite war eine Weiterentwicklung des Modus-vivendi-Plans von Anfang März, den Rusk in Lausanne Schröder

254 Diese Schilderung über den Verlauf des Gesprächs gab Schröder am 19. 4. 1962 dem Auswärtigen Ausschuß. Vgl. das nicht näher datierte Schreiben Hecks an Krone vom April 1962, ACDP, Nachlaß Krone I-028-031/1.

Erstaunlicherweise ist in dem Gesprächsprotokoll nur die Rede von der Einrichtung eines Rates der stellvertretenden Außenminister der Vier Mächte, der über das BerlinProblem und Abrüstungsfragen verhandeln sollte. Der Gedanke einer Zugangsbehörde wird dort nicht erwähnt (Information von Torsten Oppelland). Andererseits deuten Äußerungen Adenauers vom 11. 5. 1962 gegenüber Joseph Alsop darauf hin, daß in Genf auch über die Zugangsbehörde gesprochen wurde. Vgl. ADENAUER, Teegespräche 19611963, S. 180 f.

255 Vgl. ebenda, S. 181. Vielleicht waren die Informationen, die Schröder an Adenauer weitergab, deshalb so knapp gehalten, weil er das Gespräch mit Rusk ohne Zuhilfenahme eines Dolmetschers geführt hatte. Wie Hermann Kusterer berichtet, hatte Schröder seine Sprachkenntnisse überschätzt, wodurch zahlreiche Mißverständnisse aufgetreten waren. Kusterer meint, einiges, was Rusk mitgeteilt hätte, habe Schröder falsch oder gar nicht verstanden. Es ist also sehr gut möglich, daß er deswegen seinen Bericht an das Kanzleramt auf das Wesentliche beschränkt hatte. Schröder habe jedenfalls, so Kusterer, nach diesem Vorfall Unterredungen mit ausländischen Politikern nur noch mit Hilfe eines Übersetzers geführt (ZEITZEUGENBEFRAGUNG Kusterer).

256 Vgl. dazu den Bericht Rusks an das Department of State vom 26. 3. 1962, in dem er eine Bilanz seiner Unterredungen mit Gromyko zog, in: FRUS 1961-1963, XV, Dok. 27, S. $91 \mathrm{f}$.

257 Vgl. dazu die Äußerung Adenauers gegenüber dem Herausgeber der New York Times, Lester Markel, am 12. 5. 1962, in: ADENAUER, Teegespräche 1961-1963, S. 552, Anm. 18. 258 Vgl. Grewe, Rückblenden, S. 549; OSTERHELD, „Ich gehe nicht leichten Herzens ...“, S. 106. Die Übergabe des Verhandlungsvorschlags an Botschafter Grewe erfolgte am Nachmittag des 9.4. 1962 (vgl. FRUS 1961-63, XV, S. 100, Anm. 3), also nach deutscher Zeit am 10.4. 1962. 
erläutert hatte und der dem Auswärtigen Amt seit dem 22. März schriftlich vorlag259.

Am Spätnachmittag des 12. April trafen sich im Büro des Fraktionsvorsitzenden der CDU/CSU, von Brentano, der Kanzler, Außenminister Schröder, Staatssekretär Carstens, der FDP-Parteivorsitzende Mende, die Bundesminister Heinrich Krone und Werner Dollinger, sowie der Fraktionsvorsitzende der SPD, Erich Ollenhauer, um über die Antwort der Bundesregierung zu beraten ${ }^{260}$. Wer dieses Treffen veranlaßt hatte, ist noch nicht geklärt. Sowohl Adenauer wie Schröder nahmen später für sich in Anspruch, die Initiative ergriffen zu haben ${ }^{261}$. In der Diskussion sprachen sich Brentano und Krone klar gegen die amerikanischen Pläne aus: „Wenn es zu einem Abschluß mit den Sowjets auf dieser Basis käme, würden die Möbelwagen in Berlin nicht ausreichen; Berlin würde eine tote Stadt." 262 Schröder hatte ebenfalls Bedenken, wies aber daraufhin, daß die amerikanischen Papiere nichts enthielten, was der Bundesregierung nicht schon seit längerem bekannt sei ${ }^{263}$. Dies gab auch Krone zu; meinte jedoch, die „Summe der Teile“ gebe dem Ganzen „ein eigenes und größeres Gewicht". Er sah darin eine Kursänderung der amerikanischen Regierung, die sich nun ,auf dem Rücken der Deutschen" mit dem Kreml verständigen wolle264. Auch Mende kritisierte die beiden Konzepte ${ }^{265}$, obwohl die FDP seit einigen Tagen ein von Wolfgang Schollwer vorgelegtes Papier ${ }^{266}$ diskutierte, das weit über die Vorstellungen der Kennedy-Regierung hinausging und sogar eine Anerkennung der DDR sowie ein Disengagement in Mitteleuropa vorsah, falls Ulbricht abgesetzt und die Freizügigkeit zwischen den beiden deutschen Staaten wiederhergestellt würde. Doch

259 Vgl. Osterheld, „Ich gehe nicht leichten Herzens ...“, S. 106. Dieser Entwurf unterschied sich aber von der dem Auswärtigen Amt vorliegenden Version. Die Aufzeichnung trug jetzt den Titel Draft Principles, Procedures, and Interim Steps. Sie basierte zwar auf dem Verhandlungspapier, das Rusk nach Genf mitgenommen hatte, war aber am 3.4. 1962 nach seinen Gesprächen überarbeitet und erweitert worden. Die Modifikationen betrafen zum größten Teil die Paragraphen, die Berlin behandelten. Die in FRUS 19611963, XV, Dok. 30, S. 95-98, veröffentlichte Version ist bis auf ein Wort identisch mit der Grewe ausgehändigten Fassung. Vgl. ebenda, Dok. 32, S. 100. Die zweite Aufzeichnung, die die geplante Zugangsbehörde beschrieb, ist leider in FRUS nicht abgedruckt. Vgl. dazu FRUS 1961-1963, XIV, S. 784, Anm. 3.

$260 \mathrm{Vgl}$. CARSTENS, Erinnerungen, S. 290.

261 Adenauer äußerte gegenüber Joseph Alsop am 11. 5. 1962: „[...] das schien mir so wichtig, daß ich gesagt habe, dazu müssen wir hören die Vorsitzenden der Bundestagsfraktionen“. Vgl. ADENAUER, Teegespräche 1961-1963, S. 179. Schröder beteuerte hingegen am 30.4. 1962 in einem Interview mit der Kölnischen Rundschau: "Die Besprechung des Bundeskanzlers mit den Fraktionsführern am 12. April geht auf meine Initiative zurück." Vgl. Bulletin 1962, S. 685. Hans-Peter Schwarz' Behauptung, das Treffen habe gegen den Widerstand Schröders stattgefunden (vgl. ScHWARZ, Adenauer II, S. 744), läßt sich somit nicht aufrechterhalten.

262 KRONE, Aufzeichnungen, Eintrag vom 14. 4. 1962, S. 169. Vgl. auch CARSTENS, Erinnerungen, S. 290.

263 Vgl. SCHWARZ, Adenauer II, S. 744.

264 KRONE, Aufzeichnungen, Eintrag vom 14. 4. 1962, S. 169.

$265 \mathrm{Vgl}$. SCHWARZ, Adenauer II, S. 744.

266 Für den Wortlaut der Denkschrift „Verklammerung und Wiedervereinigung“ vom 9. 4. 1962 vgl. DzD IV/8, S. 376-389. 
die Debatte innerhalb der liberalen Parteispitze über den Vorschlag des Referenten für Außen- und Deutschlandpolitik in der Bundesgeschäftsstelle der FDP war noch nicht abgeschlossen ${ }^{267}$. Die Beratung führte schließlich zu dem Ergebnis, daß die Vertreter der vier Parteien einstimmig die amerikanischen Vorschläge zurückwiesen ${ }^{268}$.

Adenauer teilte dieses Ergebnis am folgenden Tag dem stellvertretenden amerikanischen Verteidigungsminister, Paul Nitze, mit, der sich zu Besprechungen in Bonn aufhielt. Der Kanzler bekannte freimütig, er sei über das Verhandlungskonzept schockiert, da die geplante Beteiligung der DDR an der Zugangsbehörde praktisch auf ihre völkerrechtliche Anerkennung hinauslaufen mußte. Zudem würde die Sicherheit des Zugangs nach Berlin letztendlich von Schweden, Österreich und der Schweiz abhängen, da bei der zur erwartenden gegenseitigen Blokkade der fünf westlichen und fünf östlichen Vertreter in dem Gremium die Stimmen der Neutralen den Ausschlag gaben 269. Adenauer kam zu dem Schluß: „Die ganze Idee ist unmöglich. " $270 \mathrm{Er}$ sah sich in seinem Mißtrauen gegenüber Kennedy bestätigt: Anstatt Sondierungsgespräche führten die Amerikaner richtige Verhandlungen! Auch von einer Begrenzung der Gespräche auf Berlin war nicht mehr die Rede271! Nach seiner Meinung war es aber der falsche Weg, wenn immer nur der Westen Konzessionen machte. Angesichts der Meinungsverschiedenheiten zwischen Bonn und Washington über die Zugangsbehörde hielt er es für dringend erforderlich, zunächst eine Verhandlungspause einzulegen ${ }^{272}$. In einem Brief an Kennedy äußerte er am 14. April „erhebliche Bedenken“ gegen die amerikanischen Pläne. Eindringlich appellierte er an den Präsidenten, die Verhandlungen mit der UdSSR vorläufig zu stoppen. Die Unterbrechung sollte für Beratungen zwischen den Drei Mächten und der Bundesrepublik genutzt werden, um wieder zu einer gemeinsamen Haltung zu finden ${ }^{273}$. Gleichzeitig protestierte Grewe beim Leiter der Europa-Abteilung im amerikanischen Außenministerium, Foy Kohler. Er wies darauf hin, daß die Vorschläge der USA die Tendenz hätten, die DDR mit der Bundesrepublik gleichzustellen. Manche Formulierung, so der Botschafter, ließe sich als Bestätigung der sowjetischen Zwei-Staaten-Theorie lesen! Außerdem sei zu erwarten, daß der Kreml auf die neutralen Mitglieder der $\mathrm{Zu}$ gangsbehörde Druck ausüben würde. Sein Gesprächspartner zeigte sich jedoch erstaunt über die negative Reaktion aus Bonn. Der Verhandlungsvorschlag sei doch im wesentlichen mit dem in Genf der Bundesregierung übergebenen Papier identisch, entgegnete Kohler. Alle nachträglichen Änderungen seien mit Außenminister Schröder abgesprochen worden ${ }^{274}$. Er gab sich zudem überzeugt, die

\footnotetext{
267 Vgl. dazu MENDE, Von Wende zu Wende, S. 34-36.

$268 \mathrm{Vgl}$. SCHWARZ, Adenauer II, S. 744.

269 Vgl. FRUS 1961-1963, XV, Dok. 34, S. 101-105.

270 "The whole idea is impossible." Vgl. ebenda, Dok. 34, S. 102.

271 Vgl. OSTERHELD, „Ich gehe nicht leichten Herzens ...“, S. 106.

272 Vgl. ebenda, S. 103.

273 Zitiert nach KOERfER, Kampf ums Kanzleramt, S. 637. Zu dem Schreiben vgl. auch FRUS 1961-1963, XV, Dok. 37, S. 112, sowie das Gespräch Adenauers mit Joseph Alsop am 11. 5. 1962, in: ADENAUER, Teegespräche 1961-193, S. 177.

274 Vgl. FRUS 1961-1963, XV, Dok. 35, S. 105-109.
} 
USA hätten mit der Schweiz, Österreich und Schweden eine gute Wahl getroffen ${ }^{275}$.

Es war aber nicht allein die negative Bewertung des amerikanischen Verhandlungskonzepts durch die Bundesregierung, die die gegenseitigen Beziehungen im Frühjahr 1962 erheblich belastete. Der entscheidende Anlaß für die Eskalation der schwelenden Vertrauenskrise war, daß der Inhalt des Verhandlungspakets der Öffentlichkeit bekannt wurde, obwohl Kennedy ausdrücklich strengste Geheimhaltung angemahnt hatte 276 . Bereits am Abend des 13. April berichtete der Deutschlandfunk über die amerikanischen Pläne. Am folgenden Tag erschienen Artikel in der New York Times und in mehreren deutschen Tageszeitungen ${ }^{277}$. Kohler beschuldigte die Vertretung der Bundesrepublik in Washington, also Grewe, der Indiskretion. Er erklärte, sowohl Kennedy als auch Außenminister Rusk seien schokkiert über den Vorfall278. Rusk ließ Schröder seine Entrüstung spüren und bezeichnete die Angelegenheit als einen schwerwiegenden Vertrauensbruch. Die Veröffentlichung geheimer Verhandlungsunterlagen schwäche die westliche Position gegenüber der UdSSR. In Washington denke man daran, das bisherige deutsch-amerikanische Konsultationsverfahren zu ändern, teilte Rusk mit ${ }^{279}$. Tatsächlich überging die amerikanische Regierung ab sofort die Botschaft der Bundesrepublik und unterrichtete die Bundesregierung direkt über die amerikanische Vertretung in Bonn ${ }^{280}$. Grewe wurde nach dem Vorfall von den Amerikanern als „persona ingrata" behandelt ${ }^{281}$. Angesichts dieser verfahrenen Situation blieb der Bundesregierung nichts anderes übrig, als seine baldige Ablösung bekannt zu geben ${ }^{282}$.

Der Verantwortliche für die Indiskretion war indes nicht in Washington, sondern in Bonn zu suchen, wie der Botschafter in seinen Rückblenden überzeugend darlegt. Grewe mutmaßt, Adenauer habe sich nicht an die Geheimhaltung gehalten und die Presse informiert, um dadurch das Verhandlungspaket zu Fall zu bringen $^{283}$. Auch wenn das Bekanntwerden der amerikanischen Pläne für die Bundesrepublik letztendlich von Nutzen war, muß es nicht zwingend bewußt in die Wege geleitet worden sein. Wie der Spiegel in seiner Ausgabe vom 25. April 1962 berich-

275 "We feel we would be in pretty good hands with the Swiss, Swedes, and the Austrians." Vgl. ebenda, S. 108.

276 Vgl. FRUS 1961-1963, XV, Dok. 32, S. 100.

277 Vgl. GrEwE, Rückblenden, S. 550. Vgl. ferner den Artikel von Sidney Gruson: „US Draft Plan on Berlin Asks Peace Pledges“, in: New YORK TIMES vom 14. 4. 1962, S. 1 f., bzw. DzD IV/8, S. 412, Anm. 1.

278 Vgl. FRUS 1961-1963 XV, Dok. 36, S. 109-111.

279 Vgl. das Schreiben Rusks an Schröder vom 14. 4. 1962, in: ebenda, Dok. 38, S. 113.

$280 \mathrm{Vgl}$. GREWE, Rückblenden, S. $551 \mathrm{f}$.

281 Vgl. die Aufzeichnung Adenauers vom 24. 4. 1962, in: KoERfER, Kampf ums Kanzleramt, S. 641 .

282 Die Abberufung Grewes wurde am 20. 4. 1962 beschlossen. Vgl. SCHWARZ, Adenauer II, S. 746. Am 3. 5. 1962 teilte Schröder die Entscheidung Rusk am Rande der NATO-Ministerratstagung in Athen mit. Vgl. dazu FRUS 1961-1963, XV, Dok. 45, S. $135 \mathrm{f}$. Vier Tage später gab Adenauer in Berlin (West) die Personalie öffentlich bekannt, ohne jedoch zuvor den Botschafter informiert zu haben. Vgl. GREWE, Rückblenden, S. 554-561.

283 Vgl. GrewE, Rückblenden, S. 547. Diesen Verdacht äußert auch Mende. Vgl. MENDE, Von Wende zu Wende, S. 37. 
tete, hatten sich während der Besprechung im Büro Brentano am 12. April eine große Anzahl Journalisten in der Nähe befunden, weil dieses im gleichen Flur lag wie der Raum, in dem zur selben Zeit der FIBAG-Untersuchungsausschuß tagte. Die Teilnehmer der Kanzlerrunde hätten durch lautes Geschrei, das bis auf den Gang gedrungen war, auf sich aufmerksam gemacht und dadurch unabsichtlich den Inhalt der amerikanischen Papiere verraten ${ }^{284}$.

Die für die Bundesrepublik vorteilhafte Konsequenz der Affäre war jedenfalls, daß die USA darauf verzichteten, Dobrynin die neuen Vorschläge zu übergeben. Um ihren Unmut deutlich zu machen, beschlossen Kennedy und Rusk, dem Kanzler diese Entscheidung lediglich mündlich durch Botschafter Dowling mitzuteilen, ihm jedoch nicht auf sein Schreiben vom 14. April zu antworten ${ }^{285}$. Dieser Affront sollte dem Kanzler signalisieren, wie entrüstet man in Washington über die Bundesregierung war. Angesichts dieser Entwicklung hielt es Schröder für erforderlich, die Wogen wieder zu glätten. Ohne den Kanzler darüber in Kenntnis zu setzen ${ }^{286}$, schrieb er am 16. April an Rusk einen in versöhnlichem Ton gehaltenen Brief, in dem er die Indiskretion, die zur Veröffentlichung der amerikanischen Pläne geführt hatte, auf das „tiefste“ bedauerte ${ }^{287}$. Als der Kanzler davon erfuhr, beschwerte er sich über die „sehr weiche Feder", die das Auswärtige Amt benutze ${ }^{288}$. Er wollte den Konfrontationskurs fortsetzen und erteilte die Weisung, ein Schreiben mit folgendem Wortlaut an das amerikanische Außenministerium zu richten: „Der Herr Bundeskanzler hat mich beauftragt, Ihnen folgendes mitzuteilen: Nach zehnjähriger einträchtiger Zusammenarbeit empfindet er den Vorwurf eines, ernsten Vertrauensbruches', der zudem noch bei völlig ungeklärtem Tatbestand erhoben wird, als sehr verletzend. Er weist ihn entschieden zurück. Schröder.“289

Der Außenminister blieb jedoch bei seiner auf Ausgleich bedachten Linie ${ }^{290}$. Er wollte nicht zu einem Zeitpunkt, da die Bundesrepublik den Rückhalt ihres wichtigsten Verbündeten dringend bedurfte, die Atmosphäre durch den Austausch gegenseitiger Anschuldigungen vergiften. Entgegen dem Willen Adenauers berichtete er am 19. April 1962 dem Auswärtigen Ausschuß über den Stand der Beratungen $^{291}$. Er wies dabei „energisch und emotional“292 die Kritik Freiherr von und zu Guttenbergs und anderer Abgeordneter der Unionsfraktion zurück, er habe die

284 Vgl. den Artikel „An Eides Statt“, in: Der SPIEgEL vom 25. 4. 1962, S. 15-17. Auch HansPeter Schwarz vermutet, die Presse hätte den Inhalt der Papiere "nach der Mosaikmethode rekonstruiert". Vgl. SCHWARZ, Adenauer II, S. 745.

285 Vgl. FRUS 1961-1963, XV, S. 112, Anm. 1.

286 Vgl. die Aufzeichnung Adenauers vom 24. 4. 1962, in: KOERFER, Kampf ums Kanzleramt,

S. 640. Vgl. ferner Adenauers Gespräch mit Joseph Alsop am 11. 5. 1962, in: ADENAUER, Teegespräche 1961-1963, S. 184.

287 Zitiert nach KOERFER, Kampf ums Kanzleramt, S. 638.

288 ADENAUER, Teegespräche 1961-1963, S. 184.

289 Zitiert nach KOERFER, Kampf ums Kanzleramt, S. 638.

$290 \mathrm{Vgl}$. GrEwe, Rückblenden, S. 552.

291 Vgl. die Aufzeichnung Adenauers vom 24. 4. 1962, in: KOERFER, Kampf ums Kanzleramt, S. 641 .

292 Vgl. das nicht näher datierte Schreiben Hecks an Krone vom April 1962, ACDP, Nachlaß Krone I-028-031/1. 
Interessen der Bundesrepublik gegenüber den Amerikanern nicht entschieden genug vertreten, und wiederholte seine Ansicht, es bestehe kein Anlaß, sich über die Pläne der Kennedy-Regierung aufzuregen: „Das Verhandlungskonzept der Amerikaner enthält im Grunde nichts Neues. Es trägt lediglich der realen Lage Rechnung. " Der Außenminister erweckte den Eindruck, als ob weiterhin Einigkeit in der Behandlung der Berlin-Frage zwischen Bonn und Washington bestünde und empfahl, den amerikanischen Vorschlägen zuzustimmen. Daß die USA die Gespräche mit Moskau nicht länger auf Berlin beschränken wollten, hielt er nicht für gravierend: Zum einen sei es „keineswegs etwas Neues, daß nicht nur über Berlin verhandelt werde", zum anderen sei ein Zusammenhang von Abrüstungsfragen mit der Lösung des Berlin-Problems geradezu „zwangsläufig“. Schröder wies die Abgeordneten zudem darauf hin, daß es sich bei den amerikanischen Papieren nicht um einen Vertragsentwurf handeln würde, sondern bloß um ein Bündel von Gesprächsvorschlägen. Es gebe deshalb keinen Grund, den USA zu mißtrauen ${ }^{293}$.

In den Reihen von SPD und FDP fand der Außenminister Zuspruch. Mende wie auch Brandt teilten Schröders Standpunkt ${ }^{294}$. Die Sozialdemokraten befürchteten weiterhin, Chruschtschow könnte einen Separatvertrag mit der DDR abschließen und eine neue Blockade Berlins durchführen, wenn der Westen Verhandlungen verweigerte. Der FDP-Vorsitzende teilte diese Einschätzung: „Besser einen Modus vivendi statt einen Casus belli." ${ }^{295}$ Die Freien Demokraten waren sowieso entschlossen, Schröder Unterstützung zu gewähren, weil er bislang nicht als außenpolitischer Dogmatiker aufgetreten war. Sie hofften, mit seiner Hilfe Modifikationen am Kurs der Bundesregierung vornehmen zu können, die sie vor allem in der Deutschland-Politik für unumgänglich hielten ${ }^{296}$. So kam es zu der merkwürdigen Situation, daß SPD und FDP einem Außenminister der CDU für eine Politik Rückendeckung gaben, die von den Abgeordneten seiner eigenen Partei mehrheitlich abgelehnt wurde ${ }^{297}$.

In vielen Punkten zeigte sich der Außenminister indessen gar nicht so kompromißbereit, wie manche Sozialdemokraten und Liberale sich dies vielleicht wünschten. Schröder stimmte der amerikanischen Linie zu, weil er zum Bündnis mit Washington keine Alternative sah: „Wissen Sie eine andere Schutzmacht für uns als die USA?", fragte er in diesen Tagen die Kritiker Kennedys ${ }^{298}$. Dies hinderte ihn nicht, in Einzelfragen eine andere Meinung als die amerikanische Regierung zu vertreten. Seine Taktik des ,Ja, aber... "läßt sich auch an weiteren Punk-

293 Vgl. den Vermerk über die Sitzung des Auswärtigen Ausschusses am 19. 4. 1962, ACDP, Nachlaß Krone I-028-031/1.

294 Vgl. das nicht näher datierte Schreiben Hecks an Krone vom April 1962, ACDP, Nachlaß Krone I-028-031/1.

295 Zitiert nach dem Artikel „An Eides Statt“, in: Der SPIEgEL vom 25. 4. 1962, S. 16.

296 Vgl. das Protokoll der FDP-Bundesvorstandssitzung am 5. 5. 1962, in: FDP-BundeSVORSTAND, S. 316 und S. 320.

297 Vgl. das nicht näher datierte Schreiben Hecks an Krone vom April 1962, ACDP, Nachlaß Krone I-028-031/1.

298 Zitiert nach dem Artikel „Sanfte Kuratel“, in: Der SPIEGEL vom 30. 5. 1962, S. 23. Zu Hermann Höcherl meinte Schröder: „Wer kann uns helfen? Nur die Amerikaner!“ Zitiert nach KOERFER, Kampf ums Kanzleramt, S. 638. 
ten seines Vortrags im Auswärtigen Ausschuß erkennen. Schröder unterstrich gegenüber den Abgeordneten erneut, die Frage der deutschen Ostgrenze müsse "unter allen Umständen“ aus den sowjetisch-amerikanischen Gesprächen herausgehalten werden. Auch dürfe der geplante Austausch von Nichtangriffserklärungen nicht zu einer offiziellen Anerkennung des Status quo in Europa und damit der Spaltung Deutschlands führen. Der Außenminister lehnte zudem eine innerdeutsche Kommission zur Vorbereitung gesamtdeutscher Wahlen in der Form ab, wie sie das amerikanische Verhandlungspapier vorsah. Ihr Auftrag sei „viel zu verschwommen formuliert", betonte er. Außerdem sei nicht klar genug ersichtlich, daß der Ausschuß unter dem Dach der Vier Mächte tätig sein sollte. Dasselbe gelte auch für die Zugangsbehörde. Auch hier, so Schröder, müßte sichergestellt sein, daß an der Spitze des Gremiums die Vier Mächte stünden und diese auch allein die Verantwortung für seine Tätigkeit trügen. Eine Aufnahme deutscher Stellen, sei es Bundesrepublik, DDR, Berlin (West) oder Ost-Berlin, lehnte er ab, weil dies wie eine Gleichstellung der beiden Teile Deutschlands wirke und als Bestätigung der sowjetischen These aufgefaßt werden könnte, Berlin sei ein eigenständiges Völkerrechtssubjekt. Allenfalls, so der Minister, sei eine Einbindung der DDR „im technischen Unterbau" der Behörde vorstellbar ${ }^{299}$. Gegenüber den Amerikanern gab sich Schröder aber wieder weitaus zurückhaltender. Als er am 27. April mit Dowling zusammentraf, wiederholte er zwar noch einmal die Einwände, die er diesem drei Tage zuvor durch Carstens übermitteln hatte lassen, doch akzeptierte er den Vorschlag, die amerikanische Regierung würde, falls es zu einem Abschluß mit der Sowjetunion käme, einseitige Erklärungen abgeben, in denen die Kontinuität der westlichen Deutschland-Politik bekräftigt werde ${ }^{300}$. Schröder bekräftigte, er stehe weiter hinter den Grundsätzen einer Berlin-Regelung, wie sie ihm von Rusk in Lausanne dargelegt worden sei, allerdings sei der Entwurf der USA „zu kompromißfreudig“. Er bat, der sowjetischen Regierung vorläufig kein Verhandlungspapier zu übergeben. Dies sagte der amerikanische Botschafter schließlich zu301. Die Strategie des Außenministers war also eindeutig: Er brachte konkrete Vorbehalte gegenüber einzelnen Punkten vor, erklärte sich aber prinzipiell mit den Verhandlungsrichtlinien der Amerikaner einverstanden.

Adenauer wollte dagegen den USA nicht freie Hand lassen. Der Inhalt des Verhandlungspakets war für ihn der Beweis, daß sein Argwohn gegenüber Washington mehr als berechtigt war. In einer Aufzeichnung, die er am 20. April 1962 in seinem Urlaubsdomizil in Cadenabbia anfertigte, kam der Kanzler zu dem Schluß, Kennedy habe eine entscheidende Richtungsänderung in der amerikanischen Deutschland- und Berlin-Politik vollzogen. Für Adenauer stand fest, die Amerikaner klagten Bonn bewußt der Indiskretion an, „um unter dem Vorwurf

299 Vgl. den Vermerk über die Sitzung des Auswärtigen Ausschusses am 19. 4. 1962, ACDP, Nachlaß Krone I-028-031/1. Freiherr von und zu Guttenberg, der Schröder zunächst heftig kritisiert hatte, war in den hier referierten Punkten einer Meinung mit Schröder. Vgl. ebenda.

300 Vgl. FRUS 1961-1963, XV, S. 119, Anm. 1, und S. 120, Anm. 4.

301 Vgl. den Drahterlaß des Staatssekretärs Carstens an Botschafter Grewe, Washington, vom 27. 4. 1962, PA/AA, B 150, Aktenkopien 1962. 
mangelnder Vertrauenswürdigkeit eine Politik zu machen, die wir nicht billigen können". Die Konsultation der Bundesregierung sei mangelhaft gewesen; so habe Rusk das Auswärtige Amt nicht vollständig informiert. „Das alles (Methode, materieller Gehalt) zeigt, daß USA sachlich von dem Kurs Eisenhower/Dulles abgeht", stellte der Kanzler fest ${ }^{302}$. Das amerikanische Verhalten sowie die Turbulenzen zwischen den sechs EWG-Mitgliedstaaten um die Bildung einer Politischen Union - auf die später noch einzugehen sein wird - brachten ihn zu dem Entschluß, künftig auf einen „Block Frankreich und Deutschland“ zu setzen ${ }^{303}$. Aufgrund der historischen Belastung Deutschlands sollte dabei die „Führung in

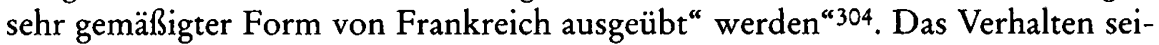
nes Außenministers verärgerte den Kanzler über alle Maßen: „Herr Schröder [...] betont in der Presse ausdrücklich hundertprozentiges Vertrauen zu der Verhandlungsführung der Amerikaner. Das ist einfach nicht richtig und nicht geeignet, Eindruck auf die Amerikaner zu machen." Er hielt hingegen an seiner Meinung fest, man sollte offen gegen die Pläne Kennedys protestieren. Schröder warf er vor, er hätte sich „von Anfang an“ nicht geschickt genug verhalten und gegenüber Rusk „zu sehr immer den treuen Gefangenen gespielt “305.

Angesichts dieser konträren Auffassungen stand das Treffen zwischen Adenauer und und Schröder am 30. April 1962 in Cadenabbia, in dem das weitere Verhalten der Bundesrepublik gegenüber den USA im Hinblick auf die Anfang Mai stattfindende Tagung des NATO-Ministerrats in Athen festgelegt werden sollte, unter keinem guten Stern. In der Tat führte die Besprechung, an der auch Krone, Globke, Carstens und Lahr sowie der Persönliche Referent des Kanzlers, Heinrich Barth, teilnahmen, nicht zu einer Annäherung der Standpunkte. Erneut verlangte Adenauer vom Auswärtigen Amt, den Vorwurf der Indiskretion entschieden zurückzuweisen und gegen die Behandlung Grewes zu protestieren. Er erklärte, daß der in dem amerikanischen Verhandlungsvorschlag erwähnte Nonproliferationsvertrag nicht hingenommen werden dürfe, weil er die Bundesrepublik diskriminiere. Wiederum sprach er sich gegen die Schaffung einer internationalen Zugangsbehörde für den Berlin-Verkehr aus. Eine derartige Aufwertung Ost-Berlins dürfe man nicht zulassen! Die Bundesregierung solle deshalb die Pläne ablehnen und die amerikanische Regierung an ihre Verpflichtung erinnern, sich für die Wiedervereinigung einzusetzen. Konzessionen an den Kreml, so Adenauer, könnten erst dann ins Auge gefaßt werden, wenn die Lebensbedingungen der Menschen in der DDR verbessert worden wären ${ }^{306}$. Um die Position Bonn gegenüber dem amerikanischen Verbündeten zu stärken, kündigte er an, er werde jetzt die deutsch-französische Karte „groß ausspielen“. Schröder entfuhr die spöttische Bemerkung „Was, dieses Kärtchen?“, worauf der Kanzler erzürnt die Besprechung unterbrach ${ }^{307}$. Aber selbst

302 Zitiert nach SCHWARZ, Adenauer II, S. 746.

303 Vgl. die Aufzeichnung Adenauers vom 24. 4. 1962, in: KOERFER, Kampf ums Kanzleramt, S. 641 .

304 So Adenauer am 7. 5. 62 zu Lucius D. Clay. Zitiert nach SCHWARZ, Adenauer II, S. 747.

305 Vgl. die Aufzeichnung Adenauers vom 24. 4. 1962, in: KOERFER, Kampf ums Kanzleramt, S. 641.

306 Vgl. OSTERHELD, „Ich gehe nicht leichten Herzens ...“, S. 110.

307 SCHRÖDER, "Je weiter östlich, desto besser". Vgl. auch LAHR, Zeuge, S. 360. 
Osterheld, der die überspitzten Aussagen Adenauers zunächst auf seine Verärgerung über die amerikanische Politik zurückführte, versuchte den Kanzler von seinem Vorhaben abzubringen. Doch dieser ließ sich nicht beirren. Adenauer war willens, die langjährigen guten Beziehungen zu den Vereinigten Staaten aufs Spiel zu setzen. Am Ende der Besprechung gab er seinem Außenminister die Anweisung, in Athen die Zugangsbehörde ohne Wenn und Aber abzulehnen und drohte ihm: „Wenn Sie meinen Richtlinien nicht folgen, dann werde ich Sie [...] desavouieren. “308 Das Tischtuch zwischen den beiden Männern war damit zerschnitten. Nachdem der Außenminister Cadenabbia bereits wieder verlassen hatte, ereiferte sich der Kanzler immer noch über ihn: „Der Herr Schröder wirkt manchmal in seinem Urteil stark gebremst", hörten seine Mitarbeiter ${ }^{309}$.

\section{Von der NATO-Ministerratstagung in Athen bis zur Kuba-Krise}

Spätestens ab Mitte April 1962 bot die Berlin-Politik der Bundesregierung ein uneinheitliches Bild. Während Adenauer für strikte Opposition gegen die Verhandlungsvorschläge der USA eintrat, bemühte sich Schröder um Einvernehmen mit dem amerikanischen Bündnispartner. Nach dem vergeblichen Versuch in Cadenabbia, sich mit dem Kanzler über die weitere Vorgehensweise zu einigen, reiste der Außenminister zur Ministerratstagung der NATO, die vom 4. bis 6. Mai 1962 in Athen stattfand. Er war nach wie vor davon überzeugt, daß das Verhältnis zu den Vereinigten Staaten nicht weiteren Belastungen ausgesetzt werden durfte. Aus diesem Grund mißachtete er die Weisung Adenauers und protestierte nicht gegen die Behandlung Grewes durch die amerikanische Regierung, sondern teilte Rusk am 3. Mai in der griechischen Hauptstadt mit, im Zuge einer allgemeinen personellen Neubesetzung an den diplomatischen Vertretungen werde es auch einen Wechsel an der Spitze der Botschaft in Washington geben. Er ersuchte seinen amerikanischen Kollegen, Grewe bis dahin wieder in den Informationsfluß einzubinden. Erneut entschuldigte er sich, daß die Geheimhaltung des Verhandlungspakets nicht gewahrt wurde. Was die Auseinandersetzung um die amerikanischen Pläne betraf, unterstrich Schröder, seine Haltung werde von der FDP, der SPD sowie einer großen Mehrheit der Union geteilt. Lediglich ein kleiner Teil seiner Parteifreunde werfe ihm vor, er habe Konzessionen zugestimmt. Dazu würde aber für die Kritiker selbst eine Nichtangriffsvereinbarung zählen, beschwerte sich Schröder, bat aber die Amerikaner, nicht länger zu behaupten, er habe bestimmten Punkten des ins Auge gefaßten Arrangements mit der UdSSR zugestimmt. Rusk beteuerte im Gegenzug, eine amerikanisch-sowjetische Abmachung über Berlin werde es nur geben, wenn Bonn sie ausdrücklich billige. Differenzen gab es aber hinsichtlich der geplanten innerdeutschen Kommissionen. Während der amerikanische Außenminister mit Blick auf den regen Interzonenhandel der Auffassung war, die Bundesrepublik verhalte sich gegenüber der DDR "wie jemand, der nachts mit einem Mädchen schlafe, sie aber am Tage nicht grüße, wenn er sie träfe“, erklärte Schröder, es müsse eindeutig zwischen technischen Kontakten, die 
akzeptabel seien, und politischen Gesprächen unterschieden werden, die zur Konsequenz hätten, „daß das Regime in der Zone in seinem Prestige gestärkt würde und die Unterdrückungspolitik gegenüber der Bevölkerung um so ungehemmter würde fortsetzen können “. Rusk vertrat hingegen den Standpunkt, derartige Gespräche würden zu einer Schwächung der SED-Herrschaft führen. Schröder konterte darauf, den Amerikanern fehle die Erfahrung mit totalitären Regimen. Engere Beziehungen seien allerdings vorstellbar, sobald in der DDR ein weniger repressives Regime als das jetzige das Ruder übernehme. Auch eine Annäherung an die osteuropäischen Staaten, insbesondere Polen, sei dann möglich, führte der Bundesminister aus. Sein Gesprächspartner hielt dies aber schon zum jetzigen Zeitpunkt für erforderlich. Er wies darauf hin, daß ein Ausbau der Kontakte zu den Ostblock-Staaten sowjetische Kräfte binden würde, da der Kreml gezwungen wäre, die Anstrengungen zu verstärken, in seinem Satellitengürtel die Ordnung aufrechtzuerhalten. Beide Politiker stimmten schließlich darin überein, die Gespräche mit Moskau fortzusetzen ${ }^{310}$. Bei dem anschließenden Treffen mit ihren britischen und französischen Kollegen stellte Schröder jedoch erneut klar, daß er eine Übergabe des amerikanischen Vorschlagspapiers an Dobrynin - auch in einer überarbeiteten Form - entschieden ablehne. Couve de Murville unterstützte ihn, während Lord Home für die Aushändigung plädierte ${ }^{311}$. In den folgenden zwei Tagen berieten Carstens und Kohler über die weitere Vorgehensweise. Sie einigten sich darauf, den Meinungsaustausch über das amerikanische Verhandlungspaket fortzusetzen, sobald der Kanzler den Inhalt nochmals einer genaueren Prüfung unterzogen hatte ${ }^{312}$.

In seiner Rede vor dem NATO-Ministerrat warnte Schröder indes eindringlich davor, der UdSSR überstürzt nachzugeben: „Wir sollten uns hüten, unsere eigenen Positionen vorzeitig und allzu leicht zu ändern, während die Sowjets ständig nur die alten Forderungen stereotyp wiederholen. " $313 \mathrm{Er}$ zählte noch einmal die Bonner essentials auf, die im Zuge einer Regelung der Berlin-Frage unbedingt zu berücksichtigen seien. Schröder ließ keinen Zweifel daran, daß die Bundesregierung auf der Aufrechterhaltung der Präsenz Frankreichs, Großbritanniens und der USA in Berlin, des freien Zugangs in die Stadt sowie der Bindungen von Berlin (West) an die Bundesrepublik bestehe ${ }^{314}$. Die letztere Bedingung wurde anschließend von den NATO-Partnern als viertes westliches essential übernommen. ${ }^{315}$ Der Außenminister verlangte zudem, wenn überhaupt, dürfe nur ein provisorisches Berlin-Abkommen geschlossen werden. Eine endgültige Regelung

310 Aufzeichnung des Staatssekretärs Carstens, z.Z. Athen, vom 3. 5. 1962, PA/AA, B 150, Aktenkopien 1962. Vgl. auch FRUS 1961-1963, XV, Dok. 45, S. 132-136; sowie den Drahtbericht des Bundesministers Schröder, z.Z. Athen, an Bundeskanzler Adenauer vom 4. 5. 1962, PA/AA, B 150, Aktenkopien 1962.

311 Vgl. FRUS 1961-1963, XV, Dok. 45, S. 136, Anm. 5.

312 Ebenda.

313 Zitiert nach dem Artikel „Die NATO-Tagung in Athen“, in: NEUE ZÜrCHER ZEITUNG, Fernausgabe vom 6. 5. 1962, Blatt 2, bzw. DzD IV/8, S. 483, Anm. 1.

314 Vgl. den Artikel „Berlin beherrscht die NATO-Tagung in Athen“, in: FrankfurTER Allgemeine ZeITUNG vom 5. 5. 1962, S. 1 und S. 4.

315 Vgl. CARSTENS, Erinnerungen, S. 291. 
über den Status der Stadt sei erst im Rahmen der Wiedervereinigung Deutschlands möglich ${ }^{316}$. Ausdrücklich stimmte er dem Konzept einer Zugangsbehörde zu, empfahl aber, bei der Umsetzung des Planes vorsichtig zu agieren. So müßte gewährleistet sein, daß die UdSSR mittels einer Blockadepolitik das Gremium nicht an der Erfüllung seine Aufgaben hindern könne ${ }^{317}$. Ferner sei zu vermeiden, zu viele Punkte, die Bestandteil eines Friedensvertrages sein sollten, in eine BerlinVereinbarung aufzunehmen, um nicht auf diese Weise einen Beitrag zur Konsolidierung der DDR zu leisten ${ }^{318}$. Gegen einen Nichtangriffspakt mit dem Osten erhob er keine Einwände ${ }^{319}$, obwohl er der Ansicht war, eine derartige Vereinbarung wäre nicht notwendig, wenn die Warschauer-Pakt-Staaten dem Beispiel der Bundesrepublik folgen und von sich aus einseitige Gewaltverzichtserklärungen abgeben würden 320 .

Es schien, als hätten sich in Athen die Bundesrepublik und die USA wieder auf eine gemeinsame Position verständigt. In der FAZ stellte Adalbert Weinstein am 7. Mai fest, die Differenzen zwischen Bonn und Washington seien nun beigelegt ${ }^{321}$. Doch noch am gleichen Tag zeigte sich, daß die Einschätzung des verteidigungspolitischen Experten falsch war. Da Schröder die Anordnungen Adenauers nicht befolgt hatte, machte der Kanzler seine Ankündigung wahr und stellte öffentlich die soeben von seinem Außenminister getroffenen Abmachungen wieder in Frage. Auf einer Pressekonferenz in Berlin brachte er in drastischen Worten seinen Unmut über die USA zum Ausdruck ${ }^{322}$. Nach der Einschätzung Osterhelds war Adenauer felsenfest davon überzeugt gewesen, daß die geteilte Stadt über kurz oder lang vollständig in sowjetische Hände geraten würde, wenn es auf der Basis der amerikanischen Vorschläge zu einem Abschluß mit dem Kreml käme. Daher wollte er um jeden Preis eine Einigung verhindern ${ }^{323}$. Folglich gab Adenauer den Journalisten zu Protokoll, daß er der Idee einer Zugangsbehörde für

316 Vgl. den Artikel „Berlin beherrscht die NATO-Tagung in Athen“, in: FRANKFURTER Allgemeine Zeitung vom 5. 5. 1962, S. 1 und S. 4.

317 Vgl. den Artikel „Die NATO-Tagung in Athen“, in: NeUE ZÜrChER ZeITUNG, Fernausgabe vom 6. 5. 1962, Blatt 2, bzw. DzD IV/8, S. 483, Anm. 1.

318 Vgl. den Artikel „Schröder vor der NATO-Konferenz: Endgültige Regelung in Berlin nicht ohne deutsche Einheit", in: DIE WELT vom 5. 5. 1962, S. 1 und S. 4.

319 Vgl. den Artikel „Berlin beherrscht die NATO-Tagung in Athen“, in: FranKfuRTER Allgemeine Zeitung vom 5. 5. 1962, S. 1 und S. 4.

320 Vgl. das Schreiben Schröders an die CDU-Bundestagsabgeordnete Margot Kalinke vom 29. 5. 1962, PA/AA, Büro Staatssekretär, Bd. 76. Die Bundesrepublik hatte sich in der Schlußakte der Londoner Neun-Mächte-Konferenz am 3. 10. 1954 verpflichtet, „ihre Politik in Übereinstimmung mit den Grundsätzen der Satzung der Vereinten Nationen zu gestalten“. Insbesondere sicherte sie zu, „die Wiedervereinigung Deutschlands oder die Ânderung der gegenwärtigen Grenzen der Bundesrepublik Deutschland niemals mit gewaltsamen Mitteln herbeizuführen und alle zwischen der Bundesrepublik und anderen Staaten gegebenenfalls entstehenden Streitfragen mit friedlichen Mitteln zu lösen“. Vgl. EUROPA-ARCHIV 1954, S. 6981. Die Erklärung wurde Bestandteil der Pariser Verträge vom 23. 10. 1954. Vgl. EUROPA-ARCHIV 1954, S. 7138.

321 Vgl. den Kommentar von Adalbert Weinstein: „Die Athener Konferenz“, in: FrankfuRTER AllgemeINe ZeITUNG vom 7. 5. 1962, S. 1.

322 Vgl. DzD IV/8, S. 486-488.

323 ZEITZEUGENBEFRAGUNG Osterheld. 
Berlin nichts abgewinnen könne. Der Vorschlag sei „undurchführbar“. Seine Ausführungen gipfelten in der Prophezeiung, die Verhandlungen zwischen den USA und der UdSSR seien von vornherein zum Scheitern verurteilt: „Ich habe nicht die Überzeugung, ja, ich habe nicht einmal die leiseste Meinung, daß es zu einem Ergebnis kommen wird." 324 Grewe nannte dies „die schärfste öffentliche Distanzierung von der amerikanischen Politik [...], die man bis dahin von einem deutschen Regierungschef erlebt hatte, und für die es auch später kein vergleichbares Beispiel mehr gegeben hat" ${ }^{325}$. Vergeblich bemühten sich Schröder und Carstens den Schaden in Grenzen zu halten, indem sie gegenüber Dowling ihr Bedauern zum Ausdruck brachten und die Aussagen Adenauers zu entschärfen suchten. Sie erklärten, daß der Kanzler weder seine Unzufriedenheit mit der amerikanischen Politik ausdrücken, noch auf eine generelle Meinungsverschiedenheit zwischen Bonn und Washington anspielen wollte ${ }^{326}$. Auch dem britischen Botschafter in Bonn, Christopher Steel, wurde mitgeteilt, die Presse habe die Äußerungen verzerrt dargestellt; Adenauer habe in Wirklichkeit die Athener Absprachen „sehr positiv bewertet “ ${ }^{327}$. Dem Pressesprecher Kennedys, Pierre Salinger, versicherte Schröder, Bonn sei nicht gegen Verhandlungen mit der Sowjetunion. Auch habe die Bundesregierung bislang den Plan einer Zugangsbehörde nicht prinzipiell abgelehnt. Sie sei jedoch der Ansicht, daß die Kommission anders konstruiert sein müsse. An ihrer Spitze habe ein Rat der Vier-Mächte zu stehen, der die Behörde leite. Außerdem dürfe die DDR nur „auf einem niedrigeren technischen Niveau“ einbezogen werden 328 .

Die Amerikaner waren über die erneute Obstruktion ihrer Verständigungsbemühungen zutiefst verärgert. Kennedy war nicht länger gewillt, das Verhalten Adenauers hinzunehmen. Im Rahmen einer Pressekonferenz am 9. Mai griff er erstmals öffentlich die Bundesregierung an. Er verlangte, Kritik an den amerikanischen Vorschlägen intern zu äußern, anstatt den Weg über die Öffentlichkeit zu suchen. Der Präsident bemerkte, man mache es sich zu einfach, wenn man stets nur widerspräche; er sei durchaus bereit zur Diskussion, wolle aber konstruktive Alternativen hören. Abschließend bekräftigte er, daß die in Athen festgelegte Politik fortgesetzt werde ${ }^{329}$. Die Geduld der amerikanischen Regierung mit dem deutschen Verbündeten war erschöpft. Am 12. Mai erteilte Rusk Botschafter Dowling die Weisung, beim Kanzler vorzusprechen und ihm zu erläutern, daß er nach der NATO-Tagung in Athen geglaubt habe, alle Meinungsverschiedenheiten seien ausgeräumt. Die USA würden nun „über die üblichen diplomatischen Kanäle" die endgültige Antwort Bonns auf das amerikanische Vorschlagspaket er-

324 Vgl. DzD IV/8, S. 487. Vgl. auch die Ausführungen Adenauers gegenüber Joseph Alsop am 11. 5. 1962, in: ADENAUER, Teegespräche 1961-1963, S. 176.

325 GREWE, Rückblenden, S. 555.

326 Vgl. FRUS 1961-1963, XV, Dok. 47, S. $140 \mathrm{f}$.

327 Gespräch des Bundesministers Schröder mit dem britischen Botschafter Christopher Steel am 9. 5. 1962, PA/AA, Ministerbüro, Bd. 242.

328 Gespräch des Bundesministers Schröder mit dem Pressesekretär des amerikanischen Präsidenten, Pierre Salinger, am 9. 5. 1962, PA/AA, Ministerbüro, Bd. 242.Vgl. ferner SALINGER, Mit J.F. Kennedy, S. 283.

329 Vgl. Public PAPERS, Kennedy 1962, S. 382. Vgl. ferner Grewe, Rückblenden, S. 555. 
warten. Dowling sollte zudem vorbringen, Kennedy könne es angesichts der zahlreichen Probleme, mit denen er sich auseinanderzusetzen habe, nur noch mit Humor aufnehmen, wenn er ständig hören müßte, John Foster Dulles habe eine bessere Politik betrieben. Der Präsident habe kein Verständnis für Zweifel an der amerikanischen Haltung und auch nicht für die Auffassung, daß die Hoffnung der Bundesrepublik auf de Gaulle ruhe. Rusk trug dem Botschafter weiter auf, Adenauer vor Augen zu führen, daß die Worte des französischen Staatspräsidenten nicht seinen Taten entsprächen, was schon allein daran zu erkennen sei, daß lediglich zwei französische Divisionen in der Bundesrepublik stationiert seien. Nicht die französische Rhetorik würde auf die UdSSR Eindruck machen, sondern die entschlossene Haltung der Vereinigten Staaten! Gerade der Kanzler, der sich stets Gedanken mache, wie der kommunistischen Expansion ein Riegel vorgeschoben werden könne, sollte deshalb verstehen, daß seine Kritik „destruktiv“ sei. Ferner wurde Dowling aufgetragen, noch einmal darauf hinzuweisen, daß zu jedem Zeitpunkt eine umfangreiche und vollständige Konsultation Bonns stattgefunden habe. Wenn Adenauer nun über die Entwicklung der amerikanischen Berlin-Politik überrascht sei, müsse dies daran liegen, daß er keine umfassende Kenntnis von der Arbeit seiner eigenen Regierung habe ${ }^{330}$.

Während die harte Linie des Kanzlers wenig Rückhalt in Bonn fand, wurde Schröders Verständigungskurs von Abgeordneten aus allen Fraktionen unterstützt ${ }^{331}$. Trotz der lautstarken Kritik an seinem Verhalten war Adenauer allerdings zunächst nicht zu der Einsicht zu bewegen, er habe nun den Bogen überspannt. Am 10. Mai 1962 führte er vor dem Bundesvorstand der CDU aus, es sei „eine gewisse Differenz zwischen den Vereinigten Staaten und uns vorhanden“. Adenauer erinnerte an die Vorgänge im April und eröffnete seinen Parteifreunden, er könne sich den Vorwurf, die Bundesregierung habe Vertrauensbruch begangen, nicht gefallen lassen ${ }^{332}$. Am folgenden Tag bekräftigte er gegenüber dem amerikanischen Journalisten Alsop seine Forderung, die USA sollten den Gedanken einer Zugangsbehörde für Berlin fallen lassen und ihre Strategie überdenken, monatelang ergebnislose Verhandlungen mit Moskau zu führen 333 .

Doch als am 14. Mai die Unterredung zwischen dem Kanzler und dem amerikanischen Botschafter stattfand, kam es nicht zu dem befürchteten Eklat. Offenbar erkannte Adenauer, daß es vernünftiger war, nicht zu einer weiteren Eskalation beizutragen, sondern zurückzustecken und die Wogen wieder zu glätten. Dowling berichtete jedenfalls später dem State Department, das Gespräch sei von der Bemühung Adenauers geprägt gewesen, die Spannungen zu entschärfen. Ausdrücklich habe er der Fortsetzung der amerikanisch-sowjetischen Gespräche zugestimmt und seinen Willen bekundet, die Anstrengungen zu verstärken, um auch

330 Vgl. FRUS 1961-1963, XV, Dok. 49, S. 142-145 (144).

331 Vgl. den Artikel „Schröder vor Parlamentsausschuß: Bonn für Sondierungsgespräche“, in: DIE WELT vom 11. 5. 1962, S. 2. So stellte sich beispielsweise der Bundesvorstand der FDP am 5. 5. 1962 demonstrativ hinter Schröder. Vgl. das Protokoll der FDP-Bundesvorstandssitzung am 5. 5. 1962, in: FDP-BUNDESVORSTAND, S. 320.

332 Protokoll der CDU-Bundesvorstandssitzung am 10.5. 1962, ACDP VII-001-011/3, bzw. PROTOKOLLE DES CDU-BundesVORSTANDS, S. 203.

333 Vgl. AdENAUER, Teegespräche 1961-1963, S. 177. 
Frankreich in die westliche Politik einzubinden. Obwohl der Bundeskanzler seine Bedenken gegen die Zugangsbehörde, den geplanten Nichtangriffspakt zwischen NATO und dem Warschauer Pakt sowie ein Nonproliferationsabkommen vorgebracht hatte, konstatierte Dowling eine prinzipielle Übereinstimmung Adenauers mit der amerikanischen Berlin-Politik und berichtete, dieser sei zu einer konstruktiven Zusammenarbeit mit den USA bereit ${ }^{334}$. Der Kanzler erklärte nach diesem Gespräch gleichfalls, alle Probleme seien aus der Welt geschafft; sein Verhältnis zu Kennedy sei wieder so gut wie nach dem Besuch in Washington im November $1961^{335}$. Freilich, selbst der optimistische Dowling bezweifelte, daß der Widerstand Adenauers endgültig gebrochen sei. Angesichts des bevorstehenden Staatsbesuchs des Kanzlers in Frankreich, schlug der Diplomat seiner Regierung vor, diesen umgehend nach Washington einzuladen, um so die Gefahr zu bannen, $\mathrm{da}$ er unter dem Einfluß de Gaulles seine Meinung erneut ändern würde. Zudem empfahl er, von Washington aus auf Brentano einzuwirken, da dieser den Kanzler aufgewiegelt habe. Schröder und Carstens, die auf der Seite der Vereinigten Staaten stünden, könnten im Moment nicht zu einer Stärkung der amerikanischen Position in Bonn beitragen, da beide im Moment in den Bannstrahl Adenauers geraten $\operatorname{seien}^{336}$.

Grund für den fortdauernden Mißmut des Kanzlers war wohl, daß der Außenminister nicht nur gegenüber dem amerikanischen Botschafter, sondern auch in der Öffentlichkeit zu erkennen gegeben hatte, daß er Adenauers Mißtrauen gegenüber den Vereinigten Staaten nicht teilte ${ }^{337}$. Beachtenswert sind vor allem seine Ausführungen am 7. und 8. Mai 1962 vor der CDU/CSU-Bundestagsfraktion bzw. dem Fraktionsvorstand, da er dort erstmals die Motive für seine Haltung offenlegte: Schröder brachte vor den Parlamentariern seine Befürchtung zum Ausdruck, daß die USA auf die Wünsche Bonns keine Rücksicht nehmen und auch ihr Interesse, sich für die Sicherheit Berlins einzusetzen, nachlassen könnte, falls die Bundesregierung den Versuch unternähme, die amerikanischen Verständigungsbemühungen zu hintertreiben. Er sah für die Bundesrepublik „die größte Gefahr“ heraufziehen, „wenn man sich auch ohne die Deutschen arrangieren würde“. Der Außenminister war überzeugt: „Das Schicksal Berlins hänge daran, daß die Amerikaner mit ihrem ganzen Engagement in Berlin bleiben." Es müsse deshalb alles unternommen werden, um einen Rückzug der USA zu verhindern. Die Bundesregierung dürfe daher nicht gegen die amerikanische Politik opponieren, sondern

334 Vgl. FRUS 1961-1963, XV, Dok. 50, S. 145-148.

335 Vgl. das Protokoll der CDU/CSU-Fraktionssitzung am 15. 5. 1962, ACDP VIII-001$1009 / 1$.

336 Vgl. FRUS 1961-1963, XV, Dok. 51, S. 148 f. Der Kanzler fragte Dowling auch, ob er den Eindruck habe, Schröder und Carstens würden sich gegenüber der amerikanischen Regierung weniger präzise als von Brentano äußern. Der Botschafter widersprach, gab aber zu, daß es im Falle des amerikanischen Vorschlagspakets ein „Mißverständnis“ gegeben hätte. Vgl. ebenda, Dok. 50, S. 147.

337 Vgl. die Artikel von Theo Sommer: „Schröders neue Sachlichkeit. Der Stil der deutschen Außenpolitik hat sich gewandelt“, in: DIE ZEIT vom 11. 5. 1962, S. 1, und Robert Strobel: „Auf Zick folgte Zack. Konrad Adenauer bekundete Linientreue“, in: DIE ZEIT vom 18. 5. 1962, S. 2. 
müsse diese unterstützen, zumal sich Washington zum Ziel gesetzt habe, den $\mathrm{Zu}$ gang nach Berlin sicherer zu machen. Schröder wies in diesem Zusammenhang darauf hin, daß die DDR in der Praxis bereits jetzt 95\% des Verkehrs nach Berlin (West) regelte. Sollte also eine Zugangsbehörde geschaffen werden, wäre dies sogar eine "großartige Verbesserung", da die ostdeutsche Kontrolle dann verschwinden würde. Den Abgeordneten versicherte er, die Bundesregierung werde unter keinen Umständen eine Zusammensetzung der Behörde in der jetzigen Form hinnehmen, sondern ihr Einverständnis nur unter der Bedingung geben, $\mathrm{da} ß$ an der Spitze der Behörde die Vier Mächte stünden. Ein prinzipielles Ja, so Schröder, bedeute im Grunde für die Bundesrepublik kein Risiko, da Moskau diesem Konzept sowieso nicht zustimmen werde - „aber das müsse man ja nicht breittreten“338. Da Bonn in aller Ruhe die Ablehnung der amerikanischen Pläne durch die Sowjetunion abwarten konnte, sah er keinen Anlaß, durch Fundamentalopposition die Beziehungen mit den Vereinigten Staaten unnötig zu belasten. Des weiteren erläuterte er der Fraktion, warum er nicht dagegen protestierte, daß die Amerikaner sich nicht länger an die vereinbarte Linie hielten, nur über das Berlin-Problem zu verhandeln. Nach seiner Auffassung konnte sich die Bundesrepublik einen Abbruch der Gespräche der beiden Supermächte nicht erlauben, da dies den Abschluß eines Separatfriedensvertrages zwischen der UdSSR und der DDR nach sich ziehe. Dies sei aber um jeden Preis zu verhindern, da Bonn dann gezwungen wäre, über den Zugang nach Berlin direkt mit Ulbricht zu verhandeln. Sollte sich die Bundesregierung in diesem Fall wegen ihrer Nichtanerkennungspolitik derartigen Gesprächen verweigern, hielt er eine Entwicklung für denkbar, die zu einer Blockade Berlins und damit sogar zur Gewaltanwendung führen könnte ${ }^{339}$. Einen militärischen Konflikt gelte es aber unter allen Umständen zu vermeiden 340 . Er plädierte deshalb dafür, auf den Verhandlungskurs der USA zu setzen und dabei die eigene Position geschickt zu wahren: „Ohne einen Millimeter nachzugeben, sollte man den Versuch machen, die Krise einzuschläfern. “ Dies, so der Außenminister, wäre seiner Ansicht nach „eine gesunde Linie der Außenpolitik“341.

Im Prinzip waren sich also Schröder und Adenauer über die Ziele der BerlinPolitik der Bundesrepublik einig. Beide wollten eine Regelung zu Lasten der Bundesrepublik vermeiden und strebten als Minimalziel an, den jetzigen Status der Stadt zu verteidigen. Der entscheidende Unterschied zwischen dem Kanzler und dem Außenminister war lediglich taktischer Natur. Das erkannte bereits Krone, der auf der Sitzung des CDU-Bundesvorstands am 2. Juni 1962 bemerkte, der Unterschied liege nicht „in der Sache, sondern nur in der Nuance“342. Adenauer

338 Protokoll der CDU/CSU-Fraktionssitzung am 8. 5. 1962, ACDP VIII-001-1009/1.

339 Vgl. ebenda. Vgl. auch das Protokoll der CDU/CSU-Fraktionsvorstandssitzung am 7. 5. 1962, ACDP VIII-001-1503/4.

340 Protokoll der CDU/CSU-Fraktionsvorstandssitzung am 7.5. 1962, ACDP VIII-0011503/4.

341 Protokoll der CDU/CSU-Fraktionssitzung am 8. 5. 1962, ACDP VIII-001-1009/1.

342 Protokoll der CDU-Bundesvorstandssitzung am 2. 6. 1962, in: PROTOKOLLE DES CDUBUNDESVORSTANDS, S. 276. So auch die Ansicht des damaligen Regierungssprechers von Hase (ZeITZEUGENBEFRAGUNG von Hase). 
war der Ansicht, die Amerikaner seien zu Konzessionen bereit, weshalb er versuchte, sie von ihrer prinzipiellen Verständigungsbereitschaft mit der UdSSR abzubringen, indem er immer wieder seine Kritik an den amerikanischen Plänen äußerte. Dies führte aber dazu, daß die USA der Bundesregierung vorwarfen, sie verlange von ihnen, das Risiko eines Krieges auf sich zu nehmen, ohne jedoch selbst einen Beitrag zur Entschärfung der Krise zu leisten. Schröder suchte diese Belastung der deutsch-amerikanischen Beziehungen, die sogar zu einer Isolierung der Bundesrepublik im Kreise ihrer Verbündeten führen konnte, zu vermeiden. Er erkannte, daß die Bundesregierung durch ihr Verhalten nur die Amerikaner gegen sich aufbrachte, aber nicht wirksam auf die Ausgestaltung der amerikanischen Verhandlungsvorschläge Einfluß nehmen konnte. Nach seiner Überzeugung würde die amerikanische Regierung die Vorstellungen Bonns in ihre Planungen einfließen lassen, sofern sie über die diplomatische Schiene und nicht in der Öffentlichkeit vorgetragen wurden. Der Außenminister spekulierte zudem darauf, daß Chruschtschow stets mehr verlangen werde, als Kennedy zu geben bereit war. Eine Einigung mit der UdSSR hielt er deswegen für äußerst unwahrscheinlich. Die Bundesregierung konnte folglich den Plänen Washingtons zustimmen, da sie kaum reale Gestalt annehmen würden. Sein Rezept zur Bewältigung der BerlinKrise lautete infolgedessen, die vertrauensvolle Zusammenarbeit mit den USA nicht zu gefährden, in der Sache aber fest zu bleiben und das Scheitern des Dialogs der beiden Supermächte an den übermäßigen Forderungen Chruschtschows abzuwarten. Seine Bereitschaft zur uneingeschränkten Kooperation steigerte Schröders Ansehen bei der amerikanischen Regierung. Während die Amerikaner über Adenauer urteilten, sein chronisches Mißtrauen bringe ihn dazu, ohne Grund ständig alles in Frage zu stellen ${ }^{343}$, sahen sie in Schröder ihren Mann ${ }^{344}$.

Nach der Unterredung Dowlings mit dem Kanzler hatte sich das Klima zwischen Bonn und Washington wieder etwas entspannt. Am 15. Mai entschuldigte sich Kennedy bei Adenauer, daß er dessen Schreiben vom 14. April nicht schriftlich beantwortet hatte. Er versprach, der sowjetischen Regierung kein Papier zu übermitteln, solange die Konsultation mit der Bundesregierung noch nicht abgeschlossen sei. Der Präsident beteuerte ferner, die USA würden in der Berlin-Krise stets die Interessen des Westens wahren, ließ aber zugleich durchblicken, daß er vom Kanzler künftig erwarte, Kritik an der amerikanischen Politik nicht mehr öffentlich zu äußern ${ }^{345}$. Eine Woche später übergab Carstens Botschafter Dowling

343 Vgl. FRUS 1961-1963, XV, Dok. 51, S. 148.

344 Charles Bohlen, einer der engsten Mitarbeiter Rusks, stellte am 2. 7.1962 in einer Aufzeichnung für seinen Außenminister fest: „Schroeder is obviously a very intelligent and effective man, and I certainly gained the impression from the talks with him that he thinks much more along our line than does the Chancellor" Vgl. FRUS 1961-1963, XIII, Dok. 147, S. 429. Der Sicherheitsberater Kennedys, McGeorge Bundy, versah im April 1962 ein Telegramm der amerikanischen Botschaft in Bonn, das dem Präsidenten vorgelegt wurde, mit der Randbemerkung: „Schröder bleibt stark - ein guter Mann.“ Zitiert nach PROwE, "Ich bin ein Berliner", S. 163. Nach seinem Besuch in Bonn im Juni 1962 berichtete Rusk, er habe sich bemüht, Schröders Position zu stärken. Vgl. ebenda; sowie FRUS 1961-1963, XV, Dok. 69, S. 200.

345 „I am sure that as long as we can keep in this kind of touch directly and through our trusted advisers we shall be all right." Vgl. ebenda, Dok. 53, S. $150 \mathrm{f}$. 
die von Kennedy gewünschte Antwort auf die amerikanischen Verhandlungsvorschläge ${ }^{346}$. In ihrer Stellungnahme erklärte die Bundesregierung ihre Bereitschaft, über alle Punkte zu diskutieren. Sie erhob aber weiterhin Einwände gegen die $\mathrm{Zu}$ sammensetzung der Zugangsbehörde und die geplanten innerdeutschen Kommissionen $^{347}$. Außerdem verlangte Bonn Garantien, daß die UdSSR durch den beabsichtigten Nonproliferationsvertrag die Schaffung einer multilateralen Atomstreitmacht der NATO nicht verhindern könnte ${ }^{348}$. Am folgenden Tag fand eine Besprechung zwischen dem Kanzler, Dowling sowie dem Staatssekretär im amerikanischen Außenministerium, George W. Ball, statt. Ihnen verkündete Adenauer, er betrachte die bilateralen Schwierigkeiten als ausgeräumt ${ }^{349}$. Vor dem Fraktionsvorstand der CDU/CSU führte er am 21. Mai 1962 seine heftige Kritik an der amerikanischen Politik allein auf seine Verärgerung über den Vorwurf des Vertrauensbruches und die schlechte Behandlung Grewes zurück ${ }^{350}$. Recht versöhnlich klang auch ein Schreiben, das er am 25. Mai an Kennedy richtete. In dem Brief regte der Kanzler an, den Gesprächsfaden mit Moskau wieder aufzunehmen, sobald eine gemeinsame Position ausgearbeitet sei. Ausdrücklich stimmte Adenauer der Ansicht des Präsidenten zu, daß alle Möglichkeiten ergriffen werden müßten, um die Berlin-Krise friedlich zu beenden. Niemand wäre glücklicher als er, wenn dies gelänge, versicherte der Kanzler. Des weiteren signalisierte er erneut, er sei bereit, über vieles zu sprechen, wenn die UdSSR für humanere Lebensbedingungen in der DDR sorgen würde ${ }^{351}$.

Im Endeffekt hatte Adenauer damit in uneingeschränkte Verhandlungen mit der sowjetischen Regierung eingewilligt. Glücklicherweise bestätigte sich nun Schröders Prognose über die Reaktion des Kreml. Chruschtschow wies das amerikanische Angebot zurück und bestand auf zusätzlichen Konzessionen des Westens. So brachte auch das vierte und fünfte Treffen zwischen Rusk und Dobrynin am 30. Mai und 18. Juni in Washington keinerlei Fortschritte ${ }^{352}$. Vom 21. bis 23. Juni hielt sich der amerikanische Außenminister in Bonn auf, um die Bundesregierung über den Stand der Dinge zu informieren und die nächsten Schritte zu

346 Vgl. ebenda, S. 155, Anm. 4.

347 Das Aide-mémoire der Bundesregierung vom 22.5. 1962 ist noch nicht deklassifiziert. Zum Inhalt des Memorandums vgl. den Artikel: „Bonn macht Washington Vorschläge für Berlin“, in: Frankfurter Allgemeine ZeITUNG vom 23. 5. 1962, S. 1 und S. 4, bzw. DzD IV/8, S. 543, Anm. 2.

348 Vgl. FRUS 1961-1963, XV, S. 155, Anm. 4.

349 Vgl. ebenda, Dok. 56, S. 157.

350 Vgl. das Protokoll der CDU/CSU-Fraktionsvorstandssitzung am 21.5. 1962, ACDP VIII-001-1503/4.

351 Vgl. FRUS 1961-1963, XV, Dok. 58, S. $159 \mathrm{f}$.

352 Zu den beiden Treffen vgl. ebenda, Dok. 59, S. 161-172, und Dok. 64, S. 177-187. Am 20.6. 1962 stellte Rusk resigniert fest, es seien keine Fortschritte in den Gesprächen mit der UdSSR zu erkennen. Zwar bekunde die sowjetische Regierung Interesse an einem Nichtangriffspakt, einem Nonproliferationsvertrag sowie deutsch-deutschen Kommissionen, jedoch verlange sie weiterhin den Abzug der westlichen Truppen aus Berlin. Der amerikanische Außenminister rechnete trotz des Mißerfolgs nicht damit, daß der Kreml nun die Krise anheizen würde. Sollte es aber dennoch zu einer Eskalation kommen, könne niemand behaupten, die USA hätten nicht alle diplomatischen Möglichkeiten ausgeschöpft, betonte Rusk. Vgl. ebenda, Dok. 65, S. 187-189. 
besprechen. Rusk bemühte sich, das formell wiederhergestellte Vertrauensverhältnis zum Kanzler weiter zu stärken und gleichzeitig Schröder zu stützen, den die Amerikaner nun zu fördern gedachten. Erfreut berichtete Rusk nach Washington, letzterer habe ihm, ebenso wie die Parteiführung von SPD und FDP, Rückendekkung für ein Berlin-Abkommen mit der UdSSR gegeben ${ }^{353}$. In der Tat beurteilte Schröder inzwischen das Konzept einer internationalen Zugangsbehörde als „an sich gut und gesund“. Über die endgültige Zusammensetzung der Behörde sollte jedoch erst nach einer grundsätzlichen Zusage Moskaus entschieden werden: „Zuviel Perfektion von Anfang an scheint mir hier eine gewisse Übertreibung." 354 Doch angesichts der strikt ablehnenden Haltung der Sowjetunion war die vorbehaltlose Zustimmung Bonns zu diesem Projekt kein großes Zugeständnis mehr.

Der letzte Versuch, doch noch eine amerikanisch-sowjetische Einigung über Berlin zu erreichen, wurde im Rahmen der internationalen Laos-Konferenz in Genf im Juli 1962 unternommen ${ }^{355}$. Auch in diesen Beratungen zeichnete sich keine Änderung des sowjetischen Standpunkts ab. Gromyko forderte weiterhin den Abzug der westlichen Truppen aus Berlin und drohte zum wiederholten Male mit dem Abschluß eines Separatfriedensvertrages ${ }^{356}$. Zwar hielt Rusk weiterhin eine Verständigung für möglich ${ }^{357}$, doch faktisch waren die Berlin-Sondierungen der Supermächte nach diesem erfolglosen Treffen beendet ${ }^{358}$. Der amerikanische Außenminister rechnete nicht damit, daß die UdSSR jetzt ihre Drohung, einen Friedensvertrag mit der DDR zu unterzeichnen, verwirklichen würde ${ }^{359}$, dennoch machten sich in Bonn diesbezügliche Befürchtungen breit. So stand zum Beispiel für Wolfgang Schollwer „ein neuer 13. August“ vor der Tür ${ }^{360}$. Auch Schröder hielt eine aggressive Reaktion Chruschtschows für möglich, anders als viele politische Beobachter aber nicht für unbedingt zwingend. Es komme darauf an, welche Ziele der sowjetische Ministerpräsident damit erreichen wolle, meinte der $\mathrm{Au}$ ßenminister. Bislang habe die UdSSR beabsichtigt, die Rechte der Westmächte in Berlin zu beseitigen. Dies könne sie aber mit einem Separatfriedensvertrag nicht erreichen, da sie praktisch einen Vertrag mit sich selber schließen würde ${ }^{361}$. Damit bliebe ihr nur die Option, durch einen solchen Schritt die Krise in Berlin zu verschärfen. Er glaubte aber nicht an eine Ausweitung des Konfliktss ${ }^{362}$, sondern ver-

353 Vgl. ebenda, Dok. 69, S. 200-203.

354 Interview Schröders mit dem HR am 23. 6. 1962, in: BULLETIN 1962, S. 982.

$355 \mathrm{Zu}$ dieser Konferenz über die Neutralisierung von Laos vgl. ADG 1962, S. 9972 und S. 10000.

$356 \mathrm{Zu}$ den Gesprächen Rusks mit Gromyko über Berlin zwischen dem 21. und 24. 7. 1962 in Genf vgl. FRUS 1961-1963, XV, Dok. 82-86, S. 236-252.

357 Vgl. ebenda, Dok. 85, S. $241 \mathrm{f}$.

$358 \mathrm{Zu}$ den unüberbrückbaren amerikanisch-sowjetischen Meinungsverschiedenheiten vgl. den Artikel „Schröder berichtet über Genf“, in: FRANKFURTER AllgEMEINE ZEITUNG vom 26. 7. 1962, S. 1.

359 Vgl. FRUS 1961-1963, XV, Dok. 85, S. 242.

360 Zitiert nach dem Artikel „Schröder informiert den Auswärtigen Ausschuß“, in: FrANKFURTER AlLGEMEINE ZEITUNG vom 25. 7. 1962, S. 3.

361 Vgl. das Interview Schröders mit dem RIAS am 24. 7. 1962, in: DzD IV/8, S. 867, Anm. 1. 362 Vgl. den Artikel „Verträge über die Neutralisierung von Laos unterzeichnet“, in: FrANKFURTER ALLGEMEINE ZEITUNG vom 24. 7. 1962, S. 1. 
mutete, mit ihren Drohungen beabsichtige die sowjetische Regierung lediglich, „Nervosität“ im Westen zu erzeugen. Man solle daher auch weiterhin nicht zurückweichen, sondern Geduld und Festigkeit zeigen. Der Westen, so Schröder, müsse gegenüber der UdSSR seine Position "einheitlich und gemeinsam" vertreten und ,in voller Klarheit" vortragen ${ }^{363}$.

In einem Interview am 8. August mit der $d p a$ präzisierte er seine Einschätzung. Im Vergleich zu seiner ersten spontanen Reaktion, in der er den Separatfriedensvertrag auf die leichte Schulter zu nehmen schien, maß er ihm jetzt größere Bedeutung bei. Zwar wiederholte er seine Ansicht, es müsse deswegen weder zu einer militärischen Auseinandersetzung kommen, noch brauche dem Vertrag automatisch eine Blockade Berlins zu folgen, doch gab er nun zu, allein die bloße Unterzeichnung eines derartigen Vertrags wäre ein bedeutsames Ereignis, da er gleichbedeutend mit dem Rückzug der UdSSR aus der Vier-Mächte-Verantwortung für Berlin und Deutschland sei. Interessant ist auch Schröders Urteil über den juristischen Wert eines solchen Abkommens. Für ihn stellte es „rechtlich ein Nullum“ dar, weil die DDR kein Völkerrechtssubjekt sei und zudem nicht über die Legitimation verfügte, „für Deutschland und das deutsche Volk oder seine Teile völkerrechtliche Erklärungen abzugeben" 364 . Außerdem würde die Sowjetunion dadurch zum einen ihre Verpflichtungen bezüglich der Einheit Deutschlands verletzen, die sie 1945 im Potsdamer Abkommen 365 und zehn Jahre später in der Genfer Direktive ${ }^{366}$ übernommen habe, und zum anderen das Selbstbestimmungsrecht des deutschen Volks mißachten. Er rechnete damit, daß sich die Ostblock-Staaten sowie andere kommunistische Länder, wie zum Beispiel Kuba, dem Separatfriedensvertrag anschließen würden, doch empfand er dies als nicht besonders gravierend, da die meisten Staaten aus diesem Kreis die völkerrechtliche Anerkennung der DDR bereits vollzogen hatten. Eine Gefahr für die Deutschland-Politik Bonns sah er lediglich für den Fall, daß auch neutrale Länder den Vertrag unterzeichneten, da sie dadurch den Alleinvertretungsanspruch der Bundesrepublik bestreiten und die DDR völkerrechtlich anerkennen würden ${ }^{367}$. Um eine derartige Erosion der Bonner Nichtanerkennungspolitik zu vermeiden, sprach er eine

363 Interview Schröders mit dem RIAS am 24. 7. 1962, in: DzD IV/8, S. 867, Anm. 1.

364 Interview Schröders mit der dpa am 8. 8. 1962, in: BULLETIN 1962, S. 1241.

365 Laut dem Kommuniqué vom 2. 8. 1945 über die Konferenz von Potsdam (Potsdamer Abkommen), sollte der Alliierte Kontrollrat die „Deutschland als Ganzes betreffenden Fragen“ erörtern. Vgl. DzD II/1, S. 2106.

366 Im Schlußkommuniqué vom 23. 7. 1955 der Konferenz der Staats- und Regierungschefs der Vier Mächte in Genf (Genfer Direktive), wurde u.a. ausgeführt: „Die Regierungschefs sind in Erkenntnis ihrer gemeinsamen Verantwortung für die Regelung des deutschen Problems und der Wiedervereinigung Deutschlands mittels freier Wahlen übereingekommen, daß die Lösung der deutschen Frage und die Wiedervereinigung Deutschlands im Einklang mit den nationalen Interessen des deutschen Volkes und den Interessen der europäischen Sicherheit herbeigeführt werden soll." Vgl. DzD III/1, S. 218.

367 Vgl. das Interview Schröders mit der $d p a$ am 8. 8. 1962, in: BULLETIN 1962, S. $1241 \mathrm{f}$. Vgl. auch die Artikel „Geschlossene Gesellschaft", in: Der SPIEGEL vom 15. 8. 1962, S. 13-15, und „Schröder warnt die Sowjets: Separatvertrag rechtswidrig“, in: DIE WELT vom 9. 8. 1962, S. 1 f. Schröder rechnete unter anderem mit einer Beteiligung Indiens. Vgl. FRUS 1961-1963, XV, S. 357, Anm. 2. 
deutliche Warnung aus: „Eine Beteiligung dritter Staaten an dem sogenannten Friedensvertrag würde als ein unfreundlicher Akt gegenüber dem deutschen Volk anzusehen sein, da er geeignet wäre, die Spaltung Deutschlands zu vertiefen." 368 Schnell machte daraufhin in Journalistenkreisen die Nachricht von der Formulierung einer „Schröder-Doktrin“ die Runde ${ }^{369}$. Dieser Begriff ist sicher zu hoch gegriffen, denn die Erklärung des Außenministers war keine neu formulierte außenpolitische Maxime. Schröder weitete im Grunde den Anwendungsbereich der Hallstein-Doktrin nur auf eine Teilnahme an einem Separatfriedensvertrag aus, wie sich auch in der identischen Wortwahl zeigt ${ }^{370}$. Staaten, die den Vertrag unterzeichneten, mußten also mit dem Abbruch der diplomatischen Beziehungen durch die Bundesrepublik rechnen.

Chruschtschow setzte aber seine Ankündigung nicht in die Tat um. Erst im Juni 1964 - darauf wird noch näher eingegangen werden - schloß er einen Bündnisvertrag mit der DDR, durch den der östliche Teil Deutschlands in das bilaterale Bündnissystem des Warschauer Pakts eingebunden wurde. Dieses Abkommen ersetzte praktisch den Separatfriedensvertrag. So blieb ab dem Sommer 1962 in Berlin die Lage zwar gespannt, jedoch einigermaßen stabil. Nachdem Grenzsoldaten der DDR den Flüchtling Peter Fechter im August 1962 schwer verletzt im Todesstreifen an der Mauer verbluten ließen, kam es im Westteil der Stadt zu schweren Unruhen, wobei unter anderem sowjetische Soldaten durch aufgebrachte Demonstranten angegriffen wurden. Die Sowjetunion respektierte aber weiterhin Kennedys essentials ${ }^{371}$. Wie Martin Hillenbrand, der damals im amerikanischen Außenministerium das Referat für deutsche Angelegenheiten leitete, schreibt, war letztendlich durch die amerikanisch-sowjetischen Berlin-Gespräche „nichts verloren und nichts gewonnen [ ...], außer Zeit" ${ }^{\text {372. }}$.

Im Herbst 1962 erwartete die amerikanische Regierung jedoch nochmals eine Zuspitzung der Situation in der geteilten Stadt. Als sich Schröder Mitte Oktober in Washington aufhielt, informierte ihn Kennedy, die Vereinigten Staaten rechneten mit einer deutlichen Verschärfung der Berlin-Krise im kommenden Monat ${ }^{373}$. Der Außenminister teilte die amerikanische Prognose nicht ${ }^{374}$ und behielt recht: Die UdSSR ergriff nicht in Berlin die Initiative, sondern in Kuba. Dort kam es Ende Oktober 1962 zur „gefährlichsten Zuspitzung des Ost-West-Gegensatzes seit Kriegsende ${ }^{\star 375}$, die die Welt an den Rand des dritten Weltkriegs brachte. Am

368 Interview Schröders mit der dpa am 8. 8. 1962, in: BULLETIN vom 9. 8. 1962, S. 1241.

369 So in einer Meldung der Nachrichtenagentur upi. Vgl. upi 128 Inland, ACDP Pressearchiv, Sammlung "Gerhard Schröder“.

370 Bundeskanzler Adenauer führte in seiner Regierungserklärung am 22. 9.1955 aus: „Ich muß unzweideutig feststellen, daß die Bundesregierung auch künftig die Aufnahme diplomatischer Beziehungen mit der,DDR' durch dritte Staaten, mit denen sie offizielle Beziehungen unterhält, als einen unfreundlichen Akt ansehen würde, da er geeignet wäre, die Spaltung Deutschlands zu vertiefen." Zitiert nach GREWE, „Hallstein-Doktrin“, Sp. 267.

371 Vgl. dazu FRUS 1961-1963, XV, Dok. 95-99, S. 272-279.

372 Hillenbrand, Berlin, S. 32.

373 Vgl. FRUS 1961-1963, XV, Dok. 134, S. 363.

374 Vgl. ebenda und Dok. 132, S. 357 f.

375 GREWE, Die deutsche Frage in der Ost-West-Spannung, S. 74. 
28. Oktober gab Chruschtschow in dem Nervenkrieg nach und verkündete, er werde die sowjetischen Raketenbasen auf der karibischen Insel abbauen. Damit, so Günther Stökl, „entschied er sich gegen die weltrevolutionäre kommunistische Aktionseinheit und für das Sicherheitsbedürfnis der sowjetischen Weltmacht"376. Mit der friedlichen Beilegung der Kuba-Krise ging zugleich ein Ende des sowjetischen Drucks auf Berlin einher, wo sich die Situation auf der Basis des Status quo vom 13. August 1961 stabilisierte. Am 12. Dezember 1962 zogen die Westmächte daraus die Konsequenz und erklärten, es gebe im Moment keinen Anlaß für weitere Gespräche mit der UdSSR über den Status der Stadt ${ }^{377}$. Somit konnte Schröder am Jahresende eine positive Bilanz ziehen: „Die amerikanische Haltung in Kuba hat auch Auswirkung auf Berlin. Die Gefahr einer sowjetischen Fehleinschätzung, die in den vergangenen Jahren gelegentlich Sorge bereitete, hat sich nun wesentlich verringert. Die Sowjetunion weiß, daß der Westen entschlossen ist, für seine lebenswichtigen Interessen - und dazu gehört auch Berlin - das volle Risiko einzugehen. Kuba hat auch zu einer Kräftigung der Position des Westens in der Berlin-Frage beigetragen. Vier Jahre nach dem sowjetischen Berlin-Ultimatum können wir feststellen, daß wir uns zusammen mit unseren Verbündeten behauptet haben, daß unsere Ausgangsposition für die Wiedervereinigung auf der Grundlage des Rechts der Selbstbestimmung unversehrt geblieben ist." ${ }^{378} \mathrm{Daß}$ am Ende des Jahres 1962 der Status von Berlin (West) unverändert geblieben und die Stadt zumindest keiner unmittelbaren Bedrohung mehr ausgesetzt war, konnte die Bundesregierung in der Tat als einen großen Erfolg ansehen. Doch weder Schröders Kooperationsstrategie noch Adenauers Ablehnung der amerikanischen Verhandlungspläne gaben letztendlich den Ausschlag, daß die Freiheit der westlichen Sektoren Berlins behauptet werden konnte. Der wohl entscheidende Punkt war, daß die UdSSR alle Verhandlungsangebote abgelehnt und statt dessen Forderungen vorgebracht hatte, die so weitreichend waren, daß selbst die auf Ausgleich bedachte Regierung Kennedy nicht bereit war, darüber zu diskutieren.

376 STÖKL, Russische Geschichte, S. 782. Aus der Fülle der Literatur zur Kuba-Krise sei an dieser Stelle auf zwei neuere Studien verwiesen: BESCHLOSS, Powergame, und GREINER, Kuba-Krise; sowie auf die Ausführungen des Sicherheitsberaters Kennedys, McGeorge Bundy: BUNDY, Danger and Survival, S. 391-462. Auch die amerikanischen Akten sind inzwischen veröffentlicht: FRUS 1961-1963, XI.

377 Vgl. die Artikel „Die vier westlichen Außenminister beraten in Paris“, in: FrANKFURTER Allgemeine ZeITUNG vom 13.12. 1962, S. 1; sowie „Kreml soll Forderung auf Abzug der Alliierten aus Berlin aufgeben" und „Rusk fordert mehr Initiative von der NATO“, in: FrankfurTer Allgemeine ZeITUNG vom 14. 12. 1962, S. 1.

378 Vgl. den im Deutschland-Union-Dienst am 28.12. 1962 veröffentlichten Artikel von Gerhard Schröder: „Mit neuem Selbstvertrauen“; ACDP Pressearchiv, Sammlung „Gerhard Schröder". 


\section{Die Erweiterung des ostpolitischen Horizonts}

\section{Der Streit um Botschafter Hans Kroll und die deutsch-sowjetischen Beziehungen bis zum Ende der Kanzlerschaft Adenauers}

Seit dem Mai 1958 leitete der aus Oberschlesien stammende Hans Kroll die Botschaft der Bundesrepublik in der UdSSR. Zuvor vertrat Kroll die Interessen Bonns als Botschafter in Belgrad (1953 bis 1955) und in Tokio (1955 bis 1958). Den Posten in Moskau verstand er als krönenden Abschluß seiner diplomatischen Laufbahn, da er 1963 wegen Erreichung der Altersgrenze aus dem Auswärtigen Dienst ausscheiden mußte 1 . Kroll galt als "eine der farbigsten Persönlichkeiten des deutschen Auswärtigen Amtes" 2 . Er verfügte über eine mehr als vierzigjährige diplomatische Erfahrung. Bereits während der Weimarer Republik im Jahr 1920 begann seine Karriere als Diplomat. Von der damaligen deutschen Ostpolitik, die eine Zusammenarbeit mit Moskau propagierte und 1922 im Vertrag von Rapallo 3 ihren Höhepunkt fand, war er entscheidend geprägt $t^{4}$. Krolls politisches Ziel war „eine Aussöhnung mit der Sowjetunion als Voraussetzung für spätere Verhandlungen über die Wiedervereinigung “5. Zu diesem Zweck wollte er ein Treffen zwischen Adenauer und der sowjetischen Regierung herbeiführen ${ }^{6}$. Selbstbewußt wie er war, verkündete er, er sei ,nicht nach Moskau gegangen, um Briefträger zu spielen“. Freimütig gab er zu, daß er nicht vorhatte, auf Instruktionen aus Bonn zu warten und verborgen im Hintergrund zu wirken. Kroll beabsichtigte, selbst aktiv $\mathrm{zu}$ werden, um seine politische Vision von einer Neugestaltung der deutsch-sowjetischen Beziehungen zu realisieren. Er wollte „Motor sein und nicht Bremse"7. Wie sein langjähriger Protokollchef und Dolmetscher an der Botschaft in Moskau, Nikolaus Ehlert, berichtet, war der Botschafter immer dann, wenn er es für erforderlich hielt, „in Weisungen Selbstversorger " 8 . Kroll war davon überzeugt, daß er „einen fruchtbaren Beitrag leisten könnte für die Lösung der deutschen Lebensfragen, für die Rettung Berlins und die schließliche Beseitigung der deutschen Spaltung "9. Der Botschafter rühmte sich eines ausgesprochen guten Verhältnisses zu der sowjetischen Führung, insbesondere zu Nikita Chruschtschow. Im April 1961 wurde ihm die Ehre einer Einladung auf die Datscha des Ministerpräsidenten am Schwarzen Meer zuteil. Kroll versäumte es danach nicht, die Presse über dieses Treffen detailliert in Kenntnis zu setzen, weshalb der damalige Außenminister von

1 Vgl. KROLL, Lebenserinnerungen, S. 529.

2 BESSON, Die Außenpolitik der Bundesrepublik, S. 290.

3 Mit dem Vertrag von Rapallo vom 16. 4. 1922 verzichteten das Deutsche Reich und die Russische Sozialistische Föderative Sowjetrepublik auf alle gegenseitigen Forderungen, die aus dem Ersten Weltkrieg resultierten. Sie vereinbarten ferner die Aufnahme diplomatischer Beziehungen und gewährten sich eine Meistbegünstigung im Handel. Für den Wortlaut vgl. EUROPA-ARCHIV 1954, S. 6791.

4 BESSON, Die Außenpolitik der Bundesrepublik, S. 290.

5 KROLL, Lebenserinnerungen, S. 529.

6 Vgl. ebenda, S. 533.

7 Ebenda, S. 530.

8 EHLERT, Große Grusinische Nr. 17, S. 320.

9 KROLL, Lebenserinnerungen, S. 530. 
Brentano eine Ablösung des Botschafters in Erwägung zog ${ }^{10}$. Wegen seines eigenwilligen Verhaltens war er in der Ostabteilung des Auswärtigen Amts nicht sonderlich beliebt ${ }^{11}$. Für Ärger sorgte auch, daß der Botschafter häufig den Dienstweg umging und sich direkt an das Bundeskanzleramt wandte. Den Zugang zu Adenauer verschaffte ihm Staatssekretär Globke, der derselben Studentenverbindung angehörte. Trotz Krolls Neigung zu Alleingängen hielt der Kanzler an ihm fest, weil er dessen guten Kontakt zu Chruschtschow nützen wollte. Mit seiner Hilfe erhoffte der Kanzler, Einblicke in die aktuellen Überlegungen des Kreml zur Berlin- und Deutschland-Politik zu erhalten. Sollte sich im Verlauf der amerikanisch-sowjetischen Berlin-Sondierungen eine Verständigung auf Kosten der Bundesrepublik abzeichnen, glaubte Adenauer, mit dem Kanal Kroll über die Möglichkeit zu verfügen, eigene Verhandlungen einleiten zu können ${ }^{12}$.

Nur wenige Tage vor Schröders Ernennung zum Außenminister erreichten die Eigenmächtigkeiten des Diplomaten einen neuen Höhepunkt. Am 9. November 1961 war Kroll mit Chruschtschow zusammengetroffen, um diesem seine „ganz persönliche Auffassung zu den schwebenden Fragen " in den bilateralen Beziehungen darzulegen ${ }^{13}$. Nach Krolls Darstellung ging die Initiative zu der Begegnung von Chruschtschow aus, der ihn zwei Tage zuvor im Rahmen eines Empfangs zum Jahrestag der Oktoberrevolution angesprochen hatte ${ }^{14}$. Hingegen berichtet Ehlert, der den Botschafter zu der Feier begleitet hatte, nicht der sowjetische Ministerpräsident, sondern Kroll habe ein Treffen unter vier Augen vorgeschlagen. Damit hatte er die eindeutige Weisung des Auswärtigen Amts, die Berlin-Sondierungen der USA nicht durch eigene Kontaktaufnahmen zu stören, ignoriert ${ }^{15}$. Die Aussage Ehlerts wird durch Krolls spätere Schilderung über den Verlauf dieses Gesprächs gestützt: Wäre Chruschtschow der Initiator des $\mathrm{Ge}$ sprächs gewesen, dann hätte die Gesprächsführung bei ihm gelegen. Der Botschafter gibt aber zu, daß er dem Ministerpräsidenten „eine Reihe persönlicher Anregungen" vortrug ${ }^{16}$. Auch Ehlerts Bericht ist zu entnehmen, daß sein Vorgesetzter von sich aus das Thema Berlin angesprochen hatte ${ }^{17}$. Die Behauptung Krolls, er habe sich, um Chruschtschow nicht zu brüskieren, der Aufforderung nicht entziehen können, seine Vorstellungen für eine friedliche Beilegung der Berlin-Krise darzulegen ${ }^{18}$, ist folglich nicht zu halten. Nein, der Diplomat meinte, die Zeit sei nun gekommen, um selbst aktiv zu werden. Seiner Ansicht nach waren die Berlin-Sondierungen in eine „Sackgasse“ geraten. Er hielt es deshalb für notwen-

$10 \mathrm{Vgl}$. das Schreiben von Brentanos an Adenauer vom 27. 4. 1961, in: BARING, Sehr verehrter Herr Bundeskanzler!, S. 377.

11 Vgl. EHLERT, Große Grusinische Nr. 17, S. $184 \mathrm{f}$.

12 Vgl. SCHWARZ, Adenauer II, S. 699-701.

13 KROLL, Lebenserinnerungen, S. 525.

$14 \mathrm{Vgl}$. ebenda, S. $524 \mathrm{f}$.

15 Vgl. EHLERT, Große Grusinische Nr. 17, S. 320.

16 KROLL, Lebenserinnerungen, S. 525.

17 Vgl. EHLERT, Große Grusinische Nr. 17, S. 322-324.

$18 \mathrm{Vgl}$. dazu die Ausführungen Adenauers in einem Hintergrundgespräch am 16.11. 1961, in: ADENAUER, Teegespräche 1961-163, S. 29 f. Diese Version wurde von Regierungssprecher Eckardt am 17.11. 1961 an die Presse weitergegeben. Vgl. EHLERT, Große Grusinische Nr. 17, S. 327. 
dig, „den Stier bei den Hörnern zu packen“ und den Abschluß eines Separatfriedensvertrags mit der DDR, und damit „die ernsteste Krise der Nachkriegszeit“ zu verhindern ${ }^{19}$. So unterbreitete er Chruschtschow eigenmächtig einen FünfPunkte-Plan zur Beilegung der Krise, wobei er zwar betonte, es handle sich dabei lediglich um persönliche Überlegungen, aber zusicherte, sich in Bonn dafür einzusetzen, falls die sowjetische Seite interessiert sei ${ }^{20}$. Wie Brentano zu Recht bemerkte, mußte Chruschtschow annehmen, Kroll sei von der Bundesregierung autorisiert worden, denn für den sowjetischen Ministerpräsidenten war es einfach „völlig undenkbar“, daß ein Diplomat seine eigene Politik betrieb21.

Was war nun der Inhalt dieses Kroll-Plans? Dem Botschafter zufolge sollte ein Vier-Mächte-Abkommen über Berlin (West) geschlossen werden, das die Freiheit und die Lebensfähigkeit der Stadt, den freien Zugang sowie die fortdauernde Anwesenheit alliierter Truppen garantierte. Kroll schlug vor, diese Vereinbarung um ein Abkommen zwischen der UdSSR und der DDR ergänzen, in dem sich OstBerlin verpflichtete, die getroffenen Regelungen zu respektieren. Außerdem sei ein Vertrag zwischen der DDR einerseits und dem Berliner Senat bzw. der Bundesregierung andererseits über die technischen Probleme des Vier-Mächte-Abkommens, wie zum Beispiel die Regelung des Verkehrs zwischen Berlin (West) und der Bundesrepublik, zu schließen. Ferner regte der Botschafter an, VierMächte-Kommissionen einzusetzen, die über eine allgemeine Abrüstung sowie einen Friedensvertrag für das vereinigte Deutschland $\mathrm{zu}$ verhandeln hatten. Schließlich sollten sich sowohl West wie Ost verpflichten, auf ihrem Territorium gegen die andere Seite gerichtete Propaganda zu unterbinden ${ }^{22}$. Krolls Plan war

19 KROLL, Lebenserinnerungen, S. 525.

20 Vgl. EHLERT, Große Grusinische Nr. 17, S. 323.

$21 \mathrm{Vgl}$. das Schreiben von Brentanos an Adenauer vom 11.11. 1961, in: BARING, Sehr verehrter Herr Bundeskanzler!, S. 380.

22 Vgl. FRUS 1961-1963, XIV, Dok. 210, S. 580f. Vgl. ferner den Vorabdruck eines Kapitels von Ehlerts Erinnerungen Große Grusinische Nr. 17 im Spiegel: EHLERT, „Die Mauer ist sehr schlecht, ich gebe es zu“. Als das Buch publiziert wurde, fehlte die Passage aus dem Vorabdruck, in der Ehlert den Kroll-Plan skizzierte, da das Auswärtige Amt eine erneute Veröffentlichung verbot. Vgl. dazu BARING, Sehr verehrter Herr Bundeskanzler!, S. 469, Anm. 114. Kroll bestritt in einem Leserbrief Ehlerts Bericht: Er würde „in wesentlichen Punkten" nicht mit dem Gesprächsprotokoll übereinstimmen. Vgl. DER SPIEGEL vom 11. 11. 1964, S. 10f. Der Dolmetscher bestätigte aber gegenüber Arnulf Baring seine Darstellung. Vgl. BARING, Sehr verehrter Herr Bundeskanzler!, S. 470, Anm. 114. In seinen Erinnerungen berichtet er des weiteren, das von ihm angefertigte Gesprächsprotokoll und die im Auswärtigen Amt aufbewahrte Fassung würden „zum Teil erheblich“ voneinander abweichen. Sein Originalprotokoll sei folglich nachträglich überarbeitetet worden. Vgl. EHLERT, Große Grusinische Nr. 17, S. 323. Ehlerts Darstellung wird durch ein Telegramm des amerikanischen Botschafters in Moskau bestätigt: Kroll informierte nämlich noch am 9.11. 1961 die Vertreter der Drei Mächte in Moskau über sein Gespräch mit Chruschtschow. Thompson teilte seiner Regierung anschließend minutiös mit, was ihm der Botschafter der Bundesrepublik erzählt hatte. Sein Bericht deckt sich sowohl mit Ehlerts Darstellung im Spiegel, als auch mit den Ausführungen Grewes am 11.11. 1961 vor dem Botschafterlenkungsausschuß in Washington über den Inhalt von Krolls Gespräch mit dem sowjetischen Ministerpräsidenten. Vgl. FRUS 1961-1963, XIV, Dok. 210, S. 581. Krolls Behauptung, Ehlert habe den Kroll-Plan sowie den ganzen Gesprächsverlauf entstellt wiedergegeben, entspricht also nicht den Tatsachen. 
somit nichts anderes als ein „Tauschgeschäft": Die De-facto-Anerkennung der DDR sollte der Preis für ein Ende des sowjetischen Drucks auf Berlin sein ${ }^{23}$. Das Konzept des Botschafters hatte ferner das Manko, daß es auf eine Bestätigung der politischen Bindungen zwischen Berlin und der Bundesrepublik verzichtete. Kroll war jedoch der Ansicht, das Angebot müßte „attraktiv genug“ sein, um auf der anderen Seite Interesse zu wecken. Da er zu Recht vermutete, daß er „wohl schwerlich" für sein Vorhaben die Zustimmung Bonns bekommen hätte, habe er selbst die Initiative ergriffen ${ }^{24}$. Chruschtschow habe auf den Vorschlag überaus positiv reagiert, behauptete der Botschafter. Es sei „das erste Mal“ gewesen, daß er aus westdeutschem Mund Dinge gehört habe, die „konstruktiv, praktisch und im Aufbau logisch erschienen", habe der sowjetische Ministerpräsident geantwortet. Er soll sogar versprochen haben, die Mauer in Berlin abzubauen, sobald sich die bilateralen Beziehungen sowie das innerdeutsche Verhältnis verbessert hätten ${ }^{25}$. Nach der Schilderung Krolls gipfelten Chruschtschows Ausführungen in der Bemerkung, die „endgültige Versöhnung“ zwischen der Bundesrepublik und der UdSSR sei für ihn die „Krönung“ seiner Außenpolitik ${ }^{26}$.

War es schon überaus bedenklich, daß ein Botschafter an einem politisch so bedeutsamen Ort wie Moskau aus eigenem Antrieb diplomatische Aktionen unternahm, so wurde Krolls Eigenmächtigkeit vollends zum Skandal, als seine Unterredung mit Chruschtschow Eingang in die Presse fand, wobei aber seine Vorschläge entstellt wiedergegeben und sie dem sowjetischen Ministerpräsidenten zugeschrieben wurden ${ }^{27}$. Die Bundesregierung mußte notgedrungen einräumen, daß ein Treffen zwischen dem Botschafter und Chruschtschow stattgefunden hatte. Sie bestritt aber, daß die Berlin-Frage dabei eine große Rolle gespielt habe. Die beiden Männer hätten sich ausschließlich „im allgemeinen mit Ost-West-Fragen beschäftigt"; auch seien keine Pläne irgendwelcher Art entwickelt worden, beteuerte Regierungssprecher von Eckardt ${ }^{28}$. Kroll bestätigte diese Version ${ }^{29}$. Als aber am 12. November die britische Nachrichtenagentur Reuters meldete, das amerikanische Außenministerium vermute, der angebliche Chruschtschow-Plan stamme in Wahrheit von Botschafter Kroll, geriet die Bundesregierung in den Verdacht, ohne Rücksprache mit den Verbündeten insgeheim Verhandlungen mit der Sowjetunion zu führen ${ }^{30}$. Bonn war nun gezwungen, die Existenz eines KrollPlans zuzugeben. Die Behauptung der Bundesregierung, ihr diplomatischer Vertreter in Moskau sei dazu nicht autorisiert gewesen und habe nur seine eigenen

23 BEsSON, Die Außenpolitik der Bundesrepublik, S. 292.

24 KROLL, Lebenserinnerungen, S. 529.

25 Ebenda, S. 526.

26 Ebenda, S. 527.

27 Vgl. BARING, Sehr verehrter Herr Bundeskanzler!, S. 378, und S. 469, Anm. 113. Der Urheber der Indiskretion konnte nie festgestellt werden. Vgl. EHLERT, Große Grusinische Nr. 17, S. 326.

28 So der Chef des Presse- und Informationsamts am 10.11. 1961. Zitiert nach EHLERT, Große Grusinische Nr. 17, S. 326.

$29 \mathrm{Vgl}$. ebenda.

30 Vgl. ebenda. 
Vorstellungen vorgetragen ${ }^{31}$, wirkte nach den Dementis der vergangenen Tagen freilich nicht besonders glaubhaft.

Der Botschafter wurde zur Berichterstattung nach Bonn zurückgerufen. Am 14. November, also am Tag der Amtseinführung Schröders, traf er in der Bundesrepublik ein. Dem neuen Außenminister mußte eine eigenwillige Persönlichkeit wie Kroll geradezu ein Dorn im Auge sein. Schröder legte allerhöchsten Wert auf die Loyalität seiner Mitarbeiter, worauf er bereits in seiner Begrüßungsansprache im Auswärtigen Amt hingewiesen hatte. Er war durchaus bereit, Kritik zu akzeptieren oder Vorschläge zu prüfen, doch hatte dies intern zu erfolgen ${ }^{32}$. Von seinen Diplomaten erwartete er, nicht das Bedürfnis zu haben, „mit großen Überschriften in den Zeitungen zu erscheinen " 33 . Nach seiner Ansicht konnte Krolls Verhalten nur dessen Abberufung zur Folge haben ${ }^{34}$. Doch der Außenminister ahnte nichts von der Verbindung Kroll-Adenauer ${ }^{35}$. Das Gespräch des Botschafters mit dem Kanzler nahm dann auch einen anderen Verlauf, als nach der scharfen Kritik der letzten Tage erwartet werden konnte. Nachdem der Diplomat seine Version der Geschehnisse vorgetragen hatte, war von Tadel oder einer Ablösung keine Rede mehr. Statt dessen wurde er mit der Botschaft nach Moskau zurückgeschickt, auch der Kanzler wünsche eine Verständigung mit der UdSSR. Nach intensiver Bearbeitung durch Kroll schloß Adenauer sogar ein Treffen mit dem sowjetischen Ministerpräsidenten nicht mehr aus ${ }^{36}$. Er bewertete die ihm von dem Botschafter übermittelten Äußerungen Chruschtschows als „nicht uninteres-

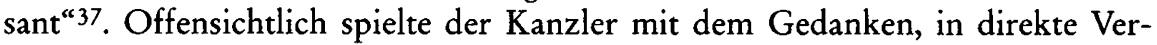
handlungen mit der Sowjetunion einzutreten. Für diese Annahme spricht auch sein Verhalten bei einer Unterredung am 5. Dezember 1961 mit dem sowjetischen Botschafter Smirnow. Diesem teilte er mit, er habe eine Abberufung Krolls verhindert, weil er ihn für einen „wertvollen Mann“ halte. Auf die Frage des Diplomaten, wie er zu Krolls Vorschlägen stehe, antwortete er sibyllinisch, er stimme "teils, teils" mit ihnen überein ${ }^{38}$. Moskau konnte dies durchaus als Signal verstehen, daß der Kanzler auf der Basis des Kroll-Plans Gespräche führen wollte. Tatsächlich vertraute Adenauer zwei Tage nach dem Gespräch mit Smirnow Bundesminister Krone an: „Für den Rest seines Lebens halte er es für das Wichtigste, [...] unser Verhältnis zu Rußland in eine erträgliche Ordnung zu bringen. “ 39

31 So die Erklärung von Eckardts am 13.11. 1961. Vgl. EHLERT, Große Grusinische Nr. 17, S. $326 \mathrm{f}$.

32 Vgl. die Rede Schröders vom 16. 11. 1961, PA/AA, Ministerbüro, Bd. 258.

33 Interview Schröders mit dem DLF am 5. 10. 1962. Zitiert nach SCHWARZKOPF/WRANGEL, Chancen, S. 169.

34 Vgl. OSTERHELD, „Ich gehe nicht leichten Herzens ...“, S. 84.

35 Vgl. SCHRÖDER, "Je weiter östlich, desto besser".

36 Vgl. Kroll, Lebenserinnerungen, S. 532-535; SCHWARZ, Adenauer II, S. 702, sowie die Aufzeichnung des Staatssekretärs Carstens vom 14. 11. 1961, PA/AA, Büro Staatssekretär, Bd. 85.

37 So Adenauer in einem Hintergrundgespräch am 16. 11. 1961, in: ADENAUER, Teegespräche 1961-163, S. 29.

38 Aufzeichnung über ein Gespräch zwischen Bundeskanzler Adenauer und dem sowjetischen Botschafter Smirnow am 5. 12. 1961, ACDP, Nachlaß Krone I-028-031/1.

39 KRONE, Aufzeichnungen, Eintrag vom 7. 12. 1961, S. 164. 
Auf Adenauers Anspielungen hinsichtlich einer eventuellen Gesprächsbereitschaft reagierte Chruschtschow mit einem Memorandum, das der Leiter der Deutschlandabteilung im sowjetischen Außenministerium, Iwan Iljitschow, am 27. Dezember 1961 Kroll aushändigte. Das Papier war kein offizielles Dokument, $\mathrm{da}$ es weder datiert und adressiert, noch unterschrieben war ${ }^{40}$. Über die Bewertung des Inhalts war man in Bonn geteilter Meinung. Obwohl keine Veränderung des sowjetischen Standpunktes festgestellt werden konnte, wies Kroll auf den "betont konzilianten und intimen Ton" hin, in dem das Dokument abgefaßt war. Es stelle deshalb „eine günstige Gelegenheit“ dar, den Dialog mit Chruschtschow weiterzuführen ${ }^{41}$. Doch Adenauer war anderer Ansicht: „Natürlich sind Köder an der Leine, aber für mich nicht! “42 Das Schreiben sei kein ernsthaftes Verhandlungsangebot, sondern „an Dumme gerichtet“, urteilte der Kanzler. Den Inhalt charakterisierte er folgendermaßen: „Es wird gesagt, die Franzosen betrügen Euch, zweitens die Engländer betrügen Euch, drittens die Amerikaner betrügen Euch. Wir sind diejenigen, die Euch nicht betrügen. Kommt zu uns, Ihr kriegt Aufträge, soviel Ihr wollt." ${ }^{43}$ Adenauer wollte die Öffentlichkeit auch nicht über die sowjetische Nachricht in Kenntnis setzen, weil sie nur einen unverbindlichen Charakter hatte: „[...] ein Schreiben, das weder eine Adresse noch eine Unterschrift hat, ist nicht an mich gerichtet und auch nicht an den Außenminister"44. Dennoch hielt sich in der Presse das Gerücht, die Bundesregierung habe eine Botschaft Chruschtschows erhalten. Das Auswärtige Amt dementierte zunächst; mußte dann aber doch einräumen, ein Schreiben aus Moskau sei eingegangen ${ }^{45}$. Eine Wiederholung der Aufregung um den Chruschtschow/Kroll-Plan vom November 1961 schien sich anzubahnen. Doch diesmal kam erschwerend hinzu, daß Kroll - anders als einige Wochen zuvor, als er den Botschaftern der drei Westmächte zumindest mitgeteilt hatte, daß er sich mit Chruschtschow treffen werde den Empfang eines sowjetischen Memorandums gegenüber seinen Kollegen verschwiegen hatte ${ }^{46}$. Angesichts der Aufregung in der Öffentlichkeit über den möglichen Inhalt wurde die Note schließlich von der Bundesregierung veröffentlicht, um allen Spekulationen den Boden zu entziehen ${ }^{47}$.

Die Bundesregierung stand nun vor der Frage, wie sie auf die Denkschrift rea-

$40 \mathrm{Vgl}$. Memorandum der sowjetischen Regierung der UdSSR an die Bundesregierung, in: DzD IV/7, S. 1211-1222. Vgl. auch KROLL, Lebenserinnerungen, S. $537 \mathrm{f}$.; sowie das Hintergrundgespräch Adenauers am 8. 1. 1962, in: ADENAUER, Teegespräche 1961-1963, S. 88.

41 KROLL, Lebenserinnerungen, S. 538.

42 So Adenauer in einem Hintergrundgespräch am 8.1.1962, in: ADENAUER, Teegespräche 1961-1963, S. 89.

43 So Adenauer am 20.2.62 zu Sidney und Flora Lewis Gruson, in: ebenda, S. 101. Vgl. auch die Ausführungen Adenauers auf der Sitzung des Engeren CDU-Bundesvorstands und des CDU-Bundesvorstands am 7.2. 1962, in: PROTOKOLlE DES CDU-BUNDESVORSTANDS, S. 108 f. bzw. S. 138.

44 So Adenauer in einem Hintergrundgespräch am 8.1.1962, in: ADENAUER, Teegespräche 1961-1963, S. 89.

45 Vgl. KROLL, Lebenserinnerungen, S. 539.

46 Vgl. ebenda, S. $538 \mathrm{f}$.

47 Vgl. das Protokoll der Sitzung des Engeren CDU-Bundesvorstands am 7. 2. 1962, in: PrOTOKOLLE DES CDU-BUNDESVORSTANDS, S. 109. 
gieren sollte. Obwohl das Memorandum keineswegs als entgegenkommend bezeichnet werden konnte, war man sowohl im Kabinett, als auch im Auswärtigen Amt über das weitere Vorgehen unterschiedlicher Auffassung. Unumstritten war lediglich, daß eine Reaktion erfolgen sollte, um mit Blick auf die Bewertung der Stalin-Noten von 1952 einer erneuten Legendenbildung, Bonn habe fahrlässig eine Chance versäumt, vorzubeugen ${ }^{48}$. Ebenso wie Adenauer sah Schröder in dem Memorandum keinen Ansatzpunkt für weitere Gespräche. Nach den Vorstellungen des Außenministers sollte die Antwort deshalb eine Darlegung der Deutschland- und Berlinpolitik der Bundesregierung, jedoch kein Angebot für die Aufnahme bilateraler Verhandlungen enthalten ${ }^{49}$. Andere Politiker sprachen sich hingegen für direkte Gespräche mit der UdSSR aus. Neben Bundestagspräsident Gerstenmaier setzte sich vor allem der FDP-Vorsitzende Mende für bilaterale Verhandlungen ein, die aber im ausdrücklichen Auftrag der Drei Mächte und in ständiger Konsultation mit ihnen geführt werden sollten ${ }^{50}$. Auf einer Botschafterkonferenz in Bonn am 9./10. Februar 1962 wurde über die Antwort der Bundesregierung diskutiert. Neben der Führungsspitze des Auswärtigen Amts nahmen die Leiter der diplomatischen Vertretungen der Bundesrepublik in Rom, London, Washington, Paris, Moskau und bei der NATO, Blankenhorn, von Etzdorf, Grewe, Klaiber, Kroll und von Walther, teil. In dieser Runde warb Kroll dafür, Chruschtschow in die Bundesrepublik einzuladen ${ }^{51}$, was aber einhellig abgelehnt wurde ${ }^{52}$. Man war sich einig, gegenüber Moskau deutlich zu machen, daß Bonn zwar prinzipiell an besseren Beziehungen interessiert sei, aber nicht von der bisherigen Deutschland-Politik abrücken werde. In diesem Sinne wurde auch die Antwortnote formuliert: Die sowjetischen Angriffe auf die Politik der Westmächte wurden zurückgewiesen und der deutschlandpolitische Standpunkt der Bundesregierung unmißverständlich dargelegt $\mathrm{t}^{53}$.

Kroll hatte wohl bereits damit gerechnet, daß er im Auswärtigen Amt für seinen Standpunkt keine Unterstützung finden würde, denn bereits einen Tag vor Beginn der Botschafterkonferenz hatte er den Kanzler aufgesucht, um ihn von der Nützlichkeit eines Gipfeltreffens mit Chruschtschow zu überzeugen. Kroll berichtete später, Adenauer habe nach einer heftigen Diskussion dem Gedanken zugestimmt und Globke sowie Krone angewiesen, Vorbereitungen für ein Treffen zu veranlassen. Schröder habe jedoch strikt dagegen Stellung bezogen und das Vorhaben verhindert ${ }^{54}$. Grewe bezeichnet in seinen Memoiren die Behauptung

48 Vgl. den Artikel: „Schröder berichtet dem Auswärtigen Ausschuß“, in: FRANKFURTER AllgemeINe ZeITUNG vom 25. 1. 1962, S. 3.

49 Vgl. den Artikel „Schröder berichtet dem CDU-Fraktionsvorstand“, in: FrankFURTER Allgemeine ZeITUNG vom 13. 2. 1962, S. 3.

50 Vgl. dazu die Berichterstattung der Rheinischen Post vom 27.1. 1962, in: DzD IV/8, S. 133, Anm. 3; Kroll, Lebenserinnerungen, S. 542; MENDE, Von Wende zu Wende, S. 20.

51 Vgl. Kroll, Lebenserinnerungen, S. 549.

52 Vgl. GREwE, Rückblenden, S. 528.

53 Vgl. Memorandum der Bundesregierung an die sowjetische Regierung vom 21.2. 1962, in: DzD IV/8, S. 162-171.

54 Vgl. KrOLL, Lebenserinnerungen, S. 546-550. Vgl. auch MENDE, Von Wende zu Wende, S. $21 \mathrm{f}$. 
Krolls, der Kanzler habe sein Einverständnis zu einem Treffen mit dem sowjetischen Ministerpräsidenten gegeben, als "völlig unglaubwürdig “55, doch Krone bestätigt die Darstellung des Botschafters. Er notierte in seinem Tagebuch, Adenauer habe ihm nach der Unterredung mit Kroll mitgeteilt, er beabsichtige, nun ein „Direktgespräch" mit dem sowjetischen Regierungschef zu führen ${ }^{56}$. Wenig später ließ er den Botschafter jedoch wissen, er müsse alles noch einmal überden$\mathrm{ken}^{57}$. Es ist nicht klar, was zu dieser Meinungsänderung führte. Tatsache ist, daß sich das Auswärtige Amt entschieden gegen ein solches Treffen aussprach. Erstens wollte man den Verständigungsbemühungen der USA nicht in den Rücken fallen; zweitens war man der Auffassung, der „Hebel Kroll“ sei für ein solches Vorhaben ohnehin zu schwach ${ }^{58}$. Schröder und seine Mitarbeiter glaubten, durch direkte Kontakte zwischen Bonn und Moskau könnten die Sondierungen zwischen Thompson und Gromyko eine für die Bundesrepublik negative Wendung nehmen $^{59}$. Wie bereits geschildert, wollte Schröder auf keinen Fall die sowieso schon brüchige Übereinstimmung mit den USA in der Berlin-Politik aufs Spiel setzen. Die Anbahnung von eigenen Gesprächen mit der sowjetischen Regierung, deren Zweckmäßigkeit er sowieso bezweifelte, hätte seiner Ansicht nach nur Mißtrauen bei den Verbündeten hervorgerufen, wie schon die negative Reaktion der Drei Mächte auf Krolls Unterredung mit Chruschtschow im November 1961 gezeigt hatte $^{60}$. Guttenbergs Einschätzung über die Nutzlosigkeit solcher Gespräche „Was könnte die Sowjetunion zwar den Deutschen, nicht aber deren Alliierten sagen wollen?" 61 - teilte er uneingeschränkt.

Trotz der eindeutigen Ablehnung eines Direktgesprächs mit der UdSSR durch seinen Vorgesetzten gab Kroll sein Vorhaben nicht auf. Als er die Antwort der Bundesregierung am 21. Februar 1962 im Kreml übergab, fügte er hinzu, Bonn beabsichtige damit, „die Tür zu Verhandlungen offenzuhalten“62. Der Schlußsatz des Memorandums - „Wir hoffen, daß der nunmehr begonnene Gedankenaustausch uns in seinem weiteren Verlauf diesem Ziele näherbringt" 63 - zeige, daß seine Regierung die Fortführung des Dialogs wünsche, erläuterte der Botschafter dem sowjetischen Ministerpräsidenten. Doch Chruschtschow erwiderte ungehalten, die Note sei nichts anderes als ein „Propagandapamphlet"64. Eine offizielle Antwort erhielt die Bundesregierung nicht, obwohl dies den diplomatischen Gepflogenheiten widersprach. Offensichtlich war Chruschtschow verärgert, daß es $\mathrm{ihm}$ nicht gelungen war, Bonn zu einem Alleingang zu bewegen. Das Memoran-

55 GREwE, Rückblenden, S. 528.

56 KRONE, Aufzeichnungen, Eintrag vom 9. 2. 1962, S. 167.

57 Vgl. KROLL, Lebenserinnerungen, S. 549.

58 CARSTENS, Erinnerungen, S. 239.

59 Vgl. VOGELSANG, Das geteilte Deutschland, S. $245 \mathrm{f}$.

$60 \mathrm{Vgl}$. GREWE, Rückblenden, S. 528.

61 Vgl. den im Deutschland-Union-Dienst am 5. 2. 1962 veröffentlichten Artikel von Freiherr von und zu Guttenberg: „Knüppel und Köder“, in: DzD IV/8, S. 134.

62 KROLL, Lebenserinnerungen, S. 553.

63 Memorandum der Bundesregierung an die sowjetische Regierung vom 21.2. 1962, in: DzD IV/8, S. 171.

64 KROLL, Lebenserinnerungen, S. 554. 
dum hatte keinen Zweifel daran gelassen, daß die Bundesregierung nicht in Versuchung gebracht werden konnte, aus der westlichen Front auszuscheren. Kroll wiederum beklagte später, das Schriftstück sei so ungünstig formuliert gewesen, daß es eine Verschlechterung der Beziehungen geradezu provoziert habe. So sei die Chance auf einen Ausgleich verspielt und „eine politische Sternstunde“ nicht genutzt worden ${ }^{65}$. Er war von seiner Sicht der Dinge derart überzeugt, daß er seine Memoiren hauptsächlich zu dem Zweck verfaßte, um diese „Kroll-Legende versäumter deutscher Möglichkeiten" zu verkünden ${ }^{66}$.

Der Trubel um seine Person hielt währenddessen an. Weiterhin war er gegenüber Journalisten mitteilsamer, als es sich für einen Diplomaten ziemte. Bereits Mitte Februar 1962 berichtete die Presse, Kroll habe Moskau unter anderem die Anerkennung der Oder-Neiße-Linie, die Akzeptierung des sowjetischen Konzepts einer Freien Stadt Berlin (West) sowie die Aufnahme beider Teile Deutschlands in die UNO angeboten. Auch habe ihn die FDP im Falle einer Ablösung Schröders als neuen Außenminister auserkoren ${ }^{67}$. Der Botschafter bestritt zwar entschieden alle diese Meldungen, doch konnte er seinen Mitteilungsdrang auch dann nicht unterdrücken, als ihm das Auswärtige Amt jede weitere öffentliche Äußerung untersagte ${ }^{68}$. Adenauer befahl schließlich erneut eine Dienstreise nach Bonn, um ihn zur Ordnung zu rufen ${ }^{69}$. Schröder brach wegen dem Fall Kroll sogar einen Urlaub in der Schweiz $a^{70}$. Abermals drängte er den Kanzler, sich einer Abberufung des Botschafters nicht länger zu widersetzen ${ }^{71}$. Ebenso wie Carstens, der deswegen schon mehrmals bei Adenauer vorgesprochen hatte, konnte sich der Außenminister jedoch nicht durchsetzen ${ }^{72}$.

Krolls Verhalten bei seiner Ankunft am 6. März 1962 in Bonn war aber von Schröder nicht mehr hinzunehmen. Auf die Frage von Journalisten, wie es ihm gehe, antwortete der Botschafter süffisant, Auskunft über ihn erteile das Auswärtige Amt; er sei ein „braver Beamter“, der die Weisung seiner Vorgesetzten befolge, keine Informationen an die Presse zu geben! Als ihn Schröder wegen dieses Auftritts am nächsten Tag zur Rede stellte, entgegnete er lapidar, der Minister

65 Ebenda.

66 BESSON, Die Außenpolitik der Bundesrepublik, S. 295. Ebenso EHLERT, Große Grusinische Nr. 17, S. 337-339.

67 Ausgangspunkt der neuerlichen Aufregung war ein Leitartikel von Georg Schröder in der Welt. Der Botschafter wurde darin nicht namentlich erwähnt. Es wurde jedoch ausgeführt, es handle sich um „einen vielgenannten Beamten [...], der den deutsch-sowjetischen Ausgleich, koste es, was es wolle, propagiert“, womit dem aufmerksamen Beobachter klar sein mußte, daß Kroll gemeint war. Vgl. den Artikel von Georg Schröder: „Die Zeit nutzen“, in: DIE WELT vom 17. 2. 1962, S. 1 f. Vgl. auch die Artikel „Brentano: Vorwürfe gegen Kroll klären“, in: DIE WELT vom 1.3. 1962, S. $1 \mathrm{f}$., „Kroll bittet Auswärtiges Amt um Schutz ${ }^{\circ}$, in: DIE WELT vom 2. 3. 1962, S. 1 und S. 4, und „Außenminister Schröder verhängt Nachrichtensperre im Fall Kroll“", in: DIE WELT vom 8. 3. 1962, S. $1 \mathrm{f}$.

$68 \mathrm{Vgl}$. KROLL, Lebenserinnerungen, S. 549-555; EHLERT, Große Grusinische Nr. 17, S. $328-$ 330.

69 Vgl. EHLERT, Große Grusinische Nr. 17, S. 330 f.

70 Vgl. den Artikel „Muß weg“, in: DER SPIEGEL vom 7. 3. 1962, S. 24.

71 Vgl. Krol, Lebenserinnerungen, S. 556.

72 Vgl. CARSTENS, Erinnerungen, S. 239. 
habe wohl vergessen, daß gestern „Fasnacht“" gewesen sei ${ }^{73}$. Dieser suchte daraufhin den Kanzler auf und erklärte ultimativ, er werde von seinem Amt zurücktreten, falls Kroll nicht aus Moskau abgezogen werde ${ }^{74}$. Jetzt ging es nicht mehr um die Frage einer Belastung der Beziehungen zu den USA durch ein Direktgespräch mit Moskau, sondern um die Wahrung von Schröders Autorität ${ }^{75}$. Adenauer sah nun ein, daß der Botschafter nicht mehr zu halten war und verkündete, Kroll sei krank - seine übliche Begründung, wenn jemand von einem Posten entfernt werden sollte ${ }^{76}$.

Schröder hatte den Machtkampf allerdings nur augenscheinlich zu seinen Gunsten entschieden. Eine sofortige Neubesetzung der Botschaft in Moskau konnte er nicht durchsetzen. Vermutlich um Chruschtschow durch die plötzliche Abberufung eines ihm genehmen Mannes nicht über die Maßen zu verärgern, wurde beschlossen, Kroll zunächst in einen „Erholungsurlaub" zu schicken. Anschließend sollte er nach Moskau zurückkehren, aber im Herbst 1962 im Zuge eines größeren Revirements im diplomatischen Korps abberufen werden. Danach war eine Tätigkeit als Berater der Bundesregierung für Ostfragen bis zu seiner Pensionierung im Frühjahr 1963 vorgesehen 77 . Der Fall Kroll, den der stellvertretende Fraktionsund Parteivorsitzende der SPD, Herbert Wehner, als einen der unerfreulichsten in der diplomatischen Nachkriegsgeschichte der Bundesrepublik bezeichnete ${ }^{78}$, schien somit gelöst. Da aber diese Vereinbarung ein vorläufiges Verbleiben des Diplomaten in Moskau ermöglichte, konnte Adenauer auch in den nächsten Monaten über die Schiene Kroll Kontakt zum Kreml halten.

Obwohl Schröder sich gegen ein Treffen des Bundeskanzlers mit der sowjetischen Führung aussprach, ist die Annahme falsch, daß er prinzipiell das Gespräch mit der sowjetischen Regierung ablehnte. Kontakte mit dem Kreml sollten aber nicht hinter dem Rücken der Verbündeten stattfinden, sondern nur in Absprache mit ihnen. Er bat daher zuerst Rusk um Zustimmung 79 , bevor er sich völlig überraschend für die Öffentlichkeit am 13. März 1962 in Genf mit Gromyko traf. Gegenüber der Presse, die sogleich von „einer kleinen Sensation“" sprach ${ }^{80}$, spielte der Minister die Begegnung mit seinem sowjetischen Amtskollegen herunter. Es habe sich um einen reinen „Höflichkeitsbesuch“ gehandelt, erklärte das Auswärtige Amt danach ${ }^{81}$. Doch ganz so unverbindlich war die Unterredung nicht. Die beiden Männer erörterten sowohl die Lage in Berlin als auch das deutsch-sowjetische Verhältnis im allgemeinen. Schröder ging es nach der negativen Reaktion der

73 KROLL, Lebenserinnerungen, S. $555 \mathrm{f}$.

74 Vgl. SCHRÖDER, "Je weiter östlich, desto besser“.

$75 \mathrm{Vgl}$. SCHWARZ, Epochenwechsel, S. 245.

$76 \mathrm{Vgl}$. CARSTENS, Erinnerungen, S. 239.

77 Vgl. Kroll, Lebenserinnerungen, S. 556f.; sowie den Artikel „Kroll zunächst wieder nach Moskau. Später ins Auswärtige Amt", in: DIE WELT vom 10. 3. 1962, S. 1.

78 Vgl. den Artikel "Der Fall Kroll gilt als erledigt“, in: DIE WELT vom 12. 3. 1962, S. 2.

79 Vgl. den Artikel „Noch zu früh“, in: DER SPIEGEL vom 21. 3. 1962, S. 29.

$80 \mathrm{Vgl}$. den Kommentar von Jürgen Tern: „Der Höflichkeitsbesuch“, in: FraNKFURTER AlLGEMEINE ZEITUNG vom 14. 3. 1962, S. 1.

81 Vgl. den Artikel „Überraschende Begegnung in Genf. Schröder heute bei Gromyko“, in:

DIE WELT vom 13. 3. 1962, S. 1. 
UdSSR auf das Memorandum vom 21. Februar vor allem darum, einer weiteren Verschlechterung der bilateralen Beziehungen vorzubeugen. Ausführlich erläuterte er Gromyko die Grundsätze der Deutschland-Politik der Bundesrepublik, die der Note zugrunde lagen, hob aber zugleich hervor, Bonn wolle die Atmosphäre zwischen den beiden Staaten verbessern. Das Memorandum sei der Ausdruck dieses ernsten Willens ${ }^{82}$. Bezüglich der amerikanisch-sowjetischen Diskussion um die Rechte der Westmächte in Berlin brachte er zum Ausdruck, daß Bonn daran zwar "höchst interessiert, aber nicht in erster Reihe beteiligt sei“83. Schröder unterstrich die Verantwortung der Vier Mächte für Berlin und Gesamtdeutschland und machte deutlich, daß es neben den amerikanischen Sondierungen keine weitere Verhandlungsebene geben würde ${ }^{84}$. Damit mußte Gromyko klar sein, daß die Bundesregierung nicht daran dachte, auf etwaige Gesprächsangebote einzugehen, sondern die Verhandlungsführung den Vereinigten Staaten überlassen wollte. Nachdem Schröder keinen Zweifel daran gelassen hatte, daß Bonn nur in Übereinstimmung mit Washington handeln werde, sprach er auch das Thema Kroll an. Gromyko äußerte Verständnis für die Entscheidung des Auswärtigen Amts und erklärte, dies sei „eine rein deutsche Angelegenheit" 85 . Nichts in seinen Ausführungen deutete allerdings darauf hin, daß die UdSSR ihre Haltung zur Berlin- und Deutschland-Frage überdenken wollte. Ohne jegliche Kompromißbereitschaft referierte Gromyko den Standpunkt des Kreml ${ }^{86}$. Wenn also Kroll in seiner Ablösung die Ursache für eine „Abkühlung“ der bilateralen Beziehungen $s{ }^{87}{ }^{87}$ dann überschätzte er zweifellos die Bedeutung seiner Person. Verantwortlich für das gespannte Klima war im wesentlichen die sowjetische Seite, die nicht daran dachte, von ihren Forderungen abzurücken.

Daß Chruschtschow kein wirkliches Interesse an einer Lösung der deutschen Frage hatte, zeigen auch die vergeblichen Bemühungen Adenauers, ihn für seinen sogenannten Burgfriedensplan zu gewinnen. Im Gegensatz zu dem sowjetischen Ministerpräsidenten war der Kanzler nämlich durchaus willens, unverrückbar erscheinende Prinzipien seiner Deutschland-Politik aufzugeben, wenn dadurch eine Verbesserung der Situation in der DDR erzielt werden könnte. Adenauers Burgfriedensplan stand in einer Linie mit der Österreich-Lösung und den Globke-Plänen ${ }^{88}$. Die Österreich-Lösung trug der Kanzler bereits am 19. März 1958 dem sowjetischen Botschafter Smirnow vor: Er konfrontierte ihn mit der Frage, ob seine Regierung unter bestimmten Bedingungen bereit wäre, der DDR den Status

82 Vgl. den Artikel „Schröder nach seinem Besuch bei Gromyko: Interessantes Gespräch“, in: DIE WeLT vom 14.3. 1962, S. 1 und S. 4; sowie das Gespräch des Bundesministers Schröder mit dem sowjetischen Botschafter Smirnow am 26. 10. 1962, PA/AA, Ministerbüro, Bd. 242.

83 Interview Schröders mit dem RIAS am 23. 7. 1962, in: BULLETIN 1962, S. 1166.

84 Vgl. den Artikel „Schröder nach seinem Besuch bei Gromyko: Interessantes Gespräch“, in: DIE WELT vom 14. 3. 1962, S. 1 und S. 4.

85 Zitiert nach dem Artikel „Noch zu früh“, in: DeR SPIEGEL vom 21. 3. 1962, S. 30.

86 Vgl. den Artikel „Schröder nach seinem Besuch bei Gromyko: Interessantes Gespräch“, in: DIE WEIT vom 14. 3. 1962, S. 1 und S. 4.

87 KROLL, Lebenserinnerungen, S. 554.

$88 \mathrm{Vgl}$. OSTERHELD, „Ich gehe nicht leichten Herzens ...“, S. 155. 
Österreichs zu geben. Im Gegenzug stellte Adenauer einen langfristigen Verzicht auf die Wiedervereinigung in Aussicht. Die Wiederherstellung der staatlichen Einheit Deutschlands sollte erst stattfinden, wenn sich die politischen Verhältnisse in Europa völlig verändert hätten ${ }^{89}$. In den folgenden Jahren entwickelte Staatssekretär Globke im Auftrag Adenauers mehrere, inhaltlich weitgehend identische Pläne zur Wiedervereinigung Deutschlands, die aber in der Schublade des Kanzleramts verblieben. Sie sahen als ersten Schritt vor, daß Ost-Berlin der Bevölkerung der DDR die Menschenrechte gewährte und die Freizügigkeit in Deutschland wiederherstellte. Danach sollte ein Vier-Mächte-Abkommen über die Abhaltung freier Wahlen in beiden Teilen Deutschlands und die Umwandlung Berlins in eine Freie Stadt unter UN-Kontrolle geschlossen werden, das ein Jahr nach seiner Unterzeichnung in Kraft treten würde. Fünf Jahre später sei dann eine Volksabstimmung über die Wiedervereinigung durchzuführen: Sollte sich die Mehrheit der Deutschen gegen die Einheit aussprechen, würden die DDR und die Bundesrepublik getrennte Wege gehen; andernfalls sei eine gesamtdeutsche Regierung zu bilden, die frei über die Bündniszugehörigkeit des vereinten Deutschlands entscheiden konnte ${ }^{90}$.

Bereits in den Monaten vor seinem berühmten Gespräch mit Smirnow am 6. Juni 1962, in dem er seinen Burgfriedensplan präsentierte, hatte der Kanzler mehrmals angedeutet, daß er eine neue deutschlandpolitische Initiative plante. Im November 1961 machte er gegenüber Kennedy die bereits erwähnte Bemerkung, wenn den Menschen in der DDR mehr Freiheit zugestanden würde, könnte er sich sogar vorstellen, auf die Wiedervereinigung zu verzichten. Einige Monate später, am 20. Februar 1962, erläuterte er seine Überlegungen dem amerikanischen Journalistenehepaar Flora und Sidney Gruson näher. Er eröffnete ihnen, er wolle die Beziehungen zur Sowjetunion normalisieren, doch müsse zuvor das totalitäre System in der DDR verschwinden. Die Bundesrepublik könnte dann ihre Politik gegenüber Ost-Berlin ändern: „Wenn in der Ostzone ein Regime wäre wie in Rußland oder wie in Polen oder der Tschechoslowakei, dann würde dadurch die Bitterkeit sehr viel gemildert werden. Denn die Frage der Ostzone ist auch ein sehr menschliches Problem. Ich habe das immer als ein menschliches Problem in erster Linie aufgefaßt, nicht als nationales Problem, sondern daß den Menschen dort geholfen wird." 91 Sollte Chruschtschow eine solche Entwicklung in die Wege leiten, dann würde sich das bilaterale Verhältnis rapide verbessern, betonte Adenauer. Der Beantwortung der Frage Sidney Grusons, ob er auch an eine völkerrechtliche Anerkennung der DDR denke, wich der Kanzler zwar aus, doch erklärte er, die Bundesrepublik beabsichtige, für die von ihm beschriebene Entwicklung, „einen Preis zu bezahlen“92. Nach Beendigung der Differenzen mit den

89 Vgl. Adenauer, Erinnerungen III, S. 377-380; GotTo, Adenauers Deutschland- und Ostpolitik, S. 34-40.

90 Für den Wortlaut der Globke-Pläne vgl. Der Globke-Plan ZUR Wiedervereinigung. Vgl. auch GOTTO, Adenauers Deutschland- und Ostpolitik, S. 49-55.

91 ADENAUER, Teegespräche 1961-1963, S. 102.

92 Ebenda. Zehn Tage später, am 2. 3. 1962, erklärte er in einem Hintergrundgespräch erneut, die Lage in der DDR sei für ihn in erster Linie ein menschliches Problem, welches für ihn „noch vor dem nationalen Problem steht“. Vgl. ebenda, S. 122. 
USA Ende Mai 1962 griff Adenauer diesen Gedanken gegenüber Kennedy erneut auf. Wie bereits ausgeführt, erklärte er in seinem Schreiben an den Präsidenten vom 25. Mai, die Bundesrepublik sei bereit, über vieles zu sprechen, wenn Moskau für humanere Lebensumstände in der DDR sorgen würde ${ }^{93}$.

$\mathrm{Da}$ die amerikanisch-sowjetischen Berlin-Sondierungen keine Fortschritte machten, sah sich der Kanzler schließlich veranlaßt, auf eigene Faust zu handeln. Er hielt die momentane Ruhe in Berlin für trügerisch und erwartete einen neuen Vorstoß Moskaus ${ }^{94}$. Ohne die Verbündeten oder sein eigenes Außenministerium zu konsultieren, unterbreitete er Smirnow am 6. Juni den Vorschlag, „für zehn Jahre eine Art Waffenstillstand [...] zu schließen"95. Während dieses Zeitraums sollte der Status quo nicht verändert werden; in der DDR müßten aber dafür Verhältnisse geschaffen werden, die den Menschen ein freieres Leben erlaubten. Nach Ablauf dieses Burgfriedens in zehn Jahren, so Adenauer, werde sich das Klima zwischen Bonn und Moskau verbessert haben, und es sei dann weniger problematisch, sich über die noch im Raum stehenden Probleme zu verständigen. Eindringlich bat er den Botschafter um eine rasche Antwort, die ihm möglichst noch vor dem für Ende Juni geplanten Besuch Rusks in Bonn vorliegen sollte ${ }^{96}$. Doch erst am 2. Juli übergab Smirnow ein Aide-mémoire, in dem die sowjetische Regierung den Plan des Kanzlers zurückwies und ihre einschlägig bekannten Parolen zur deutschen Frage wiederholte ${ }^{97}$.

Adenauer, der die Erfolgsaussichten seiner Idee von Anfang an recht skeptisch beurteilt hatte ${ }^{98}$, ließ sich durch diesen ersten Fehlschlag nicht entmutigen. Im Herbst 1962 unterrichtete er die amerikanische Regierung in groben Zügen von seinem Plan. Nachdem ihm am 26. Oktober Dowling mitgeteilt hatte, Kennedy und Rusk wünschten detailliertere Informationen, wies er Ministerialdirigent Osterheld an, eine Aufzeichnung auszuarbeiten. Der Leiter des Außenpolitischen Büros im Kanzleramt sollte sich dabei an den Globke-Plänen orientieren. Osterheld verband nun das Burgfriedenskonzept, wie es Adenauer gegenüber Smirnow am 6. Juni vorgetragen hatte, mit diesen Plänen und entwickelte es zu einem Stillhalteabkommen weiter: Die in den Globke-Plänen vorgesehene Volksabstimmung in der Bundesrepublik und der DDR über eine Wiedervereinigung sollte nun erst nach einer zehnjährigen Respektierung des Status quo erfolgen ${ }^{99}$. Schröder unterstützte Adenauers Idee. Er regte an, eine Note an die UdSSR auszuarbeiten, in die der Plan eingearbeitet werden sollte. Dies lehnte der Kanzler jedoch

93 Vgl. FRUS 1961-1963, XV, Dok. 58, S. 160. Vgl. auch OSTERHELD, S. 118.

94 Vgl. SCHWARZ, Adenauer II, S. 750.

95 Aufzeichnung des Auswärtigen Amts über das Gespräch des Bundeskanzlers Adenauer mit dem sowjetischen Botschafter Smirnow am 6. 6. 1962, in: DzD IV/8, S. 625. Vgl. auch OSTERHELD, „Ich gehe nicht leichten Herzens ...“, S. 121 f.; MENDE, Von Wende zu Wende, S. 43.

96 Vgl. die Aufzeichnung des Auswärtigen Amts über das Gespräch des Bundeskanzlers Adenauer mit dem sowjetischen Botschafter Smirnow am 6.6. 1962, in: DzD IV/8, S. $624 \mathrm{f}$.

97 Vgl. Osterheld, „Ich gehe nicht leichten Herzens ...“, S. $130 \mathrm{f}$.

98 Vgl. ebenda, S. 122.

99 Vgl. ebenda, S. 155-157. 
$a b^{100}$. Er setzte statt dessen darauf, daß sich die Vereinigten Staaten sein Konzept zu eigen machen und es selbst der Sowjetunion vortragen würden. Bei einem Besuch in Washington am 14. November 1962 weihte er Kennedy in seine Überlegungen ein und ließ ihm von Carstens die Vorteile eines solchen Stillhalteabkommens für die UdSSR schildern: So böte ein derartiges Abkommen Moskau die Möglichkeit, die Deutschen in der DDR zehn weitere Jahre in ihrem Sinne zu indoktrinieren. Auf diese Weise könnte die sowjetische Regierung die Chancen erhöhen, daß sich bei der Volksabstimmung die Mehrheit der Bevölkerung gegen die Wiedervereinigung aussprechen würde. Adenauer versprach im Falle eines negativen Ausgangs des Referendums eine völkerrechtliche Anerkennung der DDR. Zudem sah der Plan des Kanzlers offizielle Kontakte zwischen den beiden deutschen Staaten vor, womit eine alte Forderung der Sowjetunion erfüllt wurde ${ }^{101}$. Gleichwohl konnte sich Kennedy nicht für den Plan erwärmen. Er war der Ansicht, das Konzept habe keine Aussicht, von Chruschtschow akzeptiert zu werden, da es dem Kreml keinerlei Vorteile bringe ${ }^{102}$. Weder der Präsident noch Rusk waren gewillt, über den Vorschlag weiter nachzudenken. Nicht einmal einer Fortsetzung des Gedankenaustauschs im Washingtoner Botschafterlenkungsausschuß stimmten sie zu. Nur wenige Tage, nachdem die Kuba-Krise die Welt an den Rand des atomaren Abgrunds geführt hatte, wollte die amerikanische Regierung ihren Kontrahenten nicht durch einen Vorstoß in der deutschen Frage provozieren. Sie fürchtete, Moskau könnte darauf mit einer Wiederbelebung der Berlin-Krise antworten. Chruschtschow sollte nach dem Rückzug, den er in Kuba angetreten hatte, nicht weiter bedrängt werden. Erst sei der nächste Schritt des sowjetischen Ministerpräsidenten abzuwarten, gab Kennedy daher dem Kanzler zu verstehen. Er wollte vorläufig keine diplomatische Aktivitäten unternehmen, damit die Sowjetunion weiterhin in ihrer momentanen Passivität verharrte ${ }^{103}$.

Im Frühjahr 1963 griff Moskau schließlich von sich aus den Gesprächsfaden mit Bonn wieder auf. Bei einem Abendessen am 2. April, zu dem Smirnow Kroll eingeladen hatte, erklärte der sowjetische Diplomat, seine Regierung wünsche sich eine Verbesserung der Beziehungen. Kroll entgegnete darauf, der Kreml habe „im Juni 62 die Chance dafür verpaßt"104. Doch Smirnow erwiderte, Adenauer habe die damalige Antwort Chruschtschows „zu negativ interpretiert"105. Drei Wochen später sprach er den früheren Botschafter der Bundesrepublik in Moskau erneut an und eröffnete ihm, Chruschtschow sei zu einem Gespräch mit dem Kanzler bereit. Adenauer solle über Kroll seine Vorschläge übermitteln ${ }^{106}$. Im Rahmen einer Veranstaltung des Vereins der Auslandspresse am 4. Juni 1963 wandte sich der sowjetische Botschafter dann direkt an den Kanzler und informierte ihn über die Gesprächsbereitschaft seiner Regierung. Adenauer wies dar-

100 Vgl. FRUS 1961-1963, XV, Dok. 153, S. 430, und Dok. 154, S. 443.

101 Vgl. ebenda, Dok. 154, S. 436-438.

102 Vgl. ebenda, Dok. 154, S. 438.

103 Vgl. ebenda, Dok. 154, S. 439-443.

104 Aufzeichnung des Botschafters Kroll vom 29. 4. 1963, in: AAPD 1963, Dok. 155, S. 502.

105 Ebenda, S. 503.

106 Vgl. ebenda. 
aufhin Kroll an, Smirnow die Botschaft zu überbringen, die UdSSR habe seinen Burgfriedensplan vom Juni vergangenen Jahres noch nicht beantwortet ${ }^{107}$. Als Kroll deswegen am 21. Juni bei Smirnow vorsprach, vertraute ihm dieser an, die sowjetische Regierung beabsichtige, „alle Fragen, die zwischen unseren beiden Ländern heute noch ungelöst stehen, in einem streng vertraulichen Gedankenaustausch zu erörtern“. Sie sei deswegen zu einem „Treffen auf höchster Ebene bereit" ${ }^{108}$. Er unterstrich dabei explizit, daß dies "unwiderruflich der letzte Versuch [...] sei, die deutsche Frage in unmittelbaren Besprechungen mit der Bundesregierung zu klären" 109 .

Drei Tage später informierte Adenauer Kennedy über das Angebot Chruschtschows. Der Präsident reagierte zunächst nicht sehr begeistert, da „aus solchen Kontakten nichts Positives käme"110, stimmte aber einer Fortsetzung der Sondierungen $\mathrm{zu}^{111}$. Kurz darauf schickte er jedoch dem Kanzler einen Brief, in dem er ihn nun sogar nachdrücklich dazu aufrief, das Gesprächsangebot wahrzunehmen ${ }^{112}$. De Gaulle riet Adenauer ebenfalls zu einem Treffen mit dem sowjetischen Ministerpräsidenten, auch wenn er die Erfolgsaussichten einer solchen Begegnung skeptisch beurteilte. Er hielt zwar eine gewisse Entspannung im deutschsowjetischen Verhältnis für möglich, nicht aber die Zustimmung des Kreml zur Wiederherstellung der staatlichen Einheit Deutschlands ${ }^{113}$. Der Kanzler spekulierte jedoch, Chruschtschow könnte sehr wohl an einem Gespräch über die Wiedervereinigung interessiert sein, da angesichts des bevorstehenden Rücktritts Adenauers jetzt die letzte Gelegenheit zu Verhandlungen gekommen sei. Chruschtschow wisse, daß „er mit Erhard als Nachfolger nie verhandeln könne, weil dieser sich nicht stark genug fühle, für das Ergebnis solcher Verhandlungen die Verantwortung zu übernehmen ", meinte der Kanzler ${ }^{114}$. Er beabsichtigte jedoch, zunächst die sowjetischen Pläne genauer in Erfahrung zu bringen. Kroll sollte deshalb eine Einladung Chruschtschows zu einem Urlaub in der UdSSR annehmen und dabei die Absichten des Kreml eruieren ${ }^{115}$.

Nachdem Adenauer auf ausdrücklichen Wunsch Smirnows das Auswärtige Amt zunächst nicht über dessen Gespräche mit Kroll informiert hatte, da dort „Kräfte vorhanden seien, die keinerlei Beilegung der Schwierigkeiten mit der So-

107 Vgl. die Aufzeichnung des Bundeskanzlers Adenauer vom 4.6. 1963, in: ebenda, Dok. 186, S. $603 \mathrm{f}$.

108 Vgl. die Aufzeichnung des Botschafters Kroll vom 21.6. 1963, in: ebenda, Dok. 200, S. 644-646 (645).

109 Aufzeichnung des Botschafters Kroll vom 25. 6. 1963, in: ebenda, Dok. 212, S. 683.

110 Gespräch des Bundeskanzlers Adenauer mit Präsident Kennedy am 24.6. 1963, in: ebenda, Dok. 206, S. 665.

111 Vgl. ebenda, S. 662-666. Vgl. auch ADENAUER, Erinnerungen IV, S. 226.

112 Vgl. ebenda, S. 226.

113 Vgl. Gespräch des Bundeskanzlers Adenauer mit Staatspräsident de Gaulle am 4. 7. 1963, in: AAPD 1963, Dok. 216, S. 692-696; ADENAUER, Erinnerungen IV, S. 223-226.

114 Vgl. ADENAUER, Erinnerungen IV, S. 225.

115 Vgl. das Gespräch des Bundeskanzlers Adenauer mit Präsident Kennedy am 24. 6. 1963, in: AAPD 1963, Dok. 206, S. 666. 
wjetunion wünschten"116, leitete er am 29. Juli schließlich doch eine am 21. Juni gefertigte Aufzeichnung Krolls über die Kontakte mit dem sowjetischen Repräsentanten in Bonn an Schröder weiter ${ }^{117}$. Zwei Tage später fand eine Besprechung statt, in der der Kanzler den Spitzen der CDU seinen Plan vortrug, Kroll als Emissär nach Moskau zu schicken. Schröder, aber auch Krone und von Brentano waren allerdings gegen eine Fortführung der Sondierungen ${ }^{118}$. Das Auswärtige Amt hielt die Erfolgsaussichten für äußerst gering. Das Kroll von Smirnow am 21. Juni ausgehändigte Aide-mémoire, welches die Vorstellungen der sowjetischen Führung über die Fortsetzung des Dialogs enthielt ${ }^{119}$, wurde nicht als ausreichende Grundlage für weitere Gespräche angesehen: „Ich finde keinen sachlichen Anknüpfungspunkt ...", vermerkte Carstens ${ }^{120}$. Adenauer war hingegen überzeugt, der Hinweis auf die Möglichkeit einer Verständigung mit der UdSSR sei leichtfertig als ein taktischer Schachzug interpretiert worden, seinen bevorstehenden Rücktritt hinauszuzögern ${ }^{121}$. Er wollte aber unter keinen Umständen Verhandlungen mit Moskau einleiten, die er nicht zu Ende führen konnte ${ }^{122}$. So brach Bonn den Gesprächsfaden ab, ohne daß in Erfahrung gebracht werden konnte, ob tatsächlich die Chance eines Ausgleichs mit der Sowjetunion bestand.

\section{Der Beginn einer neuen Osteuropa-Politik}

Bis zum Amtsantritt Schröders waren die Beziehungen Bonns zu den kommunistischen Staaten Ostmittel- und Südosteuropas unterentwickelt. Dies war im wesentlichen auf den Alleinvertretungsanspruch der Bundesrepublik zurückzuführen. Am 21. Oktober 1949 hatte Adenauer vor dem Bundestag erklärt, die in der Sowjetzone "geschaffene Organisation" sei kein Staat, weil sie gegen den freien Willen der Bevölkerung gegründet worden sei. Er zog daraus die Folgerung: „Die Bundesrepublik Deutschland ist somit bis zur Erreichung der deutschen Einheit insgesamt die alleinige legitimierte staatliche Organisation des deutschen Volkes.“ Die Bundesregierung sei deshalb auf der internationalen Bühne „allein befugt, für das deutsche Volk zu sprechen"123. Anläßlich der Aufnahme diplomatischer Beziehungen zwischen Bonn und Moskau im Jahr 1955 unterstrich die Bundesregierung erneut die Gültigkeit des Alleinvertretungsanspruchs ${ }^{124}$. Um diesen

116 Gespräch des Bundeskanzlers Adenauer mit Staatspräsident de Gaulle am 4. 7. 1963, in: ebenda, Dok. 216, S. 692.

117 Vgl. AAPD 1963, S. 644, Anm. 1.

$118 \mathrm{Vgl}$. die Aufzeichnung des Referenten im Bundesministerium für besondere Aufgaben, Abelein, vom 12. 8. 1963, ACDP, Nachlaß Krone I-028-033/4.

119 Aide-mémoire der sowjetischen Regierung an die Bundesregierung vom 21.6. 1963, PA/ AA, B 150, Aktenkopien 1963.

$120 \mathrm{Vgl}$. AAPD 1963, S. 645, Anm. 4.

121 Vgl. ADENAUER, Erinnerungen IV, S. 226.

122 Vgl. KROLL, Lebenserinnerungen, S. 582.

123 DOKUMENTE DES GETEILTEN DEUTSChLAND, Bd. 1, S. $203 \mathrm{f}$.

124 In einem Schreiben vom 14.9. 1955 an den sowjetischen Ministerpräsidenten Bulganin führte Adenauer aus, die „Aufnahme diplomatischer Beziehungen mit der Regierung der Sowjetunion bedeutet keine Änderung des Rechtsstandpunktes der Bundesregierung in 
Anspruch durchzusetzen, formulierte sie die Hallstein-Doktrin und gab bekannt, daß sie weiterhin „die Aufnahme diplomatischer Beziehungen mit der DDR durch dritte Staaten, mit denen sie offizielle Beziehungen unterhält, als einen unfreundlichen Akt ansehen würde, da er geeignet wäre, die Spaltung Deutschlands zu vertiefen" 125 . Da die osteuropäischen Staaten die DDR zu diesem Zeitpunkt bereits anerkannt hatten, schien der Austausch von Botschaftern mit ihnen nicht möglich. Der damaligen Auffassung zufolge hätte die Bundesrepublik Ost-Berlin de facto anerkannt, wenn sie an einem Ort, an dem sich bereits eine Botschaft der DDR befand, ebenfalls eine diplomatische Vertretung eröffnet hätte. Zwar gab es Stimmen im Auswärtigen Amt, die die Ansicht vertraten, diese Staaten seien in ihrer Entscheidung, die DDR völkerrechtlich anzuerkennen, nicht frei gewesen, doch konnte sich diese sogenannte Geburtsfeblertheorie nicht durchsetzen ${ }^{126}$. Lediglich hinsichtlich der UdSSR galt eine Ausnahme. Die Aufnahme diplomatischer Beziehungen mit Moskau wurde von Bonn damit gerechtfertigt, daß die UdSSR eine der Vier Mächte war, die laut der Berliner Vier-Mächte-Erklärung vom 5. Juni $1945^{127}$ für Deutschland als Ganzes Verantwortung trug ${ }^{128}$. Aufgrund der restriktiven Auslegung der sogenannten Hallstein-Doktrin beschränkten sich die Kontakte Bonns zu den osteuropäischen Staaten in den fünfziger Jahren weitgehend auf Handelsfragen. Daß ein politischer Dialog so gut wie nicht stattfand, war jedoch auch darauf zurückzuführen, daß die Bundesregierung ihre Ostpolitik in erster Linie als Wiedervereinigungspolitik verstand und sich deswegen auf die Beziehungen zur UdSSR konzentrierte ${ }^{129}$.

Die Nachteile der Vernachlässigung des sowjetischen Satellitengürtels waren im Auswärtigen Amt bereits frühzeitig erkannt worden. Seit 1955 wurde dort die Errichtung von Handelsvertretungen in diesem Raum als "Zwischenlösung "130 diskutiert. Vor allem eine Verbesserung der Beziehungen zu Polen schien im Hinblick auf das Problem der Oder-Neiße-Linie dringend geboten. Sondierungen in Warschau blieben aber erfolglos, da die polnische Regierung die Aufnahme normaler diplomatischer Beziehungen forderte und keine Übergangslösungen akzeptierte ${ }^{131}$. Gerhard Schröder kommt nun das Verdienst zu, den Gedanken, Handelsmissionen in Osteuropa zu eröffnen, „aufgegriffen und energisch vorangetrieben“" zu haben 132. „Damit habe ich ein Stück konstruktiver Belebung in die Adenauersche Politik gebracht", bewertete er im Rückblick diese Neuausrichtung der Bonner Ostpolitik ${ }^{133}$. Die Anregung dazu kam von dem Leiter der Ostabteilung des Auswärtigen Amts, Franz Krapf. Er hielt es für dringend geboten, die politi-

bezug auf ihre Befugnis zur Vertretung des deutschen Volkes in internationalen Angelegenheiten“. Vgl. DzD III/1, S. 337.

125 Vgl. die Regierungserklärung Adenauers vom 22. 9. 1955, in: ebenda, S. 389.

126 Vgl. GREWE, Rückblenden, S. 252.

127 Für den Wortlaut vgl. DoKumente des geteilten Deutschland, Bd. 1, S. 19-24.

128 Vgl. die Regierungserklärung Adenauers vom 22. 9. 1955, in: DzD III/1, S. 384.

129 Vgl. LindemanN, Anfänge, S. 45.

130 GREWE, Rückblenden, S. 752.

131 Vgl. LiNDEMANN, Anfänge, S. 47-53.

132 GREWE, Rückblenden, S. 265.

133 Zitiert nach TiEsEnhAUSEN, Die Sache mit China, S. 31. 
sche Passivität der Bundesrepublik im osteuropäischen Raum zu beenden, um es der Sowjetunion zu erschweren, ihre Verbündeten propagandistisch gegen Bonn einzusetzen. Der Ministerialdirektor wußte, daß die Bundesrepublik nur dann auf die Politik der Osteuropäer Einfluß nehmen konnte, wenn sie über einen direkten Draht zu den osteuropäischen Regierungen verfügte ${ }^{134}$. Eine Intensivierung des Kontakts bot sich zudem an, da die Satellitenstaaten der UdSSR seit einigen Jahren bestrebt waren, „den Spielraum der eigenen Politik zu vergrößern“135. Einerseits nutzten die Osteuropäer dabei das sowjetisch-chinesische Schisma geschickt aus, andererseits hatte ihnen Chruschtschow bereits im Zuge der sogenannten ersten Entstalinisierungsphase, die er mit seiner berühmten Geheimrede auf dem XX. Parteitag der KPdSU im Februar 1956 einleitete, mehr Freiraum zugestanden ${ }^{136}$. Schröder sah in dieser Entwicklung eine Chance für die auswärtige Politik Bonns ${ }^{137}$. Er ging auf den Vorschlag Krapfs ein und beauftragte ihn, das Interesse der Osteuropäer an der Eröffnung von Handelsvertretungen in ihren Ländern $\mathrm{zu}$ eruieren ${ }^{138}$. Sein Vorhaben, die Beziehungen zu den osteuropäischen Staaten $\mathrm{zu}$ verbessern, wurde von der amerikanischen Regierung ausdrücklich befürwortet ${ }^{139}$.

Die gestiegene Bedeutung der Staaten Ostmittel- und Südosteuropas in der außenpolitischen Prioritätenskala der Bundesrepublik umriß Schröder erstmals in einer Grundsatzrede am 4. Juni 1962 auf dem 11. Bundesparteitag der CDU in Dortmund ${ }^{140}$. Er beschrieb den Delegierten seine Vision einer künftigen wirtschaftlichen Zusammenarbeit zwischen der EWG und Osteuropa, verlangte aber zunächst von der UdSSR die "Lösung der noch anstehenden politischen Fragen“, bevor eine umfangreiche ökonomische Kooperation in die Wege geleitet werden könnte ${ }^{141}$. Einer Normalisierung des Verhältnisses, so der Außenminister, stünde ferner auch die antideutsche Stimmung der Osteuropäer entgegen, die eine Folge ihrer negativen Erfahrungen mit dem ,Dritten Reich“ sei. Bedauerlicherweise fördere die "kommunistische Haßpropaganda" die Vorurteile und male ständig "das Schreckgespenst des revanchelüsternen Deutschen" an die Wand. Die Bundesrepublik betreibe aber keine revanchistische Politik, betonte Schröder: „Unsere Politik ist nicht rückwärts, sondern vorwärts gewandt." Um die vorhandenen Barrieren abzubauen, sei es daher notwendig, "bessere kulturelle und menschliche Kontakte zwischen den Deutschen in der Bundesrepublik und den osteuropäischen Völkern herzustellen“. Eine erste Annäherung sollte durch eine Auswei-

134 ZeitZeugenbefragung Krapf.

135 STÖKL, Russische Geschichte, S. 782.

136 Vgl. HACKER, Der Ostblock, S. 530-534 und S. 649-687. Ihren sinnbildhaften Ausdruck fand die neue Politik der UdSSR in der Auflösung des Kominform am 17.4. 1956. Vgl. ebenda, S. 533 f. Auf dem XXII. Parteikongreß der KPdSU vom 17. bis 31. 10. 1961 verkündete Chruschtschow dann die „zweite Entstalinisierung“. Vgl. ebenda, S. 678.

137 Vgl. das Gespräch des Bundesministers Schröder mit Abgeordneten des Bundestages am 12. 7. 1963, in: AAPD 1963, Dok. 225, S. 746.

138 ZEITZEUGENBEFRAGUNG Krapf.

139 Vgl. MCGHEE, Botschafter, S. 135.

140 Für den Wortlaut vgl. BuLletin 1962, S. 897-902.

141 Ebenda, S. 898. 
tung der Handelsbeziehungen erfolgen. Schröder gab bekannt, daß dieser Schritt im Augenblick von der Bundesregierung gründlich geprüft werde ${ }^{142}$, ließ jedoch keinen Zweifel daran, daß Bonn seiner Ansicht nach auf eine Verbesserung der Beziehungen zu den osteuropäischen Staaten hinwirken müsse: „Wir Deutschen leben nun einmal in der Mitte Europas, und unser geteiltes Volk leidet unter der Ost-West-Spaltung mehr als alle anderen europäischen Völker. Es ist daher unsere Aufgabe, trotz aller Widerstände der anderen Seite, Brücken zu schlagen und die Spaltung Europas, soweit uns dieses möglich ist, zu überwinden. "143

Bei der Verwirklichung seines Plans kam Schröder entgegen, daß das Interesse der osteuropäischen Regierungen an intensiveren Handelsbeziehungen stark zugenommen hatte, weshalb sie allmählich von ihrer starren Haltung abrückten, keine Vertretungen unterhalb der Botschafterebene zu akzeptieren. Bereits im Mai 1962 ließ die ungarische Regierung durch den Generalbevollmächtigten der Firma Krupp, Berthold Beitz, das Angebot übermitteln, sie sei bereit, über die Errichtung einer Handelsvertretung in Budapest zu verhandeln. Nur einen Monat später wurden mit der polnischen Regierung Gespräche über ein Handelsabkommen aufgenommen, wobei Warschau ebenfalls die Eröffnung einer Handelsmission der Bundesrepublik in Aussicht stellte ${ }^{144}$. Die Aufnahme von Verhandlungen mit den osteuropäischen Staaten geschah mit der Zustimmung Adenauers, wie Schröder im Rückblick ausdrücklich hervorhob ${ }^{145}$. Bei der Umsetzung dieser Politik ließ ihm der Kanzler aber viel Freiraum ${ }^{146}$. Daß Adenauer die Ostpolitik seines Außenministers vorbehaltlos billigte, wird von seinen engen Mitarbeitern bestätigt ${ }^{147}$. Für die Behauptung mancher Zeithistoriker, Adenauer habe den Plänen Schröders nur widerwillig zugestimmt ${ }^{148}$, gibt es keinen Anhaltspunkt.

Durch einen im September 1962 im Deutschland-Union-Dienst veröffentlichten Aufsatz des Vorsitzenden des außenpolitischen Arbeitskreises der CDU/ CSU-Bundestagsfraktion, Ernst Majonica, erfuhr die Öffentlichkeit, daß die Bestrebungen Bonns, Handelsvertretungen in Osteuropa zu eröffnen, viel weiter vorangeschritten waren, als man nach den vagen Ankündigungen Schröders in Dortmund angenommen hatte ${ }^{149}$. Während SPD und FDP die Aufnahme von Gesprächen mit Polen und Ungarn begrüßten, verfolgte die CDU/CSU-Fraktion die Politik des Außenministers mit Unbehagen. Vor allem der Fraktionsvorsitzende von Brentano sparte nicht an Kritik ${ }^{150}$. Er warnte unmißverständlich vor

142 Ebenda., S. $901 \mathrm{f}$.

143 Ebenda, S. 902.

144 Vgl. LiNDEMANN, Anfänge, S. $68 \mathrm{f}$.

145 Vgl. SCHRÖDER, "Je weiter östlich, desto besser“.

146 Vgl. Tiesenhausen, Die Sache mit China, S. 31.

147 Osterheld spricht beispielsweise von einem "gemeinsamen Plan“ Adenauers und Schröders. Vgl. OSTERHELD, „Ich gehe nicht leichten Herzens ...“, S. 209.

148 So z.B. GrIfFITH, Die Ostpolitik der Bundesrepublik Deutschland, S. 152.

149 Vgl. die Artikel „Bonn an Handelsmissionen im Ostblock interessiert“, in: FrANKFURTER ALlgEMEINE ZEITUNG vom 26. 9. 1962, S. 3, und „Bonn denkt an Handelsvertretungen im Ostblock“, in: FrankfurTer Allgemeine ZeITUNG vom 28. 9. 1962, S. 1 und S. 4.

150 Vgl. die Artikel „Brentano beharrt auf seinen Vorwürfen gegen Brandt“, in: FrankFURTER Allgemeine ZeituNG vom 3.10. 1962, S. 1, „Gradl schwächt Brentanos Kritik an 
einer "schleichenden Aufnahme diplomatischer Beziehungen und folgenschwerer Durchlöcherung der Hallstein-Doktrin"151. Gegen den Vorwurf, Handelsvertretungen der Bundesrepublik in den Ostblock-Staaten seien mit den Grundsätzen der Deutschland-Politik nicht zu vereinbaren, verteidigte sich Schröder entschieden. Er machte sich dabei die Argumentation der Geburtsfehlertheorie zu eigen und wies darauf hin, daß die Staaten Ostmittel- und Südosteuropas als Teil des Ostblocks gezwungen waren, von Anfang an eine andere Haltung zur deutschen Frage einzunehmen. Trotzdem dürfe sich die Bundesregierung nicht der Aufgabe entziehen, auch gegenüber diesen Staaten den Alleinvertretungsanspruch für Gesamtdeutschland zu verfechten. Schröder gab zu, daß damit deutschlandpolitisch „ein ziemlich schmaler Grat" begangen werde ${ }^{152}$. Die Problematik der Nichtanerkennung der DDR müsse eben in diesem Fall „ein bißchen beiseite gelassen werden" 153 .

Am 7. März 1963 konnten die Verhandlungen mit Polen mit der Unterzeichnung eines Handelsabkommens ${ }^{154}$ erfolgreich beendet werden. In einem Schreiben an von Brentano betonte Schröder, der Bundestag könne das Abkommen bedenkenlos ratifizieren, „weil es - ohne unsere politischen und rechtlichen Positionen in der Deutschland- und Berlinfrage zu beeinträchtigen - möglicherweise nützliche Ansätze zu einer im deutschen Interesse notwendigen Auflockerung in Osteuropa bietet" 155 . Auch gegenüber der Öffentlichkeit bekräftigte er nachdrücklich, die Eröffnung einer Handelsmission in Warschau bedeute "nicht die Aufnahme diplomatischer oder auch nur konsularischer Beziehungen"; sie sei lediglich ein Gegenstück zu der bereits seit dem Ende des Zweiten Weltkrieges in Köln befindlichen polnischen Handelsvertretung. Das Abkommen bedeute daher kein Abweichen von der Hallstein-Doktrin: „Unsere politische Linie bleibt unberührt, daß die Aufnahme diplomatischer Beziehungen mit der Sowjetischen Besatzungszone durch dritte Staaten, mit denen die Bundesrepublik diplomatische Beziehungen unterhält, einen unfreundlichen Akt darstellt, der die Spaltung Deutschlands vertiefen und verhärten würde." 156

In den Instruktionen an den Diplomaten Alfred Blumenfeld, der mit der Aufgabe betraut wurde, die Handelsvertretung der Bundesrepublik in Warschau aufzubauen, strich das Auswärtige Amt ebenfalls heraus, daß diese einen „ausschließlich wirtschaftlichen Charakter" habe. Sie sollte nur dann politisch aktiv werden,

Brandt ab“, in: Frankfurter Allgemeine Zeitung vom 4. 10. 1962, S. 1, und „Handelsmissionen noch umstritten“, in: DIE WELT vom 1. 10. 1962, S. 2.

151 Zitiert nach dem Artikel „Kuh vom Eis“, in: DeR SPIEgEL vom 10. 10. 1962, S. 23.

152 BT STENOGRAPHISCHE BERICHTE, Bd. 53, S. 3515.

153 Zitiert nach dem Artikel „Bonn wünscht den Beitritt Londons“, in: FrANKFURTER ALLGEMEINE ZEITUNG vom 20. 9. 1962, S. 4.

154 Für den Wortlaut der Vereinbarungen vom 7.3. 1963 zwischen der Bundesrepublik und Polen über den Waren- und den Seeschiffahrtsverkehr vgl. BuNDESANZEIGER, Nr. 64 vom 2. 4. 1963, S. 1-3.

155 Schreiben Schröders an von Brentano vom 12. 7. 1963. Zitiert nach LEMKE, Die Berlinkrise 1958 bis 1963, S. 218.

156 Interview Schröders mit der dpa am 7. 3. 1963, in: BULLETIN 1963, S. 389. 
falls die Initiative „von den Polen ausgehen“ würde ${ }^{157}$. Obwohl die unpolitische Ausrichtung der Handelsmission ausdrücklich hervorgehoben wurde, verstummte die Kritik an Schröders Kurs nicht. Insbesondere Brentano bekräftigte den Vorwurf, das Handelsabkommen mit Polen gefährde die Deutschland-Politik der Bundesregierung. Er stieß sich daran, daß das Abkommen keine Berlin-Klausel enthielt. Somit habe Warschau die außenpolitische Vertretung von Berlin (West) durch die Bundesrepublik nicht anerkannt ${ }^{158}$. Schröder antwortete darauf mit der rhetorischen Frage, "ob wir deshalb, weil wir die Ostblockregierungen anläßlich von Wirtschaftsverhandlungen nicht zur Aufgabe ihrer Berlin-These bewegen können, auf wirtschaftliche Vereinbarungen verzichten oder ob wir uns dieses Mittels bedienen sollen, um ein gewisses Maß von Kontakten mit diesen Regierungen aufrechtzuerhalten - dies in der Hoffnung, dann auch einmal zu Fortschritten auf anderen Gebieten zu gelangen" 159 . Ihm war also sehr wohl bewußt, daß er sich im Gegensatz zu seinen Behauptungen mit dem Abkommen durchaus abseits von der bisherigen deutschlandpolitischen Linie bewegte.

Mechthild Lindemann stellt zu Recht fest, daß der Osteuropa-Politik Schröders zunächst noch keine „ausgefeilte Konzeption mit weitgesteckten politischen Zielen" zugrunde lag 160 . Es war vielmehr ein Tasten auf unsicherem Terrain. Wie Schröders Rede vom 4. Juni 1962 in Dortmund entnommen werden konnte, waren seine Bemühungen um eine Verbesserung des Verhältnisses zu den osteuropäischen Staaten anfangs vor allem von dem Motiv bestimmt, einen Beitrag zur westlichen Entspannungspolitik zu leisten. Bereits jetzt zeigte sich, daß die damit unweigerlich verbundene Anpassung der Nichtanerkennungspolitik Bonns mit erheblichen innenpolitischen Auseinandersetzungen verbunden war, obwohl sich das Auswärtige Amt noch gar nicht schlüssig war, wie weitreichend die Neuausrichtung in der Ostpolitik sein sollte. Erst nach dem Kanzlerwechsel von 1963 legte Schröder detailliert fest, welche Intentionen Bonn mit dieser Politik verfolgte.

157 Instruktion für den Leiter des Vorauskommandos vom 25. 6. 1963, PA/AA, B 150, Aktenkopien 1963.

158 Vgl. das Schreiben von Brentanos an Schröder vom 10. 7. 1963, StBKAH C 42.

159 Schreiben Schröders an von Brentano vom 27. 7. 1963. Zitiert nach LEMKE, Die Berlinkrise 1958 bis 1963, S. 218.

160 LindemanN, Anfänge, S. 56. 


\section{Die Bundesrepublik zwischen "atlantischer Partnerschaft" und einem „europäischen Europa“}

\section{Das Scheitern der Politischen Union}

Die Europa-Politik wurde zu Beginn der sechziger Jahre von zwei Themen beherrscht, die bis zur Gegenwart nichts an Brisanz verloren haben. Es ging damals um die Vertiefung und Erweiterung der bestehenden europäischen Zusammenschlüsse von EWG, EGKS und EURATOM. Die sechs Mitgliedstaaten erörterten zum einen eine engere politische Zusammenarbeit, die zu einer Politischen Union führen sollte, zum anderen die Aufnahme weiterer Staaten in die Gemeinschaften. Der wichtigste Kandidat für einen Beitritt war Großbritannien, aber auch über die Mitgliedschaft anderer EFTA-Staaten wie Dänemark, Norwegen oder Irland mußte entschieden werden. Die Fragen, vor denen die Gemeinschaft damals stand, sind auch aus heutiger Sicht hochaktuell: War zunächst die Integration der Mitgliedstaaten zu intensivieren? Oder sollte zuerst das Problem des Beitritts weiterer Staaten im Vordergrund stehen? Konnten beide Aufgaben eventuell gleichzeitig geregelt werden?

Der Gedanke, die europäische Entwicklung voranzutreiben und die politische Integration zwischen den sechs EWG-Staaten - Bundesrepublik, Frankreich, Italien, Belgien, den Niederlanden und Luxemburg - zu verstärken, ging auf den französischen Staatspräsidenten zurück. In einer Fernsehansprache am 31. Mai 1960 vertrat de Gaulle die Ansicht, „Westeuropa müsse sich, um handlungs- und verteidigungsfähig zu sein, politisch, ökonomisch, kulturell und menschlich zusammenschließen“. Aus dieser "organisierten Zusammenarbeit der Staaten“ (Europa der Vaterländer) sollte unter Beibehaltung der nationalen Identität der Teilnehmer schließlich ein europäischer, von Amerika unabhängiger "Staatenbund“ (europäisches Europa) entstehen ${ }^{1}$. Er beabsichtigte vor allem eine engere Kooperation und Abstimmung der Sechs auf dem Gebiet der Außen-, Kultur- und Verteidigungspolitik. Die Koordination der Politik sollte auf regelmäßigen Konsultationstreffen der Regierungen erfolgen, wie de Gaulle auf einer Pressekonferenz am 5. September 1960 erläuterte. Supranationale Institutionen wie die Kommission der EWG oder die Hohe Behörde der Montanunion (EGKS), an die die Mitgliedstaaten Souveränitätsrechte abtreten würden, waren nicht vorgesehen, damit die nationale Souveränität der Teilnehmer, auf die der französische Staatspräsident großen Wert legte, gewahrt bliebe. Nach den Vorstellungen de Gaulles würde die

1 ADG 1960, S. 8427f. Vgl. auch DE GAulle, Discours III, S. 217-221. Zu den europapolitischen Vorstellungen des französischen Staatspräsidenten vgl. ders., Mémoires d'espoir, S. 177-218. Während de Gaulle den Begriff „l'Europe européene“ häufig verwendete (vgl. ebenda, S. 186, 208, 215, 216 und 236), hat er den von ihm angestrebten europäischen Zusammenschluß auf der Basis einer Zusammenarbeit der Regierungen niemals als „Europa der Vaterländer“ bezeichnet: „[...] je n'ai jamais, quant à moi, dans aucune de mes déclarations, parlé de l'Europe des patries" (Pressekonferenz de Gaulles am 15. 5. 1962, in: ders., Discours III, S. 406; Hervorhebung im Original). Die zeitgenössische Diskussion griff aber dennoch auf dieses Schlagwort zurück, um seine europapolitische Konzeption zu charakterisieren. 
Politische Union allein auf der Kooperation der Regierungen in einem Rat der Staats- bzw. Regierungschefs beruhen. Dementsprechend lehnte er eine Ausweitung der politischen Befugnisse der EWG ab und beschränkte die Aufgabe der Kommission darauf, das Zusammenwachsen der Volkswirtschaften ihrer Mitgliedstaaten in einem Gemeinsamen Markt herbeizuführen². Das Prinzip der Supranationalität, das man beim Aufbau der bisherigen drei europäischen Organisationen angewandt hatte, hielt der französische Präsident für undemokratisch, da es die vom Volk legitimierten Regierungen in ihrer Souveränität einschränkte: „Man solle doch anerkennen, daß die Staaten Europa bildeten, daß die Staaten die Beschlüsse faßten und daß die Kommissionen die Aufgabe hätten, bestimmte Beschlüsse vorzubereiten und auszuführen. "3 De Gaulle beabsichtigte, die Politische Union als Dach über die bereits existierenden europäischen Zusammenschlüsse zu stellen, um so die bisherige politische Fehlentwicklung beim Aufbau Europas nachträglich zu korrigieren und die Brüsseler und Luxemburger Behörden auf das ihnen nach seiner Ansicht zukommende Maß zurechtzustutzen: Sie würden den Mitgliedstaaten nicht länger Anordnungen erteilen, sondern nur noch als Vollzugsorgane fungieren, die den Willen des Rats der Staats- bzw. Regierungschefs umzusetzen hatten. Das Heft des Handelns bliebe damit in der Hand der sechs Regierungen, die ihre Entscheidungsbefugnisse nicht länger an supranationale $\mathrm{Be}$ hörden abtraten, sondern wieder in eigener Regie Beschlüsse faßten.

De Gaulles Pläne stießen zunächst auf den Widerstand seiner europäischen Partner. Erst nachdem er einige Abstriche an seinem Konzept der reinen Regierungskooperation machte und sich zudem bereit erklärte, die Weiterentwicklung der bereits bestehenden europäischen Institutionen zu fördern, fand er mehr Unterstützung. Am Widerstand des niederländischen Außenministers Joseph Luns scheiterte jedoch auf einer Gipfelkonferenz am 10./11. Februar 1961 in Paris der Beschluß, künftig regelmäßig Konferenzen der Staats- und Regierungschefs bzw. der Außenminister abzuhalten. Luns billigte nur die Einsetzung eines Ausschusses, der Vorschläge ausarbeiten sollte, wie die politische Zusammenarbeit zwischen den Regierungen durch Treffen auf höchster Ebene verstärkt werden könnte 4 . Zum Vorsitzenden des Ausschusses wurde der französische Diplomat Christian Fouchet berufen, weshalb die Arbeitsgruppe inoffiziell als FouchetKommission bezeichnet wurde. Auf der nächsten Konferenz der Staats- bzw. Regierungschefs der europäischen Gemeinschaften, die ein halbes Jahr später, am 18. Juli 1961 in Bonn, stattfand, gelang es, sich auf das weitere Vorgehen zu einigen und eine gemeinsame Deklaration zu verabschieden ${ }^{5}$. Diese Erklärung über die Verstärkung der europäischen Zusammenarbeit ${ }^{6}$ war, wie es Besson aus-

2 Vgl. DE Gaulle, Discours III, S. 234-251; ders., Mémoires d'espoir, S. 210 f.

3 ADENAUER, Erinnerungen IV, S. 146 Zur Ablehnung des supranationalen Prinzips durch de Gaulle vgl. auch DE GAULLE, Mémoires d'espoir, S. 184 und S. 198-200.

4 Vgl. das Gesprächsprotokoll, in: BDFD, I, Dok. 281, S. 844-850. Vgl. ferner DE GAULLE, Mémoires d'espoir, S. $211 \mathrm{f}$. Für das Kommuniqué vom 11.2. 1961 vgl. EUROPA-ARCHIV 1961, D 128.

5 Vgl. dazu den Runderlaß des Ministerialdirektors Jansen vom 19. 7. 1961, in: BDFD, I, Dok. 285, S. 860-863.

6 Für den Wortlaut vgl. EUROPA-ARCHIV 1961, D $469 \mathrm{f}$. 
drückte, ein „Formelkompromiß“ zwischen der Position der Benelux-Staaten, die einen sehr weitreichenden supranationalen Ansatz vertraten, und dem französischen Konzept der Regierungskooperation ${ }^{7}$. Ansonsten folgten die anderen fünf EWG-Staaten weitgehend den Vorstellungen de Gaulles und legten fest, auf regelmäßigen Treffen der Staats- bzw. Regierungschefs „,ihre Politik miteinander abzustimmen"8. Die Fouchet-Kommission erhielt den Auftrag, nach den Grundsätzen der Erklärung ihre Arbeit fortzusetzen und ein europäisches Statut auszuarbeiten, das die Politische Union institutionalisieren sollte. Gleichzeitig gaben die sechs Regierungen für die existierenden europäischen Zusammenschlüsse eine Bestandsgarantie ab. Der französische Präsident versprach seinen Partnern zudem, er werde die Einführung einer Direktwahl der Abgeordneten des Europäischen Parlaments durch die Bürger der Mitgliedstaaten, die Beteiligung des Straßburger Parlaments an den Regierungskonferenzen der Union sowie die Möglichkeit der Aufnahme Großbritanniens und anderer Staaten prüfen?.

Großbritannien hatte zwar seit dem Ende des Zweiten Weltkriegs stets den Zusammenschluß der europäischen Staaten gefördert, eine Beteiligung jedoch abgelehnt. Mit der EFTA initiierte das Königreich 1960 sogar ein Gegenmodell zur EWG ${ }^{10}$. Dann aber vollzog Premierminister Macmillan eine radikale Kehrtwende seiner Europa-Politik und bat am 9. August 1961 offiziell um die Aufnahme in die EWG ${ }^{11}$. Am folgenden Tag übergab auch Dänemark sein Beitrittsansuchen. Der Aufnahmeantrag Irlands war bereits am 31. Juli in Brüssel eingegangen. Schließlich stellte am 30. April 1962 auch Norwegen einen Beitrittsantrag ${ }^{12}$. Das britische Drängen in die Gemeinschaft stieß aber auf das Mißfallen de Gaulles. Seine Skepsis gegenüber einer EWG-Mitgliedschaft des Vereinigten Königreichs entsprang nicht so sehr wirtschaftlichen als politischen Gründen. Der General glaubte, daß Großbritannien sich nicht als Teil Europas fühlte, sondern sich nach wie vor als insulares Reich verstand. Auch die special relationship zwischen London und Washington bereitete ihm Kopfzerbrechen. Er fürchtete, eine Mitarbeit der Briten in der EWG würde die Schaffung einer politischen Gemeinschaft unmöglich machen und Washington noch größere Einflußmöglichkeiten auf die Politik der europäischen Staaten eröffnen. Deshalb wollte er einen Beitritt nur akzeptieren, wenn London seine proamerikanische Politik aufgab ${ }^{13}$. Hingegen suchten vor allem die Benelux-Staaten die Aufnahme Großbritanniens in den Kreis der Sechs durchzusetzen. Treibende Kräfte waren der belgische Außenminister Paul-Henri Spaak

7 BESSON, Die Außenpolitik der Bundesrepublik, S. 278.

8 Europa-ArChIV 1961, D 470.

9 Vgl. den Runderlaß des Ministerialdirektors Jansen vom 19.7. 1961, in: BDFD, I, Dok. 285, S. 860-863.; DE GAULLE, Mémoires d'espoir, S. 213.

10 Zur Haltung Großbritanniens gegenüber der EWG vgl. u.a. FranKEL, British Foreign policy, S. 233-244; LuDLOW, Dealing with Britain, S. 12-42. Für einen Gesamtüberblick über die britische Europa-Politik vgl. DenMan, Missed Chances.

11 Für den Wortlaut des Beitrittsantrags vgl. DEI, Bd. 2, Dok. 8, S. 20.

12 Für den Wortlaut der Beitrittsanträge vgl. ebenda, Dok. 3, S. 17, Dok. 9, S. 20, und Dok. 74, S. 98.

13 Zur Einschätzung der britischen Politik durch den französischen Staatspräsidenten vgl. DE Gaulle, Mémoires d'espoir, S. 203 f., S. 216 und S. 232-237. 
und sein niederländischer Kollege Luns. Beide hofften, auf diese Weise die deutsch-französische Dominanz in den Gemeinschaften zu brechen. London sollte ein Gegengewicht zu Paris und Bonn bilden und die Interessen der kleineren europäischen Staaten schützen ${ }^{14}$.

Mit der Erklärung von Bonn vom 18. Juli 1961 schien ein Weg gefunden, um dem seit der Unterzeichnung der Römischen Verträge im Jahr 1957 stagnierenden europäischen Einigungswerk neuen Auftrieb zu geben. Auf den Tagungen der Fouchet-Kommission zeigte sich aber, daß die Meinungsverschiedenheiten der Sechs nicht überwunden waren. Dort setzte sich der Streit fort, wie die Politische Union gestaltet werden sollte. Im Zentrum der Diskussion stand weiterhin die Frage, ob de Gaulles Konzept der Kooperation souveräner Regierungen realisiert werden oder ob man das bisherige Prinzip der Supranationalität beibehalten sollte. Der erste Vertragsentwurf, den die französische Delegation den Partnern präsentierte - der sogenannte Fouchet-Plan I -, versuchte, beiden Ansätzen gerecht zu werden. Er stellte die Politische Union nicht über die existierenden Gemeinschaften, sondern wies ihr einen gleichberechtigten Rang zu. Kern der Zusammenarbeit sollte der von den Staats- und Regierungschefs zu bildende Rat sein. Neben diesem Organ waren Ministerausschüsse sowie ein von den Weisungen der Regierungen unabhängiger Generalsekretär vorgesehen, der die Zusammenarbeit koordinieren sollte. Aufgabe dieser neuen Organe war die Angleichung der Außen-, Verteidigungs- und Kulturpolitik der Sechs bis zu ihrer Vereinheitlichung. Man plante zudem, die Kompetenzen des Europäischen Parlaments auf die Politische Union auszudehnen. Ein wichtiges Signal war des weiteren, daß hinsichtlich der gemeinsamen Verteidigungspolitik, deren Struktur umstritten war, der NATO die Priorität für die Organisation der europäischen Verteidigung zugesprochen wurde. Ferner enthielt der Fouchet-Plan I eine Revisionsklausel, derzufolge drei Jahre nach Inkrafttreten der Politischen Union das Statut einer Überprüfung unterzogen und, wenn es die Mitglieder für notwendig erachteten, verändert werden konnte ${ }^{15}$. Die Klausel sollte diejenigen Staaten, die in dem französischen Entwurf das Konzept der Supranationalität zu wenig berücksichtigt sahen, dazu bewegen, trotz ihrer momentanen Bedenken an der Politischen Union teilzunehmen.

Die anderen Delegationen nahmen den französischen Entwurf weitgehend positiv auf und akzeptierten ihn allgemein als Arbeitsgrundlage ${ }^{16}$. Kritisiert wurde jedoch, daß der Fouchet-Plan I nicht festlegte, in welche Richtung eine Revision tendieren sollte. So wäre auch eine Abkehr vom supranationalen Konzept vorstellbar gewesen. Bemängelt wurden auch die teilweise ziemlich unpräzisen Formulierungen des Entwurfs. Die fünf Partner Frankreichs wünschten sowohl konkretere Bestimmungen über die Rolle und die Aufgaben des Europäischen Parlaments ${ }^{17}$, als auch eine exakte Abgrenzung der Kompetenzen zwischen den alten europäi-

14 Vgl. dazu DEI, Bd. 2, Dok. 91, S. 93; SpAAK, Memoiren, S. 540-543.

15 Für den Wortlaut des Fouchet-Plans I vom 2.11. 1961 vgl. Der Aufbau Europas, S. 364 370. Vgl. auch SPAAK, Memoiren, S. 534-536.

16 Vgl. ADENAUER, Erinnerungen IV, S. 141.

17 Vgl. ebenda, S. 142. 
schen Organen und den neuen, die im Zuge der Schaffung der Politischen Union entstehen sollten. Auch das Fehlen von Erläuterungen, wie bei der Aufnahme neuer Mitglieder zu verfahren sei, wurde bemängelt. Ebenso forderte man eine Konkretisierung der Rolle der NATO bei der europäischen Verteidigung ${ }^{18}$. Eine Kuriosität des Planes war die Regelung, daß das zentrale Organ der Union, der Rat der Staats- und Regierungschefs, mit einer qualifizierten Mehrheit von vier Stimmen Beschlüsse hätte fassen können, die für die beiden, in der Abstimmung unterlegenen Länder jedoch nicht bindend gewesen wären. Adenauer stellte dazu fest, es habe „nichts mehr mit einer Gemeinschaft zu tun, wenn in einem Fall die einen vier, im anderen Fall andere vier gebunden seien, während jeweils für zwei Mitglieder die Beschlüsse nicht gelten würden" 19 . Bei aller Kritik bestand dennoch Übereinstimmung, die Diskussion auf der Basis des französischen Entwurfs fortzusetzen. Nicht nur innerhalb der Bundesregierung war man optimistisch, daß die noch bestehenden Hürden zu überwinden wären und im kommenden Jahr „Europa auf dem Wege zu seiner Einigung weitere entscheidende Schritte machen" würde, wie Schröder zur Jahreswende 1961/62 prognostizierte20.

Die allgemeine Zuversicht stützte sich vor allem auf die momentanen großen Fortschritte beim Abbau der wirtschaftlichen Schranken zwischen den EWGMitgliedstaaten. Am 14. Januar 1962 gelang der Übergang in die sogenannte zweite Phase des Gemeinsamen Markts, die eine generelle Zollsenkung um 40\% im Binnenhandel der EWG mit sich brachte. Außerdem wurde im Ministerrat in Teilbereichen erstmals das Prinzip der Einstimmigkeit aufgegeben und der Mehrheitsentscheid eingeführt ${ }^{21}$. Des weiteren vereinbarten die Sechs, eine einheitliche Agrarordnung einzuführen, wobei Frankreich seine Vorstellungen weitgehend durchsetzen konnte 22 . Im Auswärtigen Amt war man überzeugt, daß diese Beschlüsse auch die Verhandlungen über die Politische Union voranbringen würden, da die zunehmende ökonomische Verflechtung der Sechs immer dringender ihre politische Integration erforderlich machte ${ }^{23}$. Zur gleichen Zeit schien sich auch hinsichtlich des Problems der Aufnahme Großbritanniens in die EWG eine Lösung abzuzeichnen. In einer Unterredung mit Adenauer am 9. Dezember 1961 in Paris erklärte sich de Gaulle nunmehr prinzipiell mit einer Mitgliedschaft Londons einverstanden. Nur den von der britischen Regierung angestrebten Beitritt der Commonwealth-Staaten, darunter Kanada, Australien und Indien, zum Gemeinsamen Markt, mit dem das Königreich verhindern wollte, daß es von seinen bisherigen Absatzgebieten abgeschnitten wurde, lehnte der General, ebenso wie Adenauer, kategorisch ab. Ein solches Gebilde, so de Gaulle, wäre „nicht mehr

18 Vgl. BESSON, Die Außenpolitik der Bundesrepublik, S. 280.

19 Adenauer, Erinnerungen IV, S. 143.

20 Vgl. den Artikel von Gerhard Schröder: „Auf die Bewahrung des Friedens gerichtet. Unsere Außenpolitik baut weiter auf Fundamenten, die sich bereits als tragfähig erwiesen haben", in: BULLETIN 1962, S. 22.

$21 \mathrm{Zu}$ den Beschlüssen des EWG-Ministerrats vom 14.1. 1962 vgl. DEI, Bd. 2, Dok. 49, S. 64-73.

22 Vgl. ebenda; OSTERHELD, „Ich gehe nicht leichten Herzens ...“, S. 97.

23 Vgl. dazu die Ausführungen Carstens auf einer Pressekonferenz am 15. 1. 1962, in: BullETIN 1962, S. 91. 
Europa“24. Dieses Problem mußte aber kein Hemmschuh für eine Erweiterung der EWG sein, da für den britischen Handel Übergangsregelungen getroffen werden konnten. Sowohl der französische Staatschef wie der Bundeskanzler waren sich einig, daß noch 1962 das Statut für die Schaffung einer Politischen Union fertiggestellt und von den Sechs verabschiedet werden sollte. Falls ein Beitritt Großbritanniens an der Commonwealth-Problematik scheitern und die Niederlande sowie Belgien deswegen die Verhandlungen über das Statut blockieren würden, vereinbarten die beiden Politiker, den Widerstand durch ein entschlossenes, gemeinsames Auftreten zu brechen; denn de Gaulle war sich sicher, „wenn aber Frankreich und Deutschland sich einig sind, müssen die anderen wohl oder übel nachkommen" 25 .

Nach dem erfolgreichen deutsch-französischem Gipfeltreffen vom 9. Dezember 1961 und den Beschlüssen der EWG vom 14. Januar 1962 machte sich in Bonn aber zu früh Optimismus breit. De Gaulle war plötzlich mit dem Statut-Entwurf seiner eigenen Delegation nicht einverstanden und ordnete an, den Fouchet-Plan I zu überarbeiten ${ }^{26}$. Am 18. Januar 1962 legte Frankreich seinen überraschten Partnern einen revidierten Entwurf vor. Dieser Fouchet-Plan II wies gegenüber seinem Vorgänger einige gravierende Unterschiede auf. Für Unmut sorgten aber nicht so sehr die im Vergleich zur ersten Fassung vorgenommenen Änderungen, sondern die Textpassagen, die gestrichen wurden. So enthielt der neue Entwurf keine Aussagen mehr über das künftige Verhältnis zwischen der Union und der NATO. Ebenso fehlte die Bestandsgarantie für die bereits existierenden europäischen Institutionen. Der Fouchet-Plan II wies den bestehenden supranationalen Behörden den Rang bloßer Vollzugsorgane $z^{27}$. Da die Politische Union nach dem neuen Konzept auch für die Wirtschaftspolitik der Teilnehmerstaaten zuständig sein sollte, war offensichtlich, daß dieser Entwurf wieder an dem Plan de Gaulles anknüpfte, die Union solle das Dach der europäischen Gemeinschaften bilden, ihnen also quasi übergeordnet sein. Die neue Fassung des Fouchet-Plans gab eindeutig dem Gedanken der nationalen Kooperation Vorrang vor dem Prinzip der Supranationalität. Das Fehlen des Abschnitts über die Aufrechterhaltung der transatlantischen Beziehungen im Verteidigungsbereich ließ zudem befürchten, de Gaulle wolle nun mit Hilfe der Politischen Union seine Vision eines Europas als dritte Kraft neben den USA und der UdSSR verwirklichen.

Es überrascht folglich nicht, daß die anderen Delegationen in dem neuen Entwurf unisono einen Rückschritt sahen ${ }^{28}$. Die negative Reaktion auf den FouchetPlan II bewog de Gaulle, bei der Bundesregierung Rückendeckung zu suchen. Überraschend schlug er Adenauer ein sofortiges Vieraugengespräch vor ${ }^{29}$. Am 15. Februar 1962 traf man sich unter strengster Geheimhaltung in Baden-Baden.

24 AdENAUER, Erinnerungen IV, S. 130.

25 Ebenda, S. 131.

26 Vgl. KuSTERER, Der Kanzler und der General, S. $204 \mathrm{f}$.

27 Für den Wortlaut des Fouchet-Plans II vom 18.1. 1962 vgl. Der Aufbau Europas, S. 364-370.

28 Vgl. die Aufzeichnung des Referats I A 1 vom 10. 4. 1963, PA/AA, Ministerbüro, Bd. 216.

Vgl. auch KoOpManN, Das schwierige Bündnis, S. 170.

29 Vgl. OSTERHELD, „Ich gehe nicht leichten Herzens ...", S. 97. 
Der französische Staatspräsident gab gegenüber dem Kanzler eine Garantieerklärung für die Fortexistenz der bestehenden Gemeinschaften ab, verlangte aber, die „politische Union müsse über allem stehen, selbst über dem Gemeinsamen Markt". Die drei Gemeinschaften sollten daher in sie integriert werden ${ }^{30}$. Seine Mißbilligung gegenüber supranationalen Behörden bekräftigte er: $\mathrm{Da}$ es die Staaten seien, die sich zusammenschließen, könne er nicht akzeptieren, „daß eine Behörde ins Leben gerufen werde, die zwar kein Staat sei, aber die Staaten mehr oder weniger überwachen solle"31. Obgleich Adenauer sowohl bei der Schaffung der Montanunion im Jahr 1952 als auch bei den Römischen Verträgen von 1957 die zur Gründung der EWG führten, stets eine supranationale Struktur gutgeheißen hatte, war er jetzt mit dem französischen Präsidenten weitgehend einer Meinung ${ }^{32}$. Damit wurde der Gedankenaustausch über den Fouchet-Plan, der eigentlich den Anstoß zu diesem Treffen gegeben hatte, jedoch bereits wieder abgeschlossen ${ }^{33}$. Statt dessen diskutierten die beiden Staatsmänner, wie Paris und Bonn ihre Politik besser aufeinander abstimmen könnten. De Gaulle bemängelte in diesem Zusammenhang das Fehlen einer gemeinsamen deutsch-französischen Politik. Er überlege daher, „ob Frankreich und Deutschland ihre Kontakte nicht so organisieren könnten, daß jedesmal, wenn sich eine Frage stelle, diese beiden Länder gemeinsam antworteten"34. Hier wurde das Fundament für den deutsch-fran-

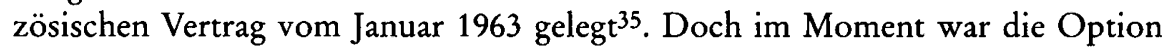
einer Intensivierung der bilateralen Zusammenarbeit noch nicht akut. Vorrangig war die Lösung des Problems, in welcher Form die Politische Union realisiert werden sollte. Nach der Begegnung von Baden-Baden konnte sich de Gaulle der Unterstützung Adenauers gewiß sein. Doch würde dies genügen, um die Zustimmung der anderen vier Partner zum Fouchet-Plan zu erreichen? Auch wenn Bonn und Paris sich einig waren, mußte dies nicht $z$ wingend zu einer Änderung der Haltung der Benelux-Staaten und Italiens führen. Es erstaunt deshalb, daß Schröder sich gleichwohl nach dem deutsch-französischen Gipfeltreffen überaus optimistisch gab und das Fazit zog, man sei der Einigung Europas um einiges näher gekommen. Er sprach sogar von der "Gewißheit", daß die Verhandlungen nun „zu einem guten Ende geführt" würden ${ }^{36}$.

Belgien und die Niederlande waren aber nur unter zwei Bedingungen bereit, sich an der Politischen Union zu beteiligen. Nach ihren Vorstellungen sollte sie nach dem bewährten Muster von EWG bzw. EGKS gestaltet werden, damit auch die Interessen der kleineren Staaten gewahrt blieben. Der Verlauf der Diskussionen in der Fouchet-Kommission hatte in Den Haag und in Brüssel allerdings zu der Einsicht geführt, daß das von ihnen favorisierte supranationale Konzept nicht

30 Adenauer, Erinnerungen IV, S. 148.

31 Ebenda, S. 144.

32 Vgl. ebenda, S. 148.

33 Vgl. KuSTERER, Der Kanzler und der General, S. 207 f. Zu den Details der zwischen Adenauer und de Gaulle getroffenen Absprachen über den Fouchet-Plan vgl. SCHWARZ, Adenauer II, S. $735 \mathrm{f}$.

34 ADENAUER, Erinnerungen IV, S. $138 \mathrm{f}$.

35 Vgl. Kusterer, Der Kanzler und der General, S. 209.

36 Erklärung Schröders gegenüber dem WDR am 18. 2. 1962, in: BULLETIN 1962, S. 298. 
durchzusetzen war. Infolgedessen setzten sie jetzt ganz auf die britische Karte und drängten auf eine Beteiligung Londons an den Beratungen über die Politische Union, um eine deutsch-französische Hegemonie zu verhindern. Sie regten an, Großbritannien solle als potentielles Mitglied der Union bereits an der Formulierung des Vertragstextes mitwirken ${ }^{37}$. Belgier und Niederländer nahmen dabei bewußt in Kauf, daß in diesem Fall die Chancen sinken würden, supranationale Strukturen zu verwirklichen, weil die Regierung Macmillan diesem Integrationsmodell mindestens genauso reserviert gegenüberstand wie die französische Regierung ${ }^{38}$.

Eine Annäherung der Standpunkte gelang auch nach dem Baden-Badener Treffen nicht. Ein Treffen der Außenminister der EWG-Mitgliedstaaten am 21. März in Brüssel endete ergebnislos. Strittig blieben vor allem drei zentrale Punkte: Erstens die Zuständigkeit der Politischen Union für wirtschaftliche Fragen, durch die es möglich geworden wäre, die Kompetenzen der EWG zu beschneiden; zweitens die beabsichtigte Abgrenzung der Union von der NATO, die den Anschein erweckte, als ob eine Abkoppelung der europäischen Verteidigungspolitik vom atlantischen Bündnis beabsichtigt sei. Drittens war man sich immer noch über die Revisionsklausel uneins. Luns und Spaak verlangten, der Union keine ökonomischen Befugnisse einzuräumen. Sie machten darauf aufmerksam, daß der Rat der Staats- und Regierungschefs laut Statut nur einstimmige Beschlüsse fassen könnte. Da dem Fouchet-Plan II zufolge die Union als Dachorganisation der bestehenden Gemeinschaften fungierte, bestand die Gefahr, daß bei Meinungsverschiedenheiten Organe, wie zum Beispiel der Ministerrat der EWG, in dem bereits teilweise der Mehrheitsentscheid eingeführt worden war, durch den Rat blockiert würden. Der niederländische Außenminister und sein belgischer Kollege gaben ihren Partnern zu verstehen, daß sie im Grunde gar nicht eine Modifikation des Statut-Entwurfs anstrebten, sondern ihnen die ganze Tendenz des FouchetPlans nicht paßte. In ihren Augen trug die geplante Union allzusehr die Handschrift de Gaulles. Sie befürchteten, daß die supranationale Struktur des europäischen Einigungswerks verlorenging, falls der Entwurf in dieser Form realisiert würde 39 .

Schröder blieb trotz der Differenzen zwischen den Sechs zuversichtlich. Er erwartete einen Durchbruch auf der nächsten Außenministerkonferenz, die drei Wochen später in Paris stattfinden sollte ${ }^{40}$. Sein uneingeschränkter Optimismus läßt den Schluß zu, daß er das Ausmaß der Differenzen im Kreis der Sechs unterschätzte. Schröder hatte allerdings sehr wohl Zweifel an einem Zustandekommen der Union. Da Defätismus nicht zu einem Erfolg beitragen konnte, setzte er sich jedoch bis zuletzt für eine Realisierung ein ${ }^{41}$. Eine Einigung hielt er für dringend

37 Vgl. SPAAK, Memoiren, S. 540. Zur belgischen und niederländischen Haltung vgl. auch KOSTHORST, Die „unerwünschte Liaison“, S. 178-181; STELANDRE, La Belgique et le Plan Fouchet, S. 227-230.

38 Vgl. OSTERHELD, „Ich gehe nicht leichten Herzens ...“, S. 116.

39 Vgl. SPAAK, Memoiren, S. $538 \mathrm{f}$. Vgl. auch den Artikel „Schröder gegen Integrationspause", in: Frankfurter Allgemeine ZeITUNG vom 22. 3. 1962, S. 4.

$40 \mathrm{Vgl}$. ebenda.

41 Vgl. KUSTERER, Der Kanzler und der General, S. $201 \mathrm{f}$. 
geboten, um EWG und EGKS, die vorwiegend ökonomischen Zwecken dienten, in eine politische Gemeinschaft einzubinden. Die wirtschaftliche Integration erforderte in seinen Augen „auf die Dauer auch eine politische Einigung Europas" ${ }^{42}$. Welch großen Stellenwert die Vereinigung Europas in Schröders politischem Konzept hatte, wurde bereits ausführlich dargelegt. Es muß aber an dieser Stelle nochmals darauf hingewiesen werden, daß für ihn die Vereinigung Europas kein Vorhaben war, das erst in einer fernen Zukunft realisiert werden sollte, sondern er sah darin eine Aufgabe der Gegenwart. Die Einigung Europas vertrug seiner Ansicht nach keinen Aufschub. Vor allem im Hinblick auf die künftige Entwicklung des Ost-West-Konflikts hielt er es für notwendig, europapolitische Fortschritte zu erzielen. Aus diesem Grund sprach er sich auch für eine Annahme des Fouchet-Plans aus, obwohl er sich der Mängel des Vertragsentwurfs durchaus bewußt war ${ }^{43}$. Der Außenminister strebte dabei eine kontinuierliche Weiterentwicklung der Integration an. Nach seiner Auffassung sollten alle europäischen Organe im Laufe der Zeit ihre Entscheidungen per Mehrheitsbeschluß treffen und die Mitgliedstaaten immer mehr Souveränitätsrechte auf diese Organe übertragen. Er war jedoch bereit, sich für den Augenblick mit weniger zufrieden zu geben, wenn in diesem Punkt noch kein Konsens zwischen den Sechs möglich war. Um den Stillstand in der Einigung Europas zu überwinden, schlug er eine pragmatische Lösung vor: Die Sechs sollten sich auf den kleinsten gemeinsamen Nenner einigen und als ersten Schritt die Institutionalisierung der Treffen der Staats- bzw. Regierungschefs beschließen ${ }^{44}$. Inständig bemühte er sich um einen Kompromiß zwischen der französischen und der niederländisch-belgischen Position ${ }^{45}$. Den Streit um die Zuständigkeit der Politischen Union für die Wirtschaftspolitik suchte er beizulegen, indem er nachdrücklich für die Aufnahme einer Bestandsgarantie in das Statut eintrat, um die befürchtete Kompetenzusurpation durch die Union von vornherein auszuschließen ${ }^{46}$.

Hinsichtlich der künftigen Rolle Großbritanniens in Brüssel machte er deutlich, daß er sich mit einer auf die EWG beschränkten Mitarbeit Londons nicht abfinden werde ${ }^{47}$. Das Vereinigte Königreich sollte sowohl an den drei europäischen Gemeinschaften als auch an der Politischen Union gleichberechtigt beteiligt sein. Den britischen Beitrittsantrag befürwortete er aus verschiedenen Gründen: $\mathrm{Zu}$ nächst einmal sah er darin die Chance, eine einseitige Ausrichtung der EuropaPolitik der Bundesrepublik auf Paris zu verhindern. Nach seiner Einschätzung

42 Vgl. die Rede Schröders auf dem 11. Bundesparteitag der CDU am 4.6. 1962 in Dortmund, in: BulletiN 1962, S. 898. Vgl. auch die Artikel „Bonn setzt die Bemühungen um Europas Union fort“ und „Schröder informiert den Auswärtigen Ausschuß“, in: FRANKFURTER ALLGEMEINE ZEITUNG vom 19. 4. 1962, S. 1.

43 Vgl. das Schreiben Schröders an den Vorsitzenden der Europa-Union Deutschland, Friedrich Carl Freiherr von Oppenheim, vom 26. 3. 1962, PA/AA, Ministerbüro, Bd. 206.

$44 \mathrm{Vgl}$. BT STENOGRAPHISCHE BERICHTE, Bd. 51, S. 1482-1492.

45 Vgl. KuSTERer, Der Kanzler und der General, S. $201 \mathrm{f}$. Vgl. auch den Artikel „Außenminister Schröder will in Brüssel vermitteln“, in: FRANKFURTER ALLGEMEINE ZEITUNG vom 10. 4. 1962, S. 3.

$46 \mathrm{Vgl}$. den Artikel „Schröder gegen Integrationspause“, in: FrANKFURTER ALLGEMEINE ZEITUNG vom 22. 3. 1962, S. 4 .

47 Vgl. FRUS 1961-63, XIII, Dok. 46, S. 110. 
würde der Beitritt Londons die europäische Waage ins Gleichgewicht bringen und der Bundesrepublik größere politische Bewegungsfreiheit eröffnen ${ }^{48}$. „Wir sollten nicht nur auf Frankreich angewiesen sein“, erläuterte er seinen Mitarbeitern ${ }^{49}$. Außerdem hätte ein Ausschluß des Vereinigten Königreichs von der europäischen Einigungsbewegung dessen Abkoppelung von der weiteren europäischen Entwicklung zur Folge gehabt. Großbritannien durfte aber seiner Ansicht nach nicht in die „insulare Isolierung“ getrieben werden ${ }^{50}$. Schröder verwies darauf, daß ein britischer Beitritt eine enorme politische und ökonomische Stärkung Europas mit sich brächte. Die EWG würde dann über eine größere Wirtschaftskraft verfügen als UdSSR und USA zusammengenommen ${ }^{51}$. Es böte sich somit „die Chance, Europa wieder einen Platz in der Welt zu geben, nicht als dritte Kraft, sondern als

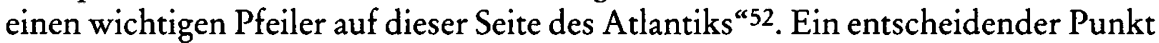
war für ihn darüber hinaus, daß die amerikanische Regierung die Aufnahme Londons nachdrücklich befürwortete ${ }^{53}$. Seiner Meinung nach war diese Frage der Prüfstein für die Schaffung der von Kennedy angeregten atlantischen Partnerschaft ${ }^{54}$. Ferner war er überzeugt, daß nur bei einem erfolgreichen Abschluß der Beitrittsgespräche die Verhandlungen mit den Vereinigten Staaten in der sogenannten Kennedy-Runde des GATT über den Abbau der Außenzölle erfolgreich verlaufen würden ${ }^{55}$. Zudem konnte nach seiner Auffassung die deutsche Wirtschaft auf die Erweiterung der Gemeinschaften nicht verzichten. Da die Bundesrepublik 30\% ihrer Güter in die EFTA-Zone exportierte und dabei eine positive Handels- und Zahlungsbilanz aufwies, lag es auf der Hand, umgehend eine wirtschaftliche Anbindung der EFTA-Mitgliedstaaten an die EWG zu bewerkstelligen ${ }^{56}$. Nachdem die Regierung Macmillan am 28. Februar 1962 auch ein Beitrittsansuchen für EGKS und EURATOM gestellt hatte ${ }^{57}$, unterstrich der Außenminister in einer Pressekonferenz am 22. März nochmals, daß die Bundesregierung die Aufnahme Großbritanniens „für eine politische Notwendigkeit“ erachte. Er sicherte der britischen Regierung zu, daß die Beitrittsverhandlungen unter dem

48 ZEITZEUGENBEFRAGUNGEN von Hase und Kusterer.

49 Zitiert nach JANSEN, Die Entstehung des deutsch-französischen Vertrages vom 22. Januar 1963, S. 263.

50 So Schröder in einem Interview mit dem Sonntagsblatt am 29.8. 1962, in: DEI, Bd. 2, Dok. 123, S. 164.

51 Vgl. die Rede Schröders auf der 10. Bundestagung des Evangelischen Arbeitskreises am 5. 10. 1962 in Wiesbaden, in: BULLETIN 1962, S. 1582; Protokoll der CDU/CSU-Fraktionssitzung am 2. 10. 1962, ACDP VIII-001-1009/2; BT STENOGRAPHISCHE BERICHTE, Bd. 51, S. 1771.

52 Protokoll der CDU/CSU-Fraktionssitzung am 2. 10. 1962, ACDP VIII-001-1009/2.

53 Vgl. FRUS 1961-1963, XV, Dok. 69, S. 201-203.

54 Vgl. BT STENOGRAPHISCHE BERICHTE, Bd. 51, S. 1483.

55 Vgl. den Runderlaß des Bundesministers Schröder vom 30.1. 1963, in: AAPD 1963, Dok. 63, S. 224. Mit dem Trade Expansion Act vom 11. 10.1962 ermächtigte der Kongreß die amerikanische Regierung, Verhandlungen mit der EWG aufzunehmen. Vgl. dazu Department OF STATE Bulletin, Bd. 47, S. 656-660.

56 Vgl. den Runderlaß des Bundesministers Schröder vom 30. 1. 1963, in: AAPD 1963, Dok. 63, S. 224.

57 Vgl. dazu DEI, Bd. 2, Dok. 61, S. 84. 
Aspekt geführt würden, den „lebenswichtigen Interessen des Commonwealth Rechnung zu tragen" 58 .

Inzwischen wurde auf höchster Ebene die Diskussion um den Fouchet-Plan fortgesetzt. Das Ergebnis der Unterredungen zwischen de Gaulle und dem italienischen Ministerpräsidenten Amintore Fanfani am 4. April 1962 in Turin sowie drei Tage später zwischen Adenauer und Fanfani in Cadenabbia war, daß der französische Staatspräsident auf die Zuständigkeit der Politischen Union für die Wirtschaftspolitik verzichtete. Um alle Befürchtungen zu zerstreuen, vereinbarten die Staatsmänner, in das Statut eine Nichtberührungsklausel für die Pariser und die Römischen Verträge aufzunehmen ${ }^{59}$. Außerdem fand man Kompromißformeln für das künftige Verhältnis zwischen der Union und der EWG bzw. der NATO60. So sollte im Statut erklärt werden, daß die verteidigungspolitische Zusammenarbeit innerhalb der Union den Zweck habe, die nordatlantische Allianz zu stärken. Nur hinsichtlich der Revisionsklausel konnte noch keine Einigung erzielt wer$\operatorname{den}^{61}$. Bei der belgischen und der niederländischen Regierung warb Schröder anschließend um die Billigung dieser Vereinbarung. Luns und Spaak blieben jedoch bei ihrer Meinung, der Statut-Entwurf sei immer noch zu sehr von de Gaulles Europa-Konzept geprägt. Schröder brachte für ihre fehlende Kompromißbereitschaft kein Verständnis auf. Er warnte davor, sich in einen nutzlosen Grundsatzstreit zu verbeißen ${ }^{62}$. Der Außenminister drängte darauf, die Sache nicht länger zu vertagen und die Union jetzt ohne weitere Verzögerungen ins Leben zu rufen. Um die Verhandlungen nicht zusätzlich zu erschweren, lehnte er eine Beteiligung Londons an den Beratungen über das Statut ab, wie sie Belgien und die Niederlande forderten und auch der für Europafragen zuständige britische Minister Edward Heath am 10. April anmahnte ${ }^{63}$. Dies müsse die Angelegenheit der derzeitigen Mitglieder der EWG bleiben, erklärte er ${ }^{64}$.

Letztlich an dieser Frage, und nicht an der Uneinigkeit über das Statut, scheiterte die Konferenz der Außenminister der sechs EWG-Mitgliedstaaten am 17. April 1962 in Brüssel. Spaak und Luns erklärten ultimativ, sie würden das Statut erst nach einem Beitritt Großbritanniens unterschreiben. Da London als Mitglied der EWG das Recht gehabt hätte, an den Beratungen über die Politische Union teilzunehmen, verlangten die beiden Außenminister damit indirekt die Beteiligung Englands an den Verhandlungen über das Statut. Die anderen vier Außenminister schlugen dagegen vor, zunächst den Vertragstext fertigzustellen und den Entwurf anschließend der britischen Regierung zur Prüfung zu übermitteln ${ }^{65}$. Sofern diese „keine größeren Einwendungen“ machen würde - was nicht

58 Bulletin 1962, S. 485.

59 Vgl. DEI, Bd. 2, Dok. 71, S. 92.

60 Vgl. die Aufzeichnung des Referats I A 1 vom 10. 4. 1963, PA/AA, Ministerbüro, Bd. 216.

61 Vgl. DEI, Bd. 2, Dok. 71, S. 92.

62 Vgl. den Artikel „Außenminister Schröder will in Brüssel vermitteln“, in: FrANKFURTER Allgemeine ZeITUNG vom 10. 4. 1962, S. 3.

63 Für den Wortlaut der Rede des Lordsiegelbewahrers Heath auf der WEU-Ministerratstagung am 10. 4. 1962 vgl. EUROPA-ARCHIV 1962, D 258-263.

64 Vgl. den handschriftlichen Vermerk Schröders, PA/AA, Ministerbüro, Bd. 206.

65 Vgl. den Drahtbericht des Ministerialdirektors Jansen, z.Z. Paris, an das Auswärtige Amt 
zu erwarten war, da sich London kaum gegen einen Vertrag wenden würde, auf den die Sechs sich nach langen Beratungen geeinigt hätten - sollte das Abkommen umgehend unterzeichnet werden ${ }^{66}$. Weil Luns und Spaak nicht nachgaben, blieb nichts anderes übrig, als den Beschluß zu fassen, die Bildung einer Politischen Union bis zu einer Aufnahme Großbritanniens in die europäischen Gemeinschaften zu vertagen. Da es aber erst acht Jahre später gelang, das Vereinigte Königreich in den Kreis der Sechs aufzunehmen und das Projekt einer Politischen Union somit gescheitert war, kann der 17. April 1962 im Rückblick tatsächlich als der „Schwarze Dienstag Europas“ bezeichnet werden ${ }^{67}$.

Zunächst schien es jedoch, als ob die Bestrebungen um eine verstärkte politische Integration der Sechs zwar einen Rückschlag erlitten hätten, aber die Politische Union noch nicht vor dem endgültigen Aus stand. Schließlich hatten die Niederlande und Belgien ihre Unterschrift zugesagt, sobald der Beitritt Großbritanniens über die Bühne gebracht wäre. Es kam also jetzt darauf an, die Beitrittsverhandlungen mit London zu intensivieren und gleichzeitig die britische Regierung stärker in die Statut-Beratungen einzubinden, um auf diese Weise die Aufnahme Großbritanniens sowie die Gründung der Union gleichzeitig unter Dach und Fach zu bringen. Andererseits war aber auch denkbar, sie mit denjenigen Staaten ins Leben zu rufen, die zu einer Teilnahme bereit waren. Dies hätte freilich bedeutet, daß die Mitglieder der Union nicht mit denen der europäischen Gemeinschaften identisch gewesen wären, was zur Entstehung einer europäischen Zweiklassengesellschaft geführt hätte. Um es mit heutigem Vokabular auszudrücken, einem politisch vereinigten Kerneuropa wäre dann ein Randeuropa gegenübergestanden, dessen Zusammenarbeit sich auf den ökonomischen Sektor beschränkt hätte. Graf Coudenhove-Kalergi, der ,Vater' der Paneuropa-Bewegung, die sich nach Ende des Ersten Weltkrieges formiert hatte, favorisierte dieses Konzept und schlug eine Dreier-Union zwischen Frankreich, Deutschland und Italien - Fralit vor ${ }^{68}$. Diese viel diskutierte Idee stieß bei Schröder auf keine große Begeisterung. Er behielt aber zumindest die Alternative im Auge, die politische Integration eventuell in einem kleineren Rahmen durchzuführen. Zunächst wollte er aber alles unternehmen, um die nach seiner Überzeugung beste Lösung, eine Union, an der alle sechs EWG-Staaten teilnahmen und die den anderen europäischen Ländern zum Beitritt offenstand, zu verwirklichen ${ }^{69}$. Immer noch hielt er eine Verständigung zwischen den Sechs für möglich ${ }^{70}$. Er plädierte deshalb dafür, die Be-

vom 17. 4. 1962, in: BDFD, I, Dok. 289, S. 879-881. Vgl. ferner SPAAK, Memoiren, S. 540542; DE GAUlle, Mémoires d'espoir, S. 214.

66 DEI, Bd. 2, Dok. 71, S. 92.

67 OSTERHELD, „Ich gehe nicht leichten Herzens ...", S. 117.

68 Die Bezeichnung leitet sich von den Namen dieser Staaten in französischer Sprache ab: France, Allemagne, Italie. Im März 1962 legte Graf Coudenhove-Kalergi in Memoranden an die Regierungen Italiens, Frankreichs und der Bundesrepublik seine Vorstellungen über die Struktur eines Europa der Drei dar. Vgl. dazu ADG 1962, S. 9937.

69 Vgl. BT STENOGRAPHISCHE BERICHTE, Bd. 51, S. 1485.

70 Vgl. die Artikel „Bonn setzt die Bemühungen um Europas Union fort“ und „Schröder informiert den Auswärtigen Ausschuß“, in: FrankfURTER ALlgemeINE ZEITUNG vom 19. 4. 1962 , S. 1. 
ratungen über die Union fortzusetzen und London über den Fortgang der Dinge auf dem laufenden zu halten ${ }^{71}$. Zudem sollten die Sechs sich umgehend darauf verständigen, daß Großbritannien nach einem Beitritt zur EWG auch an der Union teilnehmen würde ${ }^{72}$. Nach dem enttäuschenden Verlauf der Verhandlungen über die Politische Union in den vergangenen Monaten war in seinen Augen die Bedeutung einer Mitgliedschaft der Briten in den europäischen Gemeinschaften noch gewachsen. Schröder machte nämlich weder Brüssel noch Den Haag für die europäische Krise verantwortlich, sondern den französischen Staatspräsidenten. Dieser war nach der Einschätzung des Außenministers an der Misere schuld, weil er die erste Fassung des Fouchet-Plans, den die anderen Partner bereits grundsätzlich akzeptiert hätten, plötzlich zurückgezogen hatte ${ }^{73}$.

Da die Beratungen über das Statut nun für eine noch unbestimmte Zeit ruhten, befürchtete Schröder, daß die wirtschaftlichen Folgen einer Vergrößerung der EWG immer stärker in den Vordergrund rücken und für neue Schwierigkeiten sorgen könnten ${ }^{74}$. Tatsächlich richtete Adenauer seine Aufmerksamkeit zunehmend auf die ökonomischen Konsequenzen des britischen Beitritts. Am 21. Mai 1962 teilte der Kanzler seinem Außenminister mit, er befürchte durch die Mitgliedschaft Londons in der EWG „schwierige Situationen“ für die Montanindustrie in der Bundesrepublik ${ }^{75}$. Zwei Tage später erteilte er dem Auswärtigen Amt den Auftrag, einen Bericht über die Probleme anzufertigen, die die Erweiterung der EWG der deutschen Wirtschaft bereite ${ }^{76}$. Schröder versuchte die Bedenken Adenauers auszuräumen, indem er darauf hinwies, daß sich die Vertreter der Montanindustrie nicht gegen den Beitritt Großbritanniens ausgesprochen hätten. Außerdem würden alle potentiellen Gefahren für die heimische Industrie durch entsprechende Regelungen rechtzeitig entschärft ${ }^{77}$. Doch seine Bemühungen blieben vergeblich. Während seines Staatsbesuches in Frankreich im Juli 1962 erklärte der Kanzler erneut, „die englische Kohle stelle ein schweres Problem für die Bundesrepublik dar". Adenauer führte jetzt auch Währungsprobleme ins Feld: Er behauptete, wegen der anhaltenden Schwäche des britischen Pfunds hätten sich

71 So auch in einem Gespräch mit Couve de Murville am 22. 7.1962 in Genf. Vgl. den Drahtbericht des Staatssekretärs Carstens, z.Z. Genf, an das Auswärtige Amt vom 22. 7. 1962, in: BDFD, I, Dok. 304, S. 915.

72 Vgl. FRUS 1961-1963, XIII, Dok. 46, S. 110. Diese Forderung erhob Schröder auch immer wieder in der Öffentlichkeit. Vgl. die Artikel „Bonn setzt die Bemühungen um Europas Union fort“ und „Schröder informiert den Auswärtigen Ausschuß“, in: FRANKFURTER ALLGEMEINE ZEITUNG vom 19. 4. 1962, S. 1; die Rede Schröders auf dem 11. Bundesparteitag der CDU am 4. 6. 1962 in Dortmund, in: BULLETIN 1962, S. 900; BT STENOGRAPHISCHE BERICHTE, Bd. 51, S. 1482 f.; sowie das Interview Schröders mit der Deutschen Welle am 2. 7. 1962, in: BULLETIN 1962, S. 1026.

73 Vgl. FRUS 1961-1963, XIII, Dok. 46, S. 110.

74 Vgl. ebenda.

75 Vgl. das Schreiben Adenauers an Schröder vom 21. 5. 1962, PA/AA, Büro Staatssekretär, Bd. 74.

76 Vgl. die Aufzeichnung des Staatssekretärs Lahr vom 24. 5. 1962, PA/AA, Büro Staatssekretär, Bd. 74.

77 Vgl. das Schreiben Schröders an Adenauer vom 31. 5. 1962, PA/AA, Büro Staatssekretär, Bd. 74 . 
bereits fünf der sechs Notenbankpräsidenten der EWG-Staaten gegen den Beitritt ausgesprochen. Ferner sprach er das Problem an, wie die Stimmenverhältnisse in den Organen von EGKS und EWG nach der Erweiterung geregelt werden sollten. Dieses Problem, so Adenauer, sei noch gar nicht geprüft worden ${ }^{78}$. Der Kanzler war überzeugt, daß nach der Aufnahme Großbritanniens der Beitritt weiterer Mitglieder der EFTA, wie Norwegen, Dänemark, Irland und Island, nicht zu verhindern sei. Eine derart große Gemeinschaft sei aber politisch nicht mehr handlungsfähig, denn „zu elft gehe es nicht mehr gut "79. Adenauer hatte den Eindruck, das Auswärtige Amt nehme die Schwierigkeiten, die die britische Mitgliedschaft mit sich bringe, nicht ernst genug ${ }^{80}$. Dem Beitrittsgesuch Londons, so der Kanzler, dürfe nicht „mit dreimaligem Hurra" zugestimmt werden. Er wollte hinhaltend taktieren und die Auswirkungen einer Erweiterung der EWG vor einer endgültigen Entscheidung erst genau überprüfen lassen ${ }^{81}$. Für ihn stand das Ergebnis dieser Analyse aber bereits fest: Schon vor einiger Zeit hatte er dem ehemaligen französischen Ministerpräsidenten Paul Reynaud eröffnet, eine Vollmitgliedschaft Londons sei seines Erachtens nicht möglich ${ }^{82}$. Da Adenauer genau wußte, daß andererseits eine Assoziierung für die britische Regierung nicht akzeptabel war, hatte er damit den europäischen Ambitionen Londons eine klare Absage erteilt. Inwieweit die Bedenken des Kanzlers seiner Überzeugung entsprachen oder ob sie nur ein Vorwand waren, kann hier nicht weiter erörtert werden. Es war wohl ein ganzes Bündel von Motiven, das ihn dazu bewegte, sich gegen den Beitritt Großbritanniens auszusprechen ${ }^{83}$.

Adenauer war allerdings bewußt, daß es gefährlich sein konnte, damit an die Öffentlichkeit zu treten. Nicht zu Unrecht befürchtete er, die britische Regierung würde dann Bonn in der Deutschland- und Berlin-Frage in den Rücken fallen ${ }^{84}$. Eine öffentliche Brüskierung Londons hätte außerdem schwerwiegende Konsequenzen für die deutsch-amerikanischen Beziehungen gehabt, da Washington von der Bundesregierung die Unterstützung des Aufnahmegesuchs erwartete. Außerdem war der Kanzler nicht in der Lage, seinen Standpunkt auch innenpolitisch durchzusetzen. Eine große Mehrheit im Bundeskabinett sprach sich ohne Wenn und Aber für den Beitritt Großbritanniens aus ${ }^{85}$. Vor allem Wirtschaftsminister Erhard betonte die Notwendigkeit einer Erweiterung der EWG, um der deut-

78 ADENAUER, Erinnerungen IV, S. 165.

79 So Adenauer am 9. 6. 1962 zu Reynaud. Zitiert nach OSTERHELD, „Ich gehe nicht leichten Herzens ...“, S. 126. Ähnlich äußerte er sich in dem hier referierten Gespräch mit de Gaulle. Vgl. AdENAUER, Erinnerungen IV, S. 165.

80 Vgl. OSTERHELD, „Ich gehe nicht leichten Herzens ...“, S. 139; sowie das Schreiben Globkes an Krone vom 8. 8. 1962, ACDP, Nachlaß Krone I-028-011/3.

81 ADENAUER, Erinnerungen IV, S. 165.

82 Vgl. OSTERHELD, „Ich gehe nicht leichten Herzens ...“, S. 126.

83 Vgl. dazu den Tagebucheintrag Blankenhorns vom 13.6. 1962 nach einem Gespräch mit Adenauer, in: BDFD, I, Dok. 301, S. 905 f.

84 Vgl. dazu das Protokoll der CDU/CSU-Fraktionssitzung am 5. 2. 1963, ACDP VIII-0011009/2, bzw. BDFD, I, Dok. 316, S. 967.

$85 \mathrm{Vgl}$. SCHWARZ, Adenauer II, S. $763 \mathrm{f}$. 
schen Industrie den Zugang zu den Märkten der EFTA zu öffnen ${ }^{86}$. Auch im Bundestag lagen die Sympathien eindeutig auf der Seite Londons ${ }^{87}$. Schröder gab am 20. August 1962 dem Fraktionsvorstand der Union zudem zu bedenken, daß im Falle eines Scheiterns der Beitrittsverhandlungen mit einem Regierungswechsel in London zu rechnen sei. Eine Labour-Regierung würde aber die NATO-Politik des Königreichs von Grund auf neu formulieren; eventuell würde sogar die Rhein-Armee abgezogen werden ${ }^{88}$. Falls Adenauer erwartet hatte, er könne in der Union einen Meinungsumschwung bewirken, so belehrte ihn spätestens die Reaktion auf ein Fernsehinterview vom 28. August 1962, in dem er seine Vorbehalte gegenüber einem britischen Beitritt anklingen ließ, eines Besseren. Die Stellungnahmen seiner Parteifreunde zeigten, daß die Ansichten des Kanzlers von CDU und CSU nicht geteilt wurden ${ }^{89}$. Er konnte folglich de Gaulle nicht öffentlich dabei unterstützen, die Erweiterung der EWG zu verhindern. Dieser wußte allerdings, $\mathrm{da}$ Adenauer insgeheim sein Vorhaben befürwortete ${ }^{90}$.

Hinsichtlich der Politischen Union verabredeten Adenauer und de Gaulle im Juli 1962, auf einer Gipfelkonferenz der Sechs einen letzten Versuch zu unternehmen, die Gespräche wieder in Gang zu bringen und einen Kompromiß zu finden ${ }^{91}$. "Gelinge dies nicht, sollten meines Erachtens diejenigen handeln, die einig seien", meinte der Bundeskanzler92. Der General fragte ihn daraufhin, ob er notfalls auch bereit sei, allein mit Frankreich die Initiative zu ergreifen. Adenauer erklärte sich nach einigem Zögern damit einverstanden ${ }^{93}$. Zunächst wollten die beiden Staatsmänner aber in gleichlautenden Schreiben den italienischen Ministerpräsidenten bitten, zu einer Konferenz der Staats- und Regierungschefs nach Rom einzuladen, wie es auf dem letzten Gipfeltreffen der Sechs in Bonn am 18. Juli 1961 vereinbart worden war. Als Termin schlugen Adenauer und de Gaulle die zweite Septemberhälfte vor ${ }^{94}$. In seiner Antwort regte Fanfani jedoch an, zunächst eine Konferenz der Außenminister abzuhalten. Erst wenn dort eine Annäherung der Standpunkte stattgefunden habe, sollte über ein Treffen der Staatsbzw. Regierungschefs nachgedacht werden ${ }^{95}$. Da es ziemlich unwahrscheinlich war, daß eine Begegnung der Außenminister erfolgreich verlief, nachdem eine Konferenz auf gleicher Ebene im April ohne Ergebnis blieb, war dieser Vorschlag

86 Vgl. KOERFER, Kampf ums Kanzleramt, S. $708 \mathrm{f}$.

87 Dies war z. B. in der Fragestunde des Bundestags zur Europa-Politik am 27.6. 1962 deutlich geworden. Vgl. BT STENOGRAPHISCHE BERICHTE, Bd. 51, S. 1482-1492.

88 Vgl. MARCOWITZ, Option, S. 69.

89 Vgl. KOERFER, Kampf ums Kanzleramt, S. 667.

90 Vgl. das Schreiben Globkes an Krone vom 8. 8. 1962, ACDP, Nachlaß, Krone I-028-011/ 3.

91 Vgl. das Schreiben Adenauers an Rusk vom 10. 7. 1962, PA/AA, Ministerbüro, Bd. 226.

92 AdenaUer, Erinnerungen IV, S. 159.

93 Vgl. Kusterer, Der Kanzler und der General, S. 243; OSTERHELD, „Ich gehe nicht leichten Herzens ...“, S. 132.

94 Vgl. AdenAUER, Erinnerungen IV, S. 160. Vgl. ferner das Schreiben Adenauers an Rusk vom 10. 7. 1962, PA/AA, Ministerbüro, Bd. 226; das Schreiben Adenauers an Fanfani vom 10. 7. 1962, PA/AA, Ministerbüro, Bd. 215; und das Schreiben de Gaulles an Fanfani vom 10. 7. 1962, in: DE GAULLE, Lettres IX, S. $246 \mathrm{f}$.

95 Vgl. das Schreiben Fanfanis an Adenauer vom 25. 7. 1962, PA/AA, Referat 201, Bd. 375. 
nicht mehr als eine verklausulierte Absage. Das Projekt einer Politischen Union war damit vorläufig zu den Akten gelegt.

\section{Der deutsch-französische Vertrag vom 22. Januar 1963 und der Streit um den britischen $E$ WG-Beitritt}

Nach dem Scheitern der Politischen Union standen die Weichen in Richtung auf einen deutsch-französischen Alleingang. Schröder konnte sich jedoch mit den Plänen Adenauers, sich an Frankreich anzulehnen, nicht anfreunden: „Was wollen Sie - es wird immer eine deutsch-französische Rivalität geben“, hörte Kusterer von ihm. Daß Paris in diesem Bündnis nach Ansicht des Kanzlers die Führungsrolle übernehmen sollte, war ebenfalls nicht in seinem Sinn: „Wir eignen uns nun mal nicht zum Juniorpartner." 96 Adenauer ließ sich von den Einwänden nicht beirren. Während des Staatsbesuchs de Gaulles in der Bundesrepublik vom 4. bis 9. September 1962 beschlossen die beiden Politiker, als Ersatz für die Politische Union die bilaterale Zusammenarbeit zu verstärken. Beide Politiker dachten zu diesem Zeitpunkt noch nicht daran, „einen feierlichen Vertrag zu schließen und den Abschluß unter Glockengeläute und mit Feuerwerk zu feiern". Sie erwogen vielmehr eine Absprache in Form eines „Gentleman's Agreement", dessen Ergebnisse schriftlich fixiert und durch einen Briefwechsel bestätigt werden sollten. Darin wollten sie ihren Willen bekunden, in der Frage der Ost-West-Beziehungen, beim Berlin-Problem, sowie in der Verteidigungs- und Entwicklungspolitik „zu einer stärkeren Abstimmung ihrer Politik zu gelangen “97. Sie verabredeten, daß der französische Staatspräsident der Bundesregierung einen Entwurf übermitteln werde ${ }^{98}$.

Welches Ziel de Gaulle mit einer derartigen Vereinbarung verfolgte, klang bereits in seiner Tischrede am 4. September 1962 anläßlich eines Staatsbanketts auf Schloß Brühl an. Er verkündete den Anwesenden, die Zusammenarbeit Frankreichs und Deutschlands solle letztendlich dazu führen, daß beide Staaten „eine einzige und gleiche deutsch-französische Politik" verfolgen würden"9. De Gaulle plante, die Bundesrepublik aus der Hegemonie der USA zu lösen und mit ihr zusammen sein Konzept eines europäischen Europas zu verwirklichen, das als Dritte Kraft zwischen West und Ost agieren sollte. Das zweite Motiv für eine engere Zusammenarbeit war, daß er - wie ironischerweise auch Adenauer hinsichtlich der französischen Politik - eine Hinwendung der Bundesrepublik zum Osten befürchtete ${ }^{100}$. Seine Intentionen offenbarte er am deutlichsten in einem Gespräch mit dem Bundeskanzler am 23. Januar 1963 anläßlich der Unterzeichnung des deutsch-französischen Vertrags. De Gaulle betonte dabei, es sei notwendig, „einen anderen, eigenen und im eigentlichen Sinne europäischen ,Ehrgeiz' [zu] ent-

\footnotetext{
96 KUSTERER, Der Kanzler und der General, S. 201. Vgl. auch OSTERHELD, „Ich gehe nicht leichten Herzens ...“, S. 123.

97 ADENAUER, Erinnerungen IV, S. 179.

$98 \mathrm{Vgl}$. OSTERHELD, „Ich gehe nicht leichten Herzens ...“, S. 142.

99 EUROPA-ARCHIV 1962, D 456.

$100 \mathrm{Vgl}$. SCHWARZ, Eine Entente Elémentaire, S. $11 \mathrm{f}$.
} 
wickeln, der getragen sein müsse von Frankreich und Deutschland zusammen. Dieser Ehrgeiz müsse eine Antriebskraft haben und den Willen, aus sich selbst heraus existieren zu wollen neben Amerika, das natürlich Verbündeter sei, von dem man aber doch unabhängig sein müsse."101

Eine derartige Zielsetzung widersprach vollkommen den politischen Vorstellungen Schröders. Die Haltung der Führungsspitze des Auswärtigen Amtes spiegelt sich in der Weisung an Dolmetscher Kusterer wieder, den Begriff "union“, den de Gaulle bei seiner Tischrede auf Schloß Brühl zur Beschreibung des Charakters der künftigen bilateralen Kooperation verwendet hatte, im Deutschen lediglich mit dem vagen Begriff „Zusammenschluß“ zu übersetzen ${ }^{102}$. Wie bereits dargelegt, mißbilligte Schröder eine allzu enge Kooperation der beiden Staaten. Das Drängen Adenauers auf einen förmlichen Vertrag mit Frankreich erklärte er mit dessen Wunsch, dadurch in die Geschichte einzugehen ${ }^{103}$. Der Außenminister soll den deutsch-französischen Vertrag sogar als „überflüssig, unsinnig und gefährlich" bezeichnet haben ${ }^{104}$. Es erstaunt deshalb, daß er dennoch an dessen Entstehung "stets loyal und positiv mitgewirkt hat", wie Kusterer im Rückblick betont ${ }^{105}$. Näher betrachtet, ist sein Verhalten jedoch verständlich und nachvollziehbar. Im Auswärtigen Amt wußte man, daß de Gaulles Konzept eines europäischen Europas im Widerspruch zu den Vorstellungen der anderen EWG-Staaten stand. Wie sollte Bonn nun darauf reagieren? Die Bundesrepublik konnte entweder die Konfrontation suchen oder auf dem Weg der Zusammenarbeit versuchen, auf de Gaulle einzuwirken und seinen Kurs abzuschwächen. Bewußt entschied sich Schröder für die zweite, aussichtsreichere Strategie ${ }^{106}$.

Dabei darf nicht außer acht gelassen werden, daß der deutsch-französische Vertrag offiziell ein Ersatz für die nicht zustande gekommene Politische Union war. Das Ziel des Abkommens entsprach demjenigen der Union, nämlich die politische Integration zu verstärken. Zwar würde sie zunächst nur auf bilateraler Basis realisiert werden, doch gaben Bundesrepublik und Frankreich ihrer Kooperation ausdrücklich eine europäische Dimension. Die Vertragspartner erklärten nämlich, ihr Handeln sei von der Erkenntnis bestimmt, „daß die Verstärkung der Zusammenarbeit zwischen den beiden Ländern einen unerläßlichen Schritt auf dem Wege zu dem Vereinigten Europa bedeutet, welches das Ziel beider Völker ist“"107. De Gaulle bekräftigte dies anläßlich der Unterzeichnung des Elysée-Vertrags. Gegenüber Adenauer erwähnte er explizit die Option, die bilaterale Kooperation „auch

101 AdENAUER, Erinnerungen IV, S. 210.

102 KUSTERER, Der Kanzler und der General, S. 201 und S. 254.

103 In einem Gespräch mit dem britischen Journalisten Terence Prittie antwortete Schröder auf die Frage, wie er das Zustandekommen des Elysée-Vertrages sehe, mit einem Zitat des englischen Literaten John Milton: „Der Wunsch nach Nachruhm ist die letzte Krankheit edler Geister." Vgl. PRiTTiE, Konrad Adenauer, S. 421.

104 Vgl. dazu Patz, Parlamentarische Kontrolle der Außenpolitik, S. 75.

105 KUSTERER, Der Kanzler und der General, S. 300.

106 Vgl. dazu den Diskussionsbeitrag von Per Fischer in ScHWarz (Hrsg.), Adenauer und Frankreich, S. 46.

107 Vgl. die Gemeinsame Erklärung der Bundesrepublik und Frankreichs zum Vertrag über die deutsch-französische Freundschaft vom 22.1. 1963 in: Die AuswärTIGE POLITIK, Dok. 165, S. 490. 
auf andere Länder der EWG auszudehnen“108. Dies konnte dahingehend interpretiert werden, daß der Vertrag anderen Staaten zum Beitritt offenstünde. Nach Schröders Willen sollte er sogar in erster Linie der Förderung der europäischen Einigungsbestrebungen dienen ${ }^{109}$.

Vor allem im Hinblick auf diese europäische Perspektive und „nicht nur vom deutsch-französischen Blickwinkel aus“, bewerte die Bundesregierung das geplante Abkommen, teilte er im Dezember 1962 dem griechischen Außenminister Evángelos Averoff-Tositzas mit. Die Vereinbarung, so Schröder, sei „ein erster Schritt auf dem Weg, der nunmehr in Richtung auf England weiter begangen werden müsse" 110 . Er versuchte also, den Verdacht zu zerstreuen, die Bundesrepublik könnte im Zuge der Intensivierung der deutsch-französischen Zusammenarbeit das Ziel aufgegeben haben, Großbritannien in die europäischen Gemeinschaften zu integrieren. Der Beitritt Londons blieb für ihn aber „das zentrale Problem“ der Europa-Politik ${ }^{111}$. Er rückte diese Frage so sehr in den Vordergrund, daß er sich schließlich im Bundestag zu der Beteuerung gezwungen sah, daraus sei nicht der Schluß zu ziehen, er wolle Frankreich vernachlässigen ${ }^{112}$. Auf Schröders europapolitischer Landkarte nahmen Frankreich und Großbritannien einen gleichwertigen Rang ein. Deshalb war er strikt dagegen, Frankreich hervorzuheben und der Zusammenarbeit mit Paris einen exklusiven Stellenwert zu geben. In einem Artikel für den Deutschland-Union-Dienst Ende Dezember 1962 betonte er folglich, die Bemühungen um eine engere deutsch-französische Zusammenarbeit hätten „nicht den Zweck andere auszuschließen, sie sind vielmehr darauf gerichtet, in einen größeren Zusammenschluß der europäischen Staaten einzumünden“113.

Im übrigen maß er dem Vertrag keine allzu große Bedeutung zu. Er sah darin nicht den Beginn einer „,bilateralen Allianz" 114 , sondern im wesentlichen ein Konsultationsabkommen ${ }^{15}$. In der Tat enthielt der Vertragstext zwar Formulierungen, die eine intensivere Kooperation erlaubt hätten, doch handelte es sich dabei lediglich um Willensbekundungen. Beispielhaft für Schröders abwertende Einschätzung des Abkommens ist seine Antwort, als de Gaulles ihn am 21. Januar 1963 fragte, wie er sich nun die praktische Zusammenarbeit zwischen Bonn und Paris vorstelle. Der Außenminister erwiderte darauf trocken, diese sei ja „kein Novum", da schon seit längerem ein regelmäßiger, bilateraler Gedankenaustausch stattfände. Mit dem Abkommen würden bloß die Begegnungen zwischen den Repräsentanten der beiden Länder institutionalisiert! Daß Schröder eine engere

108 Elysée-Konferenz am 21.1. 1963, in: AAPD 1963, Dok. 38, S. 127.

109 Vgl. B'T STENOGRAPHISCHE BERICHTE, Bd. 52, S. 2637.

110 Gespräch Schröders mit dem griechischen Außenminister Averoff-Tositzas am 10. 12. 1962, PA/AA, Büro Staatssekretär, Bd. 76.

111 So Schröder am 10.1. 1963 vor dem Auswärtigen Ausschuß des Bundestags. Zitiert nach MARCOWITZ, Option, S. 75.

112 BT STENOGRAPHISCHE BERICHTE, Bd. 51, S. 1771.

113 Vgl. den im Deutschland-Union-Dienst am 28.12. 1962 veröffentlichten Artikel von Gerhard Schröder: „Mit neuem Selbstvertrauen“, ACDP Pressearchiv, Sammlung „Gerhard Schröder".

114 Ebenda.

115 Vgl. KuSTERER, Der Kanzler und der General, S. 300 f. 
Kooperation in der Außen-, Wirtschafts- oder Verteidigungspolitik nicht im Sinn hatte, zeigt sich daran, daß er als "Kernstück der künftigen Zusammenarbeit“ lediglich "die gegenseitige Konsultation “ zu nennen wußte ${ }^{116}$. Doch selbst die Absprache, sich vor politischen Entscheidungen zu konsultieren, war seines Erachtens nicht verpflichtend. Die diesbezügliche Vertragspassage interpretierte er als reine Absichtserklärung ${ }^{117}$.

Welche Absichten verfolgte hingegen Adenauer mit der Anlehnung an Frankreich? Oft wurde ihm unterstellt, er hätte nicht erkannt, auf welchen gefährlichen Pfad de Gaulle die Bundesrepublik führen wollte. Besson sprach sogar von einer „Altersfreundschaft der Mißverständnisse"118. Ihm zufolge war Adenauer der Fehleinschätzung unterlegen, er und de Gaulle hätten die gleichen politischen Intentionen, obwohl in Wahrheit der General Pläne verfolgte, die im Gegensatz zu den Überzeugungen des Kanzlers standen ${ }^{119}$. In Wirklichkeit hatte Adenauer auch gegenüber de Gaulle nie einen Zweifel gelassen, daß er zwar eine Reform der NATO für notwendig erachtete, aber im Prinzip die atlantische Allianz und die Integration der Streitkräfte ihrer Mitgliedstaaten für unentbehrlich hielt ${ }^{120}$. Hingegen wollte de Gaulle zwar am Bündnis mit den Vereinigten Staaten festhalten, sah aber durch die NATO die nationale Souveränität Frankreichs im Bereich der Verteidigung verletzt. Er akzeptierte jedoch die Einbindung der Bundesrepublik in die Allianz ${ }^{121}$. Adenauer seinerseits beabsichtigte keineswegs, die Verteidigungspolitik der Bundesrepublik von den USA abzukoppeln. Ihm schwebte allerdings vor, der Bundesrepublik durch die Anbindung an Paris mehr außenpolitisches Gewicht zu geben: „Mit Frankreich zusammen können wir Deutsche in der äußeren Politik einen großen Einfluß ausüben, ohne Frankreich nicht."122 In Anbetracht der Tatsache, daß Kennedy im Verlauf der Berlin-Krise wenig Rücksicht auf die Wünsche Bonns genommen hatte, suchte Adenauer jetzt bei de Gaulle Rückendeckung, um künftig eine stärkere Berücksichtigung der Interessen der Bundesrepublik durch die Vereinigten Staaten zu erreichen ${ }^{123}$. Darüber hinaus hielt Adenauer wegen des sowjetischen Expansionsdranges eine engere Kooperation mit Paris für erforderlich: "Je größer die Gefahr der Bedrohung aus dem Osten sei, um so notwendiger sei es, daß Frankreich und Deutschland eine gemeinsame Politik verfolgten." 124 Während der Kanzler einerseits die antiamerika-

\footnotetext{
116 Elysée-Konferenz am 21. 1. 1963, in: AAPD 1963, Dok. 38, S. 125. Auch am folgenden Tag erklärte Schröder in einem Interview mit der ARD, „das Entscheidende“ der Vereinbarung sei die gegenseitige Konsultation. Vgl. BulLETIN 1963, S. 119.

117 So Schröder am 22.1.1964 im Bundestag. Vgl. BT STENOGRAPHISCHE BERICHTE, Bd. 54, S. 4916.

118 BESSON, Die Außenpolitik der Bundesrepublik, S. 304.

119 Vgl. ebenda, S. 304-309.

$120 \mathrm{Vgl}$. ADENAUER, Erinnerungen IV, S. $149 \mathrm{f}$.

121 Vgl. DE Gaulle, Mémoires d'espoir, S. 193. Zu den verteidigungspolitischen Vorstellungen des französischen Staatspräsidenten vgl. ebenda, S. 215-220.

122 So Adenauer am 22. 7. 1963 zu Cyrus L. Sulzberger von der New York Times. Vgl. AdENAUER, Teegespräche 1961-1963, S. 403.

123 Vgl. SCHWARZ, Adenauer II, S. 729 f., S. 739 und S. $814 \mathrm{f}$.

124 ADENAUER, Erinnerungen IV, S. 178.
} 
nische Politik de Gaulles abschwächen wollte ${ }^{125}$, spekulierte er andererseits darauf, zusammen mit Frankreich gegenüber Moskau die deutsche Frage wieder ins Spiel zu bringen ${ }^{126}$. Auch eine bilaterale Zusammenarbeit im atomaren Bereich zog er durchaus in Erwägung 127 . Er dachte aber niemals daran, das Bündnis mit den Vereinigten Staaten zu lockern oder gar aufzugeben. Das Zusammengehen mit Frankreich sollte allerdings der Bundesrepublik ein zweites Standbein verschaffen und zudem ein Abdriften Frankreichs vom westlichen Bündnis verhindern ${ }^{128}$.

Man kann also durchaus mit Daniel Kosthorst den "tiefste[n] Beweggrund“ Adenauers für den Abschluß des deutsch-französischen Vertrages in dem Motiv sehen, die Westbindung der Bundesrepublik irreversibel zu machen ${ }^{129}$. Dennoch kam die Annäherung an de Gaulle in gewisser Weise einem Kurswechsel der Bonner Außenpolitik gleich: Erstens wollte der Kanzler die Führung in diesem Zweierbündnis de Gaulle überlassen, was die Bundesrepublik jedoch automatisch in das Fahrwasser einer gegen die NATO gerichteten Politik gebracht hätte, da der französische Staatspräsident ein von Amerika weitgehend unabhängiges Europa anstrebte. Während der Elysée-Vertrag für Adenauer den „Abschluß seiner Mission" darstellte, war er für de Gaulle "der Aufbruch zu seiner Vision"130. Bonn wäre aber von Washington für die antiamerikanische Haltung der französischen Regierung mitverantwortlich gemacht worden. Zweitens machte sich der Kanzler de Gaulles Auffassung zu eigen, Großbritannien fehle es an wahrer europäischer Gesinnung und könne deshalb am europäischen Zusammenschluß nicht teilnehmen. Damit hatte sich Adenauer gegen eine Fortsetzung der von ihm bislang geförderten Politik der europäischen Integration entschieden, da weitere Fortschritte, wie Spaak und Luns deutlich gemacht hatten, nur gemeinsam mit Großbritannien möglich gewesen wären.

Der Sinneswandel des Kanzlers war dem Auswärtigen Amt nicht verborgen geblieben. Während sich Adenauer im Verlauf des Jahres 1962 zunehmend skeptischer über das britische Beitrittsgesuch äußerte, rückte Schröder das Erfordernis, die Gemeinschaften um das Inselreich zu erweitern, immer stärker in den Vordergrund. Als sich Adenauer im Herbst 1962 in Cadenabbia zur Erholung aufhielt, drängte er ihn, den britischen Europaminister Heath zu empfangen. Der Außenminister hoffte, daß dieser proeuropäische Brite Adenauers Einstellung ändern könnte131. Tatsächlich beschwor Heath den Kanzler am 30. September, sich für den britischen Beitritt einzusetzen. Er versicherte Adenauer: „Sie werden über-

125 Vgl. SCHWARZ, Eine Entente Elémentaire, S. $11 \mathrm{f}$.

126 Vgl. Hildebrand, Von Erhard zur Großen Koalition, S. 190.

127 Vgl. KuSTERER, Der Kanzler und der General, S. 229-235.

128 Vgl. das Protokoll der CDU/CSU-Fraktionssitzung am 5.2. 1963, ACDP VIII-0011009/2, bzw. BDFD, I, Dok. 316, S. 962-965; sowie Äußerungen Adenauers in einem Hintergrundgespräch am 18.6. 1962, in: ADENAUER, Teegespräche 1961-1963, S. $211 \mathrm{f}$. Vgl. ferner OSTERHELD, „Ich gehe nicht leichten Herzens ...", S. 123; SCHWARZ, Eine Entente Elémentaire, S. $11 \mathrm{f}$.

129 Vgl. KOSTHORST, Die „unerwünschte Liaison“, S. 193.

130 Ebenda.

131 Vgl. den Artikel „Vorwärts! Vorwärts!“, in: DER SPIEGEL vom 3. 10. 1962, S. 30. 
rascht sein, wie sehr wir uns ins Zeug legen, wenn wir einmal dabei sind."132 Der Kanzler stellte Heaths europäische Gesinnung zwar nicht in Frage, doch war er überzeugt, dieser sei innerhalb der britischen Regierung eine Ausnahmeerscheinung ${ }^{133}$. Minutiös zählte er alle Punkte auf, die aus seiner Sicht gegen eine Aufnahme Großbritanniens in die EWG sprachen. Die Ausführungen des Kanzlers gipfelten in der Bemerkung, daß er an der Stelle des britischen Premierministers dieses Ziel nicht weiter verfolgen würde ${ }^{134}$. Der Sicherheitsberater Kennedys, McGeorge Bundy, versuchte ebenfalls erfolglos, ihn vom Nutzen einer Erweiterung der Gemeinschaften zu überzeugen. Ihm eröffnete Adenauer, das europäische Einigungswerk könne den Beitritt Großbritanniens nicht verkraften, da die Folge ein ständiger Streit zwischen Paris und London um die Führung in Europa wäre. Bundy entgegnete darauf, auf absehbare Zeit würden ohnehin weder Frankreich noch das Vereinigte Königreich die europäische Politik bestimmen, sondern ausschließlich die Vereinigten Staaten ${ }^{135}$. Diese Bemerkung erzürnte Adenauer so sehr, daß er künftig diesen Satz jedes Mal zitierte, wenn er die amerikanische Europa-Politik negativ charakterisieren wollte ${ }^{136}$.

Die unmittelbare Entstehungsgeschichte des deutsch-französischen Freundschaftsvertrags ist bereits an anderer Stelle ausführlich geschildert worden ${ }^{137}$. Es genügt deshalb, die wichtigsten Stationen auf dem Weg von der vertraulichen $\mathrm{Ab}$ sprache, wie sie de Gaulle und Adenauer im September 1962 planten, bis zur Unterzeichnung des Elysée-Vertrags am 22. Januar 1963 kurz nachzuzeichnen: Bereits wenige Tage nach seiner Rückkehr vom Rhein an die Seine, am 19. September 1962, übermittelte der General der Bundesregierung ein Memorandum, in welchem er den Inhalt eines bilateralen Abkommens kurz skizzierte ${ }^{138}$. Die Verantwortlichen in Bonn erklärten sich mit den französischen Vorschlägen weitgehend einverstanden, ergänzten sie jedoch an einigen Stellen. Am 12. November übergab Botschafter Blankenhorn in Paris den Entwurf eines Regierungsprotokolls ${ }^{139}$. Anschließend wurde in mehreren Gesprächsrunden zwischen dem Leiter der Europa-Abteilung im Auswärtigen Amt, Ministerialdirektor Josef Jansen, und sei-

132 OSTERHELD, „Ich gehe nicht leichten Herzens ...", S. 147.

$133 \mathrm{Vgl}$. KustereR, Der Kanzler und der General, S. 371.

134 Vgl. OSTERHELD, "Ich gehe nicht leichten Herzens ...", S. 147.

135 Vgl. ebenda, S. 147 f.; KUSTERER, Der Kanzler und der General, S. 293.

136 Vgl. Osterheld, „Ich gehe nicht leichten Herzens ...“, S. 217. McBundys Bemerkung gehörte nun zu dem Repertoire von Stereotypen, die Adenauer gegenüber Gesprächspartnern häufig wiederholte. Vgl. ebenda, S. $216 \mathrm{f}$.

$137 \mathrm{Vgl}$. ARNOLDS, Die Entstehung des deutsch-französischen Vertrages vom 22. Januar und seine Bedeutung für die Außen- und Europapolitik Konrad Adenauers; BAUER, Die deutsch-französischen Beziehungen, S. 66-124; JANSEN, Die Entstehung des deutschfranzösischen Vertrages vom 22. Januar 1963, S. 249-271; FISCHER, Der diplomatische Prozeß der Entstehung des Deutsch-Französischen Vertrages von 1963; sowie den Diskussionsbeitrag von Per Fischer in SCHWARZ (Hrsg.), Adenauer und Frankreich, S. 46-49.

138 Zum Inhalt des Memorandums vgl. die Aufzeichnung des Referats 200 vom 28. 11. 1962, PA/AA, B 150, Aktenkopien 1962. Vgl. auch SCHWARZ, Adenauer II, S. 768; den Tagebucheintrag Blankenhorns vom 12.11. 1962, in: BDFD, I, Dok. 306, S. 920 ; sowie den Diskussionsbeitrag von Per Fischer in SCHWARZ (Hrsg.), Adenauer und Frankreich, S. 47.

139 Vgl. dazu den Tagebucheintrag Blankenhorns vom 12.11. 1962, in: BDFD, I, Dok. 306; S. $920 \mathrm{f}$. 
nem Kollegen vom Quay d'Orsay, Jean Lucet, der Text der Vereinbarung ausgearbeitet. Am 16. und 17. Dezember 1962 bemühten sich Schröder und Couve de Murville, eine Einigung über die noch strittigen Formulierungen zu erzielen ${ }^{140}$. Es war beabsichtigt, das "Gemeinsame Protokoll“ während der ersten gemeinsamen Kabinettssitzung der beiden Regierungen am 21./22. Januar 1963 in Paris zu unterzeichnen. Nachdem von den beiden Verhandlungsführern Lucet und Jansen am 11./12. Januar das Protokoll in seine endgültige Form gebracht worden war, wurde es vier Tage später vom Bundeskabinett einstimmig gebilligt ${ }^{141}$. Ausschlaggebend für dieses klare Ergebnis war wohl auch Schröders nachdrückliche Befürwortung des Abkommens ${ }^{142}$. Erst in Paris entschieden de Gaulle und Adenauer, einen völkerrechtlichen Vertrag zu unterzeichnen, der nach Artikel 59 des Grundgesetzes ratifiziert werden mußte ${ }^{143}$. Das Auswärtige Amt war darauf nicht vorbereitet und hatte weder Vertragspapier noch die für völkerrechtliche Verträge übliche blaue Vertragsmappe in die französische Hauptstadt mitgenommen, so daß französisches Papier verwendet wurde und eine bei Hermès erworbene Mappe als Ersatz dienen mußte ${ }^{144}$.

Der Inhalt des deutsch-französischen Freundschaftsvertrages läßt sich grob in zwei Abschnitte gliedern. Ein Teil kann als Konsultationskalender bezeichnet werden. Er sah mindestens zwei Begegnungen des französischen Staatspräsidenten mit dem Bundeskanzler pro Jahr vor. Die Außen-, Verteidigungs- und Kultusminister (für die Bundesrepublik hatten die für Kultusfragen zuständigen Bundesländer einen Repräsentanten zu bestimmen) sollten vierteljährlich, die Familienund Jugendminister sogar alle zwei Monate zusammenkommen. Ferner wurde auf französischer und deutscher Seite jeweils eine interministerielle Kommission eingerichtet, die alle politischen Aktivitäten zwischen den beiden Staaten koordinieren und regelmäßig darüber Bericht erstatten sollte. Abgesehen von der Gründung eines deutsch-französischen Jugendwerks enthielt der Vertrag keine konkre-

140 Couve De Murville, Außenpolitik, S. 210.

141 Vgl. JaNSEN, Die Entstehung des deutsch-französischen Vertrages vom 22. Januar 1963, S. 265 f.; den Diskussionsbeitrag von Per Fischer in ScHWARZ (Hrsg.), Adenauer und Frankreich, S. 47; sowie SCHWARZ, Epochenwechsel, S. 289.

142 Vgl. OsterHELD, „Ich gehe nicht leichten Herzens ...", S. 183f. Auch am 25. 1. 1963 setzte sich Schröder nachdrücklich vor dem Fraktionsvorstand von CDU/CSU für eine zügige Ratifikation ein. Vgl. MarcowITZ, Option, S. 77.

143 Vgl. SCHWARZ, Eine Entente Elémentaire, S. 9. Für das Bundeskanzleramt stand schon seit Jahresbeginn fest, daß ein völkerrechtlicher Vertrag geschlossen werden sollte. Osterheld vertrat bereits in der zweiten Dezemberhälfte 1962 die Meinung, das Abkommen müßte ratifiziert werden. Der Kanzler lehnte zunächst ab, entschied sich aber Ende Dezember/Anfang Januar für das Ratifikationsverfahren, da er die Vorteile erkannte, wenn der Bundestag in einem feierlichen Akt dem Vertrag zustimmen würde. Vgl. den Diskussionsbeitrag von Horst Osterheld in SCHWARZ (Hrsg.), Adenauer und Frankreich, S. 108; OSTERHELD, „Ich gehe nicht leichten Herzens ...“, S. 174. Hans-Peter Schwarz vermutet, daß Adenauer die Ratifikation wollte, um auf diese Weise seinen Nachfolger zu binden. Vgl. SCHWARZ, Eine Entente Elémentaire, S. 14.

144 Vgl. den Diskussionsbeitrag von Per Fischer in SCHwarz (Hrsg.), Adenauer und Frankreich, S. 48. Henning Köhler spekuliert, daß Schröder das notwendige Material absichtlich in Bonn vergaß, um dadurch zu zeigen, daß er nichts mit dem Abschluß des Vertrages zu tun habe. Vgl. KÖHLER, Adenauer, S. 1200. Diese These läßt sich aber nicht belegen. 
ten Bestimmungen, sondern lediglich Willensäußerungen. Hinsichtlich der $\mathrm{Au}$ ßenpolitik verabredete man, "so weit wie möglich zu einer gleichgerichteten Handlung zu gelangen“. Die Entwicklungspolitik beider Länder sollte koordiniert und gemeinsame Projekte in Angriff genommen werden. Ferner wurde eine verstärkte ökonomische Zusammenarbeit vereinbart. Was den Bereich der Landesverteidigung betraf, so sprach man vage davon, "gemeinsame Konzeptionen" zu entwickeln. An keiner Stelle war aber von der Schaffung einer Politischen Union zweier Staaten die Rede ${ }^{145}$. Dennoch kann der Vertrag als „eine Art Fouchet-Plan auf bilateraler Basis" bezeichnet werden ${ }^{146}$. Zwar enthielt er „keine konkreten Übereinkommen von großer Bedeutung “147, es lag aber nur am Willen der Beteiligten, die im Vertrag verankerten, regelmäßigen Konsultationen zu einer intensiven Zusammenarbeit in allen politischen Bereichen auszubauen.

Schon vor der Fertigstellung des Vertragstextes kam es Schröder darauf an, den Verdacht zu zerstreuen, eine Achse Bonn-Paris sei im Entstehen. Ausdrücklich versicherte er der britischen Regierung, die deutsch-französische Zusammenarbeit sei nicht gegen Großbritannien gerichtet ${ }^{148}$. Daneben strich er das Interesse Bonns an einem raschen Abschluß der Beitrittsverhandlungen heraus. Im Dezember 1962 gab er als Ziel vor, die Verhandlungen mit Großbritannien binnen zwei Monaten unter Dach und Fach zu bringen. Die Aufnahme des Vereinigten Königreichs in die EWG sollte möglichst gleichzeitig mit der Unterzeichnung des Elysée-Vertrags erfolgen, um bei den Partnern der Bundesrepublik kein Mißtrauen auszulösen ${ }^{149}$. Damit in London keinerlei Zweifel an der Gesinnung Bonns aufkam, entschloß er sich zum Jahreswechsel 1962/63, eine Einladung von Heath anzunehmen und noch vor der Unterzeichnung des deutsch-französischen Vertrags mit dem britischen Europaminister zusammenzutreffen ${ }^{150}$. Adenauer, den Schröder über seine Reisepläne nicht informiert hatte, gab erst nachträglich seine $\mathrm{Zu}$ stimmung, um den bei einer kurzfristigen Absage drohenden „Eklat mit London“ zu vermeiden ${ }^{151}$. Wegen seiner probritischen Haltung machte er seinem Außenminister heftige Vorwürfe. Der Kanzler meinte, die britische Regierung werde Schröder nichts dafür geben, daß er bedingungslos die Aufnahme Großbritanniens in die EWG befürworte. Andererseits müsse es de Gaulle verstimmen, wenn er unmittelbar vor der Unterzeichnung eines bedeutenden deutsch-französischen Abkommens demonstrativ nach London reise ${ }^{152}$.

145 Vgl. den Vertrag über die deutsch-französische Freundschaft vom 22.1. 1963, in: DIE AUSWÄRTIGE POLITIK, Dok. 165, S. 490-493.

146 ZIEBURA, Die deutsch-französischen Beziehungen seit 1945, S. 166.

147 HANRIEDER, Deutschland, S. 291.

148 Vgl. den Artikel "Schröder bespricht mit Macmillan die Fortsetzung der Europapolitik“, in: FrANK FURTER AllgEMEINE ZEITUNG vom 27. 12. 1962, S. 1.

149 Vgl. das Gespräch Schröders mit dem griechischen Außenminister Averoff-Tositzas am 10. 12. 1962, PA/AA, Büro Staatssekretär, Bd. 76.

$150 \mathrm{Vgl}$. HÖLSCHER, Krisenmanagement, S. $13 \mathrm{f}$.

151 Vgl. das Schreiben Adenauers an Schröder vom 31. 12. 1962, StBKAH C 42. Vgl. auch OSTERHELD, „Ich gehe nicht leichten Herzens ...“, S. 170.

152 Vgl. ebenda. 
Am 7. Januar 1963 trafen sich Heath und Schröder auf dem Landsitz des britischen Premierministers in Chequers, um darüber zu beraten, wie die Brüsseler Verhandlungen zwischen der EWG und Großbritannien beschleunigt werden könnten. Der Außenminister der Bundesrepublik bekräftigte dabei nochmals seine vorbehaltlose Unterstützung der Aufnahme des Vereinigten Königreichs in die europäischen Gemeinschaften ${ }^{153}$. Die beiden Politiker sprachen über alle noch offenen Fragen der Beitrittsverhandlungen und stimmten überein, daß für alle Seiten akzeptable Lösungen erreicht werden könnten ${ }^{154}$. Man rechnete damit, die Beitrittsverhandlungen auf den Tagungen des EWG-Ministerrats am 14. und 29. Januar 1963 zu einem erfolgreichen Abschluß zu bringen ${ }^{155}$. Fünf Tage später konferierte Schröder in Bonn mit seinem italienischen Amtskollegen Attilio Piccioni. Diesen drängte er, die Verhandlungen mit der britischen Regierung müßten so rasch wie möglich abgeschlossen werden. Nur wenn Großbritannien Teil des integrierten Europa werde, könne die Politische Union Realität werden. Ausdrücklich warnte Schröder vor den „schwerwiegenden politischen Folgen“, die ein Scheitern des Beitritts mit sich brächte ${ }^{156}$. Obwohl er in diesem Gespräch die Auswirkungen eines Scheiterns der Brüsseler Verhandlungen an die Wand malte, war man im Grunde im Auswärtigen Amt zuversichtlich und glaubte, nur noch einen Schritt von ihrem erfolgreichen Abschluß entfernt zu sein ${ }^{157}$.

Es war dementsprechend ein Schock, daß sich der französische Staatspräsident, ohne irgend jemanden vorher zu informieren, auf einer Pressekonferenz am 14. Januar 1963 in Paris gegen einen Beitritt Großbritanniens zum jetzigen Zeitpunkt aussprach ${ }^{158}$. Sicherlich waren de Gaulles Zweifel an der europäischen Gesinnung der Briten zum Teil berechtigt ${ }^{159}$. Dennoch war diese öffentliche Absage nicht nur eine Provokation Londons, sondern aller europäischen Partner Frank-

153 Vgl. DEI, Bd. 2, Dok. 169, S. 233 f. Vgl. auch die Artikel „Schröder betont politischen Vorrang", in: DIE WELT vom 8. 1. 1963, S. 1 und S. 4; sowie "Schröder äußert sich zufrieden. Heath: Sehr gute Gespräche“, in: DiE WELT vom 9. 1. 1963, S. 1 und S. 4.

154 Vgl. LAHR, Zeuge, S. 370.

155 Vgl. STEININGER, Großbritannien und de Gaulle, S. 92.

156 Vgl. die Aufzeichnung des Vortragenden Legationsrats I. Klasse Voigt vom 14. 1. 1963, PA/AA, B 150, Aktenkopien 1963.

157 Vgl. LAHR, Zeuge, S. 370.

158 Vgl. DE GAulle, Discours IV, S. 61-79. Hermann Kusterer weist zurecht darauf hin, daß sich de Gaulle nicht prinzipiell gegen eine Aufnahme Großbritanniens ausgesprochen, sondern nur einen sofortigen Beitritt abgelehnt habe. Es habe sich somit nicht um ein Veto gehandelt, sondern um ein „Noch nicht“. Vgl. KuSTERER, Der Kanzler und der General, S. 301. Dennoch war das Verhalten des Generals ein Affront, denn schließlich stand man unmittelbar vor Beendigung der jahrelangen Beitrittsverhandlungen, als er plötzlich erklärte, eine Mitgliedschaft des Königreichs sei erst in ferner Zukunft möglich.

159 Margaret Thatcher schreibt in ihren Memoiren, sie habe die Aufregung nicht verstehen können, die um de Gaulles Pressekonferenz gemacht worden sei: „Es liegt auf der Hand, daß all dies, wenn er es wirklich anbot, die britischen Interessen sehr viel besser widergespiegelt hätte als die zehn Jahre später schließlich vereinbarten Bedingungen für den britischen Beitritt. Hier haben wir vielleicht den besten europäischen Bus verpaßt, der je bei uns vorbeifuhr." Vgl. ThATCHER, Die Erinnerungen 1925-1979, S. 156 (Hinweis bei KUSTERER, Der Kanzler und der General, S. 468). 
reichs. De Gaulle meinte aber, jemand mußte schließlich „Nein“ sagen und die europäische Gemeinschaft retten ${ }^{160}$. Er sah in den Briten das Trojanische Pferd Washingtons. Mit Hilfe Londons, fürchtete er, würden auch die Amerikaner in das europäische Boot gelangen und dort das Ruder übernehmen. Sein Alptraum war, daß „es dann zu einem Koloß von atlantischer Gemeinschaft in amerikanischer Abhängigkeit und unter amerikanischer Führung kommen, der die EuropaGemeinschaft aufsaugen würde" 161 . Das Ende Dezember 1962 geschlossene sogenannte Nassau-Abkommen zwischen Kennedy und Macmillan, auf das im folgenden Kapitel noch näher eingegangen wird, brachte beim französischen Staatspräsidenten das $\mathrm{Faß}$ zum Überlaufen ${ }^{162}$. Mit dieser Vereinbarung hatte nach seiner Auffassung die britische Regierung ihre atomare Unabhängigkeit aufgegeben und somit auf eine selbständige Verteidigung verzichtet. London hatte sich damit in den Augen de Gaulles europapolitisch disqualifiziert.

Das Veto de Gaulles machte alle Bemühungen Schröders zunichte, den wegen der Annäherung der Bundesrepublik an Frankreich entstandenen Eindruck einer europapolitischen Kehrtwende zu zerstreuen. Obwohl Bonn ebenfalls nicht über die Absichten de Gaulles unterrichtet worden war, geriet die Bundesrepublik allein durch die zeitliche Koinzidenz der Ereignisse - die Pressekonferenz fand nur eine Woche vor der Unterzeichnung des deutsch-französischen Freundschaftsvertrags statt - in den Verdacht, trotz aller gegenteiligen Beteuerungen insgeheim mit dem General gemeinsame Sache zu machen. Schröder bezog daher öffentlich Position gegen de Gaulle. In seiner Funktion als Leiter der Delegation der Bundesrepublik bei den Beitrittsverhandlungen in Brüssel erklärte er am 15. Januar, die Gespräche mit Großbritannien würden „mit dem Ziel des baldigen Abschlusses fortgesetzt“. Alle noch strittigen Fragen ließen sich in gemeinsamer Anstrengung lösen ${ }^{163}$. Auch die britische Regierung tat, als hätte die Pressekonferenz de Gaulles nicht stattgefunden. Heath führte in Brüssel am 15./16. Januar die Verhandlungen fort, als ob nichts geschehen sei. Am 17. Januar reiste jedoch Couve de Murville in die belgische Hauptstadt und verlangte die sofortige Unterbrechung der Beratungen ${ }^{164}$. Schröder beschwerte sich beim Kanzler über die französische Haltung und meinte, sie sei mit dem Inhalt des deutsch-französischen Vertrags nicht zu vereinbaren. Adenauer reagierte darauf mit der Frage, ob es ihm lieber gewesen wäre, wenn der General sein Veto erst nach der Unterzeichnung des Vertrages abgegeben hätte ${ }^{165}$. Das geschlossene Auftreten der fünf anderen EWGMitgliedstaaten bewog jedoch den französischen Außenminister, von seinem An-

160 Vgl. DE GaUlle, Mémoires d'espoir, S. $204 \mathrm{f}$.

161 So de Gaulle in seiner Pressekonferenz am 14. 1. 1963. Zitiert nach EUROPA-ARCHIV 1963, D 89.

162 Couve de Murville bestätigte Carstens am 4. 7. 1964, daß das Nassau-Abkommen den Ausschlag für de Gaulles Veto gab. Vgl. AAPD 1964, Dok. 186, S. 767.

163 DEI, Bd. 2, Dok. 174, S. 242 f. Adenauer war über Schröders Erklärung überaus verärgert, da sie mit ihm nicht abgestimmt war. Vgl. OsTERHELD, „Ich gehe nicht leichten Herzens ...", S. 183.

164 Vgl. den Drahtbericht des Staatssekretärs Lahr an Bundesminister Schröder vom 17. 1. 1963, in: AAPD 1963, Dok. 30, S. 96 f.

165 Vgl. LAHR, Zeuge, S. 372. 
sinnen abzurücken. Couve de Murville akzeptierte den Vorschlag, die Beitrittsverhandlungen bis zum 28. Januar zu vertagen und erst dann über den Abbruch der Gespräche zu entscheiden ${ }^{166}$. Dieser Beschluß kam vor allem durch die Bemühungen Schröders zustande. Sein auf Ausgleich bedachtes Krisenmanagement wurde explizit vom amerikanischen Außenminister gelobt ${ }^{167}$.

Allgemein wurde spekuliert, daß bis Ende Januar der Druck auf de Gaulle immer mehr zunähme, so daß er schließlich einlenken würde. Wegen seines besonders engen Verhältnisses zum französischen Staatspräsidenten beschworen vor allem die Amerikaner Adenauer inständig, er müsse in Paris seinen Einfluß geltend machen. Der ehemalige Hochkommissar John McCloy und der frühere Außenminister Dean Acheson verlangten, Adenauer dürfe den Elysée-Vertrag nur dann unterschreiben, wenn de Gaulle seine Meinung ändern würde ${ }^{168}$. Auch Rusk appellierte an den Kanzler, auf den General einzuwirken. Adenauer, so der amerikanische Außenminister, habe nun eine "historische Aufgabe“ zu erfüllen, denn nur er „könne und müsse das Abrutschen der Ereignisse [...] aufhalten“ ${ }^{169}$. Auch innenpolitisch geriet der Kanzler unter Druck. Am 18. Januar suchten ihn die Fraktionsspitzen von CDU/CSU, SPD und FDP auf. Der stellvertretende Fraktionsvorsitzende der SPD, Fritz Erler, verlangte von Adenauer, seine für den 20. bis 22. Januar geplante Reise nach Paris zu vertagen, zumindest aber die Unterzeichnung des deutsch-französischen Freundschaftsvertrags vorerst zurückzustellen. Auch viele Abgeordnete der Koalition waren dieser Ansicht. Schröder stellte sich dagegen hinter den Kanzler. Zwar kritisierte er de Gaulles antibritische Haltung, doch war er der Meinung: „[...] wenn wir aber jetzt nicht unterzeichneten, verlören wir wahrscheinlich auch Frankreich als engeren Verbündeten und säßen zwischen allen Stühlen". Da seine vorbehaltlose Unterstützung eines Beitritts Großbritanniens zu den europäischen Gemeinschaften allgemein bekannt war, machte diese Erklärung auf die Anwesenden großen Eindruck. Der Kanzler erklärte unmißverständlich, daß er den Vertrag nicht platzen lassen werde. Die Besprechung ging zu Ende, ohne daß er die gewünschte Zusicherung gegeben hatte, wegen des britischen Beitritts bei de Gaulle vorstellig zu werden ${ }^{170}$.

In den folgenden Tagen wurde er weiterhin von allen Seiten bedrängt, seine Begegnung mit dem französischen Staatspräsidenten abzusagen. Man erinnerte den Kanzler an den 13. August 1961. So wie es damals falsch gewesen sei, nicht nach

166 Zum Verlauf der EG-Ministerratssitzung am 17./18.1. 1963 vgl. die Aufzeichnung des Vortragenden Legationsrats I. Klasse Voigt vom 18.1. 1963, in: AAPD 1963, Dok. 31, S. 97-102.

167 Rusk sagte dem Botschafter der Bundesrepublik in Washington: „I want to express my great appreciation for the leadership shown by Mr. Schröder in Brussels. Would you please tell him that." Vgl. den Drahtbericht des Botschafters Knappstein, Washington, an Bundesminister Schröder vom 19. 1. 1963, in: ebenda, Dok. 33, S. 105.

168 Vgl. OSTERHELD, „Ich gehe nicht leichten Herzens ...“, S. 187.

169 Vgl. den Drahtbericht des Botschafters Knappstein, Washington, an Bundesminister Schröder vom 19. 1. 1963, in: AAPD 1963, Dok. 33, S. $104 \mathrm{f}$.

170 OSTERHELD, „Ich gehe nicht leichten Herzens ...", S. $184 \mathrm{f}$. Es ist umstritten, ob Adenauer eine derartige Zusage machte. Fritz Erler bestritt dies, während Erich Mende sich an eine derartige Zusage des Kanzlers erinnerte. Vgl. MarCOWITZ, Option, S. 76, Anm. 177, und KOERFER, Kampf ums Kanzleramt, S. 712. 
Berlin zu fahren, sei es nun falsch, an dem Treffen festzuhalten ${ }^{171}$. Doch Adenauer ignorierte alle Proteste und fuhr am 20. Januar in die französische Hauptstadt. Noch an der Seine riefen ihn Jean Monnet und Walter Hallstein dazu auf, die Unterzeichnung des Vertrages zu verschieben oder für seine Unterschrift der französischen Regierung die Billigung der Aufnahme Großbritanniens in die Gemeinschaften abzuringen ${ }^{172}$. Auch Staatssekretär Carstens bat noch am Morgen des 21. Januar den Kanzler, nur dann zu unterschreiben, wenn de Gaulle sein Veto zurückzöge ${ }^{173}$. Adenauer unternahm aber nicht einmal den Versuch, auf den Staatspräsidenten einzuwirken. Das Thema Großbritannien wurde in den Vieraugengesprächen nur am Rande gestreift, wobei sich der Kanzler erneut kritisch über die europäische Haltung Londons äußerte ${ }^{174}$.

Wie vorgesehen wurde am 22. Januar 1963 der deutsch-französische Freundschaftsvertrag im Elysée-Palast in einer feierlichen Zeremonie unterzeichnet. Neben de Gaulle und Adenauer unterschrieben auch die beiden Außenminister, Couve de Murville und Schröder. Der Abschluß des Vertrags wurde von den beiden Staatsmännern mit einem Bruderkuß besiegelt. Schröder, der sich ebenfalls schon erwartungsvoll de Gaulle genähert hatte, wurde von diesem zurückgewiesen: „Sie (...Pause ...) küsse ich nicht!“, stieß der General in deutscher Sprache hervor ${ }^{175}$. Ihm war nicht entgangen, daß der Außenminister einer engen Zusammenarbeit bislang reserviert gegenübergestanden hatte. Adenauer bat deshalb den französischen Staatspräsidenten, mit Schröder ein Gespräch unter vier Augen zu führen, um in vertraulicher Atmosphäre die gegenseitigen Vorbehalte zu überwinden ${ }^{176}$. Im Zentrum dieser Unterredung stand erwartungsgemäß die weitere Behandlung Großbritanniens durch die Sechs ${ }^{177}$. Schröder bemerkte dazu, das britische Beitrittsgesuch sei für ihn lediglich „ein Problem in einer Reihe von Problemen“, die Freundschaft mit Frankreich hingegen eine „Basisfrage“. Dennoch lege die Bundesrepublik Wert auf eine Aufnahme Großbritanniens in den Kreis der Sechs, da ein Drittel des deutschen Außenhandels mit Staaten der EFTA abgewikkelt werde ${ }^{178}$. Zudem hätten sich sowohl Bundesrat wie Bundestag für eine Erweiterung der EWG ausgesprochen und der Bundesregierung den Auftrag erteilt, in diesem Sinne tätig zu werden. Schröder machte den General auch auf die $\mathrm{Ge}-$ fahr aufmerksam, daß bei einem Scheitern der Beitrittsverhandlungen Macmillan die kommenden Unterhauswahlen verlieren könnte. Ein Erfolg der Labour Party, so der Außenminister, hätte jedoch eine Signalwirkung für die nächsten Bundes-

171 Vgl. Osterheld, „Ich gehe nicht leichten Herzens ...“, S. 187.

172 Vgl. ebenda, S. 188.

173 Vgl. KuSTERER, Der Kanzler und der General, S. $306 \mathrm{f}$.

174 Vgl. ebenda, S. 307-326. Vgl. auch AAPD 1963, Dok. 37, S. 111-123, besonders S. 115 f. (dort Adenauers kritische Äußerungen über die britische Politik), und Dok. 43, S. 137148.

175 KUSTERER, Der Kanzler und der General, S. 322 (Hervorhebung im Original). Vgl. auch BlankENHORN, Verständnis, S. 438, SCHRÖDER, Im Gespräch mit Meinhold Krauss, S. 53.

176 Vgl. SCHRÖdER, Mein Bild von de Gaulle.

177 Vgl. das Gespräch des Bundesministers Schröder mit Staatspräsident de Gaulle am 21. 1. 1963 in Paris, in: AAPD 1963, Dok. 39, S. 128-130.

178 Ebenda, S. 129. 
tagswahlen. Es sei dann mit einem Sieg der SPD zu rechnen, was sich jedoch „weder Deutschland noch Frankreich wünschen könnten“. Als Ausweg aus der momentanen Krise regte er an, die EWG-Kommission mit der Erstellung eines Berichts zu beauftragen, der die noch ungelösten Fragen der Beitrittsverhandlungen auflisten und Vorschläge zu ihrer Lösung enthalten sollte. De Gaulle war davon nicht sonderlich begeistert, erklärte sich aber mit diesem Verfahren einverstanden ${ }^{179}$. Schröders Idee bot beiden Seiten die Gelegenheit, ihr Gesicht zu wahren. Der Außenminister war sich im klaren, daß die Franzosen, nachdem sie öffentlich erklärt hatten, die Beitrittsverhandlungen mit Großbritannien seien aussichtslos, nicht über Nacht wieder ihre Meinung ändern konnten. Ebenso war es den anderen fünf EWG-Staaten nicht zuzumuten, gegen ihre Überzeugung in einen Abbruch der Verhandlungen einzuwilligen. Der von ihm angeregte Weg eröffnete die Möglichkeit, das Problem zu vertagen und den Aufschub zu nutzen, einen Ausweg aus der Krise zu finden ${ }^{180}$.

In der entscheidenden Sitzung am 28. Januar 1963 in Brüssel warb Schröder für die von ihm vorgeschlagene Vorgehensweise. Eine Überprüfung des bisherigen Verhandlungsstandes durch die EWG-Kommission, so der Außenminister, brächte nicht nur einen „Zeitgewinn“, sondern es würde zudem in der Zwischenzeit „etwas Konkretes“ geschehen ${ }^{181}$. Alle Anwesenden stimmten dem Antrag zu, auch Couve de Murville. Die Frage, bis wann die Kommission ihren Bericht vorlegen sollte, führte jedoch zum Eklat. Der französische Außenminister dachte an eine Unterbrechung der Beitrittsverhandlungen für mindestens sieben Monate. Zudem wollte er der Kommission keine Frist für die Abfassung des Berichts stellen und verlangte, sie dürfe keine Lösungsvorschläge machen, da dies nur den Regierungen zustehe ${ }^{182}$. Schröder verstand die Forderungen Couve de Murvilles so, daß Frankreich den Bericht der Kommission „als eine Schlußbilanz, nicht aber als Maßnahme zur Förderung der Konferenz betrachtete und daß es den sofortigen Abbruch der Konferenz erzwingen wollte"183. Die anderen Delegationen wünschten hingegen, die Verhandlungen mit London auch während der Erstellung des Berichts fortzuführen. Die französische Seite blieb jedoch bei ihrem Standpunkt, daß darüber erst nach der Vorlage des Berichts entschieden werden könnte. Zur Not hätten dies die Benelux-Staaten, die Bundesrepublik und Italien noch akzeptiert; sie bestanden aber darauf, der EWG-Kommission für die Erstellung des Berichts eine Frist von drei Wochen zu setzen. Die Ergebnisse der Untersuchung sollten dann sowohl den Sechs als auch der britischen Regierung übermittelt werden. Zehn Tage danach könnten dann die Beitrittsverhandlungen wieder aufgenommen werden. Damit war Couve de Murville nicht einverstanden ${ }^{184}$,

179 Ebenda, S. 130.

180 Vgl. den Runderlaß des Bundesministers Schröder vom 30. 1. 1963, in: ebenda, Dok. 63, S. $222 \mathrm{f}$.

181 Protokoll der Ministerkonferenz der EWG am 28./29. 1. 1963 in Brüssel, in: ebenda, Dok. 60, S. 205.

182 Vgl. ebenda, S. 203-215.

183 Runderlaß des Bundesministers Schröder vom 30. 1. 1963, in: ebenda, Dok. 63, S. 223.

184 Vgl. das Protokoll der Ministerkonferenz der EWG am 28./29. 1. 1963 in Brüssel, in: ebenda, Dok. 60, S. 203-215. 
denn das Ziel der französischen Regierung war es ja, die Einstellung, mindestens aber eine längere Pause der Gespräche, durchzusetzen! Folglich blieben auch bilaterale Vermittlungsversuche zwischen der deutschen und der französischen Delegation ohne Ergebnis ${ }^{185}$. So mußte schließlich am Morgen des 29. Januar das Scheitern der Verhandlungen konstatiert werden ${ }^{186}$. Die EWG befand sich in der schwersten Krise seit ihrer Gründung. „Der Geist der Gemeinschaft ist tot", beklagten Luns und Spaak deprimiert ${ }^{187}$.

Obwohl er dem französischen Staatspräsidenten versprochen hatte, er würde sich in Brüssel für eine Unterbrechung der Verhandlungen mit London einsetzen, hatte Schröder nun auf der Ministerratstagung gegen Frankreich gestimmt. Adenauer machte ihm deshalb schwere Vorwürfe ${ }^{188}$. Auch Kusterer, als Dolmetscher Zeuge von Schröders Unterredung mit dem französischen Präsidenten, gab dem Minister die Schuld für das Scheitern der Verhandlungen, weil er sich nicht an die mit de Gaulle getroffene Absprache gehalten hatte ${ }^{189}$. Tatsache ist aber, daß der ins Auge gefaßte Kompromiß gegenüber den anderen vier Partnern nicht durchzusetzen war ${ }^{190}$. Die Benelux-Staaten und Italien lehnten eine halbjährige Unterbrechung der Verhandlungen entschieden ab. Sie wollten nicht das Risiko eingehen, daß nach Ablauf des Moratoriums die Gespräche mit London nicht wiederaufgenommen würden, wie Couve de Murville angedeutet hatte. Ihr Gegenvorschlag, die Verhandlungen für die Dauer von höchstens vier Wochen unter der Bedingung zu unterbrechen, daß sie danach weitergeführt würden, war aber wiederum für Frankreich nicht akzeptabel. Dem Außenminister der Bundesrepublik blieb daher letztlich nichts anderes übrig, als sich für eine der beiden Positionen zu entscheiden. Eine Billigung der Vorstellungen Couve de Murvilles hätte aber die Unterstützung des französischen Vetos bedeutet, was für einen überzeugten Anhänger einer Erweiterung der EWG wie Schröder selbstverständlich nicht in Frage kommen konnte. Angesichts der weitverbreiteten Ansicht, der Elysée-Vertrag könnte eine Ära der deutsch-französischen Hegemonie in Europa einleiten, war er zudem überzeugt, er müsse jetzt den Nachweis erbringen, daß sich die Europa-Politik der Bundesregierung nicht geändert hatte. Eine Identifikation mit der Position Frankreichs hätte jedoch Zweifel an ihrer Politik hervorgerufen und Bonn letztendlich in die außenpolitische Isolierung geführt. Es entsprach also den ureigenen Interessen der Bundesrepublik, sich mit Italien und den Benelux-Staaten solidarisch zu erklären.

Mit dem 29. Januar 1963 waren die Bestrebungen, Großbritannien in die Europäische Wirtschaftsgemeinschaft aufzunehmen, fürs erste gescheitert. Es sollte acht Jahre dauern, bis der Beitritt Londons schließlich vollzogen werden konnte.

185 Runderlaß des Bundesministers Schröder vom 30. 1. 1963, in: ebenda, Dok. 63, S. 223.

$186 \mathrm{Vgl}$. das Protokoll der Ministerkonferenz der EWG am 28./29. 1. 1963 in Brüssel, in: ebenda, Dok. 60, S. 203-215; sowie DEI, Bd. 2, Dok. 191, S. 262-264.

187 Protokoll der Ministerkonferenz der EWG am 28./29. 1. 1963 in Brüssel, in: AAPD 1963, Dok. 60, S. 213.

188 Vgl. OSTERHELD, „Ich gehe nicht leichten Herzens ...“, S. 196.

$189 \mathrm{Vgl}$. KustereR, Der Kanzler und der General, S. 320.

190 So auch der Eindruck von Horst Osterheld: OSTERHELD, „Ich gehe nicht leichten Herzens ...", S. 195. 
Der Abbruch der Beitrittsverhandlungen setzte auch den Bemühungen um eine weitere politische Integration der EWG-Staaten ein Ende. Mit dem französischen Veto war „der Gedanke der Europäischen Politischen Union [...] vorläufig erledigt“", stellte Schröder nach seiner Abreise aus Brüssel trocken fest ${ }^{191}$. Obwohl er das britische Beitrittsgesuch ohne Wenn und Aber unterstützt hatte, kam durch das zeitliche Zusammenfallen des deutsch-französischen Freundschaftsvertrags mit dem endgültigen Scheitern der Beitrittsverhandlungen dennoch die Vermutung auf, Bonn habe ein doppeltes Spiel getrieben. Briten und Amerikaner glaubten, die Bundesrepublik habe ihren außenpolitischen Kurs geändert und sich nun in die Hände Frankreichs begeben. Nicht mit dem 22. Januar, dem Tag der Unterzeichnung des Elysée-Vertrags, sondern erst mit der unglückseligen Brüsseler Ministerratstagung vom 29. Januar 1963 begann nun „der Kampf um eine Abschwächung des deutsch-französischen Vertrages“ ${ }^{192}$.

\section{Der „Triumph des Atlantizismus“}

Der Abschluß des deutsch-französischen Vertrages am 22. Januar 1963 bildete den Auftakt zu einer Auseinandersetzung um die außenpolitische Orientierung der Bundesrepublik, die das letzte Jahr der Regierungszeit Adenauers und nahezu die gesamte Kanzlerschaft Erhards prägte. Es ging dabei im wesentlichen um die Frage, ob Bonn der Zusammenarbeit mit Frankreich Priorität einräumen sollte. Folgt man der einschlägigen Literatur, so standen sich zwei Gruppen gegenüber, deren außenpolitische Vorstellungen schon zur damaligen Zeit plakativ unter den Schlagwörtern Gaullisten und Atlantiker zusammengefaßt wurden. Nach der gängigen Charakterisierung traten die Gaullisten für eine engere Anbindung der Bundesrepublik an Frankreich auf der Grundlage des Elysée-Vertrags ein. Sie deuteten den deutsch-französischen Vertrag nicht als Ersatz für die gescheiterten Fouchet-Pläne und sahen deshalb in ihm auch nicht den Grundstein für eine Politische Union der europäischen Staaten. Vielmehr interpretierten sie ihn als eine bilaterale Vereinbarung, die der Bundesrepublik zu mehr außenpolitischer Handlungsfreiheit verhalf. Angesichts des atomaren Patts zwischen den Supermächten und der daraus resultierenden amerikanischen Status-quo-Politik waren die Gaullisten der Auffassung, daß sich die Bundesrepublik nicht länger auf die Sicherheitsgarantie der Vereinigten Staaten verlassen durfte. Die USA standen im Verdacht, sie würden bei einem auf Westeuropa begrenzten Angriff davor zurückschrecken, ihr nukleares Potential sofort und in vollem Umfang zum Einsatz zu bringen. Man befürchtete, daß sie im Ernstfall angesichts der Perspektive eines nuklearen Schlagabtausches mit der UdSSR, der in der beiderseitigen völligen Zerstörung enden mußte, ihre europäischen Verbündeten zugunsten einer Verständigung mit Moskau opfern würden. Da Frankreich über eigene Atomwaffen die sogenannte Force de frappe - verfügte, die, wie de Gaulle versicherte, bei einem Angriff des Ostblocks sofort zum Einsatz kämen, bot ein Zusammengehen mit

191 Runderlaß des Bundesministers Schröder vom 30.1. 1963, in: AAPD 1963, Dok. 63, S. 225.

192 KOERFER, Kampf ums Kanzleramt, S. 716. 
Paris die Möglichkeit, die Sicherheitslücke der Bundesrepublik zu schließen. Außerdem setzte man darauf, daß Bonn durch eine Kooperation mit Frankreich an politischem Gewicht gewinnen würde, was Washington dazu veranlassen könnte, mehr Rücksicht auf die Interessen seines deutschen Verbündeten zu nehmen, um die Bundesrepublik bei der Stange zu halten. Man erwartete von einer solchen Politik, daß auch das Problem der Teilung Deutschlands in den Planungen der USA wieder stärkere Berücksichtigung fände. Diese Überlegungen bewogen die Gaullisten, deren Anhänger hauptsächlich aus den Reihen von CDU und CSU stammten, für eine Intensivierung der deutsch-französischen Zusammenarbeit einzutreten. Als ihre Wortführer gelten Adenauer, Franz Josef Strauß, Freiherr von und zu Guttenberg sowie der geschäftsführende CDU-Vorsitzende, Josef Hermann Dufhues.

Die Atlantiker waren dagegen der Ansicht, daß eine vertiefte Zusammenarbeit mit Frankreich die Sicherheit der Bundesrepublik nicht erhöhte, sondern eher verringerte. Eine Kooperation mit de Gaulle, der die atlantischen Bindungen Europas aufweichen sowie die militärische Integration im Rahmen der NATO beenden wollte und mit seiner Ablehnung sowohl einer supranationalen Konstruktion des vereinigten Europas als auch der Aufnahme Großbritanniens in die EWG die anderen europäischen Staaten gegen sich aufgebracht hatte, drohte Bonn außenpolitisch zu isolieren. Ein warnendes Beispiel war in ihren Augen die negative Reaktion des Auslands auf die Unterzeichnung des deutsch-französischen Vertrags. Nach der Auffassung der Atlantiker konnte es sich Bonn nicht leisten, einseitig auf Frankreich zu setzen, da dies die Beziehungen zu den USA belastete, die Bundesrepublik aber andererseits verteidigungs- und deutschlandpolitisch auf die amerikanische Unterstützung angewiesen war. Sie betrachteten die Vereinigten Staaten als unverzichtbaren Partner und forderten deshalb eine Fortführung der bisherigen Politik der Westbindung und der engen Anlehnung an Washington. Um keine Zweifel an dem außenpolitischen Kurs Bonns aufkommen zu lassen, wollten sie den Freundschaftsvertrag mit Frankreich um eine Entschließung des Bundestags ergänzen, in der hervorgehoben werden sollte, daß die Zusammenarbeit der beiden Staaten nicht gegen die europäischen Einigungsbestrebungen, die Einbeziehung Großbritanniens in die europäischen Gemeinschaften, die sicherheitspolitische Kooperation im Rahmen der NATO und das Engagement der Vereinigten Staaten in Europa gerichtet sei. Vor allem SPD und FDP vertraten diese außenpolitische Linie ${ }^{193}$. Innerhalb der Union wurde Wirtschaftsminister Ludwig Erhard als ein Hauptvertreter der Atlantiker angesehen.

Viele Zeithistoriker rechnen Gerhard Schröder ebenfalls zu den Atlantikern. Dies überrascht nicht, denn seine politischen Überzeugungen waren mit den hier beschriebenen Vorstellungen weitgehend identisch. Doch muß nochmals darauf

$193 \mathrm{Da}$ die außenpolitische Polarisierung also vor allem in der Union auftrat, charakterisiert Hanrieder das parlamentarische System der Kanzlerschaft Erhards als eine Zeit der „Fragmentarisierung der Mitte“. Während zuvor der Bundestag durch die übliche Bipolarität zwischen Regierungspartei(en) und Opposition geprägt war, hätten sich nun die Fronten gelockert, da häufig nicht die Unionsfraktion, sondern die SPD die Regierung in außenpolitischen Fragen unterstützte. Vgl. HANRIEDER, Deutschland, S. 400. 
hingewiesen werden, daß Schröder zeit seines Lebens eine Einteilung der politischen Landschaft der Bundesrepublik in Gaullisten oder Atlantiker abgelehnt hat. Er bestritt rückblickend sogar, daß es einen wirklichen politischen Gegensatz zwischen diesen Gruppierungen gegeben habe, führte diese These aber nicht näher aus ${ }^{194}$. In der Tat bereitete es Probleme, einen Politiker einem der beiden Lager zuzuordnen, da sich die Trennlinien in der Praxis verwischten. Hans-Jürgen Grabbe und Günter Buchstab versuchten dieses Problem zu lösen, indem sie noch weiter differenzierten und eine dritte Gruppe unterschieden, die sie als Europäer bezeichneten ${ }^{195}$. Bereitet schon die Definition Schwierigkeiten, so ist in der Forschung auch umstritten, was der tiefere Beweggrund für den Streit zwischen Gaullisten und Atlantikern war. Zuweilen wurde er auf den Kampf Adenauers und Erhards um die Macht in Bonn zurückgeführt ${ }^{196}$. Nach Ansicht Klaus Hildebrands ist diese These nicht aufrechtzuerhalten, da sie „das Marginale zum Zentralen" erhebt ${ }^{197}$. Die Darstellung der inhaltlichen Positionen der beiden Gruppierungen stimmt ebenfalls mit der historischen Wirklichkeit nicht überein. Christian Hacke ist beispielsweise der Meinung: „Der Streit zwischen Gaullisten und Atlantikern läßt sich darauf reduzieren, daß erstere für ein Entweder-Oder, die Atlantiker hingegen für ein Sowohl-als-auch in den Beziehungen zu Washington und Paris plädierten. "198 In Wahrheit wollten aber selbst die Gaullisten nicht mit den USA brechen. So wie den Atlantikern klar war, daß der Weg zur Vereinigung Europas nur über eine Zusammenarbeit mit Paris führen konnte, war auch ihnen sehr wohl bewußt, daß die Bundesrepublik auf das Bündnis mit den Vereinigten Staaten nicht verzichten konnte. Aufgrund dieser Erkenntnis kommt Reiner Marcowitz in seiner verdienstvollen Studie "Option für Paris“ zu dem Schluß, daß eine Unterscheidung in Atlantiker oder Gaullisten nicht sinnvoll ist ${ }^{199}$. Marcowitz zeigt, „daß allen bundesdeutschen außenpolitischen Akteuren der sechziger Jahre im Grunde eines gemein war: das Wissen um die Notwendigkeit von guten

194 Vgl. SCHRÖDER, Im Gespräch mit Meinhold Krauss, S. 46; TiEsEnhausen, Die Sache mit China, S. 31. Mit dieser Meinung stand Schröder nicht allein. Auch Gradl meinte rückblickend, die Unterscheidung in Atlantiker und Gaullisten sei „etwas oberflächlich“ gewesen. Vgl. den Diskussionsbeitrag von Johann Baptist Gradl in ScHwaRZ (Hrsg.), Adenauer und Frankreich, S. 97.

195 Grabbe und Buchstab rechnen zu den Europäern Barzel, Dufhues und Majonica. Sie hätten sich in ihrem Eintreten für die Vereinigung Europas auf supranationaler Basis von Atlantikern wie Schröder unterschieden. Vgl. GRABBE, Unionsparteien, S. 469; BUCHSTAB, Zwischen "Zauber und Donner“, S. 102f. Abgesehen davon, daß auch Schröder den europäischen Zusammenschluß auf diesem Weg anstrebte, hat Marcowitz Recht, wenn er diese zusätzliche Differenzierung nicht für praktikabel erachtet, da diese Gruppe in den entscheidenden außenpolitischen Fragen stets die Linie Schröders unterstützte. Vgl. MarCowITZ, Option, S. 185, Anm. 43.

196 Diese These vertritt z.B. Christian Hacke: HACKE, Weltmacht, S. 116.

197 Vgl. Hildebrand, Von Erhard zur Großen Koalition, S. 102.

198 HACKE, Weltmacht, S. 118.

199 MARCOWITZ, Option. Beispielsweise weist Marcowitz dort auf S. 184-186 unter anderem nach, daß es in der Europa-Politik erhebliche Unterschiede zwischen der Auffassung de Gaulles und der der Gaullisten gab. 
und konstruktiven Beziehungen zu beiden Partnerstaaten, den USA und Frankreich gleichermaßen" 200 .

Das heißt nun nicht, daß es Mitte der sechziger Jahre keinen Streit über die Gestaltung der Außenpolitik der Bundesrepublik gegeben hätte. Mit dem Verzicht auf die Verwendung der Begriffe Atlantiker bzw. Gaullisten löst man sich aber von zwei Schlagwörtern, die zwar die damaligen Auseinandersetzungen geprägt, aber zu Pauschalisierungen geführt haben, die die Wirklichkeit mehr verzerren als erhellen. So wird man Schröder keinesfalls gerecht, wenn man ihn als Prototyp des Atlantikers präsentiert. Schon Hermann Kusterer schrieb in seinen Memoiren, daß der Außenminister natürlich kein Gaullist war, „aber ein purer Atlantiker war er gewiß auch nicht". Der ehemalige Chefdolmetscher des Auswärtigen Amts sieht in erster Linie in Schröder einen „Deutsche[n]“ - keinen Nationalisten, aber jemand, der sich in seiner Politik vorrangig an den Interessen der Bundesrepublik orientierte ${ }^{201}$. Bereits im November 1965 kam Henry Kissinger in einer Analyse für das Weiße Haus zu dem Schluß, daß Schröders Politik primär von nationalen Motiven bestimmt sei. Anders als für den Machtpolitiker Strauß, so Kissinger in seiner Studie, sei die deutsche Frage ein persönliches Anliegen des Außenministers, das sein Denken beherrsche. Sowohl seine Einstellung zu Frankreich wie zu den USA sei letzten Endes davon bestimmt gewesen ${ }^{202}$.

Unzweifelhaft war für Schröder die Wiederherstellung der staatlichen Einheit Deutschlands das oberste Ziel seiner Politik. Alle außenpolitischen Aktivitäten der Bundesrepublik sollten helfen, die Wiedervereinigung eines Tages zu verwirklichen. Solange es aber in der UdSSR keine revolutionären Veränderungen gab, konnte ihm zufolge die Tür zur Einheit nur dadurch offen gehalten werden, daß die Bundesrepublik ihren Kurs der Westorientierung fortsetzte. Kennedys Vision einer atlantischen Gemeinschaft, gegründet auf einer partnerschaftlichen Beziehung zwischen Amerika und einem politisch vereinigten und starken Europa, dem sowohl Großbritannien wie Frankreich angehören sollten, war auch seine politische Zielvorstellung ${ }^{203}$. Mit dem deutsch-französischen Vertrag wollte Schröder - wie bereits angedeutet wurde und in diesem Kapitel noch zu zeigen sein wird - Einfluß auf die französische Politik ausüben und den Versuch unternehmen, die anti-angloamerikanische Haltung de Gaulles abzuschwächen. Auch die Politik der Vereinigung Europas, die mit dem Scheitern der Fouchet-Pläne 1962 einen herben Rückschlag erlitten hatte, sollte durch das Abkommen neue Impulse erhalten ${ }^{204}$. Schröder hatte dabei stets die Wirkung der europäischen Vereinigungspolitik auf den Ostblock im Auge. Er erwartete, daß ein vereintes Europa wegen seiner ökonomischen Stärke für die osteuropäischen Staaten an Attraktivität gewinnen würde, wodurch sich langfristig eine Perspektive zur Überwindung der Teilung Europas eröffnete. Die „atlantische“ Orientierung Bonns wenn man diese Vokabel für eine Politik verwenden will, die die Bundesregierung

200 GUÉROT, Beharrliche Annäherung, S. 520.

201 KUSTERER, Der Kanzler und der General, S. 203.

202 Vgl. FRUS 1964-1968, XV, Dok. 132, S. 331-333.

203 Vgl. BT STENOGRAPHISCHE BERICHTE, Bd. 51, S. 1482-1492.

204 Vgl. BT STENOGRAPHISCHE BERICHTE, Bd. 52, S. $2636 \mathrm{f}$. 
seit 1949 verfolgt hatte - stellte also keinen Selbstzweck dar, sondern nach Schröders Überzeugung den einzigen aussichtsreichen Weg zur Wiederherstellung der staatlichen Einheit Deutschlands. Eine für ihn selbstverständliche Grundvoraussetzung für eine erfolgreiche Deutschland-Politik war, daß diese stets so weit wie möglich im Einklang mit der der drei Westmächte stand. Die politische Isolierung de Gaulles, wie sie manchem vielleicht vorschwebte, konnte deshalb nicht im Sinne der langfristigen Ziele der Diplomatie der Bundesrepublik sein. Schröder rief daher dazu auf, aus dem deutsch-französischen Vertrag „das Äußerste [zu] machen" 205 . Obwohl eine gleichgerichtete Politik der Bundesrepublik und der Drei Mächte sich zu Beginn der sechziger Jahre angesichts der divergierenden Interessenlage der vier Staaten kaum verwirklichen ließ, hatte er es sich zum Ziel gesetzt, zu einer Angleichung ihrer Politik beizutragen. Die Kuba-Krise im Herbst 1962 lieferte ihm den Beweis, welches Gewicht ein gemeinsames Auftreten des Westens hatte. Denn in seinen Augen hatte sich im Zuge dieses Nervenkriegs gezeigt, daß die UdSSR durchaus zum Umdenken gebracht werden konnte, wenn der Westen seinen Standpunkt fest und entschlossen vertrat ${ }^{206}$. Schröder war also weder ein Gaullist noch ein Atlantiker, sondern, wie Helmut Schmidt richtig erkannte, ein Politiker, der sich nicht in Schablonen pressen ließ. Er handelte „vorurteilslos" und orientierte sich an den sachlichen Gegebenheiten ${ }^{207}$. So setzte er die von ihm als richtig erkannte Adenauersche Westpolitik der fünfziger Jahre fort, auch dann noch, als sich der Kanzler selbst bereits von ihr entfernte und durch die Annäherung an Frankreich die außenpolitischen Prioritäten Bonns zu ändern beabsichtigte. Schröder bestritt allerdings im Rückblick, daß dadurch ein Gegensatz zwischen ihm und dem Kanzler aufgetreten sei: „Adenauer ist da in die falsche Schublade geraten. Von der Gewichtung seiner Argumente her gesehen war er niemals Gaullist, sondern immer Atlantiker. "208

Nach dem Abbruch der Beitrittsverhandlungen mit Großbritannien Ende Januar 1963, griff Ludwig Erhard die französische Politik scharf an. Der Wirtschaftsminister forderte, den deutsch-französischen Vertrag nicht zu ratifizieren. Doch Schröder wies dies kategorisch zurück. Das Kabinett habe sich am 16. Januar für den Vertrag ausgesprochen; nun sei er unterschrieben und man könne keinen Rückzieher mehr machen. Er war aber gleichfalls der Ansicht, es müsse dafür gesorgt werden, daß sich der Vertrag nicht gegen die atlantische Partnerschaft richte $^{209}$. Der Außenminister ließ dabei durchblicken, daß er nicht daran denke, die bisherigen Grundsätze der Bonner Außenpolitik aufzugeben und auf eine exklusive Zusammenarbeit mit de Gaulle zu setzen: „Beruhigen Sie sich, der Vertrag wird einfach nicht angewendet." 210 Doch Erhard war damit nicht besänftigt. In der Kabinettssitzung am 30. Januar, also einen Tag nach dem Eklat auf der EWGMinisterratstagung, setzte er seine Attacken gegen de Gaulle fort. So bemerkte er

205 Protokoll der CDU/CSU-Fraktionssitzung am 2. 10. 1963, ACDP VIII-001-1009/3.

206 Vgl. BT STENOGRAPHISCHE BERICHTE, Bd. 52, S. 2638.

207 SCHMIDT, Schablonen, S. 11.

208 Zitiert nach Tiesenhausen, Die Sache mit China, S. 31.

209 Vgl. KOERFER, Kampf ums Kanzleramt, S. 715 f.

210 Zitiert nach OSTERHELD, „Ich gehe nicht leichten Herzens ...“, S. 26, Anm. 3. 
unter anderem, Hitler habe vor genau 30 Jahren die Deutschen unter sein Joch gezwungen, nun habe der französische Staatspräsident dasselbe mit Europa getan ${ }^{211}$. Der Wirtschaftsminister erreichte schließlich, daß die Bundesregierung eine Erklärung verabschiedete, in der sie versicherte, sie werde ihre Politik der Einigung Europas fortführen und alles unternehmen, um einen Ausweg aus der Brüsseler Krise zu finden, damit der Beitritt Londons doch noch möglich werde ${ }^{212}$. Dies war auch Schröders Linie. In einem Runderlaß, den er am selben Tag an die Beamten des Auswärtigen Dienstes richtete, erklärte er unmißverständlich, daß das deutsch-französische Abkommen nicht bedeute, "der eine habe den Thesen des anderen unbedingt $\mathrm{zu}$ folgen". Prononciert wies er darauf hin, daß die Unterzeichnung des Elysée-Vertrags nicht als Billigung der Position de Gaulles zu deuten sei, und kündigte an, „der französischen Regierung im Rahmen der Konsultation unsere Argumente nahezubringen "213. Dabei dachte er vor allem daran, Paris die politische und ökonomische Notwendigkeit des britischen Beitritts vor Augen zu führen. Bis dieser Schritt vollzogen werden könne, sollte Großbritannien „so eng wie möglich" mit den Sechs verbunden werden. Im Gegensatz zu Erhard wollte er aber "keine Politik der Ressentiments" gegenüber Frankreich betrei$b^{2}{ }^{214}$. Trotz des nicht zu akzeptierenden französischen Verhaltens sei der ElyséeVertrag „eines der wesentlichsten Elemente unserer Außenpolitik“, da er „einen Schritt zu der von uns angestrebten politischen Einigung Europas" darstelle, rief der Minister den Diplomaten ins Gedächtnis ${ }^{215}$.

Der Sturm, der wegen der Unterzeichnung des Freundschaftsvertrags mit Frankreich aus dem Ausland über die Bundesrepublik hereinbrach, war gewaltig216. Die UdSSR protestierte energisch gegen den deutsch-französischen Schulterschluß217. Der niederländische Außenminister Luns nahm ebenfalls in einer Rede vor dem Europa-Parlament überaus kritisch Stellung. Britische Politiker machten die Bundesrepublik für das französische Veto gegen London mitverantwortlich. In Bonn wurde sogar kolportiert, Heath habe geäußert, London und Washington würden dafür sorgen, daß Adenauer in Kürze gestürzt werde ${ }^{218}$. Auch auf der anderen Seite des Atlantiks schlug der Abschluß des Vertrages „wie eine Bombe ein"219. Durch die zeitliche Nähe der Pressekonferenz de Gaulles am 14. Januar mit der Unterzeichnung des deutsch-französischen Vertrags am 22. Januar und dem Abbruch der Brüsseler Beitrittsverhandlungen am 29. Januar 1963

211 Vgl. SCHWARZ, Epochenwechsel, S. 292.

212 Vgl. KOERFER, Kampf ums Kanzleramt, S. 717.

213 Runderlaß des Bundesministers Schröder vom 30.1. 1963, in: AAPD 1963, Dok. 63, S. 223.

214 Ebenda, S. $225 \mathrm{f}$.

215 Ebenda, S. 226.

216 Vgl. OSTERHELD, „Ich gehe nicht leichten Herzens ...“, S. 119f.; KuSTERER, Der Kanzler und der General, S. 327-329.

$217 \mathrm{Vgl}$. die sowjetische Note vom 5. 2. 1963 an die Bundesregierung, in: EUROPA-ARCHIV 1963, D 225-231. Zur sowjetischen Reaktion vgl. auch KOSTHORST, Die „unerwünschte Liaison“, S. $182 \mathrm{f}$.

218 OSTERHELD, „Ich gehe nicht leichten Herzens ...“, S. 119. Zur britischen Reaktion vgl. auch STEININGER, Großbritannien und de Gaulle, S. 111-115.

219 CARSTENS, Erinnerungen, S. 251. 
entstand bei den Amerikanern der Eindruck, daß sich die Bundesregierung „mit der französischen Politik identifiziere" 220 . Dowling teilte dem Kanzler am 4. Februar mit, Kennedy sei sehr besorgt über die Stimmung in der amerikanischen Öffentlichkeit und im Senat. In Washington habe man den Eindruck, die Bundesrepublik sei offenbar ebenso wie Frankreich nicht länger an der Stationierung amerikanischer Truppen in Europa interessiert ${ }^{221}$. Staatssekretär Ball sah im ElyséeVertrag eine deutsch-französische Verschwörung. Er und der Politische Direktor des amerikanischen Außenministeriums, George McGhee, fürchteten allen Ernstes, Paris und Bonn könnten sich mit Moskau über eine politische Neuordnung Europas verständigen, an deren Ende die Wiedervereinigung eines sich für die Neutralität entscheidenden Deutschlands stehe 222 . Der frühere Hochkommissar und ständige Repräsentant des Präsidenten in Berlin, Lucius D. Clay, drohte: „Falls der Bundestag das Abkommen unverändert ratifiziert, bedeutet dies das Ende Berlins. "223 In der Absicht, eine Vertragsrevision durchzusetzen, bearbeiteten Briten und Amerikaner massiv die Fraktionsvorsitzenden von CDU/CSU, FDP und SPD 224 . Die Sozialdemokraten kritisierten die Bundesregierung ebenfalls heftigst. Sie warfen ihr vor, in Paris den Text des Vertrages in entscheidenden Punkten geändert zu haben. Schröder wies dies als infame Unterstellung zurück ${ }^{225}$.

Die Bundesregierung war von Ausmaß und Härte der amerikanischen Reaktion völlig überrascht. Adenauer meinte am 24. Januar zu Dowling, er sei „einfach platt" über die Stellungnahmen aus Washington: „John Foster Dulles wäre ihm wegen des deutsch-französischen Vertrags vor Freude um den Hals gefallen."226 Zudem seien die Amerikaner rechtzeitig informiert worden, berichtete er am 5. Februar 1963 der CDU/CSU-Fraktion. Bereits im Juni 1962 habe er den amerikanischen Außenminister über seine Pläne zur Schaffung einer Union mit Frankreich unterrichtet. Rusk habe damals keine Einwände geäußert, sondern sein Vorhaben nachdrücklich unterstützt. In den folgenden Monaten, so Adenauer weiter, habe das Auswärtige Amt die amerikanische Regierung kontinuierlich über den Stand der Verhandlungen mit Frankreich auf dem Laufenden gehal-

220 Aufzeichnung des Staatssekretärs Carstens vom 9. 2. 1963, in: AAPD 1963, Dok. 88, S. 291.

221 Vgl. OSTERHELD, „Ich gehe nicht leichten Herzens ...“, S. 199. Bereits am 23.1.1963 berichtete Botschafter Knappstein, Washington, Kennedy habe ihn „in spürbar schlechter Stimmung“ empfangen und schärfste Kritik am Abschluß des Vertrages geübt. Vgl. AAPD 1963, Dok. 49, S. 162-165 (163). Zu den Überlegungen Kennedys hinsichtlich eines eventuellen Rückzugs aus Europa vgl. FRUS 1961-1963, XIII, Dok. 169, S. $489 \mathrm{f}$.

222 Vgl. BALl, The Past has Another Pattern, S. 271; MCGHEe, Botschafter, S. 23.

223 Vgl. den Drahtbericht des Botschafters Knappstein, Washington, an das Auswärtige Amt vom 28. 1. 1963, in: AAPD 1963, Dok. 58, S. 200.

224 Vgl. den Diskussionsbeitrag von Erich Mende in SCHWARZ (Hrsg.): Adenauer und Frankreich, S. 101.

225 Vgl. den Entwurf eines Schreibens von Schröder an Erler vom 21. 2. 1963, PA/AA, Büro Staatssekretär, Bd. 128.

226 AAPD 1963, Dok. 52, S. 173. 
ten $^{227}$. In Wahrheit hatte Rusk allerdings den Kanzler ausdrücklich darauf hingewiesen, die Zusammenarbeit mit Paris dürfe nicht gegen den europäischen $\mathrm{Zu}$ sammenschluß und die Bildung einer atlantischen Gemeinschaft gerichtet sein ${ }^{228}$. Auch den französischen Botschafter in Washington, Hervé Alphand, warnte er am 7. September 1962 vor der Bildung einer Achse Paris-Bonn. Im Falle einer Annäherung der beiden Staaten, forderte Rusk, müßten negative Auswirkungen auf die NATO und die atlantischen Bindungen unbedingt vermieden werden. Alphand dementierte jedoch sofort eine derartige Intention und beteuerte, die geplante Zusammenarbeit sei nicht gegen die Vereinigten Staaten gerichtet ${ }^{229}$. Nachdem Ende September 1962 der Sicherheitsberater des Präsidenten, McGeorge Bundy, dem Auswärtigen Amt mitgeteilt hatte, seine Regierung befürchte nicht, daß die Bundesrepublik anstelle der USA ab sofort Frankreich als primären Partner betrachten würde ${ }^{230}$, mußte man in Bonn annehmen, die Amerikaner hätten ihre Bedenken nun ad acta gelegt. Doch nach den Vorgängen im Januar 1963 hatte sich in Washington wie in London die Überzeugung gefestigt, die Bundesregierung habe ihre Verbündeten getäuscht und sich nun doch die Politik de Gaulles zu eigen gemacht.

Angesichts der britischen und amerikanischen Reaktionen hielt es Schröder für dringend notwendig, einer weiteren Verschlechterung der Beziehungen entgegenzuwirken. Sogleich nach seiner Rückkehr aus Brüssel am 29. Januar 1963 versuchte er, den außenpolitischen Schaden zu begrenzen. Am 31. Januar schrieb er Heath, er bedauere den Abbruch der Beitrittsverhandlungen "zutiefst“. Der Außenminister bekräftigte: „Ich habe in Brüssel und anderenorts, wo es mir nützlich erschien, alles getan, um einen solchen Ausgang zu vermeiden, und betrachte Ihren Mißerfolg auch als den meinigen." Die Zusammenarbeit zwischen der EWG und Großbritannien sei unbedingt fortzusetzen ${ }^{231}$. Dies machte er auch seinem französischen Amtskollegen klar. Mit dem Hinweis, er habe alles unternommen, um in Bonn die Kritik an der französischen Regierung zu mildern, mahnte er am folgenden Tag Couve de Murville schriftlich, sich für eine engere Anbindung Großbritanniens an die Sechs einzusetzen. Eine Übergangslösung sei erforderlich, „um zu verhindern, daß der Zusammenhalt der westlichen Welt insgesamt gelokkert wird“232. Auch dem amerikanischen Außenminister versicherte Schröder am 1. Februar, die Delegation der Bundesrepublik habe sich in Brüssel "mit allen ihr zu Gebote stehenden Kräften“ bemüht, eine Fortsetzung der Beitrittsverhandlungen zu erreichen. Er bat Rusk, nicht daran zu zweifeln, daß die Bundesregierung "unbeirrbar" an der Atlantischen Gemeinschaft festhalte, und kündigte an, man werde sich auch weiterhin für die Schaffung eines vereinten Europas einsetzen, das Großbritannien mit einschließe. Die Entscheidung Bonns, die Zusammenar-

227 Vgl. Protokoll der CDU/CSU-Fraktionssitzung am 5. 2. 1963, ACDP VIII-001-1009/2, bzw. BDFD, I, Dok. 316, S. $964 \mathrm{f}$.

$228 \mathrm{Vgl}$. FRUS 1961-1963, XV, Dok. 69, S. $201 \mathrm{f}$.

229 Vgl. ebenda, Dok. 113, S. $311 \mathrm{f}$.

230 Vgl. das Gespräch des Staatssekretärs Carstens mit dem Sicherheitsberater des amerikanischen Präsidenten, Bundy, am 24. 9. 1962, PA/AA, Büro Staatssekretär, Bd. 79.

231 AAPD 1963, Dok. 67, S. 232.

232 Ebenda, Dok. 70, S. 238. 
beit mit Paris „trotz unserer tiefen Enttäuschung über das französische Verhalten“ fortsetzen zu wollen, begründete er damit, daß die Bundesregierung bezwecke, im direkten Kontakt de Gaulles Haltung zu ändern. Schröder sagte zu, diesbezüglich „äußerste Anstrengungen“ zu unternehmen 233. Gleichzeitig bekräftigte er, ein außenpolitischer Kurswechsel sei mit ihm nicht zu machen. In Anspielung auf Äußerungen Adenauers teilte er Rusk mit, er habe der Auffassung, die Politik der USA sei „schwankend“, immer widersprochen. Der „Beweis für die unbeirrbare Stetigkeit der amerikanischen Politik" sei das Engagement der USA in Berlin und in der NATO sowie ihre Unterstützung der Einigung Europas ${ }^{234}$.

Seine Beteuerungen genügten den Briten und Amerikanern jedoch nicht. Im Ständigen Rat der NATO verlangten sie von der Bundesrepublik, öffentlich ihre Loyalität mit dem Bündnis zu bekunden, obwohl Botschafter Grewe bereits am Tag nach der Unterzeichnung des Elysée-Vertrags eine Solidaritätserklärung abgegeben hatte 235 . Um das Vertrauen in die Politik Bonns wiederherzustellen, wurde auf Anregung von Osterheld der Beschluß gefaßt, Carstens nach Washington zu entsenden. Er sollte der amerikanischen Führung die Haltung der Bundesregierung erläutern und Mißverständnisse ausräumen ${ }^{236}$. Während der Staatssekretär sich noch auf dem Flug in die USA befand, stellte sich der Kanzler am 5. Februar 1963 der CDU/CSU-Bundestagsfraktion. Adenauer legte den Abgeordneten dar, de Gaulles Pressekonferenz am 14. Januar sei auch für ihn eine Überraschung gewesen. Die Unterzeichnung des Elysée-Vertrags und das Veto des Generals hätten sich rein zufällig in derselben Woche ereignet. Er gab aber zu, daß er im Grunde de Gaulles Ablehnung einer britischen Mitgliedschaft in den europäischen Gemeinschaften teilte. Trotzdem, so Adenauer, habe er sich gegenüber dem französischen Staatspräsidenten für eine Verhandlungspause in Brüssel eingesetzt. Dieser sei zunächst damit einverstanden gewesen, habe sich aber durch den Abschluß des Nassau-Abkommens von Macmillan getäuscht gefühlt ${ }^{237}$. Abschließend hob der Kanzler nochmals das Erfordernis einer engen Zusammenarbeit mit Paris hervor, betonte dabei allerdings, es sei ein „Unsinn“ zu glauben, „wir seien jetzt auf Tod und Leben absolut mit Frankreich verheiratet“238. Ähnlich argumentierte er am folgenden Tag im Bundestag. Erneut bestritt er einen außenpolitischen Kurswechsel und bekräftigte den Willen Bonns, die Verteidigung der Bundesrepublik „im Rahmen der NATO“ zu organisieren. Ausdrücklich gestand er der Zusammenarbeit mit den Vereinigten Staaten die Priorität zu.

233 Ebenda, Dok. 71, S. 239.

234 Ebenda, S. 240. So sagte Adenauer beispielsweise am 21.1.1963 zu de Gaulle: „Man wisse nicht, welche Pläne Amerika morgen haben werde. Sicherlich wolle Amerika niemanden täuschen, doch könne niemand wissen, wie die Amerikaner morgen dächten." Vgl. ebenda, Dok. 37, S. 113.

235 Vgl. den Drahtbericht des Botschafters Grewe, Paris (NATO), an das Auswärtige Amt vom 4. 2. 1963, in: ebenda, Dok. 75, S. 250 f.

236 Vgl. OSTERHELD, „Ich gehe nicht leichten Herzens ...", S. 197.

237 Vgl. das Protokoll der CDU/CSU-Fraktionssitzung am 5. 2. 1963, ACDP VIII-0011009/2. Vgl. auch BDFD, I, Dok. 316, S. 961-968. Das Nassau-Abkommen zwischen Großbritannien und den USA wurde aber nicht nach der Unterzeichnung des ElyséeVertrags geschlossen, wie Adenauer hier suggeriert, sondern bereits am 21. 12. 1962.

238 Protokoll der CDU/CSU-Fraktionssitzung am 5. 2. 1963, ACDP VIII-001-1009/2. 
Der deutsch-französische Freundschaftsvertrag sei nicht gegen die europäische Integration gerichtet, unterstrich Adenauer und belegte dies an Hand des Vertragstextes 239 .

Auf der gleichen Linie bewegte sich auch der Redebeitrag des Außenministers am 7. Februar in der sich an die Regierungserklärung Adenauers anschließenden Debatte. Er dementierte nochmals jeglichen Zusammenhang zwischen den Brüsseler und den Pariser Ereignissen seit Mitte Januar. Gleichwohl sei zu verhindern, daß Bonn „in ein falsches Licht" gerate, da sich besonders die Deutschen aufgrund ihrer Vergangenheit nicht erlauben könnten, im „Zwielicht“ zu stehen ${ }^{240}$. Schröder strich heraus, die Bundesregierung habe sich allerorts, besonders in Paris, für die Aufnahme Großbritanniens in die EWG eingesetzt, und versicherte, daß man mit dem Elysée-Vertrag keinen „Blankoscheck für die französische Politik“ unterschrieben habe ${ }^{241}$. Auch sei darin keineswegs eine Änderung der außenpolitischen Orientierung zu sehen, da der Vertrag ausdrücklich die Schaffung eines vereinten Europas als Ziel nenne. Um den Kontakt zwischen den Sechs und Großbritannien aufrechtzuerhalten, griff er italienisch-britische Überlegungen auf 242 und regte an, die Gespräche mit London im Ministerrat der WEU weiterzuführen. Dieses Gremium bot sich als Ausweichstelle an, weil ihm alle sieben betroffenen Staaten angehörten. Zudem hatte die Bundesrepublik im Moment dort den Vorsitz inne. Der Ministerrat, so Schröder, sollte aber erst einberufen werden, wenn bilaterale Gespräche gezeigt hätten, daß zumindest „ein Stück Fortschritt“ in der Beitrittsproblematik erreicht werden könnte. Er deutete zudem an, daß er sich für eine Übergangszeit auch eine Assoziierung Großbritanniens mit der EWG vorstellen könne ${ }^{243}$. Ferner zeigte sich der Außenminister besorgt, daß der Streit um den britischen Beitritt ungünstige Auswirkungen auf den Ost-West-Konflikt haben könnte: Noch während der Kuba-Krise habe der Westen eine für die UdSSR unerwartete Einigkeit gezeigt; die Brüsseler Ereignisse werde Moskau jedoch als "Spaltungserscheinungen“ im westlichen Lager interpretieren! Am Schluß seiner Ausführungen unterstrich Schröder, daß er sich weiterhin für den britischen Beitritt einsetzen werde. Das Scheitern der Verhandlungen sei „nicht ein definitiver Rückschlag“, sondern stelle "nur eine Verzögerung" dar ${ }^{244}$. Am folgenden Tag brachte er in einer Rede in Bremen außer der WEU auch die OECD als potentielles Gremium für Konsultationen mit Großbritannien ins Spiel. Schröder nutzte die Gelegenheit, um erneut eine Solidaritätsadresse an die atlantische Allianz abzugeben: Die NATO bleibe für die Bundesrepublik „der Ausdruck und gleichzeitig das Instrument der Unteilbarkeit der Verteidigung des freien Westens“245. De-

239 BT STENOGRAPHISCHE BERICHTE, Bd. 52, S. 2574-2577 (2576).

240 Ebenda, S. 2635.

241 Ebenda, S. 2636.

242 Vgl. dazu MaSAla, Die Bundesrepublik Deutschland, Italien und der Beitritt Großbritanniens zur EWG, S. $47 \mathrm{f}$.

243 BT STENOGRAPHISCHE BERICHTE, Bd. 52, S. 2637.

244 Ebenda, S. 2638.

245 Bulletin 1963, S. 263-265 (263). 
monstrativ fügte er hinzu: Die Führungsrolle der Amerikaner werde am Rhein „bereitwillig“" anerkannt ${ }^{246}$.

Dennoch waren in Washington die Zweifel an der Bündnistreue der Bundesregierung keineswegs ausgeräumt. Carstens' Reise in die amerikanische Hauptstadt verlief nicht allzu erfolgreich. Ebenso wie Schröder in seinem Schreiben vom 1. März an Rusk führte der Staatssekretär gegenüber seinen amerikanischen Gesprächspartnern zugunsten des Elysée-Vertrags an, daß er die Chance biete, auf de Gaulle Einfluß zu nehmen, da die französische Regierung vor allen bedeutsamen Entscheidungen Bonn zu konsultieren habe. Carstens argumentierte, es müsse auch im Sinne der Vereinigten Staaten sein, wenn die Bundesregierung zu einem Zeitpunkt, da „die Verbindung zwischen den USA und Frankreich völlig abgerissen sei", engen Kontakt zu Paris halte247. Doch in Washington blieb man reserviert. Kennedy erklärte, er könne nicht nachvollziehen, warum Bonn gerade mit de Gaulle eine intensive Bindung eingehe, obwohl dieser die Absicht habe, Europa von Amerika zu lösen und einen Ausgleich mit Moskau zu erreichen ${ }^{248}$. Am Ende seines Aufenthalts zog der Staatssekretär eine ernüchternde Bilanz ${ }^{249}$. Er berichtete Schröder, die amerikanische Regierung befürchte, durch die Politik des französischen Staatspräsidenten könnte der Isolationismus neuen Auftrieb erhalten. Schon jetzt sei vielerorts zu hören, die USA sollten sich aus Europa zurückziehen, wenn die Europäer kein Interesse an der Aufrechterhaltung der transatlantischen Zusammenarbeit zeigten. Washington, so stellte Carstens fest, sei zu der Ansicht gelangt, Bonn stimme mit der französischen Politik überein und habe sich "gegen das Atlantische Bündnis und gegen Amerika entschieden“250. Der Gedanke an eine in Kürze erfolgende Ratifikation des deutsch-französischen Vertrages würde der Kennedy-Administration "sichtliches Unbehagen“ bereiten. Beispielsweise habe Acheson gefordert, „der Vertrag dürfe nicht oder erst nach einer Abänderung, durch die die Erhaltung des nordatlantischen Bündnisses Vertragsbestandteil werde, ratifiziert werden “. Der frühere amerikanische Außenminister habe weiter kritisiert, Bonn könne nicht eine enge Zusammenarbeit mit Paris anstreben und sich gleichzeitig für den Erhalt der NATO aussprechen: „Wir ständen vor einer Alternative und müßten uns entscheiden." Um die Bedenken der Amerikaner auszuräumen, schlug Carstens vor, der Bundestag sollte gleichzeitig mit der Ratifikation des Vertrags eine Resolution verabschieden, in der deutlich gemacht werde, daß die Bundesrepublik weiterhin für die europäische Einigungspolitik unter dem Einschluß Großbritanniens eintrete und an der NATO sowie dem Bündnis mit den Vereinigten Staaten festhalte251. Damit tauchte erstmals der Gedanke auf, den deutsch-französischen Freundschaftsvertrag durch einen schriftlichen Zusatz in den Rahmen der bisherigen Politik Bonns zu stellen, wie es dann

246 Ebenda, S. 265.

247 Drahtbericht des Staatssekretärs Carstens, z.Z. Washington, an Bundesminister Schröder vom 6. 2. 1963, in: AAPD 1963, Dok. 83, S. 274.

$248 \mathrm{Vgl}$. ebenda, S. 273-275.

249 Vgl. die Aufzeichnung des Staatssekretärs Carstens vom 9. 2. 1963, in: ebenda, Dok. 88, S. 289-294.

250 Ebenda, S. 291.

251 Ebenda, S. 293. 
auch durch die vom Bundestag hinzugefügte Präambel geschah. Carstens betont in seinen Erinnerungen aber, die USA hätten keinen Druck auf Bonn ausgeübt, den Vertrag um die von ihnen gewünschte Klarstellung zu ergänzen. Dies sei allein die Entscheidung der deutschen Seite gewesen ${ }^{252}$. Der Vorschlag des Staatssekretärs wurde zunächst vom Bundesrat aufgegriffen. Die Länderkammer sprach sich in ihrer Sitzung am 1. März 1963 dafür aus, die Bundesregierung sollte bei der Anwendung des Elysée-Vertrags darauf hinwirken, daß die Partnerschaft mit den Vereinigten Staaten, der Zusammenhalt in der NATO, das integrative System der Allianz sowie die Politik der Einigung Europas und der Erweiterung der europäischen Gemeinschaften gefördert würden ${ }^{253}$.

Bevor auf die weiteren Auseinandersetzungen um den deutsch-französischen Vertrag eingegangen wird, ist es unumgänglich, zunächst ein Problem anzusprechen, das zu Jahresbeginn 1963 das Verhältnis zu den USA ebenfalls erheblich belastete. Es handelte sich dabei um das westliche Röhrenembargo gegenüber der Sowjetunion. Wie Daniel Kosthorst urteilt, wurde diese Frage „zum symbolartigen Angelpunkt der deutsch-amerikanischen Beziehungen“254. An der Haltung der Bundesregierung in dieser Frage wollte Washington überprüfen, ob der deutsche Verbündete tatsächlich einen Kurswechsel in der Außenpolitik vorgenommen hatte oder weiterhin treu zum atlantischen Bündnis stand. Konkret betroffen von dem Embargo war die geplante Lieferung von Ölleitungsrohren in Form eines sogenannten Lohnveredelungsgeschäfts an die UdSSR durch Unternehmen aus der Bundesrepublik. Der Ständige Rat der NATO hatte am 21. November 1962 die Mitgliedstaaten angewiesen, keine derartigen Geschäfte mit dem Ostblock mehr abzuschließen ${ }^{255}$. Am 14. Dezember 1962 setzte das Bundeskabinett diese Entscheidung um und erließ die Vierte Verordnung zur Änderung der Ausfuhrliste, die die rechtliche Grundlage für das Exportverbot von Ölleitungsrohren bildete. Ihr zufolge durften alle Lohnveredelungsgeschäfte, die nach dem 1. Oktober 1962 beim Bundesamt für gewerbliche Wirtschaft beantragt worden waren, nicht genehmigt werden 256 . Die Stahlindustrie, die Anfang Oktober einen Großauftrag über 163000 Tonnen mit der UdSSR abgeschlossen hatte, versuchte verständlicherweise die Verordnung zu ihren Gunsten abzumildern. Sie setzte ihre Hoffnung auf eine Bestimmung des Außenwirtschaftsgesetzes, die es dem Bundestag innerhalb einer Frist von drei Monaten erlaubte, eine derartige Verordnung für ungültig zu erklären ${ }^{257}$.

Trotz mehrmaliger Intervention des Auswärtigen Amts stimmte der Außenhandelsausschuß des Bundestags drei Tage vor Ablauf der Einspruchsfrist, am 14. März 1963, einem Antrag zu, der vorsah, das Exportverbot nur unter der Bedingung zu akzeptieren, daß es keine rückwirkende Gültigkeit haben würde 258 .

252 Vgl. CARSTENS, Erinnerungen, S. 254.

253 Vgl. BT Anlagen, Bd. 84, Drucksache IV/1157 Anlage 2.

254 KOSTHORST, Primat, S. 117.

255 Vgl. ebenda, S. 106.

256 Für den Wortlaut vgl. BUNDESANZEIGER, Nr. 238 vom 18. 12. 1962, S. 1.

257 Vgl. Kosthorst, Primat, S. 98-101.

258 Vgl. ebenda, S. 101-104. 
Dies hätte den betroffenen Firmen die Möglichkeit gegeben, ihr Geschäft auftragsgemäß durchzuführen. Am folgenden Tag stand die Verordnung im Kabinett erneut auf der Tagesordnung. Damit die Bündnissolidarität gewahrt bliebe, drängte Schröder auf eine Umsetzung des Embargos in der Form, wie sie im Dezember 1962 beschlossen worden war. Während die Mehrheit der Kabinettsmitglieder den damaligen Beschluß bestätigte, stimmten die fünf Minister der FDP dagegen ${ }^{259}$. Auf Antrag der SPD fand schließlich am 18. März 1963 eine Sondersitzung des Bundestags statt, auf der über das Schicksal der Verordnung entschieden werden sollte. In der unmittelbar vor der Plenarsitzung stattfindenden Fraktionssitzung der CDU/CSU bemühte sich der Außenminister, die Unionsabgeordneten auf die Linie der Bundesregierung zu bringen. Er wies die Parlamentarier darauf hin, daß die Röhren für die Sowjetunion große strategische Bedeutung hätten. Sollte die Bundesrepublik die Lieferung erlauben, würden sich auch die anderen NATO-Partner nicht mehr an das Embargo halten. Schröder machte darauf aufmerksam, daß das Bundesamt für gewerbliche Wirtschaft im übrigen eine Genehmigung für das Geschäft noch gar nicht erteilt habe. Die Behauptung, die Bundesregierung hätte die Röhrenlieferung zunächst erlaubt und rückwirkend wieder verboten, treffe folglich nicht zu. Ein Kompromiß sei nicht möglich, da der Beschluß der NATO keinen Spielraum lasse. Seiner Ansicht nach hatte der Bundestag im übrigen nicht das Recht, das Exportverbot für ungültig zu erklären, da das Embargo von der Nordatlantischen Allianz beschlossen worden war und die Bundesregierung verpflichtet sei, sich an diese Entscheidung zu halten ${ }^{260}$.

Adenauer teilte den Standpunkt seines Außenministers. Auch er kam zu dem Urteil, daß der Schaden, der für die Bundesrepublik entstünde, falls der Bundestag der Lieferung zustimme, „außerordentlich groß“ wäre. Der Kanzler sah sogar das Regierungsbündnis mit der FDP in Gefahr. Schröder hingegen warnte davor, „an dieser Sache die Koalition kaputtgehen zu lassen“261. Er schätzte die Stimmung beim Koalitionspartner richtig ein und ahnte, daß die Freien Demokraten dazu neigten, für die Aufhebung der Verordnung zu votieren. Dennoch versuchte er noch während der Debatte im Bundestag, das Blatt zu wenden. Mit seinem Herzen, erklärte er im Plenum, sei er auf der Seite der Industrie: „Aber ich habe hier zu wählen zwischen den Interessen der auswärtigen Politik und den Interessen der Wirtschaft. [...] Da wähle ich die auswärtige Politik." Nachdrücklich appellierte der Außenminister an die Abgeordneten, im Interesse der Staatsräson die Embargofront nicht zu durchbrechen ${ }^{262}$. Es zeichnete sich aber ab, daß die Liberalen in dieser Frage gegen die Regierung stimmen würden. Die Aufhebung der Verordnung konnte nur dadurch verhindert werden, daß die Unionsfraktion der Abstimmung geschlossen fernblieb. Zwar votierten 244 Abgeordnete aus den Reihen der SPD und FDP für den Antrag, den Erlaß außer Kraft zu setzen, doch da sich nicht genügend Parlamentarier an der Abstimmung beteiligten, war das Par-

259 Vgl. ebenda, S. 114; SCHWARZ, Epochenwechsel, S. 301.

260 Vgl. das Protokoll der CDU/CSU-Fraktionssitzung am 18.3. 1963, ACDP VIII-001$1009 / 2$.

261 Ebenda.

262 BT STENOGRAPHISCHE BERICHTE, Bd. 52, S. 3064-3074 (3072). 
lament beschlußunfähig263. Damit blieb das Exportverbot rechtskräftig. Das Koalitionsklima hatte durch diese Angelegenheit jedoch erheblich gelitten ${ }^{264}$.

Jenseits des Atlantik nahm man den Ausgang der Auseinandersetzung erleichtert zu Kenntnis. Bonn machte damit in Washington wieder Boden gut. „Die Entscheidung werde zweifellos vom Weißen Haus wie auch vom Kongreß als symptomatisch für die grundsätzliche Einstellung der Bundesregierung aufgefaßt und positiv bewertet", telegraphierte der Botschafter der Bundesrepublik in Washington, Karl Herbert Knappstein, an das Auswärtige Amt ${ }^{265}$. Eine erneute Belastung der deutsch-amerikanischen Beziehungen war damit in letzter Minute verhindert worden. Die Bundesrepublik hatte ihre Zuverlässigkeit unter Beweis gestellt. Die Aufmerksamkeit der politischen Kreise konzentrierte sich jetzt wieder auf den deutsch-französischen Vertrag, dessen Ratifikation im Bundestag nun anstand.

Es wurde dabei sehr rasch deutlich, daß die Mehrheit der Bundestags nicht bereit war, dem Elysée-Vertrag ohne eine inhaltliche Ergänzung zuzustimmen. Vor allem Sozialdemokraten und Liberale traten für die Hinzufügung einer Präambel ein. Sie sollte eine Nichtberührungsklausel für frühere völkerrechtliche Verträge der Bundesrepublik enthalten, die Fortsetzung der partnerschaftlichen Zusammenarbeit mit den Vereinigten Staaten betonen sowie das Festhalten der Bundesrepublik an der NATO und ihr Eintreten für die europäische Integration herausstellen ${ }^{266}$. Aber auch die Mehrheit der CDU/CSU-Fraktion hielt eine derartige Klarstellung der Bonner Außenpolitik für angebracht. Sie hatte das Gefühl, in der vorliegenden Form sei das deutsch-französische Abkommen ein „Vertrag über die Schaffung eines Ausschließlichkeitsverhältnisses zwischen Frankreich und der Bundesrepublik “267. Insbesondere Kurt Birrenbach warb unter den Bundestagsabgeordneten der Union für die Präambel268. Der Fraktionsvorsitzende der CDU/CSU, Heinrich von Brentano, bezeichnete den Vertrag gar als einen „Fehler“. Während einer Reise in die USA vom 19. bis 24. März 1963 verkündete er seinen Gesprächspartnern, der Vertrag habe keine große Relevanz und sei das $\mathrm{Pa}$ pier nicht Wert, auf dem er geschrieben sei269. Auch in der politisch interessierten Öffentlichkeit machte sich das Bedürfnis breit, die deutsche Position klarzustellen. Am 22. März veröffentlichten 14 führende Persönlichkeiten aus Wirtschaft, Wissenschaft und Politik, darunter Carl-Friedrich von Weizsäcker und Arnold Bergstraesser sowie Altbundespräsident Theodor Heuss, eine Erklärung, in der sie darauf hinwiesen, das deutsche Volk wünsche eine Fortsetzung der Partnerschaft mit den USA270.

$263 \mathrm{Vgl}$. ebenda, S. 3077.

264 Vgl. MENDE, Von Wende zu Wende, S. 85.

265 Drahtbericht des Botschafters Knappstein, Washington, an das Auswärtige Amt vom 19. 3. 1963, PA/AA, B 150, Aktenkopien 1963.

$266 \mathrm{Vgl}$. MENDE, Von Wende zu Wende, S. 84.

267 Vgl. den Diskussionsbeitrag von Johann Baptist Gradl in ScHwarz (Hrsg.), Adenauer und Frankreich, S. 97.

268 Vgl. LAHR, Zeuge, S. 379.

269 Vgl. KUSTERER, Der Kanzler und der General, S. 332.

270 Für den Wortlaut der Deklaration „Keiner wird das Bündnis gefährden“ vgl. DIE WELT vom 22. 3. 1963, S. $1 \mathrm{f}$. 
Trotz des starken Widerstands war Adenauer entschlossen, sich mit seiner ganzen Kraft für die Ratifikation des Elysée-Vertrags einzusetzen ${ }^{271}$. Am 4. April 1963 trafen sich in der Urlaubsresidenz des Kanzlers in Cadenabbia die Spitzen der Koalition, um über die weitere parlamentarische Behandlung des Vertrags zu beraten. Adenauer nutzte die Gelegenheit, um erneut ein Plädoyer für das Abkommen zu halten: Es schaffe ein neues Kraftzentrum in Europa und verleihe der Bundesrepublik mehr außenpolitisches Gewicht ${ }^{272}$. Die Anwesenden machten ihm hingegen klar, daß der Vertrag ohne die Präambel keine Chance habe, den Bundestag zu passieren. Mende drohte, seine Fraktion werde dann wie schon beim Röhrenembargo mit der SPD stimmen ${ }^{273}$. Einer der wenigen Teilnehmer, der sich strikt gegen die Aufnahme einer Präambel wandte, war überraschenderweise Schröder, der den Vertrag dadurch entwertet sah ${ }^{274}$. Zwar hielt er den vorgesehenen Inhalt für „hundertprozentig richtig“, führte aber zwei gewichtige Argumente gegen ein derartiges Verfahren an: Zum einen werde eine derartige Präambel eine „erhebliche Einschränkung der Bewegungsfreiheit" der Bundesregierung zur Folge haben; zum anderen sei es im Umgang zwischen Staaten nach der Unterzeichnung eines völkerrechtlicher Vertrags nicht üblich, daß ein Vertragspartner nachträglich inhaltliche Änderungen vornehme ${ }^{275}$. Gleichwohl hielt er eine Richtigstellung der Politik der Bundesrepublik für zweckmäßig, da durch de Gaulles Pressekonferenz am 14. Januar und den Abbruch der Beitrittsverhandlungen am 29. Januar 1963 im Ausland Zweifel an der Position der Bundesrepublik aufgekommen seien. Er plädierte jedoch dafür, die Unterschiede zwischen Bonn und Paris in einigen wichtigen außenpolitischen Fragen im Rahmen einer Resolution des Bundestags aufzuzeigen ${ }^{276}$. Der Kanzler hätte eine Annahme des Vertrags ohne Änderungen oder Ergänzungen bevorzugt. De Gaulle, so argumentierte er, werde die Präambel als Ausdruck des Mißtrauens empfinden ${ }^{277}$. Doch die Mehrheit der Anwesenden, unter anderem der Vorsitzende des für Außenpolitik zuständigen Arbeitskreises V der CDU/CSU-Fraktion, Ernst Majonica, sprachen sich für eine vertragliche Interpretation durch eine Präämbel aus ${ }^{278}$.

$271 \mathrm{Vgl}$. OsTERHELD, „Ich gehe nicht leichten Herzens ...“, S. 201.

272 Vgl. ebenda, S. 208.

273 Vgl. MENDE, Von Wende zu Wende, S. 85.

274 Vgl. das Protokoll der CDU/CSU-Fraktionssitzung am 2. 10. 1963, ACDP VIII-0011009/3; OSTERHELD, "Ich gehe nicht leichten Herzens ...“, S. 209; sowie den Diskussionsbeitrag von Erich Mende in SCHWARZ (Hrsg.), Adenauer und Frankreich, S. 101. Mendes Aussage, Schröder wäre gegen die Präambel gewesen, wird von Georg Kliesing, dem damaligen Vorsitzenden des Verteidigungsausschusses der WEU, bestätigt. Vgl. ebenda, S. 103. Auch Carlo Schmid berichtet, der Außenminister hätte „schärfsten Widerstand“ gegen die Präambel geleistet. Vgl. SCHMID, Erinnerungen, S. 744. Es kann also keine Rede davon sein, daß Schröder ein Befürworter oder gar der „Initiator“ der Präambel war, wie Franz Josef Strauß später behauptete. Vgl. STRAUSS, Erinnerungen, S. 416. 275 So Schröder am 13.11. 1964 im Bundestag. Vgl. BT STENOGRAPHISCHE BERICHTE, Bd. 56, S. 7231. Daß der Außenminister von Anfang an dieser Überzeugung war, bestätigt sein Persönlicher Referent, Simon; ZeITZEugenbefragung Simon.

276 Vgl. OSTERHELD, „Ich gehe nicht leichten Herzens ...", S. 208.

277 Vgl. MENDE, Von Wende zu Wende, S. 84.

278 Vgl. ebenda. Vgl. auch Osterheld, „Ich gehe nicht leichten Herzens ... “, S. 209. 
Wohl oder übel mußte Adenauer diese Entscheidung akzeptieren, um die Ratifikation nicht zu gefährden. Lieber nahm er ein modifiziertes Abkommen in Kauf, als daß dieses im Bundestag durchfiel279.

Der Beschluß von Cadenabbia beruhigte auch die Gemüter in Washington, was sich schon bei einem Treffen zwischen Rusk und Schröder am 10. April in Paris zeigte. Der amerikanische Außenminister erklärte, „nur das zeitliche Zusammenfallen" des französischen Vetos gegen den britischen Beitritt mit der Unterzeichnung des Elysée-Vertrags habe seine Regierung „beunruhigt“280. Inzwischen hatte man im Weißen Haus wie im State Department aber erkannt, daß die Befürchtung unbegründet sei, Bonn und Paris würden ab sofort eine gemeinsame Politik betreiben. Bereits am Vortag hatte Schröder seinen französischen Amtskollegen über die Entscheidung informiert. Obwohl er ausdrücklich darauf hinwies, daß die Präambel ,inhaltlich der Entschließung des Bundesrates entsprechen werde" und somit konträr zur französischen Politik stand, hatte Couve de Murville nichts dagegen einzuwenden ${ }^{281}$. Die Bundesregierung mußte folglich annehmen, daß ihr ungewöhnliches Verhalten gegenüber dem Vertragspartner toleriert würde, obwohl die weiterhin bestehenden Differenzen in der Europa-Politik das beiderseitige Verhältnis trübten. Wie bereits geschildert, hatte Schröder in seinen Reden am 7. und 8. Februar 1963 den Willen der Bundesregierung zum Ausdruck gebracht, die Beitrittsverhandlungen mit Großbritannien so schnell wie möglich wiederaufzunehmen. Der Quai d'Orsay reagierte darauf mit der Ankündigung, weder 1963 noch 1964 würden die Gespräche mit London fortgesetzt werden ${ }^{282}$. Auch Schröders Vorschlag, die WEU als Konsultationsschiene in europapolitischen Angelegenheiten einzusetzen, wurde von Paris zurückgewiesen. Couve de Murville ließ das Auswärtige Amt wissen, er werde an der für den 29. März 1963 in Bonn geplanten Sitzung des WEU-Ministerrats nicht teilnehmen, falls die Absicht bestehen sollte, in diesem Gremium die Beziehungen Großbritanniens zur EWG zu thematisieren. Daraufhin sagte Schröder die Tagung ab ${ }^{283}$. Er entschloß sich, die französische Seite nun stärker unter Druck zu setzen. Ohne Paris explizit beim Namen zu nennen, warnte er am 2. April 1963 auf der Tagung des EWG-Ministerrats in Brüssel vor der „Gefahr des Überhandnehmens nationaler Interessen gegenüber dem Gemeinschaftsinteresse "284. Schröder betonte, daß Bonn in der Vergangenheit sehr viele Vorleistungen zugunsten Frankreichs, vor allem im Agrarbereich, erbracht und dabei erhebliche finanzielle Belastungen auf sich genommen habe. Dies sei ausschließlich ,in der Erwartung künftiger weiterer Fortschritte" geschehen. So habe die Bundesregierung fest mit der Zustimmung der

279 Vgl. ebenda, S. 220-224.

280 Gespräch des Bundesministers Schröder mit dem amerikanischen Außenminister Rusk am 10. 4. 1963 in Paris, in: AAPD 1963, Dok. 145, S. 477.

281 Ebenda, Dok. 143, S. 467.

282 Vgl. das Schreiben Blankenhorns an Lahr vom 12. 2. 1963, PA/AA, Büro Staatssekretär, Bd. 128.

283 Vgl. ADG 1963, S. 10498, sowie den Artikel „Paris läiłt Schröders Konferenz der Sieben scheitern“, in: FrANKFURTER AllgEMEINE ZEITUNG vom 25. 3. 1963, S. 1.

284 Rede Schröders vor dem EWG-Ministerrat am 2. 4. 1963 in Brüssel, in: BulleTiN 1963, S. 545. 
französischen Regierung zur Aufnahme Großbritanniens in die europäischen Gemeinschaften gerechnet. Detailliert erinnerte Schröder an alle Beschlüsse der EWG, bei denen die Bundesrepublik ihre Interessen hinter denen Frankreichs zurückgestellt hatte. Die bisherige Politik der Vorleistungen, so der Außenminister, könne nicht weitergeführt werden, sondern der „Gedanke der Gleichberechtigung “ müsse wieder Vorrang erhalten ${ }^{285}$. Er forderte ein neues partnerschaftliches Verhältnis, welches er auf einer Pressekonferenz in Paris am 10. April als „Synchronisierung des Fortschritts" bezeichnete. Der Außenminister verstand darunter, daß sich bei der Weiterentwicklung der Gemeinschaft künftig für jedes Mitglied Vor- und Nachteile die Waage halten müßten ${ }^{286}$.

In welchen Bereichen verlangte die Bundesregierung konkrete Fortschritte? Schröder dachte zunächst einmal an eine Intensivierung der Außenbeziehungen der EWG. Dies hieß für ihn an erster Stelle, die ins Stocken geratenen Gespräche über die Assoziierung Österreichs und der Türkei zu einem Abschluß zu bringen. Auch trat er für eine Fusion der Exekutiven von EURATOM, EGKS und EWG ein, um so „ein Zeichen des Willens zur Überwindung der Krise“ zu setzen, und forderte mehr Kompetenzen für das Europäische Parlament. So sollte diesem das Budgetrecht und das Ratifikationsrecht für von den Gemeinschaften geschlossene Verträge zugestanden werden. Schließlich plädierte er für die Direktwahl der Europa-Abgeordneten durch die Bevölkerung der Mitgliedstaaten. Außerdem sollten sich die Sechs ausrücklich zur prinzipiellen Offenheit der Gemeinschaften für neue Mitglieder bekennen. Dies, so erläuterte der Außenminister, bedeute, daß die EWG im Verhältnis zu London nichts unternehmen dürfe, „was den späteren Beitritt Großbritanniens unangemessen erschweren könnte" 287 . Auch müßten die durch die Beitrittsverhandlungen entstandenen Kontakte zwischen der EWG und dem Vereinigten Königreich aufrechterhalten werden. Schröder regte an, entweder über den Ständigen Vertreter Großbritanniens in Brüssel oder über die WEU in Verbindung zu bleiben ${ }^{288}$. Hinsichtlich der Agrarpolitik, an der besonders Frankreich interessiert war, forderte er eine Abkehr vom „überhastete[n] Tempo“ der Vergangenheit, da dadurch der ganze Integrationsprozeß verzerrt würde ${ }^{289}$. Dem EWG-Ministerrat schlug er vor, anhand der von ihm genannten Punkte ein Arbeitsprogramm für 1963 zu entwickeln, das alle Probleme enthalten sollte, deren Lösung „jeweils von einer Mehrheit der Mitgliedsländer als wesentlich ange-

\section{Ebenda, S. 546.}

286 Rede Schröders vor der Association de la Presse Diplomatique Française am 10. 4. 1963, in: BULLETIN 1963, S. 591-593 (591).

287 Rede Schröders vor dem EWG-Ministerrat am 2. 4. 1963 in Brüssel, in: BULLETIN 1963, S. 545-548 (547).

288 Ebenda, S. 547f. Wie in seinem Gespräch am 9.4. 1963 mit Couve de Murville deutlich wurde, favorisierte Schröder jetzt die Konsultation mittels der Ständigen Vertreter. Vgl. AAPD 1963, Dok. 143, S. 469.

289 Rede Schröders vor dem EWG-Ministerrat am 2. 4. 1963 in Brüssel, in: BULLETIN 1963, S. 548. Nur wenige Wochen später teilte Bonn der französischen Regierung mit, die Bundesrepublik könnte neuen Agrarverordnungen nur zustimmen, falls die Sechs bei den Zollverhandlungen der Kennedy-Runde eine gemeinsame Haltung einnehmen würden. Vgl. dazu das Schreiben des Bundesministers Schröder an den amerikanischen Außenminister Rusk vom 8. 7. 1963, in: AAPD 1963, Dok. 221, S. 732. 
sehen werden"290. Seine Ausführungen wurden von den europäischen Partnern der Bundesrepublik „sehr positiv“ aufgenommen. Der Ministerrat beschloß, ein solches Programm auszuarbeiten ${ }^{291}$. Dies war für Schröder „ein schöner Erfolg“, wie Staatssekretär Lahr urteilte292. Das Arbeitsprogramm des Außenministers befreite „die Gemeinschaft von der Lähmung, in die sie der ihr von de Gaulle im Januar zugefügte Schlag versetzt hatte“293.

Umstritten blieb indessen die Fortführung der Kontakte zwischen den Sechs und Großbritannien. Die französische Regierung stand einer Institutionalisierung sehr reserviert gegenüber. Sie verwies darauf, daß es bereits einen Ständigen Vertreter Londons in Brüssel gebe, der von der EWG regelmäßig über die europäische Entwicklung auf dem laufenden gehalten werde. Würde man eine dauerhafte Konsultation vereinbaren, dann könne man sich dabei wohl nicht nur auf die Großbritannien tangierenden Fragen beschränken, sondern müsse vielmehr alle Probleme der EWG mit London diskutieren. An der Seine fürchtete man, daß das Vereinigte Königreich durch das geplante Verfahren den Rang eines heimlichen Mitglieds der EWG erhielte und die Sechs schließlich sogar die Zustimmung der britischen Regierung einholten, bevor sie Entscheidungen träfen ${ }^{294}$. Schröder gab aber in diesem Punkt nicht nach. Er war der Ansicht, die Gemeinschaften hätten eine Politik zu betreiben, „die Großbritannien als das willkommene Mitglied von morgen berücksichtigt" 295 . Auch anläßlich der ersten deutsch-französischen Konsultationen am 5. Juli 1963 in Bonn griff er, trotz des deutlichen Unwillens Adenauers, dieses Thema wieder auf, wobei ihn Erhard unterstützte ${ }^{296}$. De Gaulle und Couve de Murville lehnten jedoch den von Schröder bevorzugten, weil „diskreteste[n] “ Weg einer regelmäßigen Zusammenkunft der Ständigen Vertreter der Sechs in Brüssel mit ihrem britischen Kollegen ab. Sie erklärten sich aber jetzt bereit, die Konsultationen über die WEU laufen zu lassen ${ }^{297}$.

Am 11. Juli 1963 beschloß der EWG-Ministerrat schließlich, im Rahmen der WEU vierteljährlich auf Ministerebene einen „Gedankenaustausch über die wirtschaftliche Lage Europas“ durchzuführen, an der auch die Brüsseler Kommission teilnehmen sollte ${ }^{298}$. Gegenüber der Öffentlichkeit gab Schröder diese Vereinbarung als eine Einigung auf seinen ursprünglichen Vorschlag aus ${ }^{299}$. Er verschwieg dabei, daß er diesen Gedanken wieder fallengelassen hatte, weil er die Kontakte

290 Rede Schröders vor dem EWG-Ministerrat am 2. 4. 1963 in Brüssel, in: BulLETIN 1963, S. 546.

291 DEI, Bd. 2, Dok. 232, S. 332-334. Vgl. auch ebenda, Dok. 231, S. 332.

292 LAHR, Zeuge, S. 379.

293 Ebenda, S. 394.

294 Vgl. die deutsch-französische Regierungsbesprechung vom 5. 7. 1963, in: AAPD 1963, Dok. 219, S. $725 \mathrm{f}$.

295 Rede Schröders vor der Wirtschaftsvereinigung Eisen- und Stahlindustrie am 28. 6. 1963

in Düsseldorf, in: BULLETIN 1963, S. 1004.

296 Vgl. die deutsch-französische Regierungsbesprechung vom 5. 7. 1963, in: AAPD 1963,

Dok. 219, S. 723-728, sowie OSTERHELD, "Ich gehe nicht leichten Herzens ...", S. 235 f.

297 Vgl. die deutsch-französische Regierungsbesprechung vom 5. 7. 1963, in: AAPD 1963,

Dok. 219, S. $725 \mathrm{f}$.

298 EUROPA-ARCHIV 1963, D 382.

299 Vgl. die Erklärung Schröders in der ARD am 11. 7. 1963, in: BULLETIN 1963, S. 1089. 
mit Großbritannien nicht aus dem Rahmen der EWG herauslösen wollte. Intern bezeichnete er deshalb diese Entscheidung als „eine Konzession an Frankreich“ und tröstete sich damit, daß mittels der Kommission auch in Zukunft die EWG als Organisation direkt an den Gesprächen beteiligt war. Außerdem blieben auch weiterhin Besprechungen der Ständigen Vertreter der Sechs mit ihrem britischen Kollegen möglich ${ }^{300}$. Ein zusätzlicher Pluspunkt war in seinen Augen, daß mit dem Beschluß vom 11. Juli eine „Wiederbelebung der WEU“ erfolgte ${ }^{301}$. In Anbetracht der bisherigen Haltung der Franzosen gab er die Weisung, Heath mitzuteilen, die Entscheidung des Ministerrats sei „ein Erfolg im Sinne der gemein-

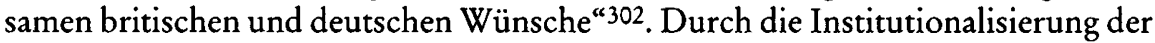
Kontakte zwischen den Sechs und London würde „das Fortbestehen der mit den Beitrittsverhandlungen geschaffenen Verbindungen zu Großbritannien“ bestätigt ${ }^{303}$.

In der Zwischenzeit war der deutsch-französische Vertrag im Bundestag beraten worden. Am 25. April 1963 fand die erste Lesung des Zustimmungsgesetzes zum Elysée-Vertrag statt. In seinem Redebeitrag erläuterte Schröder noch einmal die Motive, die die Bundesregierung zum Abschluß des Abkommens bewogen hätten. Der Außenminister fügte hinzu, in dem Vertrag sei nichts zu finden, was als „bedenklich“ eingestuft werden könnte ${ }^{304}$. Er sei bekanntlich „das Übriggebliebene" aus der einstigen französischen Initiative zur Bildung einer Politischen Union der europäischen Staaten ${ }^{305}$. Der Außenminister hob hervor, das einzige Ziel, das ausdrücklich im Vertrag erwähnt werde, sei die Schaffung eines vereinigten Europas. In diesem Sinne wolle die Bundesregierung den Vertrag anwenden und strebe vor allem konkrete Fortschritte bei der Schaffung einer Politischen Union an ${ }^{306}$. Alle Probleme könnten durch „ein sehr gutes und vertrauensvolles und freundschaftliches Verhältnis mit Frankreich [...] leichter behandelt werden". Durch den Vertrag, so bekräftigte er, werde die Bundesrepublik ,in vollem Umfang das fortsetzen können und fortsetzen werden, was bisher der Grundriß unserer auswärtigen Politik gewesen ist"307. Damit gab Schröder dem Vertrag eine ganz andere Tendenz, als de Gaulle beabsichtigte. Nach seiner Deutung des Abkommens war die Aufregung um eine angebliche Änderung der auswärtigen Prioritäten Bonns nicht nötig gewesen, weil es vollkommen auf der Linie der bisherigen Politik lag. Die Präambel bekräftigte also nur die Kontinuität der Politik der Bundesregierung, die aber zu keinem Zeitpunkt Schwankungen unterlegen sei, wie Schröder beteuerte ${ }^{308}$. „Ich denke nicht daran, mich für den Vertrag zu entschuldigen. Schließlich trägt er meine Unterschrift“, vertraute er Hermann Kuste-

300 Vgl. den Drahterlaß des Bundesministers Schröder an Botschafter von Etzdorf, London, vom 17. 7. 1963, in: AAPD 1963, Dok. 230, S. 760.

301 Ebenda, S. 761.

302 Ebenda, S. 759.

303 Ebenda, S. 760.

304 BT STENOGRAPHISCHE BERICHTE, Bd. 53, S. 3438.

305 Ebenda, S. 3440.

306 Ebenda, S. 3438.

307 Ebenda, S. 3441.

308 Vgl. ebenda, S. $3514 \mathrm{f}$. 
rer $\mathrm{an}^{309}$. Gegen seine Interpretation des Vertrages gab es, zumindest im Moment, keinen Widerspruch. Die Kreise, die die Intention verfolgten, den Vertrag als Hebel für eine Änderung der außenpolitischen Orientierung der Bundesrepublik zu nutzen, hielten sich zurück. $\mathrm{Zu}$ sehr stand man wohl noch unter dem Eindruck der jüngsten britischen und amerikanischen Proteste, die deutlich gemacht hatten, daß Bonn in die internationale Isolierung geraten würde, falls es auf eine ZweierUnion unter de Gaulles Führung hinarbeiten sollte.

Am 16. Mai 1963 ratifizierte der Bundestag den deutsch-französischen Freundschaftsvertrag mit überwältigender Mehrheit. Es wurden nur vier Nein-Stimmen und genauso viele Enthaltungen abgegeben ${ }^{310}$. Die vom Parlament eingefügte Präambel stellte den Vertrag in den Rahmen der atlantischen Zusammenarbeit und der europäischen Integration. Sie stimmte fast wortwörtlich mit der Resolution des Bundesrats vom 1. März überein. Laut der Präambel beabsichtigte Bonn, durch die Zusammenarbeit mit Frankreich „die großen Ziele zu fördern, die die Bundesrepublik Deutschland in Gemeinschaft mit den anderen ihr verbündeten Staaten seit Jahren anstrebt und die ihre Politik bestimmen, nämlich die Erhaltung und Festigung des Zusammenschlusses der freien Völker, insbesondere einer engen Partnerschaft zwischen Europa und den Vereinigten Staaten von Amerika, die Verwirklichung des Selbstbestimmungsrechts für das deutsche Volk und die Wiederherstellung der deutschen Einheit, die gemeinsame Verteidigung im Rahmen des nordatlantischen Bündnisses und die Integrierung der Streitkräfte der in diesem Bündnis zusammengeschlossenen Staaten, die Einigung Europas auf dem durch die Schaffung der europäischen Gemeinschaften begonnenen Wege unter Einbeziehung Großbritanniens und anderer zum Beitritt gewillter Staaten und die weitere Stärkung dieser Gemeinschaften" ${ }^{311}$. Wenn man vom Ziel der Wiedervereinigung absieht, sollte die Kooperation mit Frankreich also nach dem Willen der Parlamentarier all dem dienen, was de Gaulle durch den Vertrag zu verhindern suchte. Betrachtet man die Präambel aus seiner Sicht, dann trifft das Urteil Golo Manns zu, daß der Bundestag den deutsch-französischen Vertrag „in eben dem Moment nullifizierte, in dem er ihn ratifizierte" 312 . Die Präambel war, so HansPeter Schwarz, ein „Triumph des Atlantizismus“313. Am 31. Mai stimmte auch der Bundesrat dem Abkommen zu. Nach der Verkündung durch den Bundespräsidenten trat der Elysée-Vertrag am 2. Juli 1963 in Kraft.

Die Präambel war für de Gaulle eine große Enttäuschung, die er nie überwand. "Von diesem Augenblick an hat sein Verhältnis zu Deutschland einen Knacks“, beobachtete Kusterer ${ }^{314}$. Seine Frustration kam bereits in einer Botschaft zum Ausdruck, die der französische Botschafter in Bonn, Roland Jacquin de Margerie,

309 KUSTERER, Der Kanzler und der General, S. 203.

$310 \mathrm{Vgl}$. BT STENOGRAPHISCHE BERICHTE, Bd. 53, S. 3742-3754; OSTERHELD, „Ich gehe nicht leichten Herzens ...", S. 218.

311 Gesetz zu der Gemeinsamen Erklärung und zu dem Vertrag vom 22.1. 1963 zwischen der Bundesrepublik Deutschland und Frankreich über die deutsch-französische Zusammenarbeit vom 15. 6. 1963, in: DzD IV/9, S. $404 \mathrm{f}$.

312 Zitiert nach OSTERHELD, "Ich gehe nicht leichten Herzens ...“, S. 237.

313 SCHWARZ, Eine Entente Elémentaire, S. 15.

314 KUSTERER, Der Kanzler und der General, S. 334. 
am 11. Juni dem Kanzler überbrachte. Der französische Staatspräsident ließ mitteilen, er sei empört, wie die politischen Kreise der Bundesrepublik das Abkommen behandelt hätten. In Bonn sei alles getan worden, um „den Vertrag bis zur Entstellung abzuwerten und auszuhöhlen". Seit der Unterzeichnung im Januar sei zwischen Frankreich und der Bundesrepublik „nichts geschehen“. Das erste Konsultationstreffen der beiden Regierungen im Juli sehe er als einen „Test “ für das Funktionieren des Vertrags ${ }^{315}$. Adenauer beteuerte im Gegenzug den Willen Bonns zur Zusammenarbeit und bat um Verständnis wegen der langen Dauer des Ratifizierungsprozesses. Ein solcher Zeitraum sei für ein Gesetzgebungsverfahren in der Bundesrepublik völlig normal. Erstmals kritisierte er jedoch de Gaulles Pressekonferenz vom 14. Januar. Sie, so erläuterte er de Margerie, hätte unnötigerweise in Washington den Eindruck hervorgerufen, die deutsch-französische Kooperation sei gegen die Vereinigten Staaten gerichtet ${ }^{316}$. De Gaulles Ärger über die vom Bundestag eingefügte Präambel war aus seiner Sicht verständlich, da ihr Inhalt konträr zu seinen politischen Zielen stand. Dem Kanzler war durchaus bewußt, daß der französische Staatspräsident, der der Bundesrepublik die Hand zur Freundschaft gereicht hatte, das Zustimmungsgesetz des Bundestags als Kränkung empfinden mußte, weil es Frankreich signalisierte, Bonn habe andere Prioritäten ${ }^{317}$. Doch Adenauer hatte keine andere Wahl gehabt: Ohne Präambel hätte der Vertrag den Bundestag nicht passiert. Der aber dann im Verhältnis zwischen Bonn und Paris entstandene Schaden wäre aber unermeßlich größer gewesen.

Am 23. Juni, also wenige Tage vor den ersten deutsch-französischen Konsultationsgesprächen, traf der amerikanische Präsident zu einem dreitägigen Staatsbesuch in der Bundesrepublik ein. Wenn Kennedy mit diesem Besuch tatsächlich die Absicht verfolgte, die Deutschen „von de Gaulle wegzuhalten“318, dann war seine Reise ein voller Erfolg. Wo immer er auftrat, wurde er vom Publikum gefeiert; mindestens genauso euphorisch wie de Gaulle im September 1962. Schröder wertete den begeisterten Empfang, den Kennedy in der Bundesrepublik erlebte, als Zustimmung zur amerikanischen Politik. „Wir können erleben, was auch immer - einen solchen Triumphzug bestimmt nicht mehr", sagte er am Rande von Kennedys Aufenthalt in Berlin zu Rusk. Er achtete aber nicht in erster Linie darauf, wie enthusiastisch der Präsident aufgenommen wurde, sondern primär, was dieser den Deutschen mitzuteilen hatte. Besonders die Rede Kennedys in der Frankfurter Paulskirche am 25. Juni 1963 kam nach seiner Einschätzung große Bedeutung $\mathrm{zu}^{319}$. Dort skizzierte der Präsident den Grundriß einer atlantischen Partnerschaft und versprach, daß die Vereinigten Staaten bei einem Angriff auf Europa ihre Bündnispflichten erfüllen würden ${ }^{320}$.

315 OSTERHELD, „Ich gehe nicht leichten Herzens ...“, S. 219. Vgl auch die Aufzeichnung des Ministerialdirektors Jansen vom 6. 6. 1963, in: AAPD 1963, Dok. 191, S. 615 f.

316 Vgl. OSTERHELD, „Ich gehe nicht leichten Herzens ...“, S. $219 \mathrm{f}$.

317 Vgl. ebenda, S. $220 \mathrm{f}$.

318 Ebenda, S. 225.

319 SCHRÖDER, Ein Stück Geschichte, das uns bleiben wird.

320 Für den Wortlaut vgl. DzD IV/9, S. 442-449. 
Nach Beendigung des Besuches hielt Schröder vor der Mitgliederversammlung der Wirtschaftsvereinigung Eisen- und Stahlindustrie am 28. Juni in Düsseldorf eine programmatische außenpolitische Rede ${ }^{321}$. Der Schwerpunkt seiner Ausführungen lag dabei in der Darlegung der außerordentlichen Bedeutung des Bündnisses mit den Vereinigten Staaten. Er wandte sich dabei direkt an die Kritiker einer amerikaorientierten Außenpolitik und bestritt, daß eine enge Bindung an Washington zu einem Abhängigkeitsverhältnis führe. Ebenso hielt er die Angst vor einem neuen amerikanischen Isolationismus für unberechtigt. Die These der Gaullisten, angesichts des nuklearen Patts würde eine militärische Zusammenarbeit mit Frankreich die Sicherheit der Bundesrepublik erhöhen, wies er als abwegig zurück. Nicht eine Lockerung der Bindungen an die USA vergrößere den Schutz Europas vor einem sowjetischen Angriff, sondern nur eine Politik, die durch die Förderung der Einigung Europas zur Stärkung des alten Kontinents beitrage, weil dadurch „ein echtes und ausgeglichenes Partnerschaftsverhältnis zu den Vereinigten Staaten“" geschaffen würde ${ }^{322}$. Die Bundesrepublik dürfe jedoch nicht den Fehler begehen und das amerikanische Engagement in Europa für selbstverständlich halten: „Wir müssen den USA ebenso unentbehrlich bleiben wie sie uns, und zwar auf allen Gebieten, politisch, wirtschaftlich und militärisch. " ${ }^{323}$ Unmittelbar vor dem Eintreffen des französischen Staatspräsidenten in Bonn hatte der Außenminister damit aufgezeigt, wo die außenpolitischen Prioritäten der Bundesrepublik lagen. Frankreich war für ihn zwar ein unverzichtbarer Bestandteil eines mit den Vereinigten Staaten eng verbundenen Europas, aber nicht mehr.

Seine Enttäuschung über die Haltung der Bundesrepublik brachte de Gaulle zwei Tage vor seinem Besuch in Bonn sinnbildlich zum Ausdruck: „Verträge sind wie Rosen und Mädchen: Sie blühen nur einen Morgen“324. Adenauer versuchte, den General zu besänftigen und empfing ihn mit der Bemerkung: „Rosen und junge Mädchen [...], natürlich haben sie ihre Zeit, aber die Rose - und davon verstehe ich nun wirklich etwas [...] - ist die ausdauerndste Pflanze, die wir überhaupt haben - sie hält jeden Winter durch. “325 Dies ermutigte zwar den Staatspräsidenten, so daß er jetzt von einem Rosenhag sprach, den Adenauer und er gemeinsam mit dem Elysée-Vertrag gepflanzt hätten ${ }^{326}$, doch die Gespräche mit den

321 Für den Wortlaut vgl. Bulletin 1963, S. 1003-1007.

322 Ebenda, S. 1005.

323 Ebenda, S. 1006.

324 "Les traités sont comme les roses et les jeunes filles: ils ne durent qu'un matin." Zitiert nach KUSTERER, Der Kanzler und der General, S. 349.

325 Ebenda.

326 „Sie haben recht, Herr Bundeskanzler, unser Vertrag ist nicht eine einzelne Rose, er ist auch nicht ein Rosenstock - er ist ein ganzer Rosenhag, und diesen Rosenhag haben wir gepflanzt, damit täglich neue Rosen erblühen. Eine Rose [...] dauert nur einen Morgen, und auch das junge Mädchen ist nicht immer und ewig jung. Aber Sie haben das in ihrem eigenen Garten, in Ihrem eigenen Haus bewiesen, daß ein solcher Rosenhag, wenn man ihn richtig zu pflegen versteht, ein sehr, sehr langes Leben hat und daß er jeden Morgen neue Blüten treibt. Dasselbe gilt auch für unseren Vertrag. Es ist uns aufgegeben, für unsere Völker, für Europa und für die ganze Welt diesen Vertrag [...] fruchtbar zu gestalten." Vgl. ebenda. 
künftigen Verantwortlichen in Bonn demonstrierten ihm, daß nach dem Rücktritt des ,Alten' nicht mit einer Weiterentwicklung der bilateralen Zusammenarbeit in dem von ihm intendierten Sinn zu rechnen war. Gerhard Schröder sowie der designierte Nachfolger Adenauers, Ludwig Erhard, erörterten lieber die künftige Einbindung Großbritanniens in die EWG, als mit der französischen Delegation über gemeinsame Projekte zu sprechen ${ }^{327}$. Weder mit dem Außen- noch mit dem Wirtschaftsminister fand de Gaulle eine gemeinsame Basis. Gegenüber Adenauer brachte er anschließend seine Unzufriedenheit zum Ausdruck: „Er wolle dem Herrn Bundeskanzler jedoch nicht verhehlen, daß die deutsche Politik nach seinem Rücktritt für Frankreich und insbesondere für ihn [...] ein Fragezeichen sein werde." ${ }^{328}$ Dieser verfügte jedoch in den letzten Monaten seiner Amtszeit nicht mehr über die Mittel, die Weichen auf ein Zusammengehen mit Frankreich zu stellen. Schon die Auseinandersetzung um die Präambel hatte gezeigt, daß er sich in seiner eigenen Partei in entscheidenden Angelegenheiten nicht mehr durchsetzen konnte. Spätestens die Fraktionssitzungen am 22. und 23. April, als Erhard, obwohl Adenauer ihm die Befähigung zum Kanzler absprach, zu seinem Nachfolger bestimmt wurde, hatten seine Machtlosigkeit vollends offenbart ${ }^{329}$. Der Autoritätsverlust Adenauers, der mit der Akzeptanz einer Kanzlerschaft auf Zeit nach den Bundestagswahlen im Herbst 1961 begonnen hatte, war nun, da der genaue Termin seines Rücktritts und sein Nachfolger feststanden, endgültig besiegelt. De Gaulle mußte ernüchtert konstatieren, daß der Elysée-Vertrag entgegen seinen Erwartungen nicht zu einer gemeinsamen Politik geführt hatte ${ }^{330}$.

Als sich Adenauer am 22. September 1963 zu einem Abschiedsbesuch in Schloß Rambouillet aufhielt, forderte der französische Staatspräsident dennoch erneut, der Vertrag müsse so, wie von ihm intendiert, in die Praxis umgesetzt werden ${ }^{331}$. Angesichts seines unmittelbar bevorstehenden Ausscheidens aus seinem Amt konnte der Kanzler allerdings diesbezüglich nur die Hoffnung zum Ausdruck bringen, „daß jemand wie Schröder, der England als etwas Großartiges empfinde, geheilt werde“. Erhard würde aber die gemeinsame Politik mit Frankreich fortsetzen, fügte er hinzu, ohne wohl selbst daran zu glauben. Als einzige Zuversicht blieb ihm nur noch die Erwartung, daß er auch nach seinem Rücktritt immer noch „einen gewissen Einfluß ausüben“" werde ${ }^{332}$. Eine Änderung der Einstellung Erhards gegenüber de Gaulle war in der Tat reichlich unwahrscheinlich. Im Gegensatz dazu hielt der scheidende Kanzler eine Bekehrung Schröders noch für realistischer. Nachdem feststand, daß dieser auch unter Erhard Außenminister bleiben würde, beschwor er ihn, er müsse „der getreue Ekkehard der neuen Regie-

$327 \mathrm{Vgl}$. die deutsch-französische Regierungsbesprechung vom 5. 7. 1963, in: AAPD 1963, Dok. 219, S. 718-728.

328 Gespräch des Bundeskanzlers Adenauer mit Staatspräsident de Gaulle am 4. 7. 1963, in: ebenda, Dok. 216, S. 702.

329 Auf diese beiden Sitzungen wird im Kapitel „Schröder statt Erhard? Die Diskussion um die Kanzlernachfolge" noch näher eingegangen.

$330 \mathrm{Vgl}$. Ziebura, Die deutsch-französischen Beziehungen seit 1945, S. 173-175.

331 Gespräch des Bundeskanzlers Adenauer mit Staatspräsident de Gaulle am 22. 9. 1963 in Rambouillet, in: AAPD 1963, Dok. 357, S. 1202-1210.

332 Ebenda, S. 1203. 
rung sein", was selbstverständlich hieß, den von Adenauer eingeschlagenen auBenpolitischen Kurs fortzusetzen ${ }^{333}$. Doch Schröder hatte seit Beginn des Jahres einen zunehmend negativeren Eindruck von der Pariser Politik gewonnen. „Wenn die Franzosen von Europa sprächen, dann dächten sie an ein Europa unter französischer Führung. So erkläre sich auch die Bemühung der Franzosen, die Engländer aus Europa draußen zu halten“, führte er am 20. September 1963 gegenüber Rusk aus ${ }^{334}$. Die Hegemonie eines Landes in Europa müsse aber unter allen Umständen verhindert werden ${ }^{335}$. Deshalb wies er auch den Auftrag Adenauers zurück, eine auswärtige Politik zu betreiben, die den Überzeugungen des designierten Kanzlers und seinen eigenen widersprach. „In der neuen Regierung werde ich nur dann etwas im Sinne der Kontinuierlichkeit der auswärtigen Politik ausrichten können, wenn ich das volle und uneingeschränkte Vertrauen des neuen Bundeskanzlers habe“, antwortete er Adenauer ${ }^{336}$. Dies hieß nichts anderes, als daß Schröder mit und nicht gegen Erhard arbeiten wollte. Dazu gab es auch für ihn keinen Anlaß, stimmte er doch mit ihm in der Beurteilung der außenpolitischen Lage völlig überein. Wie er später berichtete, hatte er mit Erhard niemals über die Ziele der Bonner Außenpolitik ein Gespräch geführt, da er dessen Kurs „vollkommen zustimmen“ konnte ${ }^{337}$. Folglich war dieses erste Gespräch, das Schröder mit Adenauer nach dessen Rücktritt führte, zugleich das letzte. Das Tischtuch zwischen beiden Männern war endgültig zerschnitten. Alle weiteren Begegnungen, die ausnahmslos in einem größeren Kreis stattfanden, „führten nicht zu einer sachlichen Unterredung", wie Schröder im Rückblick trocken kommentierte ${ }^{338}$. Adenauer zeigte sich bitter enttäuscht über den Mann, den er einst in sein Kabinett berufen und mit dem er zehn Jahre eng zusammengearbeitet hatte: "Ich habe mich in keinem so getäuscht wie in dem Herrn Schröder“, verkündete er später ${ }^{339}$. Gegenüber dem französischen Botschafter in Bonn, François Seydoux, bemerkte er wiederholt, er könne Schröders antifranzösische Haltung nicht nachvollziehen: „Als ich ihn zum Außenminister ausgesucht habe, war er ganz, ganz anders! “ 340

333 SCHRÖDER, Außenpolitik im Übergang Adenauer-Erhard, S. $720 \mathrm{f}$.

334 Gespräch des Bundesministers Schröder mit dem amerikanischen Außenminister Rusk am 20.9. 1963 in Washington, in: AAPD 1963, Dok. 349, S. 1164.

335 Vgl. die Rede Schröders vor der Wirtschaftsvereinigung der Eisen- und Stahlindustrie am 28.6. 1963 in Düsseldorf, in: BulletiN 1963, S. 1004.

336 SCHRÖDER, Außenpolitik im Übergang Adenauer-Erhard, S. 721.

337 SCHRÖDER, Im Gespräch mit Meinhold Krauss, S. 54.

338 Ebenda.

339 Zitiert nach GoYKe, Die 100 von Bonn, S. 247.

340 Seydoux, Meine zweite Mission, S. 68. 


\section{Nach der Kuba-Krise: Bonn im Zeichen der „partiellen sicherheitspolitischen Kooperation“ der Supermächte}

\section{Die militärische Strategie der „flexible response“ und die politische Doktrin der „arms control"}

Auf der Tagung des NATO-Ministerrats am 15. Dezember 1961 in Paris informierten der amerikanische Verteidigungsminister Robert McNamara und Außenminister Dean Rusk die Mitglieder des westlichen Verteidigungsbündnisses über die Änderung der amerikanischen Militärstrategie. Das bislang gültige Konzept der massiven Vergeltung (massive retaliation) sei durch eine neue Strategie abgelöst worden, die die beiden Politiker als Theorie der beweglichen Antwort (flexible response) bezeichneten ${ }^{1}$. Was waren die Gründe für diesen militärstrategischen Kurswechsel, und in welcher Weise unterschied sich die neue Strategie von der alten? Die bisherige Doktrin der massiven Vergeltung beruhte im wesentlichen auf einer taktischen Zweiteilung der NATO-Streitkräfte. Die konventionellen Truppen hatten die Aufgabe, im Falle eines Angriffs des Warschauer Pakts auf Westeuropa den Vorstoß der feindlichen Kräfte aufzufangen und die Vorbereitung eines amerikanischen Nuklearschlags abzusichern. Die nicht-atomar ausgerüsteten Truppen sollten einen Schild bilden, um so den Einsatz des atomaren Schwertes abzudecken. Für die UdSSR bedeutete dies, daß sie bei einer von ihr ausgehenden Aggression - selbst wenn sie auf den Einsatz von atomaren Waffen verzichtete mit dem sofortigen Einsatz des gesamten Nuklearpotentials der USA rechnen mußte. Die Fähigkeit der Vereinigten Staaten, den Gegner dadurch vollständig vernichten zu können, garantierte eine glaubhafte Abschreckung2. Die Androhung, im Ernstfall mit einem atomaren Erstschlag zu reagieren, war jedoch nur glaubwürdig, solange die Sowjetunion nicht über die Möglichkeit verfügte, mit einem massiven atomaren Gegenangriff auf das Territorium der Vereinigten Staaten zu antworten. Das änderte sich mit dem Start des ersten künstlichen Erdsatelliten durch die UdSSR im Oktober 1957. Der Sputnik-Schock bewies, daß Moskau nicht nur über Interkontinentalraketen verfügte, sondern auch einen Forschungsvorsprung besaß ${ }^{3}$. Somit stand in einem Atomkrieg jetzt auch die Existenz der USA auf dem Spiel. Es begann das Zeitalter des nuklearen Patts, das „eine grundlegend veränderte strategische Lage schuf“4.

Die Herausbildung eines atomaren Gleichgewichts hatte vor allem für die europäische Sicherheit weitreichende Konsequenzen. Würde ein amerikanischer Präsident, falls die USA von einem sowjetischen Angriff nicht direkt betroffen wären, auch künftig den Einsatz seiner Atomstreitmacht anordnen, um die europäischen

1 Vgl. dazu Gablik, Strategische Planungen in der Bundesrepublik Deutschland, S. 248; HOPPE, Zwischen Teilhabe und Mitsprache, S. 60. Erst im Dezember 1967 wurde die Doktrin der flexible response offizielle Strategie der NATO. Vgl. dazu HAFTENDORN, Kernwaffen, S. 89-97.

2 Vgl. BREDOw, Nuklearstrategie und Kalter Krieg; STEINHOFF/POMMERIN, Strategiewechsel, S. 9-56; HAFTENDORN, Kernwaffen, S. 40.

3 Vgl. AdenAUER, Erinnerungen IV, S. 319 f.

4 HOPPE, Zwischen Teilhabe und Mitsprache, S. 34. 
Verbündeten zu schützen, obwohl er damit die Vernichtung des eigenen Landes riskierte ${ }^{5}$ ? Für die europäischen NATO-Mitglieder war die Antwort auf diese Frage lebenswichtig, denn angesichts des konventionellen Übergewichts der Sowjetunion hing ihr Schicksal von der Sicherheitsgarantie der Vereinigten Staaten ab. Zunehmend wuchsen unter den Europäern die Zweifel, ob man sich weiterhin auf den atomaren Schutzschild der USA verlassen konnte. Man befürchtete, daß sich die Amerikaner verteidigungspolitisch von Europa abkoppelten ${ }^{6}$. Die Bedenken wurden dadurch verstärkt, daß Kennedy 1961 den bereits pensionierten General Maxwell Taylor zu seinem persönlichen Militärberater berief und ihn ein Jahr später sogar zum Vorsitzenden des Rates der Generalstabchefs ernannte, womit er das höchste militärische Amt bekleidete, das die Vereinigten Staaten zu vergeben hatten. Taylor genoß bei den Europäern einen zweifelhaften Ruf ${ }^{7}$, seitdem er 1960 ein Buch mit dem Titel The Uncertain Trumpet veröffentlicht hatte, in dem er die These vertrat, daß keine Atommacht sich der Gefahr der eigenen Vernichtung aussetzen würde, um einen Verbündeten zu verteidigen ${ }^{8}$. Das wachsende Mißtrauen gegenüber den strategischen Planungen der USA führte zu zwei konträren Entwicklungen: Auf der einen Seite wollten die Europäer größere Mitsprache bei der amerikanischen Nuklearplanung erhalten, auf der anderen Seite verfolgten sie das Ziel, sich von den sicherheitspolitischen Entscheidungen Washingtons unabhängiger zu machen 9 . So forcierten Großbritannien und Frankreich den Aufbau eines eigenen Nuklearpotentials. 1957/58 gab es erste Ansätze zur Schaffung eines europäischen Kernwaffenprogramms zwischen Frankreich, Italien und der Bundesrepublik. Die Verhandlungen wurden jedoch unmittelbar nach der Ernennung de Gaulles zum französischen Ministerpräsidenten im Juli 1958 eingestellt, da dieser eine eigenständige Atommacht unter nationaler Kontrolle favorisierte ${ }^{10}$. Auch der damalige Oberbefehlshaber der amerikanischen und NATO-Streitkräfte in Europa (SACEUR), der US-General Lauris Norstad, erkannte die Gefahren, die die neue Entwicklung für den Zusammenhalt in der NATO darstellte. Um eine Spaltung des Bündnisses abzuwenden, schlug er vor, die Allianz mit Atomwaffen auszurüsten, die sie in eigener Verantwortung einsetzen sollte. Damit versuchte Norstad, dem Wunsch der Partner nach mehr nuklearer Mitsprache Rechnung zu tragen und die NATO wieder zu festigen ${ }^{11}$.

Die Regierung Eisenhower reagierte ebenfalls auf die divergierenden Tendenzen innerhalb der NATO. Sie fürchtete vor allem eine Vergrößerung der Zahl der Atommächte, wie sie sich durch das französische und britische Nuklearprogramm abzeichnete. Die amerikanischen Militärstrategen bezweifelten die abschreckende

5 Vgl. Haftendorn, Kernwaffen, S. 15.

6 Vgl. ebenda, S. 16.

7 Vgl. STRauss, Erinnerungen, S. 363.

8 TAYLOR, The Uncertain Trumpet, besonders S. 130-180.

9 Vgl. BESSON, Die Außenpolitik der Bundesrepublik, S. 232; HAFTENDORN, Kernwaffen, S. $107 \mathrm{f}$.

10 Vgl. SCHMIT, Auch die Bundesrepublik strebte einst nach Atomwaffen; KÜNTZEL, Bonn und die Bombe, S. 28-32; CONZE, La Coopération franco-germano-italienne dans le domaine nucléaire dans les années 1957-1958, S. 115-132.

11 Vgl. Hoppe, Zwischen Teilhabe und Mitsprache, S. 34-40. 
Wirkung kleinerer Nuklearpotentiale, sondern sahen in ihnen einen Risikofaktor, weil diese Atomwaffen einer zentralen Kontrolle entzogen waren ${ }^{12}$. Sie fürchteten, die USA könnten bei ihrem Einsatz gegen ihren Willen in einen militärischen Konflikt hineingezogen werden ${ }^{13}$. Um eine weitere Proliferation von Nuklearwaffen innerhalb der NATO zu verhindern, entwickelte die amerikanische Regierung deshalb den Plan eines gemeinsamen Besitzes von Nuklearwaffen in Form einer multilateralen Atomflotte. Auf der Tagung des NATO-Ministerrats vom 16. bis 18. Dezember 1960 in Paris schlug der damalige amerikanische Außenminister, Christian Herter, den Verbündeten den Aufbau einer solchen Flotte vor. Diese sollte fünf amerikanische Atom-U-Boote mit jeweils acht Polaris-Raketen umfassen. Zudem beabsichtigten die Amerikaner, 100 Mittelstreckenraketen auf Schiffen und U-Booten, die von den Europäern gestellt werden sollten, zu stationieren. Bis auf die fünf Atom-U-Boote sollte die Flotte nach den Vorstellungen Herters multinational bemannt sein, um auf diese Weise den gemeinsamen Besitz zu symbolisieren ${ }^{14}$. Die Reaktion der europäischen NATO-Mitglieder fiel sehr zurückhaltend aus, da die Amtszeit Eisenhowers bereits einen Monat später ablief und deshalb eine Durchführung des von Herter vorgeschlagenen Plans nicht mehr realistisch war. Es war nicht bekannt, wie die Demokraten, die Ende Januar 1961 die Macht in Washington übernehmen sollten, zu diesem Plan standen. Darüber hinaus sah Herters Konzept eine weitaus geringere Mitsprachebefugnis für die Europäer vor als der Norstad-Plan ${ }^{15}$.

Tatsächlich legte die neue Regierung unter Präsident Kennedy den Plan einer multilateralen Atomflotte vorerst auf Eis. Sie konzentrierte sich in erster Linie auf die strategischen Herausforderungen, die das nukleare Patt an die amerikanische Verteidigungsdoktrin stellte. Unter dem Eindruck der Berlin-Krise entwickelte die Kennedy-Administration die Militärstrategie der flexible response ${ }^{16}$. Im Gegensatz zum bislang gültigen Konzept der massiven Vergeltung, das im Falle eines Angriffs des Warschauer Pakts den Einsatz des gesamten atomaren Potentials vorsah, sollte nun die Art und Weise der amerikanischen Reaktion nicht länger vorhersehbar sein. Abschreckung bedeutete jetzt, den Gegner im unklaren über die Maßnahmen zu lassen, mit denen die USA auf eine Aggression antworten würden. Während es bislang im Ernstfall nur eine mögliche Antwort gegeben hatte, die angesichts des atomaren Gleichgewichts zwangsläufig die eigene Vernichtung mit sich brachte, hatte die neue Strategie den Vorteil, daß die politische Führung nun über ein weitgespanntes Spektrum von Handlungsoptionen verfügte ${ }^{17}$. In

12 Vgl. ebenda, S. 65; Kissinger, Was wird aus der westlichen Allianz?, S. $123 \mathrm{f}$.

$13 \mathrm{Vgl}$. AdenAuer, Erinnerungen IV, S. 170; BESSON, Die Außenpolitik der Bundesrepublik, S. 252.

14 Vgl. Hoppe, Zwischen Teilhabe und Mitsprache, S. 42 f.; GREwE, Rückblenden, S. 613.

15 Vgl. HoPpe, Zwischen Teilhabe und Mitsprache, S. 43.

16 Für weiterführende Literatur über die Strategie der „beweglichen Antwort“ vgl. die Angaben bei HAFTENDORN, Sicherheit, S. 180, Anm. 89; sowie das Literaturverzeichnis in STEINHOFF/POMmERIN, Strategiewechsel. Vgl. auch STROMSETH, The origins of flexible response.

17 Vgl. BESSON, Die Außenpolitik der Bundesrepublik, S. 252; HAFTENDORN, Kernwaffen, S. 31; KISSINGER, Was wird aus der westlichen Allianz?, S. 120-123. 
Berlin sahen sich die Vereinigten Staaten nämlich mit dem Problem konfrontiert, die Grenze zu ziehen, ab welchem Punkt bestimmte militärische Mittel einzusetzen waren. Wie sollte der Westen beispielsweise auf eine Sperrung der Zufahrtswege reagieren? Sollte ein gewaltsamer Durchbruch versucht und damit ein $\mathrm{Nu}$ klearkrieg in Kauf genommen werden? Konnte aufgrund des atomaren Patts die Drohung mit dem Einsatz von Kernwaffen noch glaubhaft sein? Mit Hilfe der Theorie der beweglichen Antwort ließ sich dieses Dilemma umgehen, da der Punkt, der im Ernstfall zum Einsatz von Kernwaffen führen würde - die sogenannte nukleare Schwelle -, nicht mehr definiert wurde und dadurch hinausgezögert werden konnte ${ }^{18}$. Der Weg in den totalen Atomkrieg war somit nicht länger automatisch vorgezeichnet. Die neue Strategie erlaubte es, Pausen in die Eskalation einzubauen, die den Konfliktparteien die Chance geben sollten, eine Verständigung zu erreichen. Während man also einerseits die Reaktionsmöglichkeiten erweiterte, suchte man andererseits den Eskalationsprozeß zu verlangsamen. Diese abgestufte Abschreckung sollte die nukleare Verteidigungspolitik wieder glaubwürdig machen. Praktisch bedeutete sie eine Umkehrung der Funktionen von Schwert und Schild, weil jetzt den Nuklearwaffen die Aufgabe des Schilds zu$\operatorname{kam}^{19}$.

Die Bedeutung der konventionellen Streitkräfte wuchs dadurch beträchtlich. Bislang hatte sich ihre Aufgabe im Ernstfall im wesentlichen darauf beschränkt, die gegnerischen Truppen bis zum Einsatz der Atomwaffen hinzuhalten. Sie brauchten deshalb in Stärke und Anzahl den Truppen des Warschauer Pakts nicht gleichwertig zu sein, da sie nicht das Rückgrat der Verteidigung bildeten. Die neue amerikanische Verteidigungsstrategie setzte eine Erhöhung der Truppenstärke voraus, damit der politischen Führung im Falle einer Aggression eine größere Anzahl von Optionen zur Verfügung stand. Um die atomare Schwelle zu erhöhen, sollten die NATO-Streitkräfte künftig auch in der Lage sein, einen Angriff nur durch den Einsatz konventioneller Mittel abzuwehren. Die USA verlangten deshalb von ihren Verbündeten, ihre Truppenstärke zu vergrößern ${ }^{20}$. Für eine erfolgreiche Vorwärtsverteidigung - so wurde diese Kampfplanung bezeichnet - benötigte man nach Ansicht der Experten zusätzliche 40 Divisionen. $\mathrm{Zu}$ einer Aufrüstung in diesem Ausmaß waren die Europäer aber personell, finanziell und infrastrukturell nicht in der Lage ${ }^{21}$. Die amerikanische Forderung nach einer Aufstockung der Truppen der europäischen NATO-Mitglieder führte über Jahre zu Spannungen im Bündnis.

Auch eine andere Schlußfolgerung aus der Theorie der beweglichen Antwort belasteten die Allianz, nämlich das Erfordernis, den Einsatzbefehl über die Atomwaffen in einer Hand, in der des amerikanischen Präsidenten, zu konzentrieren.

$18 \mathrm{Vgl}$. Hoppe, Zwischen Teilhabe und Mitsprache, S. 56; STROMSETH, The origins of flexible response, S. 35-41.

19 Vgl. HanRieder, Deutschland, S. 52.

20 Vgl. die Aufzeichnung des Referats II A 7 vom 27. 9. 1965, in: AAPD 1965, Dok. 368, S. 1514-1516; HAFTENDORN, Kernwaffen, S. 16; KISSINGER, Was wird aus der westlichen Allianz?, S. 120-123.

21 Vgl. HAFTENDORN, Kernwaffen, S. 42. 
In einer bipolaren Welt ließ sich eine nukleare Eskalation am effektivsten vermeiden, wenn die Entscheidung, welche Antwort auf eine Aggression zu geben sei, auf jeder Seite monopolisiert war ${ }^{22}$. Deswegen beabsichtigten die USA unter anderem, die in Europa stationierten amerikanischen Nuklearwaffen zu entfernen, damit sie bei einem Angriff auf die europäischen NATO-Staaten nicht automatisch in den Zugzwang gebracht wurden, diese einzusetzen ${ }^{23} .1962$ zogen sie ihre Mittelstreckenraketen aus Großbritannien, Italien und der Türkei ab und ersetzten sie durch Atom-U-Boote, die mit Polaris-Raketen bestückt waren. Bei den Europäern verstärkte dieser Schritt jedoch den Eindruck, daß die Amerikaner nicht länger ihr Schicksal auf Gedeih und Verderb mit ihren Verbündeten verbinden wollten ${ }^{24}$. Der amerikanische Strategiewechsel hatte den von den USA unerwünschten Effekt, daß dadurch der Wunsch der europäischen Verbündeten nach der Verfügungsgewalt über nukleare Waffen noch verstärkt wurde. Von Washington unabhängige Atomstreitmächte widersprachen zwar der nuklearen Verteidigungsplanung, doch waren sie für die Europäer „ein unverzichtbares Element der Rückversicherung - eben weil sie nicht sicher sein konnten, wann und unter welchen Bedingungen die USA Nuklearwaffen zu ihrer Verteidigung einsetzen würden" 25 .

Auch de Gaulle sah in der neuen Militärdoktrin ein Indiz für die Lockerung des Bündnisses zwischen den USA und Europa. Immer stärker verfestigte sich bei ihm die Überzeugung, daß die Europäer nicht länger auf die amerikanische Sicherheitsgarantie zählen durften. Angesichts der Tatsache, daß es der UdSSR inzwischen möglich war, einen umfassenden atomaren Schlag gegen die USA zu führen, prophezeite der französische Staatspräsident, daß die Amerikaner bei einem auf Europa begrenzten Angriff trotz aller gegenteiligen Beteuerungen ihre Atomwaffen nicht zum Einsatz bringen würden. In der Forderung, die Europäer müßten die Zahl ihrer Streitkräfte erhöhen, sah er eine Bestätigung seiner These, daß die Vereinigten Staaten einen Konflikt mit der Sowjetunion auf einen konventionellen Krieg zu begrenzen suchten. Ein derartiges Vorhaben hielt der General jedoch für „illusorisch“. Erstens waren die Europäer in einer konventionellen Auseinandersetzung dem Warschauer Pakt hoffnungslos unterlegen; zweitens war er davon überzeugt, daß bei einer militärischen Auseinandersetzung zwischen NATO und Warschauer Pakt zwangsläufig Atomwaffen eingesetzt würden - spätestens, wenn diese für eine Seite das letzte Mittel waren, um einer drohenden Niederlage zu entgehen. Ließen sich die Europäer auf die amerikanische Strategie ein, so folgerte de Gaulle, bliebe ihnen nur die Wahl, entweder eine sowjetische Herrschaft über Westeuropa oder die völlige Zerstörung des Kontinents in Kauf zu nehmen. Er zog daraus den Schluß, Frankreich müsse eine unabhängige Nuklearmacht aufbauen, um über ein eigenes Abschreckungsmittel zu verfügen. Diese Force de frappe sollte ihre Wirkung auf der Grundlage des bisherigen NATO-Konzepts der massive retaliation entfalten. Denn nach der Auffassung

22 Vgl. HAFTENDORN, Sicherheit, S. 180.

$23 \mathrm{Vgl}$. KISSINGER, Was wird aus der westlichen Allianz?, S. $123 \mathrm{f}$.

24 Vgl. Besson, Die Außenpolitik der Bundesrepublik, S. 252.

25 HAFTENDORN, Sicherheit, S. 107. 
des Generals war ein potentieller Gegner am wirksamsten von einem Angriff abzuhalten, wenn er mit dem unverzüglichen Einsatz des gesamten Nuklearpotentials des angegriffenen Staates rechnen mußte ${ }^{26}$. Die Größe und Stärke der Force de frappe spielten dabei für ihn eine untergeordnete Rolle: „Einmal töten zu können reiche aus. " ${ }^{27}$ Ein integrativer Ansatz, wie ihn das Konzept einer multilateralen Atomstreitmacht vorsah, war für ihn keine echte Alternative. Das Projekt erhöhte seines Erachtens die Sicherheit der Europäer nicht, da die Amerikaner nicht dazu bereit waren, ihre Kernwaffen mit ihren Verbündeten zu teilen. De Gaulle prophezeite, daß sie sie zwar eventuell den Europäern zur Verfügung stellen, sich jedoch die Entscheidung über ihren Einsatz vorbehalten würden. Angesichts des amerikanisches Vetorechts wäre der kollektiven Besitz von Nuklearwaffen somit nur eine „Fiktion“ 28 .

Um den Zusammenhalt im Bündnis zu stärken und den Bedenken der Europäer Rechnung zu tragen, wurde im Sommer 1962 von der amerikanischen Regierung in Erwägung gezogen, Eisenhowers Pläne einer multilateralen Atomstreitmacht wiederzubeleben ${ }^{29}$. Die Kuba-Krise, die Ende Oktober 1962 ihren Höhepunkt erreichte, ließ die Befürworter des MLF-Projekts jedoch wieder in Dekkung gehen. Die größte Krise des Kalten Krieges hatte den USA erneut das Erfordernis eines breiten Spektrums von Handlungsoptionen vor Augen geführt, um in einer Konfliktsituation auf jede Entwicklung flexibel reagieren zu können. Die Krise bestärkte zudem die Kennedy-Regierung in ihrer Überzeugung, einer weiteren atomaren Proliferation entgegenzuwirken. Die Einsicht, wie nahe die Welt

$26 \mathrm{Zu}$ de Gaulles verteidigungspolitischen Überlegungen vgl. besonders DE GAULLE, Mémoires d'espoir, S. 215-220. Vgl. auch ADENAUER, Erinnerungen IV, S. 168-171, sowie seine Ausführungen gegenüber Adenauer am 22. 9. 1963 in Rambouillet und gegenüber Erhard am 21. 11. 1963 in Paris, in: AAPD 1963, Dok. 352, S. 1205 f., bzw. Dok. 423, S. 14721477.

27 Ebenda, Dok. 423, S. 1473. De Gaulle erläuterte seine strategischen Vorstellungen erstmals ausführlich in einer richtungsweisenden Rede in der Militärschule Les Centres am 3. 11. 1959. Dort begründete er die Notwendigkeit einer eigenen Verteidigung, inklusive eigener Kernwaffen, und erteilte dem Prinzip der Integration der verschiedenen nationalen Streitkräfte, wie es innerhalb der NATO durchgeführt wurde, eine Absage. Gleichzeitig unterstrich er seinen Willen, die Zusammenarbeit mit den Verbündeten fortzusetzen. Vgl. DE GAULle, Mémoires d'espoir, S. 220 und S. 230-232.

28 Zitiert nach ADENAUER, Erinnerungen IV, S. 171. Vgl. auch das Gespräch des Bundeskanzlers Erhard mit Staatspräsident de Gaulle am 21.11. 1963 in Paris, in: AAPD 1963, Dok. 423, S. 1470-1478, besonders S. 1473.

29 Zur Geschichte des MLF-Projekts vom Dezember 1961 bis zum Sommer 1962 vgl. Hoppe, Zwischen Teilhabe und Mitsprache, S. 63-87. Bereits am 17. 5. 1961 hatte sich Kennedy vor dem kanadischen Parlament in Ottawa für die Bildung einer NATO-Atomflotte ausgesprochen, jedoch an ihre Realisierung derart viele Bedingungen geknüpft, daß es "mehr als unwahrscheinlich [war], daß die Forderungen Kennedys erfüllt werden könnten“. Vgl. ebenda, S. 52. Der Präsident verlangte nämlich von den europäischen Verbündeten eine konventionelle Aufrüstung in großem Umfang. Außerdem sollten sich die Europäer zunächst eindeutig für die MLF aussprechen und sich noch vor ihrer Realisierung über die Richtlinien der Einsatzkontrolle einigen, die den Interessen aller Beteiligten (also auch denen der USA!) gerecht werden sollten. Eine derartige Einigung war aber angesichts der zumeist negativen Beurteilung der neuen amerikanischen Militärstrategie durch die Europäer nicht zu erwarten. Vgl. ebenda, S. $51 \mathrm{f}$. 
am Rand eines Atomkriegs getaumelt war, ließ auch in Moskau die Bereitschaft wachsen, über eine Abgrenzung der Interessensphären und eine Politik der friedlichen Koexistenz zu verhandeln ${ }^{30}$. Die USA ergänzten deshalb ihre Strategie der flexible response um eine Politik der Rüstungskontrolle (arms control), um so die Wahrscheinlichkeit eines militärischen Konfliktes zu verringern. In einem Dialog mit der Sowjetunion sollte eine „kooperative Rüstungsteuerung“ zur Verhinderung eines Nuklearkriegs zwischen den Supermächten entwickelt werden. Ebenso wie das Konzept der beweglichen Antwort erforderte aber auch die Politik der arms control, auf eine Weitergabe von Atomwaffen innerhalb der beiden Bündnissysteme zu verzichten, um mittels einer Zentralisierung der Befehlsgewalt die Gefahr einer ungewollten nuklearen Auseinandersetzung zu reduzieren ${ }^{31}$. Wenn im Westen wie im Osten nur jeweils ein Mann über den Einsatzbefehl verfügte, dann konnte in einer Krisensituation durch eine rasche Kontaktaufnahme auf höchster Ebene eine weitere Eskalation eventuell vermieden werden. Aus diesem Grund vereinbarten Washington und Moskau am 20. Juni 1963, eine ständige Telefonverbindung zwischen dem Weißen Haus und dem Kreml, den sogenannten beißen Drabt, einzurichten ${ }^{32}$.

Helga Haftendorn weist zu Recht darauf hin, daß die amerikanische Politik der Rüstungskontrolle implizit die Akzeptierung des Status quo sowohl durch die USA wie durch die UdSSR voraussetzte. Die Möglichkeit, daß der Kalte in einen heißen Krieg umschlug, war nur zu reduzieren, wenn das bestehende Kräfteverhältnis zwischen den beiden Bündnissystemen nicht länger in Frage gestellt wurde, vor allem nicht mehr am neuralgischsten Punkt, in Mitteleuropa. Jeder Versuch, eine Veränderung der politischen Situation zu erreichen, hätte sich kontraproduktiv auf das Ziel dieser Politik, die Gefahr einer militärischen Konfrontation zu verringern, ausgewirkt ${ }^{33}$. Schon Waldemar Besson erkannte den fundamentalen Widerspruch zwischen der neuen amerikanischen Verteidigungsdoktrin und der Bonner Deutschland-Politik. Letztere zielte bekanntlich auf eine Veränderung der politischen Lage an ihrer sensibelsten Stelle, nämlich genau an der Schnittstelle zwischen NATO und Warschauer Pakt. Die Bundesrepublik geriet folglich mit ihrem Wunsch nach Wiedervereinigung zwangsläufig in Konflikt mit der amerikanischen Politik, die um den globalen Frieden zu erhalten, eine Abgrenzung der Interessensphären mit der Sowjetunion anstrebte ${ }^{34}$. Sie mußte damit rechnen, daß Washington sich von der gemeinsamen Deutschland-Politik distanzierte, da sie in Widerspruch zu dem amerikanischen Vorhaben stand, die Spannungen zwischen den Supermächten abzubauen. $\mathrm{Da}$ aber ohne die Unterstützung der USA die Teilung Deutschlands nicht zu überwinden war, war Bonn gezwungen, sich an den neuen Kurs anzupassen, um die amerikanische Rückendeckung

30 Vgl. ebenda, S. 87-91.

31 HAFTENDORN, Sicherheit, S. 181. Vgl auch ebenda, S. $189 \mathrm{f}$.

32 Für den Wortlaut des amerikanisch-sowjetischen Vereinbarung vom 20.6. 1963 über die Einrichtung einer direkten Nachrichtenverbindung vgl. EUROPA-ARCHIV 1963, D 391393.

33 Vgl. HAFTENDORN, Sicherheit, S. 189-191 und S. 197-199.

34 Vgl. Besson, Die Außenpolitik der Bundesrepublik, S. 250. 
nicht zu verlieren. Die Veränderungen in der amerikanischen Militärstrategie hatten zudem schwerwiegende Auswirkungen auf die sicherheitspolitische Lage der Bundesrepublik. Man befand sich in einer geographischen und strategischen Frontstellung gegenüber dem Warschauer Pakt. Im Falle einer militärischen Konfrontation würde der westliche Teil Deutschlands das Schlachtfeld bilden. Durch die Aufgabe der Doktrin der massiven Vergeltung entstand jedoch für die Bundesrepublik eine Sicherheitslücke, da sie nicht länger darauf bauen konnte, daß die USA einen sowjetischen Angriff auf ihren deutschen Verbündeten mit einem atomaren Gegenschlag beantworten würden. In Bonn war deshalb der Wunsch nach einer nuklearen Teilhabe besonders stark ausgeprägt.

\section{Das MLF-Projekt und andere Konzeptionen einer nuklearen Teilhabe der Bundesrepublik}

Die Zweifel der Bundesregierung an der Sicherheitsgarantie der USA wurden durch die amerikanische Reaktion auf den Bau der Berliner Mauer im Sommer 1961 verstärkt. Bonn klagte nun immer nachdrücklicher eine stärkere Beteiligung an den nuklearen Entscheidungen der Vereinigten Staaten ein ${ }^{35}$. Aber nicht nur aus Sicherheits-, sondern auch aus Prestigegründen strebte Adenauer eine nukleare Teilhabe an: „Wenn wir bei den Atom- und anderen modernen Waffen kein Mitspracherecht bekommen, werden wir zwangsläufig und unaufholbar eine Macht dritten Ranges werden. " 36 Der Kanzler sah in seinem Drängen nach einem Mitbesitz an Nuklearwaffen keinen Widerspruch zu seiner am 1. Oktober 1954 auf der Londoner Neun-Mächte-Konferenz abgegebenen Erklärung, derzufolge die Bundesrepublik keine ABC-Waffen herstellen werde ${ }^{37}$. Im November 1961 machte er Kennedy darauf aufmerksam, daß der damalige amerikanische Außenminister Dulles der Selbstverpflichtung der Bundesrepublik mündlich die Klausel rebus sic stantibus hinzugefügt hatte ${ }^{38}$. Der atomare Verzicht Bonns sei also nicht für alle Zeiten festgeschrieben, sondern nur gültig, solange sich die Geschäftsgrundlage nicht ändern würde. Zudem war Adenauer der Ansicht, daß damals nur von einem Produktionsverbot die Rede gewesen war. Somit sei weder die Lagerung von $\mathrm{ABC}$-Waffen auf dem Territorium der Bundesrepublik durch andere Staaten, noch der Einsatz dieser Waffen durch die Bundeswehr verboten ${ }^{39}$. Der Präsident interpretierte die Ausführungen des Kanzlers dahingehend, daß dieser

$35 \mathrm{Vgl}$. HOPpe, Zwischen Teilhabe und Mitsprache, S. 52-58.

36 OSTERHELD, „Ich gehe nicht leichten Herzens ...", S. 176.

37 Die von Adenauer abgegebene Erklärung wurde Bestandteil der Pariser Verträge vom 23. 10. 1954. Für den Wortlaut vgl. EUROPA-ARCHIV 1954, S. $6979 \mathrm{f}$.

38 Vgl. FRUS 1961-1963, XIV, Dok. 218, S. 616. Nachdem Adenauer am 1. 10. 1954 erklärt hatte, die Bundesrepublik werde auf ABC-Waffen verzichten, bemerkte Dulles: „Herr Bundeskanzler, Sie haben soeben erklärt, daß die Bundesrepublik Deutschland auf die Herstellung von $A B C$-Waffen im eigenen Land verzichten wolle. Sie haben diese Erklärung doch so gemeint, daß Sie - wie alle völkerrechtlichen Erklärungen und Verpflichtungen - nur rebus sic stantibus gilt!“ Der Kanzler entgegnete darauf: „Sie haben meine Erklärung richtig interpretiert!" Vgl. ADENAUER, Erinnerungen II, S. 347. Vgl. auch SCHWARZ, Adenauer und die Kernwaffen, S. 578.

39 Vgl. FRUS 1961-1963, XIV, Dok. 221, S. 626. 
mit dem Gedanken spielte, notfalls eigene Atomwaffen anzuschaffen. Er bestand darauf, daß Bonn sich an die Verzichtserklärung halte, solange die NATO existiere und die USA Atomwaffen in der Bundesrepublik stationiert habe. Durch den Besitz von Kernwaffen würde die Bundesrepublik nicht ihre Sicherheit, sondern die Gefahr eines Weltkrieges dramatisch erhöhen, warnte der Präsident nachdrücklich ${ }^{40}$. Kennedy stellte unmißverständlich klar, daß die USA eine Proliferation von Nuklearwaffen entschieden ablehnten, versicherte jedoch, er wolle sich um eine für alle befriedigende Lösung im Rahmen der NATO bemühen. Mit dieser Zusage gab sich Adenauer zufrieden ${ }^{41}$.

Die Befürchtung des Präsidenten, die Bundesrepublik könnte eigene atomare Ambitionen entwickeln, war jedoch unnötig. Aufgrund der deutschen Vergangenheit dachte man in Bonn nicht daran, Nuklearwaffen in eigener Regie zu produzieren ${ }^{42}$. Innerhalb des Kabinetts war man sich aber einig, daß das westliche Atommonopol der USA beendet werden müßte. Verteidigungsminister Strauß erläuterte am 29. November 1961 in einer Rede an der Georgetown-Universität das Bedürfnis nach einer nuklearen Teilhabe ${ }^{43}$. Wie ernst es Bonn mit dieser Forderung war, zeigte die Regierungserklärung, die am selben Tag abgegeben wurde. Dort strich die Bundesregierung heraus, daß eine Neuordnung des atomaren Verhältnisses zwischen Europa und den Vereinigten Staaten Priorität haben müsse. Das Projekt einer NATO-Atommacht sollte „baldmöglichst“ realisiert werden. Gleichzeitig erfüllte man die amerikanische Forderung nach einer Vergrößerung der Bundeswehr, indem die Wehrpflicht von 15 auf 18 Monate Dienstzeit heraufgesetzt wurde ${ }^{44}$. Die Bundesregierung nahm aber nicht öffentlich Stellung, welchem der beiden zur Diskussion stehenden Konzepte einer NATO-Atomstreitmacht sie den Vorzug gab. Intern favorisierte man aus strategischen und politischen Gründen Herters MLF-Plan. Wie schon ausgeführt, sah dieser im Gegensatz zum Norstad-Plan vor, die atomaren Mittelstreckenraketen, mit denen die Allianz ausgerüstet werden sollte, nicht auf dem Festland, sondern auf Schiffen oder U-Booten zu stationieren. Militärexperten hielten dies für vorteilhafter, weil dadurch die Verteidigung Westeuropas an strategischer Tiefe gewann. Außerdem fürchtete man in Bonn, daß die Aufstellung einer größeren Zahl von Atomwaffen auf dem Boden der Bundesrepublik, wie sie der Norstad-Plan vorsah, in der Bevölkerung auf starken Widerstand stoße ${ }^{45}$. Mit der MLF ließ sich zudem die Sicherheitslücke der Bundesrepublik schließen. Bislang, so argumentierten die Befürworter der MLF, konnte die UdSSR darauf spekulieren, daß die USA bei einem auf Europa begrenzten Angriff des Warschauer Pakts ihre Atomwaffen nicht einsetzen würden. Sollte die multilaterale Atomflotte aber Wirklichkeit werden, dann mußte Moskau im Falle eines Konflikts die Abfeuerung von

40 Vgl. ebenda, Dok. 218, S. $616 \mathrm{f}$.

41 Vgl. das Schreiben Kennedys an Macmillan vom 22. 11. 1961, in: ebenda, Dok. 222, S. 633.

42 Vgl. SCHWARZ, Adenauer II, S. $813 \mathrm{f}$.

43 Für den Wortlaut vgl. BuLlETIN 1961, S. 2097-2101.

44 BT STENOGRAPHISCHE BERICHTE, Bd. 50, S. 32.

$45 \mathrm{Vgl}$. Hoppe, Zwischen Teilhabe und Mitsprache, S. 59. 
Waffen der MLF aufgrund der Beteiligung der Europäer ernsthaft in Betracht ziehen $^{46}$.

Die Umstellung der amerikanischen Militärstrategie auf die neue Doktrin der beweglichen Antwort führte indes dazu, daß die USA zunächst beide Beteiligungskonzepte auf die lange Bank schoben ${ }^{47}$. Das Kommuniqué der NATO-Ministerratstagung in Athen vom 6. Mai 1962 enthielt zwar ein Angebot der Vereinigten Staaten, der Allianz Atom-U-Boote der Polaris-Klasse zur Verfügung zu stellen $^{48}$, dem Projekt einer NATO-Atommacht hatte der amerikanische Verteidigungsminister McNamara in der griechischen Hauptstadt aber mehr oder weniger eine Absage erteilt. Er bot dafür an, die Europäer erstmals detailliert über die nukleare Einsatzplanung der USA aufzuklären. Außerdem schlug er vor, Richtlinien über den Einsatz der amerikanischen Atomwaffen auszuarbeiten. Diese sogenannten „Athener nuclear guidelines" legten fest, daß der amerikanische Präsident in letzter Instanz über die Anwendung nuklearer Waffen entscheiden, aber zuvor die NATO-Partner konsultieren würde. Nur in dem Fall, daß dafür keine Zeit bliebe, sollte der Präsident eigenmächtig handeln ${ }^{49}$.

Die guidelines waren für die Bundesrepublik aber kein Ersatz für eine NATOAtomstreitmacht. Als Rusk am 22. Juni 1962 in Bonn mit Adenauer und Schröder zusammentraf, bekräftigte sein deutscher Amtskollege das fortbestehende Interesse Bonns an einer nuklearen Teilhabe. Er regte an, die Ausarbeitung einer gemeinsamen Nuklearstrategie im Rahmen der NATO mit dem Aufbau eines Systems der nuklearen Zusammenarbeit zu verbinden. Rusk hingegen versuchte, die Zweifel der Bundesregierung, ob die USA im Falle eines sowjetischen Angriffs Europa atomar verteidigen würden, auszuräumen und verwies auf die amerikanische These von der Unteilbarkeit der europäischen und der amerikanischen Sicherheit. Erneut unterstrich er in diesem Zusammenhang, die Vereinigten Staaten seien strikt gegen die Entstehung von unabhängigen Atompotentialen in Europa. Hinsichtlich der von Bonn gewünschten multilateralen Atomstreitmacht hatte der amerikanische Außenminister nichts Erfreuliches mitzuteilen. Er gab zu, daß Washington dieses Projekt eigentlich nicht weiter verfolgen wolle, da man in den guidelines sowie in der in Athen vereinbarten, verstärkten nuklearstrategischen Konsultation ein Äquivalent sehe. Rusk fügte aber hinzu, das Projekt sei noch nicht endgültig aufgegeben worden. Dies wäre erst dann der Fall, wenn zwei führende Mitglieder der NATO dagegen Stellung bezögen ${ }^{50}$. Im Falle einer Durchführung des Projekts müßten die Europäer allerdings den Hauptteil der Kosten übernehmen, da die USA sich nicht für ein Vorhaben finanziell verausgaben könnten, das

46 ZeitZeugenbefragung Krapf.

$47 \mathrm{Vgl}$. HOPPE, Zwischen Teilhabe und Mitsprache, S. 60-62.

48 Vgl. DzD IV/8, S. 483-486, besonders S. 485.

49 Vgl. Hoppe, Zwischen Teilhabe und Mitsprache, S. 65 f. McNamaras Rede war somit der erste Versuch, anstelle einer physischen Beteiligung an Kernwaffen die europäischen NATO-Mitgliedstaaten an der nuklearen Einsatzplanung zu beteiligen. Vgl. NITZE, From Hiroshima to Glasnost, S. 212.

50 Vgl. FRUS 1961-1963, XIII, Dok. 145, S. 420 f. 
sie gar nicht wollten ${ }^{51}$. Der amerikanische Außenminister ließ aber zum Schluß anklingen, daß die USA das Projekt positiver beurteilen würden, falls Großbritannien Mitglied der EWG werde ${ }^{52}$. Trotz des offensichtlich geringen Interesses der Amerikaner an dem Zustandekommen einer multilateralen Atomstreitmacht verfolgte die Bundesregierung den Plan weiter. Auch in der Öffentlichkeit trat Schröder jetzt verstärkt für eine nukleare Teilhabe der Bundesrepublik ein ${ }^{53}$. Als großen Pluspunkt dieses Projekts hob er dabei die Stärkung des Zusammenhalts der NATO-Partner durch eine Beteiligung an der Kontrolle und dem Einsatz von Atomwaffen hervor ${ }^{54}$.

Die Beteiligung der Bundesrepublik an einer Atomstreitmacht der NATO war aber nicht die einzige Möglichkeit, um in die Nähe der Kontrolle über Kernwaffen zu gelangen. Angesichts der Annäherung zwischen Bonn und Paris schien auch eine Partizipation an der im Aufbau befindlichen französischen Atommacht denkbar. Diese Frage stand im Mittelpunkt einer gemeinsamen Besprechung von hohen Beamten des Auswärtigen Amts und des Bundesverteidigungsministeriums am 1./2. Juni 1962. Die Experten der beiden Ministerien verwiesen jedoch auf die „schwerwiegende[n] Nachteile“ einer deutsch-französischen Kooperation im Bereich der nuklearen Verteidigung. Die Sicherheit der Bundesrepublik werde dadurch nicht erhöht, sondern erheblich gemindert, weil eine derartige Zusammenarbeit die Beziehungen zu den Vereinigten Staaten schwer belasten und die NATO schwächen würde. Bonn riskierte dadurch, die Unterstützung der USA zu verlieren, die als einzige die Bundesrepublik effektiv schützen konnten, und statt dessen „in eine untragbare Abhängigkeit von Frankreich“ zu geraten. Der westliche Nachbar, so die einhellige Meinung, sei aber wegen seiner „politische[n] und militärischen[n] Schwäche [...] kein auch nur annähernder Ersatz für den Verlust des Bündnispartners USA“. Der Bundesregierung wurde deshalb nahegelegt, einer nuklearen Zusammenarbeit mit Paris nicht zuzustimmen, falls die französische Regierung ein derartiges Angebot unterbreiten sollte ${ }^{55}$.

Damit hatte man sich auf eine Lösung im Rahmen der NATO festgelegt. Doch in den nächsten Monaten gab es keinerlei Bewegung in dieser Frage. Als sich im Herbst 1962 jedoch die Perspektive einer engen deutsch-französischen Zusammenarbeit abzeichnete, beabsichtigte die amerikanische Regierung, die MLFPläne wieder aus der Schublade zu holen. Die Angst vor einer Hinwendung Bonns zu de Gaulle brachten die USA zu der Einsicht, die Bundesrepublik dürfe im nuklearen Bereich nicht diskriminiert werden. Die Kuba-Krise verzögerte aber eine Wiederbelebung des Projekts. Andererseits hatte aber gerade dieser dramatische Höhepunkt im Kalten Krieg das Verlangen der Bundesrepublik nach einer nuklea-

51 „[...] the US should not pay a disproportionate part of the cost of a multilateral force which is being built for political reasons arising elsewhere." Vgl. ebenda, S. 421.

$52 \mathrm{Vgl}$. ebenda.

53 Vgl. Schröders Interview mit dem WDR am 24.6. 1962 sowie mit dem NDR am 15.7. 1962, in: BULlETIN 1962, S. 981 bzw. S. $1113 \mathrm{f}$.

54 Vgl. das Interview Schröders mit dem NDR am 15. 7. 1962, in: ebenda, S. $1113 \mathrm{f}$.

55 Ergebnis der Besprechungen in Haus Giersberg, Münstereifel, vom 1./2. 6. 1962 (Gemeinsame Fassung AA/BMVtdg), Bonn, 15.6. 1962. Zitiert nach HOPPE, Zwischen Teilhabe und Mitsprache, S. 70. 
ren Teilhabe genährt, da Bonn vor Augen geführt wurde, wie leicht für die Europäer die Gefahr bestand, in einen Nuklearkrieg verwickelt zu werden, selbst wenn die Supermächte weit entfernt vom europäischen Kontinent aneinandergerieten ${ }^{56}$. Die divergierende Interessenlage wurde bei einer Besprechung zwischen Kennedy und Adenauer am 14. November 1962 in Washington offenkundig. Zwischen den beiden Politikern kam es zum Streit, als der Kanzler den Gedanken vortrug, die Bundeswehr mit taktischen Atomwaffen auszurüsten, damit sie gegenüber der Roten Armee nicht länger im Nachteil sei. Kennedy überhörte die Idee zunächst. Als aber der Kanzler nicht locker ließ, belehrte ihn der Präsident, man hätte bereits genügend Truppen, die über Atomwaffen verfügten. Er appellierte an Adenauer, statt dessen für eine Verstärkung der konventionellen Streitkräfte zu sorgen, damit man bei einem sowjetischen Angriff nicht auf atomare Waffen zurückgreifen müßte. Wäre die Schwelle zum Nuklearkrieg nämlich erst einmal überschritten, dann bestünde die Gefahr einer raschen Eskalation, warnte Kennedy ${ }^{57}$.

Erst das sogenannte Nassau-Abkommen zwischen den USA und Großbritannien vom 21. Dezember 1962 führte dazu, daß das Projekt einer multilateralen Atomstreitmacht wiederbelebt wurde. Kennedy hatte sich am 18. Dezember auf die Bahamas-Inseln begeben, um dort mit Macmillan die gemeinsame Nuklearkooperation zu erörtern. Das Treffen war notwendig geworden, da sich der Präsident entschlossen hatte, die Entwicklung der atomaren Luft-Boden-Mittelstrekkenrakete Skybolt zu stoppen und dafür die modernere, weil auf Schiffen oder UBooten stationierbare, Polaris-Rakete zu entwickeln. Zwei Jahre zuvor hatte Präsident Eisenhower jedoch London die Lieferung amerikanischer Skybolt-Raketen zugesagt, die der britischen Luftwaffe als Ersatz für ihre veralteten Vulkan-Bombenflugzeuge dienen sollten. In Nassau einigten sich Kennedy und Macmillan, daß den Briten die Polaris- anstelle der Skybolt-Rakete zur Verfügung gestellt werde ${ }^{58}$. Die britische Atomstreitmacht sollte dafür mit Teilen der amerikanischen Atomstreitmacht kombiniert werden und den Grundstock einer NATOAtomstreitmacht bilden (Ziffer 6 des Nassau-Abkommens). Beide Regierungen bekannten sich zu dem Ziel, die Bildung einer solchen, gemeinsamen Atomstreitmacht in die Wege zu leiten (Ziffer 7 des Nassau-Abkommens). Nur wenn „höchste nationale Interessen auf dem Spiel“ stünden, könnte die britische Regierung über ihr Kontingent verfügen (Ziffer 8 des Nassau-Abkommens) ${ }^{59}$. Die Verbindlichkeit des Beschlusses, die britische Atommacht unter den Befehl der NATO zu stellen, war aber umstritten. Die Formulierung der Ziffer 7 ließ sich sowohl als Verpflichtung wie als Absichtserklärung lesen ${ }^{60}$. Gleichfalls vage waren die Aus-

56 Vgl. ebenda, S. 76-98.

57 Vgl. FRUS 1961-1963, XIII, Dok. 157, S. 450-454.

$58 \mathrm{Zu}$ den Besprechungen zwischen Macmillan und Kennedy in Nassau vom 18. bis 21. 12. 1962 vgl. ebenda, Dok. 402-410, S. 1091-1123. Zu den Hintergründen vgl. ClaRK, Nuclear Diplomacy and the Special Relationship, S. 338-373 und S. 404-418; BuNDY, Danger and Survival, S. 490-494; SCHRAFSTETTER, Die dritte Atommacht, S. 100-106.

59 Für den Wortlaut des Kommuniqués über die Besprechungen zwischen Premierminister Macmillan und Präsident Kennedy vom 18. bis 21. 12. 1962 auf den Bahamas (Nassau-Abkommen) vgl. EUROPA-ARCHIV 1963, D 30-32.

$60 \mathrm{Vgl}$. Hoppe, Zwischen Teilhabe und Mitsprache, S. 93. 
sagen über die Gestalt der künftigen Atomstreitmacht der NATO. Das Abkommen ließ offen, ob die Flotte multinational oder multilateral aufgebaut sein sollte: Multinational bedeutete die Zusammenlegung einzelner nationaler Komponenten; unter multilateral verstand man dagegen gemeinsame Besatzungen der beteiligten Staaten auf den einzelnen Schiffen, also gemischt-nationale Mannschaften. Es waren wohl diese unpräzisen Bestimmungen des Abkommens, die den Stellvertreter des amerikanischen Außenministers, Ball, zu dem Urteil veranlaßten, es habe sich bei der Nassauer Konferenz um eines der am schlechtesten vorbereiteten Gipfeltreffen der Zeitgeschichte gehandelt ${ }^{61}$.

Noch am Tag der Rückkehr Kennedys nach Washington wies Rusk den Ständigen Vertreter der USA bei der NATO in Paris, Thomas Finletter, an, Schröder zu übermitteln, daß die amerikanische Regierung im Nassau-Abkommen die europäischen und besonders die Interessen Bonns voll berücksichtigt habe. Der Botschafter hatte dem Außenminister außerdem mitzuteilen, daß das MLF-Projekt ab Januar gemeinsam mit den Verbündeten im Ständigen NATO-Rat diskutiert werde und daß Rusk hoffe, die Bundesrepublik werde dabei eine aktive Rolle spielen. An der geplanten Atomstreitmacht könnten sich alle Nicht-Nuklearstaaten des Bündnisses beteiligen, wobei man vor allem auf eine Teilnahme Frankreichs großen Wert lege. Washington hätte de Gaulle bereits das Angebot gemacht, mit der amerikanischen Regierung eine dem Nassauer Abkommen vergleichbare Vereinbarung zu schließen ${ }^{62}$.

Dieser war aber nicht bereit, darüber auch nur zu diskutieren, denn Frankreich hätte durch eine solche Vereinbarung die alleinige Verfügungsgewalt über die Force de frappe aufgegeben. In seinen Augen hatte Großbritannien mit dem Nassau-Abkommen auf eine selbständige Nuklearverteidigung verzichtet und sich ohne Notwendigkeit in die Abhängigkeit Washingtons begeben. Für den General war es unvorstellbar, das Schicksal seines Landes in die Hände der Amerikaner zu legen ${ }^{63}$. Er war zudem verstimmt, daß Macmillan, mit dem er unmittelbar vor dessen Begegnung mit Kennedy am 15./16. Dezember 1962 auf Schloß Rambouillet Besprechungen geführt hatte, an einem gemeinsamen Nuklearprojekt nicht interessiert gewesen war ${ }^{64}$. De Gaulle hielt es für ungeheuerlich, daß Großbritannien zum gleichen Zeitpunkt, da es die Mitgliedschaft in den europäischen Gemeinschaften anstrebte, ohne vorherige Konsultation seiner europäischen Verbündeten eine Sondervereinbarung mit Washington über Nuklearwaffen traf ${ }^{65}$. Auf seiner

61 Vgl. Ball, The Past has Another Pattern, S. 265.

62 Vgl. FRUS 1961-1963, XIII, Dok. 162, S. 467 f.; Ball, The Past has Another Pattern, S. 268. Zu dem Angebot an Frankreich vgl. BunDY, Danger and Survival, S. 492-494; Bozo, Deux stratégies pour l'Europe, S. $99 \mathrm{f}$. Vgl. auch den Drahtbericht des Gesandten Knodtke, Paris, an das Auswärtige Amt vom 27. 12. 1962, in: BDFD, I, Dok 307, S. $921-$ 924.

63 Vgl. dazu das Gespräch des Bundeskanzlers Adenauer mit Staatspräsident de Gaulle am 21. 1. 1963 in Paris, in: AAPD 1963, Dok. 37, S. 115 f. Vgl. auch BozO, Deux stratégies pour l'Europe S. 100f.; SCHMITT, Frankreich und die Nukleardebatte der Atlantischen Allianz, S. 150-153.

64 Vgl. das Gespräch des Bundeskanzlers Adenauer mit Staatspräsident de Gaulle am 21. 1. 1963 in Paris, in: AAPD 1963, Dok. 37, S. 116.

65 Vgl. das Gespräch des Bundeskanzlers Adenauer mit Staatspräsident de Gaulle am 22.1. 
berühmten Pressekonferenz am 14. Januar 1963 in Paris lehnte er deshalb nicht nur die Aufnahme Großbritanniens in die EWG, sondern auch eine Beteiligung Frankreichs an der MLF ab.

Mit Ausnahme Norwegens und Dänemarks reagierten die anderen europäischen NATO-Mitglieder dagegen auf das amerikanische Angebot zunächst positiv66. Der italienische Außenminister Attilio Piccioni teilte am 12. Januar 1963 Schröder mit, Italien wolle „als voll integriertes Mitglied an der NATO-Nuklearstreitmacht" teilnehmen ${ }^{67}$. Auch die Bundesregierung begrüßte erwartungsgemäß das Nassau-Abkommen. Gegenüber Lord Home äußerte sich Schröder am 8. Januar in Chequers wohlwollend über die britisch-amerikanischen Beschlüsse ${ }^{68}$. Ergänzend schlug er vor, die multilaterale Atomstreitmacht dem Oberbefehlshaber der NATO in Europa (SACEUR) zu unterstellen, damit der Einsatz der MLF "nahe genug am gefährdeten Bereich" gewährleistet wäre ${ }^{69}$. Am 14. Januar kam Ball nach Bonn, um Adenauer die Erwägungen seiner Regierung bezüglich der MLF zu erläutern. Obwohl die Frage, ob die USA auf ein Veto beim Einsatz der MLF-Atomwaffen bestehen würden, noch nicht geklärt war, stimmte der Kanzler einer Teilnahme der Bundesrepublik an dem Projekt zu ${ }^{70}$. Zwar hatte sich Adenauer bereits vor dem Gespräch mit dem amerikanischen Staatssekretär zur Mitarbeit entschlossen; ausschlaggebend für seine vorbehaltlose Zustimmung war aber, daß die Nachricht von de Gaulles Pressekonferenz, in der er sich gegen den Beitritt Großbritanniens zur EWG aussprach, während seiner Unterredung mit Ball die Runde machte ${ }^{71}$. Er hatte das Gefühl, er müßte jetzt Nägel mit Köpfen machen, um dem Unmut der Amerikaner über den geplanten deutsch-französischen Freundschaftsvertrag die Spitze zu nehmen ${ }^{72}$. Außerdem, so bekannte Ade-

1963 in Paris, in: ebenda, Dok. 43, S. 141. Macmillan behauptete im Rückblick, de Gaulle sei von ihm in Rambouillet über seine Absicht informiert worden, von den Amerikanern die Polaris-Rakete als Ersatz für Skybolt zu erbitten. Vgl. Macmillan, Memoirs VI, S. 347 f. De Gaulle äußerte hingegen am 22. 1. 1963 gegenüber Adenauer, er hätte zwar im Gespräch den Eindruck gewonnen, daß der Premierminister einen derartigen Schritt plane, jedoch: "Gesagt habe ihm Macmillan davon nichts." Vgl. AAPD 1963, Dok. 43, S. 141.

66 Vgl. die Aufzeichnung des Generalkonsuls von Schmoller vom 12.1. 1963, in: ebenda, Dok. 20, S. 66; sowie das Gespräch des Bundesministers Schröder mit dem amerikanischen Außenminister Rusk am 21. 5. 1963 in Ottawa, in: ebenda, Dok. 178, S. $582 \mathrm{f}$.

67 Runderlaß des Ministerialdirektors Jansen vom 14. 1. 1963, in: ebenda, Dok. 24, S. 79.

$68 \mathrm{Vgl}$. den Drahtbericht des Botschafters von Etzdorf, London, an Bundesminister Schröder vom 9. 1. 1963, in: ebenda, Dok. 12, S. 39-42.

69 Ebenda, S. 41. Vgl. auch Ball, The Past has Another Pattern, S. 268. Den Posten als SACEUR hatte seit dem Sommer 1962 der amerikanische General Lyman Lemnitzer als Nachfolger Norstads übernommen.

70 Vgl. OSTERHELD, „Ich gehe nicht leichten Herzens...“, S. 180. Vgl. auch das Gespräch des Bundeskanzlers Adenauer mit Staatspräsident de Gaulle am 22. 1. 1963 in Paris, in: AAPD 1963, Dok. 43, S. 139 f.

71 Vgl. Grewe, Rückblenden, S. 615.

72 Für diese These spricht ein Schreiben Adenauers an Kennedy vom 22.1.1963, in dem der Kanzler bekräftigte, mit dem Elysée-Vertrag verfolge Bonn das Ziel, die Beitrittsverhandlungen mit Großbritannien zu einem erfolgreichen Abschluß zu bringen, die Schaffung einer NATO-Atomstreitmacht zu fördern und die atlantische Gemeinschaft zu stärken. Vgl. AAPD 1963, Dok. 46, S. 153-155. 
nauer einige Monate später gegenüber de Gaulle, habe er sofort zugesagt, „um die Amerikaner festzunageln"73. Drei Motive bestimmten also das Handeln des Kanzlers: Erstens wollte er damit das Festhalten Bonns an der NATO unterstreichen, zweitens beabsichtigte er, die USA unwiderruflich auf das Projekt festzulegen, und drittens verfolgte er das Ziel, über den Mitbesitz an atomaren Waffen allmählich zur Mitbestimmung aufzurücken ${ }^{74}$. Noch am gleichen Tag gab der Chef des Presse- und Informationsamts der Bundesregierung, Staatssekretär KarlGünther von Hase, bekannt, die Bundesrepublik werde am Aufbau einer multilateralen Atomstreitmacht aktiv mitwirken ${ }^{75}$. Damit hatte sich Bonn endgültig entschieden, die nukleare Teilhabe über ein integratives System zu erreichen.

Obwohl de Gaulles militärpolitische Vorstellungen mit dem MLF-Projekt nicht in Einklang zu bringen waren, stieß er sich zunächst nicht an der Entscheidung Bonns, sich daran zu beteiligen und dadurch die militärische Zusammenarbeit mit den USA zu intensivieren ${ }^{76}$. Dies ist um so erstaunlicher, da der Staatspräsident in einer sicherheitspolitischen Kooperation den "Hauptzweck der Zusammenarbeit" zwischen Frankreich und Deutschland sah. Könnten diesbezüglich keine Fortschritte erzielt werden, werde man „auch im politischen Bereich nicht weit kommen ", prophezeite er anläßlich der Unterzeichnung des Elysée-Vertrags ${ }^{77}$. Als Adenauer jedoch für die Beteiligung Bonns an der MLF um Verständnis warb, hatte de Gaulle an dem Engagement nichts auszusetzen ${ }^{78}$. Er gestand der Bundesrepublik sogar zu, ein eigenes Nuklearprogramm zu entwickeln: „Er glaube aber, daß, wenn die nukleare Rüstung weitergehe, Deutschland eines Tages Atombomben bauen werde, und Frankreich werde Deutschland daran nicht hindern." 79

Vom 5. bis 9. März hielt sich der amerikanische Sonderbotschafter Livingston Merchant in Bonn auf, um die Bundesregierung über den aktuellen Stand der MLF-Planungen aufzuklären. Aus Kostengründen war die amerikanische Regierung inzwischen von einer reinen U-Boot-Flotte bzw. einer Beteiligung von UBooten wieder abgekommen und präferierte jetzt eine Flotte von etwa 25 gemischt-national bemannten Schiffen, die mit Polaris-Mittelstreckenraketen ausgerüstet und SACEUR unterstellt werden sollten. Im Gegensatz zu den U-Booten, deren Kosten auf 7,2 bis 8,2 Milliarden US-Dollar geschätzt wurden, veranschlagte man für die Schiffsflotte etwa 6 Milliarden US-Dollar ${ }^{80}$. Eigentlich be-

73 Gespräch des Bundeskanzlers Adenauer mit Staatspräsident de Gaulle am 22. 9. 1963 in Rambouillet, in: ebenda, Dok. 357, S. 1207.

74 Vgl. HAFTENDORN, Kernwaffen, S. 117.

75 Vgl. Bulletin 1963, S. 69.

76 Vgl. GREWE, Rückblenden, S. 619.

77 Elysée-Konferenz am 21. 1. 1963, in: AAPD 1963, Dok. 38, S. 126.

78 Vgl. das Gespräch des Bundeskanzlers Adenauer mit Staatspräsident de Gaulle am 22. 1. 1963 in Paris, in: ebenda, Dok. 43, S. 139 f.

79 Gespräch des Bundeskanzlers Adenauer mit Staatspräsident de Gaulle am 21.1.1963 in Paris, in: ebenda, Dok. 37, S. 118. De Gaulle warnte aber zugleich, daß eine solche Entscheidung der Entspannung zwischen West und Ost ein Ende setzen würde, da es für die Osteuropäer aufgrund ihrer Erfahrungen mit den Deutschen im Zweiten Weltkrieg „unerträglich" wäre, wenn die Bundesrepublik Atomwaffen besäße. Vgl. ebenda, S. $117 \mathrm{f}$.

80 Vgl. den Runderlaß des Ministerialdirektors Krapf vom 12. 3. 1963, in: ebenda, Dok. 120, S. 401. 
vorzugte die Bundesregierung Unterseeboote, da man Überwasserschiffe für zu verwundbar hielt ${ }^{81}$. Mitte April konnte aber eine amerikanische Expertendelegation unter der Leitung von Admiral Claude Ricketts die Bedenken Bonns ausräumen ${ }^{82}$. Am 24. April sprach sich das Bundeskabinett für eine aus Schiffen bestehende MLF aus und setzte fest, sich mit einem Anteil von 30\% an den Kosten zu beteiligen ${ }^{83}$.

Schröder selbst erachtete es für sekundär, ob die MLF aus Unterseebooten oder aus Schiffen bestand. Nicht der militärische Aspekt war für ihn ausschlaggebend, sondern der politische Stellenwert, der der Flotte zukam. Am 10. April 1963 führte er gegenüber seinem britischen Amtskollegen aus, er befürworte das Projekt, weil es für die europäischen Staaten „die einfachste Möglichkeit“ darstelle, sich an der Kontrolle von Nuklearwaffen zu beteiligen ${ }^{84}$. Im Gegensatz zur Force de frappe, die einen "Störungsfaktor" in der NATO bilde, würde die MLF - unter anderem durch die gemischten Besatzungen - die Integration des Bündnisses fördern und dadurch das Zusammengehörigkeitsgefühl ihrer Mitglieder stärken ${ }^{85}$. Doch Lord Home teilte die Begeisterung seines Gesprächspartners nicht. Er erklärte, im Nassau-Abkommen sei zwar die künftige NATO-Atomstreitmacht als multilateral charakterisiert worden, man habe aber damit eigentlich multi-national gemeint: „Die gemischt-bemannte Streitmacht sei darunter nicht zu verstehen gewesen." Im weiteren Verlauf des Gesprächs stellte sich heraus, daß die britische Regierung Ziffer 7 des Nassau-Abkommens, derzufolge eine multilaterale Atomstreitmacht unter Einschluß der britischen atomaren Streitkräfte aufgebaut werden sollte, nicht als verpflichtend interpretierte. Lord Home tat so, als ob in Nassau lediglich die Vereinbarung getroffen worden wäre, Teile der britischen Luftstreitkräfte und der amerikanischen strategischen Streitkräfte zu einer Inter Allied Nuclear Force (IANF) zusammenzufassen und der NATO zu unterstellen ${ }^{86}$. Diese in Ziffer 6 des Abkommens erwähnte Streitmacht sollte aus den britischen Vulkan-Bombern, drei amerikanischen Polaris-U-Booten sowie den der NATO bereits unterstellten Strike-Verbänden bestehen ${ }^{87}$. Wie Schröder richtig erkannte, erfolgte durch die IANF „praktisch nur eine gewisse Veränderung an Unterstellungsverhältnissen hinsichtlich bereits jetzt vorhandener Streitkräfte“. Sie konnte deshalb nach seiner Auffassung kein Ersatz für die MLF sein ${ }^{88}$. Doch Lord Home

81 Vgl. ebenda, S. 402.

82 Vgl. das Schreiben des Bundeskanzlers Adenauer an Präsident Kennedy vom 30. 4. 1963, in: ebenda, Dok. 156, S. 505. Vgl. auch HOPPE, Zwischen Teilhabe und Mitsprache, S. 130, Anm. 62.

83 Vgl. ebenda, S. $130 \mathrm{f}$.

84 Gespräch des Bundesministers Schröder mit dem britischen Außenminister Lord Home am 10. 4. 1963 in Paris, in: ebenda, Dok. 144, S. 473 f.

85 Ebenda, S. 475.

86 Ebenda, S. 474.

87 Vgl. die Aufzeichnung des Referats II 7 vom 2. 5. 1963, in: ebenda, Dok. 158, S. 513. Bei den Strike-Verbänden handelte es sich um F 84 und F 104-Jagdbomber-Staffeln, die für die taktische Nuklearkriegsführung vorgesehen waren. Vgl. STEINHOFF/POMMERIN, Strategiewechsel, S. 38-56.

88 Gespräch des Bundesministers Schröder mit dem britischen Außenminister Lord Home am 10. 4. 1963 in Paris, in: AAPD 1963, Dok. 144, S. 473. 
war der Meinung, die IANF reiche aus, um die NATO in dem gewünschten Maß zu stärken. Er wollte sich auf der bevorstehenden Tagung des NATO-Ministerrats in Ottawa vordringlich mit der Errichtung der IANF beschäftigen, weil die im Nassau-Abkommen erwähnte multilaterale Streitmacht „frühestens in sechs Jahren“ einsatzfähig sei. Zwar stünde London der MLF „ausgesprochen wohlwollend" gegenüber, doch hätte die britische Regierung Probleme, einen finanziellen Beitrag zum Aufbau der multilateralen Atomstreitmacht zu leisten. Der britische Außenminister stellte statt dessen in Aussicht, der IANF eines Tages eine gemischt-nationale Besatzung zu geben ${ }^{89}$. Die Regierung Macmillan hielt also im Grunde die MLF für entbehrlich und wollte sich daher keinesfalls an dem Projekt finanziell beteiligen. Schröder war aber bewußt, daß Großbritannien bei der Schaffung der MLF eine Schlüsselrolle zukam. Eine britische Mitarbeit war die Voraussetzung für eine Teilnahme anderer europäischen Staaten, wie beispielsweise Italien. Als der neue amerikanische Botschafter in Bonn, George McGhee, am 17. Mai 1963 seinen Antrittsbesuch im Auswärtigen Amt machte, verlangte Schröder deswegen von Washington unmißverständlich, darauf hinzuwirken, daß die britische Regierung das Nassau-Abkommen auch hinsichtlich der Schaffung einer gemeinsamen NATO-Atomflotte erfülle $e^{90}$.

Abgesehen von diesem Problem galt es auch noch eine Lösung zu finden, wie die Kontrolle über die atomaren Mittelstreckenraketen der MLF auszuüben sei. Kennedy wünschte definitiv keine „15 Finger am Abzugshebel“91. Die amerikanische Regierung schlug daher die Bildung eines Executive Committee als Leitungsgremium der Atomflotte vor, in dem alle beteiligten Staaten mit Sitz und Stimme vertreten sein sollten. Dieser Ausschuß hatte im Ernstfall einstimmig über den Einsatz der Atomraketen zu entscheiden ${ }^{92}$. Das war ein geschickter Schachzug des Präsidenten, denn wenn alle Beteiligten über ein Vetorecht verfügten, bestand zwar formelle Gleichberechtigung, doch konnte trotzdem nichts über die Köpfe der Amerikaner hinweg beschlossen werden. De Gaulles Prognose, „daß die Entscheidung über den Feuerbefehl immer allein in amerikanischer Hand liege"93, war damit eindrucksvoll bestätigt. Gleichwohl war die Bundesregierung bereit, das Executive Committee in der von den Vereinigten Staaten vorgeschlagenen Form zu akzeptieren, wollte aber darauf drängen, den Mehrheitsbeschluß einzuführen, sobald die MLF einsatzbereit wäre ${ }^{94}$.

Dieses Beharren der USA auf einem Vetorecht war letztlich der entscheidende Punkt, warum die britische Regierung die MLF strikt ablehnte. Am 21. Mai 1963

89 Ebenda, S. 474.

$90 \mathrm{Vgl}$. das Gespräch des Bundesministers Schröder mit dem amerikanischen Botschafter McGhee am 17. 5. 1963, in: ebenda, Dok. 172, S. 560.

91 Vgl. den Artikel „Vorerst keine Entscheidung über eine NATO-Atommacht“, in: FraNK FURTER AllgemeIne ZEITUNG vom 28. 4. 1962, S. 1.

92 Vgl. den Runderlaß des Ministerialdirektors Krapf vom 12.3. 1963, in: AAPD 1963, Dok. 120, S. 401.

93 Gespräch des Bundeskanzlers Adenauer mit Staatspräsident de Gaulle am 22.1. 1963 in Paris, in: ebenda, Dok. 43, S. 143.

94 Vgl. den Runderlaß des Ministerialdirektors Krapf vom 12. 3. 1963, in: ebenda, Dok. 120, S. 401 . 
bemühten sich der britische Verteidigungsminister Peter Thorneycroft und Außenminister Lord Home, Schröder von der Ineffizienz des Projekts zu überzeugen. Sie legten dar, daß die MLF das westliche Nuklearpotential zwar um 200 Polaris-Raketen vergrößere; aufgrund des Vetos der USA würden sie allerdings nur dann eingesetzt, wenn auch die gesamte amerikanische Atomstreitmacht den Feuerbefehl erhielte. Folglich sei das Projekt vom militärischen Standpunkt aus „unsinnig“. Außerdem bezweifelten die beiden britischen Minister das Urteil der amerikanischen Experten, die im Falle eines Angriffs mit einer Zerstörung von höchstens zehn der 25 Schiffe rechneten 95 . „Für 600 Mio. $£$ gebe es zweifellos Ausgaben von größerer Dringlichkeit“, konstatierte Thorneycroft. Schröder sperrte sich jedoch dagegen, die MLF allein nach ihrem militärischen Wert zu beurteilen. Der Bundesregierung gehe es vor allem darum, einen größeren Einfluß auf die amerikanische Atomstrategie zu erlangen und die nuklearen Verhältnisse in der NATO zu reformieren, erläuterte er seinen Gesprächspartnern ${ }^{96}$. Er sagte voraus, daß die Nicht-Nuklearstaaten der Allianz, darunter auch die Bundesrepublik, nukleare Ambitionen entwickelten, falls sie nicht stärker an der Nuklearstrategie der NATO beteiligt würden. Die Schaffung weiterer nationaler Kernwaffenpotentiale würde aber aufgrund der zu erwartenden Erosion des Atlantischen Bündnisses die Sicherheit der Europäer mindern. Ein Auseinanderfallen der NATO ließ sich nach seiner Überzeugung nur durch eine verstärkte Integration der Mitglieder verhindern. Das geeignete Mittel gegen eine derartige Entwicklung war aus seiner Sicht die MLF, weil sie auf einen integrativen Ansatz aufbaute. Des weiteren, so der Außenminister, stelle sie eine noch intensivere Verklammerung Amerikas mit dem europäischen Kontinent her und verhindere das Entstehen rivalisierender nationaler Abschreckungspotentiale, ohne selbst zur Proliferation beizutragen ${ }^{97}$. Den Einwand, daß die Europäer mit Hilfe der MLF ihr Ziel der nuklearen Teilhabe gar nicht erreichen könnten, weil die USA weiterhin die alleinige atomare Verfügungsgewalt innehätten, ließ Schröder nicht gelten. Es sei nämlich „ein großer Unterschied, ob die Amerikaner die gesamte Planung und Organisation ganz allein betrieben, oder ob die anderen Partner daran möglichst stark beteiligt seien, selbst wenn die letzte Entscheidung bei den Amerikanern verbliebe "98. In Anbetracht dieser Sachlage bezeichnete er die MLF gegenüber Thorneycroft und Lord Home als „ein notwendiges Experiment, selbst wenn es teuer sei" 99 .

Wie es der britische Außenminister angekündigt hatte, faßte der NATO-Ministerrat auf seiner Tagung in Ottawa vom 22. bis 24. Mai 1963 nur den Beschluß, die Nuklearstreitkräfte der Allianz neu zu organisieren. Auf französischen

\footnotetext{
95 Gespräch des Bundesministers Schröder mit dem britischen Außenminister Lord Home am 21. 5. 1963 in Ottawa, in: ebenda, Dok. 179, S. 585-589.

96 Ebenda, S. 587.

$97 \mathrm{Vgl}$. das Gespräch des Bundesministers Schröder mit dem kanadischen Außenminister Martin am 20. 5. 1963 in Ottawa, in: ebenda, Dok. 175, S. 575-577.

98 Ebenda, S. 576.

99 Gespräch des Bundesministers Schröder mit dem britischen Außenminister Lord Home am 21. 5. 1963 in Ottawa, in: ebenda, Dok. 179, S. 587.
} 
Wunsch wurde auf die Bezeichnung, IANF“ verzichtet ${ }^{100}$. Die amerikanische Regierung strebte zwar „eine prompte Regelung“ der MLF-Frage an, doch wollte sie angesichts der britischen Bedenken das Projekt nicht übermäßig vorantreiben, da sie auf die Mitarbeit des Königreichs großen Wert legte101. Wegen der Haltung Londons und den innenpolitischen Schwierigkeiten Italiens, wo im Moment keine handlungsfähige Regierung existierte ${ }^{102}$, konnten die Beratungen über den Gründungsvertrag der MLF - die sogenannte $M L F$-Charta - nicht wie ursprünglich vorgesehen im Juli 1963 aufgenommen werden ${ }^{103}$. Damit war der amerikanische Zeitplan, die Charta bis zum September 1963 fertigzustellen, so daß ihr der amerikanische Kongreß noch vor seiner Vertagung bis zum Januar 1964 zustimmen könnte ${ }^{104}$, hinfällig geworden.

In einer Ende Juli 1963 verfaßten Aufzeichnung warnte Botschafter Grewe die Führungsspitze des Auswärtigen Amts, die von Kennedy anläßlich seiner Europareise vom 23. Juni bis 2. Juli 1963 konstatierte derzeitige "Stagnation" des MLF-Projekts könne „unter Umständen das Scheitern dieses Projekts bedeuten“. Der Ständige Vertreter der Bundesrepublik bei der NATO machte darauf aufmerksam, daß ein Vertragsentwurf, der später als Mitte Januar 1964 dem Kongreß zugeleitet werde, aufgrund des dann einsetzenden Präsidentschaftswahlkampfs keine Chancen mehr habe, die Zustimmung des Kongresses zu finden. Man könne es sich aber nicht leisten, die MLF-Frage bis nach den amerikanischen Wahlen zu verschieben, da im Herbst 1964 in Großbritannien ein neues Unterhaus gewählt werde und mit einem Sieg der Labour-Party zu rechnen sei. Grewe prognostizierte, daß eine Labour-Regierung nicht nur eine Beteiligung an der MLF ablehnen, sondern sich bemühen würde, das Projekt in toto zu verhindern. Andererseits hinge aber die Mitarbeit Italiens von einer Teilnahme Londons ab ${ }^{105}$. Somit stehe das gesamte Vorhaben auf der Kippe. Im Falle eines Scheiterns der NATOAtomstreitmacht mußte Bonn allerdings damit rechnen, „den letzten Zeitpunkt zu verpassen, zu dem eine Beteiligung am Besitz und Gebrauch nuklearer Waffen möglich war". Eine Abwägung der Vor- und Nachteile der MLF brachte Grewe jedoch zu dem Schluß, das Projekt weise so viele Mängel auf, „daß wir seinem Einschlafen keine Träne nachzuweinen brauchten“. Der Botschafter schlug daher vor, auch Alternativen zur MLF ins Auge zu fassen, wie zum Beispiel die Schaffung einer europäischen Nuklearmacht oder eine Beteiligung der Bundesrepublik

100 Vgl. dazu den Hauserlaß des Ministerialdirektors Krapf vom 5.6. 1963, in: ebenda, Dok. 190, S. 614.

101 So Rusk am 21. 5. 1963 in Ottawa zu Schröder. Vgl. ebenda, Dok. 178, S. 582.

102 Am 16. 5. 1963 trat die Regierung Fanfani zurück. Da der Versuch des Christdemokraten Aldo Moro scheiterte, eine neue Regierung zu bilden, kam es am 22.6. 1963 schließlich zur Bildung einer christlich-demokratischen Minderheitsregierung unter Giovanni Leone. Vgl ADG 1963, S. 10658.

103 Vgl. den Drahterlaß des Staatssekretärs Carstens vom 24.6. 1963, in: AAPD 1963, Dok. 207, S. 671.

104 Vgl. das Gespräch des Bundesministers Schröder mit dem amerikanischen Außenminister Rusk am 21.5. 1963 in Ottawa, in: ebenda, Dok. 178, S. 583, sowie den Runderlaß des Ministerialdirektors Krapf vom 12. 3. 1963, in: ebenda, Dok. 120, S. 403.

105 Aufzeichnung des Botschafters Grewe, Paris (NATO), vom 26. 7. 1963, in: ebenda, Dok. 240, S. 793-801 (793). 
an der französischen Atomstreitmacht ${ }^{106}$. Die CSU-Politiker Strauß und Guttenberg warben bereits seit einiger Zeit für eine atomare Zusammenarbeit mit Frankreich, die langfristig zur Bildung einer europäischen Nuklearstreitmacht führen sollte ${ }^{107}$. Im Zuge des innenpolitischen Streits um einen Beitritt zum Moskauer Atomteststopp-Abkommen im Sommer 1963, der im folgenden Kapitel dieser Studie im Mittelpunkt steht, fand diese Option immer mehr Anhänger, da die Enttäuschung über das amerikanische Verhalten wuchs. Immer öfter war der Vorwurf zu hören, die USA würden auf Kosten der Bundesrepublik die Verständigung mit der Sowjetunion suchen. Heinrich Krone stand mit seiner Meinung, „wir müssen unser Verhältnis zu Frankreich aktivieren"108, nicht allein.

Trotz Grewes Votum entschied sich Schröder, an der MLF festzuhalten ${ }^{109}$. Er wandte sich dezidiert gegen den Standpunkt, in der Force de frappe den Kern einer künftigen europäischen Atommacht zu sehen und als Gegenmodell zur MLF zu propagieren. In einem Interview mit dem Deutschen Fernsehen am 19. Juli 1963 erklärte er unmißverständlich, er werde den Gedanken einer europäischen Atommacht niemals unterstützen, weil er zur Zerstörung der NATO führen würde. Außerdem hielt er dieses Vorhaben für unrealistisch: Erstens könne es eine europäische Atomstreitmacht erst geben, wenn die Einigung Europas erfolgt sei, zweitens wäre auch ein europäischer Staat gezwungen, seine nukleare Verteidigung "auf das Engste" mit den Vereinigten Staaten abzustimmen ${ }^{110}$. Seine Abneigung gegen eine nukleare Zusammenarbeit mit Frankreich ist nicht allein darauf zurückzuführen, daß er mit katastrophalen Auswirkungen auf den Zusammenhalt im atlantischen Bündnis und die Sicherheit der Bundesrepublik rechnete. Darüber hinaus glaubte Schröder, daß die Anhänger einer von Paris geführten, europäischen Nuklearmacht von der irrigen Annahme ausgingen, mit Frankreich könnte eine Vereinbarung leichter getroffen werden als mit den USA: „Es sei einfacher, wenn sich verschiedene Kleine mit einem Großen zusammentäten, als wenn Kleine nur unter sich zu einem Arrangement kommen wollten." 111 Das Hauptmotiv für sein Eintreten zugunsten der MLF war aber, daß die Bundesrepublik dort nach seiner Einschätzung einen größeren Anteil an nuklearer Teilhabe erhielte. Schröder und Carstens waren überzeugt, eine atomare Kooperation mit Paris brächte der Bundesrepublik ,voraussichtlich wesentlich weniger als das atomare Zusammengehen mit den Amerikanern, da die Franzosen sicher nicht

106 Ebenda, S. 801.

107 Vgl. HOPPE, Zwischen Teilhabe und Mitsprache, S. $133 \mathrm{f}$. Zu den verteidigungspolitischen Vorstellungen der beiden Politiker vgl. GuTTENBERG, Wenn der Westen will; STRAUSS, Erinnerungen, S. 355-379.

108 KRONE, Aufzeichnungen, Eintrag vom 18. 8. 1963, S. 181.

109 Die Aufzeichnung Grewes vom 26.7.1963 wurde am 30. 7.1963 von Staatssekretär Carstens an Verteidigungsminister von Hassel weitergeleitet. Carstens vermerkte in dem Anschreiben: „Die Aufzeichnung kommt nicht zu eindeutigen Ergebnissen, doch zieht Bundesminister Schröder wie er am 29. Juli 1963 schon sagte, aus der sehr sorgfältigen Gegenüberstellung aller Argumente eindeutig die Schlußfolgerung, daß wir dieses Projekt weiter verfolgen sollten." Vgl. AAPD 1963, S. 793, Anm. 1.

110 Interview Schröders mit der ARD am 19. 7. 1963, in: BULLETIN 1963, S. 1145.

111 Gespräch des Bundesministers Schröder mit dem amerikanischen Außenminister Rusk am 20. 9. 1963 in Washington, in: AAPD 1963, Dok. 349, S. 1166. 
gewillt sind, uns eine Partnerschaft auf der Grundlage der Gleichberechtigung in atomaren Dingen anzubieten" 112 . Zudem beabsichtigte der Außenminister, mit Hilfe des MLF-Projekts den „Störungsfaktor" Force de frappe auszuschalten. Die französische Atommacht, so Schröder, werde nämlich ihre Monopolstellung in Westeuropa verlieren, wenn die Europäer durch eine Beteiligung an der multilateralen Atomflotte zu Kernwaffenbesitzern würden. Davon abgesehen hätte die MLF ein größeres militärisches Gewicht: „In ihrer Atomstärke könnte die NATO-Flotte die Force de frappe deklassifizieren. Damit wäre Frankreichs Sonderrolle ausgespielt." 113 Neben Schröder war auf deutscher Seite Verteidigungsminister Kai-Uwe von Hassel der entschiedenste Befürworter des Projekts einer multilateralen Atomstreitmacht. Auch er versprach sich von der MLF eine Stärkung der sicherheitspolitischen Position der Bundesrepublik ${ }^{114}$. Sie würde zudem symbolisch zum Ausdruck bringen, daß die Bundesrepublik nun auch im militärischen Bereich mit den anderen Mächten gleichberechtigt sei: „Stellen Sie sich vor, ein atomares U-Boot läuft in den Hafen von New York ein und hat am Turm die schwarz-rot-goldene Flagge gesetzt", sagte er zu Oberst Gerd Schmückle, dem Pressesprecher des Verteidigungsministeriums ${ }^{115}$.

Auch wenn Schröder nicht daran dachte, eine nukleare Zusammenarbeit mit Frankreich in Erwägung zu ziehen, wies er ab dem Sommer 1963 Briten und Amerikaner ostentativ auf die Möglichkeit hin, die Bundesrepublik könnte sich dem französischen Atomprogramm zuwenden, falls die Schaffung der multilateralen Atomstreitmacht keine Fortschritte mache. Er setzte darauf, daß die Angst vor einer engeren deutsch-französischen atomaren Kooperation dem MLF-Plan vielleicht den entscheidenden Impuls geben würde. Diese Taktik wandte er auch in seinem Gespräch mit seinem britischen Amtskollegen am 14. August in London an ${ }^{116}$. Die britische Regierung beharrte nämlich weiterhin auf ihrem Standpunkt, das Projekt sei zu kostspielig und das Prinzip der gemischten Besatzungen "militärisch Unsinn“. Zudem befürchtete sie, daß sich die MLF kontraproduktiv auf die westlichen Entspannungsbemühungen auswirken werde ${ }^{117}$. Deswegen, so führte Lord Home gegenüber Schröder aus, gebe es für das Projekt im Unterhaus "nicht die geringste Unterstützung“. London habe es deshalb mit dem Aufbau dieser Streitmacht „auch gar nicht eilig"118. Angesichts dieses offenherzigen Bekenntnisses drohte Schröder nun mit der französischen Option. Er argumentierte, daß ein Scheitern der MLF zur Folge hätte, daß die nukleare Zusammenarbeit innerhalb der NATO auf Großbritannien und die USA beschränkt bliebe. De Gaulle werde sich dann aber bemühen, zusammen mit der Bundesrepublik ein

112 Aufzeichnung des Staatssekretärs Carstens vom 7. 8. 1963, in: ebenda, Dok. 283, S. 948.

113 Zitiert nach SCHMÜCKLE, Ohne Pauken und Trompeten, S. $320 \mathrm{f}$.

$114 \mathrm{Vgl}$. Gablik, Strategische Planungen in der Bundesrepublik Deutschland, S. 426.

115 SCHMÜCKLE, Ohne Pauken und Trompeten, S. 274.

116 Gespräch des Bundesministers Schröder mit dem britischen Außenminister Lord Home am 14. 8. 1963 in London, in: AAPD 1963, Dok. 301, S. 1020-1023.

117 Aufzeichnung des Ministerialdirigenten Reinkemeyer vom 19. 8. 1963, PA/AA, B 150, Aktenkopien 1963.

118 Gespräch des Bundesministers Schröder mit dem britischen Außenminister Lord Home am 14. 8. 1963 in London, in: AAPD 1963, Dok. 301, S. 1021. 
Gegengewicht zu bilden ${ }^{11}$. Auf diese Weise würde sich eine „Gruppierung Frankreich-Deutschland und USA-Großbritannien ergeben, was für Europa und die atlantische Politik schlecht wäre". Dem Einwand Lord Homes, ein Zusammengehen mit Paris würde sich für die Bundesrepublik nicht auszahlen, da die Franzosen einen Rückstand von mehr als zehn Jahren in der Entwicklung atomarer Waffen hätten, hielt Schröder entgegen, daß man „die Wirkung von Illusionen " nicht unterschätzen dürfe. So hätte sich im Verlauf der Auseinandersetzung um das Atomteststopp-Abkommen gezeigt, daß eine solche Entwicklung durchaus im Bereich des Möglichen liege. Schröder warnte seinen britischen Amtskollegen: „Wenn Großbritannien nicht beitrete, könnte de Gaulle einen gewissen politischen Vorsprung erlangen, was nicht gut wäre." Es müsse aber das Ziel sein, de Gaulle für die eigenen Pläne zu gewinnen und nicht umgekehrt. Er war bereit, den Briten entgegenzukommen und bot wahlweise eine Reduzierung der MLF-Flotte um die Hälfte, eine Kombination von Schiffen und U-Booten oder auch eine reine U-Boot-Flotte an. Schröder bestand aber darauf, ein System zu schaffen, das allen NATO-Mitgliedern erlaube, sich an der atomaren Kontrolle zu beteiligen. Dafür gebe es im Moment „keine zweckmäßigere Lösung als die MLF“120. Sein Plädoyer verfehlte die Wirkung nicht, denn zum Schluß des Gesprächs deutete Lord Home an, im Falle einer Kostenreduzierung könnte die britische Regierung ihre Einwände gegen die MLF zurückstellen ${ }^{121}$.

Auch anläßlich eines Aufenthalts in Washington Ende September 1963 stellte Schröder die Bedeutung der MLF für den weiteren außenpolitischen Kurs der Bundesrepublik heraus. Sollte die multilaterale Atomflotte aufgrund des britischen Widerstands nicht zustande kommen, dann könnte die Force de frappe den Entscheidungsträgern in der Bundesrepublik „im goldenen Gewande erscheinen “, gab er dem amerikanischen Außenminister zu bedenken ${ }^{122}$. In seiner Replik bekräftigte Rusk jedoch den festen Willen der Vereinigten Staaten, die MLF ins Leben zu rufen. Die Ursache für die Zurückhaltung der britischen Regierung seien nicht nur die hohen Kosten des Projekts, sondern auch ihr Interesse an einem Nichtverbreitungsabkommen für atomare Waffen, erläuterte er. Beiläufig brachte er die Überlegung ins Spiel, die multilaterale Atomstreitmacht ohne Großbritannien zu gründen. Rusk gab sich indessen überzeugt, daß an der Themse das Interesse an einer Mitarbeit steigen würde, sobald die MLF Gestalt angenommen habe ${ }^{123}$.

Noch während sich Schröder in Washington aufhielt, stellte am 23. September der Staatssekretär im französischen Außenministerium, Michel Habib-Deloncle, in einer Rede vor der Beratenden Versammlung des Europarats die Möglichkeit in Aussicht, die Force de frappe nach der politischen Vereinigung Europas in eine

119 Vgl. die Aufzeichnung des Ministerialdirigenten Reinkemeyer vom 19. 8. 1963, PA/AA, B 150, Aktenkopien 1963.

120 Gespräch des Bundesministers Schröder mit dem britischen Außenminister Lord Home am 14. 8. 1963 in London, in: AAPD 1963, Dok. 301, S. 1022.

121 Vgl. ebenda, S. $1022 \mathrm{f}$.

122 Gespräch des Bundesministers Schröder mit dem amerikanischen Außenminister Rusk am 20. 9. 1963 in Washington, in: ebenda, Dok. 349, S. 1164.

$123 \mathrm{Vgl}$. ebenda, S. $1164 \mathrm{f}$. 
europäische Atomstreitmacht umzuwandeln ${ }^{124}$. In einer ersten Stellungnahme bewertete Schröder die Andeutungen Habib-Deloncles als nicht ernst zu nehmende "Propagandamaßnahme" ${ }^{125}$, warnte aber Kennedy, daß bei vielen Politikern in der Bundesrepublik durchaus die Bereitschaft vorhanden sei, zuzugreifen, sollte Frankreich eines Tages ein konkretes Angebot machen. Dem britischen Außenminister habe er bereits deutlich gemacht, daß eine Nichtbeteiligung Großbritanniens an der MLF die Position Frankreichs stärken würde, berichtete er dem Präsidenten. Dieser teilte jedoch uneingeschränkt Schröders Analyse und versicherte, die USA würden das Projekt „so nachdrücklich wie möglich vorantreiben.“ Die Erklärung Habib-Deloncles werde man dazu nutzen, auf London Druck auszuüben. Zur Bekräftigung seines Willens, die multilaterale Atomflotte zu verwirklichen, schlug er vor, möglichst bald ein Versuchsschiff mit einer gemischten Besatzung in Dienst zu stellen. Dieser Gedanke fand Schröders ungeteilte Zustimmung, „da er einen praktischen Anfang bedeute und sich optisch, psychologisch und politisch auswirken werde" 126 .

Der Außenminister konnte folglich mit der Gewißheit die Rückreise antreten, daß die Vereinigten Staaten fest hinter dem MLF-Projekt standen. Nach langem Zögern erklärte sich auch die britische Regierung mit der Aufnahme offizieller Verhandlungen einverstanden. Ab dem 11. Oktober 1963 fanden zwischen den USA, der Bundesrepublik, Großbritannien, Italien, Belgien, Griechenland, der Türkei und den Niederlanden, die sich den Beratungen Ende November anschlossen, auf multilateraler Ebene Gespräche über die Schaffung einer multilateralen Atomflotte statt. Die militärischen Fragen des Projekts wurden in Washington erörtert, während eine zweite Arbeitsgruppe in Paris unter dem Vorsitz des amerikanischen Vertreters bei der NATO, Finletter, sich mit den politischen Aspekten beschäftigte ${ }^{127}$. Wenige Tage vor dem Rücktritt Adenauers schien das MLF-Projekt somit der Realisierung einen entscheidenden Schritt näher gekommen zu sein.

\section{Der Streit um den Beitritt zum Atomteststopp-Abkommen}

Der Plan, ein Abkommen zwischen den Atommächten zur Beendigung von nuklearen Testversuchen in der Atmosphäre zu schließen, ging auf eine amerikanisch-britische Initiative zurück. Die beiden Staaten legten am 27. August 1962 der Konferenz der 18-Mächte-Abrüstungskommission in Genf zwei Vertragsentwürfe vor ${ }^{128}$. Wegen der Verschärfung des Ost-West-Konflikts durch die KubaKrise im Herbst 1962 kam es aber darüber nicht mehr zu einem Gedankenaustausch mit der UdSSR. Erst Anfang Juli $1963 \mathrm{kam}$ wieder Bewegung in die Angelegenheit. Kennedy teilte Adenauer mit, er werde seinen Sonderbotschafter Ave-

$124 \mathrm{Vgl}$. EuROPA-ARCHIV 1963, D 546-550, besonders D 549.

125 Gespräch des Bundesministers Schröder mit dem Berater des amerikanischen Präsidenten, Sorensen, am 24. 9. 1963 in Washington, in: AAPD 1963, Dok. 362, S. 1224.

126 Gespräch des Bundesministers Schröder mit Präsident Kennedy am 24.9. 1963 in Washington, in: ebenda, Dok. 361, S. 1220 f.

127 Vgl. Hoppe, Zwischen Teilhabe und Mitsprache, S. 151, sowie die Aufzeichnung des Ministerialdirektors Krapf vom 15. 11. 1963, in: AAPD 1963, Dok. 414, S. $1439 \mathrm{f}$.

128 Vgl. dazu ADG 1962, S. 10069-10073. 
rell Harriman nach Moskau schicken. Dieser solle prüfen, ob die sowjetische Regierung bereit sei, über ein begrenztes Verbot von Atomversuchen zu verhandeln ${ }^{129}$. Am 14. Juli traf Harriman in der sowjetischen Hauptstadt ein und begann zusammen mit dem britischen Delegationsleiter Lord Hailsham mit den Sondierungen ${ }^{130}$. Außenminister Schröder nahm im Namen der Bundesregierung öffentlich dazu Stellung. Er stellte fest, die amerikanische Initiative sei zu begrüßen, sofern das geplante Abkommen den Beginn der von Bonn seit langem geforderten, allgemeinen und kontrollierten Abrüstung darstelle $e^{131}$.

Bereits am 23. Juli informierte Kennedy den Kanzler, daß die Verhandlungen kurz vor dem Abschluß stünden. Über den genauen Inhalt des Vertrages wurde die Bundesregierung jedoch im Ungewissen gelassen. Alarmierend war aber die Nachricht, die USA wünschten, daß möglichst viele Staaten dem AtomteststoppAbkommen beitreten, darunter auch die Bundesrepublik. Bislang war man am Rhein davon ausgegangen, daß nur die Atommächte die Vereinbarung unterzeichnen würden. Erst durch Kennedys Brief vom 23. Juli erfuhr die Bundesregierung, $\mathrm{daß}$ eine Globalisierung des Abkommens angestrebt wurde und deshalb auch die Bundesrepublik ihre Unterschrift leisten solle ${ }^{132}$. In Bonn sorgte man sich verständlicherweise, daß auch die DDR dem Abkommen beitreten und auf diese Weise ihre völkerrechtliche Anerkennung durchsetzen könnte. Schröder schrieb deshalb noch am gleichen Tag an Rusk und forderte, in den Vertrag eine Regelung einzufügen, die einen Beitritt Ost-Berlins verhindern würde ${ }^{133}$. Am folgenden Tag richtete Adenauer einen Brief gleichlautenden Inhalts an Kennedy ${ }^{134}$. Wie aus der Antwort Rusks hervorging, waren die Vereinigten Staaten stark daran interessiert, auch die Volksrepublik China als Vertragspartner zu gewinnen. Aus diesem Grund sollten selbst nicht allgemein anerkannte Staaten die Möglichkeit haben, den Vertrag zu unterzeichnen. Damit sei aber nicht ihre völkerrechtliche Anerkennung verbunden, stellte der amerikanische Außenminister klar. Bonn war jedoch der Ansicht, man könne die DDR und China nicht auf die gleiche Stufe stellen. Carstens wies Rusk darauf hin, daß hinsichtlich der Staatsqualität Chinas kein Zweifel bestünde; umstritten sei lediglich, ob Peking oder Taipeh diesen Staat repräsentierten. Die DDR sei aber nach der einhelligen Auffassung des Westens kein Staat ${ }^{135}$.

$129 \mathrm{Vgl}$. OSTERHELD, „Ich gehe nicht leichten Herzens ... “, S. 240.

$130 \mathrm{Zu}$ den Verhandlungen in Moskau vgl FRUS 1961-1963, VII, Dok. 235-248, S. 799-845.

Vgl. ferner SCHRAFSTETTER, Die dritte Atommacht, S. 69-72.

131 Vgl. das Interview Schröders mit der ARD am 19. 7. 1963, in: Bulletin 1963, S. 1143.

132 Vgl. KRONE, Aufzeichnungen, Eintrag vom 31. 7. 1963, S. 177; sowie das Gespräch des Bundesministers Schröder mit dem amerikanischen Botschafter McGhee am 3. 8. 1963, in: AAPD 1963, Dok. 270, S. 905. Kennedys Schreiben an Adenauer vom 23. 7.1963 ist noch nicht veröffentlicht.

133 Vgl. das Schreiben Schröders an Rusk vom 23. 7. 1963, PA/AA, B 150, Aktenkopien 1963.

134 Vgl. das Schreiben Adenauers an Kennedy vom 24. 7. 1963, in: AAPD 1963, Dok. 234, S. $776 f$.

135 Vgl. die Aufzeichnung des Staatssekretärs Carstens vom 24.7. 1963, in: ebenda, Dok. 235, S. 778. 
Die Bemühungen der Bundesregierung, auf die Verhandlungen in Moskau Einfluß zu nehmen, kamen allerdings zu spät, denn bereits am 25. Juli wurde der Atomteststopp-Vertrag zwischen den Vereinigten Staaten, der UdSSR und Großbritannien in Moskau paraphiert ${ }^{136}$. Erst einen Tag später, als der Vertragstext schon in der Presse abgedruckt war, übermittelte die amerikanische Regierung Bonn den Wortlaut des Abkommens ${ }^{137}$. Für Schröder war dieser Vorfall „sehr peinlich“. Immer wieder hatte er gegenüber den sogenannten Gaullisten seine guten Beziehungen zu Washington hervorgehoben und nun hatten es die Amerikaner nicht für nötig gehalten, ihren deutschen Verbündeten rechtzeitig zu konsultieren ${ }^{138}$ ! Es muß aber an dieser Stelle ausdrücklich betont werden, daß sich die Kritik Bonns an dem Vertrag allein gegen die mangelnde Berücksichtigung der Nichtanerkennungspolitik gegenüber der DDR richtete. Am Ziel des Atomteststopp-Abkommens hatte die Bundesregierung nichts auszusetzen, sondern befürwortete nachdrücklich, daß dadurch den Atomversuchen in der Atmosphäre und der damit verbundenen radioaktiven Verseuchung der Erde ein Ende gesetzt würde. Zudem sah man in dem Abkommen einen möglichen „ersten Schritt" auf dem Weg zu konkreten Abrüstungsvereinbarungen ${ }^{139}$.

Der amerikanische Sonderbotschafter Martin Hillenbrand, der Ende Juli zur Erläuterung des Abkommens vom State Department nach Bonn geschickt wurde, wiederholte den Wunsch Kennedys, die Bundesrepublik sollte dem Abkommen beitreten, sobald die drei Signatarstaaten, Großbritannien, die USA und die UdSSR, den Vertrag unterzeichnet hätten. Hillenbrand war der Ansicht, das Problem der völkerrechtlichen Anerkennung der DDR sei „befriedigend gelöst“"140. Er spielte dabei auf den zweiten Absatz des Artikels 3 des Abkommens an, der ein neues Verfahren in das internationale Vertragswesen einführte, nämlich die Einrichtung von drei Depositarregierungen. Er stellte es jedem Staat frei, die Ratifikationsurkunde in Washington, London oder Moskau zu hinterlegen, um den Beitritt rechtskräftig werden zu lassen ${ }^{141}$. Hinsichtlich der Anwendung dieser Klausel teilte die amerikanische Regierung mit, sie habe sich mit der britischen und der sowjetischen Regierung mündlich darauf verständigt, daß jeder der drei Signatarstaaten das Recht habe, die Annahme einer Ratifikationsurkunde eines von ihm nicht anerkannten Staates zu verweigern. Auf diese Weise würde zwischen diesem und dem Signatarstaat keine Rechtsbindung entstehen, doch wäre ersterer gegen-

136 Für den Wortlaut des Vertrags vom 5. 8. 1963 über das Verbot von Kernwaffenversuchen in der Atmosphäre, im Weltraum und unter Wasser (Atomteststopp-Abkommen) vgl. DzD IV/9, S. 608-610.

137 Vgl. OSTERHELD, „Ich gehe nicht leichten Herzens ...“, S. 241. Schröder berichtete dazu: „Den vollen Wortlaut des Vertrages habe er am Freitag, den 26. Juli, einem AP-Bericht im Bonner General-Anzeiger entnommen. Er habe zwar sehr viel Humor, doch dies sei ein bißchen viel gewesen. "Vgl. das Gespräch des Bundesministers Schröder mit dem Sicherheitsberater des amerikanischen Präsidenten, Bundy, am 20.9. 1963 in Washington, in: AAPD 1963, Dok. 348, S. 1151.

$138 \mathrm{Vgl}$. ebenda.

139 Vgl. den Drahterlaß des Staatssekretärs Carstens vom 26. 7. 1963, in: ebenda, Dok. 239, S. 790.

140 Aufzeichnung des Staatssekretärs Carstens vom 26. 7. 1963, in: ebenda, Dok. 238, S. 789.

141 Für den Wortlaut vgl. DzD IV/9, S. 609. 
über allen Vertragsparteien gebunden, zu denen er diplomatische Beziehungen unterhalte. Ebenso habe man die Absprache getroffen, daß jede Depositarregierung die Notifikation des Beitritts eines Staates, der ihr von einer anderen Depositarregierung übermittelt werde, zurückweisen könne, wenn sie diesen Staat völkerrechtlich nicht anerkenne. Die USA versicherten, daß sie diese Option wahrnehmen würden, falls die DDR das Abkommen in Moskau unterzeichnete. Die Richtlinien der WEU, demzufolge ein Beitritt der DDR zu einem internationalen Abkommen nicht zur Kenntnis genommen werden sollte, würden somit von der amerikanischen Regierung in vollem Umfang beachtet werden ${ }^{142}$.

Durch das von Hillenbrand beschriebene Verfahren wurde eine indirekte völkerrechtliche Anerkennung der DDR durch die Vereinigten Staaten und Großbritannien ausgeschlossen. Im Auswärtigen Amt stellte man sich freilich die Frage, „wie eine Anerkennung im Verhältnis zwischen der SBZ und neutralen Staaten verhindert werden kann, wenn diese neutralen Staaten, wie anzunehmen ist, ihren Beitritt sowohl in Moskau wie in Washington wie in London erklären"143. Außerdem bereitete auch Artikel 3, Absatz 1 des Atomteststopp-Abkommens den Verantwortlichen in Bonn Kopfzerbrechen ${ }^{144}$. Dieser bestimmte, jeder "Staat" könnte dem Vertrag "jederzeit beitreten"145. Erlangte die DDR, sobald sie ihre Unterschrift unter das Abkommen setzte, dadurch nicht automatisch die völkerrechtliche Anerkennung? Am 29. Juli 1963 legte Adenauer dem CDU/CSU-Fraktionsvorstand die Problematik des Abkommens dar. Nach einer längeren Debatte wurde Schröder beauftragt, gegenüber den Vereinigten Staaten darauf zu drängen, dem Abkommen ein „Interpretationsprotokoll“ beizufügen, in dem festgehalten werden sollte, daß mit dem Abkommen keine völkerrechtliche Anerkennung der DDR verbunden sei146. Noch am selben Tag machte der Außenminister seinen amerikanischen Kollegen auf die Bedenken der Bundesrepublik aufmerksam. Eine völkerrechtliche Anerkennung der DDR durch neutrale Staaten müsse unbedingt ausgeschlossen werden, verlangte Schröder. Das Moskauer AtomteststoppAbkommen sei daher um folgende Erklärung zu ergänzen: „Die Ratifizierung des Abkommens oder Beitritt zu ihm durch Gebiete oder Behörden (territories or authorities), die nicht allgemein als Staaten anerkannt sind, erzeugen Vertragsbeziehungen nur zu solchen Vertragsstaaten, die jene Gebiete oder Behörden (territories or authorities) bereits als Staaten anerkannt haben. “147 Zusätzlich sollten die USA allen Regierungen mit Ausnahme derjenigen, welche die DDR bereits völkerrechtlich anerkannt hatten, eine Note übermitteln, derzufolge sich die Haltung des Westens in Bezug auf die DDR nicht geändert habe. Schröder betonte abschließend, die Nichtanerkennungspolitik gegenüber der DDR als „Kernstück“ der Außenpolitik der Bundesrepublik sei „unverändert aufrechtzuerhalten“,

142 Vgl. die Aufzeichnung sowie den Drahterlaß des Staatssekretärs Carstens vom 26. 7. 1963, in: AAPD 1963, Dok. 238, S. 789f., und Dok. 239, S. 790-792.

143 Drahterlaß des Staatssekretärs Carstens vom 26. 7. 1963, in: ebenda, Dok. 239, S. 791.

144 Vgl. ebenda, S. $791 \mathrm{f}$.

145 DzD IV/9, S. 609.

146 OSTERHELD, „Ich gehe nicht leichten Herzens ...", S. 242.

$147 \mathrm{Vgl}$. das Schreiben des Bundesministers Schröder an den amerikanischen Außenminister Rusk vom 29. 7. 1963, in: AAPD 1963, Dok. 244, S. 809. 
andernfalls bestehe die Gefahr, daß Bonn dem Atomteststopp-Abkommen fernbleibe $^{148}$.

Rusk lehnte jedoch ein Interpretationsprotokoll kategorisch ab und war nur zur Abgabe einer Erklärung über die Nichtanerkennung der DDR bereit ${ }^{149}$. Diese Antwort trug nicht zu einer Beruhigung der Gemüter bei. Vor allem in den Reihen von CDU und CSU regte sich zunehmend Widerstand. Man war der Auffassung, das Atomteststopp-Abkommen stehe eindeutig im Widerspruch zur westlichen Deutschland-Politik ${ }^{150}$. Neben dem umstrittenen Artikel 3 des AtomteststoppAbkommens geriet auch der Artikel 2 ins Kreuzfeuer der Kritik. Dieser bestimmte, daß auf Antrag von einem Drittel der Vertragsparteien eine Generalversammlung der Unterzeichnerstaaten einzuberufen sei ${ }^{151}$. Eine Teilnahme der DDR an einer derartigen Konferenz hätte ihre völkerrechtliche Anerkennung durch die anderen Konferenzteilnehmer impliziert. Wie sollte aber die Bundesrepublik Ost-Berlin daran hindern, auf dieser Versammlung zu erscheinen? Adenauer stellte am 30. Juli William Tyler, der im State Department für europäische Angelegenheiten zuständig war, zur Rede. Er wollte von ihm wissen, ob die Vereinigten Staaten im Falle einer Einberufung einer solchen Konferenz die Teilnahme der DDR verhindern würden. Der Abteilungsleiter konnte jedoch keine Auskunft geben, wie sich seine Regierung verhalten würde ${ }^{152}$.

Am folgenden Tag diskutierte das Kabinett, wie auf das Moskauer Atomteststopp-Abkommen zu reagieren sei. Es bestand Einvernehmen, daß eine Aufwertung der DDR unterbunden werden mußte, doch war man sich bewußt, daß die Aussichten gering waren, die eigenen Vorstellungen durchzusetzen, da das Abkommen in der gesamten Welt positiv beurteilt wurde ${ }^{153}$. Schröder sprach sich für den Beitritt aus, sofern klargestellt würde, daß das Abkommen keine völkerrechtliche Anerkennung der DDR nach sich ziehe. Adenauer war hingegen anderer Ansicht: „Sollen die anderen den Pakt abschließen! Wir sind nicht gefragt worden. Wir dürfen nicht mitmachen. “154 Krone sah in dem Vertrag sogar einen „Verrat" an der Bonner Deutschland-Politik ${ }^{155}$. Er und Adenauer befürchteten, daß Chruschtschow damit die Absicht verfolgte, die internationale Anerkennung der DDR durchzusetzen und die Rahmenbedingungen für die Unterzeichnung eines Nichtangriffspakts zwischen der NATO und dem Warschauer Pakt zu schaffen. All dies sollte dazu dienen, den Status quo in Europa zu fixieren ${ }^{156}$. Aufgrund der stark abweichenden Meinungen faßte das Kabinett noch keinen Beschluß, wie

148 Ebenda, S. 810.

$149 \mathrm{Vgl}$. OSTERHELD, „Ich gehe nicht leichten Herzens ... “, S. 242.

150 Vgl. dazu das Schreiben des CDU/CSU-Fraktionsvorsitzenden von Brentano an Bundeskanzler Adenauer vom 28. 7. 1963, in: AAPD 1963, Dok. 243, S. 806-808.

151 Für den Wortlaut vgl. DzD IV/9, S. 609.

152 Vgl. dazu das Schreiben des Bundeskanzlers Adenauer an den CDU/CSU-Fraktionsvorsitzenden von Brentano vom 31. 7. 1963, in: AAPD 1963, Dok. 258, S. $866 \mathrm{f}$.

153 Vgl. OSTERHELD, „Ich gehe nicht leichten Herzens ...“", S. 242.

154 Zitiert nach KrONE, Aufzeichnungen, Eintrag vom 31.7. 1963, S. 177.

155 Ebenda.

156 Vgl. die Aufzeichnung des Referenten im Bundesministerium für besondere Aufgaben, Abelein, vom 12.8. 1963, ACDP, Nachlaß Krone I-028-033/4. Vgl. auch OSTERHELD, „Ich gehe nicht leichten Herzens ...“, S. $242 \mathrm{f}$. 
sich die Bundesrepublik verhalten werde. Man wies den Außenminister an, sich vorläufig mit weiteren Stellungnahmen zum Abkommen zurückzuhalten ${ }^{157}$. Außerdem sollte Schröder erneut bei der britischen und der amerikanischen Regierung vorstellig werden und auf die Abgabe öffentlicher Erklärungen über das Festhalten an der Nichtanerkennungspolitik gegenüber der DDR bestehen ${ }^{158}$.

Noch am selben Tag wandte sich der Außenminister schriftlich an Rusk ${ }^{159}$ und Lord Home ${ }^{160}$. Abermals unterstrich er, die Bundesregierung sehe "mit großer Sorge“, daß Ost-Berlin mit Hilfe des Atomteststopp-Abkommens die völkerrechtliche Anerkennung durchsetzen könnte ${ }^{161}$. Eine öffentliche Stellungnahme zur Behandlung der DDR im Falle ihres Beitritts hielt er deshalb für unerläßlich. Schröder ersuchte die amerikanische und die britische Regierung, anläßlich der Unterzeichnung des Vertrags eine Erklärung analog des von Bonn vorgeschlagenen Interpretationsprotokolls abzugeben. Es sei „dringend erwünscht“, diese Resolution zusätzlich an alle Staaten zu übermitteln, die die DDR nicht völkerrechtlich anerkannt hatten. Ferner stellte er die Bedingung, die DDR dürfte, falls das in Artikel 2 des Atomteststopp-Abkommens vorgesehene Verfahren zur Abhaltung einer Generalversammlung in Gang gesetzt würde, „bei der Berechnung des für die Einberufung der Konferenz erforderlichen Drittels der Mitglieder nicht mitgezählt werden, und sie dürfte, wenn sie auf der Konferenz erscheinen würde, zu ihr nicht zugelassen werden" 162 .

Adenauer war offensichtlich entschlossen, dem Vertrag fernzubleiben, sollten die USA die Auflagen Bonns nicht erfüllen. Dem amerikanischen Verteidigungsminister McNamara teilte er am 31. Juli mit, die Beteuerungen Washingtons, der Status der DDR werde sich nicht verbessern, könnten ihn nicht beruhigen. Nach seiner Ansicht ließ sich durch die Abgabe einer Nichtanerkennungserklärung nicht automatisch die völkerrechtliche Anerkennung eines Landes ausschließen. Der Bundesrepublik sei es nicht möglich eine Vereinbarung mitzutragen, die wegen der Nichteinhaltung der Nichtanerkennungspolitik im Gegensatz zur Deutschland-Politik Bonns stehe, drohte der Kanzler ${ }^{163}$. Dagegen neigte Schröder dazu, das Abkommen zu unterzeichnen. Er befürchtete, daß andernfalls der Eindruck entstehen könnte, die sowjetische Propaganda habe in der Vergangenheit die Bundesrepublik zu Recht als Gegner einer internationalen Entspannung gebrandmarkt ${ }^{164}$. Um der UdSSR keinen Anlaß zu geben, das Zögern Bonns als generelle Ablehnung des Vertrages zu deuten, empfing er am 3. August den sowje-

157 Vgl. dazu das Schreiben des Bundeskanzlers Adenauer an den CDU/CSU-Fraktionsvorsitzenden von Brentano vom 31. 7. 1963, in: AAPD 1963, Dok. 258, S. 866.

$158 \mathrm{Vgl}$. OSTERHELD, „Ich gehe nicht leichten Herzens ...", S. 243.

159 Schreiben des Bundesministers Schröder an den amerikanischen Außenminister Rusk vom 31. 7. 1963, in: AAPD 1963, Dok. 260, S. 871-874.

160 Für den Wortlaut des Schreibens vom 31. 7.1963 vgl. PA/AA, B 150, Aktenkopien 1963.

$161 \mathrm{Vgl}$. das Schreiben des Bundesministers Schröder an den amerikanischen Außenminister Rusk vom 31. 7. 1963, in: AAPD 1963, Dok. 260, S. 871.

162 Ebenda, S. 873.

$163 \mathrm{Vgl}$. OsterhelD, „Ich gehe nicht leichten Herzens ...“, S. 243f.; sowie AAPD 1963, Dok. 257, S. 853-865, besonders S. 858-861.

164 Vgl. das Interview Schröders mit dem DLF am 29. 10. 1963, in: Bulletin 1963, S. 1702. 
tischen Botschafter Smirnow. In dem Gespräch würdigte Schröder das Abkommen, weil es den radioaktiven Fallout in der Atmosphäre beende. Bonn sehe darin „einen guten Anfang für weitere Schritte auf dem Wege zu einer allgemeinen Entspannung" und beabsichtige daher, dem Abkommen beizutreten. Zuvor müsse aber noch gemeinsam mit den Verbündeten die Auswirkungen des Vertrages auf die Nichtanerkennungspolitik analysiert werden. Der Außenminister betonte, er könne noch nicht sagen, zu welchem Ergebnis die Bundesregierung gelangen werde, prognostizierte aber einen positiven Ausgang der Prüfung. Die Entscheidung werde aber aller Wahrscheinlichkeit erst nach der für den 5. August 1963 vorgesehenen Unterzeichnungszeremonie feststehen ${ }^{165}$. Unter außenpolitischen Gesichtspunkten war in der Tat ein Fernbleiben Bonns nicht zu verantworten. Schröder hatte richtig erkannt, daß sich die Bundesrepublik international isolierte, wenn sie die Unterschrift unter ein Dokument verweigerte, das allseits begrüßt wurde. Auch diejenigen Unionspolitiker, die sich bislang gegen eine Unterzeichnung gewehrt hatten, sahen dies nach und nach ein. Krone notierte am 6 . August deprimiert in sein Tagebuch: „Sollen wir unterschreiben? Es wird nichts anderes übrig bleiben. Ich denke an Versailles." 166

Die Tatsache, daß die USA die Bundesregierung unzureichend konsultiert hatten, wollte Schröder allerdings nicht widerspruchslos hinnehmen. Gegenüber dem amerikanischen Botschafter McGhee, den er unmittelbar nach Smirnow empfing, brachte er deshalb seine Verärgerung über die amerikanische Informationspolitik unmißverständlich zum Ausdruck. Die Bundesregierung sei wochenlang im Ungewissen gelassen worden, beschwerte sich der Außenminister. Man habe "nicht die geringste Vorstellung" gehabt, was in Moskau verhandelt werde und habe somit keine Einwände vorbringen können ${ }^{167}$. Schröder ließ keinen Zweifel daran, wie unerfreulich für Bonn die Vorstellung war, daß die DDR Vertragspartei eines internationalen Abkommens werde. In den letzten Jahren sei man permanent damit beschäftigt gewesen, die Aufnahme der DDR in internationalen Organisationen zu verhindern: „50\% der diplomatischen Tätigkeit sei gerade auf diesen $Z$ weck gerichtet gewesen. Nun könne man nicht einfach sagen, dies sei nicht so wichtig und habe mit der Anerkennung nichts zu tun." 168 McGhee verwies hingegen auf die große entspannungspolitische Bedeutung des Atomteststopp-Abkommens. Dafür müsse man „kleinere Schwierigkeiten, wie die Bundesregierung sie jetzt habe, in Kauf nehmen“. Eindringlich empfahl er der Bundesrepublik den Beitritt, um sich nicht dem Verdacht auszusetzen, sie verfolge nukleare Ambitionen ${ }^{169}$. Es sei auch nicht ratsam, meinte er, wenn die Bundesregierung den Eindruck erwecke, sie könne sich wegen ihrer Deutschland-Politik „an keinen konstruktiven Bemühungen beteiligen“. Diesem Vorwurf widersprach

165 Gespräch des Bundesministers Schröder mit dem sowjetischen Botschafter Smirnow am 3. 8. 1963, in: AAPD 1963, Dok. 269, S. 896-904 (898).

166 KRONE, Aufzeichnungen, Eintrag vom 6. 8. 1963, S. 178.

167 Gespräch des Bundesministers Schröder mit dem amerikanischen Botschafter McGhee am 3. 8. 1963, in: AAPD 1963, Dok. 270, S. 905.

168 Ebenda, S. 906.

169 Ebenda, S. 907. 
Schröder energisch: „Man könne aber nicht sagen, Deutschland sei nicht konstruktiv und gleichzeitig verlangen, daß man die Wiedervereinigung abschreibe." Er erinnerte an die im Deutschland-Vertrag vereinbarte Linie, sich gemeinsam für die Wiedervereinigung einzusetzen. Dies erfordere zumindest, alles zu unterlassen, was die Wiederherstellung der staatlichen Einheit Deutschlands erschweren könne ${ }^{170}$. Das Gespräch verließ nun die sachliche Ebene. McGhee ging auf die Argumente Schröders gar nicht mehr ein. Statt dessen warnte er den Außenminister, falls „die Bedenken wegen der Zone das Verhalten der Bundesrepublik beherrschten, disqualifiziere sie sich für eine Führung“. Sollte die Bundesrepublik ihre Nichtanerkennungspolitik überbetonen, dann würde der fatale Eindruck entstehen, „als ob Deutschland überallhin nur Probleme bringe“. Unverblümt drohte der Botschafter schließlich damit, „daß sich auf die Dauer ein deutscher Politiker, der gegen einen Beitritt zum Moskauer Vertrag sei, nur selber schade"171. McGhee hatte damit die Karten offen auf den Tisch gelegt. Washington bestand unmißverständlich auf einer Unterzeichnung des Atomteststopp-Abkommens durch die Bundesrepublik. Der Auftritt des Botschafters hatte deutlich gemacht, daß eine Weigerung Bonns die deutsch-amerikanischen Beziehungen erheblich beschädigen mußte. Zwar war die amerikanische Regierung bereit, den Bedenken durch die Abgabe einer Erklärung über die Nichtanerkennung der DDR Rechnung zu tragen, doch darüber hinaus hatte man kein Verständnis für die Einwände Bonns. Washington war nicht gewillt, auf den ersten konkreten Erfolg der Entspannungspolitik zu verzichten, nur weil Bonn eine internationale Aufwertung der DDR befürchtete. Krone sah deshalb die Bundesrepublik als „Opfer der amerikanischen Entspannungspolitik"172.

Auch Schröder deutete das Atomteststopp-Abkommen als den „Anfang einer weiteren Verschlechterung auf dem gesamten Gebiet der Deutschlandpolitik“, wie er am 5. August 1963 dem britischen Botschafter in Bonn, Frank Roberts, offenbarte. Erneut brachte er in dieser Unterredung zum Ausdruck, wie sehr die Bundesregierung von der Moskauer Vereinbarung überrascht worden sei. Bonn, so der Außenminister, habe nicht damit gerechnet, daß die Anerkennungsfrage dabei zu einem Problem werde. Man sei der Meinung gewesen, dieser Punkt müßte nur bezüglich des geplanten Nichtangriffspakt zwischen der NATO und dem Warschauer Pakt im Auge behalten werden. Schröder beschwerte sich zudem über die widersprüchlichen Aussagen des State Department, wie der Beitritt der DDR rechtlich zu bewerten sei. So habe Rusk am 26. Juli noch behauptet, eine Unterzeichnung des Abkommens durch die DDR würde zu keinen vertraglichen Bindungen zwischen Washington und Ost-Berlin führen; eine Woche später habe er dann erklärt, die Vereinigten Staaten wünschten die DDR durch ihre Unterschrift zu binden ${ }^{173}$. Gleichwohl war man im Auswärtigen Amt zu dem Schluß gekommen, die Bundesrepublik müsse den Vertrag unterzeichnen. Zwar gab es

170 Ebenda, S. 908.

171 Ebenda, S. 909.

172 KRONE, Aufzeichnungen, Eintrag vom 5. 8. 1963, S. 178.

173 Gespräch des Bundesministers Schröder mit dem britischen Botschafter Roberts am 5. 8. 1963, in: AAPD 1963, Dok. 274, S. 924 f. 
auch einige Stimmen, die anderer Ansicht waren, wie zum Beispiel der Botschafter der Bundesrepublik in Moskau, Horst Groepper. Seiner Ansicht nach sollte sich Bonn die Möglichkeit offenlassen, eigene Nuklearwaffen zu entwickeln. Groepper verwies auf die Furcht des Kreml vor einer atomar bewaffneten Bundesrepublik und empfahl, dies auszunutzen. Eventuell, so der Botschafter, könnte Moskau für einen Verzicht auf Atomwaffen die Wiedervereinigung abgehandelt werden ${ }^{174}$. Die Spitze des Auswärtigen Amts bezweifelte aber, daß ein Nichtbeitritt Bonns zum Atomteststopp-Abkommen die UdSSR veranlassen könnte, ihre Deutschland-Politik zu ändern. Carstens sagte voraus, daß die Sowjetunion dann eine scharfe Kampagne gegen die Bundesrepublik mit dem Ziel, sie international zu isolieren, in die Wege leiten werde. Angesichts der im Ausland vorhandenen Angst vor einer atomaren Bewaffnung der Bundesrepublik werde diese nicht nur bei den neutralen Staaten, sondern selbst bei den Verbündeten auf fruchtbaren Boden fallen. Die Aussicht, Bonn in die politische Isolierung zu treiben, könne für Chruschtschow sogar verlockender sein als „die geringfügige zusätzliche Garantie" auf einen Kernwaffenverzicht der Bundesrepublik, die der Kreml durch den Beitritt Bonns zum Teststopp-Abkommen erhielte, prophezeite der Staatssekretär ${ }^{175}$.

Im Bundeskanzleramt tendierte man ebenfalls dazu, den Vertrag zu unterzeichnen, obwohl Adenauer weiterhin große Bedenken hatte. Er sah seine Befürchtungen bestätigt, daß die USA sich ohne Rücksicht auf die Interessen der Bundesrepublik mit der UdSSR verständigen würden. Doch Osterheld vertrat den Standpunkt, die Bundesrepublik könne den Vertrag nicht verhindern und sich auch einem Beitritt nicht entziehen ${ }^{176}$. Der Einfluß Bonns sei begrenzt; die Bundesregierung sei höchstens in der Lage, darauf hinzuwirken, "die Aufwertung der DDR zu drosseln“. Er riet dazu, den Blick in die Zukunft zu richten und künftig die Amerikaner mit mehr Nachdruck an ihre Verpflichtungen zu erinnern, die sie gegenüber der Bundesrepublik eingegangen waren, um auf diese Weise „den Nichtangriffsvertrag zwischen NATO und Warschauer Pakt und Schlimmeres zu verhindern oder zu entschärfen" 177 .

Am 5. August 1963 unterzeichneten in Moskau die USA, die UdSSR und Großbritannien das Atomteststopp-Abkommen. Zwei Tage später erhielt der Kanzler einen Brief Kennedys, in dem dieser den Vorwurf Adenauers zurückwies, er habe sich gegenüber der Sowjetunion zu nachgiebig verhalten. Erneut bemühte sich der Präsident, die Bonner Bedenken hinsichtlich einer Anerkennung der DDR zu zerstreuen ${ }^{178}$. Gleichwohl konnte sich das Kabinett immer noch nicht zu einem Beitrittsbeschluß durchringen. Am 9. August faßte die Bundesregierung in einem Memorandum ihre Einwände noch einmal zusammen, wobei die Forde-

174 Vgl. dazu die Aufzeichnung des Staatssekretärs Carstens vom 7. 8. 1963, in: ebenda, Dok. 283, S. 947.

175 Ebenda.

176 Vgl. OSTERHELD, „Ich gehe nicht leichten Herzens ...“, S. 244-246.

177 Ebenda, S. 246.

178 Vgl. das Schreiben Kennedys an Adenauer vom 6. 8. 1963, in: FRUS 1961-1963, XV, Dok. 205, S. 554-556. 
rung nach einer Erklärung über die Nichtanerkennung der DDR bekräftigt wurde, die auch eine Bestätigung des Alleinvertretungsrechts der Bundesrepublik enthalten sollte ${ }^{179}$. Am Tag darauf traf Rusk zu Besprechungen in Bonn ein. Er sicherte Adenauer und Schröder nochmals zu, die Vereinigten Staaten würden einen Beitritt der DDR weder als Aufwertung noch als völkerrechtliche Anerkennung werten. Außerdem werde man weder eine Ratifikationsurkunde der DDR entgegennehmen noch ihre Teilnahme an einer Konferenz der Vertragsparteien akzeptieren. Ost-Berlin erwüchsen durch die Unterzeichnung des Atomteststopp-Abkommens somit keine Rechte, sondern nur Pflichten. Der Außenminister versprach, eine Disclaimer-Erklärung vor dem amerikanischen Senat abzugeben, die anschließend allen Staaten übermittelt würde, welche die Nichtanerkennungspolitik gegenüber der DDR befolgten. Die britische Regierung werde ebenso verfahren ${ }^{180}$. Damit hatte Washington alle Bedingungen Bonns erfüllt. Der Weg zur Unterzeichnung des Atomteststopp-Abkommen stand folglich offen, wie Staatssekretär von Hase noch am selben Tag der Presse mitteilte ${ }^{181}$. Adenauer war durch Rusks Zusagen einigermaßen zufriedengestellt. Hätten die Amerikaner die Nichtanerkennungserklärung abgelehnt, wäre er zurückgetreten, vertraute er Krone an: "Ich hätte mein Amt niedergelegt und wäre gegangen. "182 Der Öffentlichkeit versicherte Schröder, es sei nun gewährleistet, daß mit dem Vertrag keine Aufwertung der DDR einhergehe. Die Bundesregierung könne deshalb auch den bislang umstrittenen Artikeln des Teststopp-Abkommens zustimmen ${ }^{183}$.

Am 12. August informierte er das Kabinett über das Ergebnis der Besprechungen mit dem amerikanischen Außenminister. Adenauer ergänzte seine Ausführungen durch den Hinweis, die von Rusk angekündigte Erklärung enthalte alles, was man habe erreichen können: „Ein Mehr sei nicht möglich.“ Trotzdem wurde in der anschließenden Diskussion weiterhin massive Kritik geäußert. Vor allem Barzel, Heck, Dollinger, Stücklen, Niederalt und Krone brachten immer noch Einwände gegen das Atomteststopp-Abkommen vor. Keiner von ihnen stellte aber den Antrag, über einen Beitritt abzustimmen ${ }^{184}$. Man beschränkte sich darauf, Schröder zu beauftragen, die NATO-Partner darüber in Kenntnis zu setzen, daß die Bundesrepublik gegen die geplante Nichtangriffsvereinbarung mit dem Warschauer Pakt sei, weil er den Status quo in Europa festschreibe ${ }^{185}$. Nach den schlechten Erfahrungen mit dem Atomteststopp-Abkommen wollte man in dieser Frage nun rechtzeitig gegensteuern. Der Kanzler verzichtete schließlich auf eine förmliche Abstimmung über den Beitritt zum Teststopp-Abkommen, um die

179 Für den Wortlaut der Note der Bundesregierung vom 9. 8. 1963 vgl. PA/AA, B 150, Aktenkopien 1963. Vgl. auch OSTERHELD, „Ich gehe nicht leichten Herzens ...“, S. $247 \mathrm{f}$.

180 Vgl. ebenda, S. 249; sowie den Vermerk des Staatssekretärs Carstens vom 12. 8. 1963, in: AAPD 1963, Dok. 295, S. 989. Vgl. auch ebenda, Dok. 291 und Dok. 292, S. 968-985.

181 Für die Erklärungen des Staatssekretärs von Hase auf einer Pressekonferenz am 10. 8. 1963 vgl. DzD IV/9, S. 616.

182 KRONE, Aufzeichnungen, Eintrag vom 13. 8. 1963, S. 179.

183 Vgl. das Interview Schröders mit der Deutschen Welle am 11. 8. 1963, in: BuLLETIN 1963, S. 1254.

184 Aufzeichnung Krones vom 12. 8. 1963, ACDP, Nachlaß Krone I-028-033/4.

$185 \mathrm{Vgl}$. OSTERHELD, „Ich gehe nicht leichten Herzens ...“, S. 250. 
Spaltung des Kabinetts nicht offenkundig werden zu lassen. Am Ende der Sitzung stellte er formlos fest, die Bundesrepublik werde den Vertrag unterzeichnen, sobald die britische und die amerikanische Regierung die gewünschten Nichtanerkennungserklärungen abgegeben hätten. Letztlich war der Bundesregierung trotz aller Bedenken keine andere Wahl geblieben, als dem Abkommen zuzustimmen. Wie Krone richtig erkannte, hätte eine Verweigerung der Unterschrift die Beziehungen zu den Vereinigten Staaten "schwer belastet" und der Bundesrepublik großen Schaden zugefügt: „Man hätte uns letzte kalte Krieger und Feinde einer Friedenspolitik genannt“. Nach seiner Einschätzung bewies das AtomteststoppAbkommen, daß das Interesse an der deutschen Frage im Schwinden war. Koexistenz und Entspannung waren den USA wichtiger als die Unterstützung der Deutschland-Politik ihres Verbündeten ${ }^{186}$.

Am selben Tag, als das Kabinett über den Beitritt zum Moskauer Vertrag beriet, gab Rusk die versprochene Disclaimer-Erklärung vor dem Senat $a b^{187}$. Nun fehlte nur noch das Statement der britischen Regierung. London hatte es damit jedoch nicht eilig, wie Lord Home gegenüber Schröder am 14. August deutlich machte. Die britische Regierung plante, ihre Nichtanerkennungserklärung erst im Rahmen der Thronrede der Königin im November bzw. in der daran anschließenden außenpolitischen Debatte abzugeben ${ }^{188}$. Schließlich rang sich Lord Home aber dann doch durch, im Kommuniqué über den Besuch Schröders zu dieser Angelegenheit im Sinne Bonns Stellung zu nehmen ${ }^{189}$. Schröder nutzte die Besprechungen in London, um sich bei Macmillan über die Behandlung des DeutschlandProblems durch die Drei Mächte zu beklagen. Er führte gegenüber dem Premierminister aus, daß in der Bundesrepublik der Eindruck entstanden sei, die Chancen auf die Einheit Deutschlands hätten sich durch die Ereignisse in den letzten Jahren „erheblich verschlechtert“. Die Aussichten für die Wiedervereinigung würden aber noch geringer werden, falls weitere Abkommen zwischen West und Ost geschlossen werden sollten, welche "die deutschen Anliegen vernachlässigten“, erklärte Schröder in Anspielung auf den beabsichtigten Nichtangriffspakt ${ }^{190}$. Es genüge nicht, sich nur darauf zu konzentrieren, daß sich die deutschlandpolitische Ausgangslage nicht verschlechtere, sondern man müsse endlich Fortschritte erzielen. Mit Blick auf den Widerstand des CSU-Vorsitzenden Strauß gegen das Atomteststopp-Abkommen hob der Außenminister hervor, es sei auch aus innenpolitischen Gründen wichtig, Entspannungsmaßnahmen zu treffen, die nicht allein der Sowjetunion Vorteile brächten: „Der Status der SBZ dürfe deshalb nicht verbessert und der Status quo nicht zementiert werden." 191

186 Aufzeichnung Krones vom 12. 8. 1963, ACDP, Nachlaß Krone I-028-033/4.

187 Für den Wortlaut der Erklärung des Außenministers Rusk vor dem Außenpolitischen Ausschuß des amerikanischen Senats vom 12.8.1963 vgl. DzD IV/9, S. $624 \mathrm{f}$.

$188 \mathrm{Vgl}$. das Gespräch des Bundesministers Schröder mit dem britischen Außenminister Lord Home am 14. 8. 1963 in London, in: AAPD 1963, Dok. 299, S. 1002.

189 Für den Wortlaut des Kommuniqués vom 15. 8. 1963 vgl. BulleTiN 1963, S. 1273.

190 Gespräch des Bundesministers Schröder mit Premierminister Macmillan am 14. 8. 1963 in London, in: AAPD 1963, Dok. 300, S. 1016.

191 Ebenda, S. 1019. 
Nach seiner Rückkehr informierte Schröder am 16. August das Kabinett und den Außenpolitischen Ausschuß über den Inhalt der britischen und amerikanischen Erklärungen. Carstens hatte zuvor seinem Minister empfohlen, sie als Erfolg Bonns zu deuten. Zudem sollte er auf die zahlreichen diplomatischen Noten dritter Staaten verweisen, in denen diese im Zusammenhang mit dem Teststopp-Abkommen ihre Unterstützung der Nichtanerkennungspolitik der Bundesregierung zum Ausdruck gebracht hatten ${ }^{192}$. Schröder solle damit argumentieren, die Bundesregierung habe folglich „aus der Not eine Tugend gemacht“ 193 . Tatsächlich war der Widerstand gegen einen Beitritt der Bundesrepublik verstummt. Bereits am nächsten Tag konnte Schröder dem State Department mitteilen, die Bundesregierung habe einstimmig den Beschluß gefaßt, den Vertrag bei allen drei Signatarstaaten - also auch in Moskau - zu unterzeichnen. Gleichzeitig mahnte er Rusk, künftig die Bundesregierung früher und ausführlicher zu informieren. Dies sei vor allem im Hinblick auf das geplante Nichtangriffsabkommen und die Genfer Abrüstungsgespräche erwünscht ${ }^{194}$. Am 19. August 1963 trat die Bundesrepublik dem Atomteststopp-Abkommen bei. Anläßlich der Unterzeichnung erklärte die Bundesregierung, „daß sie auch weiterhin die sowjetische Besatzungszone nicht als Staat und die dort eingesetzten Stellen nicht als Regierung anerkennt". Dadurch würden „im Rahmen dieses Vertrages keine vertraglichen Beziehungen mit der sowjetischen Besatzungszone oder mit den dort eingesetzten Stellen entstehen" 195 .

Schröder war aber nicht bereit, die Angelegenheit damit abzuhaken. Die unzureichende Konsultation der Bundesregierung durch den amerikanischen Verbündeten beschäftigte ihn weiterhin. Ende September 1963 beanstandete er in Washington gegenüber Kennedy nochmals die mangelhafte Unterrichtung über das Teststopp-Abkommen. Dadurch sei die Bundesregierung in eine „peinliche Situation" geraten ${ }^{196}$. Energisch verlangte er, es dürfe nicht mehr vorkommen, daß der Eindruck entstehe, „als ob etwas hinter dem Rücken der Deutschen vereinbart werde“. Der Präsident versprach, künftig Bonn umfassender zu informieren, fügte aber hinzu, die Besorgnis über die Auswirkungen eines Beitritts der DDR zum Teststopp-Abkommen seien unbegründet gewesen. Nicht die Unterzeichnung des Vertrages habe Ost-Berlin aufgewertet, sondern der „Alarm“, den die Bundesrepublik deswegen geschlagen habe ${ }^{197}$.

Kennedy wollte nicht zur Kenntnis nehmen, daß die USA bei der Formulierung des Vertragstextes die westliche Nichtanerkennungspolitik gegenüber OstBerlin zu wenig berücksichtigt hatten. In Bonn mußte man sich die Frage stellen, ob sich die amerikanische Regierung die deutschlandpolitischen Folgen des Test-

192 Vgl. die Aufzeichnung des Staatssekretärs Carstens für Bundesminister Schröder vom 14. 8. 1963, in: ebenda, Dok. 302, S. 1024-1026.

193 Ebenda, S. 1026.

194 Vgl. das Schreiben des Bundesministers Schröder an den amerikanischen Außenminister Rusk vom 17. 8. 1963, in: ebenda, Dok. 308, S. 1039 f.

195 Erklärung der Bundesregierung anläßlich der Unterzeichnung des Teststopp-Abkommens am 19. 8. 1963, in: DzD IV/9, S. 638.

196 Gespräch des Bundesministers Schröder mit Präsident Kennedy am 24. 9. 1963 in Washington, in: AAPD 1963, Dok. 361, S. 1219.

197 Ebenda, S. 1220. 
stopp-Abkommen nicht bewußt gemacht hatte oder sie vorsätzlich ignorierte. Beides war als außerordentlich beunruhigend zu werten. Tatsache ist, daß erst die nachdrücklichen Warnungen der Bundesregierung Washington veranlaßten, sich dem Problem einer Unterzeichnung des Vertrags durch die DDR zu stellen. Auch die Nichtanerkennungserklärungen Rusks und Lord Homes kamen nur aufgrund der Intervention der Bundesregierung zustande. Für Moskau und Ost-Berlin war der Abschluß des Teststopp-Abkommens ein großer Erfolg, denn die DDR war auch wenn sie das Abkommen nur in Moskau unterzeichnen konnte - erstmals einem internationalen Vertrag von globaler Bedeutung beigetreten. Trotz aller Beteuerungen Washingtons, am Status der SBZ habe sich nichts geändert, kamen viele politische Beobachter zu einem ähnlichen Urteil wie Krone: „Es steht aber fest, daß politisch das Zonenregime aufgewertet und daß es als Mitunterzeichner am Tische sitzt." 198

Auch Schröder mußte aus der Affäre die Schlußfolgerung ziehen, daß die Interessen Bonns im Zuge der amerikanischen Entspannungsbemühungen auf der Strecke zu bleiben drohten. Nach seiner Rückkehr aus Washington zeichnete er am 2. Oktober 1963 vor der CDU/CSU-Bundestagsfraktion ein deprimierendes Bild der deutschlandpolitischen Lage. Trotzdem sah er keinen Grund, die bislang gültigen Prinzipien der Deutschland-Politik zu ändern, sondern forderte, „das äußerst Mögliche zum Halten der gegenwärtigen Position zu tun und zu ihrer Weiterentwicklung beizutragen“. Zwar werde der Druck, bestimmte Positionen aufzugeben, wie zum Beispiel den Standpunkt, die endgültige deutsche Ostgrenze könnte erst von einer gesamtdeutschen Regierung festgelegt werden, immer mehr zunehmen, dennoch dürfe die Bundesregierung keine voreiligen Konzessionen machen: „Wenn man anfange, über diese oder jene Position Ausverkaufserklärungen abzugeben, bliebe für den Friedensvertrag nichts mehr übrig." Das Ziel der UdSSR sei die Fixierung des Status quo. Dies gelte es aber um jeden Preis zu verhindern: „Ein Interesse an einem Friedensvertrag mit Deutschland werde man nur haben, wenn Fragen blieben, über die noch gesprochen werden müsse." Obwohl der Außenminister wußte, daß die Forderung nach der Wiederherstellung der staatlichen Einheit Deutschlands im Ausland zunehmend auf Desinteresse stieß, kündigte er an, die bisherige Deutschland-Politik weiterhin "mit aller Intensität" zu vertreten: „Man müsse dafür sorgen, daß die deutschen Probleme in keinem Augenblick west-östlicher Entspannung vergessen werden." Er versprach den Abgeordneten, diese Richtlinie auch bei der Diskussion um einen Nichtangriffspakt zwischen NATO und Warschauer Pakt sowie einem Nonproliferationsvertrag mit Nachdruck zu verfolgen ${ }^{199}$.

\section{Die Bemübungen um einen neuen Deutschland-Plan}

In dem Abschluß des Atomteststopp-Abkommens sahen die USA eine Bestätigung ihres Kurses, zu einem Abbau der Spannungen zwischen Ost und West beizutragen und eine Atmosphäre des Vertrauens und der friedlichen Koexistenz

199 Protokoll der CDU/CSU-Fraktionssitzung am 2. 10. 1963, ACDP VIII-001-1009/3. 
aufzubauen. Diese neue amerikanische Politik hatte Kennedy in seiner sogenannten Friedensrede am 10. Juni 1963 vor der Universität Washington erstmals gegenüber der Öffentlichkeit ausführlich dargelegt. Der Präsident hatte dabei unter anderem an den Friedenswillen Moskaus appelliert und das gemeinsame Interesse der beiden Supermächte herausgestrichen, das Wettrüsten einzustellen und Abrüstungsabkommen zu schließen ${ }^{200}$. Der erste konkrete Erfolg dieser Politik war die Vereinbarung über die Beendigung der nuklearen Tests in der Atmosphäre. Es war also möglich, mit der UdSSR pragmatische Vereinbarungen zu treffen, die den Frieden sicherer machen konnten. Nachdem man im Herbst 1962 im Verlauf der Kuba-Krise die Klippe des Nuklearkriegs gerade noch umschifft hatte, bot sich nun die Aussicht auf eine Phase der Entspannung zwischen West und Ost.

Nach der Auffassung der Bundesregierung sollte in diesem Prozeß des Spannungsabbaus auch das Problem der Teilung Deutschlands Berücksichtigung finden, um das es seit dem Ende der Berlin-Krise ruhig geworden war. Während dieser Phase der Auseinandersetzung im Ost-West-Konflikt hatte zwar die deutsche Frage die Schlagzeilen beherrscht, doch war die westliche Seite ausschließlich bemüht gewesen, eine Verschlechterung des Status Berlins und der Bundesrepublik zu verhindern. Trotz der schwierigen Ausgangssituation hatte sich Schröder in den vergangenen Jahren bemüht, daß das Problem der deutschen Teilung auf der Tagesordnung der Weltpolitik blieb. Seine Wiedervereinigungspolitik war auf mehreren Ebenen angelegt, wie er gegenüber Rusk am 24. Juni 1963 andeutete ${ }^{201}$. Schröder hat sein Konzept nie detailliert erläutert. Es lassen sich aber drei Ebenen erkennen, die die Bühne für die deutschlandpolitische Tätigkeit der Bundesrepublik bildeten: Die erste Ebene war der direkte Kontakt mit der DDR. Anders als ihm manchmal unterstellt wird ${ }^{202}$, scheute Schröder nicht vor innerdeutschen $\mathrm{Ge}$ sprächen zurück. Aufgrund der Nichtanerkennungspolitik fanden die Kontakte nur auf inoffizieller Ebene statt und wurden streng geheimgehalten. Schröder und Adenauer wagten diesen Schritt, weil sie hofften, die wirtschaftliche Notlage könnte Ost-Berlin zu Konzessionen zwingen. Über den Leiter der Treuhandstelle für den Interzonenhandel, Kurt Leopold, stellten sie im Sommer 1962 der Führung der DDR einen Kredit von 400 Millionen DM in Aussicht. Dafür sollte Ulbricht politische Zugeständnisse machen und unter anderem den Ostdeutschen mehr Freiheit gewähren ${ }^{203}$. Dieser Weg erwies sich aber als Sackgasse. Zwar wurde der Überziehungskredit im Interzonenhandel, der sogenannte Swing erhöht, doch konnte daraus kein politisches Kapital geschlagen werden. Ost-Berlin

200 Für den Wortlaut vgl. Public PAPERS, KenNEDY 1963, S. 459-464.

201 Vgl. dazu den Drahterlaß des Staatssekretärs Carstens vom 24.6. 1963, in: AAPD, Dok. 207, S. $672 \mathrm{f}$.

202 So wirft z.B. Peter Bender der damaligen Bundesregierung vor, sie hätte eine Politik der „Mißachtung der Ostdeutschen“ betrieben. Vgl. BENDER, Die „Neue Ostpolitik“ und ihre Folgen, S. 111.

203 Zum Angebot Bonns vgl. die Besprechung des Interministeriellen Ausschusses für den Interzonenhandel am 4. 1. 1963, in: AAPD 1963, Dok. 3, S. 10; sowie das Protokoll der CDU/CSU-Fraktionsvorstandssitzung am 20. 8. 1962, ACDP VIII-001-1503/4. Vgl. auch LEMKE, Trotz des Baus der Mauer in Berlin blieb Adenauer verhandlungswillig; sowie ders., Die Berlinkrise 1958 bis 1963, S. 270-272. 
war nicht bereit, auf die Forderungen Bonns einzugehen ${ }^{204}$. Schröder zog aus den gescheiterten Verhandlungen die Lehre, daß sich mit wirtschaftlichen Lockangeboten keine Änderung des Kurses der DDR erreichen ließ205. Die zweite Ebene der deutschlandpolitischen Aktivitäten Schröders war die von ihm initiierte Osteuropa-Politik. Sie war, wie noch ausführlich dargelegt wird, wesentlich von dem Motiv bestimmt, das Interesse der Staaten Ostmittel- und Südosteuropas an der Wiedervereinigung Deutschlands zu fördern und die DDR im Ostblock zu isolieren. Sie bildete somit die aktive, auf eine Änderung des Status quo gerichtete Komponente der Deutschland-Politik des Außenministers. Die dritte Ebene stellte schließlich der Bereich der internationalen Politik dar. Hier war die Bundesrepublik weitgehend damit beschäftigt, eine Aufwertung der DDR zu verhindern. Die Aktivitäten Bonns in diesem Bereich hatten sich in den vergangenen Jahren darauf beschränkt, den Alleinvertretungsanspruch der Bundesrepublik durchzusetzen und einer weiteren Verfestigung des Status quo in Mitteleuropa entgegenzuwirken ${ }^{206}$. Schröder hatte eine Akzentuierung vorgenommen, indem er den Anspruch des deutschen Volks auf Ausübung des Selbstbestimmungsrechts stärker betonte. Außerdem wies er seine Diplomaten an, die Tatsache, daß die Wiedervereinigung letztendlich vom Willen Moskaus abhängig sei, nicht länger in den Vordergrund ihrer deutschlandpolitischen Ausführungen zu stellen, sondern statt dessen die Vorteile verstärkt hervorzuheben, die sich - auch für die UdSSR durch die Wiederherstellung der deutschen Einheit ergeben würden, wie zum Beispiel eine politische „Beruhigung“ Mitteleuropas ${ }^{207}$.

Von der rein defensiven Deutschland-Politik auf dieser Ebene wollte der AuBenminister im Sommer 1963 nun wieder abgehen und das Problem der Teilung Deutschlands in die westliche Entspannungspolitik einbinden. Er hielt den amerikanischen Ansatz für falsch, nicht die zentrale Ursache für die Spannungen - die ungelöste deutsche Frage - in den Mittelpunkt des Dialogs mit dem Ostblock zu stellen, sondern zunächst über Randprobleme des Ost-West-Konflikts Vereinbarungen mit der UdSSR zu treffen. Seiner Ansicht sollte der Westen „nicht erst eine Entspannung versuchen und dann die verschiedenen Lösungen anstreben, sondern gleichzeitig beides tun“. Es müßten "Fortschritte in der allgemeinen Entspannung und gleichzeitig in der Lösung des deutschen Problems“ angestrebt werden ${ }^{208}$. Der Außenminister ließ daher von seinen Beamten eine deutschlandpolitische Initiative ausarbeiten, die den Weg zur staatlichen Einheit aufzeigen sollte. Dieser Deutschland-Plan, der am 13. August 1963 endgültig fertiggestellt

204 Vgl. ebenda; sowie das Schreiben des Bundesministers Barzel an Bundeskanzler Adenauer vom 29.1. 1963 und die Aufzeichnung des Legationsrats I. Klasse Oncken vom 21. 5. 1963, in: AAPD 1963, Dok. 61, S. 216-218 bzw. Dok. 180, S. 589 f.

205 Vgl. das Gespräch des Bundesministers Schröder mit dem amerikanischen Außenminister Rusk am 20. 9. 1963 in Washington, in: ebenda, Dok. 349, S. 1169.

206 Vgl. den Drahterlaß des Staatssekretärs Carstens vom 24. 6. 1963, in: ebenda, Dok. 207, S. 673.

207 Ebenda, S. 672.

208 Vgl. das Gespräch des Bundesministers Schröder mit dem britischen Außenminister Lord Home am 14. 8. 1963 in London, in: ebenda, Dok. 299, S. 1011. 
wurde 209 , entsprach inhaltlich dem westlichen Friedensplan, den der amerikanische Außenminister Herter am 14. Mai 1959 auf der Genfer Außenministerkonferenz vorgelegt hatte. Die Fassung des Auswärtigen Amts war aber im Vergleich zum Herter-Plan "stark vereinfacht und verkürzt “210. So verzichteten die Autoren auf die sicherheitspolitischen Regelungen, die unter anderem die Schaffung von Zonen mit militärischem Sonderstatus vorgesehen hatten. Auch der Gedanke, einen Gemischten Ausschuß zu bilden, in dem die Bundesrepublik durch 25, die DDR durch 10 Mitglieder vertreten sein sollte, wurde nicht mehr aufgegriffen. Wie bereits erwähnt, hatte sich Bonn mit den Drei Mächten bereits im Herbst 1961 darauf verständigt, statt dessen drei für den innerdeutschen Handel, die Herstellung der Freizügigkeit zwischen den beiden Teilen Deutschlands sowie die Beratung eines Gesetzentwurfs für die Abhaltung gesamtdeutscher Wahlen zuständige, paritätisch besetzte Kommissionen einzusetzen. Innerhalb der Washingtoner Botschaftergruppe war allerdings umstritten, was geschehen sollte, falls sich die Wahlvorbereitungskommission nicht auf ein gemeinsames Wahlgesetz einigte. Die USA und Großbritannien wollten in diesem Fall Beratungen zwischen den Vier Mächten aufnehmen. Der Entwurf des Auswärtigen Amts sah dagegen vor, einen Volksentscheid über die beiden konkurrierenden Entwürfe durchzuführen. Zusätzlich setzte er die Frist, daß spätestens 30 Monate nach der Unterzeichnung des Plans durch die Vier Mächte gesamtdeutsche Wahlen stattfinden müßten. Bonn beabsichtigte, mit dem Deutschland-Plan zunächst in eigener Verantwortung an die Öffentlichkeit zu treten. Anschließend sollten nach den Vorstellungen der Bundesregierung Frankreich, Großbritannien und die USA erklären, daß sie den Plan begrüßten, und Beratungen über den Zeitpunkt der Weiterleitung des Entwurfs an die Sowjetunion mit ihrem deutschen Verbündeten aufnehmen ${ }^{211}$.

Nach Schröders Vorstellungen sollte die Übergabe möglichst rasch erfolgen. Unmittelbar nach der Unterzeichnung des Atomteststopp-Abkommens sei es nun an der Zeit, einen deutschlandpolitischen Vorstoß zu unternehmen, argumentierte er am 14. August 1963 gegenüber Macmillan. Dies habe „psychologisch eine sehr gute Wirkung“, da dadurch der Öffentlichkeit eindrucksvoll vor Augen geführt werde, daß der Westen die deutschen Interessen nicht vernachlässige. Außerdem werde man auf diese Weise „den Widerstandswillen der Menschen in der SBZ stärken“212. Die Erfolgsaussichten des Plans schätzte der Außenminister jedoch gering ein. Zu Recht bezweifelte er, ob die sowjetische Regierung tatsächlich bereit wäre, auf der Grundlage eines Konzepts über die Wiedervereinigung zu verhandeln, das im Kern dem Herter-Plan entsprach, den der Kreml vier Jahre zuvor bereits abgelehnt hatte. Ihm kam es vielmehr auf die Außenwirkung einer neuen deutschlandpolitischen Initiative an. Der Plan war seines Erachtens in erster Linie ein „im Hinblick auf die öffentliche Meinung“ notwendiges „Gegenge-

209 Für den Wortlaut des Vorschlags des Auswärtigen Amts zur Lösung des DeutschlandProblems vom 13. 8. 1963 vgl. AAPD 1963, Dok. 296, S. 990-996.

210 Ebenda, S. 990.

211 Vgl. ebenda, S. 990-993.

212 Gespräch des Bundesministers Schröder mit Premierminister Macmillan am 14. 8. 1963 in London, in: ebenda, Dok. 300, S. 1016. 
wicht" zu den sowjetischen Stellungnahmen zur deutschen Frage ${ }^{213}$. Schröder hielt es für erforderlich, daß der Westen eigene Vorschläge machte, da die UdSSR ihre Vorstellungen zur Lösung der deutschen Frage monoton wiederholte und sie „als ungeheure Friedenstaten“ pries. Die Öffentlichkeit, so der Außenminister, warte auf eine Reaktion der Bundesrepublik und ihrer Verbündeten ${ }^{214}$. Mit dem Deutschland-Plan vom 13. August 1963 bezweckte er folglich, die Initiative in der Deutschland-Politik, die der Westen seit der Genfer Konferenz im Jahr 1959 mehr oder weniger der UdSSR überlassen hatte, wieder zurückzugewinnen. Er wollte der Öffentlichkeit zeigen, daß die Bundesregierung gemeinsam mit den Drei Mächten weiterhin aktiv an der Wiedervereinigung arbeitete, und dem durch den Abschluß des Atomteststopp-Abkommens entstandenen Eindruck entgegentreten, die amerikanische Regierung habe das Interesse an der Überwindung der deutschen Teilung verloren. Würden die USA sich hinter seine deutschlandpolitische Initiative stellen, so wäre dies ein Beleg, daß sich Entspannungs- und Wiedervereinigungspolitik nicht gegenseitig ausschlossen.

Gerade diese Meinung herrschte indessen am Potomac wie auch an der Themse vor. Nachdem man mit dem Atomteststopp-Abkommen zum ersten Mal eine konkrete Vereinbarung mit der Sowjetunion zur Sicherung des Weltfriedens getroffen hatte, wollten weder Washington noch London die ersten Früchte der Entspannungspolitik aufs Spiel setzen, indem sie das im Moment unlösbar scheinende Problem der deutschen Teilung in den Vordergrund des Dialogs mit Moskau rückten und damit die Fronten zwischen West und Ost wieder verhärteten. Rusk teilte der Bundesregierung mit, „die richtige Zeit" für einen neuen Vorstoß in der deutschen Frage sei noch nicht gekommen. Der amerikanische Außenminister äußerte die Befürchtung, daß dadurch sowjetische Aktionen gegen Berlin (West) provoziert werden könnten ${ }^{215}$. Auch sein britischer Amtskollege trat dafür ein, die Sache nicht weiter zu verfolgen. Im Gegensatz zu Schröder rechnete Lord Home mit einer negativen Reaktion der Öffentlichkeit, falls die Drei Mächte einen Plan präsentierten, bei dem es sich "nur um die Wiederholung alter Modelle“ handeln würde. Im übrigen war er der Meinung, daß Bonn keinen Grund hatte, mit der westlichen Deutschland-Politik unzufrieden zu sein: „Die Situation heute sei doch besser als vor drei Jahren." 216 Derartiger Schönfärberei widersprach Schröder sogleich energisch. Er erinnerte an den Bau der Berliner Mauer, der zweifellos eine "eindeutige Verschlechterung der Situation" zur Folge gehabt habe. Durch die Abriegelung von Berlin (West) sei unwiderlegbar ein „Status quo minus" entstanden 217 ! Sein Protest verhallte jedoch wirkungslos. Der britische Außenminister weigerte sich, einen Plan zu billigen, der nach seiner Auffassung lediglich das Ziel hatte, die öffentliche Meinung günstig zu stimmen. Er schlug

213 Gespräch des Bundesministers Schröder mit dem britischen Außenminister Lord Home am 14. 8. 1963 in London, in: ebenda, Dok. 299, S. 1009.

214 Ebenda. Vgl. auch das Gespräch des Bundeskanzlers Adenauer mit dem amerikanischen Außenminister Rusk am 10. 8. 1963, in: ebenda, Dok. 291, S. 976.

215 Ebenda, S. 975.

216 Gespräch des Bundesministers Schröder mit dem britischen Außenminister Lord Home am 14. 8. 1963 in London, in: ebenda, Dok. 299, S. 1009.

217 Ebenda, S. 1010. 
vor, ihn an die Washingtoner Botschaftergruppe zur weiteren Beratung zu überweisen $^{218}$. Während die britische wie die amerikanische Regierung die Angelegenheit auf die lange Bank zu schieben suchten, bestand Schröder hingegen auf einer sofortigen Behandlung seines Deutschland-Plans. Er argumentierte, im Hinblick auf den baldigen Wechsel im Kanzleramt sei es vorteilhafter, nicht die neue Bundesregierung den Plan der Öffentlichkeit präsentieren zu lassen, da dies den Anschein eines Kurswechsels in der Deutschland-Politik erwecken könnte. Im Hinblick auf eine Erörterung des Plans mit der UdSSR sei es zudem besser, wenn ein neuer Plan zur Lösung der deutschen Frage noch vor der Einberufung der UNGeneralversammlung am 17. September 1963 auf dem Tisch läge, bei der sich dann die Gelegenheit zu Gesprächen mit dem sowjetischen Außenminister bieten würde. Trotz aller Anstrengungen ließ sich Lord Home nicht umstimmen. Selbst die Behauptung, Adenauer wünsche sich zu seinem Abschied aus dem Palais Schaumburg eine neue Wiedervereinigungsinitiative des Westens, half nicht ${ }^{219}$.

In Wirklichkeit war Adenauer aber selbst nicht vom Deutschland-Plan seines Außenministers überzeugt. Im Gegensatz zu den Briten und Amerikanern, die darin nur die Wiederholung alter Vorschläge sahen, gingen ihm viele Formulierungen bereits wieder zu weit. Er stieß sich hauptsächlich daran, daß der Plan die Möglichkeit offen ließ, im Rahmen eines Friedensvertrags dem vereinigten Deutschland "gegebenenfalls Einschränkungen der vollen Entscheidungsfreiheit" 220 aufzuerlegen. Daher wies er am 28. August Schröder an, gegenüber den Alliierten „hinhaltend zu operieren und die Beratung der Vorlage in der Botschaftergruppe zu stoppen "221. Doch nach der absolut negativen Reaktion Londons und Washingtons war dies nicht mehr nötig. Im Auftrag des Außenministers teilte Staatssekretär Lahr am 6. September dem Bundeskanzleramt mit, angesichts der "sehr lauen Aufnahme“ der Initiative des Auswärtigen Amts sei mit Fortschritten ohnehin nicht zu rechnen. Es sei deshalb nicht beabsichtigt, die Beratungen in der Botschaftergruppe zu forcieren 222 .

218 Vgl. ebenda, S. $1010 \mathrm{f}$.

219 Vgl. das Gespräch des Bundesministers Schröder mit dem britischen Außenminister Lord Home am 14. 8. 1963 in London; ebenda, Dok. 301, S. 1020.

220 Vorschlag des Auswärtigen Amts zur Lösung des Deutschland-Problems vom 13.8. 1963, in: ebenda, Dok. 296, S. 992.

221 Vgl. das Schreiben des Bundeskanzlers Adenauer an Bundesminister Schröder vom 28. 8. 1963, in: ebenda, Dok. 321, S. 1074.

222 Vgl. das Schreiben des Staatssekretärs Lahr an Staatssekretär Globke, Bundeskanzleramt, vom 6. 9. 1963, in: ebenda, Dok. 329, S. 1098. Bereits am 30. 8. 1963 hatte Ministerialdirigent Reinkemayer die Leitungsebene des Auswärtigen Amts darauf hingewiesen, „daß es keines besonderen Zutuns von uns bedarf, um diese Entwicklung herbeizuführen. Es wären von uns aus keine besonderen Schritte zu ergreifen, um dem Wunsch des Herrn Bundeskanzlers zu entsprechen." Vgl. ebenda, Dok. 322, S. 1075. 


\section{7. „Schröder statt Erhard?“: Die Diskussion um die Kanzlernachfolge}

Im Dezember 1961 befragte das Institut Allensbach die Bundesbürger, welchen Politiker der CDU/CSU sie sich als Nachfolger Adenauers wünschten. 54\% der Befragten meinten, Erhard solle Kanzler werden. Lediglich 3\% stimmten für Schröder ${ }^{1}$. Für jemanden, der als Bundesminister seit fünf Jahren im Rampenlicht der Politik stand, war dies kein berauschendes Ergebnis. Der geringe Zuspruch der Bevölkerung hätte aber für eine Kanzlerschaft Schröders nicht unbedingt ein entscheidendes Hindernis sein müssen. Bekanntlich wurde im Zuge der Regierungsbildung 1961 ein Kanzlerwechsel ungefähr zur Mitte der Legislaturperiode beschlossen. Die Bestimmung des Nachfolgers Adenauers oblag den Parteigremien der Union. Sie mußten dabei nicht unbedingt Rücksicht auf die Popularität des Kandidaten nehmen, denn die nächsten Bundestagswahlen fanden erst im Herbst 1965 statt. Dem neuen Mann würde also genügend Zeit bleiben, sich einzuarbeiten und sich einen Amtsbonus zu erwerben. Andererseits war es kaum vorstellbar, daß die verantwortlichen Gremien der Union jemanden zum Kanzler kürten, der in der Öffentlichkeit auf Ablehnung stieß. Zudem verfügte Schröder innerhalb von CDU und CSU über keine große Anhängerschaft. Er wurde zwar geachtet, war aber nicht sonderlich beliebt ${ }^{2}$. Der fehlende Rückhalt an der Parteibasis war gewiß auch darauf zurückzuführen, daß er parteipolitisch kaum aktiv war, obwohl er seit 1956 dem Bundesvorstand der CDU angehörte 3 . Er konzentrierte sich weitgehend auf seine ministeriellen Aufgaben. Gerade bei der Regelung personeller Fragen konnte aber das Votum der Basis den entscheidenden Ausschlag geben. Auch Schröders Amt als Vorsitzender des Evangelischen Arbeitskreises von CDU/CSU war bei weitem nicht so einflußreich, wie es auf den ersten Blick scheinen mag. Dieses innerparteiliche Gremium war in erster Linie eine Interessenvertretung der protestantischen Parteimitglieder, aber keine Plattform, die eine bestimmte politische Richtung innerhalb der Partei vertrat ${ }^{4}$. Die Mitglieder des Arbeitskreises stimmten in ihrer Konfession überein, vertraten aber unterschiedliche politische Positionen. Aufgrund seiner heterogenen Zusammensetzung konnte der Kreis nicht zu einem Instrument im innerparteilichen Machtkampf werden. So waren Schröders Aussichten, die Kanzlerschaft zu erringen, nicht günstig.

Hinzu kam, daß seine Beziehungen zu vielen Mitgliedern der Parteispitze getrübt waren, beispielsweise zum Fraktionsvorsitzenden von Brentano. Bereits als dieser noch an der Spitze des Auswärtigen Amts stand, verfolgte er Schröders Weg mißtrauisch. Ihm war nicht entgangen, daß es der Innenminister Schröder auf seinen Stuhl abgesehen hatte. Nachdem von Brentano sein Amt tatsächlich für ihn

\footnotetext{
Vgl. JAHRBUCH DER ÖFFENTLICHEN MEINUNG 1958-1964, S. 307.

Vgl. SCHWARZKOPF/WRANGEL, Chancen, S. $151 \mathrm{f}$.

Vgl. ebenda, S. $152 \mathrm{f}$.

4 Zum Evangelischen Arbeitskreis und seinem Selbstverständnis vgl. KLEINMANN, Geschichte der CDU, S. 137-141; OPPELlAND, Der Evangelische Arbeitskreis der CDU/ CSU, S. 105-143.
} 
räumen mußte, war das Verhältnis zwischen beiden endgültig zerrüttet ${ }^{5}$. Krone stand Schröder ebenfalls überaus skeptisch gegenüber ${ }^{6}$. Das Verhältnis zu Franz Josef Strauß war von gegenseitiger, tiefer Antipathie geprägt. Das war nicht nur auf ihre politischen Differenzen zurückzuführen, sondern zu einem großen Teil auf den erheblichen Unterschied ihrer Charaktere ${ }^{7}$. Im Verlauf der sogenannten Spiegel-Affäre im Herbst 1962 wurde aus den Spannungen dann offene Feindschaft, da Schröder seinem Kabinettskollegen nicht, wie dieser verlangte, den Rücken deckte, sondern zur Aufklärung des Falles beitrug 8 . Strauß warf ihm deshalb im Rückblick vor, er sei der Hauptverantwortliche für seinen Sturz als Verteidigungsminister gewesen ${ }^{9}$, und sprach von "unkollegiale[r] Rücksichtslosigkeit"10. Der CSU-Vorsitzende setzte alle Hebel in Bewegung, um eine Kanzlerschaft seines Rivalen zu verhindern. Als kollegial kann dagegen Schröders Verhältnis zu Erhard beschrieben werden ${ }^{11}$. Es sollte aber nicht vergessen werden, daß er bereits mehrmals versucht hatte, diesen aussichtsreichsten Kandidaten für die Nachfolge Adenauers von seinem Weg ins Kanzleramt abzubringen. Wie erwähnt, hatte er 1959 den Wirtschaftsminister bedrängt, das Amt des Bundespräsidenten zu übernehmen. Zwei Jahre später, als Erhard nach der Bundestagswahl aufgefordert wurde, den Kanzler zu entthronen, empfahl ihm Schröder im Hinblick auf die prekäre außenpolitischen Lage, seine Ambitionen noch eine Weile zurückzustellen ${ }^{12}$. Man darf vermuten, daß er diesen Ratschlag nicht ohne Hintergedanken gab; konnte er doch so darauf hoffen, daß in den zwei Jahren, um die Adenauers Kanzlerschaft verlängert wurde, sich das Blatt zuungunsten Erhards wendete und seine eigenen Chancen stiegen.

Um den Wirtschaftsminister in der Rolle des Kronprinzen abzulösen, war es für den Außenminister unerläßlich, sein Image zu ändern und zu versuchen, an Popularität zu gewinnen. Politische Beobachter stellten dann auch wesentliche Veränderungen in Schröders Verhalten nach seinem Wechsel in das Auswärtige Amt fest. Wolfgang Wagner sprach von einer „wundersame[n] Wandlung"13 und Georg Schröder meinte im Juli 1962 in der Welt über seinen Namensvetter, es sei faszinierend zu beobachten, "wie er sich häutete, wie er das Gehabe des Polizeiministers und des gelegentlich arrogant wirkenden Flügelmannes der CDU abstreifte und das Habit des verbindlichen Außenministers anlegte“ ${ }^{14}$. Tatsächlich

5 Vgl. BARING, Sehr verehrter Herr Bundeskanzler!, S. 376.

6 Vgl. z. B. KRONE, Tagebücher, Einträge vom 27. 2. 1953 und 9. 10. 1954, S. 115 bzw. S. 146. Hans-Peter Schwarz bezeichnet Krone als „den ärgsten Gegner“ des Außenministers. Vgl. SCHWARZ, Adenauer II, S. 697.

7 Vgl. Adelbert SCHRÖDER, Mein Bruder Gerhard Schröder, S. 155; SCHWARZKOPF/WRANGEL, Chancen, S. 155; STRAUSS, Erinnerungen, S. 421.

$8 \mathrm{Vgl}$. CARSTENS, Erinnerungen, S. $238 \mathrm{f}$.

9 „Schröder hat dann im Zusammenhang mit der ,Spiegel'-Krise meinen Sturz betrieben.“ Vgl. StRauss, Erinnerungen, S. 417.

10 Ebenda, S. 421.

$11 \mathrm{Vgl}$. SCHWARZ, Adenauer II, S. 832.

12 Vgl. KOERFER, Kampf ums Kanzleramt, S. $578 \mathrm{f}$.

13 WAGNER, Der neue Mann im Außenamt, S. 24.

14 Vgl. den Artikel von Georg Schröder: „Wer nicht steigt, hat verloren“, in: DIE WELT vom 14. 7. 1962, S. 3. 
stiegen bis zum Februar 1963 die für Schröder ermittelten demoskopischen Werte: Nur noch 38\% plädierten jetzt für eine Kanzlerschaft Erhards, 24\% der Befragten wollten hingegen den Außenminister als Nachfolger des ,Alten' sehen ${ }^{15}$. Auch gegenüber der FDP und vor allem der SPD trat Schröder nun anders auf. Am Tag seiner Vereidigung im Bundestag kündigte er führenden Sozialdemokraten an: "Jetzt werden Sie meine angenehmeren Seiten kennenlernen." ${ }^{16}$ In der Tat führte er eine Informationspolitik ein, wie sie die Parlamentarier vom Auswärtigen Amt bislang nicht gewohnt waren. Sowohl die sozialdemokratische wie die liberale Bundestagsfraktion wurde kontinuierlich über die außenpolitische Entwicklung auf dem laufenden gehalten. Dem Auswärtigen Ausschuß erstattete Schröder regelmäßig und ausführlich Bericht. Schon bald äußerten sich führende Sozialdemokraten begeistert: „Wir haben jetzt endlich einen Außenminister, der uns unterrichtet und mit dem man diskutieren kann “, verkündete Herbert Wehner ${ }^{17}$. Auch sachliche Übereinstimmungen gab es jetzt mit der SPD, unter anderem in der Berlin-Politik ${ }^{18}$. Während der Streitigkeiten im Frühjahr 1962 um die Haltung Bonns in der Berlin-Krise nahmen die Sozialdemokraten den Außenminister sogar gegen die Kritik in Schutz, die ihm aus der eigenen Partei entgegenschlug ${ }^{19}$. Natürlich beabsichtigte die SPD damit auch, den Streit für ihre Zwecke auszunutzen ${ }^{20}$; dennoch galt Schröder im Frühjahr 1962 als „Lieblingsminister der Opposition“21. Adenauers Reaktion auf die Beliebtheit seines Außenministers im oppositionellen Lager fiel pikiert aus. Er verbreitete, ein Minister, der vom politischen Gegner gelobt werde, müsse sich fragen, ob er nicht irgend etwas falsch gemacht habe ${ }^{22}$.

Von den Freien Demokraten erntete Schröder ebenfalls Zustimmung für seine Amtsführung. Im März 1962 rühmte der FDP-Vorstand das „besonders gute Verhältnis" zum neuen Außenminister. Vor allem seine Informationspolitik fand Anerkennung ${ }^{23}$. Mende forderte seine Parteifreunde auf, die Linie des Ministers in der Berlin-Politik zu unterstützen ${ }^{24}$. Der stellvertretende FDP-Fraktionsvorsitzende, Ewald Bucher, vertrat die Ansicht, durch Schröders Ressortwechsel vom Innen- ins Außenministerium sei eine bessere personelle Besetzung von gleich zwei Ministerien erreicht worden ${ }^{25}$. Auch in den Medien wurde nun zunehmend ein positiveres Bild von ihm gezeichnet, besonders von den liberal bis linkslibera-

15 Vgl. JahrbuCH DER ÖFFENTLiChEN MEINUNG 1958-1964, S. 307.

16 Zitiert nach dem Artikel „Englisch gut“, in: DER SPIEGEL vom 24. 10. 1962, S. 26.

17 Ebenda.

18 Vgl. dazu den Auszug aus dem Bericht der Arbeitsgemeinschaft B "allgemeine Politik“ vom 30. 5. 1962 auf dem Parteitag der SPD in Köln, in: DzD IV/8, S. 589.

19 Vgl. den Artikel "Was denkbar ist“, in: DER SPIEGEL vom 6. 6. 1962, S. 22 f.

20 Vgl. SCHWARZKOPF/WRANGEL, Chancen, S. $159 \mathrm{f}$.

21 Vgl. den Artikel von Eberhard Bitzer: „Schröder und die Sozialdemokraten“, in: FRANKFURTER ALLGEMEINE ZEITUNG vom 16. 6. 1962, S. 1.

22 Vgl. den Artikel von Hans-Werner Graf von Finckenstein: „In Bonn tut sich etwas“, in: DIE WELT vom 14. 6. 1962, S. 3.

23 Protokoll der FDP-Bundesvorstandssitzung am 16. 3. 1962, in: FDP-BUNDESVORSTAND, S. 307.

24 Vgl. das Protokoll der FDP-Bundesvorstandssitzung am 5. 5. 1962, in: ebenda, S. 316.

25 Vgl. den Artikel von Georg Schröder: "Wer nicht steigt, hat verloren“, in: DIE WELT vom 14. 7. 1962, S. 3 . 
len Zeitungen und Zeitschriften. Bislang war er nämlich kein „Lieblingskind der Hamburger Publizistik" gewesen, obwohl Franz Josef Strauß dies in seinen Memoiren empört behauptet ${ }^{26}$. Es sei beispielsweise nur an die bereits erwähnte, diffamierende Titelgeschichte des Spiegel vom Sommer 1959 erinnert ${ }^{27}$. Inzwischen hatte er jedoch kaum mehr Anlaß, sich über die Berichterstattung von Rudolf Augsteins Magazin zu beschweren. Die Wochenzeitschrift rühmte nun die politische Beweglichkeit des Außenministers, die sich vorteilhaft vom "Immobilismus“ des Kanzlers abhebe ${ }^{28}$, und zitierte die amerikanische Journalistin Marguerite Higgins, die über Schröder urteilte, er sei „der erste Diplomat, der auf der gleichen Wellenlänge denkt wie Präsident Kennedy und Außenminister Dean Rusk"29. Auch in der Zeit wurde seine politische Arbeit gewürdigt: Theo Sommer zollte Schröders Bemühungen, ohne ideologische Scheuklappen Politik zu machen, Lob und charakterisierte seine Amtsführung als einen „Stil der neuen Sachlichkeit“30. Der Stern kürte ihn 1962 sogar zum „Mann des Jahres“31. Die bürgerliche Presse hielt den Außenminister nun für höhere Weihen befähigt. Die Frankfurter Allgemeine Zeitung brachte ihn im Juni 1962 als möglichen Kanzler einer Großen Koalition ins Spiel ${ }^{32}$. Nur wenige Monate später sah die Welt in ihm sogar den einzigen ernsthaften Kandidaten für die Nachfolge Adenauers ${ }^{33}$.

Trotz der publizistischen Unterstützung gelang es Schröder in seiner Partei nicht, Boden gut zu machen. Während Sozialdemokraten und Liberale mit der Unterrichtung durch das Auswärtige Amt mehr als zufrieden waren, geriet er diesbezüglich mit dem CDU/CSU-Fraktionsvorsitzenden aneinander. Brentano forderte, besser informiert zu werden. Nachdem seine Beschwerde keinen Erfolg hatte, wandte er sich an den Kanzler ${ }^{34}$. Auch der Chef des Presse- und Informationsamtes der Bundesregierung, von Hase, und der Beauftragte der Bundesregierung für Berlin, von Eckardt, beklagten sich bei Adenauer über die unzureichende Weitergabe von Informationen durch Schröders Ministerium ${ }^{35}$. Der Kanzler stellte daraufhin seinen Minister vor dem Fraktionsvorstand der CDU/CSU zur Rede: „Kein Kabinettsmitglied ist dafür da, nur für sich Politik zu machen, sondern dafür gemeinsam Politik zu machen", mahnte er Schröder. Doch dieser blieb stur. Für die Unterrichtung von Eckardts sei nicht das Auswärtige Amt, sondern das Kanzleramt zuständig, erwiderte er. Was die CDU/CSU-Fraktion betreffe, werde man „eine neue Form“ der Benachrichtigung finden, versprach er auswei-

26 STRAUSS, Erinnerungen, S. 422.

27 Vgl. den Artikel „Der Mitschreiber“, in: Der SPIEGEL vom 22. 7. 1959, S. 16-25.

28 Vgl. den Artikel "Sanfte Kuratel“, in: DER SPIEGEL vom 30. 5. 1962, S. 23.

29 Zitiert nach dem Artikel „Englisch gut", in: DER SPIEGEL vom 24. 10. 1962, S. 27.

30 Vgl. den Artikel von Theo Sommer: „Schröders neue Sachlichkeit. Der Stil der deutschen Außenpolitik hat sich gewandelt", in: DIE ZEIT vom 11. 5. 1962, S. 1.

31 So der Titel des STERN vom 6. 1. 1963. Vgl. auch die Titelgeschichte ebenda, S. $22 \mathrm{ff}$.

32 Vgl. den Artikel von Eberhard Bitzer: „Schröder und die Sozialdemokraten“, in: FRANKFURTER ALLGEMEINE ZEITUNG vom 16. 6. 1962, S. 1.

33 Vgl. den Artikel von Georg Schröder: „Der Kanzler von morgen“, in: DiE WeLT vom 13. 10. 1962, S. 3.

34 Vgl. Baring, Sehr verehrter Herr Bundeskanzler!, S. 479, Anm. 145.

35 Vgl. das Schreiben Globkes an Krone vom 27. 7. 1962, ACDP, Nachlaß Krone I-028-011/3. 
chend $^{36}$. Der Außenminister war nicht daran interessiert, von Brentano zu viele Informationen zukommen zu lassen, da der Fraktionsvorsitzende sie dazu benutzte, seine Politik zu kritisieren, wie sich bei den Auseinandersetzungen um die Berlin-Politik in der ersten Jahreshälfte 1962 gezeigt hatte. In Wahrheit fand hier nichts anderes als ein „Machtkampf“" $z$ wischen den beiden Politikern statt ${ }^{37}$.

Selbst Adenauer wurde von Schröder zunehmend aus dem außenpolitischen Entscheidungsprozeß ausgeschaltet. Der Kanzler „mußte erleben, daß er sicher die Richtlinien der Politik bestimmte, in ihrer Durchführung aber ich in eigener Verantwortung zu handeln hatte - und handelte“, gab Schröder im Rückblick offen $\mathrm{zu}^{38}$. Wie bereits ausgeführt, ließ er sich nicht länger in seinen Aufgabenbereich hineinreden. Adenauers Argwohn wuchs: „[D]er ist nicht loyal“, urteilte er über seinen Außenminister ${ }^{39}$. Ende Juli vertraute Globke Krone an, sein Chef sei höchst beunruhigt über Schröders Außenpolitik. Dessen Verhalten würde ihm „schlaflose Nächte" bereiten ${ }^{40}$. Offen beschwerte sich Adenauer bei Journalisten über Schröder und äußerte den Verdacht, dieser wolle ihn mit der Hilfe von Bundestagsabgeordneten aus allen Fraktionen stürzen ${ }^{41}$. Im August 1962 spielte er sogar mit dem Gedanken, eine Kabinettsumbildung vorzunehmen, wobei er in erster Linie an einen Wechsel an der Spitze des Auswärtigen Amts dachte ${ }^{42}$. Nach seiner Überzeugung war eine Ablösung Schröders „unvermeidlich“. Als möglichen Nachfolger nannte er Birrenbach und Freiherr von und zu Guttenberg ${ }^{43}$. Auch eine Rückkehr von Brentanos erwog der Kanzler. Schröder sollte statt dessen auf die Hardthöhe wechseln ${ }^{44}$. Dadurch wäre er auch Strauß losgeworden, dem er ebenfalls mißtraute ${ }^{45}$. Doch alle personellen Alternativen überzeugten ihn nicht: „Wen soll ich denn nehmen?", fragte er ratlos seine Sekretärin, Hannelore Siegel ${ }^{46}$. Folglich begnügte er sich damit, seinen Außenminister zu maßregeln. Mitte August schrieb er ihm, sein Vertrauen in ihn habe „einen nicht unerheblichen Stoß bekommen". Adenauer drohte, er werde sich Schröders Gebaren nicht länger gefallen lassen: „Ich werde nicht zulassen, daß Sie die auswärtige Politik als einen besonderen Bereich der Bundesrepublik, den Sie ausschließlich zu betrauen hätten, ansehen." 47 Doch der Außenminister ignorierte den Tadel des Kanzlers. Eigenmächtig vereinbarte er Gesprächstermine mit ausländischen Politikern. Es

36 Protokoll der CDU/CSU-Fraktionsvorstandssitzung am 20. 8. 1962, ACDP VIII-001$1503 / 4$.

37 OSTERHELD, „Ich gehe nicht leichten Herzens ...", S. 118.

38 SCHRÖDER, "Je weiter östlich, desto besser".

39 Zitiert nach SCHWARZ, Adenauer II, S. 697.

40 Vgl. das Schreiben Globkes an Krone vom 27. 7. 1962, ACDP, Nachlaß Krone I-028-011/ 3.

41 Vgl. KOERFER, Kampf ums Kanzleramt, S. 644.

42 Vgl. das Schreiben Globkes an Krone vom 4. 8. 1962, ACDP, Nachlaß Krone I-028-011/3.

43 Vgl. das Schreiben Globkes an Krone vom 8. 8. 1962, ACDP, Nachlaß Krone I-028-011/3.

${ }^{4}$ Vgl. das Schreiben Globkes an Krone vom 19.11. 1962, ACDP, Nachlaß Krone I-028$011 / 3$.

${ }^{45} \mathrm{Zu}$ Adenauers Haltung gegenüber Strauß im Sommer 1962 vgl. SCHWARZ, Adenauer II, S. $724 \mathrm{f}$.

46 ZeitZeugenbefragung Osterheld.

47 Vgl. das Schreiben Adenauers an Schröder vom 17. 7. 1962, StBKAH C 42. 
sei dabei an den bereits erwähnten Vorfall im Januar 1963 erinnert, als er ein Treffen mit der britischen Regierung arrangierte, ohne Adenauer über seine Pläne zu informieren ${ }^{48}$.

Erstaunlicherweise geriet Schröder dennoch zu Beginn des Jahres 1963 aus dem Schußfeld des Kanzlers. Adenauers Gedanken konzentrierten sich jetzt vordringlich darauf, eine Kanzlerschaft Erhards zu verhindern. Dessen einziger ernsthafter Konkurrent war aber Schröder. Adenauer war nun bereit, letzteren als das kleinere Übel in Kauf zu nehmen, wenn er dadurch dem in seinen Augen ungeeigneten Erhard den Weg ins Kanzleramt verbauen konnte ${ }^{49}$. Außerdem brauchte er Schröder, um den in der Union umstrittenen Elysée-Vertrag im Bundestag durchzubringen ${ }^{50}$. Die Entscheidung über seine Nachfolge suchte er so lange wie möglich hinauszuzögern, in der Hoffnung, es würde im Laufe der Zeit immer offenkundiger werden, daß der Wirtschaftsminister nicht die für einen Kanzler notwendigen Qualitäten vorzuweisen hatte ${ }^{51}$. Im Februar 1963 berichtete der Spiegel, der Fraktionsgeschäftsführer der CDU/CSU, Will Rasner, plane, die Kanzlerschaft Adenauers bis zum Herbst 1964 zu verlängern. Schröder solle dann auf dem Kanzlerthron Platz nehmen, während Erhard mit der Nachfolge von Bundespräsident Lübke abgefunden werde ${ }^{52}$. Auch die Welt titelte bereits: „Schröder statt Erhard?"53. Selbst die Zeit, die der Erhard-Intimus Gerd Bucerius herausgab, konstatierte: „Erhards Chancen sinken“. Sie sah in Schröder nun den „Kronprinz[en] " für das Erbe Adenauers ${ }^{54}$. Insbesondere der CDU-Abgeordnete Adolf Süsterhenn kämpfte in der Fraktion verbissen gegen eine Kanzlerschaft des Wirtschaftsministers ${ }^{55}$. Aus der Union war bereits zu hören, Erhard werde vermutlich nur für eine Übergangszeit, eventuell bis zu den Bundestagswahlen 1965, Kanzler sein $^{56}$. Anders als zu früheren Zeiten gab jener trotz des Widerstands, der ihm entgegenschlug, jedoch nicht klein bei, sondern bestand darauf, die Entscheidung über die Nachfolge Adenauers ohne weitere Verzögerungen zu treffen ${ }^{57}$. Sollte es keine „befriedigende Lösung“" geben, werde er zurücktreten ${ }^{58 !}$ Diesmal war er entschlossen, seine vermeintlichen Ansprüche auf die Kanzlerschaft zu wahren.

Die CDU/CSU-Bundestagsfraktion handelte dann auch in seinem Sinn. Sie bestimmte am 5. März 1963, Brentano solle den aussichtsreichsten Kandidaten den

$48 \mathrm{Vgl}$. das Schreiben Adenauers an Schröder vom 31. 12. 1962, StBKAH C 42.

49 ZEITZEUGENBEFRAGUNGEN Osterheld, von Hase und Kusterer.

$50 \mathrm{Vgl}$. SCHWARZ, Adenauer II, S. 826-835.

51 Vgl. ebenda, S. 835.

52 Vgl. den Artikel "In einem Monat, in einem Jahr“, in: DeR SPIEGEL vom 27. 2. 1963, S. 13.

53 Vgl. den Artikel „CDU will schnell Nachfolge des Bundeskanzlers klären. Konsequenzen aus der Wahlniederlage in Berlin. Schröder statt Erhard?“, in: DIE WELT vom 20. 2. 1963, S. 1.

54 Vgl. den Artikel von Robert Strobel: „Erhards Chancen sinken“, in: DiE ZEIT vom 22. 2. 1963, S. 1.

$55 \mathrm{Vgl}$. KoERfer, Kampf ums Kanzleramt, S. $730 \mathrm{f}$.

56 Vgl. ebenda, S. 731.

57 Vgl. den Auszug aus dem Schreiben Erhards an von Brentano vom 1.3. 1963, in: ebenda, S. 732-734.

58 Vgl. ebenda, S. 735. 
Abgeordneten zur Wahl vorschlagen ${ }^{59}$. Nach Lage der Dinge konnte dies nur Erhard sein. Dennoch bestürmte Rasner den Kanzler, sich nun eindeutig für Schröder auszusprechen. Er hoffte, dieser könnte sich mit der Rückendeckung Adenauers in der Fraktion gegen den Wirtschaftsminister durchsetzen ${ }^{60}$. Auch die Bundesminister Heck und von Hassel machten sich für ihn stark ${ }^{61}$. Brentano hingegen prophezeite, daß Schröder keine Chance habe. Er sagte voraus, daß bei einer Kampfabstimmung ungefähr $70 \%$ der Abgeordneten für Erhard votieren wür$\operatorname{den}^{62}$. In der Tat hatte dessen Rücktrittsdrohung auf die Unionsabgeordneten großen Eindruck gemacht - auch auf die Sympathisanten Schröders. So schrieb Alfred Burgemeister nach einer Sitzung der niedersächsischen Bundestagsparlamentarier an von Brentano: „Bei der Nominierung unseres Freundes Gerhard Schröder würde nach meinem Gefühl Dr. Erhard auch nicht bereit sein, das Amt des Bundesministers für Wirtschaft weiter zu führen. Das gäbe dann erst recht in der Öffentlichkeit Diskussionsstoff gegen uns. “ Außerdem täuschte sich der Abgeordnete nicht, wenn er annahm, daß die Partei mehrheitlich letzteren unterstützte ${ }^{63}$. Auch wenn Zweifel an seiner Befähigung zum Kanzler bestanden, war man doch der Meinung, daß man ihn nicht brüskieren konnte, indem man ihm Schröder vorzog. Erhard war der ältere und erfahrenere. Er gehörte dem Bundeskabinett seit 1949 an und war neben Adenauer die bedeutendste Persönlichkeit, die die CDU vorzuweisen hatte, auch wenn er kein Mitglied der Partei war. Der Minister wurde als Vater des Wirtschaftswunders verehrt, und seine Fähigkeiten als Wahlkampflokomotive waren unbestritten. Hinzu kam, daß die CSU geschlossen hinter ihm stand 64 . Er war somit der eindeutige Favorit und natürliche Anwärter auf die Nachfolge Adenauers.

Wohl in realistischer Einschätzung der Machtverhältnisse schreckte Schröder davor zurück, selbst in die Nachfolgediskussion einzugreifen. Als im Frühjahr 1963 in Bonn die personellen Weichen gestellt wurden, trat er einen vierwöchigen Urlaub an ${ }^{65}$. Er war im übrigen der Auffassung, daß für ihn die Kanzlerschaft noch zu früh komme66. Diese Zurückhaltung war in Anbetracht der Stimmung in der Partei wohl vernünftig. Falls die Kanzlerschaft Erhards tatsächlich nur eine "Zwischenlösung“ wäre, wie die Neue Zürcher Zeitung annahm ${ }^{67}$, dann würde sich rascher als erwartet die Kanzlerfrage erneut stellen. Da Schröder bereits jetzt der einzige Mitbewerber war, konnte er darauf spekulieren, daß beim nächsten Mal alles auf ihn zulaufen würde. In der Tat verhielt er sich später im Kabinett Er-

59 Vgl. das Protokoll der CDU/CSU-Fraktionssitzung am 5.3. 1963, ACDP VIII-001$1009 / 2$.

$60 \mathrm{Vgl}$. SCHWARZ, Adenauer II, S. 835.

61 Vgl. SCHWARZ, Epochenwechsel, S. 313.

62 Vgl. ebenda, S. 314.

$63 \mathrm{Vgl}$. den Auszug aus dem Schreiben Burgemeisters an von Brentano vom 4. 4. 1963, in: KOERFER, Kanzleramt, S. 738.

64 Vgl. SCHWARZ, Epochenwechsel, S. 313.

65 Vgl. ebenda.

66 Vgl. SCHRÖDER, Im Gespräch mit Meinhold Krauss, S. 54.

67 Vgl. den Artikel von Fred Luchsinger: „Die Diskussion um die Nachfolge Adenauers. Der CDU-Fraktionsvorstand für einen raschen Entscheid“, in: NEUE ZÜRCHER ZEITUNG vom 21. 2. 1963, S. 1. 
hard absolut loyal und versuchte, sich auf diese Weise als Nachfolger zu empfehlen. Da ihm letztendlich die Kanzlerschaft versagt blieb, stellt sich die Frage, ob er nicht doch, wie Volker Hentschel meint, mit dem Verzicht auf eine Kandidatur gegen Erhard „den schwersten taktischen Fehler seiner Laufbahn" beging68.

Am Ostersonntag, dem 14. April 1963, reiste von Brentano nach Cadenabbia, um das Placet Adenauers für eine Kanzlerschaft Erhards einzuholen. Doch dieser wollte das Thema nicht einmal diskutieren. Statt dessen bekam der Fraktionsvorsitzende lobende Worte über Schröder zu hören. Weiterhin versuchte der Kanzler auf Zeit zu spielen, was die Fraktion aber nicht länger mitmachen wollte. Sie verlangte umgehend eine Entscheidung, zur Not auch ohne sein Einverständnis ${ }^{69}$. Kaum war Adenauer am 19. April nach Bonn zurückgekehrt, setzte von Brentano das Thema Kanzlernachfolge auf die Tagesordnung der für den 22. April anberaumten Sitzung des CDU/CSU-Fraktionsvorstands. Adenauer beschwor ihn vergebens, die Debatte so zu leiten, daß noch kein definitiver Beschluß gefaßt werde. Sehr schnell wurde im Verlauf der Sitzung deutlich, daß sich der Vorstand ohne weitere Verzögerung auf einen Kandidaten einigen wollte, der der Fraktion am kommenden Tag präsentiert werden sollte. Der,Alte' war jedoch nicht bereit, das fait accompli ohne Gegenwehr hinzunehmen. Er wies den Vorstand darauf hin, daß es neben Erhard drei weitere Kandidaten gebe, nämlich Schröder, von Brentano und Krone. Die beiden zuletzt genannten erklärten allerdings sogleich, sie stünden nicht zur Verfügung. Schröder deutete prinzipiell seine Bereitschaft an, doch hielt er die Zeitspanne zwischen der Nominierung des Kandidaten und der Wahl im Bundestag für zu lang: „Ein solches Verfahren ist nicht zu verantworten. Ich stehe für ein solches Verfahren nicht zur Verfügung." letzte Versuch Adenauers, ein weiteres Pferd ins Rennen zu schicken, gescheitert.

Dennoch bemühte er sich in der entscheidenden Fraktionssitzung am 23. April nach Kräften, doch noch ein Votum gegen Erhard herbeizuführen. „Es kann jemand der beste aller Wirtschaftsminister sein, ohne daß er deswegen für die politischen Fragen dasselbe Verständnis aufbringt", stellte Adenauer despektierlich fest und fügte unmißverständlich hinzu, er halte Erhard „nicht für geeignet“. Doch lediglich Süsterhenn pflichtete dem Kanzler bei. Der Abgeordnete bedauerte, es gebe leider keine personelle Alternative. Dieser indirekten Aufforderung, doch noch gegen Erhard in den Ring zu steigen, kam Schröder jedoch nicht nach. Völlig konträr zu dem, was er am Vortag verkündet hatte, trat er jetzt dafür ein, sofort eine Entscheidung zu treffen, da bei einer weiteren Verschiebung der Angelegenheit die Autorität des Kandidaten beeinträchtigt werde. Man gefährde dadurch die Aussichten der Union, die Bundestagswahlen im Jahr 1965 zu gewinnen. Demonstrativ stellte er sich hinter Erhard und schlug den Abgeordneten vor, ihn als „Punkt der Integration“ zu wählen. Wegen dessen Fähigkeit, die Partei zu einen, nehme er auch von einer Gegenkandidatur Abstand, erklärte er. Strauß sprach sich ebenfalls für Erhard aus. Den Kritikern beschied er: „Es bestehe die

68 HENTSCHEL, Ludwig Erhard, S. 424.

69 Vgl. KOERFER, Kampf ums Kanzleramt, S. $741 \mathrm{f}$.

70 Protokoll der CDU/CSU-Fraktionsvorstandssitzung am 22.4. 1963, ACDP VIII-0011504/1. 
Hoffnung, daß ein Mann wie Prof. Erhard mit seinen 67 Jahren noch durchaus entwicklungsfähig ist." Somit war der Weg für den Wirtschaftsminister frei. Bei der anschließenden Abstimmung der Fraktion votierten 159 Abgeordnete für ihn. Es gab 19 Enthaltungen und 47 Gegenstimmen ${ }^{71}$. Knapp ein Drittel der Anwesenden hatte also gegen eine Kanzlerschaft Erhards Position bezogen. In Anbetracht der Tatsache, daß er der einzige Kandidat war, war das Ergebnis kein großer Vertrauensbeweis. Doch die Entscheidung war nun getroffen und unumkehrbar. Erhard sollte im Herbst das Ruder im Bundeskanzleramt übernehmen.

71 Protokoll der CDU/CSU-Fraktionssitzung am 24. 4. 1963, ACDP VIII-001-1009/2. 